
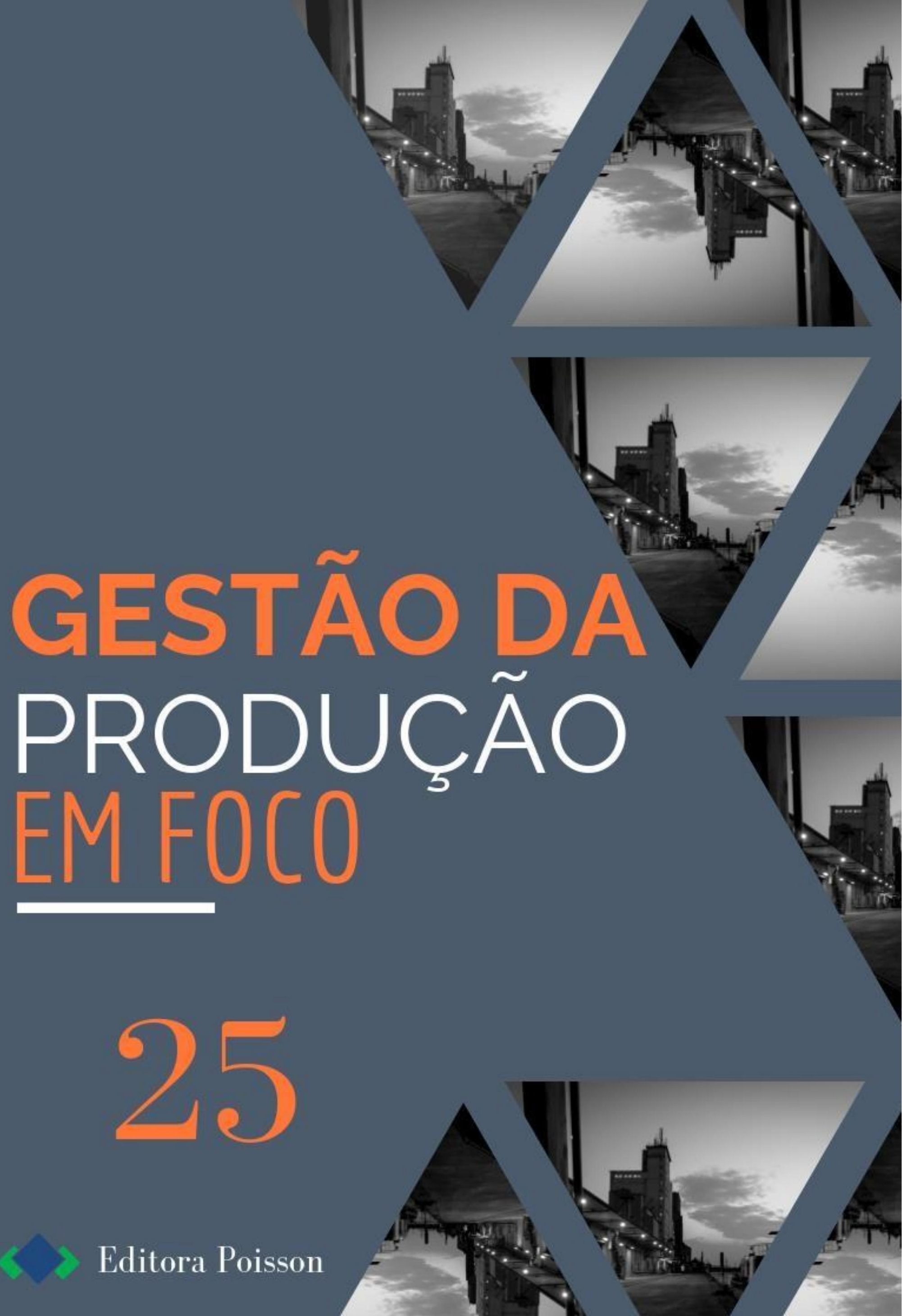
Editora Poisson

\title{
Gestão da Produção em Foco Volume 25
}

\author{
1a Edição
}

Belo Horizonte

Poisson

2018 
Editor Chefe: Dr. Darly Fernando Andrade

\section{Conselho Editorial}

Dr. Antônio Artur de Souza - Universidade Federal de Minas Gerais

Dr. José Eduardo Ferreira Lopes - Universidade Federal de Uberlândia

Dr. Otaviano Francisco Neves - Pontifícia Universidade Católica de Minas Gerais

Dr. Luiz Cláudio de Lima - Universidade FUMEC

Dr. Nelson Ferreira Filho - Faculdades Kennedy

Ms. Valdiney Alves de Oliveira - Universidade Federal de Uberlândia

Dados Internacionais de Catalogação na Publicação (CIP)

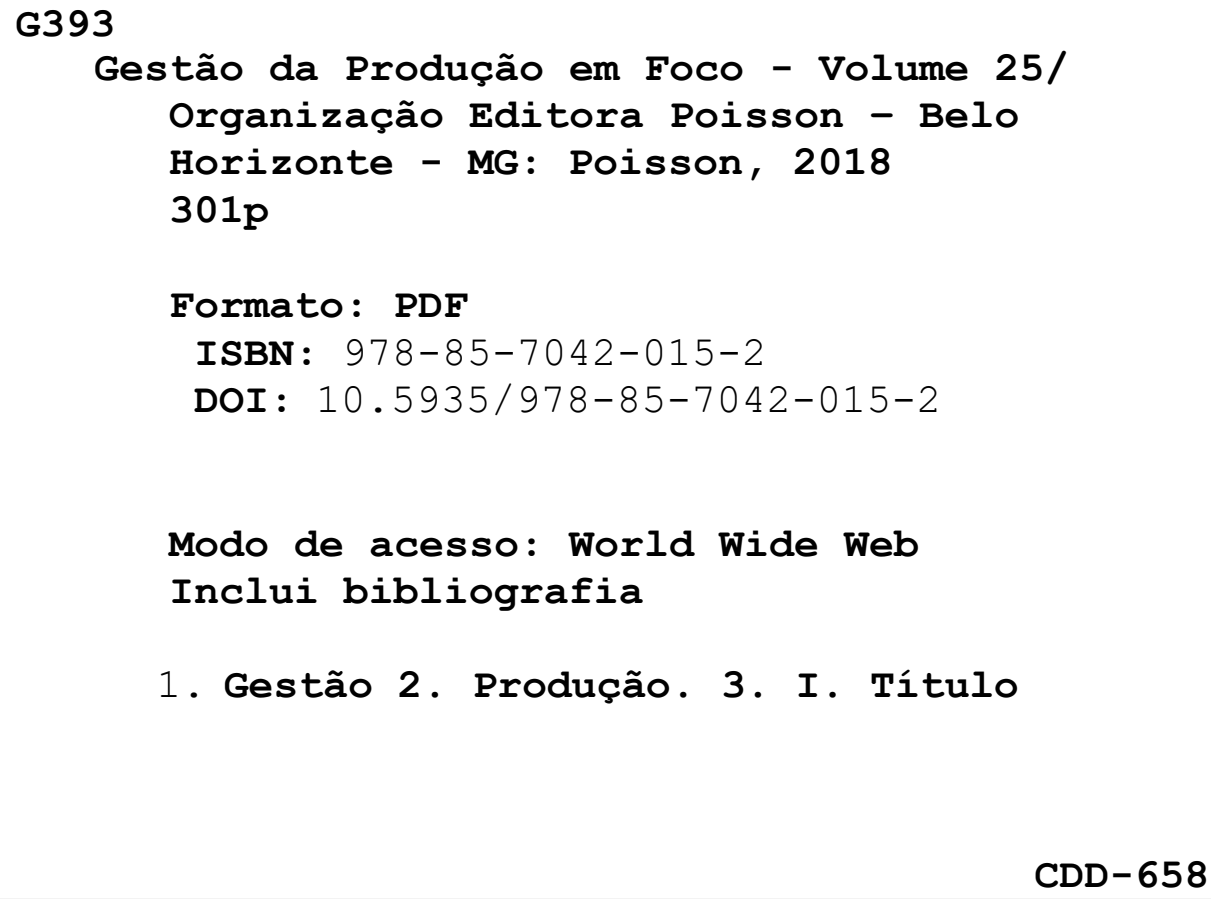

O conteúdo dos artigos e seus dados em sua forma, correção e confiabilidade são de responsabilidade exclusiva dos seus respectivos autores.

$\underline{\text { www.poisson.com.br }}$

contato@poisson.com.br 


\section{Sumário}

Capítulo 1: A importância das ferramentas de gestão da qualidade na identificação de problemas organizacionais: estudo de caso em uma indústria do sul de Santa Catarina

Patrícia Pereira Pacheco, Vilson Menegon Bristot, Leopoldo Pedro Guimarães Filho, Vilmar Menegon Bristot, Simone Milioli da Luz

Capítulo 2: Sumarização do processo de certificação de tipo da aeronáutica Brasileira

Cristiane Mariano Zavati Silva, Guilherme Moreira de Souza, Marcelo Lopes de Oliveira e Souza

Capítulo 3: Avaliação e melhoria dos processos relacionados à segurança do trabalho através da aplicação de ferramentas de qualidade.

Michellen dos Santos Vasques da Silva, Jesimar da Cruz Alves, Adauri Silveira Rodrigues Junior

Capítulo 4: Proposta de melhoria de processo em uma linha de produção de equipamentos hospitalares utilizando a Filosofia Lean

Ingrid de Figueiredo Astigarreta, Luiz Antonio da Paz Campagnac, Marcelo Arese

Capítulo 5: Estudo para implantação do programa de uso racional da água em uma escola de Catalão - GO ........................................................48

João Cândido Júnior, Ed Carlo Rosa Paiva, José Waldo Martínez Espinosa

Capítulo 6: Avaliação dos fatores críticos de sucesso na aplicação de workshops Lean de 7 fases na construção pesada.......................................58

Deísa Valéria Costa Conegundes

Capítulo 7: Produção enxuta e produção mais limpa - comparativos para uma produção eficiente e sustentável

Laura Neves Folly, Michele Pereira Figueiredo de Abreu, Luiz Augusto Cescon Tavares

Capítulo 8: Lean Seis Sigma - aplicabilidade da metodologia para redução do tempo de espera para atendimento médico em unidades ambulatoriais

Elisangela Elias de Souza, Adriano Olivieri Brito, Larissa Vilela Cruz, Leonardo de Abreu Ferreira, Priscila Fernanda Morais Chaves

Capítulo 9: Similaridades Lean Seis Sigma: uma abordagem a partir da análise de conteúdo 


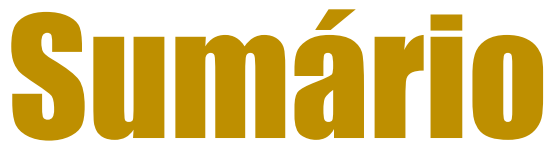

Capítulo 10: Aplicação do controle estatístico de processos em uma indústria de produção de bandejas de ovos

Franciele Bonatto, Bárbara Dacal de Azevedo, João Dallamuta

Capítulo 11: Implantação do programa 5s no setor de empacotamento em uma indústria de torrefação de café

Lucas Carvalho Martins, Murilo Carvalho Franco Barros, Vitor Camargo da Silva, Vitor de Carvalho Pisco

Capítulo 12: Utilização do mapeamento de processos para identificação de falhas e melhoria contínua em uma indústria produtora de sacos de lixo

Lucas Carvalho Martins, Isabella Silveira Ferro, Isabela Lopes Gomes Torres, Isabela Gonçalves Bastianini

Capítulo 13: Gestão avançada como fundamento para a implantação de conceitos da indústria 4.0

Mari Tomita Katayama, João Carlos Martins Coelho, Henrique Jun Muramatsu Seguchi

Capítulo 14: Processo de implantação da drenagem pluvial provisória de uma refinaria de petróleo, na cidade de Ipojuca/PE

Fagner Tavares Xavier

Capítulo 15: Processo produtivo de leite condensado em um laticínio em Araxá MG e seus aspectos logísticos

Bárbara Andrino Campos Silva, Humberto Elias Giannecchini Fernandes Rocha Souto, Marcelo Teotônio Nametala, Rafael Izidoro Martins Neto

Capítulo 16: Estudo do processo produtivo e comercial do queijo minas artesanal canastra de uma fazenda em Medeiros-MG

Bárbara Andrino Campos Silva, Humberto Elias Giannecchini Fernandes Rocha Souto, Marcelo Teotônio Nametala, Rafael Izidoro Martins Neto, Júlio César Benfenatti Ferreira

Capítulo 17: Um estudo bibliométrico sobre a utilização de análise multicritério na indústria do óleo e gás com enfoque em descomissionamento.

Thiago José da Costa Muniz, Marcilene de Fatima Dianin Vianna, Dalessandro Soares Vianna, Edwin Benito Mitacc Meza

Capítulo 18: Estudo comparativo das características físico-químicas dos biodieseis obtidos a partir de óleo residual de fritura e do óleo do coco...

Gisela Kloc Lopes, Flávia Targa Martins, Maycon Tavares Morete 


\section{Sumárīo}

Capítulo 19: Previsão de demanda num simulador de gestão da produção: ações estratégicas....

Luan Bahia Araújo, Sávio de Araújo Almeida, Taís Santos Barreto, Juliano Zaffalon Gerber, Luane Alcântara Nunes

Capítulo 20: Métodos de previsão de demanda baseados em séries temporais em uma lanchonete

Lucas Carvalho Martins, Roberta Oliveira Gonçalves

Capítulo 21: Visita técnica à Glass Co. Brasil Ltda.: motivação de análise preliminar da importância do planejamento e controle da produção e arranjo físico em uma indústria de vidro plano

Leonardo dos Anjos Fernandes da Cruz, Marcos Felippe Gallo Veríssimo, Matheus Peccin Amaral, Renata Larcher Cury, Mario Santos de Oliveira Neto

Capítulo 22: Aplicação da teoria das restrições em uma indústria de confecções....244 Manoel Isac Maia Júnior, Plácido Carlos Fernandes de Queiroz,

Capítulo 23: Resolução de problemas de programação linear utilizando o método gráfico na plataforma Excel

Deyvid Ricardo Ramos Gonçalves, Erika Mayra Antunes Rocha, Gilberto Antunes de Sousa Junior, Giuseppe Bruno de Almeida Mendes Rocha, Oscar Martins Rennó, Eliane Aparecida dos Santos Silva, Marcos Vinícius Maia Fonseca

Capítulo 24: Elaboração do conceito do aplicativo mesa Brasil

Rodrigo Lanzoni Fracarolli

Capítulo 25: Otimização em redes utilizando o algoritmo do caminho mínimo para roteirização de uma cooperativa agropecuária...................................268

Jarbas Ancelmo da Silva Júnior, Natália Cibele de Sousa Santos, Lara Cristine Pereira dos Santos, Nayara Felício de Oliveira

Capítulo 26: Análise da aplicação do balanced scorecard em um hotel

Vitor de Carvalho Pisco, Lucas Carvalho Martins, José Carlos de Toledo 


\section{Capítulo 1}

\section{A IMPORTÂNCIA DAS FERRAMENTAS DE GESTÃO DA QUALIDADE NA IDENTIFICAÇ̃̃O DE PROBLEMAS ORGANIZACIONAIS: ESTUDO DE CASO EM UMA INDÚSTRIA DO SUL DE SANTA CATARINA}

\section{Patrícia Pereira Pacheco \\ Vilson Menegon Bristot \\ Leopoldo Pedro Guimarães Filho \\ Vilmar Menegon Bristot \\ Simone Milioli da Luz}

Resumo: A gestão de processos produtivos permite às organizações visualizar seus resultados e ter controle sobre suas operações. Para isso, são utilizados programas e ferramentas de gestão, e entre eles, estão as ferramentas de gestão da qualidade, que auxiliam na identificação de causas raiz e de soluções. Esse estudo tem como objetivo destacar a importância das ferramentas de gestão da qualidade na identificação de problemas no setor de expedição de uma empresa do sul de Santa Catarina, e também na apresentação de soluções propostas. Tratase de uma pesquisa qualitativa e de campo em que, através do uso de algumas ferramentas de gestão da qualidade, foi possível identificar atrasos, desperdício de tempo e operaçõess repetidas. Foi possível otimizar a utilização do espaço para a preparação de cargas e reduzir o número de operações no manuseio de produtos.

Palavras-Chave: Gestão da Qualidade; Processo Produtivo; Ferramentas de Gestão; Organização.

*Artigo apresentado no Simpósio de Engenharia de Produção (SIMEP) 2017, em Joinville 


\section{INTRODUÇÃO}

Os setores de uma organização requerem procedimentos que facilitem a gestão do processo produtivo em todos os setores, para organizar documentos, contas, estoque ou movimentação. Esses procedimentos podem ser criados pela própria empresa, ou adquiridos de terceiros, como é o caso dos softwares de gestão.

A adoção de sistemas de gestão e métodos de controle tem o objetivo de tornar o processo mais claro, para que as informações trocadas entre os setores seja eficaz, evitando fallhas de comunicação e erros em determinado ponto em que o produto se encontra.

As falhas, por sua vez, dificultam as ações de todos os departamentos, desde o recebimento de pedidos até sua saída. Geralmente elas ocorrem pela falta de controle de informações ou da atualização destas.

Para controlar essa mudança de informações e facilitar o fluxo de produção até a entrega do produto, existe uma série de ferramentas e modelos de gestão que podem ser seguidos pelos colaboradores da empresa. Essas ferramentas controlam, levantam dados, apontam problemas e fornecem medidas que facilitam a obtenção de ideias e propostas de melhorias, tornando-se aliadas das empresas na definição de ações e estratégias.

Algumas dessas ferramentas de gestão se enquadram na Gestão da Qualidade que, através de indicadores, visa apontar causas raiz e determinar ações de melhoria contínua, buscando eficiência e bom desempenho das atividades.

O presente estudo buscou destacar a importância do uso das ferramentas de gestão da qualidade, na análise do setor de expedição de uma empresa de equipamentos de avicultura e suinocultura do sul de Santa Catarina, para a obtenção de ideias de melhorias a serem propostas em relação ao desempenho do setor.

\section{REVISÃO BIBLIOGRÁFICA}

\subsection{ORGANIZAÇÃO}

Para Kanaane (1994) organização é um sistema onde os indivíduos que dela fazem parte expressam valores que são transmitidos de forma sucessiva. Assim, há uma responsabilidade que passa de geração em geração.

Peter Drucker (1997) vincula organização ao conhecimento. Para ele, conhecimento é a base em que a organização deveria ter especialidade e as funções definidas pela tarefa para que o conhecimento se torne produtivo. Quanto mais especializadas forem, mais eficazes serão.

Daft (2002) relata a dificuldade em conceituar organização, pois é algo abrangente e com objetivos variados.

O papel das organizações está em servir a sociedade e apresentar soluções para as necessidades. Ao serem usadas constantemente, há uma contribuição para manter o princípio de construção constante no qual estão inseridas (PRÉVE, 2012).

\subsection{MELHORIA CONTÍNUA}

Neco (2011) considera a melhoria contínua como um dos fatores determinantes para uma organização enfrentar os desafios de um mundo competitivo e de muitas mudanças.

Através da melhoria contínua é possível aperfeiçoar e aprender a inovar, adquirindo conhecimento para construir processos para transformar o produto com vantagem competitiva, eliminando desperdícios, reduzindo custos e tempo, envolvendo os colaboradores da organização de forma sincronizada (MACHADO; FRANCISCO, 2005).

É o conjunto de atividades planejadas em que a organização objetiva aumentar a satisfação do cliente. Sua aplicação se dá pelas metodologias sistemáticas que permitem uma análise rigorosa dos problemas que afetam os resultados. Com isso, é possível identificar as causas raízes e desenvolver planos de ação (NECO, 2011).

A autora ainda destaca que durante a implantação de programas de melhoria contínua, são utilizadas algumas ferramentas para identificar problemas que são adaptadas de acordo com a empresa e suas especificidades, como metas a serem alcançadas, medição, comparação, entre outras necessidades. 


\subsection{GESTÃO DA QUALIDADE}

Gestão da Qualidade é definida como o conjunto de ações adotadas para se obter características do produto ou serviço capazes de satisfazer as necessidades e expectativas do cliente. (JUNIOR; BONELLI, 2006).

Para Carvalho e Paladini (2005), a Gestão da Qualidade são atividades coordenadas para dirigir e controlar uma organização englobando planejamento, controle, garantia e melhoria da qualidade. Já a Qualidade Total trata-se do modo de gestão de uma organização baseado na participação dos seus membros, que visa sucesso a longo prazo por meio da satisfação do cliente e dos benefícios para os colaboradores e a sociedade.

Dentro da Gestão da Qualidade, tem-se a Gestão da Qualidade Total (GQT) que tem como pontos básicos: foco no cliente; trabalho em equipe em toda a organização; decisões baseadas em dados; e busca constante da solução de problemas e diminuição de erros (CARVALHO e PALADINI, 2005).

Barros (1999), ao afirmar que Qualidade Total é uma estratégia de mobilização, dá destaque à característica de que todos os colaboradores da organização participam do desafio constante de satisfazer clientes.

\subsection{FERRAMENTAS DE PLANEJAMENTO E GESTÃO DA QUALIDADE}

As ações gerenciais tornam-se viáveis quando se utiliza ferramentas, programas e métodos para a qualidade, pois assim é possível a otimização dos processos e a identificação, compreensão e solução de problemas (SILVA; FLORES, 2011). Rodrigues (2010) dividiu as ações operacionais para a qualidade em três campos: ferramentas e técnicas para a melhoria dos processos e da qualidade, confiabilidade e análise das falhas para a melhoria da qualidade e programas e métodos para a melhoria da qualidade. Conforme o Gerenciamento pela Qualidade Total (GQT) se desenvolveu, houve um incremento das ferramentas, programas $e$ métodos da qualidade.

\subsubsection{CICLO PDCA}

Xenos (2014) aponta o PDCA como o método universal para atingir metas, que serão atingidas através do giro sistemático da ferramenta. Para Pessoa (2007), essa sequência de atividades é percorrida de forma cíclica para melhorar os resultados.

É preciso seguir as quatro fases do PDCA para que os objetivos sejam alcançados, e consistem em: Plan (Planejamento): estabalecer claramente as metas e os métodos para alcançá-las; Do (Execução): Educar e treinar as pessoas envolvidas, e colocar o plano em prática; Check (Verificação): Observar a situação e verificar o progresso dos recultados e Action (Ação): Se o resultados não estão progredindo, deve-se atuar em função dos resultados obtidos (XENOS, 2014). A Figura 1 representa a sequência do ciclo PDCA.

Figura 1 - Ciclo PDCA

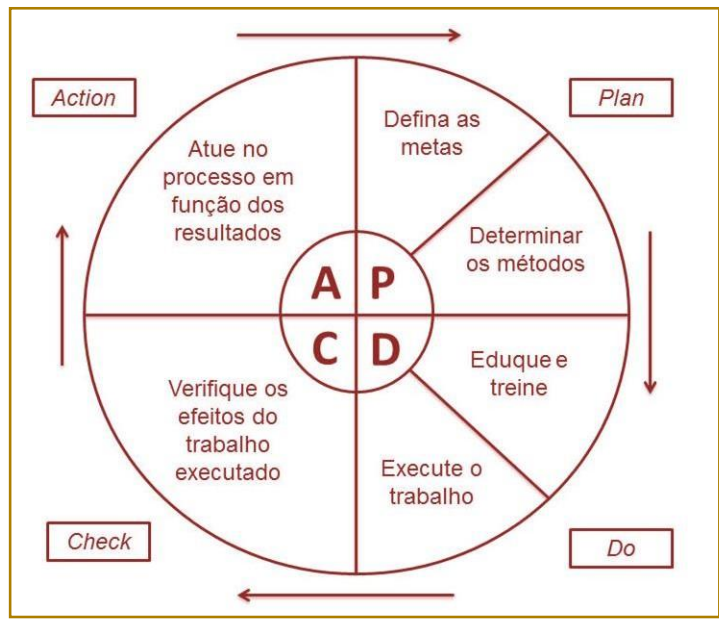

Fonte: Adaptado de Xenos (2014). 


\subsubsection{MATRIZ GUT}

Leal et. al. (2011) define a Matriz GUT como uma das ferramentas mais simples de se aplicar, pois separa e prioriza os problemas para fins de análise e solução.

Cesar (2013) classifica os fatores Gravidade, Urgência e Tendência como:

Gravidade - Impacto do problema sobre coisas, pessoas, resultados, processos ou organizações e efeitos que surgirão em longo prazo, caso o problema não seja resolvido; Urgência - Relação com o tempo disponível ou necessário para resolver o problema; Tendência - Potencial de crescimento do problema, avaliação da tendência de crescimento, redução ou desaparecimento do problema.

Para cada item (causa/problemas) é atribuído uma nota para três fatores (gravidade, urgência e tendência) que varia de 1 a 5 , onde é 1 tem o menor grau e 5 o maior grau. As linhas representam as causas do problema ou o problema em si, e as colunas, os fatores a serem pontuados de 1 a 5 . Após a atribuição dos pontos, deve-se multiplicar os fatores GxUxT para obter a prioridade. Quanto maior o resultado da multiplicação, maior a prioridade (GOMES, 2006; CESAR, 2013).

\subsubsection{DIAGRAMA DE CAUSA E EFEITO (ISHIKAWA)}

O Diagrama de Causa e Efeito, criado por Kaoru Ishikawa (1915-1989), consiste em interligar resultados (efeitos) com os fatores (causas). Possibilita descobrir as causas que produzem efeitos indesejados, para que se possa corrigi-los. Ajuda a sistematizar e dividir causas e efeitos devido à sua simples visualização (RIBEIRO, 2005).

Nele, a forma "espinha-de-peixe" é usada para classificar os problemas, onde se define, primeiramente, o "efeito". Em seguida, definem-se as ramificações, que são os fatores detalhados, considerados causas secundárias. Outros fatores podem ser descritos em ramificações menores e assim por diante (SILINGOVSCHI, 2001).

Para Martini Junior (2009) o diagrama de Ishikawa pode ser empregado tanto para a investigação de um efeito negativo e corrigi- lo, como o de um efeito positivo, e incorporálo ao processo.

Uma das formas de identificar as causas do problema estudado antes de montar o Diagrama de Ishikawa é a realização do Brainstorming, que segundo Minicucci (2011) é uma técnica de geração de idéias, que na língua inglesa significa "explosão de idéias". Consiste nas etapas de exposição do problema, em que se aponta o objetivo, exposição das ideias, onde são lançadas todas as ideias, e a fase onde são selecionadas as melhores ideias para se implantar. 0 autor destaca que é importante considerar todas as ideias sem críticas, e que é possível associá-las e selecionar a melhor delas.

\section{METODOLOGIA}

Este estudo teve como objetivo destacar a importância do uso das ferramentas de gestão da qualidade na resolução de problemas organizacionais, determinando assim as causas raiz e elaborando planos de ação, para apresentar uma proposta de melhoria. Para isso, foi realizada uma pesquisa de campo, que permitiu a coleta e análise de dados. Segundo Gonsalves (2001), esse tipo de pesquisa busca a informação de forma direta com a população pesquisada. Assim, o pesquisador precisa ir até 0 fenômeno e reunir um conjunto de informações a serem documentadas.

A abordagem utilizada neste estudo de caso é qualitativa, pois o estudo visa comprovar a importância do uso de ferramentas através dos resultados obtidos, mas não faz uso de dados comparativos e estatísticos. Embora a obtenção de resultados seja numérica através das ferramentas, o foco está em comprovar a importânciaa do uso das ferramentas de gestão da qualidade na resolução de problemas. 0 método qualitativo é útil e necessário para que os significados dos fenômenos estudados e suas interações sejam identificados, fazendo com que seja possível o desenvolvimento de novas compreensões sobre a variedade e a profundidade dos fenômenos sociais (BARTUNEK; SEO, 2002).

Quanto ao referencial teórico, embora a gestão da qualidade tenha diversas ferramentas, apenas as que foram utilizadas na resolução do problema do presente estudo 
foram abordadas, tornando a linguagem do artigo mais objetiva, trazendo também os conceitos de melhoria contínua.

A coleta de dados se deu através de visitas à empresa, onde foi apresentada a questão a ser estudada, que consistia em aumentar a capacidade de carregamentos no setor de expedição de uma empresa de grande porte, de equipamentos de avicultura e suinocultura do sul de Santa Catarina. O setor estudado foi o de expedição, onde foram feitas todas as análises do processo e coleta de dados. As informações eram fornecidas pelos funcionários que acompanhavam as visitas.

Conforme as informações eram obtidas, faziase a análise dos dados para atribuir às ferramentas de gestão da qualidade, as quais foram elementos de obtenção dos resultados.

0 estudo apresentou limitações, pois o período entre a análise do problema, coleta dos dados e uso das ferramentas para propor a solução foi de três meses, sendo que as visitas eram semanais, ou quando havia necessidade de mais informações.

\section{APRESENTAÇÃO DOS RESULTADOS}

O primeiro passo após conhecer o processo de expedição da empresa foi coletar informações sobre o problema em questão. A expedição fazia em média 8 carregamentos diários, e propôs um aumento para 14 carregamentos diários, ou ações que ajudassem a reduzir o desperdício de tempo e operações. A empresa não pretendia fazer maiores investimentos, por isso optou-se por apresentar uma solução que otimizasse o local de trabalho, dando vazão a mais espaço para preparar mais carregamentos.

Na primeira parte da coleta de informaçõess, foi realizado um brainstorming, primeiro entre os funcionários do setor, depois com a equipe que auxiliou nas visitas e coleta de dados. Essas informações foram coletadas e analisadas junto a alguns dados fornecidos pela empresa, dando origem a uma matriz GUT (Gravidade, Urgência, Tendência) dos problemas, que pode ser observada na Figura 2.

Figura 2 - Matriz GUT

\begin{tabular}{||l|c|c|c|c|}
\hline \multicolumn{5}{|c|}{ Matriz de Priorização - Expedição } \\
\hline Problemas / Oportunidades de Melhoria & G & U & T & TOTAL \\
& (gravidade) & (urgência) & (tendência) & \\
\hline Alteração de projeto & 3 & 3 & 2 & 18 \\
\hline Atraso de entrega do fornecedor & 5 & 5 & 5 & 125 \\
\hline Aumento de consumo & 2 & 1 & 5 & 10 \\
\hline Erro Cadastro & 4 & 3 & 1 & 12 \\
\hline Erro PCP & 5 & 4 & 3 & 60 \\
\hline Inconsistência de Estoque & 5 & 4 & 5 & 100 \\
\hline Erro Comercial & 5 & 2 & 1 & 10 \\
\hline Reprovado pela Qualidade & 4 & 2 & 1 & 8 \\
\hline Erro produção & 4 & 3 & 1 & 12 \\
\hline Atraso do carregamento & 5 & 5 & 5 & 125 \\
\hline Erros no packing-list & 5 & 4 & 5 & 100 \\
\hline
\end{tabular}

Fonte: Autores (2016)

o brainstorming realizado e a análise dos materiais fornecidos resultaram nas causas descritas no quadro acima. Com a matriz de priorização, foi possível chegar na causa de maior impacto. Como houve empate entre as causas "atraso de entrega do fornecedor" e "atraso do carregamento", a equipe de trabalho optou por considerar o atraso do carregamento como mais influente e mais acessível para ser estudado. Segundo os funcionários da empresa, o atraso no carregamento se dá por outro problema listado, os erros no packing-list, que contém todas as informações e componentes do que vai ser carregado. Segundo eles "acontece de um componente estar listado no 
carregamento, mas ainda não ter chegado até a preparação. Algumas caixas são fechadas com falta de componente devido à esse problema."
Para analisar mais detalhadamente as causas do problema e juntar mais informações para solucioná-lo, foi utilizado o Diagrama de Ishikawa, na Figura 3.

Figura 3 - Diagrama de Ishikawa

Fonte: Autores (2016)

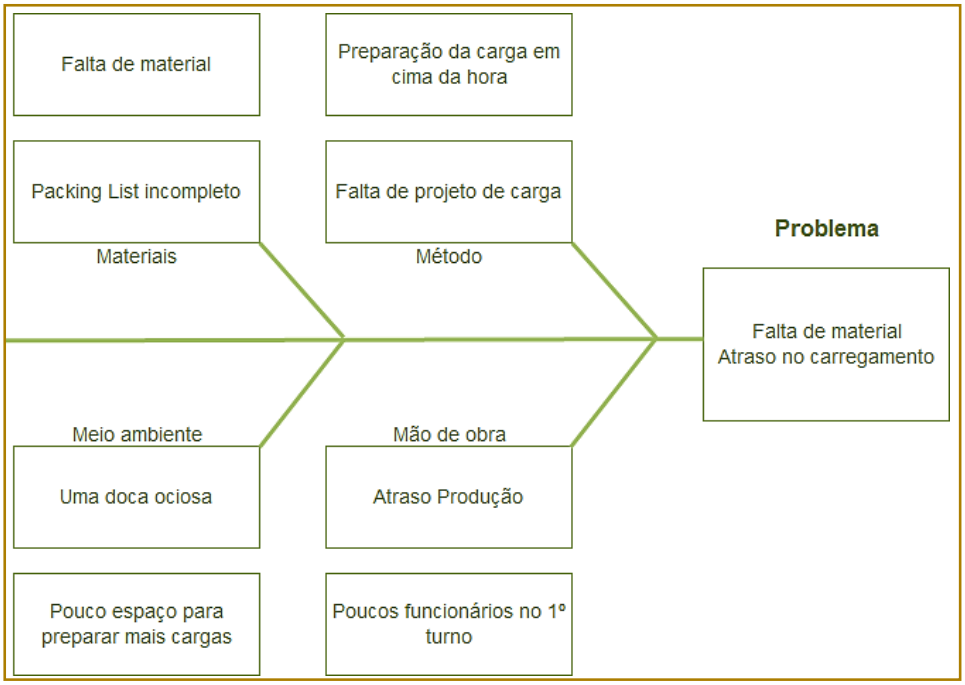

A apresentação desses problemas foi feita após o brainstorming, e para classificá-los, foram atribuídas a elas notas, conforme sua gravidade, que iam de 0 a 10 . Isso deu origem a um gráfico com as causas mais relevantes, as três maiores podem observadas nas Figuras 4 (a, b e c).

Figuras 4 - Análise gráfica dos problemas

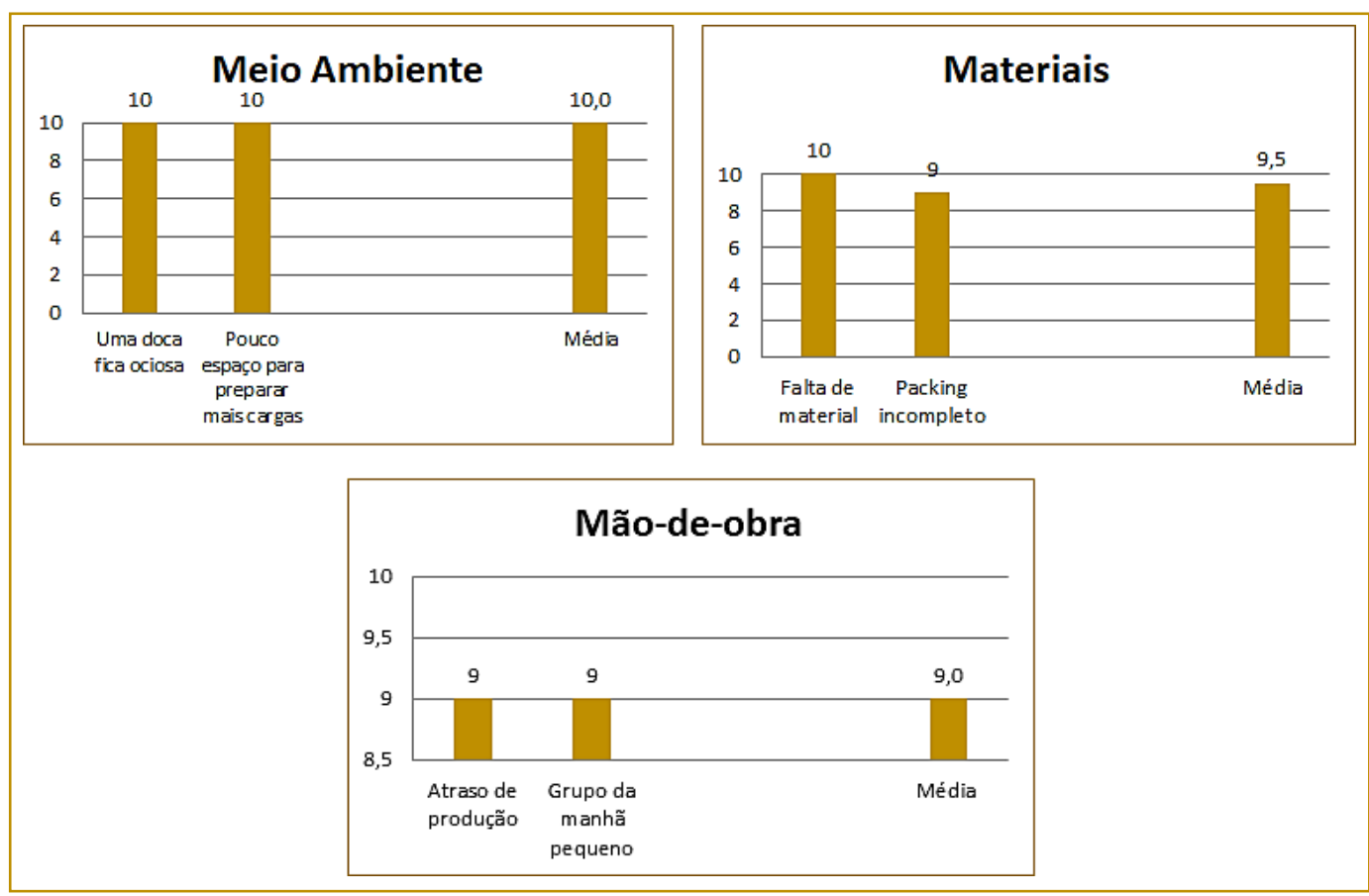

Fonte: Autores (2016). 
Dentre as causas obtidas pelo Diagrama de Ishikawa, a equipe optou por buscar uma solução para os seguintes pontos: Atraso de produção e pouco espaço para preparar mais cargas.

A falta de material e os erros do Packing List, embora tenham sido causas mais relevantes, não foram colocados em questão pelo fato de a empresa em estudo estar trabalhando na implantação de um programa que pretende resolver os problemas com materiais. Quanto à doca de caminhões que fica ociosa, seria necessário construir outra base de concreto para que ela pudesse ser utilizada, dando espaço para movimentação, porém o custo é bem alto, e foi optado por não considerar essa opção por enquanto; o mesmo para a quantidade de funcionários trabalhando no setor, que permanecerá a mesma.

Então, a opção mais relevante foi a alteração no arranjo físico de uma parte da expedição. Havia um box de carregamento em que era utilizada apenas a metade; a outra metade era ocupada por um estoque de tecidos, que são lonas que fazem parte de alguns pedidos, mas que às vezes ficam estocadas e inutilizadas.

Com isso, a proposta foi encontrar uma forma mais fácil de armazenar os tecidos, para que a área de carregamento pudesse ser totalmente utilizada. A melhor solução encontrada foi armazenar os tecidos em porta pallets, pois além de ocuparem menos espaço por poderem ser feitos sob medida (nesse caso, mais altos e estreitos), colocar os tecidos nos pallets irá economizar operações no carregamento e, com isso, tempo. O planejamento das ações de trabalho foram controladas por um PDCA (A Figura 5 mostra o PDCA da alteração do arranjo físico, com o estudo em andamento). O espaço ganho com a modificação no arranjo físico corresponde a um box inteiro de preparação, facilitando a movimentação da equipe que prepara as cargas, agilizando assim o trabalho de expedição dos pedidos. Além disso, essa alteração não tem custo de material, pois a empresa dispõe de porta pallets.

As Figuras 6 ( $a$ e b) ilustram o espaço ganho com a nova proposta dos porta pallets.

Figura 5 - PDCA em andamento

\begin{tabular}{|c|c|c|c|c|c|c|c|c|}
\hline \multicolumn{4}{|c|}{ Planejar } & \multicolumn{5}{|c|}{ Fazer } \\
\hline Ação & Prioridade & Benefício & Custo & Responsável & Início & Fim & Execução & Comentário \\
\hline Alterar arranjo físico & Alta & \begin{tabular}{|c|} 
Ganho de \\
espaço \\
para \\
carregam \\
ento
\end{tabular} & $\mathrm{R} \$ 0,00$ & Equipe & 10/mai & $15 /$ jun & $\begin{array}{c}\text { Em } \\
\text { andament } \\
\text { o }\end{array}$ & $\begin{array}{c}\text { Verificar } \\
\text { aplicação } \\
\text { do projeto } \\
\text { na empresa }\end{array}$ \\
\hline \multicolumn{9}{|c|}{ Checar } \\
\hline Situação & \multicolumn{2}{|c|}{ Riscos } & Estratégias & \multicolumn{5}{|c|}{ Lições aprendidas e ações corretivas } \\
\hline Em dia & \multicolumn{2}{|c|}{$\begin{array}{l}\text { Espaço pode ser } \\
\text { insuficiente }\end{array}$} & $\begin{array}{l}\text { Verificar } \\
\text { e medir }\end{array}$ & \multicolumn{5}{|c|}{$\begin{array}{l}\text { Medições e estudo de possibilidades dão melhor } \\
\text { visão do problema }\end{array}$} \\
\hline
\end{tabular}

Fonte: Autores (2016)

Figuras 6 - Situação atual do box de carregamento e situação proposta

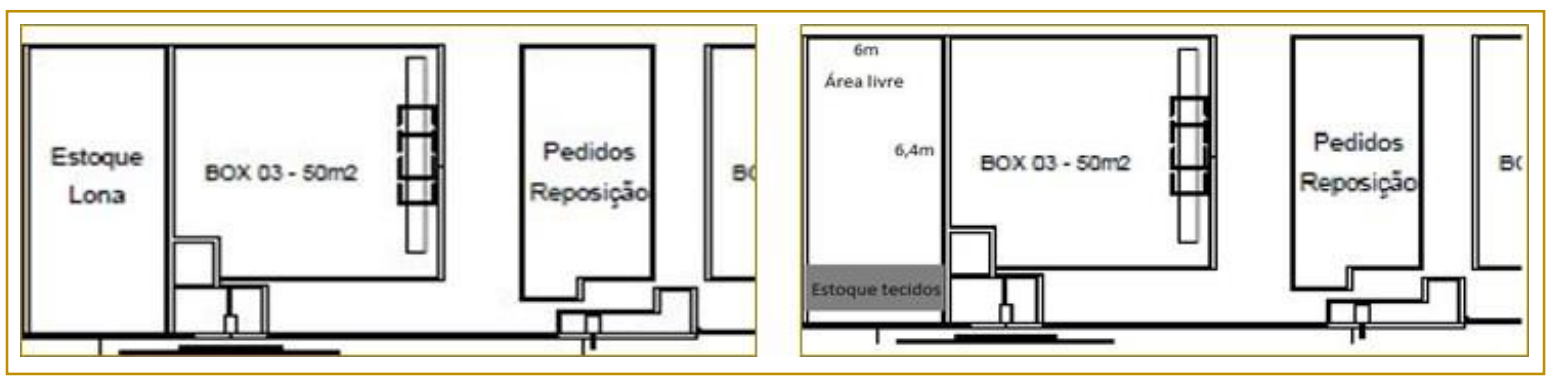




\section{CONSIDERAÇÕES FINAIS}

Os problemas e contratempos estão sempre presentes nas organizações, e cabe aos colaboradores estudarem a melhor maneira de resolvê-los, utilizando os recursos da melhor forma possível. Isso pode ser feito através de troca de ideias, estudos e uso de ferramentas.

Neste estudo foi possível perceber a influência da gestão da qualidade nos processos e a importância do uso de suas ferramentas, que são simples e podem ser utilizadas de diversas maneiras, depende da metodologia de trabalho da equipe. Uma série de informações organizadas e analisadas com certa ordem torna o problema mais claro, assim, é mais fácil saber por onde começar.

Inicialmente, a proposta era aumentar 8 carregamentos diários em 14, mas as limitações de tempo e a implantação de um sistema que a empresa já estava executando

\section{REFERÊNCIAS}

[1]. BARRETO, J; LOPES, L. Análise de falhas no processo logístico devido a falta de um controle de qualidade. Revista Produção on line. Universidade Federal de Santa Catarina. Florianópolis. Vol 5. Numero 2. Junho de 2005.

[2]. BARTUNEK, J. M.; SEO, M. Qualitative research can add new meanings to quantitative research. Journal of Organizational Behavior, v. 23, n.2, , mar., 2002

[3]. BERNARDES, C; MARCONDES, R. C. Sociologia aplicada á administração. São Paulo: Saraiva, 2005.

[4]. CARVALHO, M. M., PALADINI, E. P. Gestão da Qualidade: Teoria da Qualidade. Rio de Janeiro: Campos. 2005.

[5]. CESAR, F. I. G. Ferramentas Gerenciais $\mathrm{Da}$ Qualidade. $1^{\circ}$. ed. São Paulo: Biblioteca24horas, Seven System International Ltda., 2013.

[6]. COTEC. Pautas Metodológicas en Gestion de la tecnologia y de la Inovación para Empresas. Madrid: Innovation, 1999. 135; 141 p.

[7]. DAFT, R. L. Organizações: teoria e projetos. São Paulo: Pioneira, 2002.

[8]. DRUCKER, P. Sociedade pós-capitalista. 6 ed. São Paulo : Pioneira, 1997.

[9]. GOMES, Luis G. S. Reavaliação e melhoria dos processos de beneficiamento de não tecidos com base em reclamações de clientes. Revista dificultaram um pouco o trabalho, além da complexidade do processo, já que a variedade de produtos era grande. Mas a gestão da qualidade está também em observar os detalhes, como foi feito neste trabalho.

Uma proposta de mudança de arranjo físico desencadeou em ganho de espaço e tempo, que não aumentou visivelmente o número de carregamentos, porém agilizou o processo e deu mais espaço para a execução do trabalho da expedição, permitindo que mais carregamentos sejam preparados. Isso, atrelado a outras melhorias futuras, vai proporcionar um ganho positivo, pois segundo um dos funcionários da empresa que acompanhou o desenvolvimento do estudo "às vezes não conseguimos chegar ao objetivo real, mas uma sequência de pequenas melhorias é sempre positiva. Esse processo pode ser complexo, então, tentem modificar os detalhes".

Fae, Curitiba, v. 9, n. 1, p.35-50, jul. 2006.

Disponível em <http://www.fae.edu/publicacoes/pdf/revista_da_fa e/fae_v9_n1/rev_fae_v9_n1_04_luis_gustavo.pdf >. Acesso em: 24 nov. 2016.

[10]. JUNIOR, A. R.; BONELLI, V. V. Gestão da Qualidade e do Meio Ambiente: Enfoque econômico, financeiro e patrimonial. Editora: Atlas. São Paulo. 2006.

[11]. KANAANE, R. Comportamento humano nas organizações: o homem rumo ao século XXI. São Paulo: Atlas, 1994.

[12]. KOTLER, P. Administração de Marketing: A edição do novo milênio. Edição: $10^{\circ}$ edição. Editora Prentice Hall. São Paulo. 2000.

[13]. LEAL, A. S. et al., (2011) - Gestão da qualidade no serviço público. Disponível em: <http://www2.ufpel.edu.br/cic/2011/anais/pdf/SA/S A_00440.pdf>. Acesso em: 24 nov. 2016.

[14]. MACHADO, R. ; FRANCISCO, A. C. Melhoria contínua como ferramenta para o aumento da competitividade organizacional: um estudo de caso no setor metal metalúrgico. In: SIMPEP SIMPÓSIO DE ENGENHARIA DE PRODUÇÃO, 12., 2005, Bauru. São Paulo: 2005.

[15]. MARTINI JUNIOR, L. C. Use armas na defesa do meio ambiente. Revista BQ-Qualidade fevereiro/99, p. 78-81.

[16]. MINICUCCI, A. Técnicas do trabalho de grupo. São Paulo: Atlas, 2001. 
[17]. NECO, M. R. A. MELHORIA CONTÍNUA: UM ESTUDO DE CASO SOBRE A IMPLANTAÇÃO NA ÁREA ADMINISTRATIVA DE UMA EMPRESA E OS SEUS RESULTADOS. 2011. $51 \mathrm{f}$. Monografia (Especialização) - Curso de Gestão de Negócios, Departamento de Contabilidade, Universidade Federal do Paraná, Curitiba, 2011.

[18]. PESSOA, G. A. Círculos de controle da qualidade como instrumento de gestão participativa e motivacional. In: XVIII Enangrad, 2007. Anais do XVIII Enangrad, 2007.

[19]. PIANA, M. C. A construção do perfil do assistente social no cenário educacional [online]. São Paulo: Editora UNESP; São Paulo: Cultura Acadêmica, 2009. 233 p. ISBN 978-85-7983-038-9. Disponível em: <http://books.scielo.org/id/vwc8g/pdf/piana9788579830389-06.pdf>. Acesso em: 5 jan. 2017.

[20]. PRÉVE, A. D. OSM - Organização, Sistemas e Métodos. Florianópolis: Departamento de Ciências da Administração, 2012. 152 p. Apostila.

[21]. RIBEIRO, L. F. M. Fundamentos e Bases da Qualidade. Engenharia da Qualidade, curso de Engenharia Mecânica, Departamento de Tecnologia Unijuí. Rio Grande do Sul, 2005.
[22]. RODRIGUES, M.V. Ações para a qualidade: gestão estratégica e integrada para a melhoria dos processos na busca da qualidade e competitividade. 3. ed. Rio de Janeiro: Qualitymark, 2010.

[23]. SILVA, L. S.; FLORES, D. GESTÃO DA QUALIDADE EM ARQUIVOS: FERRAMENTAS, PROGRAMAS E MÉTODOS. In: Simpósio Baiano de Arquivologia, 9., 2011, Salvador. Anais... Salvador: 2011. Disponível em: < http://www.arquivistasbahia.org/3sba/wpcontent/uploads/2011/09/Silva-Flores.pdf>. Acesso em: 17 nov. 2016.

[24]. SILINGOVSCHI, R. A gestão da qualidade na administração e organização da unidade de informação 4 da rede de bibliotecas UNOESTE de Presidente Prudente. 2001. Monografia (Especialização) - Programa de Gerência de Unidades de Informação, Universidade Estadual de Londrina, Londrina, 2001.

[25]. XENOS, H. G.. GERENCIANDO A MANUTENÇÃO PRODUTIVA: O CAMINHO PARA ELIMINAR FALHAS NOS EQUIPAMENTOS E AUMENTAR A PRODUTIVIDADE. 2. ed. Nova Lima: Falconi, 2014. 312 p. 


\section{Bapítulo 2}

\section{SUMARIZAÇÃO DO PROCESSO DE CERTIFICAÇÃO DE TIPO DA AERONÁUTICA BRASILEIRA}

\section{Cristiane Mariano Zavati Silva}

\section{Guilherme Moreira de Souza}

Marcelo Lopes de Oliveira e Souza

Resumo: Este trabalho contextualiza a certificação para produtos aeronáuticos e sua importância no cenário nacional e internacional. Além disso, apresenta a sumarização do processo aeronáutico de Certificação de Tipo, processo esse aplicado a novos projetos. Para isso, o trabalho: 1) revisa e analisa o contexto nacional e internacional; 2) identifica o processo de certificação de tipo da indústria aeronáutica civil (ANAC); 3) elenca algumas contribuições originadas na certificação aeronáutica militar brasileira e na certificação civil internacional. Ao fim do trabalho, é possível compreender os processos utilizados e seus padrões, bem como apresentar algumas atividades e exemplos de utilização. Adicionalmente, as práticas adotadas podem servir de exemplo para outras indústrias e aplicações.

Palavras-Chave: certificação, processos, garantia do produto, aeronaves, aeronavegabilidade. 


\section{INTRODUÇÃO}

O uso comercial da indústria aeronáutica vivenciou um enorme crescimento após o fim da Segunda Grande Guerra. Se antes eram usadas apenas por aventureiros, ilustres abastados ou como mais uma máquina bélica, a qual, por sinal, reescreveu as estratégias de combate, as aeronaves conheceram naquele momento a sua maior vocação: o transporte de passageiros em larga escala. A maior prova dessa inata aptidão foi o Boeing 707, maior sucesso de vendas entre as fabricantes de aeronaves das décadas de 50 e 60 . Foram 1010 unidades produzidas, marca de difícil obtenção mesmo nos dias atuais.

Todavia, caso tivéssemos hoje os mesmos índices de acidentes aeronáuticos da década de 50 , teríamos os noticiários repletos de relatos de tragédia, tendo ceifadas centenas de vidas semanalmente. Isso ocorreria ou a aviação comercial simplesmente não seria um setor economicamente viável.

A avaliação independente da conformidade dos produtos aeronáuticos por uma terceira parte, ou seja, a certificação foi a grande solução ao problema que se erguia frente às ambições das fabricantes e operadoras de aeronaves civis. Além de ser uma ferramenta governamental de supervisão à segurança dos usuários finais -, os passageiros - a certificação aeronáutica e seus desdobramentos têm como principal objetivo impedir que acidentes causados pelas mesmas falhas de projeto ocorram mais de uma vez. Em complemento, a certificação força a indústria aeronáutica a níveis elevadíssimos de confiabilidade, utilizando elaboradas ferramentas probabilísticas e estatísticas para mitigar potenciais problemas de projeto, sem inviabilizar, contudo, o uso comercial das aeronaves. Muitos desses potenciais problemas são tratados precocemente durante as fases de desenvolvimento e certificação, evitando a necessidade de retrofits ou pagamento de indenizações que tornariam a fabricação e operação aérea inexequíveis.

No contexto internacional, a certificação aeronáutica conta com organismos respeitados e bem estabelecidos, os quais visam estabelecer requisitos mínimos para o ciclo de vida do produto aeronáutico de forma a garantir a segurança dos passageiros e das populações sobre as quais voam as aeronaves, e sua operacionalidade.

Embora os regulamentos básicos da certificação sejam objeto de um acordo internacional no âmbito da ICAO (International Civil Aviation Orgaanization), cada país tem a liberdade de possuir um corpo de regulamentação aeronáutica próprio, desde que cumpram, no mínimo, com os acordos internacionais.

Os requisitos de certificação aeronáutica obrigam os fabricantes de aeronaves e seus componentes a incorporarem exigências necessárias em todas as fases de seus respectivos projetos.

Destacam-se alguns organismos certificadores tidos como referência internacional, sendo no cenário civil o FAA (Federal Aviation Administration) nos Estados Unidos e a EASA (European Aviation Safety Agency) na Europa Ocidental; e, ainda, no contexto militar, o DoD (Departament of Defense) e NAC (national airworthiness council) dos Estados Unidos. Suas normas, regulamentos e atividades são seguidas por diversas nações, total ou parcialmente.

\section{DIAGRAMA IDEF O DE NÍVEL SUPERIOR DO PROCESSO ADOTADO NO BRASIL PARA A CERTIFICAÇÃO DE TIPO DA AVIAÇÃO CIVIL BRASILEIRA}

A Figura 1 apresenta o resumo do processo adotado pela certificação aeronáutica civil brasileira, especificando algumas entradas, saídas, recursos e limitações possíveis. 
Figura 1 - Diagrama IDEF0 de nível superior para o processo de certificação de tipo adotado pela aeronáutica civil brasileira.

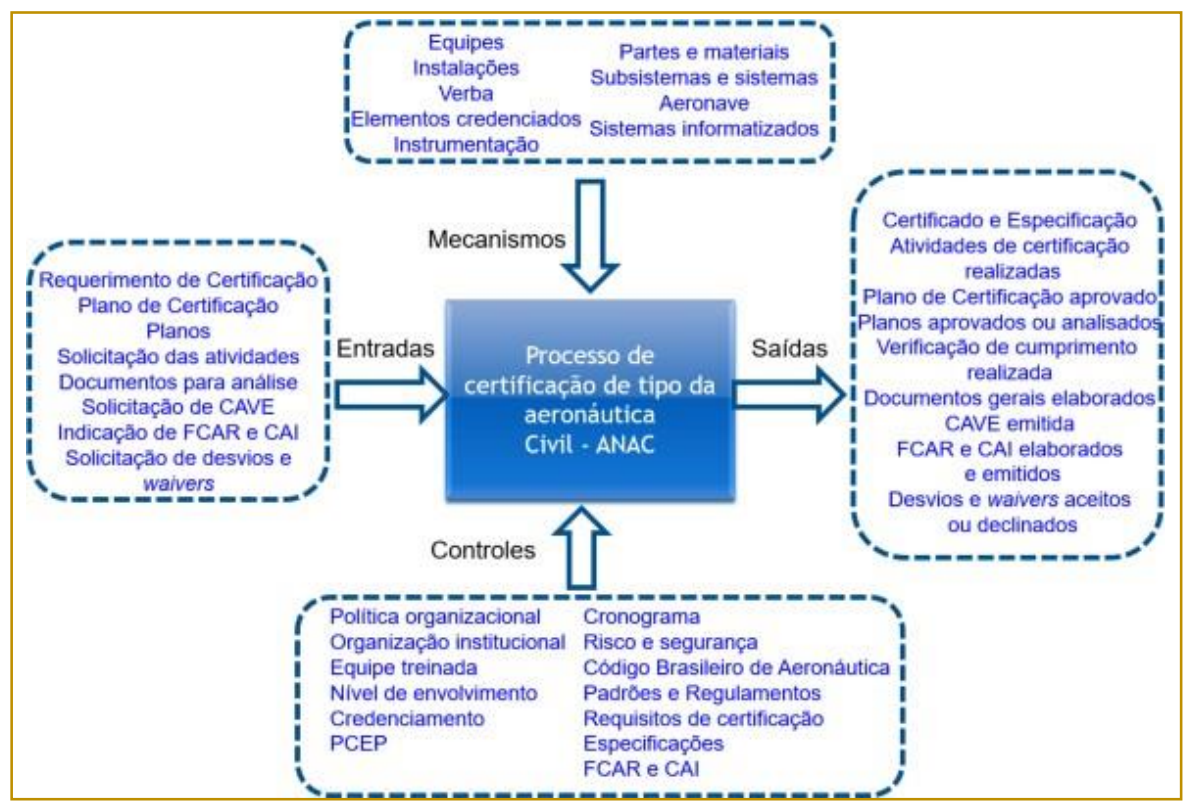

Fonte: Silva (2017)

A Figura 2 apresenta o resumo do processo adotado pela certificação aeronáutica militar brasileira, especificando algumas entradas, saídas, recursos e limitações possíveis.

Figura 2 - Diagrama IDEF0 de nível superior para o processo de certificação de tipo adotado pela aeronáutica militar brasileira.

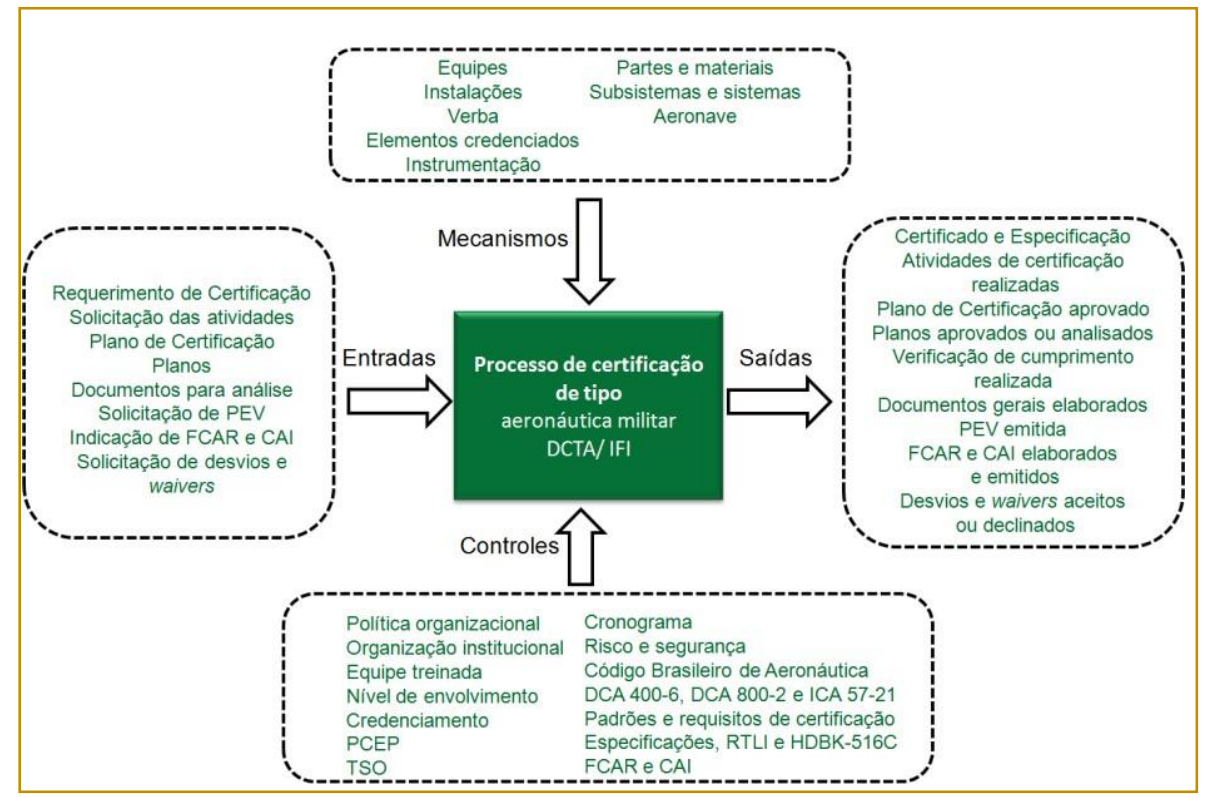

Fonte: Silva (2017). 


\section{PROCESSO DE CERTIFICAÇÃO AERONÁUTICA}

\subsection{DEFINIÇÃO DO PROCESSO}

Cf. adaptado de ANAC (2009) o produto aeronáutico deve demonstrar concordância com as exigências (regulamentos). Ou seja, para ANAC (2009) deve ser demonstrado que o projeto do produto em questão não apresenta nenhum aspecto ou característica insegura, quando operado dentro dos limites estabelecidas, para o uso pretendido. No caso de aeronaves (projeto de tipo), essas devem satisfazer as exigências vindas dos requisitos de aeronavegabilidade para uma determinada categoria, exceto aqueles considerados, pela agência reguladora, não apropriados para a missão da aeronave, baseado em ANAC (2009).

\subsubsection{PROCESSOS DE CERTIFICAÇÃO ADOTADOS NO BRASIL}

O processo de certificação aeronáutica civil adotado no Brasil segue, em boa parte, o padrão adotado pelos Estados Unidos (FAA). 0 documento que descreve o modelo de certificação utilizado na aviação civil brasileira é o RBAC 21, ANAC (2009). Nele, especificam-se os tipos de certificação existentes para um produto aeronáutico.

\subsection{DESCRIÇÃO DA CERTIFICAÇÃO DE TIPO}

Primeiramente, para Silva (2017), Certificação é atestar que o produto (aeronáutico) cumpre com os requisitos, estabelecidos pela autoridade competente, por meio de um processo pelo qual uma organização certificadora reconhece o seu projeto, após verificação técnica adequada, da conformidade com as especificações e então, emite um certificado formal para o requerente da certificação, definição essa adaptada de ANAC (2017) e COMAER (2014a).

$\mathrm{Na}$ aviação civil, a certificação de tipo é uma das ferramentas pelas quais a ANAC promove a segurança de voo, dentro do território brasileiro.

Para ANAC (2017), o Certificado de Tipo (CT) é emitido pela ANAC (autoridade de aviação civil competente), com o objetivo de atestar o cumprimento dos requisitos de certificação pelo fabricante. Adicionalmente, o CT atesta que a aeronave não possui nenhuma característica que a torne insegura, na categoria certificada. Isso ocorre através de análises de dados técnicos submetidos pelo requerente, realização de inspeções e acompanhamento de ensaios, cf. adaptado de ANAC (2017).

Já para COMAER (2014b), o processo de certificação de tipo consiste em verificar que o "projeto de tipo do produto está em conformidade com os requisitos técnicos relativos ao cumprimento da missão com segurança e reconhece oficialmente essa conformidade, mediante a emissão de um Certificado de Tipo".

\subsection{CERTIFICAÇÃO DE TIPO NACIONAL, INTERNACIONAL E DE AERONAVEGABILIDADE}

A Certificação de Aeronavegabilidade é exigida pela ANAC para todas as aeronaves civis que sobrevoam o território brasileiro, exigência solicitada através do RBAC 21, ANAC (2009). No caso dos USA, o FAA solicita através do 14 CFR Part 21, FAA (2017a). E para a Europa, a EASA faz a solicitação através do Part 21 Subpart B, EASA (2012b). Nos três casos, as aeronaves precisam possuir um Certificado de Tipo reconhecido pelo Organismo Certificador competente de cada país onde serão executadas as operações aéreas.

Tanto o FAA quanto a EASA utilizam o processo da certificação de tipo com o mesmo objetivo que a ANAC.

A ANAC possui um documento intitulado "Manual de Procedimentos - Certificação de Projeto de Tipo Brasileiro", ANAC (2010), que apresenta a política e procedimentos gerais. Além de detalhar 0 procedimento de certificação de tipo, aprovação de modificações ao projeto de tipo aprovado e base de certificação.

\subsection{CERTIFICAÇÃO DE TIPO NO COMAER (COMANDO DA AERONÁUTICA)}

De acordo com COMAER (2014a), o COMAER é a autoridade aeronáutica com a responsabilidade de gerir e regular os Sistemas de Controle do Espaço Aéreo e de Investigação e Prevenção de Acidentes Aeronáuticos, conforme previstos no Código Brasileiro de Aeronáutica (CBA), PRESIDÊNCIA DA REPÚBLICA - CASA CIVIL (1986). Como país signatário da Convenção 
de Chicago e membro do Conselho da Organização da Aviação Civil Internacional (ICAO), desde a sua fundação, o Brasil tem optado pela adoção da maior parte das normas e práticas recomendadas pela ICAO.

É tendência mundial que as aeronaves militares somente entrem em operação após a certificação de aeronavegabilidade. 0 próprio CBA, PRESIDÊNCIA DA REPÚBLICA - CASA CIVIL (1986), dispõe que a operação de uma aeronave militar fica sujeita às disposições sobre a proteção ao voo e ao tráfego aéreo, salvo quando se encontrar em missão de guerra ou treinamento em área específica. Ainda sobre o tráfego aéreo, o CBA, PRESIDÊNCIA DA REPÚBLICA - CASA CIVIL (1986) dispõe que, salvo permissão especial, nenhuma aeronave pode voar no espaço aéreo brasileiro, aterrissar no território subjacente ou dele decolar, a não ser que possua marcas de nacionalidade e matrícula, e esteja munida dos respectivos certificados de matrícula e aeronavegabilidade.

A Autoridade Certificadora do COMAER, de acordo com COMAER (2014a), é definida como sendo o Departamento de Ciência e Tecnologia Aeroespacial (DCTA), para os setores espacial (lançamentos espaciais), aeronáutico e de defesa (especificamente para aeronavegabilidade continuada e dificuldades em serviços). No DCTA, o órgão que executa as atividades de certificação de produtos e de sistemas de gestão da qualidade relacionadas ao setor aeroespacial é o Instituto de Fomento e Coordenação Industrial (IFI), cf. adaptado de COMAER (2014b).

\section{FASES DO PROCESSO DE CERTIFICAÇÃO DE TIPO CIVIL}

Abaixo estão relacionadas as fases do processo de certificação constantes no "Manual de Procedimentos - Certificação de Projeto de Tipo Brasileiro", ANAC (2010).

- Pré-requerimento

- Planejamento

- Determinação de cumprimento de requisitos

- Pós-Certificação

\section{DOCUMENTOS IMPORTANTES PARA A CERTIFICAÇÃO DE TIPO}

Seguem as descrições de alguns documentos importantes para a certificação de tipo.

\subsection{PLANO DE CERTIFICAÇÃO DA AUTORIDADE (PCA)}

O plano de certificação definido pela autoridade é estratégico, pois ele será atualizado no decorrer do processo. Este plano assegura que $o$ requerente $e$ a autoridade possuem o mesmo nível de entendimento do requisito, cf. baseado em ANAC (2009).

\subsection{BASE DE CERTIFICAÇÃO}

A base de certificação consiste dos requisitos exigidos para certificação. Ela também contempla os requisitos de aeronavegabilidade, ruído, emissões, condições especiais, níveis equivalentes de segurança, isenções, etc, cf. baseado em ANAC (2009).

Para a composição dos requisitos de certificação, no caso da aviação civil, é necessário adotar os regulamentos em vigor na data da entrada do requerimento, cf. baseado em ANAC (2009).

\subsection{PLANO DE CERTIFICAÇÃO ESPECÍFICO PARA O PROGRAMA (PCEP)}

Devido à grande troca de informações entre a autoridade de aviação civil e o requerente, é estabelecido um acordo de cooperação denominado "Plano de Certificação Específico para o Programa" (PCEP). Esse plano visa criar condições que otimizem o processo de certificação, cf. baseado em ANAC (2009).

0 acordo de cooperação consiste em uma ferramenta de gerenciamento e coordenação de atividades entre as partes. O PCEP combina informações do PCR (Plano de Certificação do Requerente) e do PCA (Plano de Certificação da Autoridade), adicionando detalhes fundamentais para a execução do programa. O PCEP é a soma do PCR com o PCA, além de possuir outas informações relevantes. Embora o PCEP esteja sujeito a revisões, os compromissos assumidos pelas partes são as expectativas de seus signatários, cf. baseado em ANAC (2009). 


\subsection{NECESSIDADE OPERACIONAL (NOP)}

Documento originado e utilizado na área militar brasileira, cf. adaptado de COMAER (2007), onde são formalizadas as carências ou deficiências constatadas, cuja superação dependa do fornecimento de um novo sistema ou material, ou ainda modificação em um já existente.

\subsection{REQUISITOS OPERACIONAIS (ROP)}

Contribuição da área militar brasileira, cf. adaptado de COMAER (2007), o documento intitulado "Requisitos Operacionais" utilizado na área militar, baseado no NOP, apresenta uma descrição das características iniciais de desempenho solicitadas para o sistema ou material, em termos quantitativos e qualitativos, levando em consideração as características da missão pretendida e segurança envolvida.

\subsection{REQUISITOS TÉCNICOS, LOGÍSTICOS E INDUSTRIAIS (RTLI)}

Outra contribuição advinda da área militar brasileira e utilizada por ela, cf. adaptado de COMAER (2007), o RTLI é um documento que se origina no ROP e consiste na fixação das características técnicas, logísticas e industriais que o sistema ou material deverá contemplar, para poder cumprir os requisitos operacionais estabelecidos.

\subsection{TECHNICAL STANDARD ORDER (TSO)}

Cf. baseado em FAA (2017b), o TSO é um documento que apresenta o padrão mínimo de desempenho para materiais, peças e equipamentos utilizados em uma aeronave civil. Quando autorizada a fabricação do material, parte ou equipamento, essa precisa estar de acordo com o TSO. O cliente deve utilizar o TSO atualizado e aprovado pela autoridade. Esse documento não autoriza a instalação e o uso do artigo na aeronave, especifica apenas que o requerente está autorizado para fabricá-lo.

\subsection{DECLARATION OF DESIGN PERFORMANCE (DDP)}

A DDP, cf. baseado em EASA (2015), é um documento que contém a definição e todas as referências relevantes do artigo desenvolvido. Seu conteúdo informativo pode ser, de certa forma, comparado com TCDS (Type Certificate Data Sheet) que acompanha o Certificado de Tipo e tem uma função de substituir uma TSO, para itens não padrão. $\mathrm{Na}$ DDP, o requerente deve declarar que o artigo foi desenvolvido, testado e fabricado com conformidade com as seções aplicáveis do Part 21, EASA (2012b) e da CS-ETSO, EASA (2017).

\section{ATRIBUTO DO DIAGRAMA IDEFO: CONTROLE DO PROCESSO DE CERTIFICAÇÃO DE TIPO ANAC}

Foi realizada a seleção de alguns fatores que contribuem positivamente para o controle da qualidade do processo ANAC, tendo como exemplo, ferramentas, práticas e critérios.

\subsection{CONTROLE DO PROCESSO: DELEGAÇÃO}

Cf. adaptado de ANAC (2009), após definir a determinação de cumprimento de requisitos, a agência opta pelo envolvimento direto ou indireto no acompanhamento do cumprimento. A ANAC opta por disponibilizar recursos nas áreas mais críticas, maximizando o uso de sistema de delegação e seus recursos próprios na supervisão.

Cf. baseado em EASA (2012a) e EASA (2012b), como contribuição adicional, oriunda da certificação aeronáutica europeia, a EASA utiliza o termo "Design Organization Approval" (DOA) para identificar organizações de projeto que possuem um sistema denominado "Design Assurance System". Tal sistema permite a implementação de uma filosofia, que traz ao processo de desenvolvimento um alto nível de qualidade desde o seu mais embrionário início. A ideia é que a organização de projeto execute atividades de comprovação e verificação de cumprimento, ao invés de ter a autoridade de aviação verificando, de perto, o cumprimento da base de certificação, como ilustrado nas Figuras 3 e 4 .

No entanto a EASA decide qual será seu Nível de Envolvimento (sigla em Inglês LoL - Level of Involvement) para cada assunto relativo ao processo de certificação, de acordo com as regras do DOA. A autoridade de aviação pode, a seu critério, solicitar maior envolvimento no processo, com o objetivo de ter maior controle sobre assuntos considerados sensíveis. Por exemplo, sobre 
apectos nos quais a organização de projeto, no decorrer das atividades de supervisão realizadas pela autoridade, tenha se mostrado deficiente no cumprimento ou verificação de um determinado requisito. Por vezes, a autoridade deseja adquirir maior conhecimento sobre determinado assunto ou tecnologia e, assim, solicita maior envolvimento no processo para capacitação de seu próprio pessoal.

Figura 3 - Conceito tradicional de certificação.

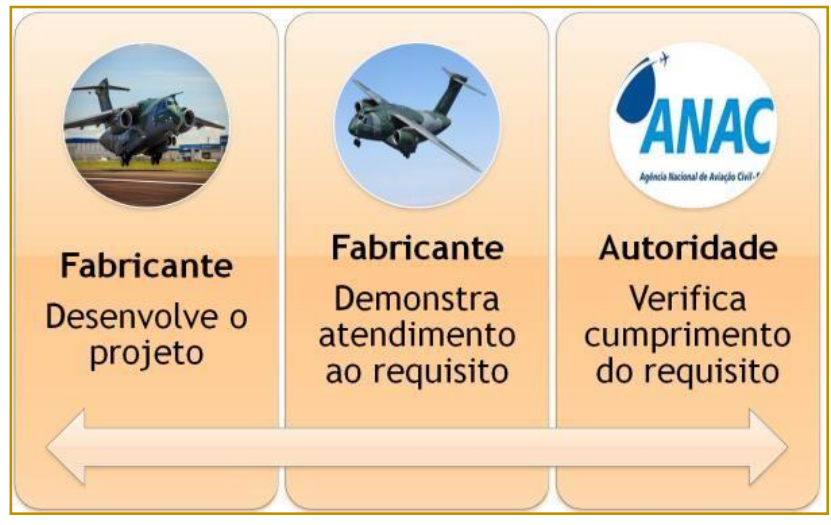

Fonte: Silva, C.M. Z. (2017).

Figura 4 - Conceito DOA (EASA) de certificação.

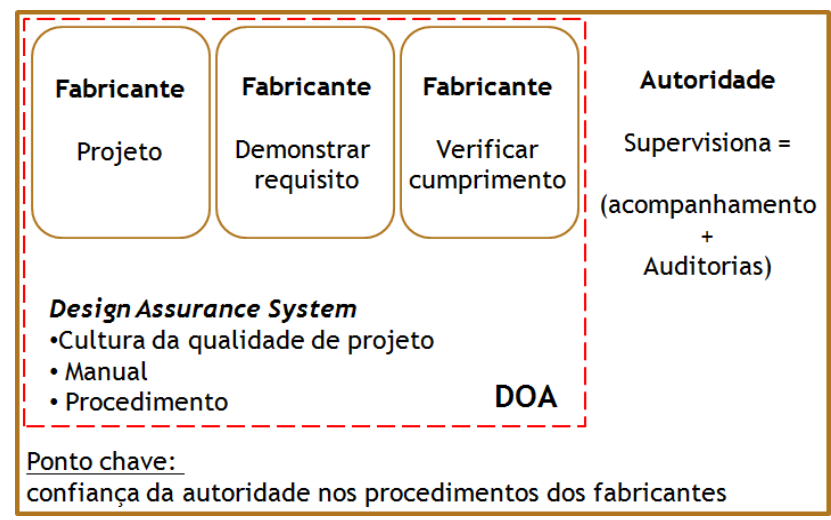

Fonte: Silva, C.M. Z. (2017).

\subsection{CONTROLE DO PROCESSO: NÍVEL DE ENVOLVIMENTO NA AERONÁUTICA CIVIL BRASILEIRA}

De acordo com ANAC (2009), mesmo que a determinação de cumprimento do requisito tenha sido delegada, é possível haver algum envolvimento adicional da ANAC. Entretanto, este envolvimento deverá ser definido com base no valor que será agregado ao processo. Quanto maior for a confiança e a capacidade técnica do representante, menor será o valor agregado devido ao envolvimento da ANAC.

Outras razões podem justificar o envolvimento direto da ANAC, as quais incluem a supervisão do projeto ou do representante, ou o desenvolvimento da capacitação técnica da equipe da ANAC. Este tipo de envolvimento direto deve ser planejado de tal forma que o cronograma do programa não seja afetado adversamente.

Além da definição do nível de envolvimento, os membros da equipe devem estabelecer o grau de supervisão que exercerão em relação ao representante, baseados na importância para a ANAC e no risco envolvido em não revisar a determinação de cumprimento de requisito delegada. 


\subsection{EXIGÊNCIAS DO PROCESSO DE} CERTIFICAÇÃO DE TIPO

A certificação da ANAC obedece à Convenção de Chicago (1944), da qual o Brasil é signatário, sendo essa reconhecida por diversos países com os quais existem acordos internacionais, cf. adaptado de ANAC (2016).

A regulamentação do setor é compreendida por Decretos, Leis, Código Brasileiro de Aeronáutica, Portarias, Decisões, Resoluções, Regulamentos, Medidas Provisórias, Instruções Normativas, Boletim de Pessoal e Serviço, Condicão Espacial, dentre outras, cf. baseado em ANAC (2017). Para a Certificação de Tipo é exigido o cumprimento dos Regulamentos Brasileiros de Aviação Civil (RBAC), cf. baseado em ANAC (2017).

No contexto da certificação aeronáutica militar brasileira, o documento que rege o ciclo de vida de sistemas e materiais utilizados é a DCA 400-6, COMAER (2007), documento intitulado "Ciclo de Vida de Sistemas e Materiais da Aeronáutica". Além disso, as diretrizes para aprovação, certificação e avaliação da conformidade, de todos os sistemas e produtos adquiridos ou desenvolvidos pelo COMAER, são estabelecidas na DCA 800-2, COMAER (2014a), documento intitulado "Garantia da Qualidade e de Segurança de Sistemas e Produtos no COMAER".

Ainda no cenário militar brasileiro, a ICA 5721, COMAER (2014b), intitulada "Procedimento de Aeronavegabilidade Militar - Procedimentos para Certificação de Produto Aeronáutico" objetiva complementar as disposições da DCA 800-2, COMAER (2014a), referentes às atividades de certificação de produto aeronáutico, de competência do DCTA. Somando-se a isso, o documento utilizado para orientar quanto aos requisitos de aeronavegabilidade é a MIL-
HDBK-516C, DoD, intitulada "Airworthiness Certification Criteria" (Critério de Certificação de Aeronavegabilidade).

Outra exigência utilizada na área militar brasileira é o RTLI (Requisitos Técnicos, Logísticos e Indústriais) que é caracterizado como um documento originado no ROP (Requisitos Operacionais) e contém as características técnicas, logísticas e industriais que o sistema ou material deverá contemplar para poder cumprir os requisitos operacionais estabelecidos, cf. adaptado de COMAER (2007).

Ainda pode-se citar o documento intitulado Technical Standard Order (TSO) que consiste do padrão mínimo de desempenho para materiais, peças e equipamentos utilizados em uma aeronave civil, cf. baseado em FAA (2017b). Esse documento é exigido tanto pela aeronáutica civil quanto pela militar brasileira.

\subsection{CONTROLE DA UTILIZAÇÃO DO PRODUTO E CONFIABILIDADE DO PROJETO: DIFICULDADES EM SERVIÇO}

De acordo com o COMAER (2014a), "Dificuldades em Serviço" é definida como: todo e qualquer evento com potencial de diminuir o nível de segurança na operação dos produtos aeronáuticos, tais como acidentes, incidentes, erros em procedimentos e documentos de operação e manutenção, falhas, mau funcionamentos e defeitos. A atuação em "Dificuldades em Serviço" durante o Ciclo de Vida do produto pode ser vista na Figura 5.

O RBAC 21, ANAC (2009), também estabelece que todas as informações referentes a ocorrências em operação, mau funcionamento, defeitos e falhas de um produto aeronáutico certificado devem ser reportadas à ANAC. A submissão de ocorrências pode ser vista na Figura 
Figura 5 - Submissão de ocorrência à ANAC.

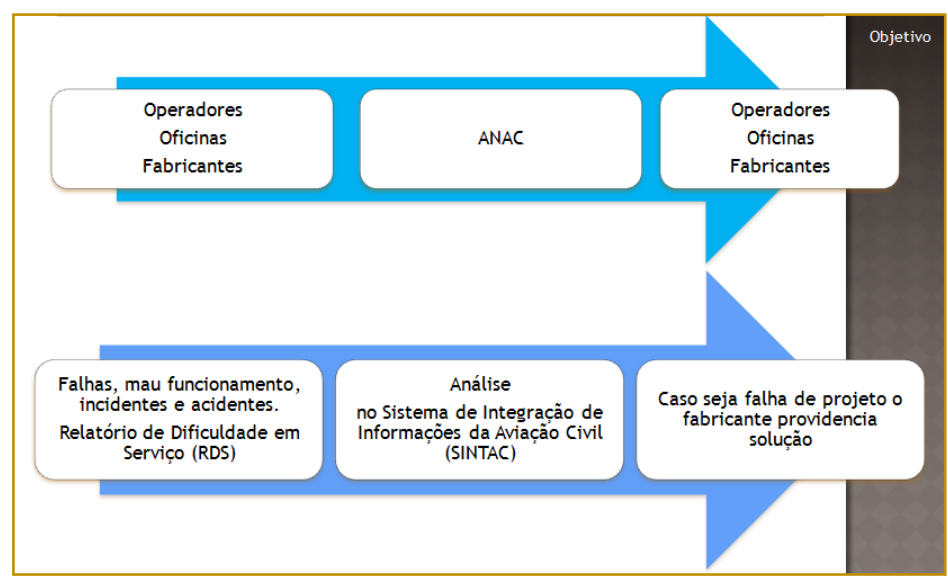

Fonte: Silva, C.M. Z. (2017).

\subsection{CONTROLE DE DOCUMENTOS: FICHA DE CONTROLE DE ITENS RELEVANTES E CERTIFICATION ACTION ITEM (FCAR E CAI)}

Conforme ANAC (2009), os itens de maior relevância deverão ser controlados via FCAR (Ficha de Controle de Assunto Relevante); outros itens, também importantes, porém com menor relevância, poderão ser acordados via CAl (Certification Action Items).

A FCAR e o CAl são registros que servem como instrumentos de modo a permitir a identificação, registro e resolução dos itens relevantes aos requisitos de certificação, com relação aos aspectos técnicos e administrativos, cf. adaptado de ANAC (2009).

\section{ATRIBUTO DO DIAGRAMA IDEFO: MECANISMO DO PROCESSO DE CERTIFICAÇÃO DE TIPO ANAC}

Relembrando, "recurso" ou "mecanismo" consiste do que é necessário para que a atividade ocorra. Exemplos: recursos humanos especializados (disciplinas específicas, individualmente ou em grupos ou equipes), equipamentos, serviços, suprimentos, commodities, materiais, orçamentos ou fundos, cf. baseado em PMBOK $5{ }^{\circ}$ ed., PMI (2013).

\subsection{RECURSOS HUMANOS: INSTITUIÇÃO RESPONSÁVEL}

Criada pela Lei 11.182 de 2005, PRESIDÊNCIA DA REPÚBLICA - CASA CIVIL (2005), a ANAC é uma das agências reguladoras federais do Brasil, cujo objetivo é regular e fiscalizar a aviação civil e a infraestrutura aeronáutica e aeroportuária do Brasil. Iniciou suas atividades em substituição ao DAC (Departamento de Aviação Civil).

"A agência é uma autarquia federal de regime especial sendo vinculada ao Ministério dos Transportes, Portos e Aviação Civil. Suas atividades são de certificação, fiscalização, normatização e representação institucional", PRESIDÊNCIA DA REPÚBLICA - CASA CIVIL (2005).

\subsection{RECURSOS HUMANOS: CREDENCIAMENTO DE PESSOAS}

O RBAC 183, ANAC (2011), intitulado "Credenciamento de Pessoas", define os requisitos para o credenciamento de pessoas, com notória especialização, para a emissão de laudos, pareceres ou relatórios que demonstrem o cumprimento das exigências (requisitos) à emissão de certificados ou atestados relativos às atividades de competência da ANAC.

A ANAC credencia pessoas físicas vinculadas a um detentor de certificado emitido pela ANAC, pessoas físicas autônomas e pessoas jurídicas.

\subsection{MECANISMOS GERAIS DO PROCESSO DE CERTIFICAÇÃO DE TIPO}

Seguem alguns mecanismos necessários para a execução das atividades de certificação listadas nesta seção:

- $\quad$ partes e componentes das aeronaves; 
- $\quad$ equipamentos, subsistemas, sistemas das aeronaves;

- instalações, instrumentações, laboratórios de aplicações aeronáuticas; e

- RIGs (ferramenta/ dispositivo que permite ao piloto a interação em ambiente controlado, através dos novos sistemas embarcados) das aeronaves.

\section{CONCLUSÃO}

Este trabalho, primeiramente, apresentou um breve histórico da certificação aeronáutica e sua atuação no contexto internacional, onde foi possível citar alguns exemplos e práticas utilizados.

Posteriormente, foi sumarizado o processo utilizado pela certificação de tipo da aeronáutica civil brasileira (ANAC). E ainda, acrescentou contribuições vindas da certificação aeronáutica europeia, americana e militar brasileira (IFI).

\section{REFERÊNCIAS}

[1]. AGÊNCIA NACIONAL DE AVIAÇÃO CIVIL (ANAC). Regulamento Brasileiro de Aeronáutica Civil (RBAC) - certificação de produto aeronáutico. Brasília, 2009. n. 21.

[2]. AGÊNCIA NACIONAL DE AVIAÇÃO CIVIL (ANAC). Manual de Procedimentos (MPR). Certificação de projeto de tipo brasileiro. Brasília, 2010. (MPR 200).Rev. 02, 11 mai. 2010. (MPR-200).

[3]. AGÊNCIA NACIONAL DE AVIAÇÃO CIVIL (ANAC): Regulamento Brasileiro de Aeronáutica Civil (RBAC). Credenciamento de pessoas. Brasília, 2011. (RBAC) $\mathrm{N}^{\circ} 183$ Emenda $\mathrm{N}^{\circ} 00$. Disponível em:

http://www.anac.gov.br/assuntos/legislacao/legisla cao-1/rbha-e-rbac/rbac/rbac-183-emd-

00/@@display-

file/arquivo_norma/RBAC\%20183.pdf> Acesso em: 9 out. 2016. AGÊNCIA NACIONAL DE AVIACC̃̃O CIVIL (ANAC). Certificação. Brasília, 2016. Atualizado em: 29 fev. Disponível em: <http://www.anac.gov.br/A_Anac/o-que-

fazemos/certificacao>. Acesso em: 09 mar.2017.

[4]. AGÊNCIA NACIONAL DE AVIAÇÃO CIVIL (ANAC). Legislação. Brasília, 2017. Atualizado em: 19 out. Disponível em: <http://www.anac.gov.br/assuntos/legislacao>. Acesso em: 09 mar.2017.

[5]. COMANDO DA AERONÁUTICA MINISTÉRIO DA DEFESA (COMAER). Logística ciclo de vida de sistemas e materiais da aeronáutica. Brasília, 2007. (DCA 400-6). Diretriz.
Ainda, foram apresentados conceitos e práticas utilizadas na indústria aeronáutica e os alguns processos foram ilustrados através de diagramas IDEF 0 , tanto para a aeronáutica civil quanto para a militar, no cenário brasileiro. Juntamente com 0 aprofundamento de cada atributo apresentado.

Finalmente, houve a possibilidade de compreender, brevemente, os processos, as práticas e os padrões utilizados pela indústria em questão. Evidenciando a estruturação das atividades e a padronização da atuação, que visam promover a segurança e atender a missão pretendida.

Ao sumarizar o processo de certificação aeronáutica, teve-se como objetivo evidenciar práticas adotadas para podem servir de exemplo para outras indústrias e suas aplicações.

[6]. COMANDO DA AERONÁUTICA MINISTÉRIO DA DEFESA (COMAER). Garantia da qualidade e da segurança de sistemas e produtos no COMAER. São José dos Campos, 2014a. (DCA 800-2). Diretriz.

[7]. COMANDO DA AERONÁUTICA MINISTÉRIO DA DEFESA (COMAER). Regulamento de aeronavegabilidade militar - procedimentos para certificação de produtos aeronáuticos. São José dos Campos, 2014b. (ICA 57-21). Instrução.

[8]. EASA (2012a) - EUROPEAN AVIATION SAFETY AGENCY (EASA): Acceptable Means of Compliance and Guidance Material to Part 21 (AMC and GM to Part 21). Amendement Subpart B, Issue 2. The European Parliament and of the Council, 3 out. 2012. Disponível em: < https: / /www.easa.europa.eu/system/files/dfu/Annex \%20I\%20to\%20ED\%20Decision\%202012-020-

R.pdf>. Acesso em: 15 mar. 2017. EUROPEAN AVIATION SAFETY AGENCY (EASA): Regulamento (UE) $\mathrm{N}^{\circ} 748 / 2012$. The European Parliament and of the Council, 3 ago. 2012bDisponivel em: < http://www.anac.pt/vPT/Generico/LegislacaoRegula mentacao/LegislacaoSector/Documents/Aeronaveg abilidade/Regulamento_UE_748_2012_Comissao_r evoga_CE\%201702_2003).pdf>. Acesso em: 9 mai. 2016.

[9]. EUROPEAN AVIATION SAFETY AGENCY (EASA): Regulamento (UE) N748/2012.The European Parliament and of the Council, 3 ago. 2012b. Disponível em: < http://www.anac.pt/vPT/Generico/LegislacaoRegula mentacao/LegislacaoSector/Documents/Aeronaveg 
abilidade/Regulamento_UE_748_2012_Comissao_r evoga_CE\%201702_2003).pdf>. Acesso em: 9 mai. 2016.

[10]. EUROPEAN AVIATION SAFETY AGENCY (EASA): FAQ n. 19457 (DDP). The European Parliament and of the Council, 7 mai. 2015. Disponível em: < http:// www.easa.europa.eu/faq/19457>. Acesso em: 21 mar. 2017.

\section{[11]. EUROPEAN AVIATION SAFETY AGENCY} (EASA): CS-ETSO European Technical Standards Orders. The European Parliament and of the Council, mar. 2017. Disponível em: < https: / /www.easa.europa.eu/certificationspecifications/cs-etso-european-technicalstandard-orders>. Acesso em: 21 mar. 2017.

[12]. FEDERAL AVIATION ADMINISTRATION (FAA). Title 14 - Part 21 - certification procedures for products and articles, Subpart C, Aircraft. Washington, atualizado em 13 mar. 2017a. . Electronic Code of Federal Regulation. Disponível em: < http://www.ecfr.gov/cgi-bin/textidx? rgn=div5;node=14\%3A1.0.1.3.9>. Acesso em: 15 mar. 2017.
[13]. FEDERAL AVIATION ADMINISTRATION (FAA). Technical Standard Orders (TSO) Washington, atualizado em mar. 2017b. Electronic Code of Federal Regulation. Disponível em: < http://rgl.faa.gov/Regulatory_and_Guidance_Library /rgTSO.nsf/MainFrame?OpenFrameSet>. Acesso em: 21 mar.2017.

[14]. PRESIDÊNCIA DA REPÚBLICA - CASA CIVIL.Lei 7.565 - Código Brasileiro de Aeronáutica. Brasília, 19 dez. 1986. Disponível em: <http://www.planalto.gov.br/ccivil_03/leis/L7565.ht m> Acesso em: 10 mar. 2016.

[15]. PRESIDÊNCIA DA REPÚBLICA - CASA CIVIL.Lei 11.182- Criação da Agência Nacional de Aviação Civil.Brasília, 27 set. 2005. Disponível em: <http://www.planalto.gov.br/ccivil_03/_ato20042006/2005/Lei/L11182.htm> Acesso em: 2 mar. 2016.

[16]. SILVA, Cristiane Mariano Zavati. Identificação de um processo da garantia do produto espacial (INPE) e proposição de seu aperfeiçoamento baseada na sumarização de um correspondente processo aeronáutico (ANAC) São José dos Campos : INPE, 2017. xxx + 191 p. ; (sid.inpe.br/mtc-m21b/2017/02.06.19.45-TDI). 


\section{Bapítulo 3}

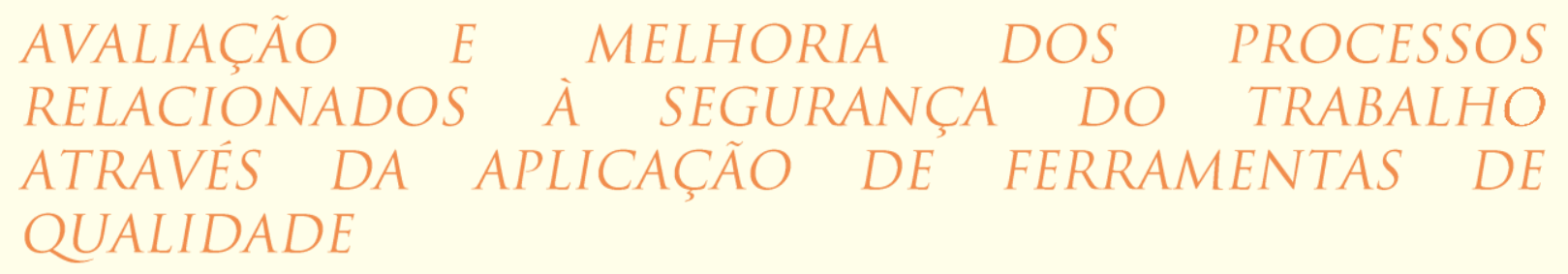

\section{Michellen dos Santos Vasques da Silva}

Jesimar da Cruz Alves

Adauri Silveira Rodrigues Junior

Resumo: 0 presente artigo tem como objetivo a aplicação das ferramentas de qualidade na solução de problemas relacionados à processos da área de Segurança do Trabalho de uma empresa do ramo ferroviário. Para isto, utilizou-se como metodologia uma pesquisa-ação de natureza aplicada com abordagem qualitativa e quantitativa, com base na revisão de literatura realizada, fazendo coleta de dados, análises e elaboração e implementação de plano de ações. 0 trabalho apresentou resultados satisfatórios, visto que foi alcançada a reestruturação da ferramenta de segurança em foco no estudo de caso e implantação de melhorias obtendo alavancagem dos resultados dos processos e na auditoria, mostrando a eficácia da utilização das ferramentas de qualidade, independente do ramo e do tipo de aplicação.

Palavras-chave: Qualidade; Segurança; Melhorias. 


\section{INTRODUÇÃO}

A globalização causou mudanças no mercado devido a evolução da tecnologia, a rapidez na divulgação das informações e a constante necessidade de novos produtos, com isso houve o surgimento de diversas empresas, e a concorrência no mercado tornou-se cada vez mais forte, obrigando as empresas a planejarem seus negócios com estratégias competitivas, pois os consumidores tornaram-se mais exigentes, desejando produtos que atendam às suas necessidades e desejos e superem suas expectativas. Devido a essa nova forma do mercado se apresentar, surge a necessidade de priorizar a melhoria nos processos, visando um bom padrão de qualidade, com produto seguro, com preço justo e com atratividade aos clientes.

Por isso, as empresas, atualmente, com o objetivo de manter-se no mercado competitivo e melhorar seus negócios, estão preocupando-se mais com os pilares manutenção, qualidade e segurança, já que anteriormente o foco do meio industrial era para o processo com produção em grande volume. Com essa mudança comportamental das organizaçõos, uma das vertentes que tem se fortalecido e merece destaque é a preocupação com o Controle da Qualidade Total, em que há aumento da utilização de ferramentas de qualidade para analisar e modificar diversos setores da empresa, resolvendo problemas e melhorando o ambiente de trabalho, tendo como finalidade o atendimento às necessidades e a superação das expectativas do cliente ao ofertar seus produtos e/ou serviços.

As ferramentas da qualidade são técnicas que auxiliam na obtenção, organização e análises das informações necessárias para resolução de problemas (TRIVELLATO, 2010). As ferramentas de qualidade podem ser utilizadas na resolução e melhoria das mais diversas situações, portanto, podem ser aplicadas em diversos assuntos e segmentos dentro de uma empresa, como, por exemplo, aplicação para solução de problemas e adequações dentro da Segurança do Trabalho que tem ganhado destaque cada vez maior nas organizações.

A Segurança do Trabalho é um conjunto de medidas aplicadas na busca pela prevenção de acidentes durante a realização de atividades nas empresas, visando evitar a existência de condições inseguras no ambiente de trabalho. Os desperdícios provenientes da ausência ou precariedade das ações de prevenção de acidentes do trabalho conspiram contra a saúde financeira e a sobrevivência das empresas (ZOCCHIO, 1980).

0 problema principal abordado neste estudo foi a pontuação insatisfatória ao final da Auditoria de Certificação, e ao analisar com a equipe multidisciplinar os impactos de cada pilar e as suas notas foi levantada a fragilidade do pilar de Equipamentos/Ferramentas/ Instrumentos, e teve como foco para tratativa o item referente à Inspeção Planejada de Segurança em equipamentos e ferramentas antes da sua utilização, devido a não adequação aos processos, pois mostrou-se não bem implementada e não atendendo à total realidade e necessidade da rotina da empresa, impactando assim nos resultados de qualidade e podendo afetar o índice de acidentes da empresa. Sendo assim, este trabalho buscou avaliar a eficiência da aplicação das ferramentas de qualidade em uma importante ferramenta da rotina de Segurança do Trabalho da empresa $X$ do ramo ferroviário, a partir de uma auditoria de processo, realizando assim a análise do cenário e a aplicação de ações buscando melhoria dos resultados.

\section{FUNDAMENTAÇÃO TEÓRICA}

\subsection{SEGURANÇA DO TRABALHO}

As constantes mudanças no mercado atual são perceptíveis, sendo assim fica claro que as empresas precisam se adaptar para conseguirem satisfazer as necessidades e desejos dos consumidores, e para isso ocorre a produção de bens e serviços através de atividades nos postos de trabalho, onde são realizadas diversas etapas intermediárias até que seja obtido o produto ou serviço final que será disponibilizado no mercado.

No entanto, se essas atividades nos postos de trabalho forem realizadas sem planejamento, podem gerar perdas nos ativos tangíveis e intangíveis da empresa. As perdas em ativos tangíveis seriam na parte patrimonial que são os bens materiais e as perdas em ativos intangíveis seriam a saúde e a segurança expressa na forma de acidentes de trabalho ou doenças ocupacionais (BARBOSA E BARSANO, 2014). Pode-se dizer assim que um planejamento inadequado 
do processo produtivo e das atividades de trabalho refletem no índice de ocorrência de acidentes de trabalho na organização.

As estatísticas de acidentes de trabalho possibilitaram às organizações uma nova percepção de que competitividade e lucro não são suficientes para a sobrevivência no mercado, e sim de que necessitam ter atitudes éticas e responsáveis quanto à segurança e saúde no trabalho e para isso devem desenvolver e implementar um eficiente sistema de Segurança e Saúde no Trabalho (MATTOS E MÁSCULO, 2011).

Segurança do Trabalho é um conjunto de medidas técnicas, administrativas, educacionais, médicas e psicológicas aplicadas para prevenir acidentes nas atividades das empresas, indispensável à consecução plena de qualquer trabalho, essas medidas têm por finalidade evitar a criação de condições inseguras e corrigi-las quando existentes nos locais ou meios de trabalho, bem como preparar as pessoas para a prática de prevenção de acidentes (ZOCCHIO, 1980).

A Segurança do Trabalho tem sido considerada pelas empresas como parte importante do negócio e não mais apenas como algo a ser cumprido devido às leis, e sim vista como um bem intangível que agrega valor ao produto ou serviço, gerando assim um destaque à empresa no seu ramo de negócio (PITTA, 2008).

\subsection{GESTÃO DA QUALIDADE}

As organizações atingem um diferencial competitivo quando privilegiam processos de qualidade nas suas práticas administrativas. Ou seja, ao ter a visão de que a qualidade deve ser tratada de forma estratégica, consegue envolver toda a organização na gestão de qualidade através de atividades e procedimentos que buscam atingi-la, tornando-se assim uma filosofia de sobrevivência (SOUZA E MACHADO, 2011).

Segundo Oakland (1994, p.15), "qualidade é o atendimento das exigências do cliente". Para Feigenbaum (1994, p.8), "qualidade é a combinação de características de produtos e serviços referentes a marketing, engenharia, produção e manutenção, através das quais produtos e serviços em uso corresponderão às expectativas do cliente". Juran (1992, p.9), afirma que "qualidade é ausência de deficiências, ou seja, quanto menos defeitos, melhor a qualidade".

Diante dessas diversas variações sobre o conceito de qualidade que se reformulam ao longo do tempo como pôde ser observado, pode-se entender qualidade como o atendimento às necessidades e exigências do cliente através da combinação de características desejadas pelo mercado no produto que se apresentarão sem defeitos e máxima adequação ao uso. No entanto, o grande desafio das empresas seria conseguir fazer todas as adequações nos seus processos e produtos de forma a cumprir esse conceito máximo sugerido, por isso deve focar no que the é possível realizar a curto e a longo prazo, entendendo o mercado e assim buscando adequar-se para participar ao máximo atendendo a essa qualidade buscada pelo mercado fortemente competitivo.

Por que a qualidade total? Clientes cada vez mais exigentes quanto a qualidade $e$ competência das empresas, a concorrência acentuada exigindo competitividade e competência, processo de rápidas mudanças e obrigando as organizações terem ações rápidas de forma flexível e inteligente, desenvolvimento de pessoas através de treinamento e qualificação para valorização do funcionário, comprometimento social e ambiental cuidando da imagem em assuntos relacionados a sustentabilidade (CAMARGO, 2011).

Na Gestão pela Qualidade Total, o foco não é apenas nos produtos e processos visando o atendimento das exigências e necessidades dos clientes, são envolvidos também saúde, segurança e motivação dos colaboradores. Além disso, é visada a simbiose da empresa com a comunidade e com o meio ambiente (NEVES, 2007).

\subsection{FERRAMENTAS DA QUALIDADE}

As ferramentas da qualidade são recursos usados no TQC (Total Quality Control Controle Total da Qualidade) que tornam possível analisar os fatos e os dados para as tomadas de decisões mais assertivas com a situação em estudo (DIGROCCO, 2008). Elas têm como finalidade estruturar esse processo produtivo, pois permitem coletar os dados, organizá-los, estudá-los, visando auxiliar o controle de qualidade (PALADINI, 1997). Percebe-se assim a relevância e a aplicabilidade das ferramentas de qualidade 
para proporcionar melhorias nos processos organizacionais e ajuda gestores nos processos de decisão, além de entender que pode ser utilizada em qualquer setor da empresa. De acordo com Dias (2016), as ferramentas da qualidade são utilizadas para definir, mensurar, analisar e propor soluções aos problemas identificados que interferem no desempenho dos processos organizacionais.

\subsubsection{FOLHA DE VERIFICAÇÃO}

A folha de verificação é uma planilha para o registro de dados com objetivo de facilitar e organizar a coleta de dados referentes ao problema, proveniente de fontes históricas ou observações dos processos, pois ela torna a coleta de dados mais rápida e garantindo objetividade ao definir antes quais dados serão necessários coletar para estudo (Menezes, 2013).

\subsubsection{GRÁFICO DE PARETO}

A análise de Pareto foi criada pelo economista Vilfredo Pareto e aplicada por Juran como forma de classificar os problemas de qualidade em "poucos vitais" e "muitos triviais" (CAMPOS, 2004). Vilfredo Pareto dizia que poucas causas são vitais, sendo a maioria delas triviais. O gráfico de Pareto demonstra de forma quantitativa as causas mais significativas, em ordem decrescente, montadas a partir do uso das ferramentas de coleta de dados e estratificação (SILVA, 1995). O princípio de Pareto é conhecido pela proporção $80 / 20$, ou seja, $80 \%$ dos problemas resultam de apenas $20 \%$ das causas potenciais. Isso significa que a maior parte dos defeitos, falhas e reclamações é proveniente de um pequeno número de causas, fazendo assim uma priorização de ações sobre as causas que terão maior impacto se forem resolvidas (WERKEMA, 2013; MENEZES, 2013).

\subsubsection{DIAGRAMA DE CAUSA E EFEITO}

O diagrama de causa e efeito é usado para demonstrar a relação entre o efeito de um processo (resultado) e as causas possíveis que possam afetar o resultado considerado (WERKEMA, 2006). É conhecido como espinha de peixe devido ao formato do diagrama, onde o efeito (problema) é colocado na extremidade ("cabeça") e o "corpo" são as causas possíveis, mostrando como estão inter-relacionados. Esse diagrama está definido em seis categorias conhecido como 6M's: método (procedimentos, maneiras de executar as tarefas); mão-de-obra (conhecimentos e habilidades das pessoas envolvidas); material (recursos para o processo); máquina (condições e capacidade das instalações e equipamentos); meio ambiente (fatores do ambiente); medida (medições) (WERKEMA, 2013; MENEZES, 2013).

\subsubsection{PLANO DE AÇÃO (5W2H)}

Para Meireles (2001), o plano de ação pode ser representado através do $5 \mathrm{~W} 2 \mathrm{H}$ cujas perguntas tem origem em inglês: what (o que) em que descreve o que será feito (etapas); who (quem) em que descreve quem realizará as tarefas (responsáveis); when (quando) em que descreve quando cada uma das tarefas deverá ser executada (tempo); where (onde em que descreve onde cada tarefa será executada (local); why (por que) em que descreve por que deve ser executada a tarefa (justificativa); how (como) em que descreve como deverá ser realizada cada tarefa (método); howmuch (quanto) em que descreve quanto custará cada etapa (custo).

\section{METODOLOGIA}

A pesquisa realizada neste estudo pode ser classificada como de natureza aplicada, quanto ao objetivo é uma pesquisa exploratória, com abordagem qualitativa e quantitativa, e quanto ao tipo classifica-se como pesquisa-ação. De acordo com Silva e Menezes (2001), a pesquisa aplicada tem objetivo de gerar conhecimentos para aplicação prática, voltado à solução de problemas. Para Gil (2002), a pesquisa exploratória tem o objetivo de constituir hipóteses para tornar o problema mais claro e envolve levantamento bibliográfico e entrevista com pessoas que possuem experiência com o cenário analisado e com o problema pesquisado. Para Thiollent (1992), pesquisa-ação é um tipo de pesquisa onde os pesquisadores analisam e adquirem conhecimento da situação ou do problema e estão envolvidos de modo participativo também na aplicação das ações e na resolução do problema. 


\section{DESCRIÇÃO DA PESQUISA E APLICAÇÃO DAS FERRAMENTAS DE QUALIDADE}

A pesquisa foi realizada em uma empresa $X$ do ramo ferroviário da região Sudeste que possui um projeto de certificação conhecido como Oficina Modelo com foco em segurança operacional e pessoal, qualidade na execução (confiabilidade) e eficiência da mão de obra (produtividade).

A Auditoria de Oficina Modelo é uma auditoria de qualidade de processo que visa avaliar a aderência da unidade ao projeto Oficina Modelo avaliando a aderência à itens importantes para o funcionamento dentro de procedimentos, diretrizes e padrões de gestão definidos pela Diretoria Corporativa, e ao atender satisfatoriamente considera-se a unidade como certificada.

A oficina é analisada, auditando através de um check-list diversos itens que fazem parte de capítulos gerais: A - Identificação da Oficina; B - Condições Físicas de Suporte da Oficina; C - Equipamentos, Ferramentas e Instrumentos; D - Materiais e Partes; E Literatura Técnica; $F$ - Registros de Manutenção; G - Pessoal Técnico; H - Meio Ambiente. Os itens analisados de cada capítulo recebem pontuação que varia de 0 a 5 , e para receber a certificação a oficina precisa atingir uma pontuação final entre 4,5 e 5,0 .

Fazendo uma análise dos resultados de 2015 e 2016, buscando assim encontrar oportunidades de melhoria para alavancar o processo e a nota de 2017, pode-se traçar a figura 1 que mostra a pontuação de cada capítulo na auditoria de 2015 e na auditoria de 2016, podendo perceber como foram as evoluções ou involuções.

FIGURA 1 - Gráfico das Notas por Capítulo das Auditorias de 2015 e 2016.

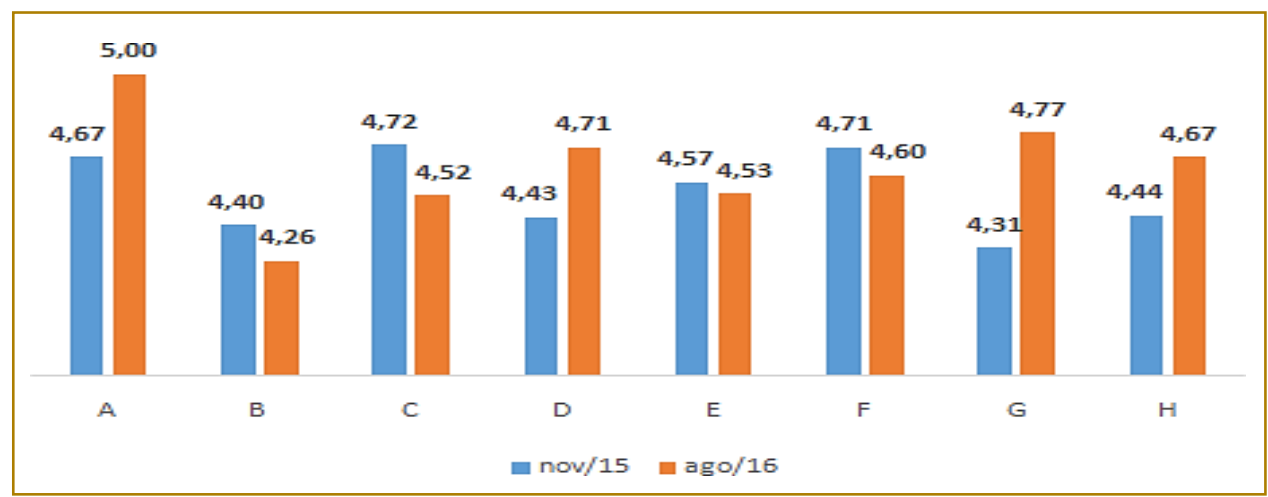

Fonte: Autores (2017)

Nota-se que o Capítulo B - Condições Físicas de Suporte da Oficina - foi o mais impactante, necessitando de ações imediatas para obter melhorias nos resultados, tendo como principais desvios questões estruturais ruins ou inadequadas referente a pisos, sinalização, telhados, iluminação. No entanto, estes desvios estão relacionados à necessidade de recursos financeiros, então não há efetiva atuação sobre este capítulo, dependendo de Defesa de Investimentos feito ao final de cada ano. Por isso, o outro capítulo analisado foi o $\mathrm{C}$ referente a equipamentos, ferramentas e instrumentos, entendendo $o$ que houve de desvio, podendo citar equipamentos/ferramentas/painéis elétricos sem a devida identificação, divergência entre a área física e o sistema (lista mestra), falha no controle de instrumentos calibráveis, equipamentos sem formulário de pré-uso, ausência de assinatura e validação em documentos, rasuras em documentos, formulários de inspeção de pré-uso sem tratativa de não conformidades (NC).

Dentre os desvios identificados, o de maior valorização para a empresa $X$ são aqueles relacionados a questões de segurança e dentre os itens de desvio foi detectada a inspeção de pré-uso com pontuação zero nas auditorias dos dois anos seguidos, o que fez o olhar ser direcionado para este ponto pois a execução incorreta do pré-uso ou a não execução gera impactos negativos nos resultados de segurança, pois está relacionado com a prevenção de incidentes e acidentes. 
A Inspeção de Pré-Uso é uma inspeção feita em todos os equipamentos, máquinas $e$ ferramentas que, em caso de falha, poderão provocar perda às pessoas, à propriedade, ao processo e/ou ao ambiente. O colaborador deve realizar a inspeção de pré-uso antes de executar a atividade, utilizando o formulário específico contendo os itens a serem checados considerados como relevantes para garantir a segurança do colaborador e a boa realização da tarefa.
Fazendo um diagrama de Pareto baseado no número de itens avaliados em cada capítulo, conforme figura 2, permite perceber que $56 \%$ do total de itens inspecionados fazem parte dos capítulos B e C, logo as maiores chances de ocorrência de desvios ocorrem dentro deles e mostra a relevância desses capítulos para a composição da nota final da auditoria.

FIGURA 2 - Gráfico de Pareto de Itens Avaliados por Capítulo na Auditoria.)

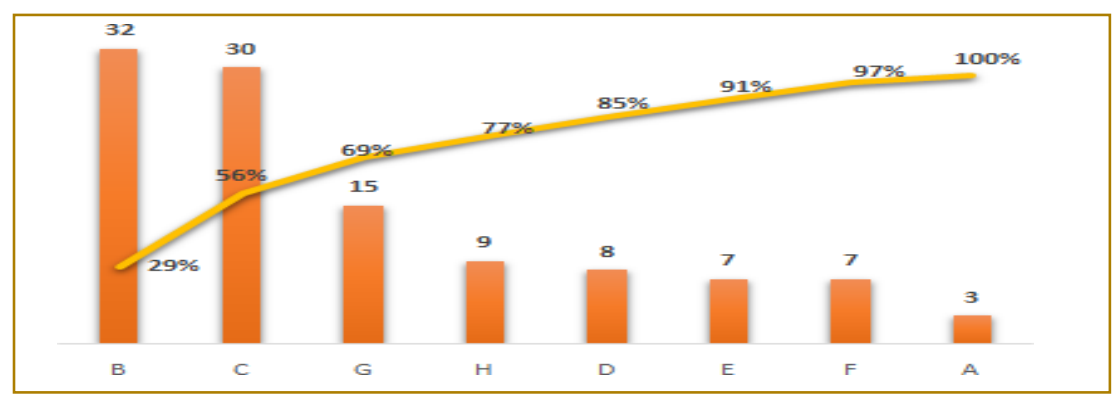

Fonte: Autores (2017

Sendo assim, pode-se desenhar, através da observação da oficina e entrevista dos colaboradores e líderes envolvidos, o cenário atual encontrado como: pré-uso não atende a real necessidade dos equipamentos e ferramentas da oficina; não conformidade (NC) de itens críticos não tem o devido tratamento, pois não há comunicação no momento da ocorrência; risco de acidente, pois o equipamento não conforme é utilizado e os colaboradores não percebem a devida relevância para essa ferramenta de segurança; não há acompanhamento efetivo das informações provenientes desse checklist.

Através dos dados coletados auxiliado por essa folha de verificação, conforme figura 3, nota-se que havia um elevado número de desvios de diversas naturezas, mas que o maior destaque era referente a não conformidades (NC) não relatadas que representavam $47 \%$ dos desvios totais e não conformidades (NC) não tratada que representavam $23 \%$.

A figura 4 apresenta o Diagrama de Ishikawa elaborado pela equipe interfuncional.

FIGURA 3 - Folha de Verificação Sobre Desvios de Pré-Uso.

\begin{tabular}{|c|c|c|}
\hline \multicolumn{3}{|c|}{ FOLHA DE VERIFICAÇÃOO PARA CLASSIFICAÇÃO DE DESVIOS DE PRÉ-USO } \\
\hline \multicolumn{3}{|c|}{ Período: Julho/2016 a Dezembro/2016 } \\
\hline Ocorrência & Verificação/Contagem & Total \\
\hline NC não relatada & 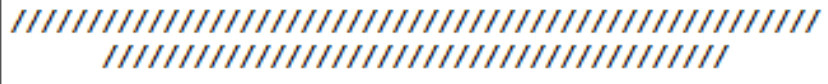 & 94 \\
\hline NC não tratada & 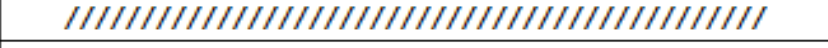 & 46 \\
\hline Rasuras & $/ / / / / / / / / / / / / / / / / / / / / / / / / / / / / / / / / / / / / / /$ & 37 \\
\hline Não realizado & $/ / / / / / / / / / / / / / / / / / / / / / / / / /$ & 24 \\
\hline Total de Desvios & \multicolumn{2}{|l|}{201} \\
\hline
\end{tabular}

Fonte: Autores (2017) 
FIGURA 4 - Diagrama de Ishikawa.

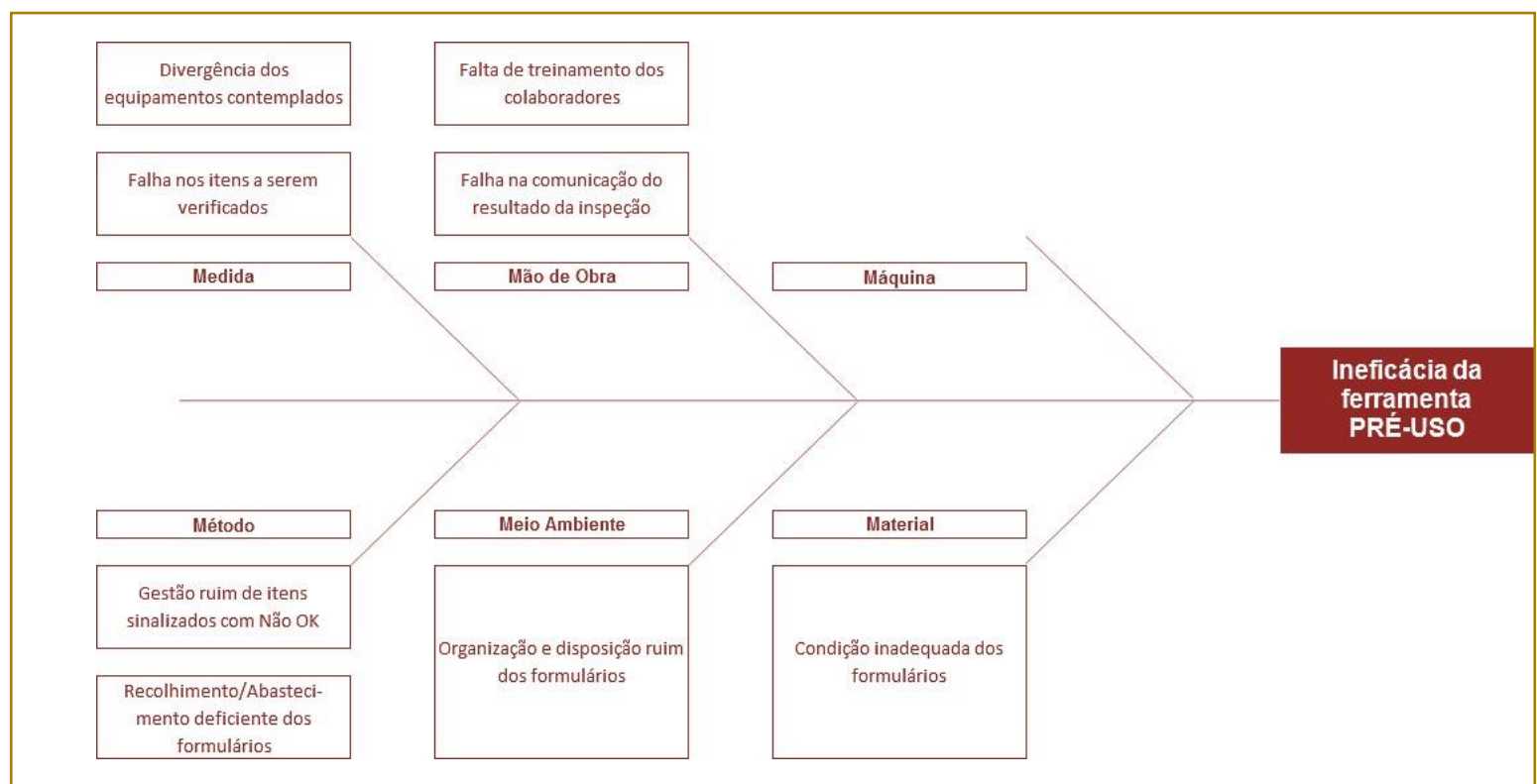

Fonte: Autores (2017)

Baseada nas causas encontradas foi traçado o plano de ação (5W2H) com os responsáveis e os prazos, detalhando o que será feito e como será realizado, de acordo com a figura 5.

FIGURA 5 - Plano de Ação (5W2H)

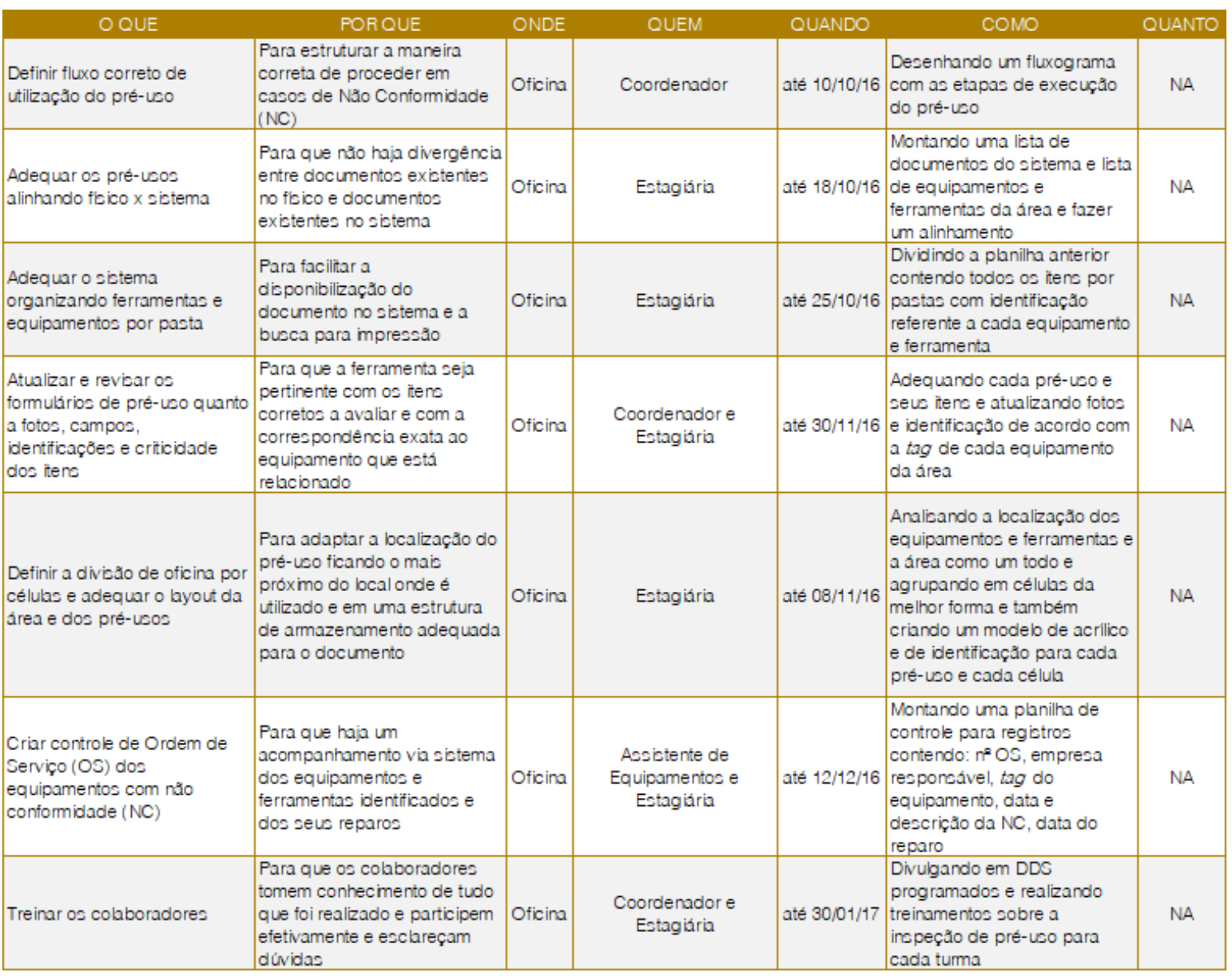

Fonte: Autores (2017) 
Após a realização do plano de ação foram feitas novas observações do processo de realização de inspeção de pré-uso na oficina verificando se houve melhoria dos resultados, adaptação às mudanças e manutenção dos bons resultados, onde se observou, conforme figura 6: redução de $78,6 \%$ no total de desvios, redução de $72,3 \%$ nas nãoconformidades não relatadas, redução de $84,8 \%$ nas não-conformidades não tratadas, redução de $83,8 \%$ nas rasuras e redução de $83,3 \%$ nos desvios de não realizado, redução do número total de desvios onde tinha-se um valor médio de 33,5 desvios/mês de julho a dezembro de 2016, e passou para uma média de 7,2 desvios/mês de janeiro a junho/2017, mostrando a efetividade das ações aplicadas na oficina para solução do problema de ineficácia da ferramenta pré-uso.

FIGURA 6 - Classificação dos Desvios de Pré-Uso

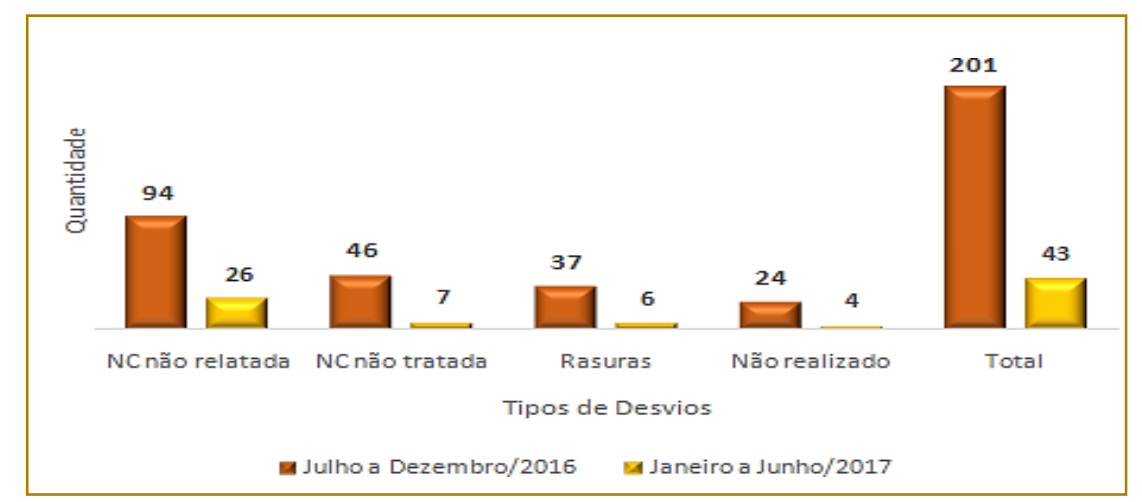

Fonte: Autores (2017)

O capítulo $C$ que foi trabalhado teve evolução, saindo de -0,20 de 2015 para 2016 (4,72 para 4,52), para +0,01 de 2016 para $2017(4,52$ para 4,53), mostrando o bloqueio das ações, além da evolução de outros capítulos que eram impactados de forma indireta, mostrando assim de forma geral melhorias significativas. Quanto a Inspeção de Segurança Pré-uso, que havia tido pontuação zero em duas auditorias consecutivas, obteve em 2017 pontuação 4 na escala de 0 a 5 , demonstrando a efetividade do projeto com a aplicabilidade das ferramentas de qualidade.

Fazendo uma análise da nota total da auditoria da oficina também é notável a melhoria, mostrando assim satisfatórias as ações aplicadas, saindo de 4,53 em 2015 e 4,54 em 2016 para 4,58 em 2017.

A longo prazo, os resultados dessa melhoria de processo poderão impactar também nos índices de segurança da empresa como um todo, quanto ao registro de acidentes e incidentes da empresa $X$, visto que a proposta da ferramenta é a prevenção, então sendo aplicado em demais unidades e sendo eficaz na rotina gerará benefícios devido as adequações em layout e em condições de trabalho quanto a equipamentos $e$ ferramentas e na maior aderência dos colaboradores na rotina de segurança, pois conforme pode-se perceber pela figura 7 , a empresa tem reduzido seu número de acidentes devido à forte valorização do colaborador e de sua segurança como um patrimônio da empresa, e um exemplo foi esta atenção voltada para a ferramenta de pré-uso que tem impactos em segurança, baseado nos resultados da auditoria de processo de Oficina Modelo que é tão relevante para a empresa X. 
FIGURA 7 - Gráfico de Acidentes na Empresa X

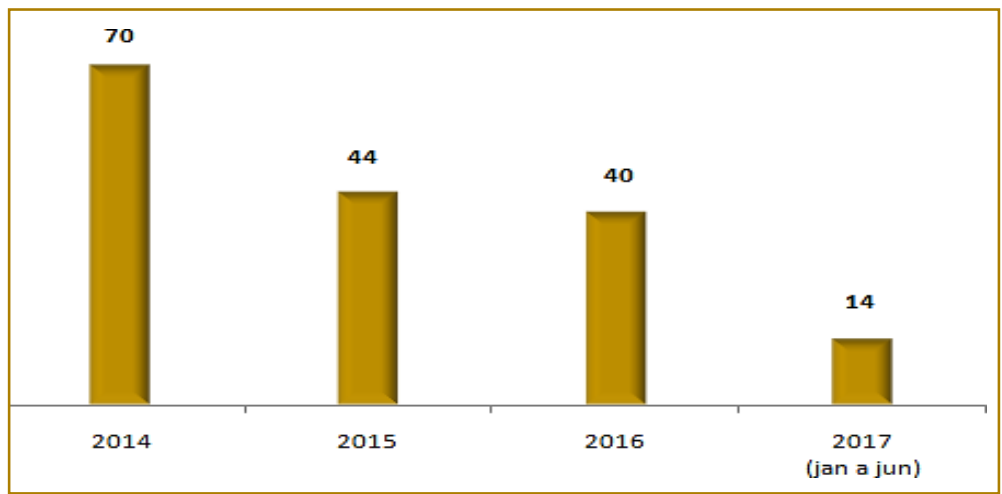

Fonte: Autores (2017)

\section{CONSIDERAÇÕES FINAIS}

O desenvolvimento deste estudo permitiu concluir quanto à efetividade da utilização das ferramentas de qualidade na busca por analisar desvios, solucionar problemas e proporcionar melhorias através da busca das causas, independente da sua área de aplicação, pois teve uma aplicação diferenciada através da análise de uma ferramenta de segurança de uma empresa devido a sua relevância e impactos pro processo.

Os resultados deste estudo foram satisfatórios, visto que o objetivo foi

\section{REFERÊENCIAS}

[1]. BARBOSA, R.P.; BARSANO, P.R. Higiene e Segurança do Trabalho. São Paulo: Saraiva, 2014.

[2]. CAMARGO, W. Controle da Qualidade Total. Instituto Federal Paraná (EAD). (Apostila). Rede e-Tec Brasil: Curitiba (PR), 2011.

[3]. CAMPOS, V.F. Gerenciamento da Rotina do Trabalho do Dia a Dia. Nova Lima: INDG Tecnologia e Serviços Ltda, 2004.

[4]. DIAS, F.A.A. 7 Ferramentas da Qualidade. UNIFACS. Bahia, 2016.

[5]. DIGROCCO, J.R. Ferramentas da Qualidade. São Paulo: Administradores, 2008.

[6]. FEIGENBAUM, A.V. Controle da Qualidade Total: Gestão e Sistemas. São Paulo: Makron Books, 1994.

[7]. GIL, A.C. Como elaborar projetos de pesquisa. 4.ed. São Paulo: Atlas, 2002.

[8]. JURAN, J.M.A. A Qualidade desde o Projeto: novos passos para o Planejamento da Qualidade em produtos e serviços. São Paulo: Pioneira, 1992. alcançado, pois a aplicação das ferramentas de qualidade permitiu analisar e solucionar os desvios referentes à inspeção planejada de pré-uso dentro dos processos de segurança do trabalho, realizando melhorias no processo em geral, adequando às regras e à real necessidade da empresa.

Diante de tudo que foi estudado, observado e implementado foi percebido como a área de segurança do trabalho e da qualidade de processo podem ser trabalhadas juntas e como elas tem tido cada vez mais relevância dentro das empresas.
[9]. MATTOS, U.A.O.; MÁSCULO, F.S. Higiene e Segurança do Trabalho. Rio de Janeiro: Elsevier, 2011.

[10]. MEIRELES, M. $\quad$. Ferramentas Administrativas. São Paulo: Arte e Ciência, 2001.

[11]. MENEZES, F.M. MASP - Metodologia de Análise e Solução de Problemas. (Apostila). Agência Brasileira de Desenvolvimento Industrial. Porto Alegre: Produttare, 2013.

[12]. NEVES, T.F. Importância da Utilização do Ciclo PDCA para Garantia da Qualidade do Produto em uma Indústria Automobilística. Dissertação (Graduação em Engenharia de Produção) - Universidade Federal de Juiz de Fora - UFJF, Juiz de Fora, 2007.

[13]. OAKLAND, J.S. Gerenciamento da Qualidade Total - TQM: o caminho para aperfeiçoar o desempenho. São Paulo: Nobel, 1994.

[14]. PALADINI, E.P. Qualidade Total na Prática: Implantação e Avaliação de Sistema de Qualidade Total. 2 ed. São Paulo: Atlas, 1997. 
[15]. PITTA, D.F.R. Uma compreensão relevante do ativo intangível saúde e segurança ocupacional: uma proposta de modelo. Dissertação (Mestrado em Engenharia de Produção) - Universidade Federal do Rio de Janeiro - UFRJ, Rio de Janeiro, 2008.

[16]. SILVA, D.C. Metodologia de Análise e Solução de Problemas. Especialização em Qualidade Total e Marketing da UFSC. Florianópolis: Fundação CERTI, 1995.

[17]. SILVA, E.L.; MENEZES,E.M. Metodologia da Pesquisa e Elaboração de Dissertação. 3 ed. Florianópolis, 2001.

[18]. SOUZA, E.K.; MACHADO, F.O. A Gestão da Qualidade e suas Práticas: estudo de caso em Caruaru/PE. INGEPRO, vol 03, $\mathrm{n}^{\circ}$ 10. 2011.

[19]. THIOLLENT, M. Metodologia da PesquisaAção. São Paulo: Cortez, 1992.
[20]. TRIVELLATO, A.A. Aplicação das Sete Ferramentas Básicas da Qualidade no Ciclo PDCA para Melhoria Contínua: um estudo de caso numa empresa de autopeças. Trabalho de Conclusão de Curso - Escola de Engenharia de São Carlos, Universidade de São Paulo. São Paulo, 2010.

[21]. WERKEMA, M.C.C. Métodos PDCA e DMAIC e suas Ferramentas Analíticas. Série Werkema de Excelência Empresarial. Rio de Janeiro: Elsevier, 2013.

[22]. WERKEMA, M.C.C. Ferramentas Estatísticas Básicas para o Gerenciamento de Processos. Belo Horizonte: Werkema Editora Ltda, 2006.

[23]. ZOCCHIO, Á. Prática da Prevenção de Acidentes: $A B C$ da Segurança do Trabalho. 4.ed. São Paulo: Atlas, 1980. 


\section{Bapítulo 4}

\section{PROPOSTA DE MELHORIA DE PROCESSO EM UMA LINHA DE PRODUÇÃO DE EQUIPAMENTOS HOSPITALARES UTILIZANDO A FILOSOFIA LEAN}

\section{Ingrid de Figueiredo Astigarreta \\ Luiz Antonio da Paz Campagnac \\ Marcelo Arese}

Resumo: Independente do ramo de atuação, cada dia mais o mercado exige redução de desperdícios em todo e qualquer processo, seja este no setor de vendas, administrativo ou operacional, considerando diferentes tipos de fatores como a qualidade, o custo, a flexibilidade e a inovação na produção. Segundo Lacy (2015), a economia circular defende o conceito de eliminar o desperdício e reinserir os produtos descartados na produção como forma de reaproveitamento e redução de custos.

Devido à exigência de rápidas mudanças no meio organizacional referente a uma atmosfera mais tecnológica, complexa e correlacionada, as organizações buscam respostas e estratégias mais eficientes visando à otimização de seus fluxos produtivos e a redução de custos.

0 estudo de caso apresentado neste artigo ocorre em uma linha de produção de equipos hospitalares, localizada no Rio de Janeiro. Para este estudo foi utilizada a Metodologia Lean Manufacturing e a Metodologia Joint Application Development a fim de organizar o processo de desenvolvimento do projeto e propor melhoria para a linha de produção reduzindo e relacionando os desperdícios da linha de produção com os oito desperdícios apresentados pela filosofia Lean. Além dessas, foram utilizadas ferramentas da qualidade como gráfico de Ishikawa, Brainstorming e gráfico de Pareto para auxiliar no processo de identificação de riscos do processo. 
1. INTRODUÇÃO

\subsection{FORMULAÇÃO DA SITUAÇÃO} PROBLEMA

As constantes paralisações no processo produtivo de montagem de equipos hospitalares podem em relacionados a oito tipos de desperdícios Lean, sejam eles referente a retrabalho, mão de obra, defeito, espera, transporte, movimentações, processamento inapropriado ou estoque. Analisar, identificar e tratar os principais problemas relacionados às paralisações do sistema produtivos pode significar resultar em melhorias significativas para o processo em si e para os colaboradores em geral.

\subsection{OBJETIVO GERAL}

O presente artigo tem como objetivo apresentar o processo de desenvolvimento de melhorias em uma linha de produção de montagem manual de equipamentos hospitalares baseados em metodologias específicas. Foi realizado uma pesquisa de campo afim de identificar as principais fragilidades relacionadas ao processo produtivo.

Com a utilização de técnicas Lean Manufacturing e ferramentas da qualidade foi possível desenvolver e propor melhorias para o processo de produção em questão.

\section{METODOLOGIA}

A metodologia utilizada para a elaboração deste trabalho é considerada de caráter exploratório qualitativo, fundamentado em pesquisas bibliográficas como livros, artigos e de portais eletrônicos além de pesquisas de campo realizadas na própria linha de produção estudada.

O estudo foi dividido conforme o fluxograma abaixo (Figura 1). Primeiramente foram realizadas pesquisas sobre a Metodologia Lean Manufacturing e Joint Application Development para ser utilizadas como base para o estudo de caso de redução de desperdício na linha de produção.

Figura 1 - Fluxo da metodologia

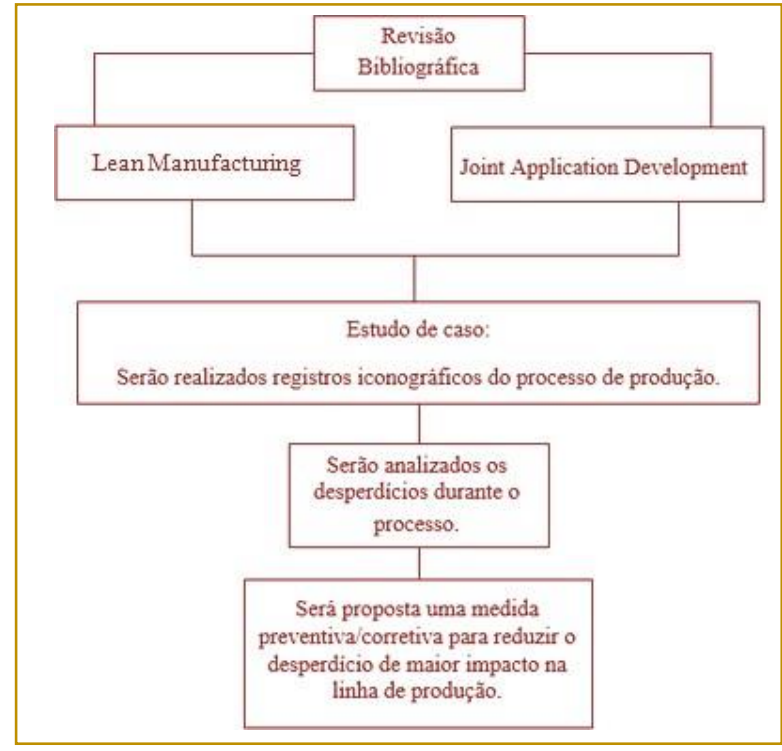

Fonte: O próprio autor

\section{REVISÃO DA LITERATURA}

\subsection{METODOLOGIA LEAN}

Originada das evoluções do Toyota Production System, a metodologia tem como foco a produção enxuta que representa a eliminação de desperdícios em sistemas produtivos (SHINGO, 1996). Atualmente, pode-se perceber a utilização desta metodologia em diferentes ramos do mercado, seja na área de compras de uma empresa de logística ou no setor de qualidade de uma grande fábrica de produtos hospitalares.

Segundo o Lean Institute Brasil, a abordagem Lean pode ser aplicada em diferentes áreas, 
contudo devem-se priorizar as que possuem maior quantidade de desperdícios em seus processos, enxergando o negócio como um todo.
A fim de facilitar o entendimento desta metodologia criou-se o modelo metafórico conhecido como Casa do Lean com o objetivo de torná-lo mais visual.

Figura 02 - Casa do Lean

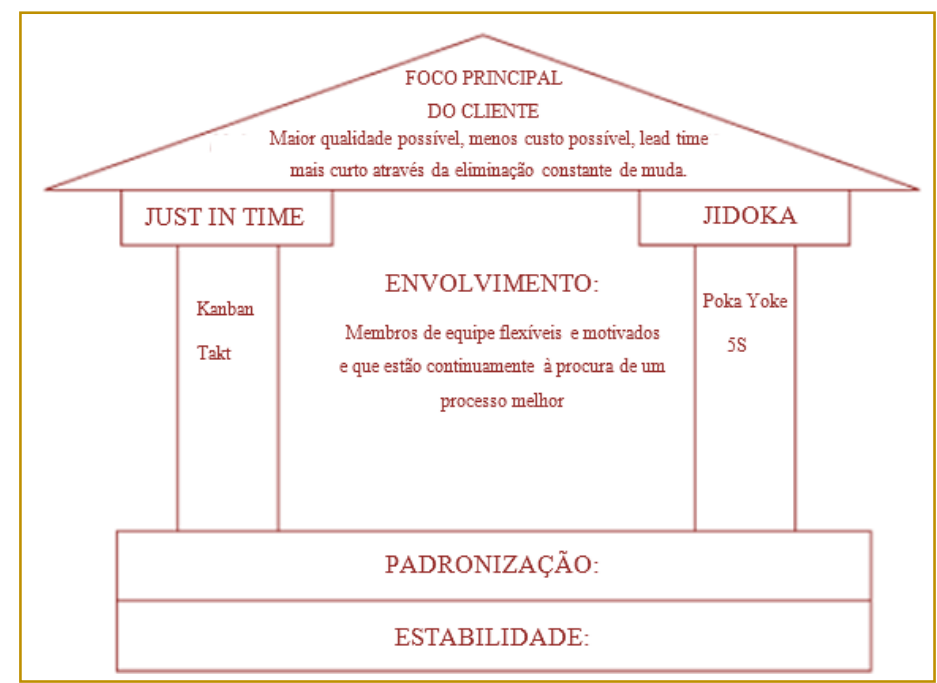

Fonte: Adaptado de Produção Lean Simplificada - Um guia para entender o sistema de produção mais poderoso do mundo, 2008.

A casa Lean é uma estrutura composta por uma base construída por atividades padronizadas, sem desperdícios para a organização.

Seus pilares, responsáveis por sustentar a construção, são compostos por Poka Yoke e Just in Time. O pilar Poka Yoke representa uma metodologia antierro, onde são usadas ferramentas que mitigam os erros frequentes da operação. Em contrapartida o pilar Just in Time define a quantidade necessária de produtos fabricados, o material necessário para aquela produção e o momento ideal para que ambos estejam integrados no sistema estudado.

No telhado da casa, pode-se observar que os pilares sustentam o objetivo desta metodologia que é atingir a melhor qualidade, com custo mais inferior de forma mais rápida possível com base numa fundação estável.
No interior da casa, protegidos por toda a estrutura estão os recursos humanos, a minimização de desperdícios e a melhoria contínua (Kaizen) representando todas as atividades executadas para que a metodologia seja alcançada com sucesso.

A metodologia Lean tem por objetivo analisar fluxos de produção com intuito de minimizar as perdas dentro do processo trazendo resultados concretos, quantitativos e qualitativos para a empresa.

"Para chegar até as causas do desperdício, faz parte da filosofia Just in Time tornar todo o desperdício visível, pois o desperdício só pode ser eliminado quando é visto e identificado" (MOREIRA, 2008, p. 507). Com o objetivo de eliminar desperdícios a metodologia Lean é dividida em oito categorias: 
Quadro 1 - Categorias Lean

\begin{tabular}{|c|c|}
\hline Categoria & Descrição \\
\hline Defeitos & $\begin{array}{l}\text { Processamento de produtos defeituosos e retrabalho na } \\
\text { produção }\end{array}$ \\
\hline Excesso de produção & $\begin{array}{l}\text { Superprodução, quantidades superiores a necessárias ou } \\
\text { produzidas em momentos errados. }\end{array}$ \\
\hline Espera & Equipamentos/colaboradores ociosos \\
\hline Transporte & Movimentação de produtos desnecessária. \\
\hline Movimentação nas operações & Movimentação de colaboradores desnecessária. \\
\hline Processamento inapropriado & $\begin{array}{l}\text { Etapas de produção desapropriados que não agregam valor ao } \\
\text { processo como um todo. }\end{array}$ \\
\hline Estoque & $\begin{array}{l}\text { Excesso de materiais estocados e produtos acabados entre as } \\
\text { operações. }\end{array}$ \\
\hline Talento & $\begin{array}{l}\text { Desperdício de talentos humanos, pessoas com conhecimento } \\
\text { não aproveitadas no processo produtivo. }\end{array}$ \\
\hline
\end{tabular}

Com base nesta filosofia pode-se afirmar que os desperdícios relacionados à espera, movimentação e talento estão relacionados à mão de obra e equipamento, em contrapartida referente ao fluxo de produção está o excesso de produção, o transporte, o processamento inapropriado, o estoque e por fim os defeitos. As categorias listadas podem estar presentes em diversos seguimentos do mercado independente da área de atuação da empresa.

\subsection{METODOLOGIA JAD (JOINT APPLICATION DEVELOPMENT)}

A metodologia JAD foi criada pela IBM nos anos setenta com o objetivo de tornar o levantamento de requisitos para projeto ou processo mais fácil, mais prático e com mais eficiência. Para isto, dois princípios básicos devem ser utilizados para o sucesso da aplicação desta metodologia:

- A presença de pessoas que trabalham efetivamente no processo analisado;

- Toda a equipe deve estar comprometida com os resultados da análise, pois o resultado é compartilhado por todos.

Para o levantamento de requisitos, a metodologia propõe que sejam realizadas sessões que envolvam toda a equipe. Segundo Jobs (2010) e JAD Guidelines (2012) a equipe deve ser composta por participantes chaves, são eles: facilitador, gestor, especialista, clientes/patrocinador, anotador e observadores. A presença de cada componente listado é de extrema importância para que o projeto obtenha resultados positivos, contudo esta organização pode sofrer alterações com a necessidade do serviço. "A atividade do processo de levantamento de requisitos é composta de quatro fases: estudo de viabilidade, levantamento e análise de requisitos, documentação e validação dos requisitos", SILVA (2012, p. 8).

O facilitador deve ser neutro no processo estudado, responsável por determinar os planos e evitar que outros colaboradores tentem dominar a situação. 0 gerenciador de tempo controla o tempo das discussões fazendo com que o tempo não seja desperdiçado com assuntos irrelevantes. 0 anotador ou escriba, por sua vez, registra os assuntos discutidos durante as sessões para que sejam retomados nas futuras reuniões. 0 especialista é o colaborador que realmente entende do processo e deve estar presente em todas as sessões. O documentador é responsável por produzir os documentos abordando todos os requisitos do processo que será assinado por todas as partes interessadas. Por fim, os observadores que são membros da equipe do processo estudado, mas que não possuem autorização para se manifestarem.

Para este estudo de caso foi escolhida a utilização da metodologia Joint Application 
Development devido a sua maturidade, segurança e facilidade no levantamento de requisitos, atendendo assim, de forma assertiva na solução do problema tratado.

\section{MÉTODO}

\subsection{A EMPRESA}

A empresa $X$ analisada, possui foco no mercado farmacêutico desde 1970. Pioneira no mercado hospitalar produz instrumentos cirúrgicos, soluções de soro, equipos diversos, bombas de infusão e outros. A missão da empresa é baseada em dois pilares, o compartilhamento de experiências e a tecnologia que representam questões de extrema importância para a organização, integrando a fácil utilização de seus produtos com a alta tecnologia sem deixar de lado a eficiência dos procedimentos hospitalares.

A garantia da qualidade é parte integrante das atividades executadas na fábrica, todos os produtos são testados conforme instruções antes de serem inseridos no mercado. Desta forma é possível manter o padrão e o alto nível de qualidade de forma global em todos os setores.

\subsection{FLUXO CONTINUO DE PRODUÇÃO DE EQUIPOS}

A fabricação do produto ocorre em um salão, denominado área branca da fábrica. Por motivos de segurança higiênica o ambiente é estritamente controlado com o menor contato humano possível. Os colaboradores utilizam equipamentos de proteção individual, como roupas específicas para a atividade, máscara de proteção, toucas, óculos de proteção, sapatilhas higiênicas e outros visando a proteção dos colaborados e do cliente.

Neste salão estão posicionados 110 postos de trabalho onde são montados manualmente os equipos hospitalares (figura 3 ) utilizados cotidianamente em hospitais para injeção de medicamentos e soro fisiológico em pacientes debilitados.

Figura 3 - Equipos Hospitalares

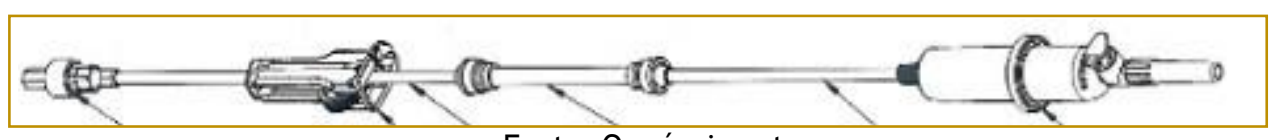

Fonte: 0 próprio autor

A produção do equipo ocorre em um fluxo contínuo composto por postos de trabalho individuais onde são realizadas as colagens dos componentes nos tubos plásticos, obtendo como resultado final o equipo.

Os postos de trabalho são abastecidos com um solvente, produto responsável pela colagem dos componentes, e silos, onde são armazenados os componentes que integram o produto final.

O sistema de alimentação de solvente é realizado através de garrafas de armazenamento localizadas nas extremidades dos postos de trabalho. Por sistema de gravidade o solvente passa por tubos que alimentam o pote, onde fica armazenado o produto. Entre os tubos e o pote, existem válvulas corta fluxo que possuem a função de controlar o fluxo de solvente dentro do pote, podendo ser fechadas quando o solvente não estiver sendo utilizado ou aberta para abastecer o pote. 0 processo de abre e fecha da válvula é realizado constantemente durante o turno de produção pelos colaboradores da montagem.

A quantidade de solvente dentro do pote é definida conforme especificações de qualidade. Para manter o controle da quantidade de solvente, os potes possuem um dispositivo de drenagem com a função de manter a mesma quantidade durante todo o turno de trabalho. Caso a quantidade seja ultrapassada o solvente é descartado através do um dreno localizado no interno do pote.

Após a montagem manual do produto, que consiste em reunir os componentes em um tubo plástico com o auxílio do solvente, o mesmo é posicionado em uma esteira rolante responsável por transportar o equipo montado até o setor de embalagem da fábrica.

Com a utilização da metodologia JAD (Joint Application Development), foi realizado o levantamento de dados sobre o fluxo de produção dos equipos. Como consequência, o esquema abaixo foi elaborado utilizando a ferramenta da qualidade Diagrama de 
Ishikawa, onde são listadas as possíveis causas referentes a método, mão de obra, máquina e materiais que implicam diretamente no problema principal, linha de produção interrompida.

Figura 4 - Diagrama de Ishikawa

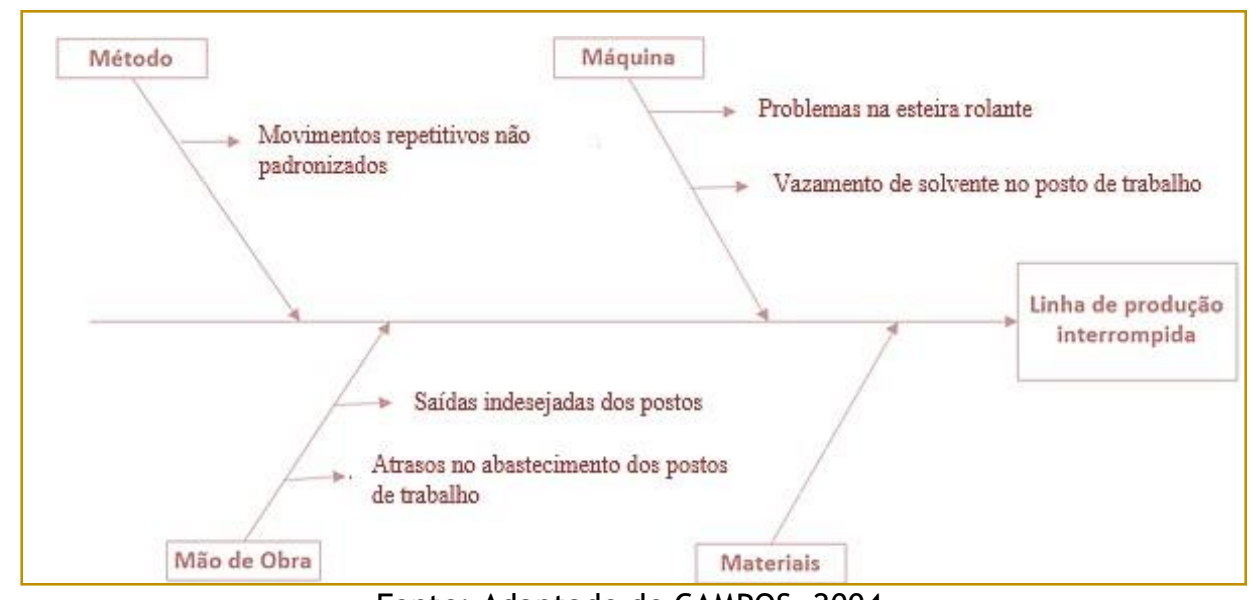

Fonte: Adaptado de CAMPOS, 2004

Os problemas listados, identificados como deficiências do processo, foram organizados no Quadro 2- Desperdícios da Linha de
Produção e relacionados com a influência de cada um deles no processo de montagem manual.

\section{Quadro 2 -Desperdícios da Linha de Produção}

\begin{tabular}{|c|c|c|}
\hline \multicolumn{2}{|r|}{ Problema } & Descrição \\
\hline 1 & $\begin{array}{l}\text { Movimentos } \\
\text { repetitivos não } \\
\text { padronizados }\end{array}$ & $\begin{array}{l}\text { Devido à grande produção de itens, os movimentos realizados pelos } \\
\text { colaboradores da colagem são repetidos durante todo o turno de trabalho. } \\
\text { Existem instruções baseado em estudos dos movimentos com o objetivo de } \\
\text { padronizá-los, contudo as instruções não são seguidas por todos os } \\
\text { colaboradores. }\end{array}$ \\
\hline 2 & $\begin{array}{l}\text { Saídas } \\
\text { indesejadas do } \\
\text { posto }\end{array}$ & $\begin{array}{l}\text { A necessidade de levantar do posto de trabalho para realizar o descarte de } \\
\text { componentes defeituoso impacta diretamente na produção individual do } \\
\text { colaborador }\end{array}$ \\
\hline 3 & $\begin{array}{l}\text { Vazamento de } \\
\text { solvente no } \\
\text { posto de } \\
\text { trabalho }\end{array}$ & $\begin{array}{l}\text { Durante o processo de colagem foram identificados vazamentos de solvente } \\
\text { nos postos de trabalho. Este vazamento representava um risco para a } \\
\text { qualidade do produto montado além de desperdício de material, custo, } \\
\text { exposição aos colaboradores do setor e alto risco ao meio ambiente. }\end{array}$ \\
\hline 4 & $\begin{array}{l}\text { Abastecimentos } \\
\text { dos postos de } \\
\text { trabalho }\end{array}$ & $\begin{array}{l}\text { O abastecimento de componentes e de solvente é realizado de forma manual } \\
\text { por um colaborador do setor. A falta de abastecimento dos postos, causa } \\
\text { frequentes atrasos na produção. }\end{array}$ \\
\hline 5 & $\begin{array}{l}\text { Problemas na } \\
\text { esteira rolante }\end{array}$ & $\begin{array}{l}\text { Após a montagem do equipo, os colaboradores posicionam o produto na } \\
\text { esteira rolante responsável por levar o material ao setor de embalagem. Com } \\
\text { a parada deste equipamento, a produção é acumulada nos postos. }\end{array}$ \\
\hline
\end{tabular}

Fonte: O próprio autor 
Após a análise detalhada de cada problema, na segunda etapa do processo, os problemas identificados como causas da interrupção frequente do processo de montagem, foram relacionados com as oito categorias de desperdícios Lean, com o objetivo de verificar o item que representa maior impacto no processo.

Quadro 3 - Oito Desperdícios Lean

\begin{tabular}{|c|c|c|c|c|c|c|c|c|}
\hline Problema & 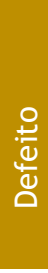 & 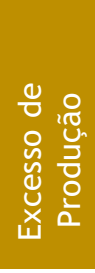 & $\begin{array}{l}\frac{\sigma}{0} \\
\frac{0}{4} \\
\text { 山ै }\end{array}$ & 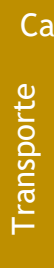 & 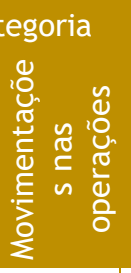 & 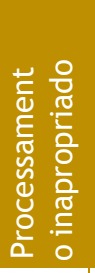 & 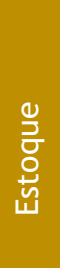 & 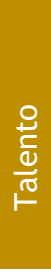 \\
\hline $\begin{array}{l}\text { 1- Movimentos repetitivos não } \\
\text { padronizados }\end{array}$ & & & & & $x$ & & & \\
\hline 2- Saídas indesejadas dos postos & $x$ & & & & & & & \\
\hline $\begin{array}{l}\text { 3- Vazamento de solvente no posto } \\
\text { de trabalho }\end{array}$ & $x$ & & & & & $x$ & & \\
\hline $\begin{array}{l}\text { 4- Abastecimentos dos postos } \\
\text { de trabalho }\end{array}$ & & & $x$ & & & & & \\
\hline 5- Problemas na esteira rolante & & & $\mathrm{x}$ & & & & & \\
\hline
\end{tabular}

Dessa forma, foi possível constatar que o problema 3, caracterizado pelo vazamento de solvente no posto de trabalho, Figura 5, representava maior desperdício na linha de produção, desperdício este causado pela categoria "defeito", representando o contato inapropriado do equipo com o solvente, fazendo com que houvesse desperdício de material e pelo "processamento inapropriado" devido ao retrabalho que não agrega valor a operação.

Figura 5- Válvula apresentando vazamento de solvente

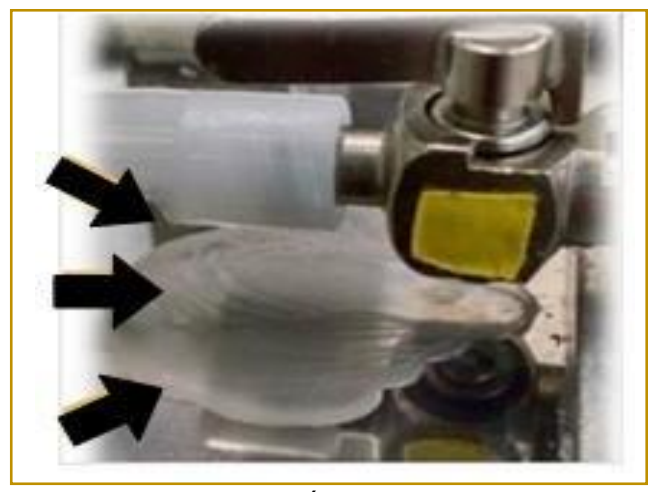

Fonte: 0 próprio autor

Posteriormente, com base em informações coletadas do ambiente de produção durante sessões JAD com a participação dos principais protagonistas do processo e de acordo com os problemas citados no Quadro 2 - Oito Desperdícios Lean, foi construído o gráfico de Pareto.
Este tipo de gráfico, também conhecido como Regra $80 / 20$ ordena a frequência de determinadas ocorrências, com o objetivo de analisar a que possui maior frequência no processo estudado. 
Para este estudo de caso, o gráfico auxiliou no processo de identificação dos itens que possuem maior frequência no processo de interrupção da linha.

\section{Gráfico I- Gráfico de Pareto}

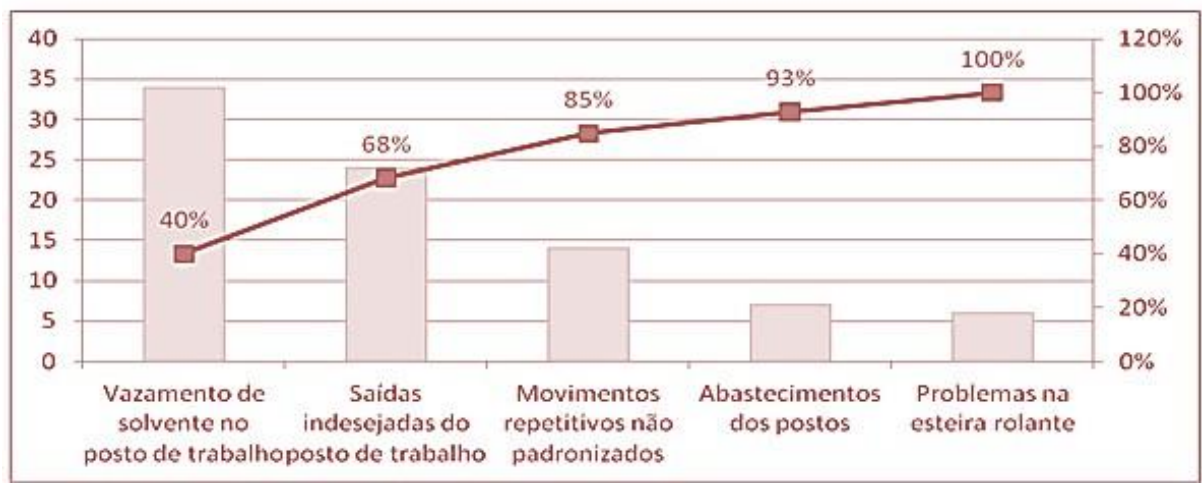

Fonte: 0 próprio autor

Dessa forma foi possível afirmar que durante o processo de colagem o vazamento de solvente nos postos de trabalho representa $40 \%$ das interrupções da produção de equipos hospitalares comparado com problemas na esteira rolante que representa apenas 7\% das interrupções. Assim, concluiu- se que o vazamento representava um risco para a qualidade do produto montado além de desperdício de material, custo, exposição aos colaboradores do setor e alto risco ao meio ambiente como identificado pela matriz de riscos abaixo.

Figura 6 - Matriz de Riscos

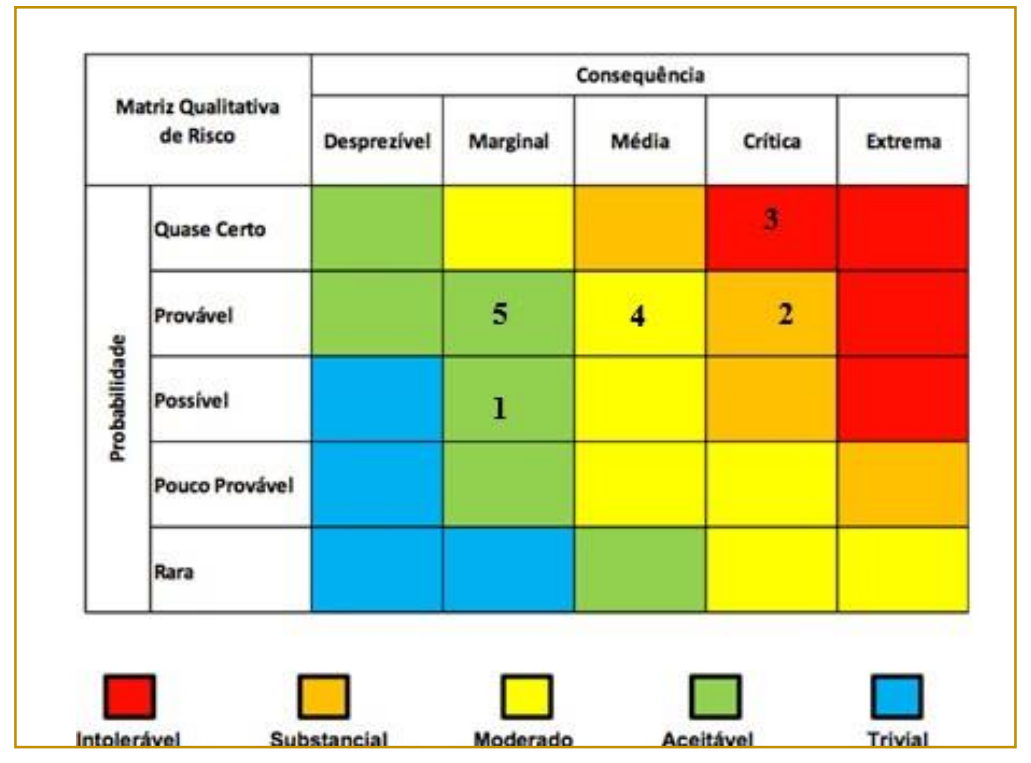

A matriz de risco foi discutida e construída pela equipe participante, o problema 3 , representado pelo vazamento de solvente no posto de trabalho foi disposto na categoria de probabilidade "quase certo" de ocorrer e na de consequência "crítica". Com isso, foi possível afirmar que este problema representava maior gravidade para o processo.

Tomando como base, as análises do Diagrama de Ishikawa, do quadro de desperdício e da matriz de risco, foi realizado um planejamento com o objetivo de propor uma melhoria no processo de forma simples, 
rápida e sem grandes custos para a produção.

Segundo o Lean Institute Brasil, a metodologia Lean "Trata-se de um corpo de conhecimento cuja essência é a capacidade de eliminar desperdícios continuamente e resolver problemas de maneira sistemática", dessa forma foram utilizadas técnicas da metodologia Lean a fim de otimizar o desperdício do solvente na produção englobando aspectos ambientais, sociais e de saúde ocupacional.

Conforme o PMBOK (Project Management Body of Knowledge), garantir a qualidade representa executar o processo da forma mais eficiente possível, respeitando os requisitos impostos no projeto. Garantir a qualidade no processo de alimentação do posto de trabalho da montagem manual de equipos hospitalares significa um fluxo de solvente eficiente para abastecer os potes no sistema, sem desperdício e interferências na produção.

\section{RESULTADO}

A fim de identificar as possíveis causas raízes do vazamento de solvente pelas válvulas corta fluxo, utilizou-se a metodologia de Brainstorming durante as sessões de JAD. Após discussões e levantamento de ideias, concluiu-se que dentre as causas discutidas três possuíam maior influencia no processo. A Figura 7 representa o funil de ideias que apresenta as ideias discutidas destacando-se as de maior impacto.

Figura 7 - Funil de ideias

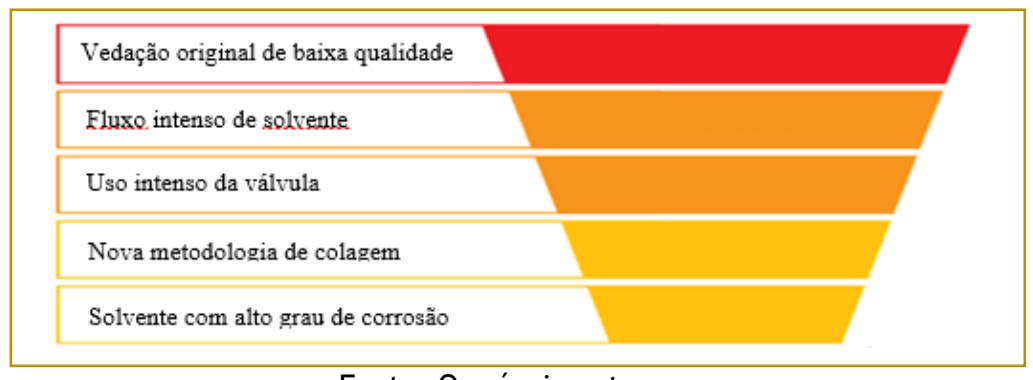

Fonte: 0 próprio autor

Dessa forma, com base nos principais problemas identificados os três principais problemas que agravam o vazamento dos solventes para analise de ações corretivas / preventivas foram:

- Vedação de baixa qualidade;

- Uso intenso da válvula;

- Fluxo intenso de solvente.

O solvente utilizado na operação possui grande teor corrosivo e deve ser manipulado em condições rigorosamente específicas. Por suas características específicas foi determinado como premissa para melhoria do fluxo o desenvolvimento de um dispositivo de vedação específico para este sistema a fim de garantir uma melhoria no abastecimento do posto de trabalho reduzindo os desperdícios da linha.

O desenvolvimento da vedação foi realizado com base em fatores como:
- Resistência do material da vedação em relação ao solvente;

- Resistência de atrito da vedação com a válvula;

- Dimensões singulares.

Dessa forma foi desenvolvido o gerenciamento das aquisições de compras das vedações para a linha de montagem em estudo. Com base em pesquisas e testes de resistência de atrito e contato com o solvente, foi identificado à necessidade de duas vedações fabricadas com materiais distintos.

Para a parte inferior da válvula foi identificada a necessidade de uma arruela de teflon com bronze com medidas de $\varnothing \quad 9,4 \mathrm{~mm}$ e espessura de $0,3 \mathrm{~mm}$.

Para a parte superior da válvula foi identificada a necessidade de um o ring com dimensões $4,5 \mathrm{~mm} \times 4,0 \mathrm{~mm} \times 0,6 \mathrm{~mm}$ de material de Borracha Nitrílica como mostrado na figura 8 . 
Figura 8 - Registro da Válvula corta-fluxo

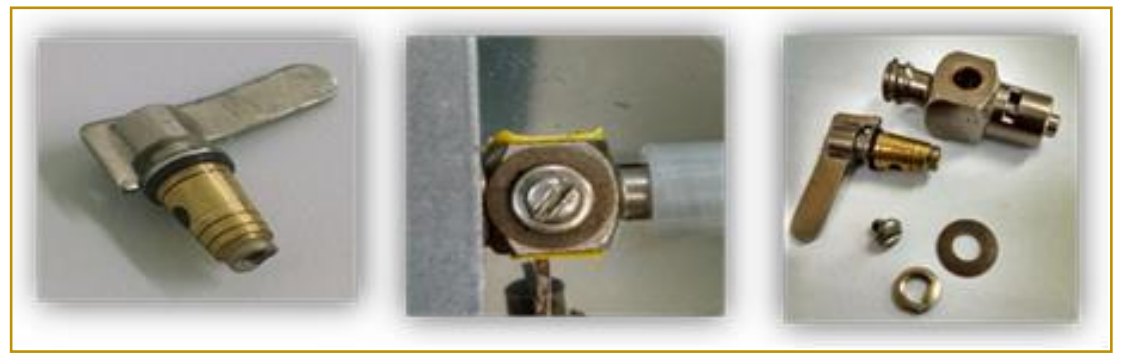

Fonte: 0 próprio autor

\section{CONCLUSÕES}

Com este estudo de caso foi possível concluir que a introdução das vedações nas válvulas corta fluxo nos postos de trabalho trouxe melhorias significativas no processo. As paradas de produção devido ao vazamento e acúmulo de solvente no posto, assim como o número de materiais descartados por contato indevido com solvente e a redução do contato direto com os colaboradores da montagem sofreram grandes reduções, como apresentado no Gráfico 2 abaixo.

Gráfico 2 - Indicadores de Desempenho

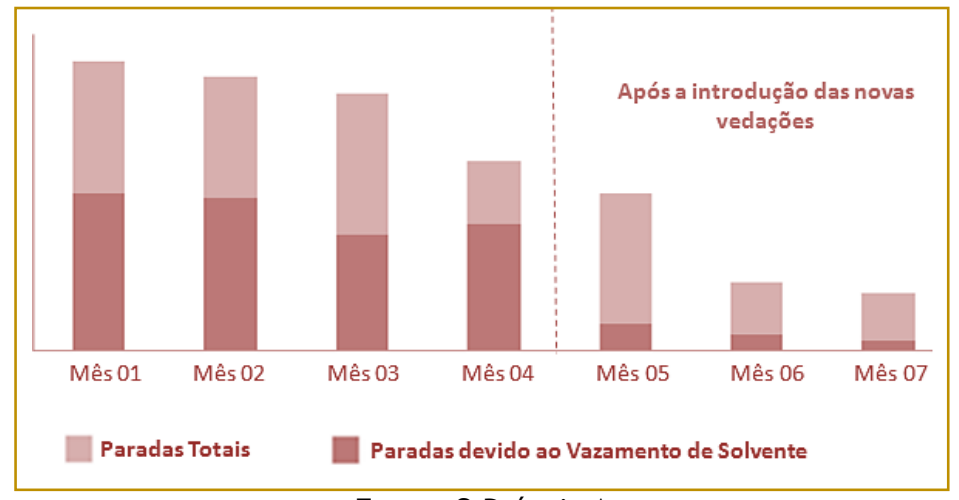

Fonte: O Próprio Autor

A crescente produção industrial que por sua vez está relacionada com conhecimentos e ferramentas Lean é discutida frequentemente no âmbito internacional em conferências e reuniões que propõem soluções de produção com a utilização de conceitos de minimização e otimização de desperdícios.

\section{REFERÊNCIAS}

[1] Campos, V. F. Gerenciamento da rotina do trabalho do dia-a-dia. Nova Lima: INDG Tecnologia e Serviços, 2004.

\section{[2] Jad Guidelines. IT Project} Management Certificate Program (v.0). Knowledge Structures, Inc. Disponivel em: http://www.ksinc.com/itpmcptools/JADGuideli nes.pdf. Acesso em 24 jan. 2018.
Mesmo que o principal objetivo das empresas seja o crescimento econômico, as melhorias contínuas em um fluxo de operações estão se tornando cada vez mais importante dentro das organizações e está presente em 27 das 50 maiores empresas de todos os setores, segundo o Institute Lean Brasil.

[3] Jobs, Marc Fast. JAD (Joint Application Design) - Técnica de levantamento interativo. Disponível em: http://www.ksinc.com/itpmcpTools.html. Acesso em 24 jan. 2018.

[4] Lacy, Peter; Rutqvist, Jakob. Waste to wealth: The circular economy advantage. $1^{\text {a }}$ ed. Springer, 2015. 
[5] Lapa, R. "A Matriz de Risco". Disponível em: http://segurancatemfuturo.com.br/index.php/h ome/gerenciamento-de-riscos/a-Matriz-derisco. Acesso em 14 de fevereiro de 2018.

[6] Lean Institute Brasil. "Lean é uma filosofia de gestão inspirada em práticas e resultados do sistema Toyota". Disponível em: https://www.lean.org.br/. Acesso em: 13 fev. 2018.

[7] Moreira, Daniel Augusto. Administração da produção e operações. $2^{\mathrm{a}}$. ed.- São Paulo: Cengage Learning, 2008.

[8] Project Management Institute. A Guide to the Project Management Body of Knowledge - PMBOK® Guide $6^{\mathrm{a}}$ Ed., Pennsylvania-USA 2013.
[9] Slack, N. et al. Administração da produção. São Paulo: Atlas, 2008. WOMACK, J. Consumo Enxuto, Provisão Enxuta e Soluções Enxutas. 2008.

[10] Shingo, Shingeo. O Sistema Toyota de produção do ponto de vista da Engenharia de Produção. $2^{\mathrm{a}}$ Ed. Porto Alegre: Bookman, 1996.

[11] Silva, Samuel Fabiano Barbosa. "Engenharia de requisitos: uma análise das técnicas de levantamento de requisitos". Belo horizonte, jan. 2015. Disponível em: http://professores.dcc.ufla.br/ terra/publicatio ns_files/students/2012_fumec_silva.pdf.

Acesso em: 12 jan. 2012 


\section{Eapítulo 5}

\section{ESTUDO PARA IMPLANTAÇÃO DO PROGRAMA DE USO RACIONAL DA ÁGUA EM UMA ESCOLA DE CATALÃO - GO}

\section{João Cândido Júnior}

Ed Carlo Rosa Paiva

José Waldo Martínez Espinosa

Resumo: Ações que visam a redução do consumo de água, em edificações, têm sido implementadas de forma generalizada nos centros urbanos, por conta da real e crescente escassez deste recurso em suas fontes de abastecimento, seja pela baixa quantidade ou pela ausência de qualidade. Este trabalho tem como objetivo principal o diagnóstico do consumo de água de uma escola da cidade de Catalão GO, bem como a substituição das bacias sanitárias com válvulas de descargas do mesmo por bacias sanitárias com caixa acoplada. Para tanto se utilizou de métodos e conceitos referentes ao uso racional da água em edificações. 0 procedimento metodológico foi dividido em quatro etapas, seguindo a seguinte ordem: auditoria do consumo de água, diagnóstico, plano de intervenção e estimativa do impacto e redução do consumo. 0 resultado deste estudo estima o potencial de impacto no consumo de água da edificação perante as alterações sugeridas, concluindo uma estimativa de redução entre $16 \%$ a $20 \%$ no consumo mensal de água da escola.

Palavras-chave: Água. Consumo, Uso Racional, Bacia Sanitária. 


\section{INTRODUÇÃO}

A água é insumo essencial à vida e é empregada para diversos fins. Sua degradação e consumo desenfreado têm causado uma crise hídrica acompanhada por grandes danos ao meio ambiente. Assim, em vista da extrema importância desse recurso vê-se a necessidade de uma melhor gestão do mesmo. Por exemplo, o crescimento desordenado das cidades tem contribuído para a crise da água resultando na diminuição de água doce disponível e também contribuindo para a deterioração da sua qualidade. Dessa forma, surge a necessidade de uma conscientização da população quanto ao uso desse insumo visando não só a oferta de água de boa qualidade para toda população, mas também para as gerações futuras. Nas cidades a maior parte da água é destinada aos chamados consumidores em potencial que são divididos em industriais, comerciais e institucionais. Portanto, através da conservação da água nessas tipologias de edifícios é possível obter muitos benefícios, como um maior número de usuários atendidos com a mesma oferta de água, preservação dos recursos hídricos, redução da demanda de energia elétrica, entre outros. Várias medidas de conservação de água têm sido adotadas nos chamados consumidores em potencial, classificados como: institucionais, industriais e comerciais, visando minimizar o consumo. Vale ressaltar que, em média, $90 \%$ da produção de água nas cidades se destinam a esses setores (ILHA et al. 2006).

A população do município de Catalão - GO é de 102.393 habitantes (IBGE, 2017). A cidade já vem enfrentando problemas com relação à oferta e demanda de água mostrando assim a necessidade de um uso eficiente e racional da água. Gonçalves et al. (2005) afirmam que "a implantação de um Programa de Uso Racional da Água (PURA) parte da premissa de que o consumo de água na edificação pode ser otimizado". Nesse sentido, o presente trabalho propõe uma metodologia para a implantação de um Programa de Uso Racional da água em uma escola da cidade de Catalão - GO.

\section{REVISÃO DA LITERATURA}

\subsection{RECURSOS HÍDRICOS, CONSUMO E DISTRIBUIÇÃO}

A água não apenas se movimenta através dos rios, correntes de ar e correntes marinhas, mas também sob a forma social, por meio de mercadorias tangíveis de diversas formas, tais como: minerais, automóveis, produtos agrícolas, tecidos, dentre outros (PortoGonçalves, 2004).

Segundo a Organização das Nações Unidas (ONU), as zonas urbanas, em 2014, abrigavam $54 \%$ da população mundial, sendo que essa proporção deve chegar a $66 \%$ no ano de 2050. Nessas áreas a poluição age combinada com a escassez, valendo ressaltar que um habitante urbano em média consome três vezes mais água em relação a um habitante rural (Porto-Gonçalves, 2004).

A distribuição de água no mundo ocorre da seguinte forma: 0,3\% (rios e lagos), 29\% (águas subterrâneas), 69,8\% (calotas polares) e $0,9 \%$ (outros), sendo $97,5 \%$ (água salgada e 2,5\% (água doce). A Agência Nacional de Água (ANA) relatou, em 2011, que em um horizonte de 30 anos as estimativas de crescimento populacional indicam que 5,5 bilhões de pessoas estarão habitando locais com moderada ou com grande escassez de água. Considerando que apenas $0,30 \%$ do total de água presente no planeta são de água doce facilmente explorada e sua distribuição é muito heterogênea, isso irá acarretar grandes transtornos e problemas de escassez regionalizados. Segundo relatos de Fietz (2006), o consumo diário de água na Roma antiga era de apenas 20 litros por pessoa. No Brasil essa média atualmente está em torno de 150 litros de água, sendo que a média européia é de 350 a 400 litros e dos norte-americanos cerca de 550 a 700 litros de água. Em contraste a esses dados, em certas regiões da África, o consumo "per capita" é de impressionantes 15 litros por dia. O Brasil é considerado como o país de maior detenção de água, com disponibilidade hídrica de $35.732 \mathrm{~m}^{3}$ hab $^{-1}$ ano $^{-1}$, possuindo em torno de $12 \%$ da água doce do planeta (TOMAZ, 2001). Porém, a mesma não se apresenta distribuída de uma forma homogênea dentre suas regiões.

A Concentração dos recursos hídricos (\%) e densidade demográfica no Brasil (hab $\mathrm{km}^{-2}$ ) são distribuídas, respectivamente, da seguinte forma: Norte $(68,50 ; 4,12)$; Nordeste $(3,30 ; 34,15)$; Centro-Oeste $(15,70 ; 8,75)$; 
Sudeste $(6,00 ; 86,92)$ e Sul $(6,50 ; 48,58)$ (Ana, 2010).

O consumo de água pode ser influenciado por diversos fatores como, características físicas (temperatura do ar, intensidade $e$ frequência de precipitação da chuva), renda familiar, características da habitação (área do terreno, área construída e número de habitantes), características do abastecimento (pressão e qualidade da água), forma de gerenciamento do sistema de abastecimento (micromedição e tarifas) e características culturais (TSUTIYA, 2006). As regiões com maior densidade demográfica, em geral, costumam apresentar maiores índices de consumo.

Segundo relatado, em publicação da Folha de São Paulo de 2013, o estado do Rio de Janeiro é o que apresenta maior consumo médio diário por habitante com 253 I hab $^{-1}$ $\mathrm{dia}^{-1}$, enquanto que o estado de Alagoas é o que registrou o menor consumo $100 \mathrm{l} \mathrm{hab}^{-1}$ $\mathrm{dia}^{-1}$. Nesse mesmo relatório é apresentado o consumo médio por região Norte $(159,29)$, Nordeste $(131,89)$, Sudeste $(197,75)$, Centro Oeste $(164,25)$ e Sul $(151,00)$. Assim, analisando esses valores, é possível verificar que a região sudeste possui a maior densidade demográfica, juntamente com uma das menores concentrações dos recursos hídricos e o maior consumo de água do país. A região Nordeste apresentou o menor índice de consumo per capta do Brasil, fato esse justificado devido à escassez proveniente do processo cíclico da seca. Gonçalves e Hespanhol (2004) definem a conservação da água como sendo práticas, técnicas e tecnologias que possam garantir uma melhor eficiência do seu uso. Os mesmos autores destacam que conservar a água consiste em se atuar, de forma sistêmica, tanto na demanda quanto na sua oferta.

\subsection{USO RACIONAL DA ÁGUA.}

A água pode ser definida como um bem natural comum, vital e insubstituível. A contínua urbanização, seguida da grande densidade demográfica das regiões metropolitanas, contribuem para o gradativo aumento da demanda de água, bem como para a sua poluição e degradação. (Oliveira Júnior e Silva Neto, 2004). Gonçalves e Hespanhol (2004) definem o "uso racional da água" como ação que: reduz a quantidade de água extraída das fontes de abastecimento; reduz o consumo; reduz o desperdício; reduz as perdas; aumenta a eficiência do seu uso; aumenta a reciclagem e o reuso e evita a poluição. A Implementação do PURA consiste em sistematizar um plano de intervenções para serem efetivadas em uma edificação. 0 plano deve ser resultado de um extenso conhecimento do sistema em questão, para que se possa garantir, através das ações propostas, a qualidade necessária aos usuários da edificação, na realização de suas atividades (Gonçalves et al. 2005). Em casos de edifícios que não contam com sistema de medição de água, é necessária sua implantação e também realizar o monitoramento por um período mínimo de trinta dias (Oliveira, 1999). O consumo total de um edifício, independente de sua tipologia, é representado por uma parcela de água efetivamente usada, necessária para a prática de diferentes atividades, e outra, pela desperdiçada, decorrente do uso excessivo e/ou perdas (Tsutiya, 2006). Portanto, o consumo total pode ser representado pela Eq. (1):

$$
\text { CONSUMO DE ÁGUA }=U S O+D E S P E R D I ́ C I O
$$

$\mathrm{Na}$ Tab. (1) estão relacionados os valores comumente desperdiçados pela sociedade de acordo com a situação do vazamento. 
Tabela 1: Perda de água diária por vazamento em torneiras.

\begin{tabular}{|c|c|c|c|}
\hline \multicolumn{1}{|c|}{ Vazamento } & Frequência $\left(\right.$ gotas min $\left.^{-1}\right)$ & $\begin{array}{c}\text { Perda diária } \\
\left(\text { l dia }^{-1}\right)\end{array}$ \\
\hline Gotejamento lento & Até 40 gotas min $^{-1}$ & 06 a 10 & 10 a 20 \\
\hline Gotejamento médio & $40<\mathrm{n}^{\circ}$ gotas min $^{-1} \leq 80$ & 20 a 32 & $>32$ \\
\hline Gotejamento rápido & $80<\mathrm{n}^{\circ}$ gotas min $^{-1} \leq 120$ & $>114$ & \\
\hline Gotejamento muito rápido & Impossível contar & $>333$ & \\
\hline Filete diâmetro $\approx 2 \mathrm{~mm}$ & - & & \\
\hline Filete diâmetro $\approx 4 \mathrm{~mm}$ & &
\end{tabular}

O significado de desperdício, quando associado a termos como vazamentos, perda ou uso excessivo possui conceitos diferentes quando aplicados aos sistemas hidráulicos. 0 desperdício é toda água que esteja disponível em um sistema hidráulico e seja perdida antes do seu uso para uma atividade qualquer. Pode ocorrer tanto por perda quanto pelo uso excessivo (OLIVEIRA, 1999). A autora define Perda como sendo a água que escapa do sistema antes de ser utilizada, podendo ser devido ao Mau desempenho do sistema, vazamento ou negligencia do usuário e o Uso excessivo: água utilizada de forma inadequada, devido ao Mau desempenho do sistema ou Procedimentos inadequados.

Os vazamentos são definidos como qualquer escoamento que fuja das tubulações e/ou equipamentos hidráulicos de um determinado sistema predial. Eles podem ser classificados como visíveis ou não visíveis (OLIVEIRA, 1999). Vazamentos visíveis são facilmente detectados por usuários, ocorrendo, principalmente, em componentes de utilização, registros e tubulações. Por outro lado, os nãos visíveis se manifestam de maneira indireta, podendo ser por meio de manchas de umidade apresentando descolorido ou aspecto esponjoso nos revestimentos de parede ou piso; som de escoamento quando nenhum ponto de utilização está em uso; ocorrência de vegetação em juntas de assentamento de pisos externos; ativação continua do sistema de recalque e entrada constante de água nos reservatórios e aumento de consumo sem justificativa. O fim do desperdício de água tem por objetivo impedir que não se pague por um consumo maior do que o necessário, como também evitar patologias no sistema estrutural do edifício ocasionadas pelos vazamentos.
Para evitar o desperdício, Oliveira (1999) destaca que é necessário focar em áreas econômicas, que tem por objetivo proporcionar incentivos econômicos para instalação de dispositivos economizadores ou criar formas de elevar as tarifas de consumo de água para impedir o consumo excessivo; sociais, que se baseiam em mudanças comportamentais dos usuários, por meio de campanhas educativas, bem como buscar a sensibilização coletiva para adequação das práticas quanto aos procedimentos eficientes ao uso da água em suas atividades e tecnológicas, que se fundamentam na redução do consumo através da substituição de componentes convencionais por economizadores de água, detecção e correção de vazamentos, reuso de efluente tratado, implementação de sistema de medição setorizada. É importante que para a implementação do PURA seja realizado um diagnóstico do consumo de água da edificação em estudo, para obtenção de resultados efetivos.

\subsection{AÇÕES QUE CONTRIBUEM PARA A REDUÇÃO DO CONSUMO DE ÁGUA EM EDIFICAÇÕES.}

Diversas medidas, visando à economia de água podem gerar redução significativa no consumo de água em edifícios. Algumas delas podem sem aplicadas em qualquer sistema predial, já outras apenas no caso de sistemas específicos (OLIVEIRA, 1999). Griggs e Shouler (1994) destacam algumas alternativas de redução de consumo para o Reino Unido, são elas: Programa de "Rotulação" para componentes, o que possibilita ao usuário a escolha do componente por meio de comparações de consumo, o que incentiva os fabricantes na 
evolução de seus produtos para alcançar melhores índices de economia; Volumes de descarga inferiores a 6 litros, utilizando-se de tecnologias inovadoras; Medição do consumo visando economia financeira para os consumidores economizarem e detectarem vazamentos; Aproveitamento de água das chuvas para atividades como, regar jardins, lavagem de pisos e outros usos externos e Reciclagem da água para seu uso em irrigação e descarga em bacias sanitárias.

\subsubsection{DETECÇÃO E OCORRÊNCIA DE VAZAMENTOS.}

A ocorrência de vazamentos pode acontecer pelo simples fato do desgaste natural do sistema hidráulico que, geralmente, apresenta vida útil menor quando comparado com a da edificação. Quando o sistema hidráulico apresenta difícil acesso as perdas podem levar longos períodos de tempo para serem detectadas, proporcionando, além do desperdício, danos a outros sistemas do edifício (OLIVEIRA, 1999). Segundo a mesma autora, existem vários fatores que influenciam o surgimento e a detecção de vazamentos, tais como: Pressão hidráulica, mesmo que não seja comum a ruptura de sistemas hidráulicos prediais, elas podem ocorrer caso o sistema esteja solicitado a valores iguais ou superiores a $400 \mathrm{KPa}$, ou menores dependendo de sua qualidade.

Essa situação pode ser evitada através do uso de válvulas redutoras de pressão; Condições da tubulação, embora a grande maioria dos sistemas hidráulicos seja projetada em PVC, existem aqueles que apresentam, em sua totalidade ou em alguns de seus elementos, o aço como material de fabricação, como no exemplo de tubulações de sistema de recalque. Desta forma, é conveniente considerar a deterioração das paredes, decorrente da corrosão das paredes internas e externas dos tubos. Este processo é responsável pela redução da espessura de suas paredes, tornando-os menos resistentes as pressões internas; Materiais, componentes e execução, devem ser especificados de acordo com os esforços atuantes, porém apenas a garantia de sua qualidade não é suficiente para o bom desempenho do sistema. É importante também atender as técnicas de execução compatíveis, além de supervisão e fiscalização adequadas; A falta de manutenção do sistema atua como uma das principais causa de perdas de água nos sistemas prediais.

0 usuário muitas vezes percebe um vazamento em uma torneira, porém o mesmo permanece estático, pois o problema não o está incomodando, "apenas" desperdiçando água; A idade do sistema, não se apresenta como fator determinante para o surgimento de vazamentos, porém a deterioração do sistema aumenta com o passar do tempo, evento que influencia diretamente na probabilidade na ocorrência de vazamentos em sistemas hidráulicos; Tipo de solo: a permeabilidade do solo é uma característica de ajuda fundamental na detecção de vazamentos, muitas vezes só é possível perceber um vazamento quando a água aflora à superfície, assim, em solos com baixo índice de permeabilidade, as perdas podem ocorrer por anos ou até mesmo por toda a vida útil do sistema sem que sejam localizadas.

\section{MATERIAIS E MÉTODOS}

A metodologia proposta do presente trabalho visa à sugestão de medidas economizadoras de água de acordo com o Programa de Uso Racional da água (PURA), para serem implantadas em uma escola de Catalão. A mesma conta com uma área construída de 1969,56 $\mathrm{m}^{2}$, um quadro de 84 funcionários e 568 alunos distribuídos em turmas que vão desde o maternal ao pré-vestibular. 0 ensino fundamental I conta com 161 alunos, o ensino fundamental II com 141 alunos, o ensino médio com 238 alunos e por fim o prévestibular com 28 alunos. A água utilizada para consumo em toda a escola é proveniente de um poço artesiano, sendo importante destacar que não era utilizado nenhum mecanismo de medição de consumo no local.

A metodologia utilizada neste trabalho, para a implantação do PURA, se dividiu em: Auditoria do consumo de água: corresponde a primeira etapa, a qual possibilita o conhecimento da forma como a água é utilizada na edificação. Nesta etapa são feitas as observações preliminares do sistema hidráulico predial e dos procedimentos dos usuários; Diagnóstico: pode ser definido como a junção das informações obtidas na auditoria do consumo de água, identificando assim as condições de operação do sistema, os problemas encontrados e pontos frágeis, define-se assim como etapa indispensável para o planejamento de intervenções compatíveis a do sistema de operação da 
edificação; Plano de intervenção: é o conjunto de ações definidas em função do diagnóstico e condições técnico-econômicas encontradas, com o objetivo de redução dos desperdícios no consumo de água, levandose em consideração a manutenção do nível conforto, higiene, porém sem colocar em risco a saúde do usuário, pelo fato da menor quantidade de água a ser utilizada no sistema; Avaliação do impacto: apresenta-se através da verificação das ações implementadas no sistema em estudo, por meio do acompanhamento do consumo diário, semanal ou mensal do volume de água consumido.

Os valores obtidos nesta etapa devem ser comparados ao valor médio de consumo medido no período anterior à implementação do PURA. Depois da instalação do hidrômetro, foram realizadas as medições de consumo para duas épocas distintas do ano (período chuvoso e período de seca), contemplando também dois períodos distintos na escola (período letivo e férias). Nas duas fases de medição, acompanhou-se o consumo por um período de trinta dias. Foi realizado o monitoramento do consumo de água da edificação por um período mínimo de trinta dias. 0 primeiro entre os dias $07 / 11 / 2016$ à $06 / 12 / 2016$ e o segundo entre os dias 08/06/2016 e 07/07/2017, sempre tomando o cuidado de se realizar as mesmas no mesmo horário do dia. A seguir foi realizada uma vistoria completa em toda a edificação, fazendo o levantamento de todos os aparelhos hidráulicos, bem como a verificação de ocorrência de vazamentos nos mesmos. Por fim, nas etapas referentes ao plano de intervenções e avaliação de impacto, foram realizadas suposições e estimativas, tomando como referência trabalhos realizados utilizando a mesma linha de pesquisa.

\section{RESULTADOS E DISCUSSÕES.}

$\mathrm{Na}$ Tab. (2) estão relacionados os valores medidos nos diferentes períodos.

Tabela 2: Medições realizadas nos períodos de consumo analisados

\begin{tabular}{|c|c|c|c|c|c|}
\hline $\begin{array}{c}\text { Período } \\
\text { Consumo } \\
\text { (litros) }\end{array}$ & $\begin{array}{l}\text { Ano } \\
2016\end{array}$ & $\begin{array}{c}\text { Medição } \\
\mathrm{m}^{3}\end{array}$ & $\begin{array}{l}\text { Período } \\
\text { Consumo } \\
\text { (litros) }\end{array}$ & $\begin{array}{l}\text { Ano } \\
2017\end{array}$ & $\begin{array}{c}\text { Medição } \\
\mathrm{m}^{3}\end{array}$ \\
\hline 1 & 07/nov & 26,487 & 2 & 08/jun & 1214,045 \\
\hline \multirow[t]{20}{*}{214.304} & $08 / \mathrm{nov}$ & 38,265 & 143.142 & 09/jun & 1223,701 \\
\hline & $09 /$ nov & 50,916 & & 12 /jun & 1236,556 \\
\hline & $10 /$ nov & 60,063 & & $13 /$ jun & 1246,165 \\
\hline & $11 /$ nov & 69,337 & & 14/jun & 1256,416 \\
\hline & $14 /$ nov & 83,347 & & 19/jun & 1270,892 \\
\hline & $16 /$ nov & 95,889 & & $20 /$ jun & 1283,135 \\
\hline & $17 /$ nov & 102,942 & & $21 /$ jun & 1293,291 \\
\hline & $18 /$ nov & 113,942 & & $22 /$ jun & 1300,854 \\
\hline & $21 / \mathrm{nov}$ & 130,296 & & $23 /$ jun & 1308,434 \\
\hline & $22 /$ nov & 137,399 & & $26 /$ jun & 1321,151 \\
\hline & $23 /$ nov & 144,418 & & $27 /$ jun & 1329,099 \\
\hline & $24 /$ nov & 153,99 & & $28 /$ jun & 1338,95 \\
\hline & $25 /$ nov & 164,604 & 3 & 29/jun & 1349,718 \\
\hline & $28 /$ nov & 177,191 & 33.554 & $30 /$ jun & 1357,187 \\
\hline & $29 /$ nov & 186,545 & Férias & 03/jul & 1361,568 \\
\hline & $30 /$ nov & 205,07 & & 04/jul & 1365,872 \\
\hline & $01 / \mathrm{dez}$ & 212,571 & & 05/jul & 1370,249 \\
\hline & 02/dez & 219,809 & & 06/jul & 1380,705 \\
\hline & 05/dez & 234,538 & & 07/jul & 1386,236 \\
\hline & $06 / \mathrm{dez}$ & 240,791 & & 08/jul & 1390,741 \\
\hline
\end{tabular}

\subsection{CÁlCULO DO INDICADOR DE CONSUMO.}

O período de atividades considerado para o cálculo do indicador de consumo depende da tipologia do edifício (OLIVEIRA, 1999). Neste estudo tratou-se de um edifício escolar, onde existem interrupções das atividades durante finais de semana, feriados e período de férias. Assim, foi considerado como período de 
atividades apenas os dias letivos. 0 valor do indicativo de consumo $(I C)$ foi calculado de acordo com a Eq. (2) (OLIVEIRA, 1999):

$$
I C=\frac{\text { consumo de água do perído }}{n^{\underline{0}} \text { de agentes consumidores } x \text { período de atividades }}
$$

A partir dos dados da Tab. (2) e da Eq. (2) foi possível calcular o IC (l/hab.dia) para cada período 15,65 (período 1 com 652 consumidores), 14,64 (período 2 com 652 consumidores) e 349,52 (período 3 com 12 consumidores). A média de consumo diária (l $\mathrm{dia}^{-1}$ ) em cada período foi de 10.204,95 (1), 9.542,80 (2) e 4.194,25 (3).

0 consumo na escola foi dividido e quantificado em três períodos (Tab. 2), que expõe o grande aumento do IC no período das férias (3). Isso é justificado pela grande redução da população da escola, que nesse período apenas composta por funcionários da limpeza e administrativos, além de ter sido comunicado pela direção do colégio que nesta ocasião estavam sendo realizadas faxinas na edificação. Mesmo sendo feito o acompanhamento do consumo em períodos distintos, o valor do IC encontrado nos dois casos, referentes aos dias letivos, foram semelhantes, 16,20 l/hab.dia e 15,15 l/hab.dia para o consumo 1 (período chuvoso) e consumo 2 (período de seca), respectivamente, pois esperava-se obter valores com maior variação, por conta da mudança climática entre os dois.

Os valores dos IC calculados podem ser comparados com aqueles apresentados na Tab. (3).

Tabela 3: Indicadores de Consumo (IC) de água para escolas.

\begin{tabular}{|c|c|c|}
\hline IC (litros/pessoas & Categoria & Autor \\
\hline 81,1 & Ensino fundamental ( 11 a 14 anos $-5^{\circ}$ a $8^{\circ}$ série) & Oliveira (1999) \\
\hline 18,6 a 30,9 & Educação infantil ( 3 a 6 anos) & \multirow{3}{*}{ Barreto; Chicchi (2001) } \\
\hline 7,6 a 11,6 & Ensino fundamental ( 7 a 14 anos $-1^{\circ}$ a $8^{\circ}$ série) & \\
\hline 4,0 a 13,4 & Ensino médio ( $2^{\circ}$ grau - 15 a 17 anos) & \\
\hline 25,0 & Ensino fundamental e médio & São Paulo (2001) \\
\hline 3,79 a 12,1 & Educação infantil & \multirow{3}{*}{ Wernek (2006) } \\
\hline 0,51 a 11,6 & Ensino fundamental & \\
\hline 4,5 a 7,5 & Ensino fundamental e médio & \\
\hline
\end{tabular}

A variabilidade valores dos encontrados para - IC pode ser justificada por hábitos e regimes educacionais diferentes, condições climáticas, além de cada autor realizar suas próprias considerações para o cálculo do IC, como no caso do número de agentes consumidores e período de atividades. Portanto, seria importante uma padronização de um método para determinação do IC para que resultados obtidos em diferentes situações possam ser comparáveis. Os valores encontrados para o consumo mensal de água nos dois períodos podem também ser comparados aos obtidos por meio de equações. Assim, foram consideradas duas equações para a estimativa de consumo mensal, a Eq. (3) (TSUTIYA, 2006) e a Eq. (4) (BERENHAUSER \& PULICI, 1983).

$$
\begin{gathered}
-28,1+0,0191 x(A C)+2,85 x(N B)+4,37 x(N D C)+0,430 x(V P)+1,05 x(N F) \\
0,05 x(A C)+0,1 x(N V)+0,7 x(N F)+20
\end{gathered}
$$


Onde: $A C=$ área construída; $N B=\mathrm{n}^{\circ}$ de bacias; $N D C=n^{\circ}$ de duchas/chuveiros; VP = volume das piscinas; $\mathrm{NF}=\mathrm{n}^{\circ}$ de funcionários; $\mathrm{NV}=\mathrm{n}^{\circ}$ de vagas;

A estimativa de consumo por meio de equações (3) e (4) foram, respectivamente, 188.720 litros e 230.680 litros. Observa-se que, mesmo com as duas equações apresentando uma variação considerável, elas oferecem um parâmetro de estimativa quando não se tem nenhuma informação do histórico de consumo da edificação a ser estudada. Outro fator importante a ser mencionado são os valores obtidos com relação ao consumo diário. Através dele é possível observar os valores de pico do consumo no período considerado e também dos dias de menor consumo. Na Fig. (1) se faz um comparativo entre os consumos diários medidos nos dois períodos e pode-se observar que, para o Consumo 1, obteve-se o maior consumo com valor aproximado de 18 mil litros de água e o menor valor ficou em torno de 6 mil litros. Para o Consumo 2 os valores aproximados, de maior e menor consumo, foram 14 mil e 4 mil litros, respectivamente. Vale destacar que este valor de 4 mil litros para o consumo 2 foi medido no período de férias.

Figura 1: Consumo diário nos dois períodos

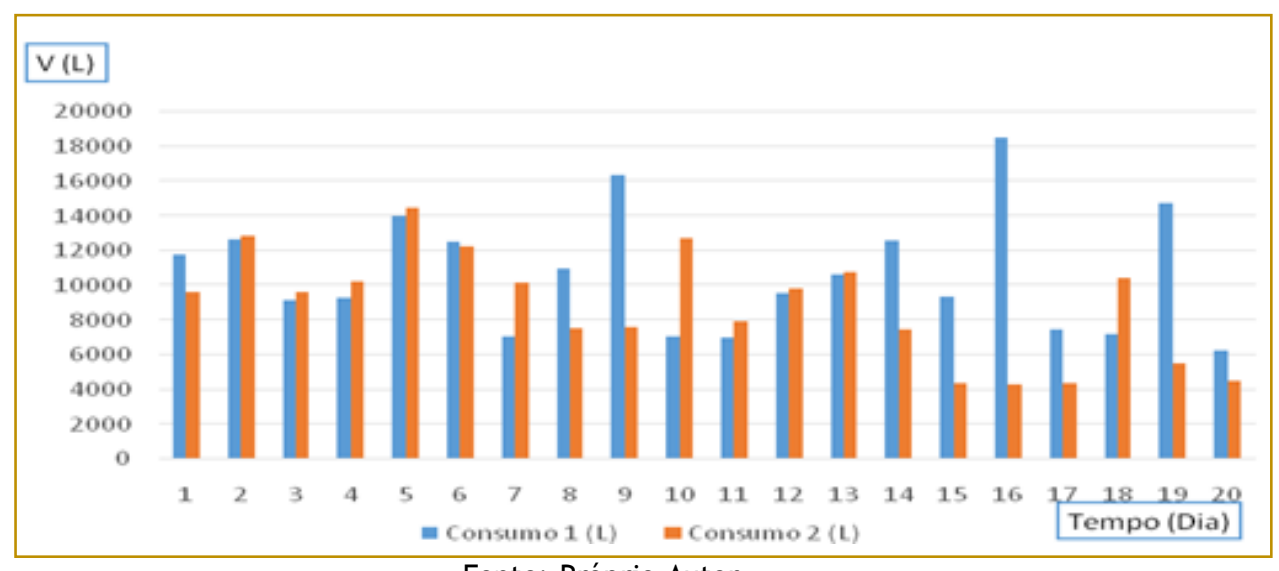

Fonte: Próprio Autor

$\mathrm{Na}$ Fig. (2), nas letras a e b, estão representados os valores de consumo em cada período e o consumo médio diário.

Figura 2: Consumo diário e médio nos dois períodos

a) Parte 1 - dias letivos.

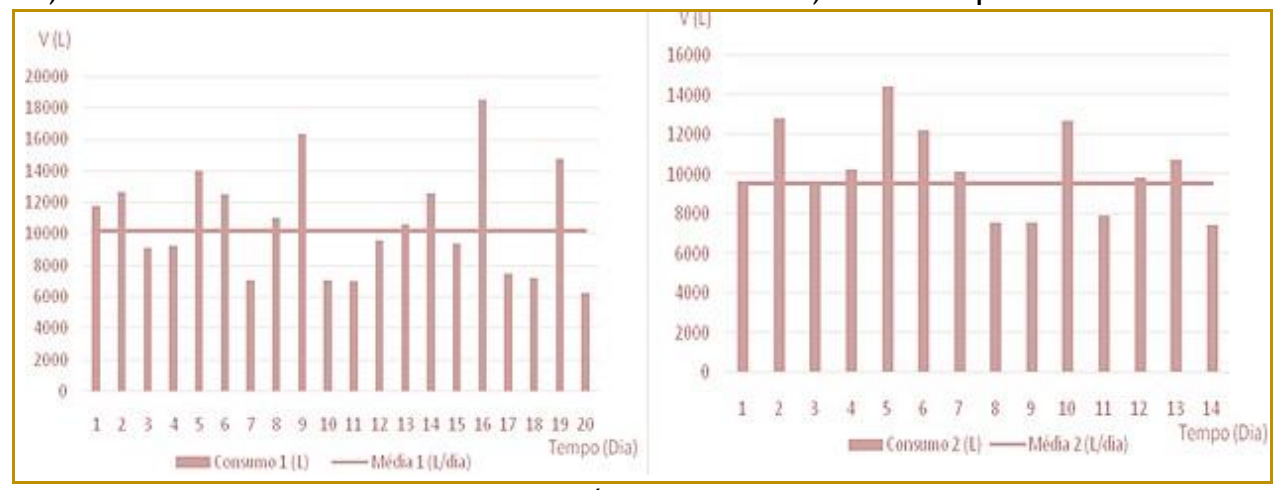

(Fonte: Próprio Autor) b) Parte 2 - período de férias 


\subsection{DIAGNÓSTICO E VISTORIA DOS APARELHOS HIDRÁULICOS DA ESCOLA ESTUDADA。}

Com o objetivo de detectar vazamentos e possíveis perdas água, na edificação em estudo, foi realizada uma vistoria para o levantamento de todos os aparelhos hidráulicos do colégio. Observou-se que a maioria dos aparelhos apresentava bom funcionamento e não apresentavam sinais de vazamento, a exceção ficou por conta de apenas duas torneiras. Uma apresentava gotejamento ininterrupto, sendo que a outra apresentou vazamento na ligação na curva de PVC onde a mesma é fixada a tubulação que a alimenta.

$\mathrm{Na}$ vistoria realizada foi possível fazer um levantamento dos tipos de aparelhos hidráulicos e suas quantidades, descritas a seguir: Torneira de Jardim (5), Torneira de Lavatório (25), Torneira Tanque (2), Torneira de Cozinha (2), Válvula de Descarga (24), Bacia Sanitária (17), Bacia Sanitária Com Caixa Acoplada (1), Bacia Sanitária Infantil (7), Ducha Higiênica (16), Mictório (7), Bebedouro (3) e Chuveiro (5). Não foi possível detectar os vazamentos provenientes das tubulações do sistema predial da escola, pois não se dispunha de equipamentos necessários, como haste de escuta, geofone eletrônico e correlacionador de ruídos.

\subsection{PLANO DE INTERVENÇÃO E ESTIMATIVA DE IMPACTO.}

O plano de intervenção foi elaborado a partir da vistoria feita no local, no qual como citado anteriormente, foram detectados apenas dois pontos de vazamento, porém, o sistema conta com um total de 24 válvulas de descarga, tal dispositivo apresenta um consumo bem maior quando comparado ao das bacias sanitárias com caixa acoplada. As bacias sanitárias são apontadas por diversos autores como as principais responsáveis pelo consumo de água em edificações, estudos apontam que elas contribuem para um percentual de $32 \%$ a $40 \%$ do consumo mensal (Griggs, Shouler, 1994; Shouler, Thomas, 2000).

Tsutiya (2006) fixa um valor de consumo de 10 litros para cada acionamento de uma válvula de descarga bem regulada, já Oliveira (1999) define um valor médio de consumo de 12 litros por acionamento, não levando em consideração a regulagem. Para as bacias com caixa acoplada, ambos os autores definem o valor de consumo de 6 litros por acionamento. Portanto, como não se pode afirmar que as válvulas apresentam boa regulagem, para efeito de cálculo, foi considerado o consumo igual a 12 litros por acionamento das mesmas. Na Tab. (4) são apresentados os valores estimados de consumo mensal pelas válvulas de descarga e também os valores percentuais de economia de água estimados através da implantação do plano de intervenções proposto.

Tabela 4: Percentual estimado de economia de água mensal

\begin{tabular}{|l|c|}
\hline \multicolumn{1}{|c|}{ Consumo médio nos dois períodos (litros) } & 195.500 \\
\hline Valor estimado de consumo pelas válvulas de descarga (litros) & 62.560 a 78.200 \\
\hline Percentual estimado economia das bacias com caixa acoplada & $50 \%$ \\
\hline $\begin{array}{l}\text { Valor estimado de economia de água pela substituição das válvulas de descarga por } \\
\text { bacias com caixa acoplada (litros) }\end{array}$ & 31.280 a 39.100 \\
\hline Percentual estimado de economia real $\quad$ (Fonte: Próprio Autor & $16 \%$ a 20\% \\
\hline
\end{tabular}

Conforme valores encontrados na Tab. (4), o percentual estimado de economia real representa uma redução significante no consumo mensal na escola, podendo chegar aos $20 \%$, apenas sendo feito a substituição das bacias sanitárias com válvula de descarga por aquelas com caixa acoplada.

\section{CONSIDERAÇÕES FINAIS.}

Como a escola não paga pela água consumida pode-se pensar no fato de não haver interesse, por parte da mesma, em realizar as modificações apresentadas, porém, por outro lado, a questão ambiental pode viabilizar o processo, visto que a edificação em estudo trata-se de uma 
instituição formadora de opinião, assim, a adoção e divulgação do PURA, dentro da escola, faria com que a economia de água ultrapassasse os limites da mesma. Outra observação pertinente seria referente ao marketing que pode ser realizado pela escola, pois como se trata de uma instituição de ensino particular e as questões ambientais estão cada vez mais em evidencia, poderiam ser realizadas propagandas sobre o assunto para conscientização dos alunos matriculados na escola, atrair novos alunos e se tornar

\section{REFERÊNCIAS}

[1] Ana - Agência Nacional de Águas. Disponível em: <http://www2.ana.gov.br/Paginas/ imprensa/noticia.aspx?id_noticia $=12683>$ Acesso em: 03 de Agosto de 2017.

[2] Barreto, D.; Chicchi, C. A. Programa de Economia de Água em Escolas: Desenvolvimento elmplantação da Metodologia e no Setor de Abastecimento de Água na Cidade de Santo André - SP. $21^{\circ}$ Congresso Brasileiro de Engenharia Sanitária e Ambiental, João Pessoa, 2001.

[3] Fietz, C. R. Água, o recurso natural do terceiro milênio. Revista A Lavoura, Rio de Janeiro. Ano 109, n. 657 pg. 18-19, jun. 2006.

[4] Folha DE SÃO paulo. Disponível em: <http://www1.folha.uol.com.br/infograficos /2015/01/118521-agua-no-brasil.shtml> Acesso em: 01 de Agosto de 2017.

[5] Gonçalves, O., Hespanhol, I. (coords). Conservação e Reuso de água: Manual de orientação para o setor industrial. São Paulo: CIRRA/ MMA/ ANA/ FIESP, 2004.

[6] Gonçalves, O., et al. Conservação e Reuso de Água em edificações. São Paulo: MMA/ ANA/ Fiesp/ SindusCon-SP, Prol Editora Gráfica, 2005.

[7] Griggs J.C.; Shouler, Martin. An examination of water conservation measures. In: CIB W62 SEMINAR 1994, England. Proceedings... England: CIB, 1994. 11p.

[8] Ibge - Instituto Brasileiro de Geografia e Estatística. Disponivel em: <http://www.censo2010.ibge.gov.br/sinopse/index. php?dados $=4 \& u f=00>$. Acesso em: 03 de Agosto de 2017. exemplo de uso racional da água no município de Catalão. Por fim, para que os resultados possam alcançar valores ainda mais significativos, seria aconselhável que a escola realizasse campanhas educativas voltadas para a importância de economizar água, pois nos últimos anos a população da cidade de Catalão já vem sentindo os impactos causados pela falta deste precioso e importante elemento na vida de toda a população do Brasil e do mundo.

[9] Ilha, M. S. DE O.; Pedroso, L. P.; Ywashima, L. Indicadores de consumo de água em escolas. XII Encontro Nacional de Tecnologia do Ambiente Construído, Fortaleza, out 2008.

[10] Melo, V.O.; Netto, J.M.A. Instalações Prediais Hidráulico-Sanitárias. $1^{\circ}$ ed. São Paulo: Editora Edgard Blücher, 1988. 185 p.

[11] Oliveira, L. H. Metodologia para implantação de programa de uso racional da água em edifícios. Tese (Doutorado em Engenharia da Construção Civil) - Escola Politécnica da Universidade de São Paulo, São Paulo 1999.

[12] Porto-Gonçalves, C. Os porquês da desordem mundial: o desafio ambiental. Rio de Janeiro: Ed. Record, 2004.

[13] São Paulo. Decreto $n^{\circ} 45.805$, de 15 de maio de 2001. Institui o programa estadual do uso racional da água potável e das providências correlatas. São Paulo, 16p.

[14] Shouler, M.; Thomas, F. Water efficient housing in the UK. In: CIB w62 International Symposium, 26.2000, Rio de Janeiro. Proceedings... Rio de Janeiro: CIB, 2000, 10p.

[15] Tomaz, P. Economia de Água: Para empresas e residências. São Paulo: Navegar, 2001.

[16] Werneck, G. A. M. Sistemas de utilização da água da chuva nas edificações: o estudo de caso da aplicação em escola da Barra do Piraí, RJ. 2006. 201f. Dissertação (Mestrado em Ciências da Arquitetura) - Faculdade de Arquitetura e Urbanismo, Universidade Federal do Rio de Janeiro, Rio de Janeiro, 2006 


\section{Gapítulo 6}

\section{AVALIAÇÃO DOS FATORES CRITTICOS DE SUCESSO NA APLICAÇÃO DE WORKSHOPS LEAN DE 7 FASES NA CONSTRUÇÃO PESADA}

\section{Deísa Valéria Costa Conegundes}

Resumo: Com a mudança de mercado já representada em diversas indústrias somada a transformação digital, a competitividade vem se acirrando cada dia mais e neste contexto é colocada no centro das atenções a necessidade de melhorarmos nossos processos a fim de entregar sempre o que mais agrega valor para o nosso cliente com o menos desperdício possível. Neste cenário e considerando como base a filosofia lean, o Sistema Toyota de Produção, o pensamento A3, e o PDCA o Workshop de 7 fases foi criado, a fim de propor melhorias nas variadas frentes de trabalho existentes. Este artigo visa avaliar os fatores críticos de sucesso na aplicação de Workshops Lean de 7 fases na construção pesada além de aprofundar, disseminar e facilitar a utilização desta metodologia, reduzindo os riscos de uma utilização incorreta e ajudando outros a alcançar resultados operacionais consistentes, além de comparar os resultados alcançados nas diversas iniciativas e propor melhorias para as oportunidades identificadas.

Palavras-chave: Lean Construction, Workshop 7 fases, Lean, Gestão de processos. 


\section{INTRODUÇÃO}

Em 2010 a jornada de transformação lean da empresa objeto desse estudo foi iniciada em obra de copa do mundo até 2012 as expansões foram para obras de usinas e regaseificação, em 2013 a empresa consolida o propósito da sua unidade de construção em cumprir o combinado e afim de manter seu propósito perene inicia a formação de consultores internos em Lean além de expandir as melhorias já implantadas para os mercados de Brasil e América latina.

Neste contexto, a atuação dos consultores lean foi voltada a melhoria de processos considerando a implantação de diversas ferramentas e métodos, entre eles 0 Workshop de 7 fases. Todos os métodos visavam o aumento de valor agregado para o cliente a partir da redução dos desperdícios identificados nas áreas de produtivas.

Desde então, houveram inúmeras iniciativas, especialmente voltados aos processos produtivos das obras. Aplicou-se a metodologia em diversas frentes de obras.

\subsection{IDENTIFICAÇÃO DA SITUAÇÃO PROBLEMA}

A empresa objeto deste estudo é uma grande empresa brasileira de infraestrutura com 69 anos de existência, atuação multinacional em 15 obras diferentes. Seu quadro funcional possui aproximadamente 2000 funcionários no público indireto. Atua na construção de obras classificadas como construção pesada, a exemplo portos, usinas, rodovias.

Neste contexto, e considerando as mudanças de mercado, é essencial que as organizações estejam adaptadas a atender as necessidades de seus clientes a fim de disponibilizar um ambiente flexível e eficaz (FIORE, 2003) que permita a integração entre todos os processos ao longo da organização, um método que contribua para a identificação, análise e correção dos problemas identificados. No entanto, nem todas as iniciativas implantadas nesse sentido alcançaram o êxito previsto.

\subsection{OBJETIVOS}

0 presente trabalho teve como objetivo geral avaliar dos fatores críticos de sucesso na aplicação de Workshops Lean de 7 fases na construção pesada.
Como objetivos específicos este trabalho visa aprofundar, disseminar e facilitar a utilização de uma metodologia do Workshop Lean de 7 fases, reduzindo os riscos de uma utilização incorreta e ajudando outros a alcançar resultados operacionais consistentes, além de comparar os resultados alcançados nas diversas iniciativas e propor melhorias para as oportunidades identificadas.

\section{METODOLOGIA}

O estudo foi realizado em quatro etapas: levantamento de referencial teórico já existente acerca do tema, apresentação do método aplicado, análise comparativa dos fatores de sucesso e proposição de melhorias.

A revisão bibliográfica, visa esclarecer alguns dos conceitos relacionados a base do método a fim de contextualizar o leitor com as motivações do método. Este estudo não se propõe a descrever os detalhes teóricos que embasam a construção do método aplicado, no entanto sugere-se ao leitor a consulta mais aprofundada das bibliografias citadas afim de que melhor compreenda as motivações que tornaram o método aplicado.

O Workshop Lean de 7 fases que será apresentado neste estudo é fruto do aprendizado empírico de aplicações anteriores e do conhecimento acumulado dos consultores que aplicaram o método diversas vezes, o formato escrito visa tornar o entendimento o mais acessível possível a qualquer público que almeje o uso.

A avaliação comparativa foi elaborada considerando as perguntas do Anexo Modelo detalhado de A3 (Shook, 2008) e perguntas qualitativas adaptadas do modelo Likert, 1932.

A análise de resultados foi realizada considerando o conteúdo de referência oferecido pela empresa e as notas atribuídas a cada item de avaliação.

A amostra que será analisada será de $90 \%$ dos trabalhos a que a autora teve acesso, os $10 \%$ não são aplicáveis a essa análise.

\section{REVISÃO BIBLIOGRÁFICA}

\subsection{DO SISTEMA TOYOTA DE PRODUÇÃO AO LEAN}

O livro a Máquina que Mudou o Mundo (1990) revela a arma secreta do Japão, da migração de uma produção em massa liderada pela 
americana Ford para uma produção enxuta nascida no pós-guerra japonês.

Em 1955, o sistema de produção em massa entrou em crise devido a seus altos níveis de estoque produzidos desconectados da necessidade do cliente. No Japão, altamente afetado pelo pós-guerra o cenário era diferente da rica América, o país estava em escassez de recursos e sérios problemas com a força de trabalho.

Portanto, era grande a necessidade por um sistema que evitaria altos custos e que possuísse menor rigidez na linha de produção. A produção enxuta busca a perfeição de seus produtos, trabalha com estoque mínimo e baixa ocorrência de defeitos com máquinas mais flexíveis e automatizadas. Exige qualificação dos colaboradores trazendo a responsabilidade para a base da pirâmide organizacional.

Durante o estabelecimento do Sistema Toyota de Produção, Ohno realizou diversas inovações no seu método produtivo sempre estando onde as coisas acontecem (do japonês: gemba), seu objetivo era melhorar a eficiência e acompanhar os principais concorrentes norte americanos (Ohno, 1997) mas suas práticas promoveram inspiração para a mudança de diversas indústrias, extrapolando o potencial automobilístico.
O Sistema Toyota de Produção deu origem ao pensamento Lean e mostrou a capacidade de melhorias constantes nas linhas de produção e em vários ambientes dentro das fábricas e empresas de diversos setores. Mostrou também a capacidade de adaptação das empresas às mudanças ocorridas ao longo das décadas e até mesmo algumas fragilidades suas que podem ser usadas para o próprio desenvolvimento e melhoramento do ambiente organizacional.

\subsection{PDCA}

Neves (2007) afirma que o ciclo PDCA auxilia na resolução de problemas e tomadas de decisões, sendo um meio eficaz para se atingir as metas. Se executado corretamente pode trazer vantagens enormes de qualidade, produtividade e de custos para a organização.

O ciclo PDCA é projetado para ser utilizado como um modelo dinâmico. Ao término de uma volta do ciclo irá fluir no início do próximo ciclo, e sucessivamente. Seguido na essência de melhoria de qualidade contínua, o processo sempre pode ser reanalisado e um novo processo de transformação poderá ser estreado (NASCIMENTO, 2011).

Figura 1: 0 ciclo PDCA. Fonte: Godoy (2010)

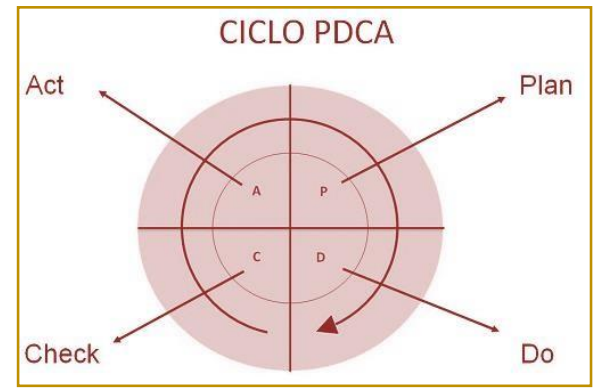

\subsection{PENSAMENTO A3}

Segundo Shook (2008) o termo "A3" refere-se a uma folha de papel de tamanho internacional, com $29,7 \mathrm{~cm}$ por $42 \mathrm{~cm}$. $\mathrm{Na}$ Toyota e em outras empresas lean, o termo significa muito mais. O A3 proporciona uma forma estruturada de resolver problemas de forma disciplicana, como afirma Shook:

A ideia da Toyota há muitos anos foi que cada problema que uma organização enfrenta pode e deverá ser capturado em uma única folha de papel. Isso possibilita que todos aqueles que enfrentam um problema enxerguem por meio da mesma lente. Embora a mentalidade básica para um $\mathrm{A} 3$ siga uma lógica comum, o formato e o conteúdo precisos são flexíveis, e a maioria das organizações ajusta o modelo para atender seus requisitos particulares” (Shook, 2008) 
Figura 2: Modelo de A3

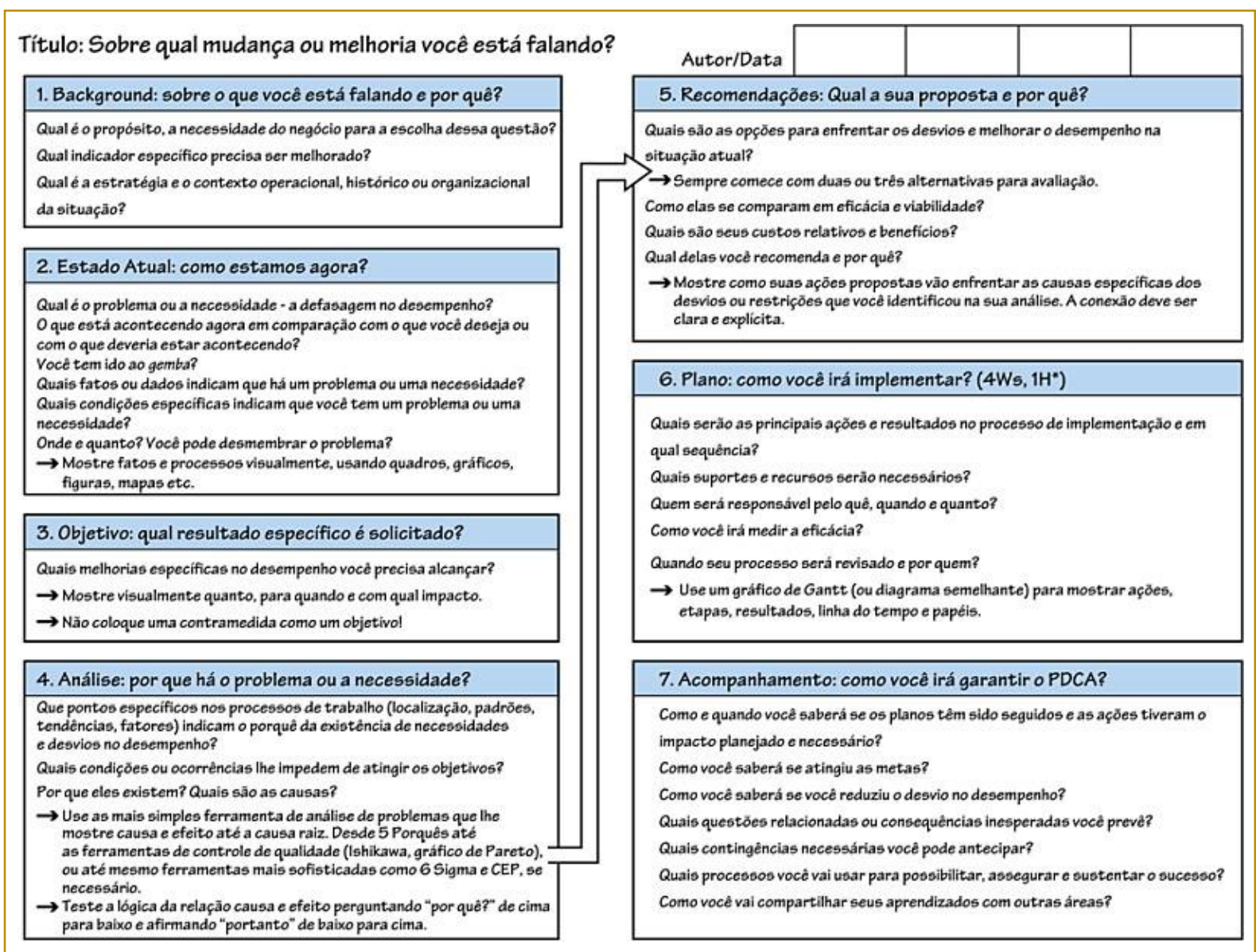

Fonte: Shook, 2008

O Sistema Toyota de Produção, o pensamento Lean, PDCA e o A3, cada um com sua abordagem e nível de aprofundamento juntos propõe melhorar continuamente os processos e aumentar a agregação para o cliente, é neste contexto e com essa fundamentação que nasce o Workshop Lean de 7 fases, uma abordagem prática do pensamento enxuto que proporcionou as atividades onde foi aplicado, melhor entendimento do processo, identificação de oportunidades, proposição de melhorias e resultados operacionais consistentes.

\section{APRESENTAÇÃO DO WORKSHOP (WS) LEAN DE 7 FASES}

\subsection{CARACTERIZAÇ̃̃O}

0 workshop de 7 fases foi desenhado para ser aplicado a necessidade de qualquer área da empresa que pretenda resolver um problema. A fim de se tornar uma forma padronizada de uso geral na solução de problemas, diálogo e tomada de decisões na empresa, criando uma organização de cientistas que melhoram os processos e os resultados continuamente por meio do aprendizado constante do trabalho a ser feito.

Workshop (WS) é um projeto estruturado e realizado com equipes multidisciplinares, para implementação de melhorias processuais. Durante o trabalho, os participantes são habilitados a otimizar seus processos através da aplicação de ferramentas customizadas para eliminar ou mitigar as interferências ou resultados indesejados e promover a melhoria contínua em processos estabilizados.

0 decorrer dos Workshops seguiram o fluxo do círculo PDCA (em português: Planejar, Fazer, Controlar, Agir) anteriormente citado na revisão bibliográfica que é dividido em sete fases, sendo elas:

i. Fase 0: Preparação do Projeto;
Planejar

ii. Fase 1: Treinamento; Planejar 
iii. Fase 2: Contexto é Esclarecimento do projeto; Planejar

iv. Fase 3: Análise da situação atual e definição de objetivos; Planejar

v. Fase 4: Analise das causas Raiz; Planejar

vi. Fase 5: Propostas de Contramedidas e soluções; Fazer vii. $\quad$ Fase 6: Plano de ataque e Introdução das melhorias; Fazer

viii. Fase 7: Acompanhamento e Verificação das melhorias; Controlar e Agir

$O$ pensamento $A 3$ possibilitou que as equipes que enfrentam o problema, enxergassem o processo de solução por meio da mesma lente, então idealmente o $\mathrm{A} 3$ foi construído ao longo da execução das fases.

Figura 3: Exemplo de A3 usado durante aplicação de WS Lean 7 fases

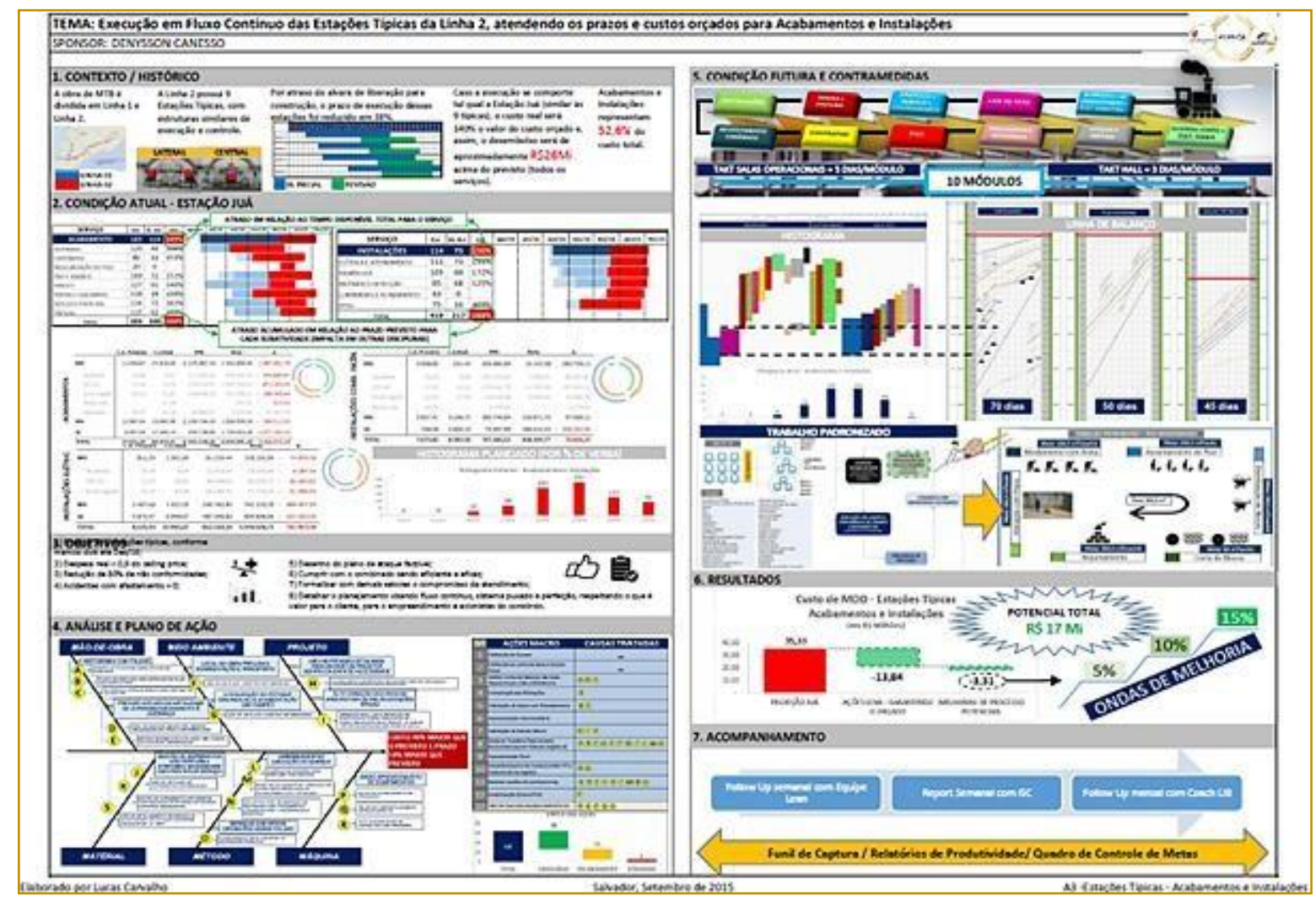

A "Fase 0" não foi contabilizada oficialmente como uma das fases do WS, embasou todos os estudos do projeto, pois este foi o momento em que o levantamento de dados para a Análise do Estado Atual é realizado. A partir deste mapeamento da atual situação, foi possível entender em que situação e contexto estava inserido o objeto de cada estudo, escolher as pessoas que atuaram no projeto bem como todos os recursos necessários para realização dos mesmos.

Abaixo a representação das fases do WS. Cada fase possuía meta, atividades e referências descritas a fim de esclarecer ao leitor a metodologia implantada na empresa do estudo de caso. 
Figura 4: As 7 fases de um Workshop com Pensamento A3

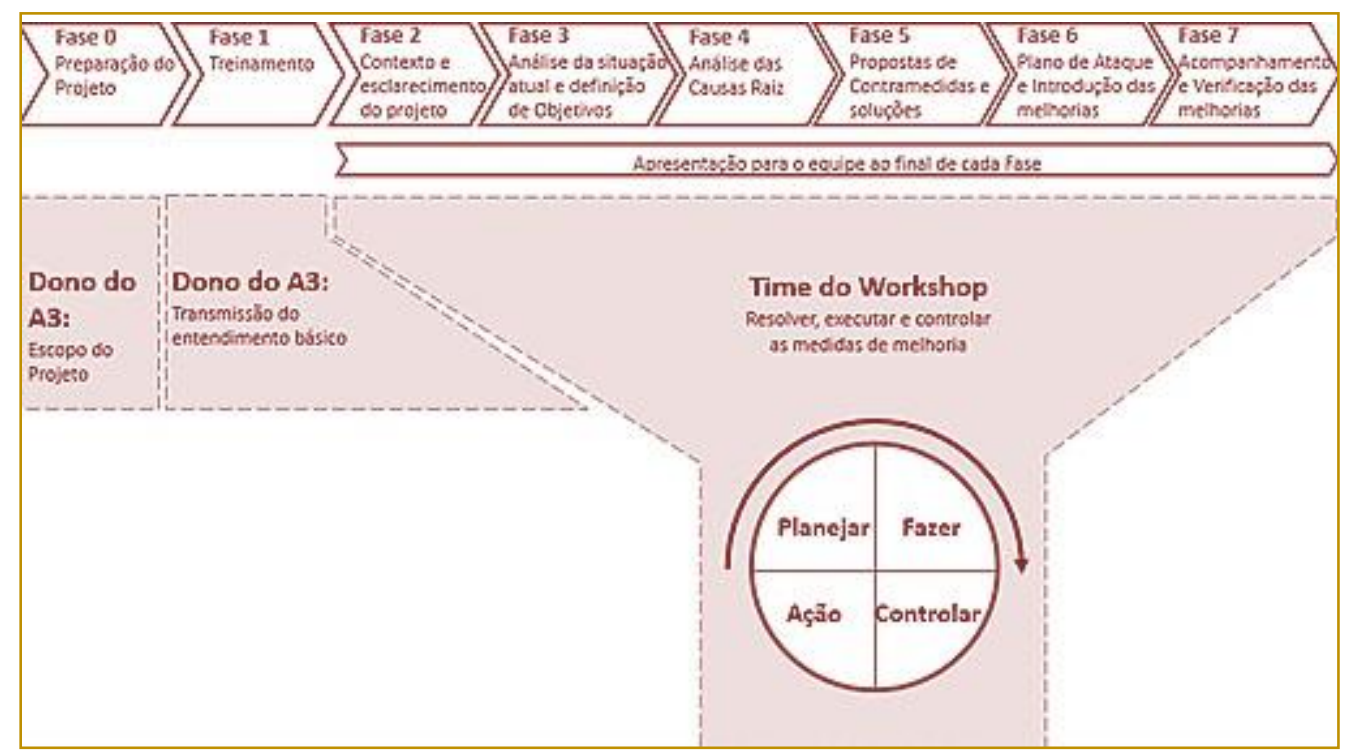

\subsection{FASE 0 - PREPARAÇÃO DO PROJETO}

Figura 5: Detalhes Fase 0

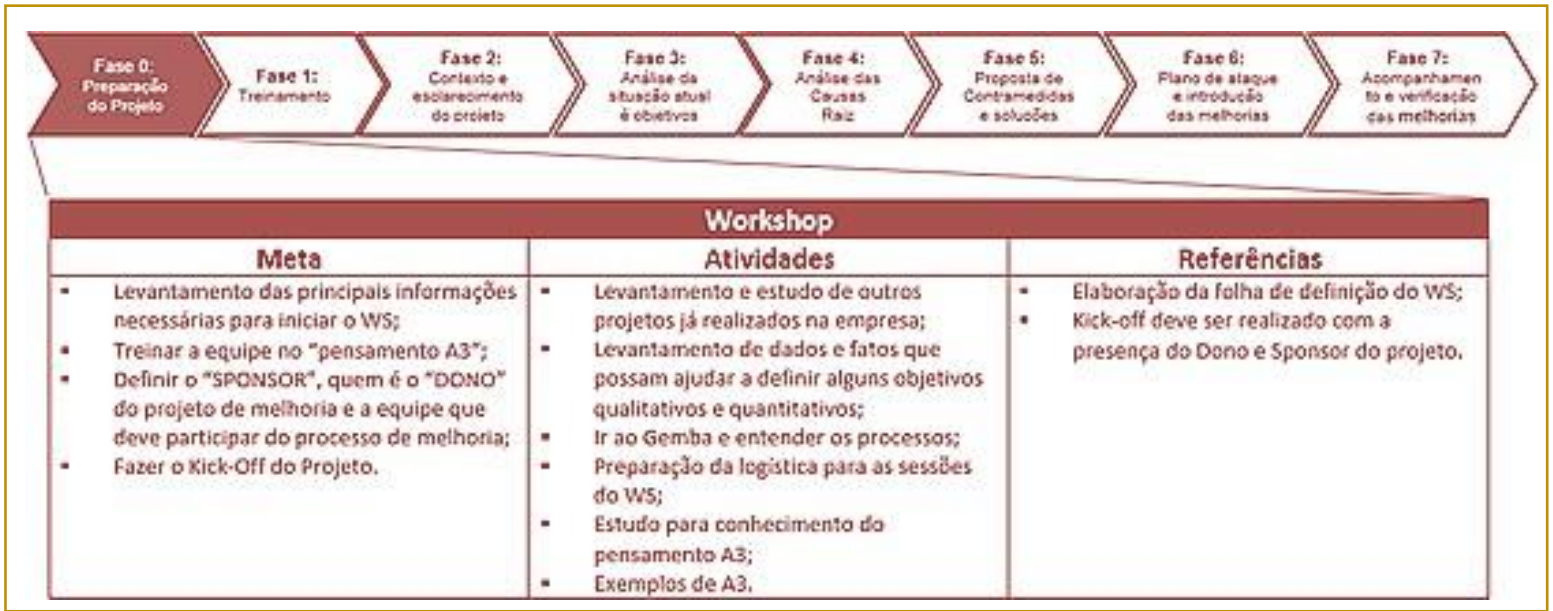

Através das atividades citadas acima as preparações de projeto foram concluídas, a emissão das folhas de definição para cada ws e uma agenda de trabalho considerada durante o tempo de ws, em conjunto formavam parte importante da apresentação do "kick off" feito com a equipe do ws e os envolvidos no mesmo (sponsor, gestores, etc.).
Uma semana antes do início dos WS's o dono do Workshop e responsável pelo $\mathrm{A} 3$ garantia que todos os itens necessários para a realização do evento estivessem disponíveis e previamente agendados, conforme o Check List de Preparação: 
Figura 6: Check list de preparação

\begin{tabular}{|c|c|c|c|c|}
\hline Nr. & Descrição & Prazo & Responsável & Status \\
\hline 1. & Definir participantes para fase de análise & & & 0 \\
\hline 2. & Fazer análise & & & 0 \\
\hline 3. & Definir atuação do workshop & & & 0 \\
\hline 4. & Definir metas e temas do workshop em conjunto & & & 0 \\
\hline 5. & Preparar agenda e decorrer do workshop & & & 0 \\
\hline 6. & Informações internas aos empregados e ao sindicato & & & 0 \\
\hline 7. & Definir participantes do workshop & & & 0 \\
\hline 8. & Sala de treinamento com flipchart e projetor & & & 0 \\
\hline 9. & Sala de treinamento perto do local das atividades & & & 0 \\
\hline 10. & $\begin{array}{l}\text { Material de escritório: Apostilas, Canetas, Tesoura, Régua, } \\
\text { Prancheta, Calculadora, Etiqueta com nome }\end{array}$ & & & 0 \\
\hline
\end{tabular}

\subsection{FASE 1 - TREINAMENTO LEAN BÁSICO}

A fase de treinamento aproximou os participantes do Workshop ao tema, através do entendimento básico dos princípios e ferramentas Lean e os preparou para a transformação do mindset necessária para este tipo de aplicação. A fase de treinamento teve três níveis:

No primeiro momento, apresentou-se a história e conceitos do Lean na Indústria e sua evolução através do tempo dos e casos de sucesso em diferentes setores, entre outros que o líder considere necessário contemplar no treinamento.

Na segunda parte do treinamento, são abordados os três tipos de atividades ligadas à produtividade (Valor Agregado - VA, Desperdício Oculto - DO e Desperdício Evidente - DE), detalhando e exemplificando os 9 tipos de desperdícios presentes em as atividades do dia a dia em nossa indústria. Adaptado de (WOMACK/JONES, 1996).

Figura 7: Detalhes Fase 1

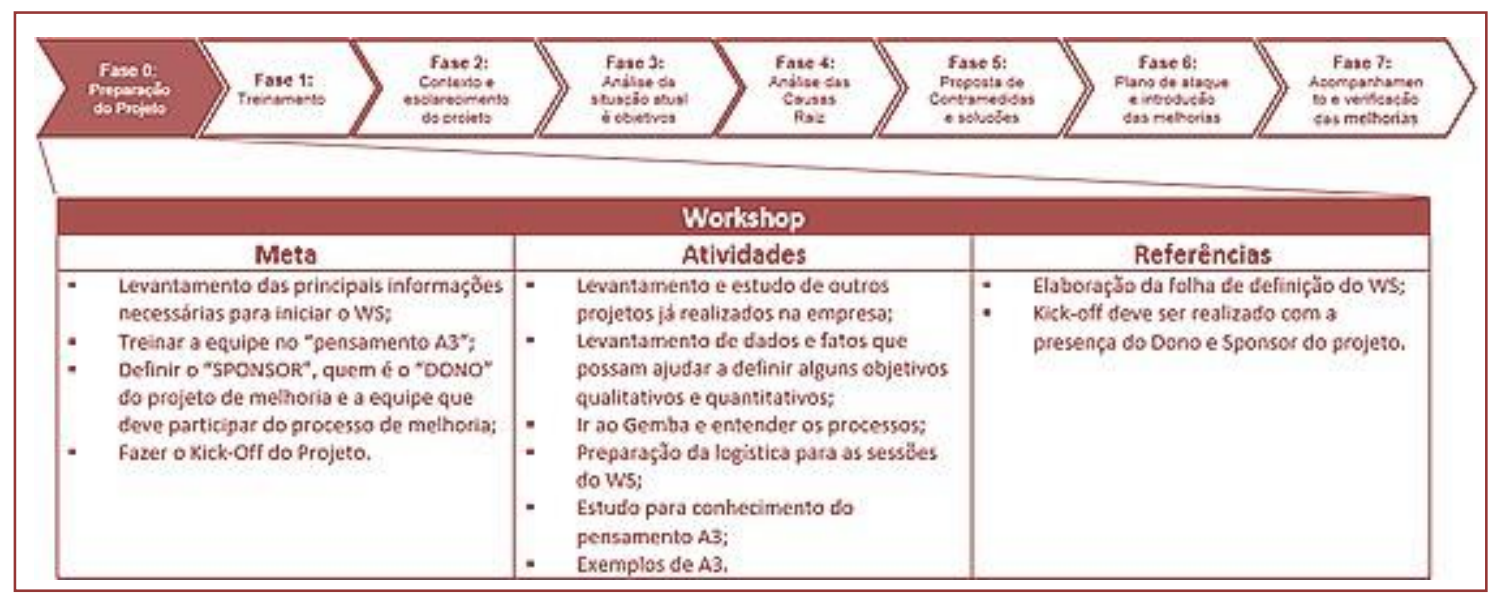


Figura 8: 3 tipos de atividade VA, DO, DE. 9 tipos de desperdício.

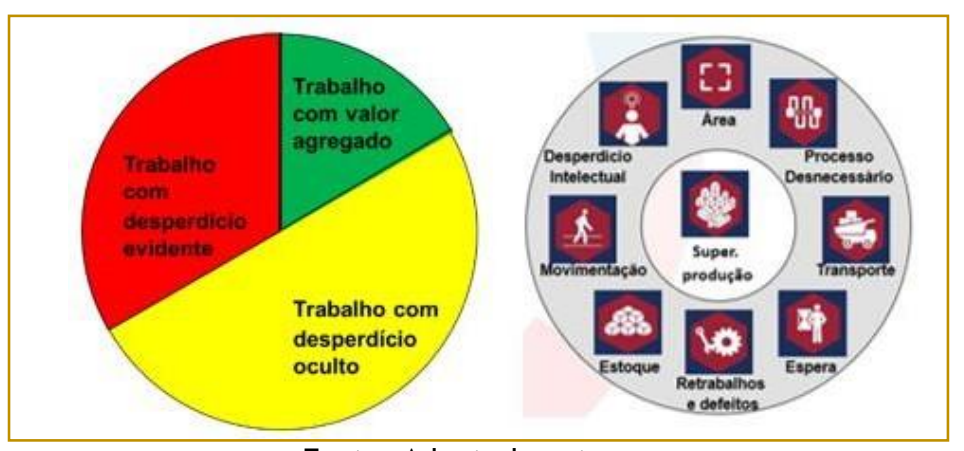

Fonte: Adaptado autora

$\mathrm{Na}$ terceira parte se realizou o treinamento teórico/prático sobre os conceitos de fluxo, puxar, takt e zero defeito.

Uma vez o time treinado a condução das próximas etapas se mostrou mais eficaz.

\subsection{FASE 2 - CONTEXTO E} ESCLARECIMENTO DO PROJETO

A segunda fase do Workshop consistiu no conhecimento do escopo e campo de atuação do projeto de melhoria de processos, para isto foi necessário ter "claramente definido" o problema que deveria ser resolvido.

Durante a segunda fase, foi importante que houvesse consenso com dados e fatos entre todos envolvidos no estudo sobre as expectativas do projeto.

Com estas informações, foi possível, então, preencher o campo "Contexto" do A3 de forma a deixar bem claro em qual cenário o problema estava inserindo e os motivos claros de análise de causa e necessidade de soluções o processo exigia.

Figura 9: Detalhes Fase 2

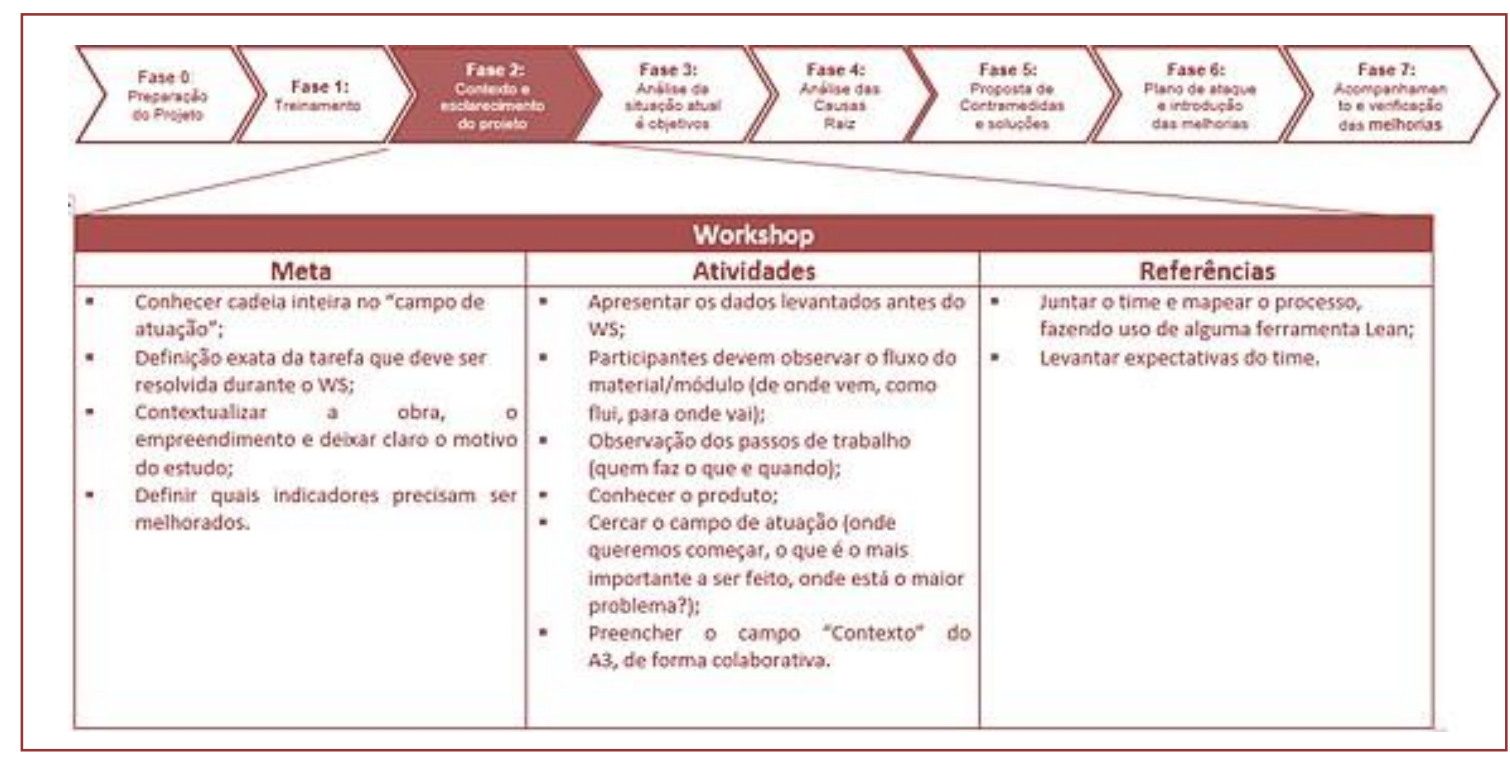

Problema é a lacuna entre o que está acontecendo realmente (condição atual) e o que deveria/precisa acontecer descrito em termos de desempenho. Um problema claramente definido acontece quando a lacuna subdividida em partes claramente observáveis (menores problemas na lacuna ou no processo relacionado) que estão contribuindo para a lacuna completa e podem ser investigadas em primeira mão.

Para o entendimento do Problema a ser tratado, analisou-se os dados sobre as principais perdas e definiram-se quais os 
problemas prioritários, tendo em consideração diversos fatores:

- Quais os problemas que nos provocam maiores dificuldades no dia-a-dia da obra?

- Quais os problemas que mais afetam o cliente?

- 0 que provoca problemas no processo seguinte?

- Quais os problemas que mais dificultam que os objetivos da empresa sejam atingidos?

- Quais os problemas que podem ser provocados por inexistência de norma ou por falta de cumprimento desta?

- Quais os problemas que também afetam outras áreas ou mesmo outras obras?

\subsection{FASE 3 - ANÁLISE DA SITUAÇÃO ATUAL E DEFINIÇÃO DE OBJETIVOS}

Nesta fase a equipe tinha como objetivo a análise de maneira detalhada do estado atual do processo que se estudava, para isto foi necessário:
- Verificar no gemba (lugar onde as coisas acontecem) se a situação atual condizia com realidade e analisar criticamente pontos de melhoria que não foram reconhecidos;

- Analisar o que estava acontecendo em comparação com o que a equipe deseja ou com o que deveria estar acontecendo;

- Levantar os dados e ir ao gemba para verificar os fatos que indicam que há um problema ou uma necessidade;

- Conhecer as condições especificas que indicavam um problema ou uma necessidade;

- Avaliar Custo e Prazo (custo unitário de MO, saldo a executar em quantidade e $\mathrm{R} \$)$.

- Checar a condição atual da obra a partir do objetivo estabelecido;

- Compilar materiais, organiza-los, mensurar dados e analisar problemas;

- Validar materiais elaborados com o time do workshop e puxar mais problemas;

Mostrar fatos e processos visualmente, usando quadros, gráficos, figuras, mapas, etc.

Figura 10: Detalhes Fase 3

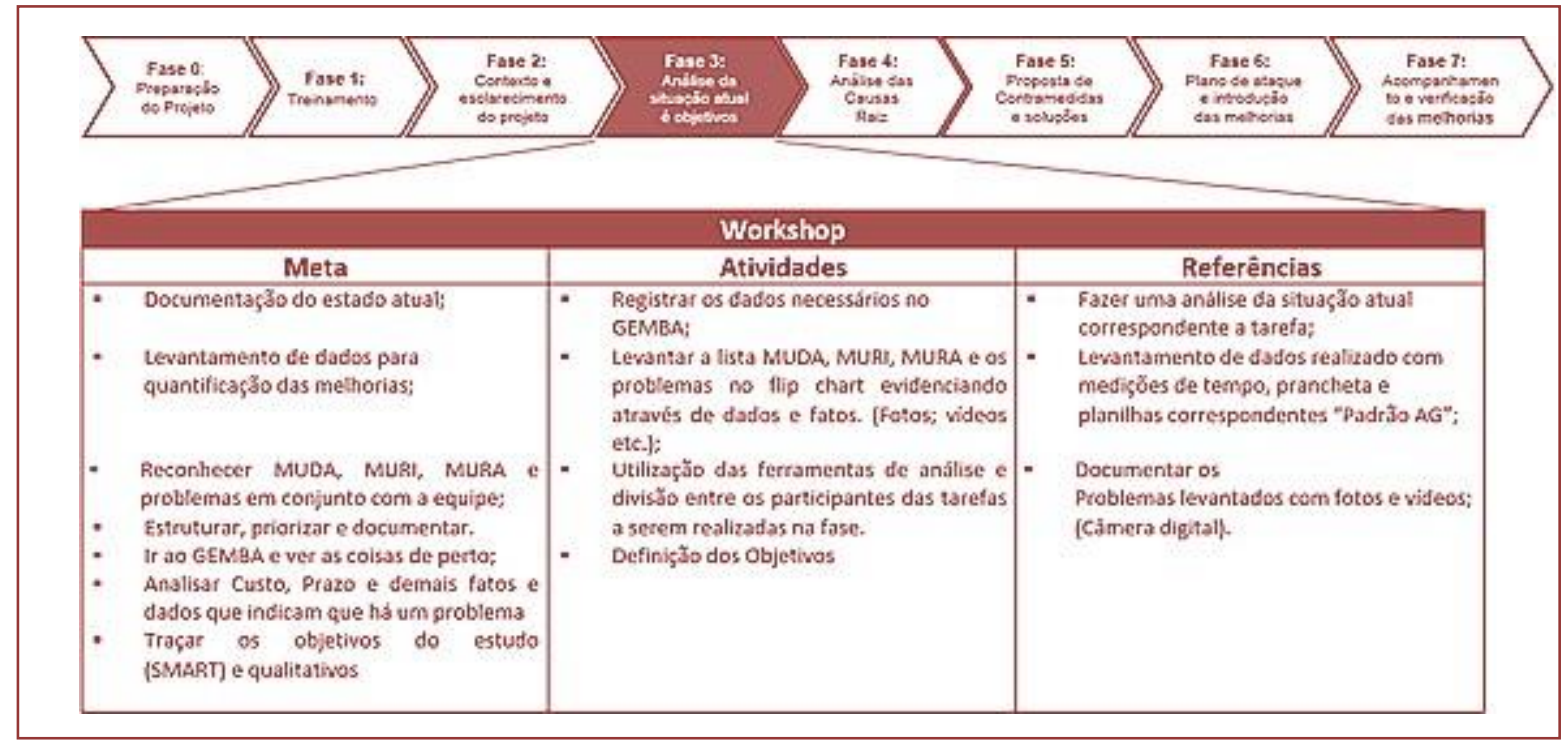


Figura 11: Modelo de detalhamento diagnóstico da situação atual

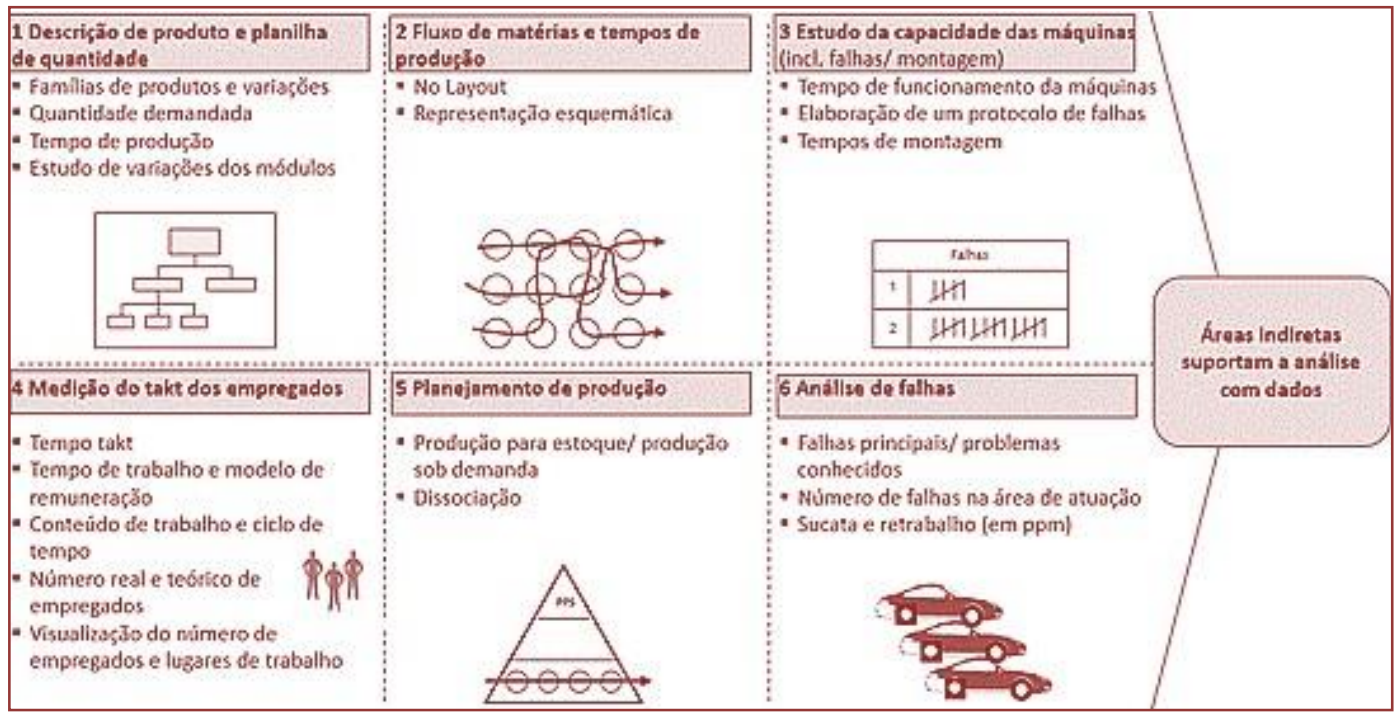

Ainda nesta fase, após a Análise da Situação Atual concluída, os anseios e objetivos traçados inicialmente são reafirmados e consolidados de forma detalhada. Para a definição dos objetivos foi necessário:

- Saber quais melhorias especificas no desempenho que a equipe precisa alcançar;

- Mostrar visualmente quanto, para quando e com qual impacto;

- Não colocar uma contramedida como um objetivo;

- Determinar um objetivo SMART que busque eliminar/mitigar a existência daquela lacuna (Caracas, 2015):

- Simples: a meta traçada deve ser objetiva e de fácil percepção. Os objetivos generalistas tendem a ser menos eficazes;

- Mensuráveis: numéricos, de forma a ser possível avaliar o sucesso ou insucesso das ações;

- Atrativos: os objetivos devem ser estimulantes e com impacto para o negócio;

- Realistas: os objetivos somente serão eficazes se forem exequíveis;

- $\quad$ Tempo Limite: deve haver um prazo concreto para atingir o objetivo.

\subsection{FASE 4 - ANÁLISE DE CAUSA RAIZ}

A finalidade da análise dos problemas levantados com as ferramentas Lean citadas foram necessárias para encontrar a causa raiz para que o problema seja efetivamente resolvido. Geralmente utiliza-se duas técnicas em conjunto: o "Diagrama de Ishikawa" e os "5 Porquês".

- 0 "Diagrama de Ishikawa", também conhecido como "Espinha-de-peixe" ou "Diagrama de Causa e Efeito" é uma ferramenta gráfica utilizada para a análise das causas dos problemas (Ishikawa,1993). Este diagrama divide as causas de um problema em categorias; realizado;

- Matéria-prima: características dos artigos necessários para a realização do processo;

- Mão-de-obra: todas as intervenções humanas na realização do trabalho;

- Máquinas: todos os equipamentos e sistemas utilizados para a realização do trabalho;

- Meio ambiente: características físicas do ambiente de trabalho, bem como a relação entre as pessoas da organização.

- Métrica: Forma como o processo e medido

- 0 “5 Porquês" é uma técnica para encontrar a causa raiz de um problema 
através de perguntas sequenciais em relação aos motivos daquele acontecimento indesejado (Ohno, 1997). Esta ferramenta é muito versátil, podendo ser aplicada em qualquer área:

- 0 princípio é muito simples: ao encontrar um problema, deve-se perguntar 5 vezes o porquê daquele problema, questionando sempre a causa anterior;

- $\quad$ A análise dos 5 Porquês é um método simples que geralmente permite obter bons resultados quando utilizado em equipa;

- Esta técnica é geralmente utilizada conjuntamente com o Diagrama de Ishikawa, para se encontrar as causas raiz das causas identificadas inicialmente no diagrama.

Figura 12: Detalhes Fase 4

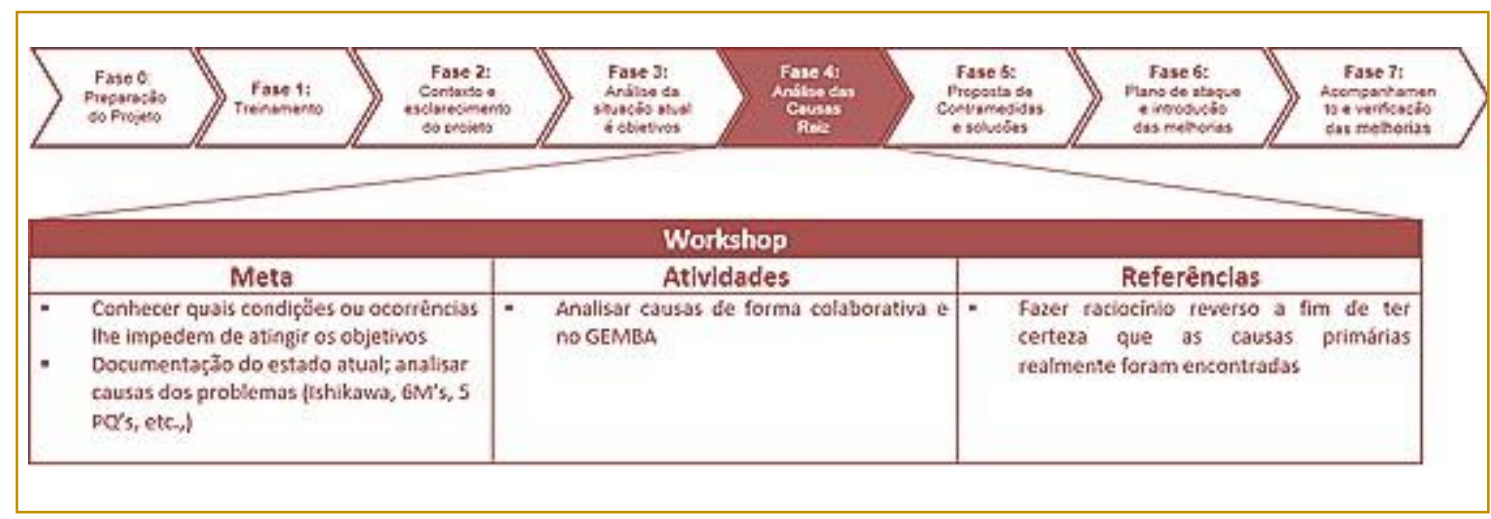

4.7 FASE 5 - PROPOSTA DE CONTRAMEDIDAS E SOLUÇÕES

Figura 13: Detalhes Fase 5

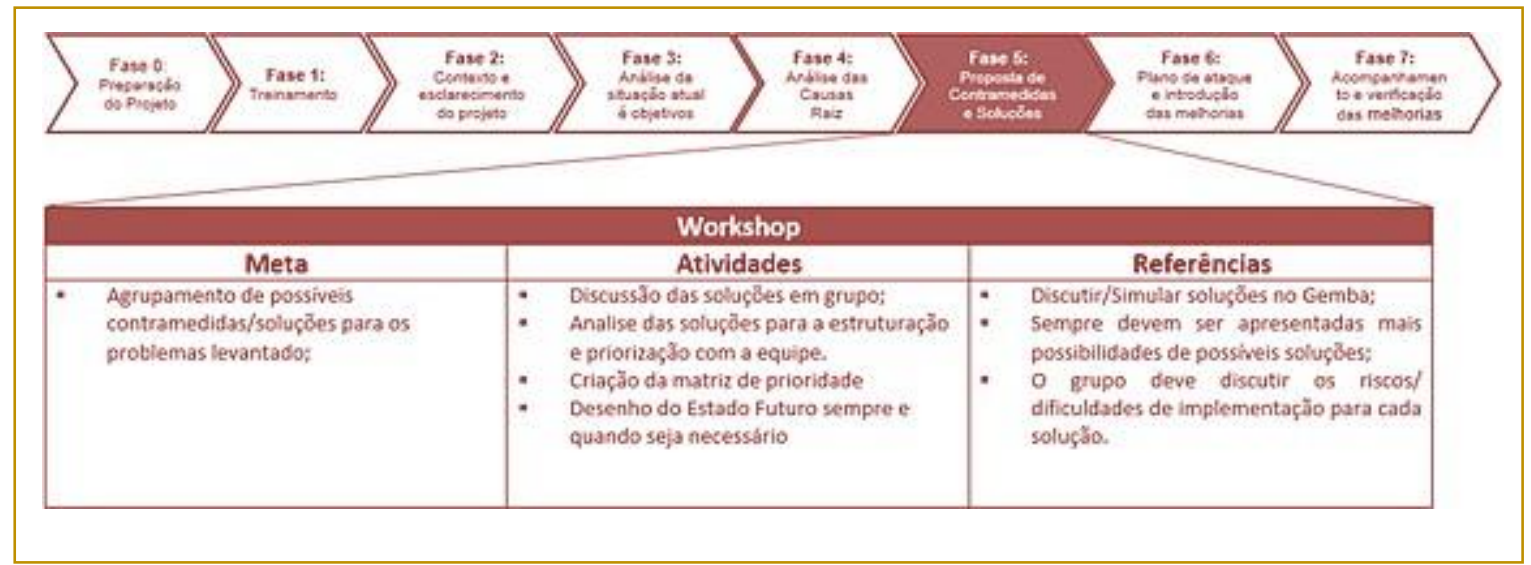

\subsection{FASE 6 - PLANO DE ATAQUE E INTRODUÇÃO DAS MELHORIAS}

Nesta fase a equipe teve como objetivo definir as contramedidas/soluções para as causas raiz dos problemas que temos como objetivo resolver, para isto foi necessário:

- Conhecer quais são as opções para enfrentar os desvios e melhorar o desempenho na situação atual;
- Começar com duas ou três alternativas para avaliação e como elas se comparam em eficácia e viabilidade, quais são ou custos relativos e benefícios, quais são as mais recomendadas e por que;

- Mostrar como as ações propostas enfrentam as causas especificas dos desvios ou restrições identificadas na análise com conexões claras e explícitas 
- Identificar contramedidas que eliminam ou reduzem causas

- Priorizar contramedidas

$\mathrm{Na}$ fase de proposta de contramedidas/soluções, devemos objetivar o PQCDSM de forma estruturada (Nakajima, 1989):

- P: Aumentar a Produtividade (Productivity) através da criação de fluxo, puxado e ritmo;

- Q: Alcançar Zero defeitos de
Qualidade (Quality);

- C: Reduzir os Custos (Cost);
D: Melhorar o Serviço (Delivery);

- S: Atingir zero defeitos na Segurança (Safety);

- M: Melhorar a Moral/Motivação (Motivation) dos colaboradores.

$\mathrm{Na}$ fase de Proposta de Soluções foram levantadas as contramedidas necessárias para cada causa raiz levantada durante a fase de Análises da situação atual.

Figura 14: Detalhes da Fase 6

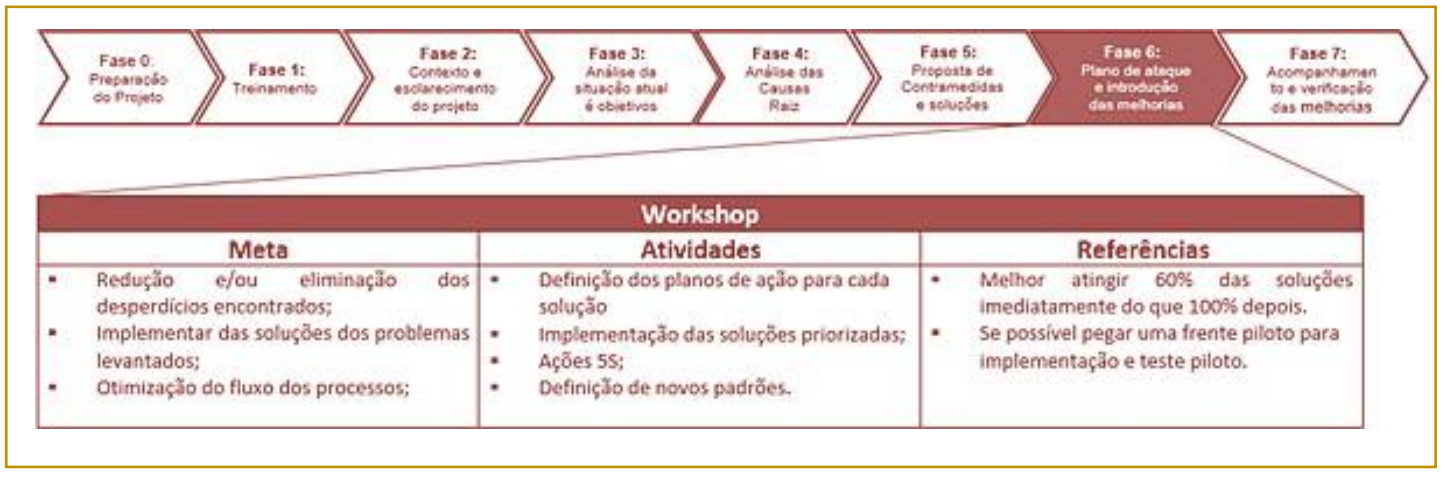

Nesta fase a equipe teve como objetivo definir o plano de ataque e a implementação imediata das melhorias e contramedidas propostas na fase anterior, para isto foi necessário:

- Dentre todas as soluções e ações levantadas nas etapas anteriores, priorizar as mais impactantes

- Definir o Plano de Ações para a implementação das soluções encontradas, atribuindo responsabilidades e definindo prazos;

- Garantir consenso com todos os stakeholders envolvidos no Plano de Ação para validar contramedidas e prazos;

- Apoiar na implementação das melhorias no lugar onde as coisas acontecem
- Definir quais suportes e recursos serão necessários;

- Definir quando seu processo será revisado e por quem;

- Usar gráfico de Gantt, Slack, Chambers e Johnston (2002) para mostrar ações, etapas, resultados, linha do tempo e papéis.

- Aplicar os novos padrões para área, setor ou departamento

- Aplicar gestões visuais de acompanhamento

- Introduzir o fluxo dos novos processos conforme o estado futuro

- Implementar novos layout definido pelo time (caso necessário); 


\subsection{FASE 7 - ACOMPANHAMENTO E VERIFICAÇÃO DE MELHORIAS}

A fase 7 do Workshop verificou a estabilidade das atividades propostas no Plano de Ação através de mecanismos formais. Deve-se acompanhar as contramedidas, apoiar na disseminação dos novos padrões para as demais frentes de serviço e levantar os resultados gerados.

Foi necessário focar nos seguintes itens:

- Depois de implementadas as soluções, verificar se o problema foi resolvido e se os objetivos foram atingidos comparando a situação inicial com a situação atual;
- Utilizar indicadores visuais com o objetivo de disponibilizar a todos os colaboradores a informação relativa à evolução dos processos assim como o Plano que gerencia quais são os indicadores escolhidos, pontos de medição, qual a frequência de monitoramento, método de medição e responsáveis;

Criar painéis visuais que reflitam o status dos indicadores elaborados para tomada de decisão de forma rápida e focada de tal forma que os indicadores possuam rastreamento $\mathrm{e}$ monitoramento;

Figura 15: Detalhes Fase 7

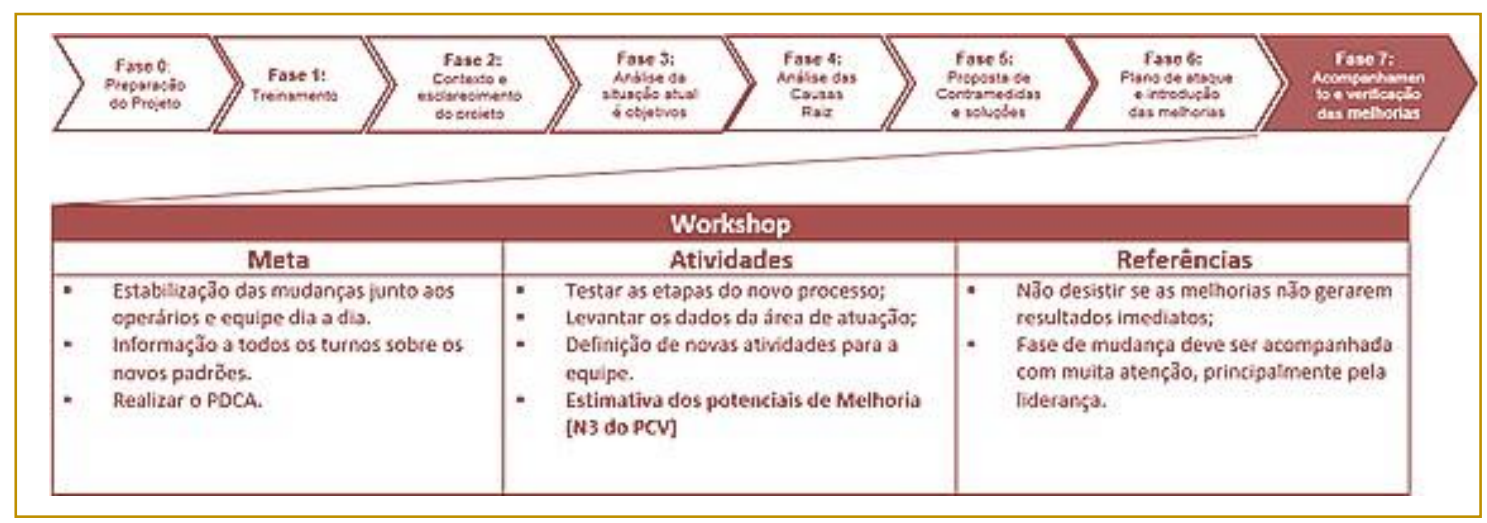

Figura 16 - Exemplo de Lista Mestra para rastreamento de KPIs

\begin{tabular}{|c|c|c|c|c|c|c|}
\hline & NQ & KPI & Ponto de Medicjo & Frequềncia & Método de Mediçăo & Responsive \\
\hline \multirow[t]{7}{*}{ EXEMPLO } & 1 & Lesd Time Proposto & $\begin{array}{l}\text { Renda Proposta } \\
\text { Resultado Proposto }\end{array}$ & $\begin{array}{l}1 \text { vez por semana } \\
\text { Toda Quinta-Feira }\end{array}$ & Ficmula $=\frac{\text { Data proposta o/ selar }}{\text { Tempo o/ retorno de resultado }}$ & Neymur \\
\hline & 2 & Quantidade de chamadas & Chamadas Intemas e Extema & Diariamente & No de chamadas realizadas (contagem manual) & Martha \\
\hline & & & & & & \\
\hline & & & & & & \\
\hline & & & & & & \\
\hline & & & & & & \\
\hline & & & & & & \\
\hline
\end{tabular}

- Entrevistar o time que participou do processo de melhoria e stakeholders;

- Recomeçar as análises de causa raiz e seguir novamente as fases seguintes quando os objetivos não forem atingidos;

- Acompanhar graficamente através dos dados de controle.

- Preencher semanalmente o checklist de estabilização que identifique se as melhorias previstas continuam sendo implantadas

\section{ESTUDO DE CASO E RESULTADOS}

Foram analisadas 18 amostras (9 estáveis e 9 não estáveis), de WS 7 com pensamento $A 3$ aplicados em 8 obras diferentes e 1 sede, 6 tipos de obras conferiram a amostra: adutora, 
túnel, metroviárias, barragem, termoelétrica,

edificação.

Figura 17: Identificação das amostras

\begin{tabular}{|c|c|c|c|c|c|c|c|c|c|c|c|c|c|c|c|c|c|}
\hline \multicolumn{9}{|c|}{ AMOSTRAS ESTÁVEIS } & \multicolumn{9}{|c|}{ AMOSTRAS NÄO ESTÁVEIS } \\
\hline $\mathbf{M}$ & AM & AM & AM & AM & AM & AM & AM & AM & AM & AM & AM & AM & AM & AM & AM & AM & AM \\
\hline & , & & & & & & & & & 117 & & & & & & 203 & 62 \\
\hline 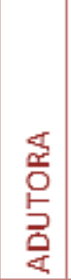 & 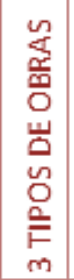 & 랄 & 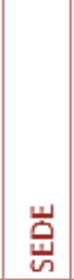 & 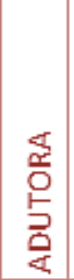 & 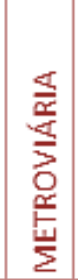 & 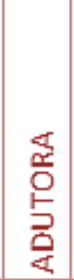 & 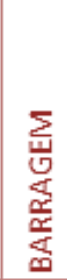 & 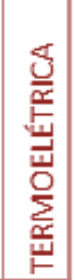 & 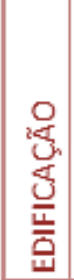 & 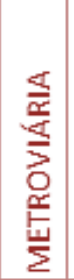 & 离 & 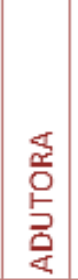 & 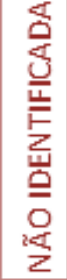 & 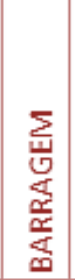 & 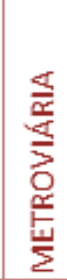 & 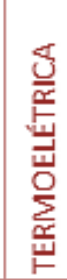 & 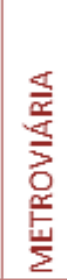 \\
\hline
\end{tabular}

Todas as amostras foram analisadas na escala Likert (1932), para cada pergunta identificada pela autora como referência de qualidade do WS. A tabela comparativa,

identifica correspondentemente a fase de WS 7 fases, a etapa de A3 e a etapa do PDCA, a fim de demonstrar a ligação entre os métodos.

Figura 18: Ligação entre métodos e itens de avaliação das amostras

\begin{tabular}{|c|c|c|c|c|}
\hline $\begin{array}{l}\text { LINHA } \\
\text { REF }\end{array}$ & PDCA & $\mathrm{A} 3$ & TEM DE AVALLAC̆GO & WS 7 FASES \\
\hline 1 & - & - & Resul tados estão sen do obtidos conf orme p revisto? & - \\
\hline 2 & PLANEAR & TITULO & Deixa dar oo gap de desempenho? & FASE 0 E 1 \\
\hline 3 & PLANEAR & CONTEXTO & Contexto apresenta relevánda do $A 3$ ? & FASE 2 \\
\hline 4 & PLANEAR & ESTADO ATUAL & Deixa daro o gap de desempenho? & FASE 3 \\
\hline 5 & PLANEAR & ESTADO ATUAL & Há dados e fatos? & FASE 3 \\
\hline 6 & PLANEAR & OBJETVO & É SMART? & FASE 3 \\
\hline 7 & PLANEAR & OBJETMO & Elimina ou r eduz o gap de desempenho? & FASE 3 \\
\hline 8 & PLANEAR & ANÁLISE DE CAUSA RAL & Caless apontadas sāo as raizes? & FASE 4 \\
\hline 9 & FAZER & CONTRAMEDIDAS & O vinaulo entre causa e contramedida esta dar o? & FASE 5 \\
\hline 10 & FAZER & CONTRAMEDIDAS & Contr amedida elimina ou redur causas? & FASE 5 \\
\hline 11 & FAZER & PLANO DE ATAQUE & Deixa dar o res ponssive is, pranos? & FASE 6 \\
\hline 12 & FAZER & PLANO DE ATAQUE & Açōes est jo ligadas as cont rame didas? & FASE 6 \\
\hline 13 & VEPAFICAR E AGIR & ACOMPANHAMENTO & Indicadores est jo ligados ao obje tivo? & FASE 7 \\
\hline 14 & VEPAFICAR E AGIR & ACOMPANHAMENTO & Indicadores est jo at uvlizados? & FASE 7 \\
\hline 15 & VEPAFICAR E AGIR & ACOMPANHAMENTO & Frequència de acompanhamento é dara? & FASE 7 \\
\hline 16 & - & GERAL & A3 é 'entendive[?' (gráficos, textos) & - \\
\hline 17 & - & GERALL & Ferramentas sio ut ilizadas corr et amente? & $\cdot$ \\
\hline
\end{tabular}

O agrupamento em estáveis/não estáveis visa identificar quais os fatores de sucesso que resultaram em estabilidade. A pergunta usada para fazer a identificação foi: Resultados estão sendo alcançados conforme previsto? Consideradas estáveis as amostras que obtiveram nota 4 e 5 na escala Likert (1932), segundo análise do autor. 
Figura 19: Notas item a item, atribuídas pela autora

\begin{tabular}{|c|c|c|c|c|c|c|c|c|c|c|c|c|c|c|c|c|c|c|c|c|c|c|}
\hline \multirow[b]{2}{*}{$\lim _{\text {ing }}$} & \multirow[b]{2}{*}{ noca } & \multirow[b]{2}{*}{ a } & \multirow[b]{2}{*}{ 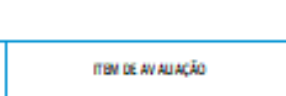 } & \multirow[b]{2}{*}{ wstrass } & \multicolumn{9}{|c|}{ 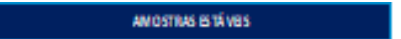 } & \multicolumn{9}{|c|}{ 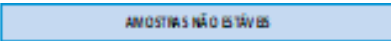 } \\
\hline & & & & & ${ }_{120}^{A N}$ & an 14 & ${ }_{i 2 s}^{a w}$ & $\begin{array}{l}\text { AN } \\
\text { S11 }\end{array}$ & ${ }_{196}^{A N}$ & ${ }_{140}^{A N}$ & $\begin{array}{l}4 N \\
s t 4\end{array}$ & $A N 15$ & an 61 & $\begin{array}{l}\text { AN } \\
\text { s18 }\end{array}$ & $\begin{array}{l}\text { AN } \\
111\end{array}$ & ${ }_{24}^{A N}$ & ${ }_{418}^{20}$ & an 13 & ${ }_{411}^{2 N}$ & sen 45 & $\begin{array}{c}\text { AN } \\
\text { ates }\end{array}$ & $\begin{array}{l}\text { AN } \\
161\end{array}$ \\
\hline 1 & . & . & 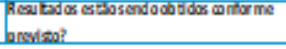 & . & 5 & 5 & $s$ & 4 & 4 & 4 & 4 & 4 & 4 & 3 & 3 & 3 & 3 & 3 & 3 & 3 & 3 & 1 \\
\hline 2 & MUEEAR & mue & 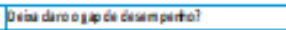 & FAE 6E 1 & 4 & $I$ & 4 & 3 & 4 & 3 & 5 & $\frac{3}{3}$ & 3 & 3 & 4 & 4 & 5 & 5 & 4 & 3 & 5 & 3 \\
\hline 3 & MaNEak & $\triangle N E x D$ & 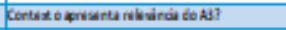 & $\operatorname{RA} \times 2$ & 4 & 5 & 4 & 3 & 4 & 4 & 3 & 3 & 3 & 2 & 4 & 3 & 4 & 3 & $I$ & 4 & $I$ & 3 \\
\hline 4 & nenesh & BWOOATU & 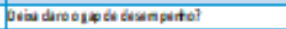 & FAES & 4 & 4 & 4 & $i$ & 4 & 4 & 5 & 5 & 3 & 2 & 4 & 3 & 5 & 1 & 1 & 3 & $i$ & 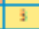 \\
\hline 5 & MUEEAR & BDOOATA & 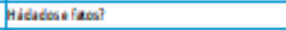 & $\operatorname{AAX3}$ & 5 & 4 & 4 & 4 & 4 & 4 & 1 & 4 & 3 & 5 & 5 & 4 & 5 & 2 & 3 & 3 & 4 & 3 \\
\hline 6 & DUELAR & o6two & Esment? & 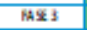 & 5 & 4 & 4 & 4 & 4 & 2 & $\frac{5}{3}$ & $i$ & $I$ & 1 & 4 & 3 & 5 & 2 & 4 & 4 & 4 & 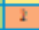 \\
\hline 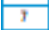 & nuNEAR: & outwo & 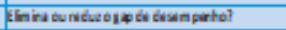 & NAE: & 4 & 5 & 4 & 4 & 4 & 4 & $i$ & $i$ & 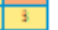 & $I$ & 4 & $i$ & 5 & 2 & 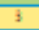 & $i$ & $i$ & $i$ \\
\hline 8 & MUEE:AR & ANALLE OE CAISAIAR & 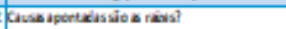 & AAE 4 & 5 & 5 & 3 & 5 & 4 & 4 & 2 & 4 & 4 & 2 & 3 & 4 & 3 & 1 & 4 & 2 & 3 & I \\
\hline$g$ & FANB & ConThamedo as & 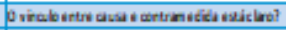 & PAE 5 & 5 & 4 & 4 & 5 & 4 & 4 & 3 & 3 & 3 & 3 & 5 & 3 & 5 & 2 & 3 & 3 & 1 & 1 \\
\hline 16 & FABS & CONTIRMEdots & 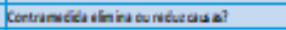 & FAs 5 & $\$$ & 4 & 4 & 5 & 4 & 3 & 3 & 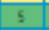 & 5 & 1 & 4 & 3 & 5 & 2 & 4 & 3 & 5 & 1 \\
\hline 11 & FABS & MANO OEA ROXUE & 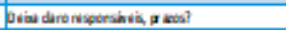 & AEX 6 & 5 & 5 & 3 & $\$$ & 4 & 3 & 1 & 5 & 5 & 1 & 3 & 4 & 3 & 2 & 5 & 5 & 2 & 3 \\
\hline 12 & FNB & MANOELAZAOUE & 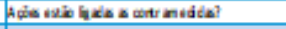 & RAXE & 5 & 5 & 3 & 5 & 4 & 3 & 3 & 5 & 3 & 3 & 4 & 3 & 3 & 1 & 3 & 3 & 3 & 3 \\
\hline 13 & verancake wath & ACONPANHAMETTE & 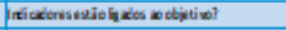 & FAET & 5 & 5 & 5 & 3 & 4 & 4 & 3 & 4 & 3 & 2 & 3 & 5 & 5 & 3 & 2 & $I$ & 4 & 1 \\
\hline 14 & VEGARCARE ALER & ACONFANHAMETTE & 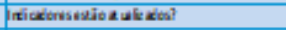 & $\operatorname{RAXY}$ & 5 & 5 & 5 & 3 & 4 & 4 & 2 & $I$ & 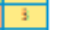 & 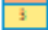 & 4 & 3 & $i$ & 1 & 3 & $I$ & 5 & 1 \\
\hline 15 & VERTCARE ACOE & ACOURANHAMEKTO & 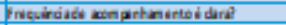 & MAET & 5 & 5 & 5 & 5 & 4 & 4 & 2 & 2 & 3 & 1 & 3 & 5 & $i$ & 2 & 1 & $i$ & 4 & 1 \\
\hline 16 & \begin{tabular}{|c|}
- \\
\end{tabular} & EAL & 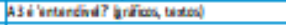 & $\therefore$ & 5 & 5 & 4 & 3 & 3 & 4 & 3 & 3 & 3 & 3 & 4 & 4 & 4 & 2 & 3 & 3 & 1 & 3 \\
\hline 1f & - & EAL & 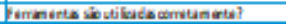 & & 5 & 4 & 4 & 5 & 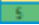 & 4 & 2 & 5 & 3 & 1 & 4 & 4 & 5 & & & & & 3 \\
\hline
\end{tabular}

\subsection{RESULTADOS}

As mostras estáveis apresentam resultado $50 \%$ superior as amostras não estáveis no item de avaliação na Fase 4: Análises de causa raiz (linha ref 8 ). Esta constatação revela a importância de uma consistente análise de causa para garantia de estabilidade dos resultados. As amostras estáveis continham análises profundas, comumente apresentadas em formato de 5 porquês e Diagrama de Ishikawa (Ishikawa, 1993).

As amostras estáveis também apresentaram desempenho superior na Fase 7: Acompanhamento e verificação de melhorias. Os resultados variam de $32 \%$ a $46 \%$ superior às amostras não estáveis (linhas ref 13 a 15).
Esta constatação revela a importância da etapa de Verificar e Agir, para a garantia de sustentabilidade dos resultados identificados nos WS lean de 7 fases.

Outra constatação fruto deste estudo é o pequeno delta sobre 0 impacto nos resultados dos itens de Fase 3: Análise da situação atual é objetivos (linhas ref 4 a 7), variam apenas de $6 \%$ a $23 \%$. Podemos concluir que mesmo com uma boa análise de estado atual e consistente definição de objetivos o que mais gera sustentabilidade dos trabalhos é o constante acompanhamento e verificação de melhorias que possibilita reação rápida aos novos problemas que surgem.

Figura 20: Resultado da análise comparativa entre amostras estáveis e não estáveis

\begin{tabular}{|c|c|c|c|c|c|c|c|}
\hline $\begin{array}{l}\text { UNHA } \\
\text { ney }\end{array}$ & roch & as & TEM DE AVALACĞO & WS 7 FASES & $\begin{array}{l}\text { (A) MEOA } \\
\text { NOTAS AM. ETŔ }\end{array}$ & $\begin{array}{l}\text { (8) MEOAA } \\
\text { NOTASAM. } \\
\text { NĀO ETŔ丶 }\end{array}$ & $\underset{(A-B)-1}{\Delta}$ \\
\hline 1 & - & - & $\begin{array}{l}\text { Resul tados estão sendo obtidos conforme } \\
\text { previsto? }\end{array}$ & - & $87 \%$ & $56 \%$ & $56 \%$ \\
\hline 2 & MANELA: & nTue & 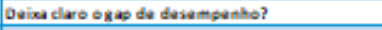 & FASE OE 1 & $64 \times$ & $76 \times$ & $-15 x$ \\
\hline 3 & MANEASR & CON TExTo & 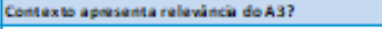 & FASE 2 & $73 \times$ & tex & $22 \%$ \\
\hline 4 & MANEAS: & ESTADO ATUAL & 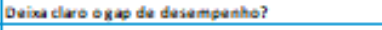 & FASE 3 & 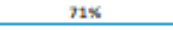 & 58x & $23 x$ \\
\hline 5 & MANEAR & ESTAOO ATUAL & Hádades é Gaes? & FASE 3 & $76 \times$ & 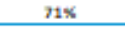 & $6 \times$ \\
\hline 6 & MANELA: & ossenvo & ESMakn? & FASE 3 & $69 \times$ & $64 \%$ & $7 \mathbf{x}$ \\
\hline 7 & MANEASR & OBNE TVO & 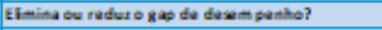 & FASE 3 & $76 \%$ & $62 \%$ & $211 \times$ \\
\hline 8 & MANEAR & ANRLISE OE CAUSA RAC & 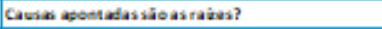 & FASE 4 & aex & 53x & sex \\
\hline 9 & FAEER & CONTEAMEDIDAS & O vinculo antre censa e costramedida está claro? & FASE 5 & $78 x$ & $60 \%$ & $30 \times$ \\
\hline 10 & FAEER & CONTRAMEOIOAS & Contram adda ofimita ou redur cavise? & FASE 9 & \$4x & $64 \times$ & 316 \\
\hline 11 & FAEER & MANO DE ATAQUE & 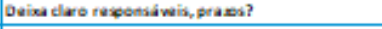 & FASE 6 & sex & $64 \%$ & $24 \times$ \\
\hline 12 & FAEER & MANO OE ATAQUE & 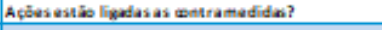 & FASE 6 & sex & 5ax & $38 x$ \\
\hline 13 & VEATICAR EAGR & ACOM PANHA MENTO & 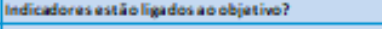 & FASE 7 & $80 \times$ & $60 \times$ & $39 \%$ \\
\hline 14 & VERFICARE EAGR & ACOMPANHA MENTO & Indicadoressushio atudiaden? & FASE 7 & $73 \times$ & $96 \mathrm{~K}$ & $32 \times$ \\
\hline is & VERTICAR EAGR & ACOMPANHAMENTO & 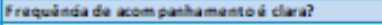 & FASE 7 & $78 \times$ & 53\% & $46 x$ \\
\hline 16 & - & Geat & A3 b'astandival? (Grificen textes) & - & $73 \times$ & 6ex & $22 \%$ \\
\hline 17 & $\cdot$ & GEeAL & 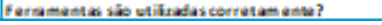 & 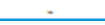 & $32 \times$ & $67 x$ & $23 x$ \\
\hline
\end{tabular}




\section{CONCLUSÃO}

0 objetivo específico de disseminar o conteúdo deste trabalho será medido após a exposição deste trabalho a terceiros, pós avaliação externa a autora medirá a percepção dos usuários para entender se o material foi suficiente para garantir uma utilização correta, consistente do método.

o objetivo de comparar os resultados alcançados nas diversas iniciativas foi alcançado e encontra-se detalhado no Estudo de caso deste trabalho

Em resposta ao objetivo geral traçado neste estudo "avaliar dos fatores críticos de sucesso na aplicação de Workshops Lean de 7 fases na construção pesada" conclui-se que os fatores críticos são dois: a fase de análises de causas (4) e a fase de acompanhamento (7). Considerando que para realizar uma consistente análise de causa é necessário levantar fatos e dados e uma qualificada definição de problema e, portanto, das fases anteriores realizadas, concluo reforçando que a fase mais crítica para garantir o sucesso de um projeto de melhoria como os apresentados neste estudo, é a fase 7 de acompanhamento e verificação de melhorias, mesmo com fases 1 a 6 inconsistentes, a fase

\section{REFERÊNCIAS}

[1] Caracas, C. O método SMART: simples e eficiente para traçar metas. 2015. Disponível em: http: / / carolinecaracas.com.br/metodo-smarteficiente-para-metas/ Acesso em: 10/05/2018

[2] Fiore, C. Lean Strategies for product development: achieving breakthrough performance in bringing products to market. Wisconsin: Quality Press, 2003.

[3] Godoy, A. L. de. Ciclo PDCA (Plan-DoCheck-Act / Planejar-Fazer-Verificar-Agir). Cedet Centro de Desenvolvimento Profissional e Tecnológico. Disponível em: <http://www.cedet.com.br/index.php?/Tutoriais/Ges tao-da-Qualidade/ciclo-pdca-plan-do-check-actplanejar-fazer-verificar-agir.html>. Acesso em: 17 dez 2012.

[4] Ishikawa, Kaoru; Controle de qualidade total: à maneira japonesa. Rio de Janeiro: Campos, 1993. pág. 79

[5] Likert, R. A technique for the measurement of attitudes. Archives in Psychology, 140, p. 1-55, 1932

[6] Nakajima, Seiichi. Introdução ao TPM Total Productive Maintenance. São Paulo: IMC Internacional Sistemas Educativos, 1989.
7 deve ser executada consistentemente. Esse check permite reação rápida aos problemas ou oportunidades não detectados nas fases anteriores.

Desafio atual da aplicação desta metodologia é que o time envolvido possua a disciplina necessária para aplicar e revisar as ações levantadas. Em geral os times gastam mais energia com o Planejar e menos energia no Verificar e Agir.

Como proposta de melhorias sugere-se que os trabalhos que forem aplicados considerando esta metodologia considerem a fase 7 de acompanhamento e verificação de melhorias por mais tempo que a fase de levantamento de estado atual. Outra proposta é completa integração dos indicadores de desempenho frutos do trabalho nos meios formais que a empresa considera, de modo que o resultado seja acompanhado de forma constante.

Para trabalhos futuros sugere-se avaliação de ações de Gestão da Mudança integradas a este tipo de aplicação de modo a identificar que ações de Gestão da Mudança potencializam a disciplina de sustentar resultados.

[7] Nascimento, A. F. G. A utilização da metodologia do ciclo PDCA no gerenciamento da melhoria contínua. Tese (MBA em Gestão Estratégica da Manutenção, Produção e Negócios) - Núcleo de Pós Graduação e ao Instituto Superior de Tecnologia - ICAP-MG, Faculdade Pitágoras, Minas Gerais, 2011

[8] Neves, T. F. Importância da utilização do Ciclo PDCA para garantia da qualidade do produto em uma indústria automobilística. Tese (Graduação em Engenharia de Produção), Universidade Federal de Juiz de Fora, Minas Gerais, 2007.

[9] Ohno, Taiichi. O sistema Toyota de produção: além da produção em larga escala. Porto Alegre: Bookman, 1997.

[10] Shook, John. Gerenciando para o aprendizado: usando o processo de gestão $\mathrm{A} 3$ para resolver problemas, promover alinhamento, orientar e liderar. São Paulo, 2008.

[11] Slack, N.; Chambers, S.; Johnston, R.. Administração da Produção. 2.ed. São Paulo: Atlas, 2002.

[12] Womack, J. P.; Jones, D. T. Lean thinking: Banish waste and create wealth in your corporation. New York: Simon \& Schuster, 1996.

[13] Womack, J.P.; jones, D. T.; Roos, D. A Máquina que Mudou o Mundo. 7. ed. Rio de Janeiro: Campus Ltda, 2004 


\section{Gapítulo 7}

\section{PRODUÇÃO ENXUTA E PRODUÇÃO MAIS LIMPA - COMPARATIVOS PARA UMA PRODUÇÃO EFICIENTE E SUSTENTÁVEL}

\section{Laura Neves Folly \\ Michele Pereira Figueiredo de Abreu \\ Luiz Augusto Cescon Tavares}

Resumo: Este artigo busca apresentar uma abordagem integrada das metodologias Produção Enxuta e Produção mais Limpa. A primeira propõe eliminar os desperdícios de produção com a melhoria da qualidade e da produtividade, e a segunda é voltada para ecoeficiência. Para tanto, realiza-se num primeiro momento a contextualização sobre a produção enxuta, bem como a explicação dos seus princípios básicos e sobre os oitos tipos de desperdício que este sistema procura minimizar. Em sequência é apresentado o conceito de produção mais limpa e seus métodos, sistema e tecnologias para sua implantação. E por fim, é apresentada a interligação entre as duas técnicas e como podem ser benéficas para a indústria. Para isso, foi realizado um estudo bibliográfico para conhecimento de tais metodologias. Os resultados obtidos sugerem que a aplicação dessas metodologias contribui para ganhos ambientais, redução de custos e geração de vantagens competitivas.

Palavras-chave: Produção Enxuta; Produção Mais Limpa; Sustentabilidade 


\section{INTRODUÇÃO}

A humanidade sofreu diversas mudanças nos últimos séculos. A intensificação da industrialização, taxa de crescimento populacional, a produção e o consumo em massa, a urbanização e a modernização agrícola são algumas delas. Mas essas mudanças geraram degradação ambiental incomparáveis.

$\mathrm{Na}$ década de 50 que surgiu a primeira percepção dos impactos gerados pelo homem sobre o meio ambiente, devido à queda na qualidade de vida causados pela rápida degradação ambiental. Assim, surgiram os movimentos ambientalistas pelo mundo, não-governamentais e agências do governo, iniciando as discussões sobre os problemas ambientais.

Essas preocupações com os efeitos ou impactos ambientais, obrigaram as indústrias evoluírem implantando sistema de gestão ambiental e adequando as novas normas e legislação. Mas, para muitas industrias, é apenas um custo à mais no seu orçamento, enquanto a minoria enxergar uma oportunidade de inovar, reduzir custos e inclusive aumentar sua competividade perante as demais.

No entanto, uma questão deve ser levada em consideração: como uma indústria pode aumentar sua produção sem causar danos ao meio ambiente, de forma sustentável?

Sendo assim, a finalidade deste artigo é apresentar as metodologias Produção Enxuta e Produção mais Limpa, e como elas podem contribuir para o crescimento de indústrias com inovação, competitividade, reduzindo os desperdícios.

\subsection{OBJETIVO GERAL}

Este artigo visa mostra os pontos em comum entre as metodologias Produção Enxuta e Produção Mais Limpa: identificar e descrever os métodos, sistemas e técnicas utilizados na Produção Enxuta, identificar e descrever os métodos, sistemas e tecnologias utilizados na $\mathrm{P}+\mathrm{L}$ e analisar os pontos comuns entre as duas e ressaltando seus benefícios para as indústrias.

\subsection{METODOLOGIA}

Apresenta-se uma pesquisa bibliográfica desenvolvida com base em material já elaborado, constituído principalmente de livros e artigos científicos que contém informações publicadas por outros autores com enfoque qualitativo, pois auxilia a explicar o porquê das coisas e a expor o que pode ser feito. Tais pesquisas foram realizadas de diversos meios de comunicação diversificados como livros, revistas e monografias publicadas na internet. Dados e informações extraídos de portais eletrônicos como; Scielo; LATEC; Capes; sites de universidades; sites de eventos, e revistas científicas como: GeP; NAVUS; FGV; CNEG; PA; CET; INTER SCIENCE PLACE e outros.

\section{REVISÃO DA LITERATURA}

\subsection{PRODUÇÃO ENXUTA}

Na década de 1950, Taiichi Ohno, executivo da Toyota, iniciou a criação e implantação de um sistema de produção com foco principal na identificação e posteriormente na eliminação dos desperdícios.

Porém, foi na década de 1980, "quando ficou claro que havia algo de especial na qualidade e eficiência japonesa" (LIKER, 2005, p.25), pois mesmo com a crise do petróleo, algumas industrias continuavam crescendo e apresentando bons resultados. Estudiosos e de organizações de todo o mundo ficaram curiosos com "as peculiaridades do sistema de produção que vinha sendo utilizado por muitas instituições japonesas, e, particular a Toyota" (RODRIGUES, 2005, p.5).

Esse modelo de produção foi denominado pela Toyota como Sistema Toyota de Produção (STP). Ele representa "uma forma de produzir cada vez mais com cada vez menos, foi denominado produção enxuta (Lean Production ou Lean Manufacturing)" (WERKENA, 2011, p.13).

Segundo Rodrigues (2016, p.5), o grande diferencial desse modelo está relacionado ao conceito e à visão de desperdício em todas as etapas do processo, e na liderança e no comprometimento de seus colaboradores.

Silva, Souza e Silva (2013) complementam dizendo que este método busca o que tem valor para o cliente e adaptando a velocidade para a empresa com qualidade e flexibilidade.

"Os métodos, sistemas e técnicas utilizados no Lean Manufacturing hoje tem sido aplicados nos diversos setores organizacionais, em alguns casos com certas 
mudanças na denominação, em outros mantendo os termos iniciais, mas o que é importante é o entendimento de que o Pensamento Lean, seja na manufatura ou nos serviços, busca melhores resultados a partir do combate ao desperdício em um conceito amplo em todos os níveis, uma vez que ter a organização enxuta, sem desperdício, não é mais um diferencial, mas sim, uma condição de sobrevivência nesse mercado global e competitivo."(RODRIGUES, 2016, p.7)

A ideia central da produção enxuta está na "eliminação de mudas (desperdícios) em todas as etapas e em todos os níveis do processo produtivo por meio de otimização ou de mudanças de ações que as geram" (RODRIGUES, 2016, p.21).

\subsubsection{DESPERDÍCIO}

Para Elias e Magalhães (2003, p. 2), desperdício representa toda atividade utiliza de recursos, porém não agrega valo ao produto. Eles afirmam ainda que o fundamento da produção enxuta é visto que eliminados os desperdícios, diminuir os custos de produção e maximizar a satisfação do cliente.

Werkena (2011, p. 13) sita que Taiichi Ohno identificou sete grandes tipos de perdas sem agregação de valor em processos administrativos ou de produção e Liker (2005, p. 47) acrescentou um oitavo tipo de desperdício posteriormente, conforme descrição abaixo:

- Superprodução - produção de itens sem demanda, gerando perda com excesso de pessoal e estoque, além de custos com transporte causado pelo estoque excedente;

- Espera (tempo sem trabalho) funcionários sem trabalho devido a falta de matéria-prima, atrasos em processamentos, interrupção do funcionamento de equipamentos e gargalos de capacidade;

- Transporte ou movimentação desnecessários - transporte ineficiente ou movimentação desnecessária de materiais, peças ou produtos acabados entre processos ou estoques;

- Superprocessamento ou processo incorreto - passos desnecessários para processar as peças, podendo ser movimento exagerado de uma ferramenta e assim produzindo defeitos;
- Excessos de estoque - excesso de matéria-prima, de estoque em processo ou de produtos acabados;

- Movimento desnecessário - um movimento desnecessário realizado pelo funcionário durante o trabalho coo procurar uma peça.

- Defeitos - produção de bens ou serviços fora das especificações de necessidades dos clientes internos ou externos, que provoca retrabalho ou refugo, acarretando;

- Desperdício de criatividade dos funcionários - não ouvir ou envolver os funcionários, desperdiçando assim ideias, habilidades e melhorias de aprendizagem.

\subsubsection{FERRAMENTAS DA PRODUÇÃO ENXUTA}

Segundo Elias e Magalhães (2003, p. 2), a mentalidade enxuta pode ser definida como uma filosofia que busca tempos menores de processamento na entrega de produtos ou serviços de qualidade com baixos custos, com melhorias no fluxo produtivo após a eliminação de desperdícios no fluxo de valor.

Logo, para que a produção enxuta seja implementada, algumas técnicas deverão ser adotadas, para que juntas, se tornem possíveis. Elas buscam eliminar todas as atividades que não agregam valor ao produto aos olhos do cliente. Essas técnicas são: kanban, célula de produção, programa 5 Ss, redução de setup, manutenção produtiva total, dispositivos a prova de erros (pokayoke), entre outras.

O kanban, palavra japonesa para "cartão", "etiqueta" ou "sinal", é uma ferramenta para o gerenciamento e a otimização do fluxo de materiais em um sistema de produção STP através de controle visual.

Rodrigues (2016, p.128) diz que o kanban "tem como objetivo maior não somente o controle de estoque das unidades envolvidas, mas o de gerenciar o fluxo de materiais entre estações de trabalho ou unidades. Para isso, o controle dos lotes de produção é disciplinado pelos operadores."

A definição do layout de uma unidade do setor produtivo é muito importante, pois as etapas do processamento de um determinado item acontecem imediatamente umas após as outras, assim as peças se movem de modo 
contínuo, podendo ser de uma única vez ou em quantidade pequena, mantidos ao longo do processo produtivo.

O $5 \mathrm{~S}$ é um método cujo objetivo é promover e manter a limpeza e a organização das áreas de trabalho - tanto administrativas quanto de manufatura -, funcionando com o um pilar básico do Lean Manufacturing (Werkema, 2011, p.69). Os 5s são cinco palavras japonesas: seiri (senso de utilização); seiton (senso de organização); seiso (senso de limpeza); seiketsu (senso de padronização); e shitsuke (senso de autodisciplina).

"Na busca de maior eficiência da manutenção produtiva, por meio de um sistema compreensivo, baseado no respeito individual e na total participação dos empregados, surgiu a TPM" (SAMPAIO, 1993, p.4).

"O TPM - Total Productive Maintenance (Manutenção Produtiva Total) - é o conjunto procedimentos que têm como objetivo garantir que os equipamentos de um processo produtivo sejam capazes de executar as tarefas necessárias, de modo a não interromper a produção. Para que o TPM seja efetivo, deve haver o envolvimento direto de todas as pessoas que operam os processos" (WERKEMA, 2011, p.81).

O Poka-Yoke é um termo japonês que significa mistake-proofing (a prova de erro). Ele é um dispositivo que identifica desvios ou erros de operação e desliga a máquina.

Segundo Rodrigues (2016, p.93), “a operacionalização da Poka-Yoke ocorre por meio de dispositivos ou de ações para prevenir as prováveis falhas dos operadores que trariam como consequência defeitos nas peças, nos produtos ou causariam acidentes de diversas naturezas".

A tabela 1 apresenta um resumo das ferramentas da Produção Enxuta.

Tabela 1: Ferramentas da produção enxuta

\begin{tabular}{|c|c|c|c|}
\hline Ferramentas & Descrição & Ferramentas & Descrição \\
\hline KANBAN & $\begin{array}{l}\text { cartões que auxiliam no gerenciamento e } \\
\text { otimização de fluxo de material }\end{array}$ & $\begin{array}{l}\text { REDUÇÃO DE } \\
\text { SETUP }\end{array}$ & $\begin{array}{l}\text { método para a diminuição do tempo } \\
\text { necessário para a troca da fabricação de um } \\
\text { tipo de produto para outro (tempo de setup) }\end{array}$ \\
\hline $\begin{array}{l}\text { CÉLULA DE } \\
\text { PRODUÇÃO }\end{array}$ & $\begin{array}{l}\text { layout por células caracteriza-se por ter } \\
\text { como suporte o agrupamento de peças em } \\
\text { grupos ou famílias para que sejam } \\
\text { executadas açães de mesma finalidade, } \\
\text { aumenta a eficácia da produção com a } \\
\text { otimização dos recursos disponíveis }\end{array}$ & $\begin{array}{l}\text { MANUTENÇÃO } \\
\text { PRODUTIVA } \\
\text { TOTAL }\end{array}$ & $\begin{array}{l}\text { o conjunto procedimentos que têm como } \\
\text { objetivo garantir que os equipamentos de um } \\
\text { processo produtivo sejam capazes de } \\
\text { executar as tarefas necessárias, de modo a } \\
\text { não interromper a produção }\end{array}$ \\
\hline PROGRAMA $5 S$ & $\begin{array}{l}\text { Seiri - Classificar } \\
\text { Seiton - organizar } \\
\text { Seison - limpar } \\
\text { Seiketsu - padronizar } \\
\text { Shitsuke - disciplinar }\end{array}$ & POKA-YOKE & $\begin{array}{l}\text { dispositivos ou ações para prevenir as } \\
\text { prováveis falhas dos operadores que trariam } \\
\text { como consequência defeitos nas peças, nos } \\
\text { produtos ou causariam acidentes de diversas } \\
\text { naturezas }\end{array}$ \\
\hline
\end{tabular}

Elaborado pelo autor

\subsection{PRODUÇÃO MAIS LIMPA (P+L)}

Para Oliveira (2006), “a abordagem de Prevenção da Poluição, o modelo de gestão ambiental denominado Produção Mais Limpa é uma ferramenta eficaz para cumprir com as necessidades ambientais e promover 0 desenvolvimento sustentável”.

De acordo com o CNTL (2003), a P+L é uma junção de técnicas, econômicas e ambientais ligadas a processos ou produtos, com a finalidade reduzir 0 uso excessivo de matérias-primas, como água e energia, mediante a não geração, diminuição ou reciclagem de resíduos, para o beneficiamento do meio ambiente, da saúde ocupacional e econômico.

A PML considera a variável ambiental em todos os níveis da empresa desde a compra de matérias-primas, como a engenharia de produto, o design e o pós-venda, além de relacionar as questões ambientais com ganhos econômicos para a empresa.

A P+L também é caracterizada por ações implementadas dentro da empresa com 
finalidade de tornar o processo mais eficiente na utilização de insumos, aumentando a quantidade de produtos e gerando menos resíduos.

Vale ressaltar também que por meio da implantação de um programa de Produção Mais Limpa é possível identificar quais são as tecnologias limpas mais adequadas para o processo produtivo de uma empresa ou processo, contribuindo positivamente sobre saúde ocupacional e levando a um melhor ambiente de trabalho.

Elias e Magalhães (2003, p.5) citam que a $\mathrm{P}+\mathrm{L}$ é uma ferramenta completa quando se deseja a otimização de processo produtivo e sua melhoria contínua, já que engloba os pontos que levam a qualidade, ao planejamento, a segurança, ao meio ambiente, ao design, a saúde ocupacional, a eficiência.
Para Santos et al (2006) a Produção Mais Limpa é uma estratégia aplicada aos produtos e processos de forma preventiva, continua e integrada a vários viveis da empresa, com o propósito de racionalizar a utilização de todos os recursos produtivos, sejam eles materiais, humanos ou energéticos, na busca pela redução dos desperdícios de matéria-prima, resíduos e retrabalhos antes de sua geração, sendo traduzidos em resultados nas esferas sócioeconômico-ambiental.

Werner et al (2009) diz que a $\mathrm{P}+\mathrm{L}$, “com seus elementos essenciais, adota uma abordagem preventiva, em resposta à responsabilidade financeira adicional trazida pelos custos de controle da poluição e dos tratamentos de final de tubo" conforme apresenta a Figura 1.

Figura 1: Elementos essenciais da estratégica de $\mathrm{P}+\mathrm{L}$ -

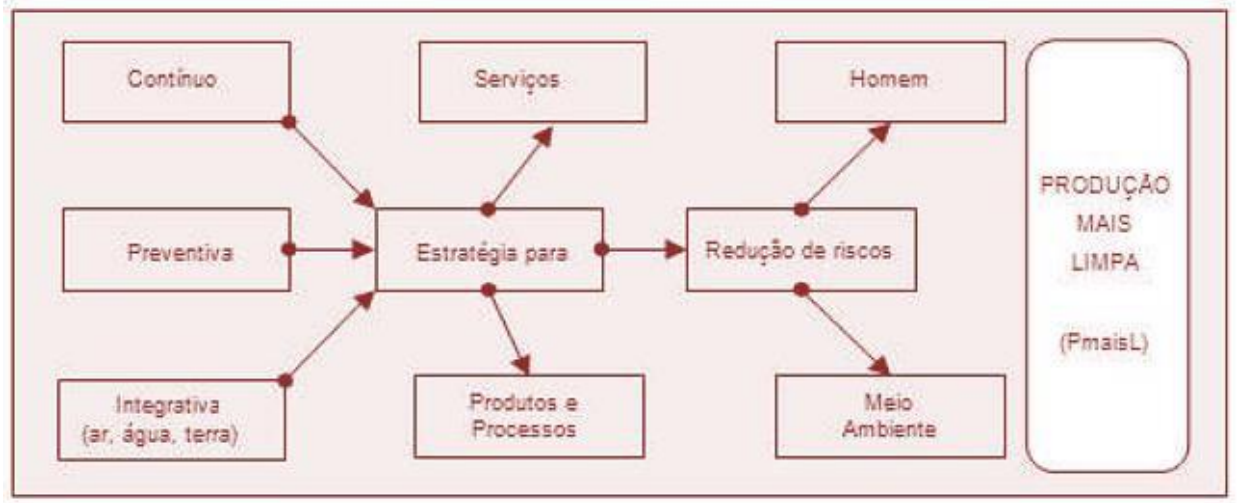

Fonte: Werner et al

A $\mathrm{P}+\mathrm{L}$ busca evitar os impactos negativos ao meio ambiente desde o design do produto no momento de sua criação, da estratificação da matéria prima ao descarte do produto final. Ela visa eliminar o uso de materiais tóxicos, reduzindo a eliminação dos resíduos.

\subsection{P+L X PRODUÇÃO ENXUTA}

Para correlacionar as duas metodologias, primeiro é necessário mostrar que com a implantação e aplicação da Produção Enxuta, evidenciam vários benefícios da Produção Mais Limpa, pois quando uma empresa opta pela utilização do Sistema Toyota de Produção, o primeiro passo começa com a identificação eliminação dos desperdícios através da superprodução, espera, transporte, processos, estoque, movimentação e na produção de produtos defeituosos.

Para Santos et al (2006) a Produção Mais Limpa objetiva preservar o meio ambiente, o consumidor e a comunidade, juntamente com a busca do crescimento sustentável das organizações através da melhoria de sua eficiência, lucratividade e competitividade.

Rodrigues (2016, p.7) confirma que a Produção Enxuta, busca melhorar resultados a partir do combate ao desperdício em um conceito amplo e em todos os níveis, uma vez que ter a organização enxuta, sem desperdício, não é apenas um diferencial, mas sim uma condição de sobrevivência no mercado global e competitivo. 
Quando as duas metodologias são executadas de forma correta, pode melhorar a eficiência das operações, gerando redução nos custos e consequentemente proporcionando ganhos financeiros, além de conseguir um diferencial em relação a seus competidores.

Porém, muitas empresas ainda não perceberam que, implementando a Produção Mais Limpa juntamente com a Produção Enxuta, a relação custo/benefício que a ambas proporcionam, pois produz ganho ambiental, promove inovações, reduz custos e gera vantagens competitivas.

Liker (2005, p. 47) diz que, quando um processo produtivo possui desperdícios, ocorre aumento no custo na produção e não agregam valor ao produto final. Por isso, a importância em eliminá-los.

Para Nishida (2006), "o foco principal da produção lean é a eliminação sistemática dos desperdícios, ou seja, de tudo aquilo que não agrega valor às atividades no processo de produção". Eles afirmam ainda que através de uma pesquisa patrocinada pela Agência de Proteção Ambiental dos Estados Unidos (EPA, Environmental Protection Agency), concluiu que a utilização destes princípios e de seus métodos resulta também na melhoria dos indicadores ambientais, tais como porcentagem de geração de resíduos, consumo de energia.

Quando se refere a superprodução ou excesso de produção, é possível perceber que cada produto produzido a mais, sem demanda, gera custos com material e mão de obra além resíduos desnecessários. Já o desperdício relacionado a espera está associado ao tempo parado da mão de obra no aguardo de um processamento ou ferramenta e com isso, geram gastos de energia inútil.

A movimentação desnecessária de peças, estoques ou equipamentos devido a erro na projeção do layout de uma empresa pode acarretar a utilização de transportes internos, como empilhadeiras, e assim maior consumo de combustível, acarretando no aumento de emissão de gases poluentes.

O desperdício proveniente do processamento incorreto é resultado de procedimentos ou atividades dispensáveis, o que leva a questionar se realmente é necessária tal etapa do processo produtivo, e por fim, eliminando algo que não agrega valor ao produto, apenas custos e como consequência, minimizando a necessidade de utilização de recursos, energia e matériaprima.

Uma empresa com excesso de estoque depara-se com vários contratempos, como excesso de matéria-prima, produto semiacabados ou acabados podem gerar obsolescência e até mesmo produtos danificados, portanto, desperdício de recursos naturais.

Produtos defeituosos, isto é, fora da especificação e da necessidade do cliente interno ou externo causam perdas de manuseio, tempo e esforço, já que muitas dessas peças precisam sofrer retrabalho ou refugo e até mesmo devem ser descartadas. Desta maneira, maior consumo de insumos e energia.

A tabela 2 mostra como os desperdícios afetam as duas metodologias.

Tabela 2: Produção Enxuta X Produção mais Limpa

\begin{tabular}{|c|c|c|}
\multicolumn{1}{|c|}{ Desperdício } & $\begin{array}{c}\text { Produção } \\
\text { Enxuta }\end{array}$ & Produção Mais Limpa \\
\hline Superprodução & $\mathrm{X}$ & $\mathrm{X}$ \\
\hline Espera & $\mathrm{X}$ & $\mathrm{X}$ \\
\hline Transporte & $\mathrm{X}$ & $\mathrm{X}$ \\
\hline Superprocessamento & $\mathrm{X}$ & $\mathrm{X}$ \\
\hline Excesso de Estoque & $\mathrm{X}$ & $\mathrm{X}$ \\
\hline Movimento Desnecessário & $\mathrm{X}$ & $\mathrm{X}$ \\
\hline Defeitos & $\mathrm{X}$ & $\mathrm{X}$ \\
\hline $\begin{array}{c}\text { Desperdício de criatividade } \\
\text { dos funcionários }\end{array}$ & $\mathrm{X}$ & $\mathrm{X}$ \\
\hline
\end{tabular}

Elaborado pelo autor 
Nishida (2006) cita ainda que para sustentar estas melhorias, o trabalho deve ser padronizado, que cada procedimento possua seu desempenho apropriado de acordo com a atividade de trabalho e o controle visual reforça estas práticas.

Como a Produção Enxuta, a Produção Mais Limpa também é uma metodologia de aplicação contínua, e para a implementação de delas, mudanças deverão ocorrer na cultura organizacional da empresa.

A importância de uma gerência ativa para motivar e monitorar a equipe por um objetivo comum, por isso, é fundamental envolver os funcionários do chão de fábrica na identificação dos desperdícios e eliminá-los, com intuito que ocorra melhoria contínua no processo de produção.

Também é fundamenta estimular a criatividade dos trabalhadores para aprimorar e inovar os processos para que melhorem a eficiência e a eficácia de todo o sistema produtivo e com isso, contribua na redução dos impactos ambientais.

\section{CONCLUSÃO}

A Produção Enxuta é a junção de técnicas com objetivo de eliminar os desperdícios que afetam o processo produtivo e a Produção mais Limpa busca tornar o sistema produtivo mais eficiente quanto a utilização de insumos gerando menos resíduos. Ambas são metodologias de aplicação contínua e para a

\section{REFERÊNCIAS}

[1] Cntl, Centro Nacional de Tecnologias Limpas. Implementação de Programas Produção Mais Limpa. Disponível em: <http://www.pha.poli.usp.br/LeArq.aspx?id\%5Farq =7985. $>$ Acesso em: 31 de ago de 2017.

[2] Cntl, Centro Nacional de Tecnologias Limpas. Questões Ambientais e Produção Mais Limpa. Disponível em: http://institutossenai.org.br/public/files/manualquesto-es-ambientais-e-p-l-pdf.pdf. > Acesso em: 31 de ago de 2017.

[3] Elias, Sérgio José Barbosa; Magalhães, Liciane Carneiro. Contribuição da Produção Enxuta para obtenção da Produção Mais Limpa. Disponível em: <https://www.producaoonline.org.br/rpo/article/vie w/577/623> Acesso em: 29 de ago de 2017.

[4] Environmental Protection Agency. Lean Manufacturing and the Environment: Research on Advanced Manufacturing Systems and the Environment and Recommendations for Leveraging implantação delas, são necessárias mudanças na cultura organizacional da indústria.

Quando são implementadas juntas, a indústria beneficia-se com vantagens econômicas, pois com a eliminação ou redução de desperdícios é possível otimizar o processo, reduzir o consumo de matéria-prima com a finalidade de atingir metas, por consequência, redução dos preços dos produtos e assim, aumentando sua produtividade de forma sustentável.

Por isso, é importante estabelecer metas de redução nos indicadores ambientais, pois elas ajudarão a atingir melhores resultados quando são vinculadas às metas da área produtiva. Todos os esforços na implementação dos conceitos da Produção Enxuta em diversos processos, tendo em vista a melhoria sistêmica poderão beneficiar as empresas também na melhoria das condições do meio-ambiente.

Logo, é fundamental que a indústria incentive, na formação dos seus profissionais, a conscientização ambiental, principalmente na gerência de processos produtivos. A preservação dos recursos naturais e a utilização deles de forma responsável auxiliam de forma significativa o início e a continuidade do conceito de desenvolvimento sustentável, na qual a $\mathrm{P}+\mathrm{L}$ possui um dever crucial.

Better Environmental Performance. Disponível em: $<$ https://www.lean.org/Search/Documents/387.pdf > Acesso em: 18 de out de 2017.

[5] Liker, Jeffrey K. O modelo Toyota: 14 princípios de gestão do maior fabricante do mundo. Porto Alegre: Bookman, 2005.

[6] Mello, Maria Cecília Abreu de. Produção Mail Limpa: Um estudo de caso na AGCO do Brasil. Disponível em:

<http://www.lume.ufrgs.br/bitstream/handle/10183/ 3706/000341804.pdf?sequenc> Acesso em: 05 de set de 2017.

[7] Nishida, Lando Tetsuro. Redução do impacto ambiental através das práticas lean. Disponível em: <http://www.lean.org.br/artigos/111/reducao-doimpacto-ambiental-atraves-das-praticaslean.aspx> Acesso em: 07 de ago de 2017.

[8] Oliveira, Márcio de. A produção mais limpa como ferramenta de gestão ambiental para as indústrias do município de Juiz de Fora. Disponível 
<http://www.ufff.br/ep/files/2014/07/2006_1_M\%C3 \%A1rcio.pdff > Acesso em: 16 de out de 2017.

[9] Rodrigues, Marcus Vinícius. Entendendo, aprendendo e desenvolvendo sistema de produção Lean Manufacturing. 2. ed. Rio de Janeiro: Elsevier, 2016.

[10] Santos, Elaine Maria dos et al. Produção Mais Limpa: elementos para discussão e análise. Disponível em: <https://www.researchgate.net/profile/Jose_Oliveira _Neto/publication/260061066_Producao_mais_Lim pa_elementos_para_discussao_e_analise/links/569 a737208ae748dfb07fd4e/Producao-mais-Limpaelementos-para-discussao-e-analise.pdf > Acesso em: 16 de out de 2017
[11] Werkema, Cristina. Lean Seis Sigma: introdução às ferramentas do lean manufacturing. 2. ed. Rio de Janeiro: Elsevier, 2011.

[12] Sampaio, Adrian. TPM/ MPT: manutenção produtiva total. Disponível em: http://www. mantenimientomundial.com/sites/mm/no tas/TPMtotal.pdf> Acesso em: 17 de set de 2017.

[13] Werner, Eveline de Magalhães et al. Produção Mais Limpa: Conceitos e Definições Metodológicas Disponível em: <https://www.aedb.br/seget/arquivos/artigos09/306 _306_PMaisL_Conceitos_e_Definicoes_Metodologi cas.pdf> Acesso em: 20 de maio de 2018 


\section{Bapítulo 8}

\section{LEAN SEIS SIGMA - APLICABILIDADE DA METODOLOGIA PARA REDUCCÃO DO TEMPO DE ESPERA PARA ATENDIMENTO MÉDICO EM UNIDADES AMBULATORIAIS}

Elisangela Elias de Souza

Adriano Olivieri Brito

Larissa Vilela Cruz.

Leonardo de Abreu Ferreira

Priscila Fernanda Morais Chaves

Resumo: Os serviços de assistência a saúde enfrentam cada vez mais desafios que obrigam o setor a buscar estratégias capazes de melhorar os processos e a qualidade dos serviços. Os problemas frequentemente enfrentados estão relacionados a elevados tempos de espera para atendimento, custos, qualidade e segurança do paciente. É nessa perspectiva que este estudo se insere, tendo como objetivo apresentar a importância da adoção de metodologias de melhoria de processos no âmbito das organizações, com ênfase em particular para o Lean Seis Sigma, especialmente no setor de serviços de saúde. Para tanto, realizou-se um estudo com abordagem quantitativa em duas unidades de atendimento médico ambulatorial, a fim de se identificar os saberes, práticas e principais desafios encontrados na aplicação da metodologia Lean Seis Sigma. Foi realizado o levantamento e análise das informações relativas ao processo de intervenção assistencial nessas unidades. Foram propostas soluções que visam reduzir o tempo de espera para atendimento médico após o horário agendado para consulta médica. Os resultados em busca da resposta para a situação problema foram alcançados e apontam ganhos na satisfação do cliente e melhoria da qualidade.

Palavras-chave: Lean Seis Sigma, Qualidade, Serviços, Saúde, Governança Clínica 


\section{INTRODUÇÃO}

\subsection{CONSIDERAÇÕES INICIAIS}

O Seis Sigma é uma metodologia que surgiu em meados dos anos 80 quando a empresa Motorola adotou métodos capazes de enfrentar os problemas de concorrência. Incialmente a técnica foi utilizada nos processos produtivos, mas logo foi aplicada as atividades administrativas das organizações. De acordo com Werkema (2012), "Seis Sigma é uma estratégia gerencial disciplinada que tem por objetivo aumentar drasticamente a lucratividade das empresas por meio da melhoria da qualidade de produtos e processos e do aumento da satisfação do cliente". O Lean é uma iniciativa introduzida pela Toyota, na década de 50, com o objetivo de eliminar desperdícios.

A aplicação da metodologia Lean Seis Sigma nos mais diversos segmentos, em especial na indústria, já é uma prática bem difundida. Cenários econômicos em constante mudança, avanços tecnológicos, concorrência e mudanças no comportamento do consumidor são alguns dos fatores que exigem das empresas a adoção de estratégias que garantam o crescimento e sustentabilidade dos negócios. Cada vez mais as empresas vêm buscando métodos para melhorias dos processos, garantia da qualidade, redução de desperdícios e aumento da lucratividade.

Neste sentido, a adoção da metodologia Lean Seis Sigma na solução de problemas é um meio para padronizar os procedimentos reduzindo a variabilidade dos processos, garantindo a qualidade e contribuindo para o alcance da satisfação dos clientes. Por se tratar de uma metodologia aplicável tanto na produção quanto para melhorar a qualidade dos serviços, o Lean Seis Sigma é uma abordagem que traz melhorias significativas para as empresas.

A utilização dessa metodologia implica no uso de uma ferramenta identificada pelo acrônimo DMAIC - D (Define - definir), M (Measure medir), A (Analyze - analisar), I (Improve melhorar) e C (Control - controlar) - essas etapas compõem a aplicação do método. Em cada etapa são utilizadas técnicas e principalmente a estatística para definir o problema, identificar as causas e determinar as melhores soluções para melhoria do processo.

Este artigo tem como proposta apresentar a aplicação do Lean Seis Sigma para melhoria contínua de um processo de Governança Clínica.

Governança Clínica é um sistema através do qual as organizações são responsáveis por melhorar continuamente a qualidade dos seus serviços e a garantia de elevados padrões de atendimento, criando um ambiente de excelência de cuidados clínicos. Nascido a partir das mudanças mais recentes que o Sistema de Saúde do Reino Unido vem implantando ao atendimento de seus usuários, o conceito propõe a fusão no sentido mais amplo de iniciativas voltadas para a melhoria da assistência, utilizando como pano de fundo os processos de Qualidade (principalmente hospitalar) e Governança Organizacional. A Governança Clínica está fundamentada basicamente na premissa de que os serviços de saúde precisam incentivar os profissionais (principalmente o Corpo Clínico, ou seja, médicos) a seguirem normas elementares de qualidade assistencial em benefício dos pacientes para os quais sua atividade-fim é voltada. Para tanto, são preconizadas atitudes de incentivo à regimentalização, criação de comissões, resgate e valorização do papel do auditor, adoção de diretrizes e protocolos clínicos, regras de relacionamento multi-profissional, valorização da percepção do paciente a respeito do seu tratamento e de sua experiência dentro da organização, e o registro adequado de todos os eventos relacionados à sua prática (documentos, prontuários, justificativas, dentre outros).

0 objeto desse estudo será o tempo de espera para atendimento após o horário agendado para consulta médica em duas unidades de atendimento médico, no setor de saúde suplementar, de nível ambulatorial, na cidade de Belo Horizonte/Minas Gerais.

\subsection{FORMULAÇÃO DA SITUAÇÃO PROBLEMA}

As unidades ambulatoriais de assistência à saúde, objetos de estudo desse artigo compõem a rede de serviços próprios de uma operadora de planos de saúde suplementar de Belo Horizonte. Essas unidades desempenham um papel de promoção e prevenção à saúde de seus usuários, nesses ambulatórios são realizados atendimento médico especializado, exames laboratoriais e de imagens. Para fins de classificação esses ambulatórios serão identificados no estudo como Unidade Oeste e Unidade Norte. 
Os usuários das Unidades Oeste e Norte são atendidos para consultas médicas em horários previamente agendados. É comum ocorrerem atrasos para atendimento, que podem estar associados a causas como: atraso na chegada do profissional médico, sobreposições de horários devido a encaixes solicitados pelos clientes, atrasos durantes os atendimentos, atrasos na chegada dos clientes e nos atendimentos de casos mais complexos que superam o tempo de consulta. Há que se considerar ainda um fator cultural do brasileiro de falta de pontualidade. Comumente a demora na espera para atendimento gera insatisfação do cliente.

Com o objetivo de acompanhar o tempo de espera do cliente para atendimento médico nesses ambulatórios, considerou-se 20 minutos o tempo máximo de tolerância para possíveis atrasos para um atendimento agendado. Então, foi criado pelos gerentes dessas unidades um indicador que visa medir o percentual de clientes atendidos com até 20 minutos de atraso após o horário agendado para consulta médica.

Esse trabalho pretende apresentar a aplicação de uma inciativa Lean na redução do tempo de espera para atendimento nas consultas médica nas Unidades Oeste e Norte, através do aumento do índice do indicador criado, pois essas Unidades vêm apresentando resultado elevado em relação ao tempo de espera para atendimento dos clientes após o horário agendado para consulta médica.

\subsection{OBJETIVO GERAL}

O objetivo geral desse estudo é demonstrar o uso da Metodologia Lean Seis Sigma para redução do tempo de espera para atendimento médico após o horário agendado pelo cliente. Com isso, avalia-se o Lean Seis Sigma e sua relevância na melhoria do desempenho de processos no setor da saúde, no aumento da qualidade e na satisfação do cliente.

\subsection{METODOLOGIA}

0 artigo desenvolvido pode ser classificado como um estudo de caso exploratório, descritivo, quantitativo baseado na metodologia Lean Seis Sigma. É exploratório porque até o presente momento não havia nos ambulatórios em estudo pesquisa voltada para aplicação da metodologia Lean Seis Sigma. É descritivo, pois foram descritos os processos para aplicação do método. Quanto aos meios, a pesquisa utilizada nesse estudo foi tanto bibliográfica quanto pesquisa de campo porque para a fundamentação teórica dos assuntos levantados realizou-se uma investigação em livros, artigos científicos e sites para embasar a argumentação e também foram coletados dados no universo dos ambulatórios objeto deste estudo.

\section{REVISÃO DA LITERATURA}

\subsection{ORIGENS DA METODOLOGIA LEAN SEIS SIGMA}

Segundo Werkema (2012), o Seis Sigma tornou - se um programa reconhecido como capaz de melhorar o desempenho de uma organização a partir de 1988, quando a Motorola recebeu um prêmio de qualidade pelo uso da metodologia. Sigma é uma letra do alfabeto grego que na estatística é utilizada para representar medida de variação, representando um desvio padrão. Seis Sigma significa um alto nível de excelência dentro da proposta da metodologia.

0 pensamento Lean tem origem no Sistema Toyota de produção que se difundiu na da década de 90 a partir de uma publicação feita pelo Massachusetts Institute of Technology (MIT) sobre o modelo e produção da Toyota. A pesquisa realizada pela MIT evidenciou que o sistema adotado pela Toyota era mais eficiente que o sistema convencional de produção representando uma mudança de paradigma.

A integração entre as duas metodologias é uma estratégia que pode ser adotada pelas organizações para o alcance de seus objetivos. De acordo com Werkema (2012) as empresas podem e devem usufruir os pontos fortes de ambas as metodologias. A figura a seguir mostra como a integração do Seis Sigma e Lean contribui para a melhoria de processos. 
Figura 1 - Integração Seis Sigma e Lean

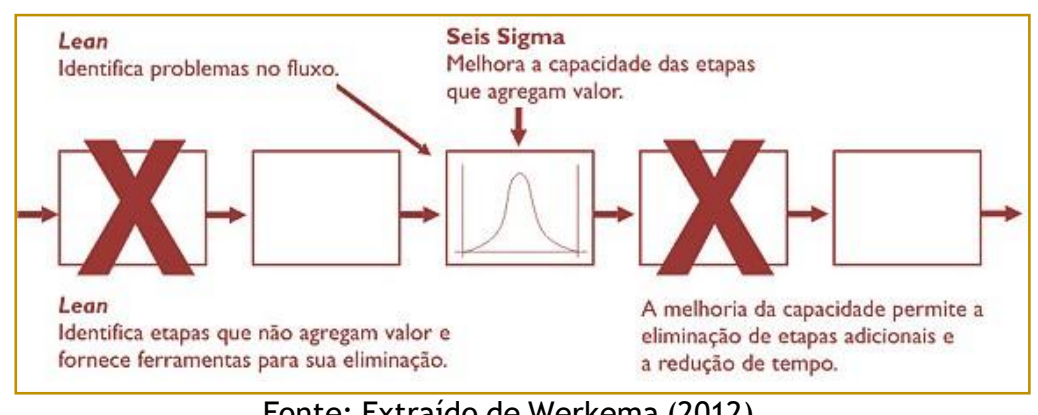

Fonte: Extraído de Werkema (2012),

\subsection{OS PRINCÍPIOS DO PENSAMENTO LEAN}

Womack e Jones (2003), propuseram cinco princípios como uma estrutura a ser seguida para implementação do pensamento Lean Thinking (pensamento enxuto) nas organizações. Esses princípios podem ser resumidos da seguinte maneira:

1- Especificar o valor: fornecer aos clientes o que eles buscam, quem cria o valor é o cliente.
2- $\quad$ Mapear o fluxo de valor: identificar a cadeia de valor e os processos que criam valor para o cliente.

3- $\quad$ Criar um fluxo: alinhar os processos para garantir um fluxo continuo

4- Estabelecer um sistema de puxar: fornecer ao cliente o que ele precisa quando ele desejar.

5- $\quad$ Buscar a perfeição: garantir que somente os processos que criam valor que estejam presentes no ciclo.

Figura 2 - Os 5 Princípios do Pensamento Lean

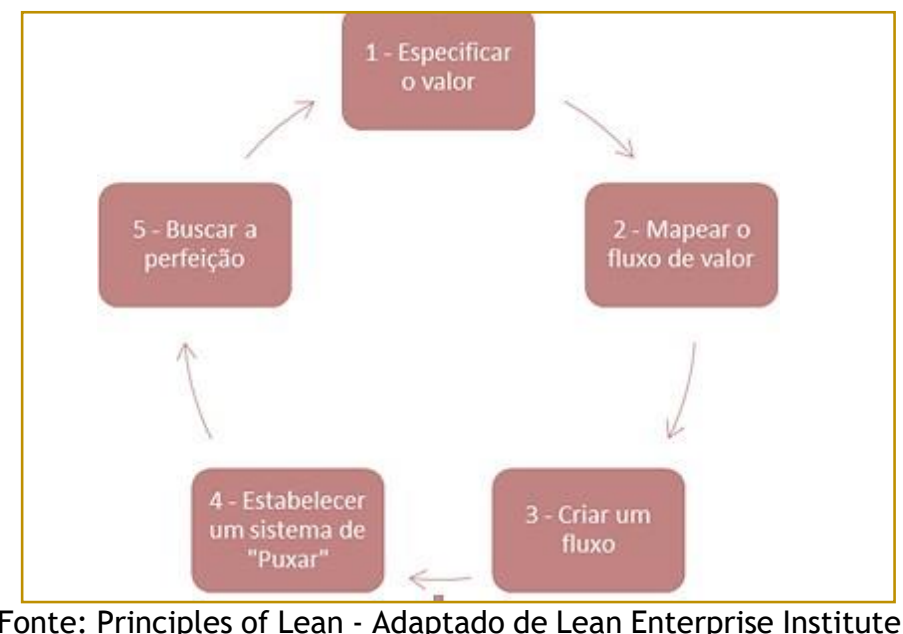

A implementação do Pensamento Lean implica na adoção de diversas ferramentas e métodos. As principais ferramentas usadas nas organizações para colocar em prática os princípios do Lean Thinking são: Mapeamento de Fluxo de Valor, Métricas Lean, Seis Sigma, Kaizen, Kanban, Padronização, 5S, Redução de Setup, TPM (Total Productive Maintenance), Gestão Visual e Poka-Yoke. Nesse trabalho será detalhado a ferramenta DMAIC, acrônimo das palavras - Define, Measure, Analyze, Improve e Control - empregado pela estratégia Seis Sigma para melhoria de processos.

\subsection{LEAN SEIS SIGMA - FERRAMENTA DMAIC}

O DMAIC é um método estruturado utilizado no Lean Seis Sigma que visa o alcance de metas através da aplicação de ferramentas capazes de avaliar o desempenho e melhorar a variabilidade dos processos. Para uma organização, alcançar o nível Lean Seis 
Sigma significa atingir o mais alto nível de qualidade dentro da proposta da metodologia.

De acordo com Werkema (2012), um dos requisitos para aplicação da metodologia Lean Seis Sigma é a constituição de equipes para executar projetos que contribuam para o alcance dos objetivos estratégicos da organização, para o desenvolvimento desse projeto é adotado o método denominado DMAIC. Esse método é composto por cinco etapas definidas a seguir:

1- Define (Definir): nessa etapa são definidos os problemas e as metas de melhorias desejadas. Essas metas serão o desafio a ser alcançado pelo projeto e devem estar vinculadas a objetivos estratégicos $\mathrm{da}$ organização.

2- Measure (Medir): momento de compreender como os processos ocorrem dentro da empresa, quais são os sistemas usados para coleta de informação e como se comportam os dados históricos.

3- $\quad$ Analyze (Analisar): fase de determinar as causas prioritárias dos problemas. Essa etapa deve ser fundamentada por dados confiáveis e análises estatísticas.

4- Improve (Melhorar): nessa etapa são propostas e implementadas as soluções para os problemas com o objetivo de melhorar os processos.

5- $\quad$ Control (Controlar): com a melhoria implementada faz-se necessário monitorar os resultados alcançados. O objetivo dessa etapa é cuidar para que as metas alcançadas permaneçam no longo prazo.

\subsection{LEAN SEIS SIGMA NOS SERVIÇOS DE SAÚDE}

O pensamento Lean tem como base a eliminação dos desperdícios que está presente em todos os tipos de organização. 0 uso da metodologia Lean nos serviços de saúde envolve benefícios na segurança do paciente, qualidade no atendimento e eliminação de desperdícios, com atendimentos mais rápidos e efetivos.

Para Graban (2013), a metodologia Lean pode mudar a forma como as organizações de assistência à saúde são organizadas e administradas. 0 método proporciona condições para melhorar a qualidade da assistência aos pacientes por meio da redução de erros e do tempo de espera. 0 Lean é uma abordagem que pode dar suporte as equipes profissionais eliminando obstáculos e permitindo que se concentrem na provisão da assistência.

Luzes (2013) aponta que a melhoria do desempenho nos processos dos serviços de saúde associadas a aplicação da metodologia Lean passa pela diminuição do tempo total que os pacientes gastam nos cuidados, no aumento do número de pacientes que podem ser atendidos, na diminuição dos erros e incidentes, redução do tempo de espera para atendimento médico e para recebimento de cuidados, no aumento da satisfação de clientes e funcionários e na redução dos custos.

De acordo com o Lean Institute Brasil, os benefícios mais evidentes da aplicação do Lean no setor da saúde estão exatamente na solução de problemas comuns ao sistema: longas filas de esperas, custos crescentes e diversos tipos de desperdícios recorrentes em todos os estabelecimentos de assistência à saúde sejam estes de baixa, média ou alta complexidade. Nesse sentido, a adoção de pequenas iniciativas Lean são capazes de reduzir o tempo de espera para atendimento, aumentar a agilidade nos processos, reduzir erros e custos indireto (estoques, administração, logística) eliminando diversas formas de desperdícios.

O desenvolvimento do pensamento Lean no setor de saúde a partir da implementação de projetos Lean é uma estratégia para os estabelecimentos de assistência à saúde enfrentar os desafios da melhoria dos processos sendo uma metodologia comprovadamente eficaz para aumentar a qualidade, os custos, a segurança e a satisfação dos clientes.

Gaspar (2015), ressalta que o Seis Sigma pode ser uma ferramenta para melhoria de processos, devido a eficácia no aumento da qualidade (melhoria do desempenho global), quando implementada com sucesso. Entretanto a metodologia exige das organizações uma mudança cultural, como envolvimento de todos os níveis - estratégico, tático e operacional - bem como a formação contínua dos profissionais.

Portanto o Lean Seis Sigma além de ser um modelo de gestão é uma filosofia e para que sua adoção traga resultados efetivos faz-se necessário que a prática seja disseminada em todos os níveis hierárquicos. Trata-se de uma mudança de pensamento onde todas as pessoas da organização devem ser 
envolvidas onde o papel da liderança será decisivo.

\section{RESULTADOS}

0 desenvolvimento do projeto ocorreu num período de seis meses, de abril a novembro de 2017, em dois ambulatórios de atendimento médico, no setor de saúde suplementar, na cidade de Belo Horizonte/Minas Gerais. Foi estabelecido um calendário para execução de cada fase do DMAIC. A cada fase do DMAIC foram aplicadas técnicas e ferramentas - opinião especializada, técnicas analíticas, reuniões que auxiliaram na coleta de dados e documentos que forneceram os subsídios necessários para entrega de cada fase do projeto.

\subsection{FASE DEFINE (DEFINIR)}

Essa fase consiste na definição do problema, uma descrição detalhada do escopo do projeto deve ser elaborada para se obter com clareza qual será o objetivo da iniciativa. Para construção dessa etapa são respondidas questões que visam fornecer a visão dos clientes sobre o problema, qual o processo envolvido, perdas resultantes do problema e os ganhos potenciais relacionados ao projeto. A fase Define se encerra com a aprovação do projeto pelo gestor do processo e a coordenação do programa Seis Sigma.

Após o levantamento com os responsáveis pelas Unidades Oeste e Norte objetivando a definição do problema e a definição das metas a serem alcançadas elaborou-se 0 Project Charter ou Termo de abertura do projeto, documento que contem a descrição detalhada do que será desenvolvido e autorização para execução das atividades. Para elaboração desse documento foram realizadas reuniões com consultores, partes interessadas e outras unidades dentro da organização. Uma análise preliminar dos dados disponíveis sobre o problema foi elaborada a fim de se conhecer 0 desempenho atual e estabelecer uma linha com o grau de diferença entre o desempenho desejado. A tabela a seguir apresenta os principais itens do Termo de abertura desse projeto.

Tabela 1 - Principais itens do Termo de abertura do projeto

\begin{tabular}{|c|c|}
\hline Descrição do problema & $\begin{array}{l}\text { As Unidades Oeste e Norte vêm apresentando baixo percentual de } \\
\text { atendimentos em até } 20 \text { minutos após o horário agendado para } \\
\text { consulta médica gerando insatisfação dos clientes. }\end{array}$ \\
\hline $\begin{array}{l}\text { Indicador que será usado para medir } \\
\text { o resultado do projeto }\end{array}$ & $\begin{array}{l}\text { Percentual de atendimentos em até } 20 \text { minutos após o horário } \\
\text { agendado para consulta médica. }\end{array}$ \\
\hline Avaliação do histórico do problema & $\begin{array}{l}\text { No período analisado, que compreendeu os meses de janeiro, } \\
\text { fevereiro e março de } 2017 \text {, verificou-se que: A Unidade Oeste } \\
\text { apresentou média de } 73,82 \% \text { dos atendimentos médicos eletivos } \\
\text { realizados em até } 20 \text { minutos após o horário agendado para } \\
\text { consulta médica. A Unidade Norte apresentou média de } 69,63 \%\end{array}$ \\
\hline Definição da Meta & $\begin{array}{l}\text { A meta é atingir até } 31 / 11 / 2017 \text {, os seguintes resultados: Unidade } \\
\text { Oeste: realizar } 80 \% \text { dos atendimentos em até } 20 \text { minutos após o } \\
\text { horário agendado para consulta médica. Unidade Norte: realizar } \\
75 \% \text { dos atendimentos em até } 20 \text { minutos após o horário agendado } \\
\text { para consulta médica. } \\
\text { (continua) }\end{array}$ \\
\hline Restrições e Suposições & $\begin{array}{l}\text { Para tempo de espera considera-se: horário entre a hora agendada } \\
\text { até a consulta médica. Para paciente atendido antes do horário } \\
\text { agendado será considerado o tempo de espera igual a zero. } \\
\text { Pacientes que chegaram após o horário agendado para a consulta } \\
\text { serão expurgados do cálculo. }\end{array}$ \\
\hline Equipe de trabalho & $\begin{array}{l}\text { Gerente, Coordenador médico, Coordenadores de enfermagens, } \\
\text { Supervisor de atendimento e Analistas. }\end{array}$ \\
\hline
\end{tabular}

Para definição da meta do projeto analisou-se dados fornecidos pelas unidades, foram disponibilizados dados do período que compreendeu os meses de janeiro, fevereiro e março de 2017, verificou-se que: a Unidade
Oeste apresentou média de $73,82 \%$ dos atendimentos médicos eletivos realizados em até 20 minutos após o horário agendado para consulta médica. A Unidade Norte apresentou média de $69,63 \%$ dos atendimentos 
realizados em até 20 minutos após o horário agendado para consulta médica. Os gráficos a seguir apresentam o resultado de cada unidade, mês a mês e a média, em relação a meta do projeto.

Gráfico 1 - Percentual de Atendimentos em até 20 minutos após o horário agendado para consulta médica eletiva Unidade Oeste. Período janeiro a março de 2017.

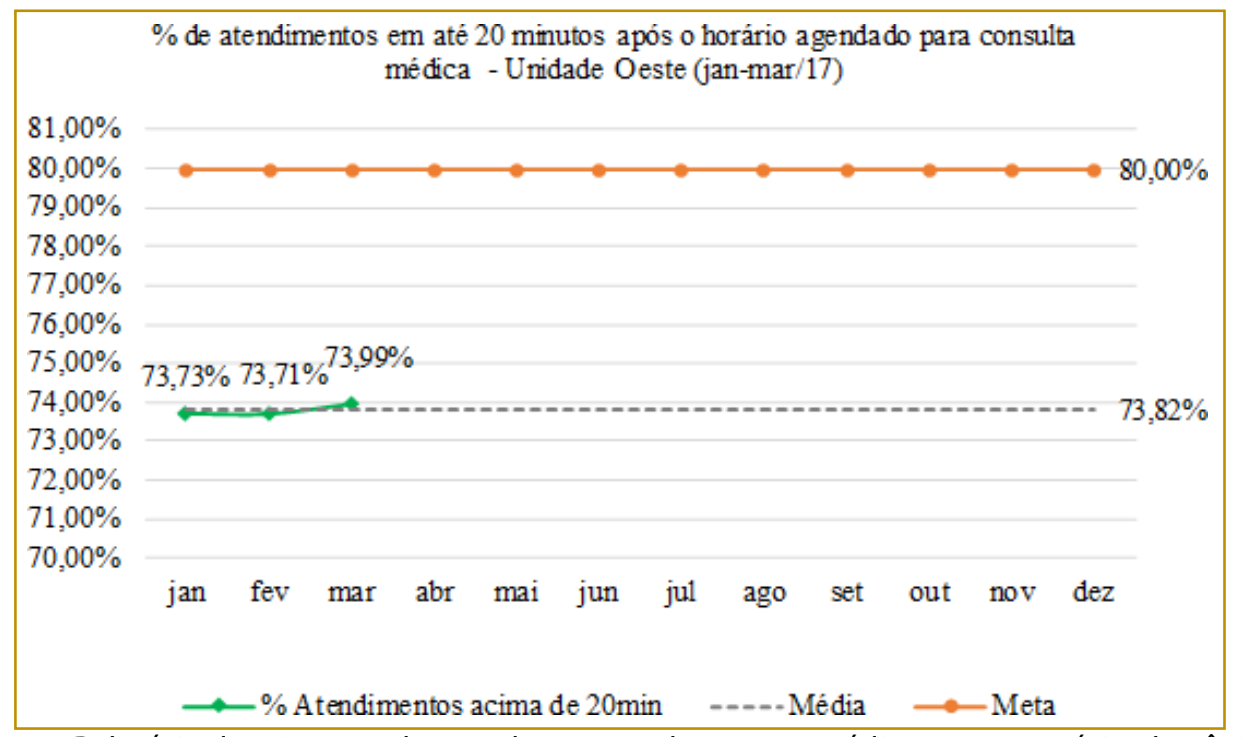

Fonte: Relatório dos sistemas de agendamento e de registro médico em prontuário eletrônico

Gráfico 2 - Percentual de Atendimentos em até 20 minutos após o horário agendado para consulta médica eletiva Unidade Norte. Período janeiro a março de 2017.

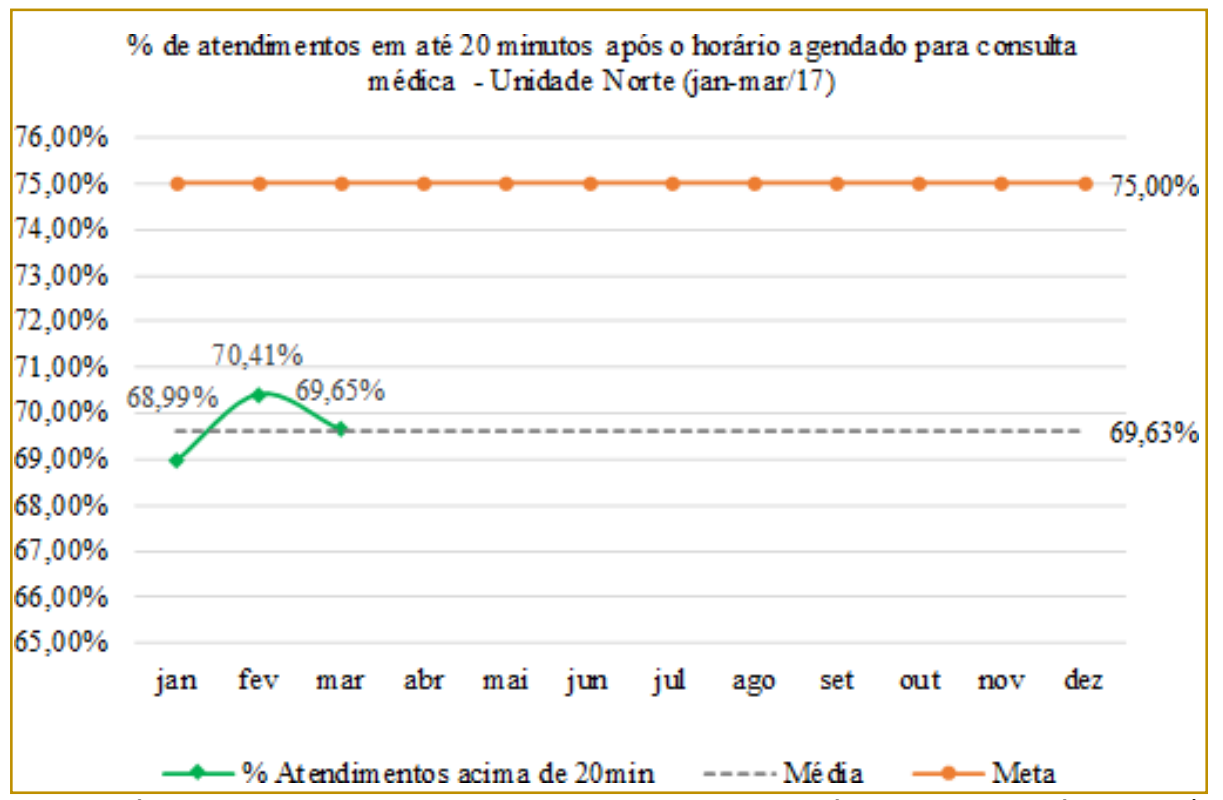

Fonte: Relatório dos sistemas de agendamento e de registro médico em prontuário eletrônico 


\subsection{FASE MEASURE (MEDIR)}

Nessa etapa a equipe do projeto deve planejar a estratificação do problema que envolve análises e validação de dados produzidos nos sistemas utilizados pela organização para medir o processo e o uso de ferramentas de qualidade e de controles estatísticos. No Measure faz-se necessário conhecer o estado atual do processo, verificar quais dados relativos ao processo estão disponíveis, analisar a confiabilidade dos bancos de dados e o comportamento histórico.
São algumas ferramentas utilizadas para medição do processo, mas não se limitam: Plano de coleta de dados, Estratificação, Folha de Verificação, Gráfico Sequencial, Diagrama de Pareto, Cartas de controle e Métricas Lean. Nesse projeto adotou-se a análise de Pareto para identificar quais eram as principais categorias geradoras do problema, com o objetivo de avaliar os focos de variação, conforme apresentado nos gráficos a seguir:

Gráfico 3 - Pareto Especialidades - Percentual de atendimentos acima de 20 minutos Unidade Oeste. Período janeiro a maio de 2017.

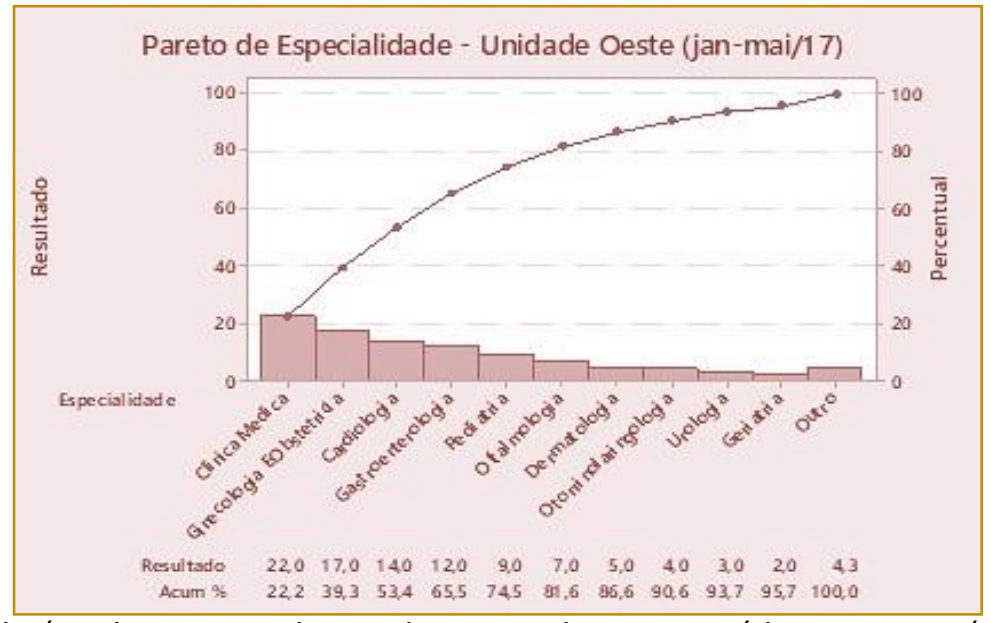

Fonte: Relatório dos sistemas de agendamento e de registro médico em prontuário eletrônico

Gráfico 4 - Pareto Especialidades - Percentual de atendimentos acima de 20 minutos. Unidade Norte. Período janeiro a maio de 2017.

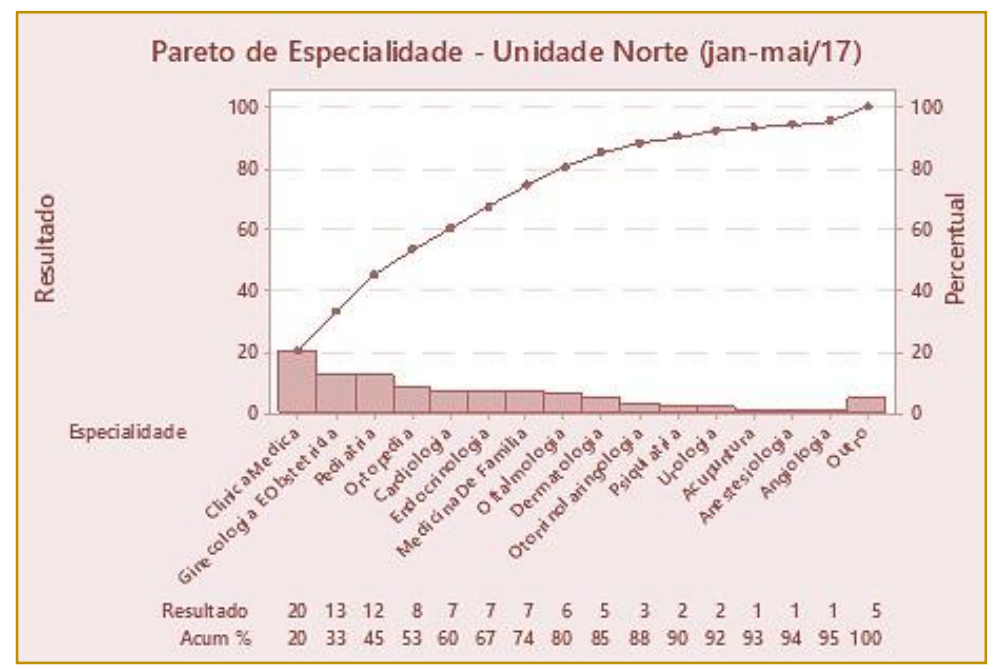

Fonte: Relatório dos sistemas de agendamento e de registro médico em prontuário eletrônico 
A análise de Pareto, dos dados, referente ao período de janeiro a maio de 2017, mostrou que: na Unidade Oeste as especialidades Clínica Médica, Ginecologia e Obstetrícia, Cardiologia, Pediatria, Gastroenterologia e Oftalmologia respondem por $80 \%$ dos atendimentos com atraso acima de 20 minutos. Na Unidade Norte as especialidades Clínica Médica, Ginecologia e Obstetrícia, Pediatria, Ortopedia, Medicina de Família, Cardiologia, Endocrinologia e Oftalmologia são responsáveis por $80 \%$ dos atendimentos acima de 20 minutos.

\subsection{FASE ANALYZE (ANALISAR)}

Essa fase tem como objetivo principal analisar as informações coletadas na etapa anterior, sendo que algumas das principais atividades desenvolvidas são: análise dos dados processo gerador do problema, identificação das causas do problema. As principais ferramentas e técnicas utilizadas nessa etapa são: mapa de processo, brainstorming, diagrama de causa e efeito matriz de priorização, tais instrumentos permitem detectar os fatores que mais afetam o processo.

O digrama de causa e efeito elaborado para o projeto foi construído a partir das reuniões de equipe do projeto onde puderam ser conhecidos os principais fatores relacionados ao problema, conforme apresentado a seguir:

Figura 2 - Diagrama de Causa e Efeito Atendimento médico iniciado acima de 20 minutos após o horário agendado para consulta médica

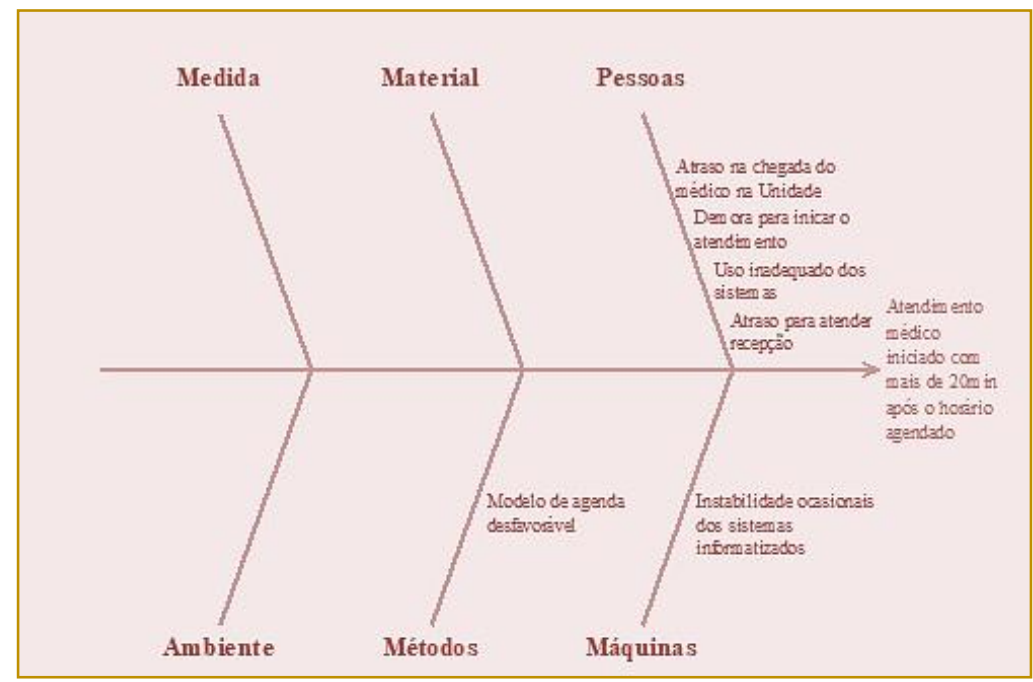

Ao fim dessa etapa foi elaborada a matriz de priorização e lista com as causas fundamentais do problema, essas análises serviram de base para as propostas de soluções que serão desenvolvidas na fase Improve.

\subsection{FASE IMPROVE (MELHORAR)}

No Improve o objetivo é propor, avaliar e executar as melhorias propostas para o problema, identificadas nas etapas anteriores. As principais ferramentas e técnicas utilizadas nessa etapa são: brainstorming, diagrama de causa e efeito matriz de priorização, matriz de risco e tabela 5W2H. As soluções propostas para o problema foram definidas após reuniões de brainstorming realizadas pela equipe do projeto. Na tabela abaixo são apresentadas as soluções propostas para cada causa principal. 
Tabela 2 - Causas Fundamentais

Causa Fundamental

Modelo de agenda desfavorável: consultas de retornos intercaladas entre os horários de consultas

Atraso para atender na recepção

Atraso na chegada do médico na Unidade

Demora do médico para iniciar o atendimento
Solução proposta

Revisar os cadastros de todas as agendas médicas das Unidades Oeste e Norte.

Propor aos médicos alteração no modelo de agenda com a criação de turnos em blocos, onde os horários de retornos são agrupados no fim do favorecendo a pontualidade entre as consultas.

Reorganizar a entrada de clientes sem agendamento prévio.

Direcionar clientes para agendamento de retorno e outros tipos de marcação para agendamento em postos de atendimento num setor de pós consulta

Realizar feedback com os médicos com registros de atrasos recorrentes

Realizar feedback com os médicos com registros de reclamações por motivo de demora para atender

Estabelecidas às soluções propostas foi elaborado um plano para execução de cada uma delas. Usou-se para criação do plano de ação a ferramenta $5 \mathrm{~W} 2 \mathrm{H}$ que descreve as atividades que deverão ser realizadas para implementação de cada ação proposta.

\subsection{FASE CONTROL (CONTROLAR)}

No Control, última fase do DMAIC, o objetivo é garantir que os resultados alcançados sejam monitorados e mantidos no longo prazo. Algumas das principais ferramentas e técnicas utilizadas nessa etapa são: Diagrama de Pareto, Procedimento Padrão, Poka-Yoke e OCAP. Avalia-se nessa etapa se a metas definidas para o projeto foram alcançadas e define-se quais instrumentos de controle serão adotados na manutenção dos resultados.

$\mathrm{Na}$ apuração dos resultados do projeto observou - se que as metas definidas foram alcançadas. Em dezembro de 2017, a Unidade Oeste apresentou $81,23 \%$ dos atendimentos realizados em até 20 minutos após o horário agendado para consulta médica. Em relação a janeiro de 2017 houve uma melhora de 7,5 pontos percentuais. Em dezembro de 2017, a Unidade Norte apresentou $75,66 \%$ dos atendimentos realizados em até 20 minutos após o horário agendado para consulta médica. Em relação a janeiro 2017 houve uma melhora de 6,67 pontos percentuais.

Gráfico 5 - Resultado do indicador: Percentual de Atendimentos em até 20 minutos após o horário agendado para consulta médica, posterior a implementação da fase Improve - Unidade Oeste.

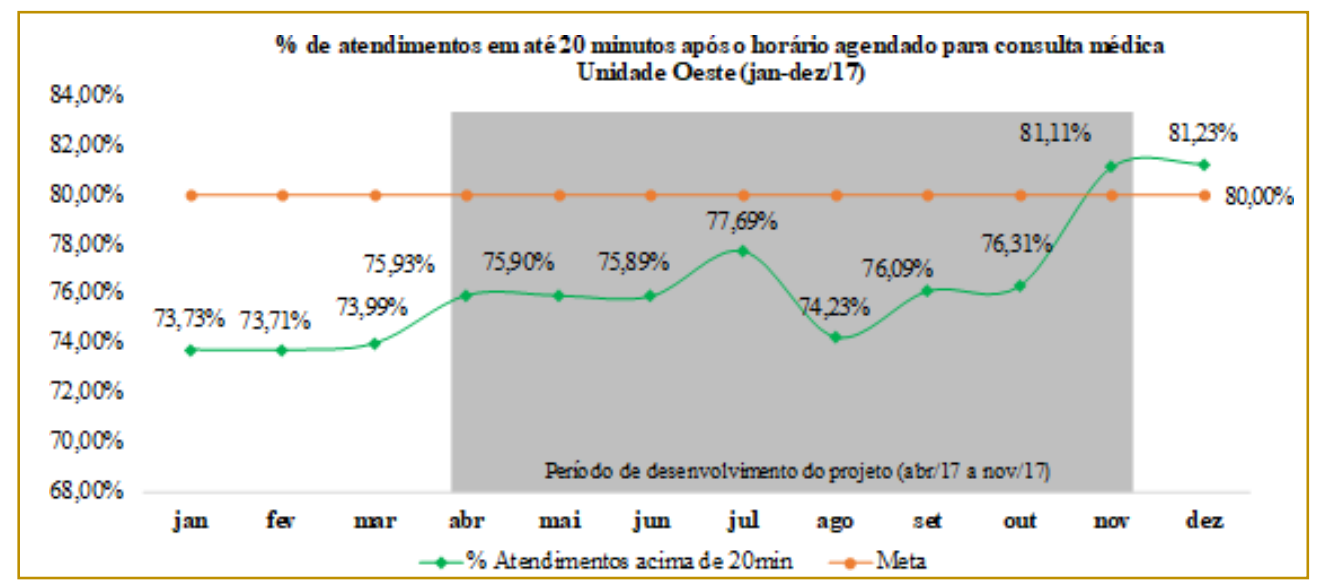

Fonte: Relatório dos sistemas de agendamento e de registro médico em prontuário eletrônico 
Gráfico 6 - Resultado do indicador: Percentual de Atendimentos em até 20 minutos após o horário agendado para consulta médica, posterior a implementação da fase Improve - Unidade Norte.

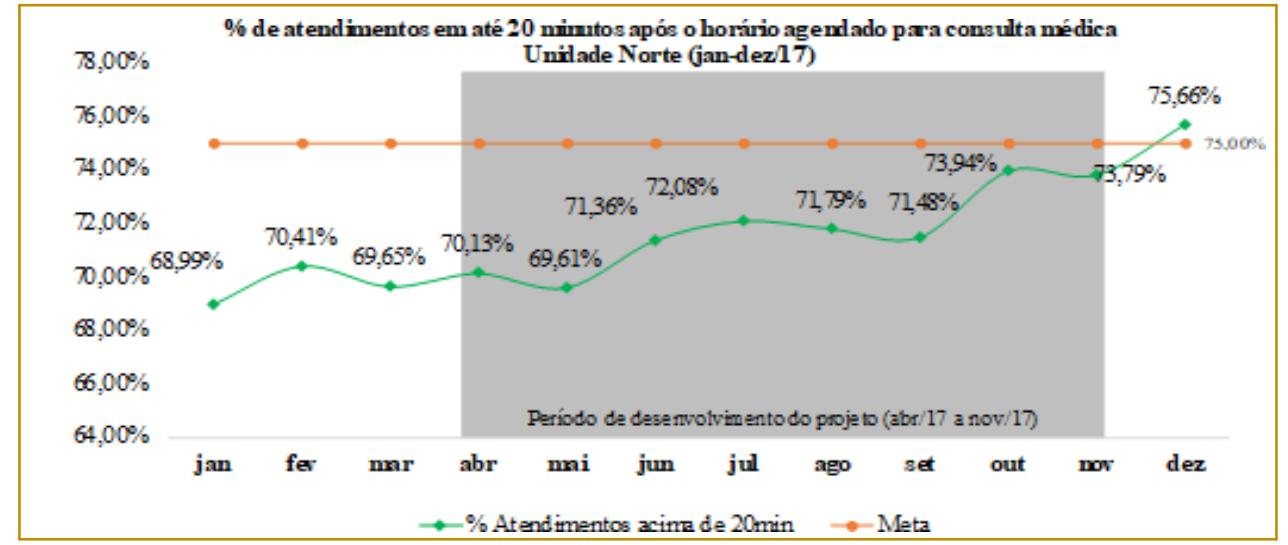

Fonte: Relatório dos sistemas de agendamento e de registro médico em prontuário eletrônico

Para monitoramento dos resultados obtidos nesse projeto foi adotada a ferramenta OCAP, acrônimo para as palavras - Out, Control, Action, Plan - que consiste num plano de ação para correção de desvios. O OCAP elaborado para o projeto é apresentado abaixo:

Figura 3 - OCAP - Aumentar o percentual de clientes atendidos em consultas médicas com até 20 minutos após o horário agendado para a consulta médica das Unidades Oeste e Norte.

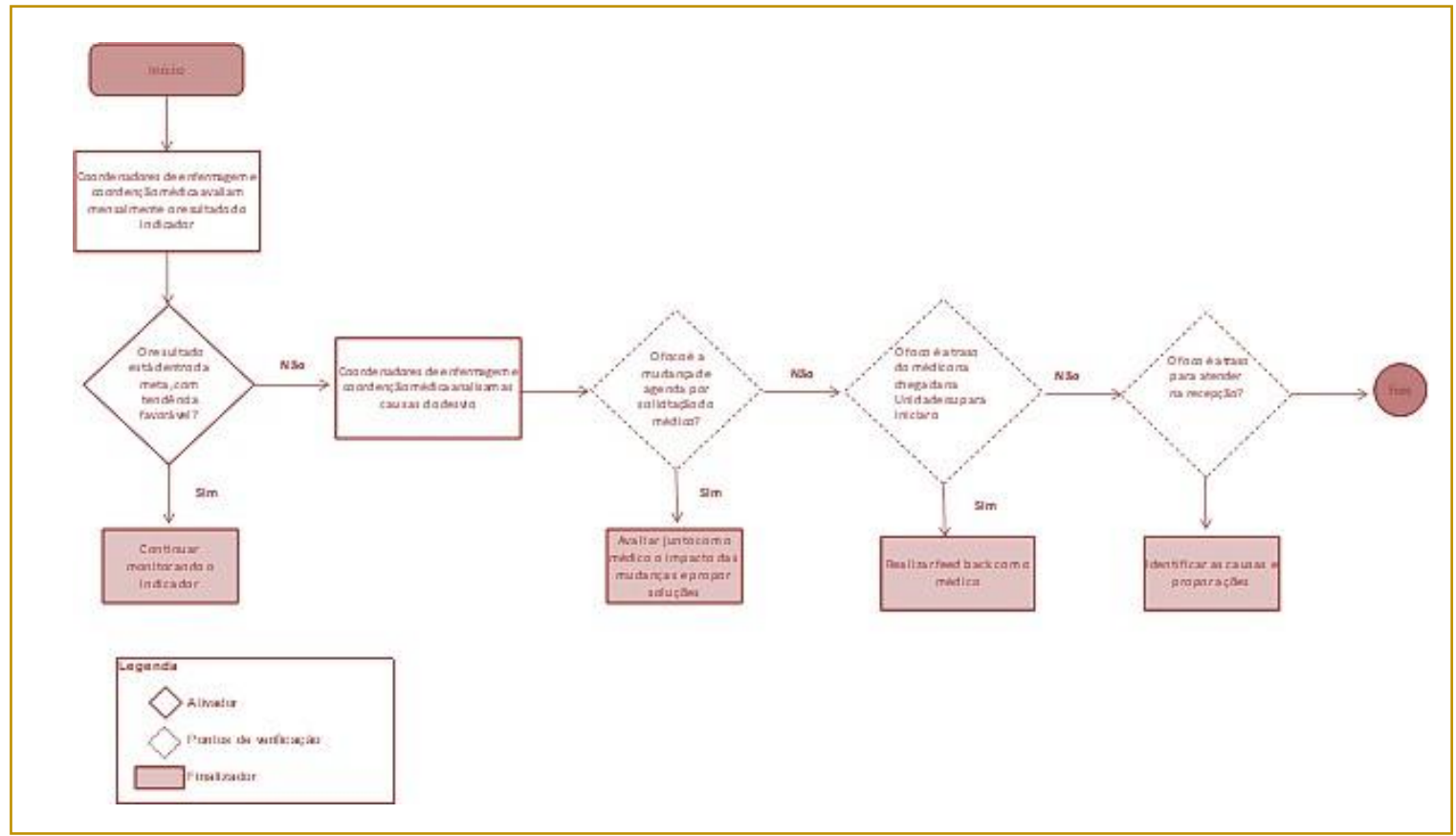

Fonte: Elaborado pelos autores 


\section{CONSIDERAÇÕES FINAIS}

Ao longo deste estudo apresentou-se a aplicabilidade da metodologia Lean Seis Sigma no contexto dos serviços de saúde. Demonstrou-se a importância das etapas da ferramenta DMAIC que direcionou o uso dos instrumentos mais adequados em cada fase. Em seguida, foram analisados os dados levantados no projeto para posteriormente apresentar 0 resultado conclusivo desse estudo.

Definido o problema, especificado o processo e identificado os fatores que o afetavam negativamente buscou-se através do método estuda-lo de maneira que pontos de melhoria pudessem ser identificados e trabalhados. Observou-se, ao longo do desenvolvimento desse trabalho a relevância da aplicação da metodologia Lean Seis Sigma no âmbito dos serviços de saúde na melhoria da qualidade e na satisfação dos clientes. Diante do exposto, considerando os objetivos propostos nesse

\section{REFERÊNCIAS}

[1] Aplicando Lean na Saúde. Disponível em https://www.lean.org.br/artigos/262/aplicando-leanna-saude.aspx. Acesso em 4 de maio de 2018

[2] Graban, Mark. Hospitais Lean [recurso eletrônico]: melhorando a qualidade, a segurança dos pacientes e o envolvimento dos funcionários. Porto Alegre: Bookam, 2013

[3] Luzes, Catarina S. A. Implementação da Filosofia Lean na Gestão dos Serviços de Saúde: 0 Caso Português Dissertação apresentada para a obtenção do grau de Mestre em Gestão das projeto, conclui-se que a aplicação da metodologia contribuiu significativamente para que as metas fossem atingidas.

Os resultados alcançados decorrentes das ações implementadas muito provavelmente trarão benefícios para médicos e clientes como: redução da insatisfação pela demora para atender, aumento da satisfação do corpo clínico com a organização das agendas médicas e melhoria no modelo de gerenciamento das agendas médicas. Esses resultados só foram possíveis com o envolvimento de toda a equipe do projeto.

Por fim, diante dos conceitos apresentados aqui espera-se que o estudo desenvolvido contribua para melhorar o entendimento da aplicação da metodologia Lean Seis Sigma revelando-se ser um tema oportuno para novos estudos dada sua importância para as organizações, independentemente de seu tamanho ou segmento de negócio.

Organizações, Instituto Politécnico do Porto, Portugal, 2013.

[4] Principles of Lean. Disponível em: https: / / www.lean.org/WhatsLean/Principles.cfm. Acesso em 4 de maio de 2018

[5] Werkema, Cristina. Criando a Cultura Lean Seis Sigma [recurso eletrônico]. Rio de Janeiro: Elsevier, 2012

[6] Womack, J. E Jones, D., Daniel, T., Lean Thinking: Banish Waste and Create Wealth in Your Corporation., NewYork: Free Pass, 2003 


\section{Capítulo 9}

\section{SIMILARIDADES LEAN SEIS SIGMA: UMA ABORDAGEM A PARTIR DA ANÁLISE DE CONTEÚDO}

\section{Christian Pacheco de Moraes \\ Elisa Henning \\ Olga Maria Formigoni Carvalho Walter \\ Claudio Decker Junior \\ Edson Pacheco Paladini}

Resumo: 0 presente artigo trata de um estudo exploratório, que tem como objetivo analisar artigos nacionais sobre estudos de casos de implementação da metodologia Lean Seis Sigma (LSS), buscando similaridades entre eles. A busca dos artigos foi realizada nas fontes de dados Portal Periódicos CAPES e em periódicos específicos. A pesquisa resultou em doze artigos, dos quais seis deles abordam estudos de casos. A análise foi realizada com o auxílio do software Nvivo, que possibilitou uma comparação entre os artigos por meio da análise de conteúdo de palavras e análise de clusters. Conclui-se que a implantação das metodologias Lean e Seis Sigma de forma integrada pode trazer resultados superiores à soma dos ganhos que podem ser alcançados com as duas metodologias implantadas de maneira isoladas. Do mesmo modo os fatores cultura organizacional, apoio da liderança e o treinamento dos profissionais são essenciais na implantação das metodologias Lean Production e Seis Sigma de forma integrada.

Palavras-chave: Lean Seis Sigma, análise de conteúdo, similaridades, Fatores Críticos de Sucesso. 


\section{INTRODUÇÃO}

Considerando o crescente interesse sobre o Lean Seis Sigma (LSS) na última década, tanto no meio empresarial quanto no acadêmico (Rebelato; Rodrigues; Rodrigues, 2009), o presente trabalho tem por objetivo analisar artigos de eventos e periódicos nacionais com estudos de casos de implementação da metodologia LSS, buscando similaridades entre eles, a partir da análise de conteúdo. Tanto Endler et al. (2016) quanto Sreedharam e Raju (2016) analisaram base de dados internacionais, deixando uma lacuna no que se refere ao cenário de publicações brasileiras.

Segundo Fernandes e Marins (2012), O Lean busca a eliminação de desperdício em todas as áreas da empresa, incluindo as relações com os clientes, desenvolvimento de produtos, rede de fornecedores e gestão da fábrica. Já o Seis Sigma é uma estratégia de negócio usada para reduzir a variabilidade do processo através da efetiva utilização de técnicas estatísticas. Estes dois programas de melhorias juntos são uma poderosa ferramenta para alavancar os resultados da empresa.

Tagge et al. (2017) conseguiram resultados significativos através do LSS em salas de cirurgia de um Hospital Infantil. Aumento de 712 pacientes atendidos em seis meses e o intervalo entre a saída de um paciente e a chegada de outro caiu de 41 para 32 minutos.

O Lean e o Seis Sigma têm sido altamente explorados individualmente pelas comunidades acadêmicas nas últimas décadas. Endler et al. (2016) e Sreedharam e Raju (2016) citam que a metodologia LSS pode ser considerada recente, tendo como referência os últimos 15 anos.

Para atender o objetivo desta pesquisa, a procura por similaridades entre os artigos pesquisados foi em relação aos temas abordados, aos tipos de empresa, às variáveis que influenciam no sucesso, ou insucesso, na implantação da metodologia estudada, entre outros. Além da realização da análise de frequência das palavras foi feita a análise de similaridade por meio de clusters.

Este artigo está estruturado da seguinte maneira: na próxima seção é apresentado o embasamento teórico sobre LSS. Em seguida são abordados os aspectos metodológicos utilizados, na sequência é apresentada a análise e discussão dos resultados, e por fim, as considerações finais.

\section{LEAN SEIS SIGMA}

O LSS é um método de gestão da qualidade que vêm ganhando popularidade significativa desde que foi proposto (CHUGANI et al., 2017). O Lean concentra-se principalmente na redução de desperdícios (Drohomeretski et al., 2014) e na identificação de atividades que não agregam valor a um determinado produto. O Seis Sigma se concentra nas características críticas de qualidade dos produtos que são importantes para os clientes, eliminando erros, defeitos ou falhas que podem afetar os processos (GARZAREYES et al., 2014).

Segundo Dias (2011) o LSS é uma iniciativa de gestão da qualidade de âmbito organizacional focada em atingir resultados concretos e tangíveis, melhorar a qualidade do processo, torna-los mais eficientes e criar valor acrescentado. Para Mani e Pádua (2008) o LSS é um método evolutivo de conceitos da Produção Enxuta e da Qualidade Total e suas aplicações são feitas por meio de análises e controles estatísticos de processos, com o objetivo de melhoria da qualidade e aumento da competitividade. 0 método propõe analisar e prever as variabilidades, melhorar a qualidade dos produtos e serviços, aumentar a velocidade dos processos, buscar a satisfação dos consumidores e com isso alavancar os negócios.

Pepper e Spedding (2010) afirmam que o LSS é ideal para ser usado como uma metodologia abrangente, incorporando elementos-chave tanto do Lean como do Seis Sigma, pois cada abordagem pode ganhar com as ferramentas e técnicas de cada uma das metodologias.

As metodologias Lean Production e Seis Sigma estão cada vez mais sendo executadas de maneira integrada, sendo que as empresas passaram a entender que sua integração possibilita usufruir dos pontos fortes das duas estratégias (GUTIERREZ, 2010).

Chen, Li e Shady (2010) identificaram que o LSS eliminou tempo de trabalho, melhorou a produtividade, aumentou a flexibilidade do sistema e consequentemente reduziu os níveis de estoque em processo. Shah, Shandrasekaran e Linderman (2008) entrevistaram 2215 empresas que 
combinaram a implementação de ferramentas Lean com projetos Seis Sigma, identificando que certas práticas Lean têm maior influência nos projetos Seis Sigma, impactando no resultado alcançado na implementação. Os autores atestam a complementariedade das estratégias. A Figura 1 ilustra os resultados alcançados pelas metodologias.

Figura 1 - Resultados alcançados pela metodologia LSS

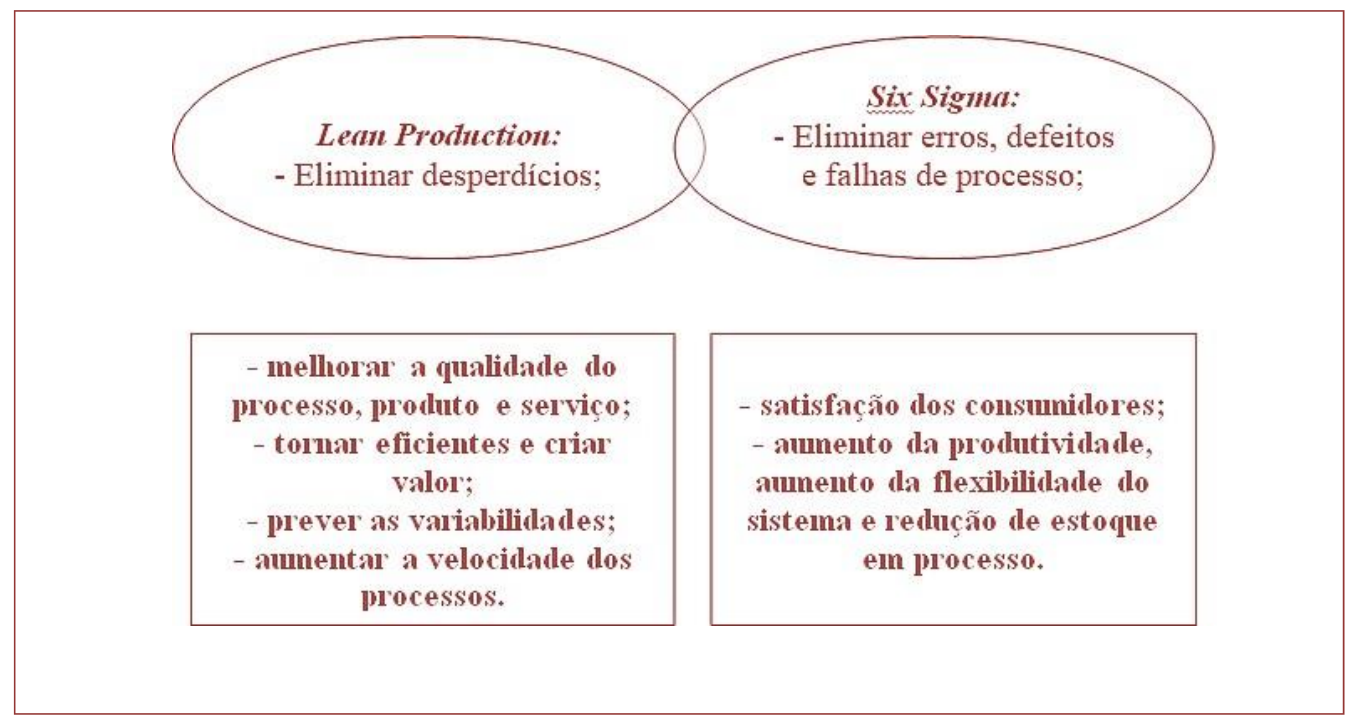

Fonte: Os Autores (2017

De modo geral o Lean Production foca no processo e o Six Sigma tem foco no produto. Apesar de focos diferenciados entre o Lean e o Seis Sigma, verifica-se uma complementaridade da natureza das metodologias, o que as torna suscetíveis de serem aplicadas de forma integrada.

\section{METODOLOGIA}

As fontes de dados utilizadas nesta pesquisa foram o Portal Periódicos da Coordenação de Aperfeiçoamento de Pessoal de Nível Superior (CAPES) e o periódico Produção Online buscando demonstrar a situação nacional do LSS.

A partir desta busca foram encontrados 12 artigos sobre o tema proposto, entre 2008 e 2016, que foram tratados seguindo o fluxograma da Figura 2. As strings de busca utilizadas foram "Lean Seis Sigma" e "Lean Six Sigma".

A metodologia escolhida para análise dos textos foi a "análise de conteúdo". A análise de conteúdo é utilizada para aperfeiçoar a interpretação e compreensão do conteúdo de um ou vários documentos que se encontram no estado bruto e precisam ser processados para gerar informações. De acordo com Moraes (1999), essa análise ajuda a reinterpretar as mensagens e a atingir uma compreensão de seus significados num nível que vai além de uma leitura comum.

Segundo Bardin (2011) a análise de conteúdo é um "conjunto de técnicas de análise das comunicações" por procedimentos sistemáticos, que tem por finalidade a interpretação dessas mesmas comunicações, que podem ser qualquer material verbal ou não verbal. Conforme / metodologia adotada na Figura 2, a partir da leitura dos resumos e da metodologia dos artigos, foi possível classificá-los de acordo com o método de pesquisa. A classificação resultou em um número maior de artigos do tipo estudo de caso, que foram selecionados e analisados integralmente. Realizou-se uma leitura completa, para verificar as principais características de cada artigo, as variáveis e aspectos mais importantes na implantação do LSS e encontrar similaridades e características entre os trabalhos científicos. 
Figura 2 - Metodologia para coleta dos artigos

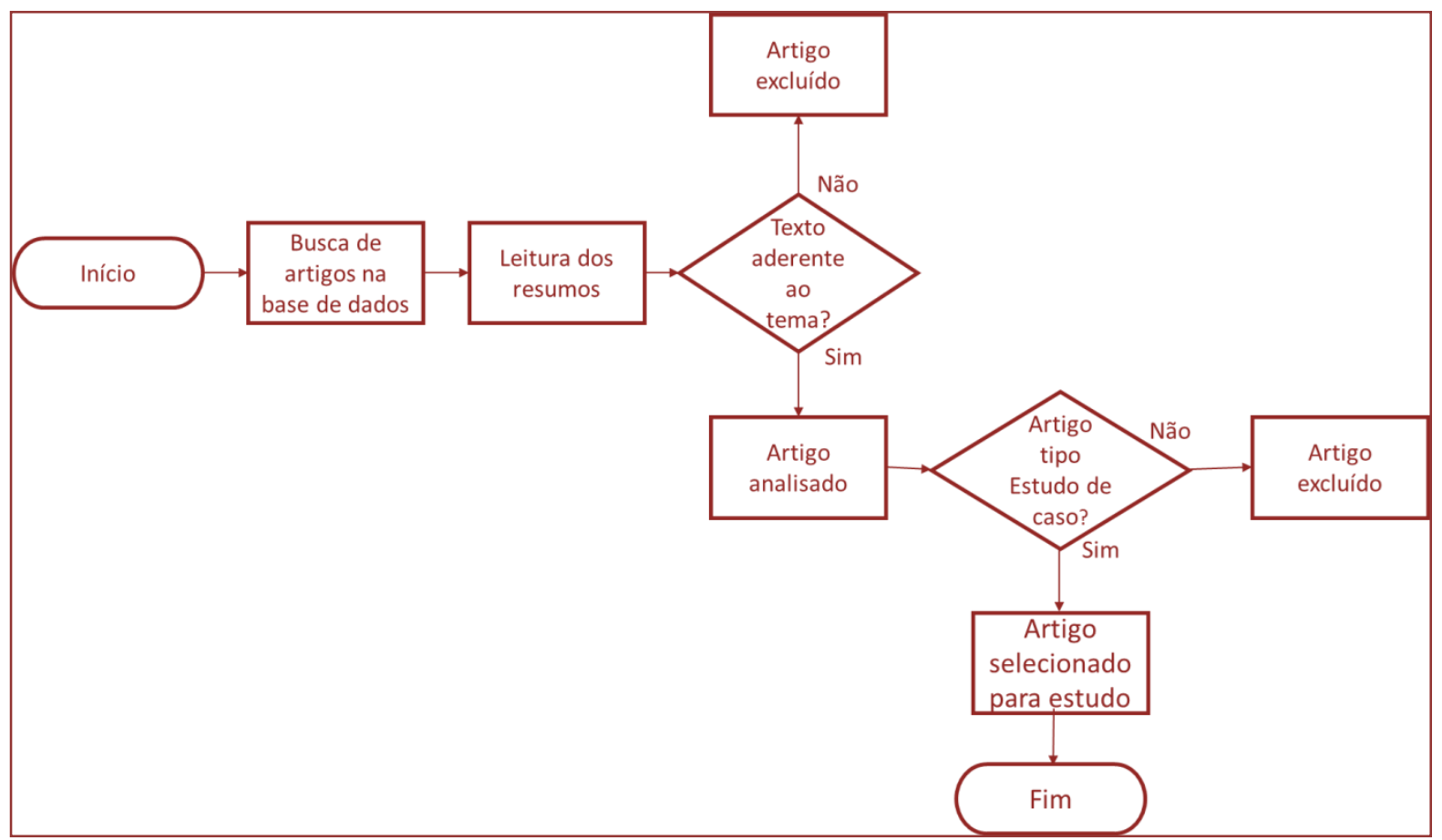

Fonte: Os autores (2017)

Para auxiliar na verificação de similaridades e encontrar os termos mais importantes e comuns entre os artigos, utilizou-se o software Nvivo.

Uma nuvem de palavras é uma visualização especial do texto em que as palavras mais usadas são efetivamente destacadas por ocuparem mais destaque na representação geral do texto (MCNAUGHT; LAM, 2010). A nuvem de palavras permite encontrar quais as palavras com maior frequência nos artigos, indicando os aspectos e temas mais importantes. A análise de cluster, ou análise de aglomerados, é uma técnica para agrupar dados de acordo com as similaridades entre eles.

Após a análise de clusters realizou-se uma investigação para encontrar os motivos da aproximação entre os artigos realizada pelo software. A procura por similaridades foi realizada para encontrar exemplos de aplicação de sucesso nas empresas. As similaridades foram em relação aos temas abordados, aos tipos de empresa, às variáveis que influenciam no sucesso, ou insucesso e na implantação da metodologia estudada.

\section{VISÃO GERAL DAS PUBLICAÇÕES LEAN SEIS SIGMA}

Dois artigos, cujos autores efetuaram estudos teóricos sobre LSS, auxiliam na compreensão do tema.

Endler et al. (2016) procuraram identificar tendências de crescimento nos estudos sobre o LSS. Observou-se que estudos nessa área aumentaram a partir de 2008. A distribuição de publicações possui uma grande dispersão, onde nenhum dos autores têm uma quantidade de publicações que se destaca. No estudo de Endler et al. (2016), foi observado apenas um artigo nacional.

Rebelato, Rodrigues e Rodrigues (2009) fizeram um estudo sobre as lacunas entre o Lean e o Seis Sigma, revelando que existem diferenças principalmente em questões relacionadas à meritocracia. 0 Seis Sigma dá valor ao talento e meritocracia, enquanto que o Lean dá maior importância à dedicação e esforço.

Nenhum dos trabalhos fez uso da técnica proposta neste trabalho, análise de conteúdo por meio da busca de similaridades no texto. 


\section{DISCUSSÃO E ANÁLISE DOS RESULTADOS}

O Quadro 1 mostra todos os artigos selecionados após a leitura dos resumos e identificação das metodologias. 0 artigo de
Santos e Martins (2010) foi descartado da análise por se tratar de um estudo de caso apenas de Seis Sigma.

Quadro 1 - Tipologia dos artigos

\begin{tabular}{|l|l|}
\hline Referência & Tipo de Estudo \\
\hline Revisão de Literatura & Godinho e Fernandes (2004) e Endler et al. (2016) \\
\hline Teórico-Conceitual & Lima, Garbuio e Costa (2009), Rebelato, Rodrigues e Rodrigues (2009) \\
\hline Estudo de caso & $\begin{array}{l}\text { Mani e Pádua (2008), Santos e Martins (2010), Silva et al. (2011), Fernandes e } \\
\text { Marins (2012), Hors et al.(2012), Pinheiro, Scheller e Miguel (2013) e Scheller e } \\
\text { Miguel (2014) }\end{array}$ \\
\hline Pesquisa Exploratória & \begin{tabular}{l} 
Pacheco (2014) \\
\hline
\end{tabular}
\end{tabular}

Fonte: Os autores (2017)

Os artigos de estudo de caso selecionados foram sintetizados para encontrar semelhança entre eles, e são apresentados em ordem cronológica no Quadro 2. A seleção desta amostra de artigos está diretamente relacionada ao objetivo de, através das similaridades, apresentar casos de sucesso da implantação do LSS.

Quadro 2 - Síntese dos artigos analisados

\begin{tabular}{|c|c|c|}
\hline Autor & Objetivo do Artigo & Variáveis Explanatórias \\
\hline $\begin{array}{lll}\text { Mani } \\
(2008) & \text { e } & \text { Pádua } \\
\end{array}$ & $\begin{array}{l}\text { Demonstrar a importância da junção dos } \\
\text { métodos Lean e Seis Sigma para reduzir } \\
\text { desperdícios e custos }\end{array}$ & $\begin{array}{l}\text { Integração entre os setores; Apoio da alta } \\
\text { direção; Controle dos processos; Uso das } \\
\text { ferramentas metodológicas. }\end{array}$ \\
\hline Silva et al. (2011) & $\begin{array}{l}\text { Apresentar uma iniciativa de integrar a } \\
\text { promoção das metodologias Lean } \\
\text { Production e Seis Sigma na busca de } \\
\text { um melhor desempenho operacional }\end{array}$ & $\begin{array}{l}\text { Estrutura organizacional; Seleção de } \\
\text { projetos de melhoria; Ambiente entre os } \\
\text { funcionários envolvidos; Área de atuação da } \\
\text { empresa. }\end{array}$ \\
\hline Hors et al. (2012) & $\begin{array}{l}\text { Implementar um programa de gestão da } \\
\text { pesquisa científica em um hospital geral } \\
\text { aplicando as ferramentas de gestão } \\
\text { empresarial, Lean Seis Sigma e PMBOK }\end{array}$ & $\begin{array}{l}\text { Envolvimento dos profissionais de diferentes } \\
\text { áreas; Indicadores de processos; Cultura } \\
\text { Organizacional; Estratégia da empresa. }\end{array}$ \\
\hline $\begin{array}{l}\text { Fernandes } \\
\text { Marins (2012) }\end{array}$ & $\begin{array}{l}\text { Demonstrar a aplicabilidade do Lean } \\
\text { Seis Sigma em um problema logístico } \\
\text { real de transporte de produtos entre as } \\
\text { unidades de uma indústria metalúrgica }\end{array}$ & $\begin{array}{l}\text { Escolha das ferramentas a utilizar; } \\
\text { Capacitação das equipes; Estruturação da } \\
\text { resolução de problemas. }\end{array}$ \\
\hline $\begin{array}{l}\text { Pinheiro,Scheller, e } \\
\text { Miguel (2013) }\end{array}$ & $\begin{array}{l}\text { Demonstrar os resultados de um } \\
\text { trabalho de campo, cujo propósito foi } \\
\text { identificar os fatores importantes para } \\
\text { implementação do Seis Sigma } \\
\text { combinado com os princípios do Lean } \\
\text { Production }\end{array}$ & $\begin{array}{l}\text { Setor econômico; Faturamento; Número de } \\
\text { funcionários; Origem da empresa; Apoio da } \\
\text { alta direção; Capacitação de funcionários; } \\
\text { Recursos financeiros; Cultura dos } \\
\text { funcionários. }\end{array}$ \\
\hline $\begin{array}{l}\text { Scheller e Miguel } \\
\text { (2014) }\end{array}$ & $\begin{array}{l}\text { Identificar e analisar as características } \\
\text { relevantes na adoção e integração da } \\
\text { metodologia Lean Seis Sigma. }\end{array}$ & $\begin{array}{l}\text { Capacitação dos profissionais Seis Sigma; } \\
\text { Método padrão de resolução de problemas; } \\
\text { Acompanhamento dos projeto; Apoio e } \\
\text { comprometimento da liderança; Aspectos } \\
\text { culturais. }\end{array}$ \\
\hline
\end{tabular}

Fonte: Os autores (2017) 
A partir da análise verifica-se que três dos seis artigos tem como objetivo apresentar a implantação do LSS como um estudo de caso. Dois artigos buscaram identificar fatores ou características mais importantes na integração do Lean com o Seis Sigma. Um deles demonstrou a importância da junção das duas metodologias para a redução de desperdícios e custos.

\subsection{FATORES QUEM INFLUENCIAM NA IMPLANTAÇÃO LSS}

É possível identificar os fatores que mais apareceram como variáveis influentes na aplicação do LSS: capacitação dos funcionários envolvidos na implantação; a cultura organizacional das empresas; apoio e comprometimento da alta direção e liderança.

A capacitação dos funcionários está mais relacionada com o Seis Sigma, principalmente no treinamento dos Green Belts e Black Belts no início da aplicação dos programas. Segundo Fernandes e Marins (2012), a capacitação das equipes para a condução dos projetos foi um dos principais fatores que trouxeram benefícios para a empresa estudada. Para os autores na implantação dos programas Seis Sigma e Lean Production é necessário primeiramente formar uma infraestrutura que deve ter, como um dos principais componentes, profissionais qualificados e treinados para a condução dos projetos.

Pinheiro, Scheller e Miguel (2013) afirmam que a principal dificuldade encontrada na introdução do Lean está relacionada com a cultura dos funcionários, pois além de conhecer as ferramentas e suas aplicações, os funcionários devem primeiramente entender a filosofia, compreendê-la e considerá-la parte de sua cultura. 0 apoio dos líderes da empresa foi um fator essencial para obter resultados eficazes com 0 programa.

\subsection{NUVEM DE PALAVRAS}

Foram selecionados os 30 termos mais frequentes com no mínimo três letras, sendo que preposições, artigos, advérbios, e outras palavras que foram consideradas irrelevantes ao tema foram excluídas da análise. A Figura 3 apresenta a nuvem de palavras gerada.

Figura 3 - Nuvem de palavras

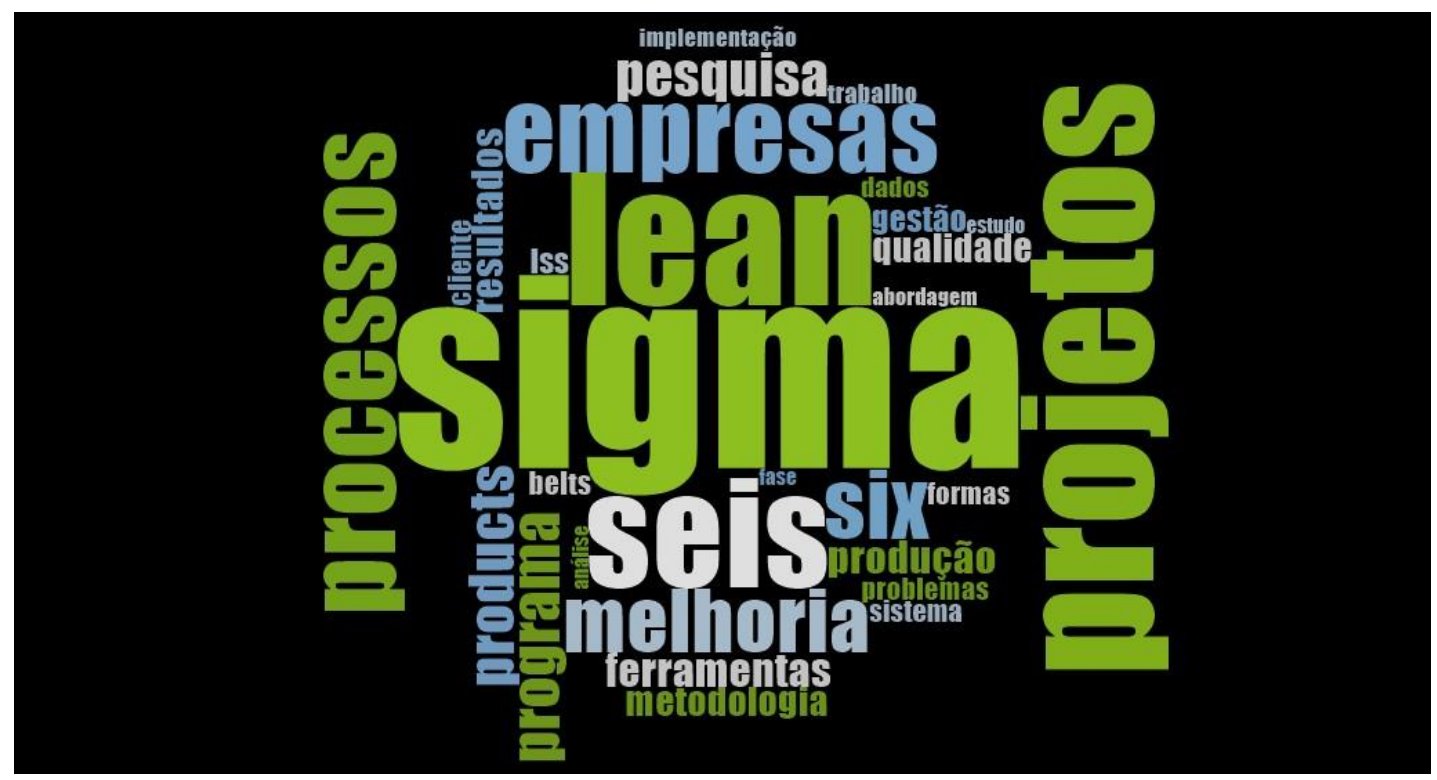

Fonte: Os autores (2017)

Além das palavras Lean, Seis/Six e Sigma, que são o tema da pesquisa, as mais frequentes em ordem decrescente são: "projetos”, “processos”, “empresas”, "melhoria” e "programa”. As palavras “projetos", “dados", “ferramentas" e "metodologia" estão relacionadas diretamente com os programas de implantação do LSS, pois todo projeto de melhoria necessita de 
dados, ferramentas e uma metodologia de aplicação.

A palavra "projeto" é a que aparece com a maior frequência, depois de Lean, Seis/Six e Sigma. A implementação do LSS vêm a partir da filosofia do Lean e do Seis Sigma, mas acontece por meio de projetos, com inicio, meio e fim definidos, duração e recursos limitados, em uma sequencia de atividades. 0 desenvolvimento dos projetos foi realizado por meio do DMAIC na maioria dos artigos analisados.

A palavra "processo" também aparece entre as mais citadas porque os processos produtivos são onde ocorre a aplicação da maioria dos projetos apresentados, tendo grande ligação com as palavras "melhoria", "desperdício", "variabilidade" e "medição", sendo que as duas primeiras estão mais relacionadas com o Lean, e as outras duas com o Seis Sigma.

Os termos "melhoria", "resultados" e "qualidade" também estão relacionados entre si por se tratarem de objetivos almejados nos estudos de caso.

As citações da palavra "ferramentas" aparecem várias vezes apenas como uma generalização ou como uma ferramenta específica de uma das metodologias do tema em estudo. As ferramentas mais citadas do Lean são: Kaizen, Mapeamento de Fluxo de Valor e 5S. Dentro do Seis Sigma, as mais frequentes são: DMAIC, Diagrama de Ishikawa, Controle Estatístico do Processo (CEP), FMEA, entre outras ferramentas estatísticas.

Ao se comparar a nuvem de palavras gerada com a apresentada no artigo de Endler et al. (2016) verifica-se a concordância em várias expressões. Além das palavras Lean e Six
Sigma, termos da pesquisa, vale destacar: "processo", "gestão" e "qualidade".

\subsection{RESULTADO DE INSUCESSO NA IMPLANTAÇÃO LSS}

o único caso onde não houve sucesso na integração do Lean com o Seis Sigma foi na empresa que não utilizou a ferramenta DMAIC (PINHEIRO; SCHELLER; MIGUEL, 2013).

Os colaboradores destacaram que 0 programa Seis Sigma teve um grande apoio da alta direção no início, porém, com o passar do tempo e o surgimento de problemas inesperados, tal apoio foi perdendo força. Este resultado está de acordo com Pamfilie, Petcu e Draghici (2012) que apontam que apoio e liderança são essenciais para o sucesso do LSS.

Outro fator importante que influenciou no insucesso do programa foi o fato de que os colaboradores não viam proveito nas ferramentas sofisticadas do Seis Sigma e não sabiam ao certo utilizá-las. A empresa também tentou implantar o Lean Production, mas os mesmos problemas voltaram a ocorrer. Dessa forma, nenhuma das metodologias se estendeu, e não houve oportunidade de integração entre elas.

\subsection{ANÁLISE DE CLUSTERS}

Após a análise de frequência de palavras, realizou-se uma análise de clusters. Para simplificar o estudo e por um número pequeno de artigos a serem relacionados, foi pré-estabelecida a formação de dois clusters conforme a Figura 4. 
Figura 4 - Clusters de proximidade dos artigos

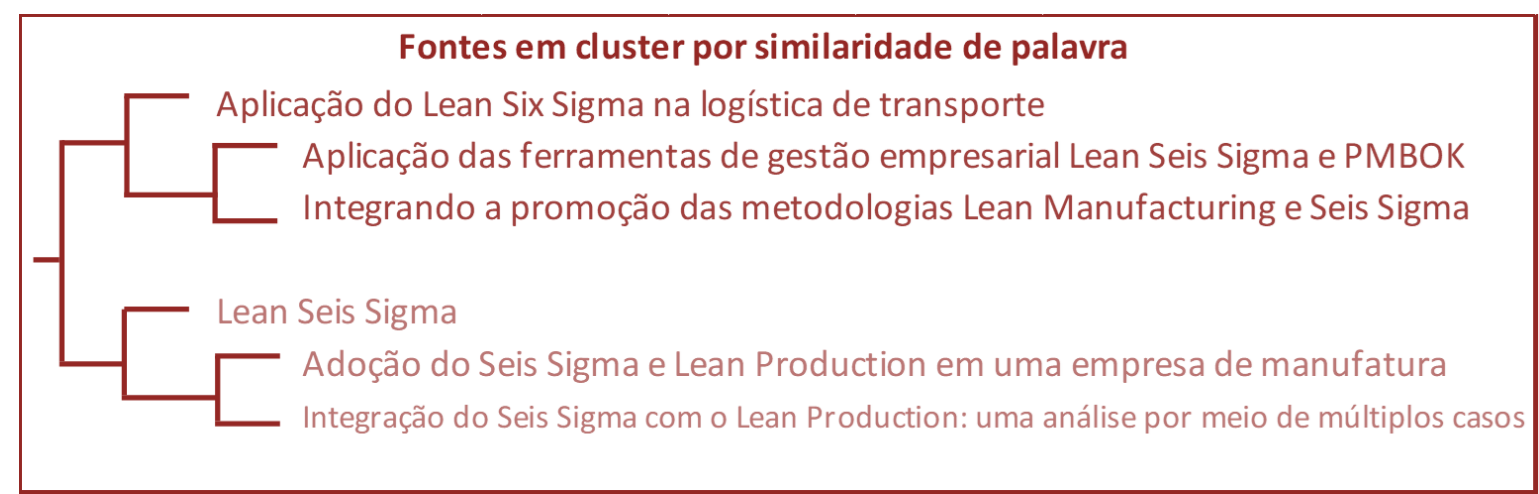

Fonte: Os autores (2017)

Separando os artigos em dois grupos de clusters, verificou-se um maior grau de correlação entre os artigos "Aplicação das ferramentas de gestão empresarial Lean Seis Sigma e PMBOK no desenvolvimento de um programa de gestão da pesquisa científica" e "Integrando a promoção das metodologias Lean Manufacturing e Six Sigma na busca de produtividade e qualidade numa empresa fabricante de autopeças", e entre "Adoção do Seis Sigma e Lean Production em uma empresa de manufatura" e "Integração do Seis Sigma com o Lean Production: uma análise por meio de múltiplos casos". Os dois primeiros também estão relacionados, mas com um grau menor, com o artigo "Aplicação do Lean Seis Sigma na logística de transporte", enquanto que os outros dois se relacionam com o artigo "Lean Seis Sigma".

No primeiro grupo, tanto a empresa de logística (Fernandes; Marins, 2012) quanto a fabricante de autopeças (SILVA et al. 2011) tem como objetivo na implantação LSS a redução de custos, que em ambos os casos a redução do lead time foi um dos fatores que levaram ao sucesso do projeto.

Outra semelhança dentro do primeiro cluster é que os artigos "Aplicação das ferramentas de gestão empresarial Lean Seis Sigma e PMBOK no desenvolvimento de um programa de gestão da pesquisa científica" e "Aplicação do Lean Seis Sigma na logística de transporte" apresentam o estudo de caso por meio da metodologia DMAIC, discorrendo cada fase desta ferramenta.

Já no segundo grupo, a maior correlação está entre dois artigos que possuem os mesmos autores e que tem objetivos muito parecidos. Os dois trabalhos científicos também citam que a capacitação dos funcionários e o apoio da liderança são fatores críticos para o sucesso do LSS. A Figura 5 ilustra os fatores similares encontrados nos artigos que obtiveram sucesso na implantação do LSS.

Figura 5 - Fatores comuns aos artigos que obtiveram sucesso na implementação do LSS

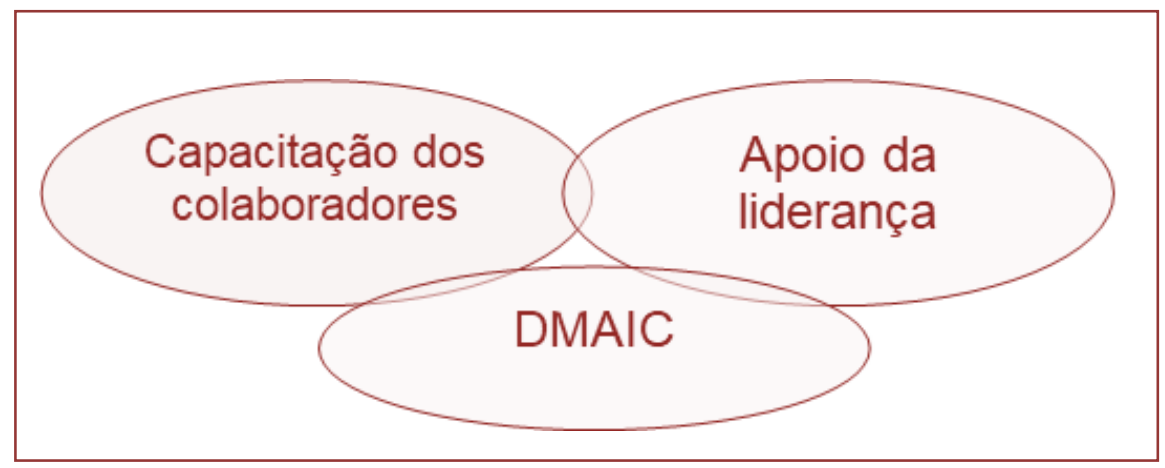

Fonte: Os autores (2017) 


\section{CONSIDERAÇÕES FINAIS}

Este artigo teve por finalidade fazer uma análise de artigos científicos, do tipo estudo de caso, que abordam a implantação da metodologia LSS, na tentativa de encontrar similaridades entre os trabalhos e identificar fatores críticos para o sucesso da metodologia. Os termos "metodologia", "projetos", "processos" e "ferramentas" ficaram entre os mais frequentes nos artigos, enquanto que as palavras "filosofia" e "cultura", não entraram na lista, fato que explica os casos de não integração, já que foram utilizados os programas como ferramentas pontuais apenas para certos projetos. Também fica o questionamento se as empresas que integraram as metodologias realmente as têm como filosofias de gestão, e não só como uma metodologia usada para projetos de melhoria.

Tais resultados revelaram características semelhantes entre os artigos analisados quanto às variáveis influentes no sucesso do LSS, sendo que a capacitação dos

\section{REFERÊNCIAS}

[1] BARDIN, L. Análise de conteúdo. São Paulo: Edições 70, 2011.

[2] CHEN, J. C.; LI, Y.; SHADY, B. D. From Value Stream Mapping Toward a Lean/Sigma Continuous Improvement Process: An Industrial Case Study. International Journal of Production Research, v. 48, n. 4, p. 1069-1086, 2010.

[3] CHUGANI, N.; KUMAR, V.; GARZAREYES. J.A.; ROCHA-LONA, L.; UPADHYAY, A. Investigating the green impact of Lean, Six Sigma and Lean Six Sigma A systematic literature review. International Journal of Lean Six Sigma, v. 8, n. 1, p. 7-32, 2017.

[4] DIAS, S. M. Implementação da metodologia Lean Seis-Sigma - O caso do Serviço de Oftalmologia dos Hospitais da Universidade de Coimbra. 2011. 63 f. Dissertação (Mestrado em Engenharia Biomédica), Universidade de Coimbra, Coimbra, Portugal, 2011.

[5] DROHOMERETSKI, E.; GOUVEA DA COSTA, S.E.; PINHEIRO DE LIMA, E. GARBUIO, P.A.D.R. Lean, Six Sigma and Lean Six Sigma: an analysis based on operations strategy. International Journal of Production Research, v. 52 n. 3, p. 804824, 2014.

[6] ENDLER, K.D.; BOURSCHEIDT, L.E.; SCARPIN, C.T.; STEINER, M.T.A.; GARBUIO, P.A.R. Lean seis sigma: uma contribuição bibliométrica funcionários, a cultura organizacional e o apoio dos líderes da empresa foram os fatores que apareceram como mais importantes.

Conclui-se que a implantação das metodologias Lean e Seis Sigma de forma integrada pode trazer resultados superiores à soma dos ganhos que podem ser alcançados com as duas metodologias implantadas de maneira isoladas.

Como sugestão para a continuidade deste trabalho está a ampliação da amostra de artigos, agregando outras fontes de dados como o SciELO e anais de congressos da área de Engenharia de Produção e Gestão de Operações para aplicação de outras técnicas de agrupamento e também explorar a aplicação de outros softwares de análise de conteúdo como o pacote tm (FEINERER; HORNIK; MEYER, 2015) que pode ser utilizado no R (R CORE TEAM, 2016).

dos últimos 15 anos. Produção Online, v. 16, n. 2, p. 575-605, 2016.

[7] FEINERER, I.; HORNIK, K.; MEYER, D. Text Mining Infrastructure in R. Journal of Statistical Software, n. 25, v.5, p. 1 - 54, 2015.

[8] FERNANDES, S. T.; MARINS, F. A. S. Aplicação do Lean Six Sigma na logística de transporte. Produção Online, v. 12, n. 2, p. 297 327, 2012.

[9] GARZA-REYES, J.A., FLINT, A., KUMAR, V., ANTONY, J. SORIANO-MEIER, H. A DMAIRC approach to lead time reduction in an aerospace engine assembly process. Journal of Manufacturing Technology Management, v. 25, n. 1, p. 27-48, 2014.

[10] GODINHO, M.F.; FERNANDES, F.C.F. manufatura enxuta: uma revisão queclassifica e analisa os trabalhos apontando perspectivas de pesquisas futuras. Gestão \& Produção, v.11, n.1, p.1-19, 2004.

[11] GUTIERREZ, N. Lean Six Sigma. Banas Qualidade, v. 18, n. 218, p.33, 2010.

[12] HORS, C.; GOLDBERG, A.C.; ALMEIDA, E.H.P.; BABIO JÚNIOR, F.G.; RIZZO, L.V. Aplicação das ferramentas de gestão empresarial Lean Seis Sigma e PMBOK no desenvolvimento de um programa de gestão da pesquisa científica. Einstein, v.10, n.4, p. 480-90, 2012. 
[13] LIMA, E. P.; GARBUIO, P. A. R.; COSTA, S. E. G. Proposta de modelo teórico-conceitual utilizando o Lean Seis Sigma na gestão da produção. In: Encontro Nacional de Engenharia de Produção, 29, 2009. Salvador, Anais... Salvador, 2009.

[14] MANI, G.M.; PÁDUA, F.S.M. Lean seis sigma. Interface Tecnológica, v.5, n.1, p. 115-126, 2008.

[15] MCNAUGHT, C.; LAM, P. Using Wordle as a Supplementary Research Tool. The Qualitative Report, v. 15, n. 3, p. 630-643, 2010.

[16] MORAES, R. Análise de conteúdo. Educação, Porto Alegre, v. 22, n. 37, p. 7-32, 1999.

[17] PACHECO, D. A. J. Teoria das Restrições, Lean Manufacturing e Seis Sigma: limites e possibilidades de integração. Production, v. 24, n. 4, 2014.

[18] PAMFILIE, R.; PETCU, A. J.; DRAGHICI, M. The importance of leadership in driving a strategic Lean Six Sigma management. Procedia-Social and Behavioral Sciences, v. 58, p. 187-196, 2012.

[19] PEPPER, M. P. J., SPEDDING, T. A. The Evolution of Lean Six Sigma. International Journal of Quality \& Reliability Management, v. 27, n. 2, p. 138-155, 2010.

[20] PINHEIRO, T.H.; SCHELLER, A.C.; MIGUEL, P.A.C. Integração do seis sigma com 0 lean production: uma análise por meio de múltiplos casos. Produção Online, v.13, n. 4, p. 1297-1324, 2013.

[21] R CORE TEAM. 2016. R: A language and environment for statistical computing. R Foundation for Statistical Computing, Vienna, Austria. Disponível em: https://www.R-project.org/. Acesso em: 14 Out. 2016.

[29]
[22] REBELATO, M. G.; RODRIGUES, A. M.; RODRIGUES, I. C. Análise das lacunas presentes na integração da Manufatura Enxuta com a metodologia Seis Sigma. In: Encontro Nacional de Engenharia de Produção, 29, 2009. Salvador, Anais. Salvador, 2009.

[23] SANTOS, A.B.; MARTINS, M.F. Contribuições do Seis Sigma: estudos de casos em multinacionais. Production, v. 20, n.1, p.42-53, 2010.

[24] SCHELLER, A. C.; MIGUEL, P.A.C. Adoção do Seis Sigma e Lean Production em uma empresa de manufatura. Produção Online, v.14, n. 4, p.1316-1347, 2014.

[25] SILVA, I. B.; MIYAKE, D. I.; BATOCCHIO, A.; AGOSTINHO, O. L. Integrando a promoção das metodologias Lean Manufacturing e Six Sigma na busca de produtividade e qualidade numa empresa fabricante de autopeças. Gestão \& Produção, v. 18, n. 4, p. 687-704, 2011.

[26] SHAH, R., SHANDRASEKARAN, A., LINDERMAN, K. In pursuit of Implementation Patterns: The Context of Lean and Six Sigma. International Journal of Production Research, v. 46, n. 23, p.6679-6699, 2008.

[27] SREEDHARAM, V. R; RAJU, R. A systematic literature review of Lean Six Sigma in different industries. International Journal of Lean Six Sigma, v. 7, n.4, p. 430-466, 2016.

[28] TAGGE, E. P., LENART, J.; THIRUMOORTHI, A. S.; GARBEROGLIO C.; MITCHELL K. W. Improving Operating Room Efficiency in Academic Children's Hospital Using Lean Six Sigma Methodology. Journal of Pediatric Surgery, 


\section{Gapítulo 10}

\section{APLICAÇÃO DO CONTROLE ESTATÍSTICO DE PROCESSOS EM UMA INDÚSTRIA DE PRODUÇÃO DE BANDEJAS DE OVOS}

\section{Franciele Bonatto}

\section{Bárbara Dacal de Azevedo}

João Dallamuta

Resumo: Com o aumento do grau de exigência do mercado consumidor e nível de competitividade nos últimos tempos, as empresas precisam procurar atingir um melhor desempenho global no que se refere à qualidade/custo, na busca constante por uma vantagem competitiva em relação aos concorrentes e consequentemente, tornando seu produto e/ou serviço atraente aos olhos do consumidor. Neste contexto, o objetivo deste trabalho foi aplicar o controle estatístico de processos (CEP) em uma empresa de produção de bandejas de ovos que não faz uso de métodos e ferramentas para controle de qualidade. A aplicação do estudo ocorreu por meio de um estudo de caso em um processo de produção de bandejas de ovos de uma empresa localizada no interior do Paraná. Posteriormente, foram aplicados os gráficos de média e desvio-padrão (X-S) para as variáveis peso e espessura e o gráfico de número de não-conformes ( $\mathrm{Np}$ ) para o número de bandejas defeituosas por amostra, tornando possível a análise da estabilidade e capacidade do processo. Como resultado, verificou-se que tanto para a variável espessura e peso, o processo é estável, porém ao analisar a capacidade do processo, para a variável peso, o processo é considerado capaz, enquanto que para a variável espessura o processo é considerado incapaz, e ao analisar o gráfico de $\mathrm{Np}$, o processo é considerado sob controle estatístico. Nesse sentido, foram utilizadas o diagrama de Ishikawa e plano ação para investigação da incapacidade do processo para a variável espessura e proposta de ações de melhorias do processo produtivo da empresa.

Palavras-chave: Controle de qualidade; Controle estatístico de processos; Variabilidade; Cartas de controle 


\section{INTRODUÇÃO}

Segundo Samohyl (2009), a aplicação de ferramentas da área de Controle Estatístico de Qualidade (CEQ) geram níveis melhores de qualidade nos processos e produtos de uma empresa. Essas ferramentas podem ser gráficos de controle, planos de amostragem e planejamento de experimentos.

Ribeiro e Caten (2012, p. 5) dizem que de acordo com Taguchi, "um produto ou serviço de qualidade é aquele que atende perfeitamente às especificações, atingindo o valor alvo com a menor variabilidade possível em torno dele".

Samohyl (2009) afirma que a variabilidade pode ser vista em dois aspectos. O primeiro é quando os valores medidos aparecem distantes do alvo da característica (viés), e o outro é quando o alvo é respeitado, porém o desvio padrão ou dispersão não é aceitável.

Melhor será a qualidade de um produto quanto menor for a variabilidade em suas características, porém em qualquer processo de produção haverá um certo nível desta característica (Montgomery, 2009).

Quem primeiro definiu o conceito de controle estatístico de qualidade foi o físico Walter Andrew Shewhart. De acordo com Samohyl (2009), nessa época Shewhart começou a aplicar nas fábricas conceitos em Estatística e Metodologia Científica, o que fez dele pioneiro nessa área. Ele percebeu que "qualidade e variabilidade são conceitos antagônicos", ou seja, quanto maior o número de algo produzido, menor sua qualidade. 0 físico entendeu que medir, analisar e monitorar a variabilidade é o campo do estudo estatístico e, aplicando isso nas fábricas os processos e produtos chegariam a um nível de qualidade muito superior. Então ele definiu que quanto menor o nível de variabilidade nas características dos processos e produtos, maior seria a exatidão em alcançar alvos e metas.

Costa, Epprecht e Carpinetti (2012), dizem que Shewhart desenvolveu gráficos de controle para processos e definiu que nestes gráficos quando um ponto se destaca é preciso iniciar uma investigação para encontrar as causas que afetam a qualidade dos produtos.

Sabe-se, de acordo com Lowry e Montgomery (1995), que os gráficos de Shewhart são ferramentas de monitoramento simples e, por isso, muito utilizadas naquela época, já que não é necessário a utilização de recursos computacionais. Porém nos dias atuais vem ocorrendo uma crescente busca por suporte computacional para que se possa atender a complexa demanda de monitoramento simultâneo das várias características de qualidade, as variáveis do processo.

È inegável que uma das metodologias mais utilizadas para auxiliar no controle da qualidade é o Controle Estatístico de Processo (CEP). Através da utilização de suas ferramentas é possível reduzir a quantidade de produtos fora de especificações e com isso os custos da produção (Lima et al., 2006)

Nesse sentido, o objetivo deste trabalho é aplicar o controle estatístico de processo em uma indústria de produção de bandejas de ovos. A indústria objeto do estudo de caso não utiliza métodos e ferramentas para analisar e controlar o nível de qualidade do processo produtivo e do produto da empresa. Diante disso, o presente estudo vem de encontro à oportunidade de proporcionar ao gerente da empresa, uma visão sobre o nível de qualidade do processo e produto da empresa.

\section{CONTROLE ESTATÍSTICO DE PROCESSOS (CEP)}

A base para o controle estatístico de processos, como o próprio nome diz, está na estatística. a estatística surgiu para auxiliar indústrias na melhoria da qualidade de seus produtos. o princípio de funcionamento do cep se dá através de cartas de controle, que de acordo com Pires (2000) são ferramentas que previnem e bloqueiam reincidências das chamadas causas especiais, as quais tratamse de problemas detectados na identificação do comportamento do processo ao longo do tempo.

Segundo pires (2000), a utilização das cartas de controle fornece um diagnóstico da situação atual dos processos; evita ajustes desnecessários no processo; previne a incidência de defeitos e proporciona aumentos de produtividade. elas têm por objetivo analisar a estabilidade do processo e identificar variações no processo, ou seja, as causas especiais.

Pires (2000) afirma que "o sucesso na implantação do CEP depende do grau de entendimento e compreensão da empresa acerca das cartas de controle por ela utilizadas". cartas de controle auxiliam na 
identificação de ações a serem tomadas nos processos sendo monitorados e fornecem informações que podem ser utilizadas para reduzir em um curto período de tempo os defeitos.

Carvalho e Paladini (2012), dizem que "as ferramentas da gestão da qualidade exercem um papel essencial no êxito da aplicação prática dos princípios e definições que caracterizam esta área", pois tornam viáveis a sua estrutura conceitual e diretrizes básicas. conceitualmente, essas ferramentas são simples mecanismos que selecionam, implementam ou avaliam alterações em um processo produtivo através de análises de partes do processo. As sete ferramentas básicas do controle da qualidade, são: a estratificação, as cartas de controle, as folhas de verificação, os gráficos de dispersão, os diagramas de causa-efeito, os diagramas de pareto e os histogramas.

\subsection{CARTAS DE CONTROLE}

As cartas de controle são as principais ferramentas utilizadas pelo CEP. Elas nada mais são que gráficos, os quais são plotados através da coleta de dados do objeto de estudos em um período de tempo tendo como objetivo, avaliar o comportamento dinâmico da variável a partir das medições efetuadas.

De acordo com Spiegel e Stephens (2009), todo processo possui variações e elas podem ser comuns ou especiais. As causas comuns são aquelas que advêm de variações naturais que existem em máquinas, materiais $e$ pessoas. Já as causas especiais, ou causas associadas, advêm de desgastes excessivos de ferramentas, novos operadores, mudanças de materiais, novo alimentador, entre outros. Spiegel e Stephens (2009) ainda afirmam que, uma das finalidades dos gráficos de controle é localizar e, se possível, eliminar as causas especiais de variação. A Figura 1 mostra uma composição geral das cartas de controle.

É possível observar que existem limites de controle e uma linha central. Os limites de controle são denominados como Limite Superior de Controle (LSC) e Limite Inferior de Controle (LIC). Após plotar o gráfico, observase a localização dos pontos. Quando existem pontos fora dos limites de controle é considerado que o processo está fora do controle estatístico. 0 que se busca é que o processo esteja sob controle e assim considera-se que seu comportamento é previsível (Spiegel \& Stephens, 2009).

Figura 1 - Composição geral das Cartas de Controle

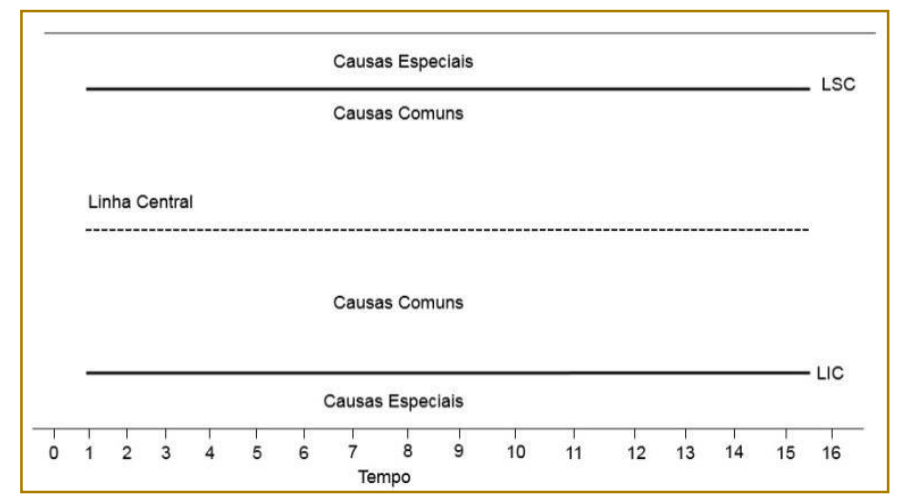

Fonte: Spiegel e Stephens (2009)

As cartas de controle são divididas entre variáveis e atributos. De acordo com Ribeiro e Caten (2012) e Toledo e Alliprandini (2004), os gráficos de controle por variáveis podem ser:

X e $\mathrm{R}$ (gráficos da média e da amplitude): Costumam ser os mais utilizados e devem ser usados simultaneamente, pois se complementam. O gráfico $\mathrm{X}^{-}$controla a variabilidade no nível médio do processo e suas mudanças. É importante analisar também a dispersão do processo que gera variabilidade e isso pode ser detectado pelo gráfico $\mathrm{R}$ das amplitudes.

- $\quad$ Xe $R$ (gráficos da mediana e da amplitude): Também devem ser aplicados juntos. Tratam-se de gráficos de fácil aplicação e com isso podem ser usados em amostras pequenas $(n<=5)$. Para amostras grandes $(n>=5)$ mostram-se ineficazes, pois podem apresentam erros de cálculo das medianas amostrais. 
e da amplitude):Esses gráficos são mais usuais quando se quer controlar um processo através de leituras individuais e não por amostras. Por exemplo, quando a inspeção e a medida são caras; para ensaios destrutivos ou quando a característica que se está sendo analisada for homogênea ( $\mathrm{pH}$ de uma solução química).

- Xe S (gráficos da média e do desviopadrão): Em alguns casos, o monitoramento do desvio-padrão (S) pode ser mais conveniente que o monitoramento da amplitude. Trata-se de um indicador mais eficiente da variabilidade, principalmente para amostras grandes $(n>=10)$.

- Gráficos de Pré-Controle: São baseados nos limites de especificação do produto e limites naturais de variação do processo.

Quanto aos gráficos de atributos, de acordo com Toledo e Alliprandini (2004), estes são utilizados quando o número de características a controlar em cada produto é muito grande, ou quando em lugar de mensurações convém empregar calibradores do tipo passa nãopassa, ou o custo de mensuração é elevado em relação ao custo da peça, ou ainda, a verificação da qualidade pode ser feita por simples inspeção visual. Os principais tipos de gráficos de atributo são:

- Gráficos de p: para o controle da proporção de unidades defeituosas em cada amostra;

- Gráficos de np: para o controle do número de unidades defeituosas por amostra;

- Gráficos de c: para o controle do número de defeitos por amostra;

- Gráficos de u: para o controle do número de defeitos por unidade de produto (Toledo \& Alliprandini, 2004).

\subsubsection{GRÁFICOS ${ }^{-}$XE S}

Segundo Falcão (2001), para avaliar a capacidade de um processo aplica-se o método do $6 \sigma$, onde calculam-se os limites naturais considerando a extensão de seis desvios-padrão $(6 \sigma)$ em torno da média e assim, o processo apresenta distribuição normal de probabilidades.

De acordo com Ribeiro e Caten (2012, os limites de controle da média são calculados usando:

$$
\begin{aligned}
& \mathrm{LCS}={ }^{=} \mathrm{x}+\mathrm{A}_{3}^{\bar{S}} \mathrm{~S} \\
& \mathrm{LCI}={ }^{\mathrm{x}}-\mathrm{A}_{3}^{\bar{S}} \mathrm{~S}
\end{aligned}
$$

Onde $A_{3}, B_{4}$ e $B_{3}$ são constantes que dependem do tamanho da amostra, ${ }^{\prime} \mathrm{x}$ é a média da média das amostras, $\mathrm{e}^{-} \$$ a média do desvio padrão.

\subsubsection{GRÁFICO DE NP PARA NÚMERO DE NÃO-CONFORMES}

De acordo com Ribeiro e Caten (2012, p. 90), a carta $\mathrm{Np}$ mede o número de produtos defeituosos ou produtos não-conformes em uma amostra. Para cada subgrupo, anota-se os valores:

$n=$ número de itens inspecionados.

$d=$ número de itens defeituosos (nãoconformes).

Calcula-se então:

$$
\mathrm{p}=\mathrm{d} / \mathrm{n}
$$

0 número médio de não-conformes:

$$
n \bar{p}=(\mathrm{d} 1+\mathrm{d} 2+\ldots+\mathrm{dk}) / \mathrm{k}
$$

E o desvio-padrão:

$$
\sigma_{n p}=\sqrt{n \bar{p}(1-\bar{p})}
$$

Onde di é o número de não-conformes no subgrupo $i$, ni é o tamanho da amostra do subgrupo $i$ e $k$ é o número de subgrupos. Os limites de controle são calculados da seguinte forma:

$$
\begin{aligned}
& L C S=n \bar{p}+3 \sigma_{n p} \\
& L C I=n \bar{p}-3 \sigma_{n p}
\end{aligned}
$$

\subsection{INTERPRETAÇÕES PARA CARTAS DE CONTROLE}

Para a interpretação dos gráficos, é preciso analisar dois itens. Primeiramente é verificado se o processo está sob controle estatístico, baseado no comportamento atual do processo. O segundo item a ser analisado é se os bens ou serviços do processo correspondem às especificações do planejamento (Triola, 2008).

Segundo Triola (2008), existem três critérios para se determinar quando um processo não é estatisticamente estável (fora do controle estatístico), são eles:

- $\quad$ Existe um padrão, uma tendência, ou um ciclo que não é aleatório. 
- Existe um ou mais pontos fora dos limites de controle

- Regra da sequência de 8: Há oito pontos consecutivos, todos acima ou todos abaixo da linha central.

Conforme Leite (2010), a verificação do controle estatístico do processo pode ser feita de acordo com vários testes que detectam pontos fora de controle, sendo eles:

Teste 1: verifica se o ponto está localizado acima do LSC ou abaixo do LIC;

- Teste 2: analisa a presença de nove pontos consecutivos localizados acima ou abaixo da LC;

- Teste 3: testa se existem seis ou mais pontos consecutivos crescentes ou decrescentes;

- Teste 4: verifica a existência de quatorze pontos alternados em uma linha;

Teste 5: Dois de três pontos localizados no mesmo lado a dois desviospadrão acima ou abaixo da linha central;

- Teste 6: testa se existem quatro de cinco pontos localizados no mesmo lado a um desvio-padrão acima ou abaixo da linha central;

- Teste 7: quinze pontos consecutivos localizados, em qualquer lateral, a menos de um desvio-padrão da linha central;

Teste 8: verifica se existem oito pontos consecutivos acima ou abaixo, em qualquer lateral, a mais de um desvio-padrão da linha central.

\subsection{CAPACIDADE DO PROCESSO}

De acordo com Falcão (2001), se um processo apresenta apenas causas comuns de variação, ele será estável ao longo do tempo, ou seja, está sob controle estatístico. Se apresenta causas especiais de variabilidade ele não será estável ao longo do tempo. A estabilidade é um fator muito importante na análise de um processo. Se um processo é instável, consequentemente é imprevisível e isso torna difícil a análise da sua capacidade de gerar produtos dentro do padrão esperado. Uma vez considerado estável o processo, sua capacidade pode ser avaliada (Toledo \& Alliprandini, 2004).

No caso dos atributos, o estudo da capacidade de processo consiste na comparação do valor considerado aceitável (especificação) para o atributo em estudo com a média calculada para o atributo no processo que está sendo analisado.

Para o cálculo da capacidade utilizando variáveis, é utilizado a equação a seguir:

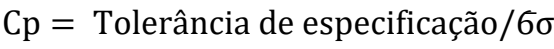

O cálculo dessa tolerância consiste na determinação do desvio padrão natural a partir das amplitudes das amostras que vem sendo coletadas na produção.

Desvio-padrão:

$\sigma \overline{\mathrm{Rd}_{2}}$

Onde, $\bar{R}$ é a média das amplitudes amostrais e $d_{2}$ é um fator de correção que depende do tamanho (n) das amostras. A variabilidade natural ou o limite natural de tolerância do processo será o equivalente a $6 \sigma$, o qual contém 99,73\% da produção (Toledo \& Alliprandini, 2004).

Ainda de acordo com Toledo e Alliprandini (2004), dessa forma um processo será considerado capaz quando o $\mathrm{Cp}$ for maior que 1 , ou seja, quando a variabilidade natural do processo $(6 \sigma)$ for menor que a tolerância admissível da especificação. Como é utilizado o $\sigma \mathrm{R}$ (desvio padrão calculado a partir das amplitudes), alguns autores consideram a necessidade de que o Cp seja maior que 1,33 .

Se um processo não é capaz de atender as especificações pode ser porque a média não está sendo estimada da forma correta ou a variação do processo é muito grande e ultrapassa os limites naturais do processo (Falcão, 2001).

Para análise da capacidade do processo também é importante verificar a centralização do resultado do processo em relação aos limites de especificação. Por isso, deve-se utilizar o índice de capacidade Cpk. Este índice considera a diferença que possa existir entre a média do processo e o valor nominal (ou valor central da especificação), ou seja, a descentralização do processo (Toledo \& Alliprandini, 2004).

$$
C_{p k}=\min \left|\frac{L E S-\bar{X}}{5 \sigma}, \frac{\bar{X}-L E I}{5 \sigma}\right|
$$

A interpretação do resultado para o $C_{p}$ e $C_{p k}$ podem ser feitas conforme o Quadro 1. 
Quadro 1 - Interpretação da capacidade do processo.

\begin{tabular}{|l|c|l|}
\multicolumn{1}{|c|}{ Cp ou Cpk } & Nivel \\
\hline Maior que 1,33 & A & $\begin{array}{l}\text { CAPAZ - Confiável, os operadores do processo exercem completo } \\
\text { controle sobre o mesmo, pode-se utilizar o pré-controle. }\end{array}$ \\
\hline Entre 1 e 1,33 & B & $\begin{array}{l}\text { RELATIVAMENTE CAPAZ - Relativamente confiável, os operadores do } \\
\text { processo exercem controle sobre as operações, mas o controle da } \\
\text { qualidade deve monitorar e fornecer informações para evitar a } \\
\text { deterioração do processo. }\end{array}$ \\
\hline $\begin{array}{l}\text { Entre 0.75 e } \\
0,99\end{array}$ & C & $\begin{array}{l}\text { INCAPAZ - Pouco confiável, requer controle contínuo das operações, } \\
\text { pela fabricação e pelo controle da qualidade, visando evitar descontroles } \\
\text { e perdas devido a refugos, retrabalhos, paralisações, etc. }\end{array}$ \\
\hline Menor que 0,75 & D & $\begin{array}{l}\text { TOTALMENTE INCAPAZ - O processo não tem condições de atender às } \\
\text { especificações ou padrões, por isso, é requerido o controle, revisão e } \\
\text { seleção de 100\% das peças, produtos ou resultados. }\end{array}$ \\
\hline
\end{tabular}

Fonte: Toledo e Alliprandini (2004)

\subsection{DIAGRAMA DE ISHIKAWA}

O diagrama de Ishikawa ou diagrama de causa e efeito, trata-se de uma ferramenta que permite a representação gráfica de uma análise criteriosa que define as causas que estão levando a um acontecimento ou efeito.
Esse diagrama mostra a relação entre uma característica da qualidade e seus diversos fatores determinantes (Seleme \& Stadler, 2008).

A Figura 2 representa um modelo genérico de diagrama de Ishikawa.

Figura 2 - Modelo de Ishikawa

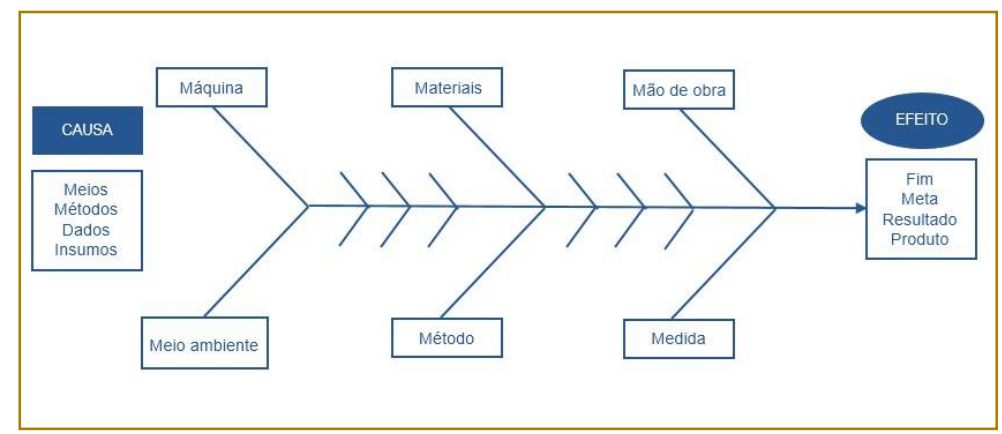

Fonte: Seleme e Stadler (2008)

0 diagrama baseia-se em $6 \mathrm{Ms}$, que segundo Seleme e Stadler (2008), têm os seguintes significados:

- $1 \mathrm{M}$ (máquina): refere-se à operacionalização do equipamento e ao seu funcionamento adequado;

- $2 \mathrm{M}$ (materiais): Análise das características dos materiais quanto ao seu padrão, sua uniformidade, etc.;

- $\quad 3 \mathrm{M}$ (mão de obra): Caracteriza-se se a mão de obra é devidamente treinada, se tem as habilidades necessárias, e se está qualificada para o desempenho da tarefa;
- $\quad 4 \mathrm{M}$ (meio ambiente): avalia-se se situações de execução e/ou infraestrutura fixa podem ser a causa de um determinado efeito;

- 5M (método): considera-se a forma como serão desenvolvidas as ações;

- 6M (medida): traduz-se pelos instrumentos de medição utilizados e pela forma como os valores são representados (por distância, tempo, temperatura etc.).

\section{METODOLOGIA}

\subsection{CARACTERIZAÇÃO DA PESQUISA}

Para Moresi (2003, p. 8), "Pesquisa é um conjunto de ações, propostas para encontrar a solução para um problema, que têm por 
base procedimentos racionais $\mathrm{e}$ sistemáticos." Quando não se consegue obter informações para solucionar um problema, a pesquisa é realizada.

De acordo com Silva e Menezes (2005), a pesquisa pode ser classificada do ponto de vista da sua natureza: pesquisa básica ou pesquisa aplicada e também do ponto de vista da forma de abordagem do problema: pesquisa Quantitativa ou Qualitativa.

Silva e Menezes (2005), definem que a pesquisa básica não apresenta uma aplicação prática prevista, mas tem como objetivo gerar novos conhecimentos úteis para o avanço da ciência. Já a pesquisa aplicada tem como objetivo gerar conhecimentos para aplicação prática para, assim, solucionar problemas específicos.

Do ponto de vista da forma de abordagem do problema, Silva e Menezes (2005, p. 20) definem que pesquisa quantitativa coloca em números informações para análise e classificação. Este tipo de pesquisa utiliza-se de técnicas estatísticas como percentagem, média, moda, mediana, desvio-padrão, coeficiente de correlação, análise de regressão, entre outras. Já a pesquisa qualitativa utiliza-se da interpretação de fenômenos e atribuição de significados. Não usa métodos e técnicas estatísticas, mas sim o ambiente natural para coleta de dados. "Os pesquisadores tendem a analisar seus dados indutivamente. $O$ processo e seu significado são os focos principais de abordagem". Para Gil (1991), do ponto de vista de seus objetivos a pesquisa pode ser exploratória, descritiva ou explicativa.

Esta pesquisa se encaixa, do ponto de vista de sua natureza, como pesquisa aplicada, pois existe uma aplicação em uma empresa. Do ponto de vista da forma de abordagem, como pesquisa quantitativa, pois existe uma coleta de dados para análise e classificação. E do ponto de vista de seus objetivos, como descritiva, pois visa descrever as características de uma produção em uma empresa e a relação entre suas variáveis.

\subsection{ESTUDO DE CASO}

O estudo de caso aconteceu em uma indústria de produção de bandejas de ovos através da coleta de dados da produção e posterior aplicação do CEP.

Situada em Cruzeiro do Sul, no interior do Paraná, a Essencial Bandejas foi fundada em novembro de 1999 por Kelser Baroni. Atualmente conta com cinco máquinas de capacidade para 1800 bandejas por hora e duas com capacidade para 800. A empresa trabalha atualmente 24 horas por dia o ano todo, com paradas programadas para manutenção. A Figura 3, mostra de forma simplificada como se dá a produção de bandejas de ovos.

A matéria-prima base para a produção de bandejas de ovos é conhecida como aparas de papéis, que se trata de qualquer tipo de papel. Porém para uma melhor qualidade da bandeja é preferível o uso de jornal reciclado. Esta matéria prima é coloca em um tanque hidrapulper ou pulper, que é como um liquidificador gigante com peneiras para retenção de impurezas. Após passar por ele, segue para um tanque mestre com agitador para que não haja decantação do produto. Este tanque mantém a massa preparada para ir para a produção, porém sua consistência ainda não é a ideal e com isso a massa é bombeada para uma caixa de nível.

A caixa de nível fica situada numa altura acima da máquina para que a mistura possa se encaminhar para a máquina por gravidade. $\mathrm{Na}$ saída da caixa de nível, é controlada a gramatura ideal para ir para a produção. A gramatura é controlada manualmente através de registros de água (válvulas), os quais podem ser acionados ou desligados para o correto controle de gramatura antes de seguir para a próxima etapa. Chegando na máquina, a matéria-prima se transformará no produto quase acabado. A máquina faz sozinha todo o processo de produção, depositando as bandejas ainda molhadas em uma esteira, a qual entra em uma estufa para secagem do produto. A esteira faz um caminho de ida e volta dentro da estufa, que dura em torno de 22 minutos, fazendo com que o produto saia em sua forma final e pronta para empacotamento. 
Figura 3 - Processos de produção de bandejas de ovos

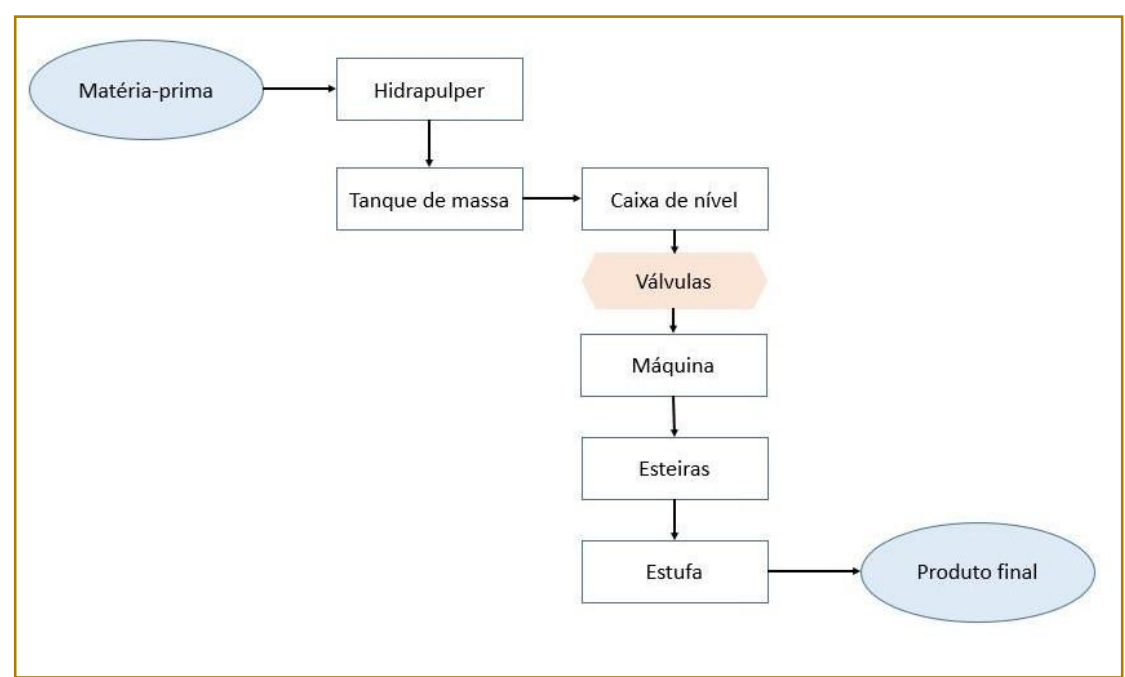

Fonte: Autoria própria

Para a aplicação do CEP na empresa, as seguintes ações foram seguidas:

- Inicialmente foi feito a definição do projeto, onde definiu-se a equipe de trabalho, assim como cronograma de atividades;

- Por conseguinte, as variáveis definidas para análise foram: espessura da bandeja em milímetros $(\mathrm{mm})$, peso em gramas (g) e bandejas que estivessem definidas como Não-Conformes. Dado que cada lote apresenta 100 unidades, definiu-se 20 amostras (lotes) com subgrupos (n) de 10 unidades. Com isso especificou-se que a espessura e peso seriam variáveis de controle, bem como as bandejas decretadas como não-conformes seriam atributos. Utilizou-se os gráficos X-S para espessura e peso e gráfico de np para os não-conformes. Para a coleta de dados, foi acompanhada a produção de uma das máquinas da empresa.

Figura 4 - Gráfico X (média) para espessura

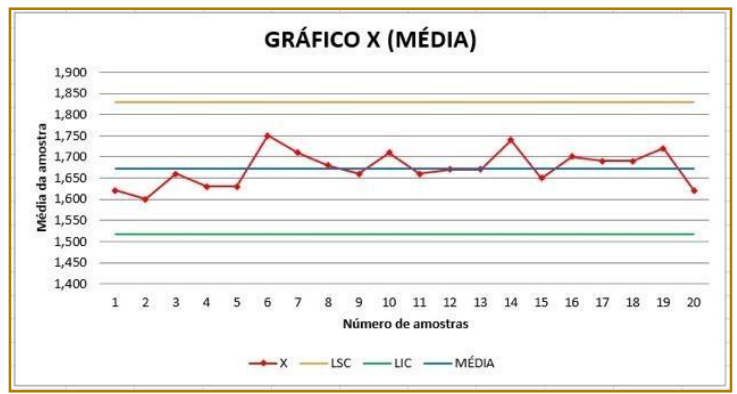

- Em seguida, coletou-se os dados e construiu-se os gráficos de controle

- $\quad$ Posteriormente foi feita a análise da estabilidade e capacidade do processo.

- Por fim, foi feito um estudo de possíveis melhorias para posterior otimização do processo.

\section{RESULTADOS}

A empresa não faz nenhum controle de espessura, porque as bandejas saem de acordo com o molde da máquina. Os limites de tolerância da espessura das bandejas são definidos pelo fabricante da máquina sendo entre $1,5 \mathrm{~mm}$ a $2 \mathrm{~mm}$. A Figura 4 e 5 apresenta o gráfico de controle para média e desvio padrão da variável espessura, respectivamente.

Figura 5 - Gráfico S (desvio-padrão) para espessura

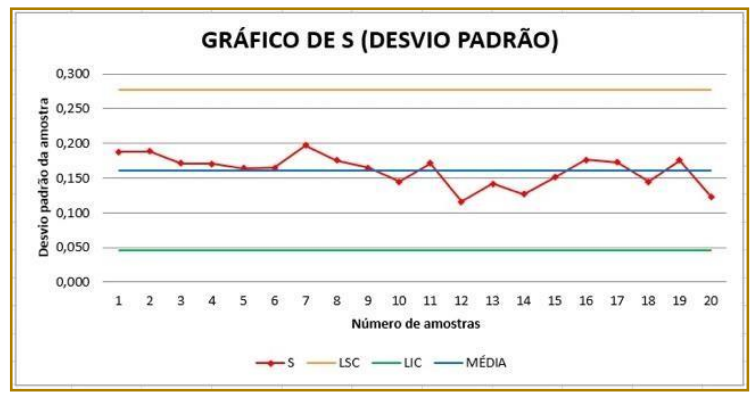


Tanto para a média como a dispersão dos dados, a distribuição dos pontos encontra-se de forma aleatória e dentro dos limites de especificação. Conforme a análise proposta por Triola (2008) e Leite (2010), os pontos não apresentam tendência, deslocamento e padrão cíclico não-aleatório e por isso é considerado estável. Deste modo, conseguinte, calculou-se a capacidade do processo baseado em Toledo e Alliprandini (2004) e obteve-se cp: 0,558 e cpk: 0,517

De acordo com Toledo e Alliprandini (2004) constata-se que tanto $\mathrm{Cp}$ quanto $\mathrm{Cpk}$ são

Figura 6 - Gráfico X (média) para peso

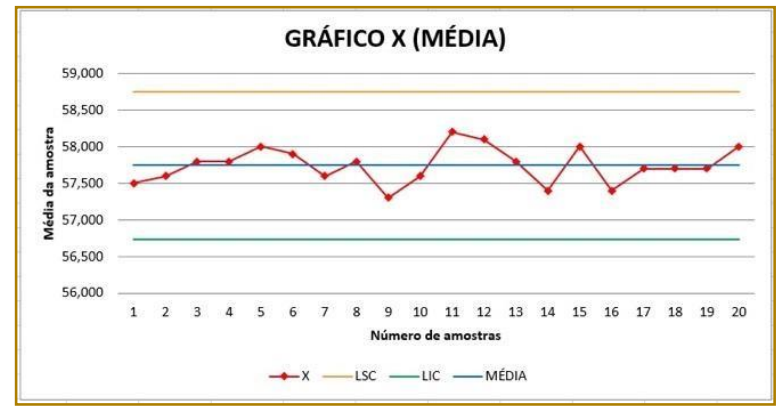

Conforme a de Triola (2008) e Leite (2010), percebe-se que não houve pontos fora dos limites de especificação, não houveram casos cíclicos não aleatórios, ou pontos extremos dentro das margens de especificação ou ainda vários pontos consecutivos acima ou abaixo das linhas. Sendo assim, neste caso também constatou-se que não houve causas especiais dentro do processo e com isso tratase de um processo estável. 0 valor do menores que 0,75 caracterizando o processo como incapaz, ou seja, o processo apesar de ser estável, não tem capacidade de produzir no padrão de qualidade requerido e por isso, é requerido o controle, revisão e seleção de $100 \%$ das peças, produtos ou resultados.

Quanto a variável peso, os limites de tolerância definidos pelo fabricante da máquina é de $55 \mathrm{~g}$ a $62 \mathrm{~g}$. A Figura 6 e 7 apresentam os gráficos de média e dispersão do peso das amostras.

Figura 7 - Gráfico S (desvio-padrão) para peso

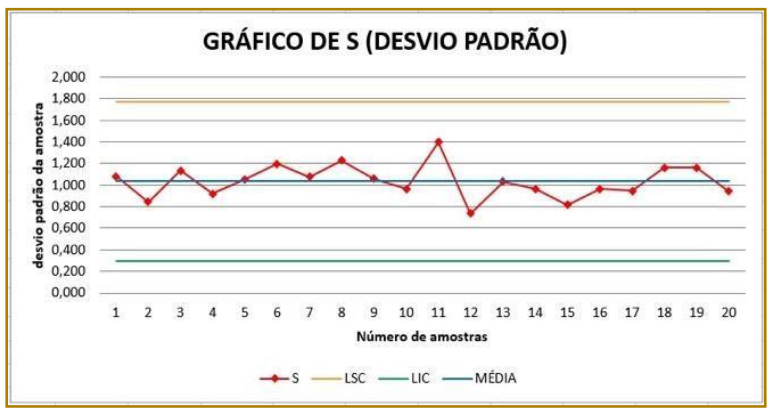

cp e cpk para o peso foram ambos 1,177 , que por sua vez, caracteriza um processo capaz, e o controle da qualidade deve monitorar e fornecer informações para evitar a deterioração do processo (Toledo \& Alliprandini, 2004).

Para os dados de bandejas não-conformes foi gerado um gráfico do tipo $\mathrm{np}$, conforme Figura

8.

Figura 8 - Gráfico Np para número de não-conformes

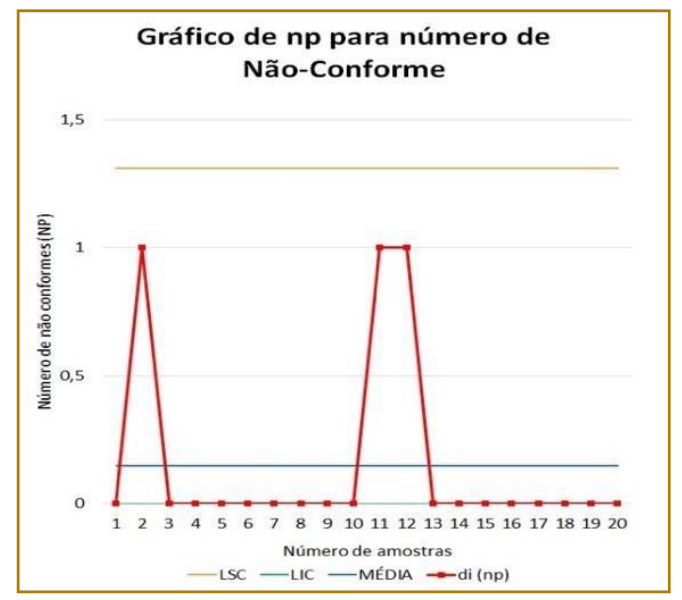


O processo não possui a atuação de causas especiais e é considerado estável. Quanto à capacidade do processo, este consiste na comparação do valor considerado aceitável (especificação) para o atributo em estudo com a média calculada para o atributo no processo que está sendo analisado. No caso do número de bandejas não conformes, é considerado aceitável, 1 unidade defeituosa a cada lote de 100 unidades, considerando 99\% de conformidade. Nesse sentido, apenas a amostra 2, 11 e 12 tiveram lotes com 1 produto não conforme e o restante das amostras apresentaram 100\% de conformidade, caracterizando o processo como capaz.

Devido a incapacidade do processo para a variável espessura, foi construído um diagrama de Ishikawa e sugerido por meio de um plano ação, possíveis ações de melhorias.

Após a realização do brainstorming com o gerente industrial e o operador da máquina, sobre os possíveis motivos que geram a incapacidade do processo, foi factível a criação do diagrama de causa e efeito, representado na Figura 9.

Figura 9 - Diagrama Ishikawa

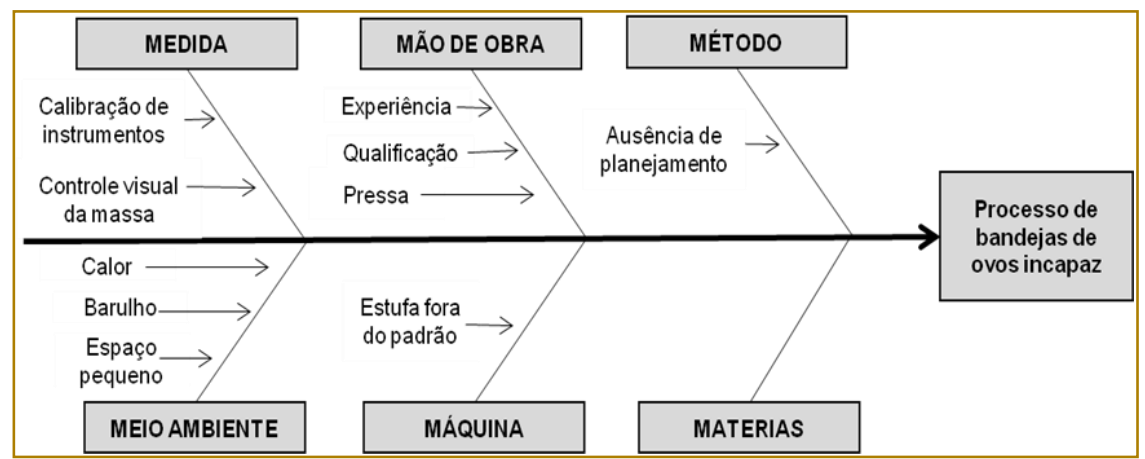

Após a identificação dos fatores que geravam a incapacidade do processo, se fez necessário a elaboração de um Plano de Ação, conforme Quadro 2.

\section{Quadro 2 - Plano ação proposto}

\begin{tabular}{|c|c|c|c|c|c|}
\hline O quê? & Quem? & Onde? & Por que? & Quando? & Como? \\
\hline $\begin{array}{l}\text { Ajustar as } \\
\text { temperaturas } \\
\text { dos fornos }\end{array}$ & Gerente & $\begin{array}{l}\text { Linha de } \\
\text { produção }\end{array}$ & $\begin{array}{l}\text { Para que as estufas } \\
\text { trabalhem de maneira } \\
\text { ideal, sem alterar no } \\
\text { produto final }\end{array}$ & $\begin{array}{l}\text { Imediata- } \\
\text { mente }\end{array}$ & $\begin{array}{l}\text { Orientando } \\
\text { funcionários }\end{array}$ \\
\hline $\begin{array}{l}\text { Agendar } \\
\text { treinamentos } \\
\text { para } \\
\text { funcionários }\end{array}$ & Gerente & $\begin{array}{l}\text { Dentro ou } \\
\text { fora da } \\
\text { empresa }\end{array}$ & $\begin{array}{l}\text { Para funcionários } \\
\text { poderem trabalhar de } \\
\text { forma correta na } \\
\text { produção }\end{array}$ & $\begin{array}{l}\text { Imediata- } \\
\text { mente }\end{array}$ & $\begin{array}{l}\text { Aplicar treinamento } \\
\text { dentro da empresa ou } \\
\text { contratar treina-mentos } \\
\text { terceirizados. }\end{array}$ \\
\hline $\begin{array}{l}\text { Ação corretiva } \\
\text { para meio } \\
\text { ambiente }\end{array}$ & Gerente & $\begin{array}{l}\text { Linha de } \\
\text { produção }\end{array}$ & $\begin{array}{l}\text { Para melhorar o meio } \\
\text { ambiente onde os } \\
\text { funcionários produzem }\end{array}$ & $\begin{array}{l}\text { Imediata- } \\
\text { mente }\end{array}$ & $\begin{array}{l}\text { Incentivar uso de EPIs. } \\
\text { Fazer análi-se de } \\
\text { refrigeração e } \\
\text { ventilação no local }\end{array}$ \\
\hline $\begin{array}{l}\text { Corrigir falta de } \\
\text { planejamento }\end{array}$ & Gerente & $\begin{array}{l}\text { Toda a } \\
\text { empresa }\end{array}$ & $\begin{array}{l}\text { O planejamento é a } \\
\text { base para o correto } \\
\text { funcionamento da } \\
\text { empresa }\end{array}$ & $\begin{array}{l}\text { Imediata- } \\
\text { mente }\end{array}$ & $\begin{array}{l}\text { Continuar aplicando } \\
\text { ferramentas da } \\
\text { qualidade }\end{array}$ \\
\hline $\begin{array}{l}\text { Corrigir falta de } \\
\text { controle de } \\
\text { ferramentas. }\end{array}$ & Gerente & $\begin{array}{l}\text { Toda a } \\
\text { empresa }\end{array}$ & $\begin{array}{l}\text { Pode gerar erros na } \\
\text { produção }\end{array}$ & $\begin{array}{l}\text { Imediata- } \\
\text { mente }\end{array}$ & $\begin{array}{l}\text { Aplicar controle de } \\
\text { metrologia para } \\
\text { ferramentas }\end{array}$ \\
\hline
\end{tabular}




\section{CONCLUSÃO}

Os processos estudados demonstraram resultados diferentes em relação à sua estabilidade e capacidade e com isso percebe-se a importância de se investigar mais de um quesito a fim de se chegar na excelência de qualidade.

Tanto para a variável espessura e peso, o processo é estável, porém ao analisar a capacidade do processo, para a variável peso, o processo é considerado capaz, enquanto que para a variável espessura o processo é considerado incapaz, e ao analisar o gráfico de $\mathrm{Np}$, o processo é considerado sob controle estatístico. Nesse sentido, através da construção do diagrama

\section{REFERÊNCIAS}

[1]. Carvalho, M., \& Paladini, E. (2013). Gestão da qualidade: teoria e casos. Elsevier Brasil.

[2]. Caten, T., \& Schwengber, C. (1999). Controle integrado da qualidade de processos de manufatura de revestimentos cerâmicos.

[3]. Costa, A. F. B., Epprecht, E. K., \& Carpinetti, L. C. R. (2005). Controle estatístico de qualidade (pp. 185-94). São Paulo: Atlas.

[4]. Falcão, A. S. G. (2001). Diagnóstico de perdas e aplicação de ferramentas para o controle da qualidade e melhoria do processo de produção de uma etapa constrututiva de edificações habitacionais.

[5]. Gil, A. C. (2002). Como elaborar projetos de pesquisa. São Paulo, 5(61), 16-17.

[6]. Leite, S. J. S. Aplicação do controle estatístico no processo de embalagem de biscoitos na indústria de alimentos.

[7]. Lowry, C. A., \& Montgomery, D. C. (1995). A review of multivariate control charts. IIE transactions, 27(6), 800-810.

[8]. Montgomery, D. C. (2009). Introduction to statistical quality control. John Wiley \& Sons (New York).
Ishikawa e foi possível investigar as causas que estavam levando a incapacidade do processo e proposta ações de melhorias do processo produtivo da empresa.

A empresa em questão não apresenta nenhum tipo de controle de qualidade, o que fica evidente a necessidade dessa implantação para o seu desenvolvimento. È evidente a possibilidade de coletar dados, analisar e sugerir melhorias através do CEP e ferramentas da qualidade, pois através dessas ferramentas é possível analisar a qualidade do produto por meio da variabilidade do processo.

[9]. Moresi, E. (2003). Metodologia da pesquisa. Brasília: Universidade Católica de Brasília, 108, 24.

[10]. Pires, V. T. (2000). Implantação do controle estatístico de processos em uma empresa de manufatura de óleo de arroz.

[11]. Ribeiro, J. L. D., \& ten Caten, C. S. Controle Estatístico do Processo.

[12]. Samohyl, R. W. (2009). Controle estatístico de qualidade. Elsevier.

[13]. Seleme, R., \& Stadler, H. (2008). Controle da qualidade: as ferramentas essenciais. Editora Ibpex.

[14]. Silva, E. L. D., \& Menezes, E. M. (2005). Metodologia da pesquisa e elaboração de dissertação.

[15]. Spiegel, M. R., \& Stephens, L. J. (2009). Estatística: Coleção Schaum. Bookman.

[16]. TOLEDO, J. C. D., \& ALLIPRANDINI, D. E. (2004). Controle estatístico da qualidade. Apostila CEP/UFSCAR. São Paulo.

[17]. Triola, M. F. (2008). Introdução à estatística: atualização da tecnologia. In Introdução à estatística: atualização da tecnologia. 


\section{Capítulo 11}

\section{IMPLANTAÇÃO DO PROGRAMA SS NO SETOR DE EMPACOTAMENTO TORREFAÇÃO DE CAFÉ}

\section{Lucas Carvalho Martins}

\section{Murilo Carvalho Franco Barros \\ Vitor Camargo da Silva \\ Vitor de Carvalho Pisco}

Resumo: 0 presente trabalho consiste na implantação de um estudo de caso realizado em uma indústria de torrefação de café, com a intenção de analisar os impactos da qualidade no setor de empacotamento da empresa através da metodologia $5 \mathrm{~S}$ aplicada com o auxílio do ciclo PDCA. A essência do programa foi melhorar tanto a qualidade de vida dos colaboradores quanto os processos, promovendo a nova cultura empresarial através dos parâmetros dos cinco sensos. Após a implantação do programa no dia "D", os sensos foram mensurados por meio dos check-lists realizados pelos auditores internos de acordo com as particularidades do setor. Os dados eram divulgados e analisados pela equipe $5 \mathrm{~S}$ para planejar atividades corretivas para atingir a conformidade na organização inteira. Ao término do estudo, foi possível identificar a importância do PDCA na implantação do programa assim como as mudanças que a nova metodologia gerou e se espera que o programa continue com as orientações passadas a empresa. 


\section{INTRODUÇÃO}

Em quase todas as indústrias produtivas da atualidade a gestão da qualidade tem demonstrado um papel fundamental e decisivo para a busca de sobrevivência do empreendimento. 0 mercado do café está cada vez mais competitivo e se encontra nessa busca pela maior qualidade possível, assim as empresas buscam a maior satisfação dos clientes e maior organização interna de suas atividades.

Os programas de qualidade estão se tornando cada vez mais populares, e a adesão ou não a esses programas tornou-se não mais uma questão de destaque, mas sim uma questão de permanência no mercado.

Dentro desses quesitos, o programa $5 \mathrm{~S}$ pode ser empregado como um importante programa de qualidade, impulsionador de outros programas e facilitador de conquista de certificações, pois é um procedimento de simples entendimento, e que se aplicado corretamente, gera bons resultados em questões de qualidade para a empresa. Portanto, além de melhorar o ambiente interno, produtividade e a satisfação de ganho da empresa, 0 5S pode ser a apoio para melhoria constante, pois a aplicação do programa busca envolver todas as áreas da organização.

Este trabalho propõe um estudo e análise da implantação do programa $5 \mathrm{~S}$ através do ciclo PDCA no setor de empacotamento em uma indústria de café no triângulo mineiro, vale relatar aos leitores que o $5 \mathrm{~s}$ foi implantado em todos os setores da empresa, porém para o presente artigo, foi enfatizado o setor de empacotamento. O objetivo é conhecer e analisar as dificuldades e os facilitadores na implementação do programa neste departamento através do ciclo PDCA e os impactos da nova metodologia para a organização.

\section{REFERENCIAL TEÓRICO}

Estão presentes neste estudo alguns conceitos como: a qualidade nas indústrias de café, o ciclo PDCA, o programa 5S, a implantação do programa e o conceito de auditoria.

\subsection{QUALIDADE NA INDÚSTRIA DE CAFÉ}

A partir do início da década de 90, a Associação Brasileira da Industria de Torrefação e Moagem de café (ABIC) elaborou o "selo de pureza", que certifica que as torrefadoras não cometem fraudes $e$ ofertem um produto com pureza não garantida, buscando com isso uma grande qualidade no produto.

Em resposta às ações tomadas pela $A B I C, 0$ consumidor começa a valorizar produtos com o selo de pureza em detrimento dos que não possuem, e assim, torna-se um diferencial de qualidade. Desta forma o crescimento da procura por cafés certificados elevou o consumo de café na década de 90 (SAES E FARINA, 1998).

\subsection{PDCA}

O PDCA elaborado por Deming (1990) é um poderoso instrumento da gestão da qualidade, este método é definido por quatro etapas que auxiliam na produção dos resultados esperados pelo projeto ou processo. As etapas são:

a) Plan (Planejamento): o planejamento consiste em traçar as metas (plano de metas) da atividade em questão, e criar passos para serem seguidos. 0 orçamento do projeto pode estar incluso na parte do planejamento.

b) Do (Execução): por em pratica o que foi planejado, buscando sempre seguir o plano de metas traçado no planejamento.

c) Check (Controle): nesta etapa são analisados indicadores de desempenho e consequentemente as falhas e os sucessos da implementação feita na ação.

d) Act (Ação): De posse dos resultados e análises realizadas na fase anterior, esta etapa pode ser dividida em duas partes, são elas: atuar corretivamente e agir para melhorar.

\subsection{PROGRAMA $5 S$}

Segundo Falconi (1996), o 5S tem como meta organizar o ambiente de trabalho, através da participação de todos os envolvidos da organização, da base ao topo da pirâmide hierárquica. Ressalta ainda a importância da mudança da forma de se trabalhar e de se comportar, o que pode elevar 
consideravelmente a produção e também a qualidade de vida de seus membros.

O nome desta ferramenta foi escolhido é devido a 5 sensos, que estão interligados através de atividades sequenciais, sendo uma dependente da outra, devendo coexistirem para a efetividade do programa. Os sensos do programa são respectivamente: Senso de Utilização, Senso de Ordenação, Senso de Limpeza, Senso de Saúde e Senso de Autodisciplina (RIBEIRO, 1994).

\subsubsection{SENSO DE UTILIZAÇÃO}

Segundo Gonzalez (2009), o senso de utilização é a atividade de separação dos materiais no ambiente de trabalho, de tal forma que se organize de forma eficiente $e$ eficaz o local, separando o útil do inútil.

Para Cordeiro (2013), é importante salientar que esse senso não envolve somente a separação e eliminação do desnecessário para o setor, deve-se avaliar a aplicabilidade desses materiais em outros setores, para isso, é importante o envolvimento de outros setores nas atividades desse senso.

\subsubsection{SENSO DE ORDENAÇÃO}

O senso de ordenação é definir o local para cada coisa, identificando e utilizando comunicação visual, além de ter um layout prático e funcional, que torne o trabalho seguro e facilite $o$ acesso imediato às ferramentas, materiais e postos de trabalho. (JESUS, 2003).

\subsubsection{SENSO DE LIMPEZA}

Para Lapa (1998), implantar esse senso é eliminar as sujeiras ou materiais estranhos para manter o ambiente limpo e manter as informações e dados sempre atualizados para auxiliar a tomada de decisão. Neste senso, mais importante que limpar o ambiente, é identificar a fonte de sujeira para evitar as ocorrências de sujeiras.

\subsubsection{SENSO DE SAÚDE}

Segundo Gandra (2006), este senso está ligado aos 3 sensos anteriores de forma sistematizada, ou seja, descartar o não útil, organizar o que for útil de forma ideal e manter um padrão de limpeza periódico, contribui para a saúde física, mental e emocional das pessoas inseridas neste ambiente. Assim resulta na padronização das atividades anteriores de forma sistêmica, com manutenção do que foi alcançado, para que não retrocedam.

\subsubsection{SENSO DE AUTODISCIPLINA}

Neto (2015), afirma que o Senso de Autodisciplina é uma peça importante para o sucesso do programa, em vista que é ele que incentiva a contínua melhoria do uso dos outros sensos, tais como o hábito de observar, seguir e manter os procedimentos, regras e especificações.

\subsection{AUDITORIA}

Esta parte é indispensável para a continuidade e manutenção do programa $5 \mathrm{~S}$, pois segundo Ribeiro (2006), ela é responsável por gerar os resultados do programa, que posteriormente serão analisados, e a partir destas, propor ações de melhorias para o programa. As auditorias são reuniões dos membros e devem acontecer periodicamente, seguindo o que foi definido no plano do programa e tem como os principais objetivos: mensurar a evolução do programa estabelecido, gerar resultados quantitativos e qualitativos, verificar como o programa está fluindo com relação ao planejamento, servir de ferramenta para a melhoria contínua e elaborar novas ideias.

\section{METODOLOGIA}

A metodologia utilizada neste trabalho foi o estudo de caso no setor de empacotamento de uma empresa de processamento de café, na região do triângulo mineiro, através de análise quantitativa e qualitativa. A aplicação do estudo de caso foi feita através da ferramenta PDCA, em que a primeira etapa foi a identificação das oportunidades de melhoria, e a partir desta, foi elaborado um planejamento de como o programa $5 \mathrm{~S}$ iria ser implantado, desde o treinamento dos colaboradores até a listagem dos recursos necessários.

\section{ESTUDO DE CASO}

Nessa seção do trabalho, será apresentado a descrição da empresa e como o estudo de caso foi realizado, junto a metodologia $5 \mathrm{~S}$ e detalhes da sua implantação no setor de empacotamento. Este setor é o responsável pelos processos de empacotamento de café 
torrado e moído em embalagens do tipo "almofada" em duas linhas (250g e $500 \mathrm{~g})$, à vácuo, café cru, e café torrado em grãos. Responsável também pela confecção de datas em alguns tipos de embalagem, enfardar os pacotes e unitizá-los em palhetes. Composto por 6 funcionários, este setor possui a etapa mais crítica de toda a operação, pois o empacotamento é o gargalo do sistema, sendo a empacotadora o equipamento que define o ritmo do processo.

\subsection{IMPLANTAÇÃO DO PROGRAMA 5S UTILIZANDO PDCA}

Nesta parte será mostrada as etapas do PDCA para implantação do programa $5 S$ no setor de empacotamento da empresa de processamento de café, explicando cada atividade desenvolvida em cada parte do ciclo. O ciclo PDCA para este projeto e suas subatividades pode ser analisado na Figura 1.

Figura 1 - Cronograma do ciclo PDCA.

\begin{tabular}{|c|c|c|c|c|c|c|c|c|c|c|c|}
\hline \multirow{2}{*}{ PDCA } & \multirow{2}{*}{ Atividades } & \multicolumn{10}{|c|}{ Semanas } \\
\hline & & 28 & 29 & зо & 31 & 32 & 33 & 34 & 35 & 36 & 37 \\
\hline \multirow{4}{*}{ 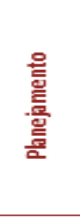 } & Definição da Equipe $5 \mathrm{~s}$ & & & & & & & & & & \\
\hline & Identificação das oportunidades de melhoria & & & & & & & & & & \\
\hline & Treinamento da Equipe $5 \mathrm{~s}$ & & & & & & & & & & \\
\hline & Definição dos objetivos e metas & & & & & & & & & & \\
\hline \multirow{3}{*}{ 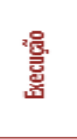 } & Treinamento da Equipe Operacional & & & & & & & & & & \\
\hline & Aquisição dos recursos & & & & & & & & & & \\
\hline & Dia D & & & & & & & & & & \\
\hline $\begin{array}{l}\text { 올 } \\
\text { 홍 }\end{array}$ & Treinamento dos Auditores & & & & & & & & & & \\
\hline
\end{tabular}

Fonte: Autoria própria (2017).

\subsubsection{PLANEJAMENTO}

A diretoria realizou um levantamento dos problemas no setor de empacotamento: necessidade de manutenção preventiva, reduzir paradas não programadas, ambiente de trabalho desorganizado, falta de padrão de limpeza, falta de lubrificação de equipamentos.

Inicialmente a diretoria decidiu pela implantação do programa $5 \mathrm{~S}$ como forma de organizar o ambiente de trabalho. Alguns objetivos traçados: criação de um equipe de trabalho, melhoria no ambiente de trabalho, melhoria no aproveitamento de espaço de recursos, tornar a administração mais participativa, otimizar a execução de tarefas, reduzir custos e implantar a responsabilidade compartilhada.

Foi definido um "Líder 5S" para o setor de empacotamento, sendo este responsável por coordenar o $5 \mathrm{~S}$ no seu posto e influenciar o comprometimento da equipe. Após levantadas as irregularidades e oportunidades de melhorias do posto de trabalho e repassadas à equipe $5 S$, foram realizadas discussões acerca das melhorias viáveis. Foi realizado um Brainstorming para a escolha de quais sugestões eram viáveis para o momento, quais deveriam ser postergadas e quais deveriam ser descartas. Após a realização de um segundo brainstorming, que contou com a presença do Líder $5 \mathrm{~S}$, o gerente financeiro e um sócio-diretor, foi aprovado o lançamento de alguns itens para o plano de ação.

O plano de ação foi elaborado com base nas demandas identificadas ao longo da etapa de planejamento, segundo o ciclo PDCA. Para gerenciar o plano de ação foi criada uma estrutura que define 0 que, Como, Quem e Quando, assim como, o status de realização da atividade, para controle do progresso do plano e para contornar rapidamente desvios na execução das atividades.

\subsubsection{EXECUÇ̃̃O}

Elaborado o plano de ação, a primeira atividade importante é a confecção da 
apresentação para a diretoria, a fim de sensibilizá-los quanto a importância do projeto, obter a aprovação e estimulá-los a impulsionar o programa. Sendo propagadores do $5 \mathrm{~S}$, estes assumem o compromisso de incentivar a promoção de ações que motivem os colaboradores na manutenção do programa, como fazer elogios às realizações dos funcionários, além de coibir atitudes que possam vir a desestimular o progresso do programa. Elaborado o material, foi marcado um dia para a apresentação, que contou com a presença de dois sócios-diretores, o gerente financeiro, o gerente de manutenção, um consultor externo e o líder $5 \mathrm{~S}$.

A apresentação foi composta por uma introdução e conceituação do programa 5S, importância do programa, diagnóstico da situação atual, plano de implantação do programa, juntamente com o cronograma e a metodologia para manutenção da prática. Após a apresentação foram discutidas questões sobre a importância da liderança para impulsionar o programa, e com a aprovação unanime de toda a diretoria, foi aprovado o lançamento do programa. Foi feita e assinada uma carta de compromisso para a concretização da implantação do programa.

Foi elaborada uma apresentação para todos os colaboradores do setor de empacotamento com intuito de apresentar os conceitos, objetivos, planos de implantação, discutir pontos cruciais para o sucesso do programa e motivá-los a participarem ativamente do desenvolvimento do projeto e manutenção do programa após implantá-lo. A apresentação foi marcada para o início do turno, que começa s 07:30 horas, com um café da manhã especial. Foram explicadas todas as propostas e discutidas todas as sugestões dadas por alguns funcionários. Ao final da apresentação, foi passado o cronograma com as atividades e datas programadas, assim como os avisos de "Falta $x$ dias para o Dia D (Dia em que o setor para suas atividades para ser apresentado o programa 5S)" nos quadros de aviso em toda a empresa.

Foi confeccionada, fixada aos murais de avisos e entregue aos colaboradores uma cartilha explicativa dos conceitos e práticas do Programa 5S, a fim de reforçar as informações passadas na apresentação.

Com a data do Dia D já marcada, a próxima etapa é aquisição dos recursos necessários para implementar as melhorias solicitadas. Os membros da Equipe $5 \mathrm{~S}$ fizeram orçamentos dos materiais necessários. Até a semana do Dia $D$ todos os produtos orçados e aprovados pela gerencia foram adquiridos, para que fossem implantados no dia.

A programação do Dia $D$ foi definida conforme o cronograma Figura 2. As atividades foram divididas a partir dos sensos, sendo destinada 2 horas para aplicação de cada senso. Foram distribuídos folhetos com a programação e algumas orientações quanto as atividades a serem realizadas.

Figura 2 - Programação do dia "D". Fonte: Autoria própria (2017)

\begin{tabular}{|c|c|c|}
\hline $7 \mathrm{~h} 30$ & \multirow{6}{*}{ 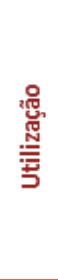 } & Café da Manhã \\
\hline $8 \mathrm{~h}$ & & Apresentação da programação dia "D" \\
\hline $8 \mathrm{~h} 30$ & & Identificar útil e não útil \\
\hline $9 h 30$ & & Identificar útil e não útil \\
\hline $10 \mathrm{~h}$ & & Destinar o não útil para o local ideal \\
\hline $10 \mathrm{~h} 30$ & & Destinar o não útil para o local ideal \\
\hline $11 \mathrm{~h}$ & & Almoço \\
\hline $12 \mathrm{~h} 30$ & 윰 & Destinar o útil para o local ideal \\
\hline $13 \mathrm{~h} 30$ & 穿 & Demarcar área do local ideal \\
\hline $14 \mathrm{~h} 30$ & ¿ & Organizar os insumos/recursos \\
\hline $15 \mathrm{~h} 30$ & $\mathbb{N}$ & Limpar toda a área \\
\hline $16 \mathrm{~h} 30$ & $\stackrel{\check{L}}{E}$ & Apresentação motivacional sobre a continuidade do programa \\
\hline $17 \mathrm{~h} 30$ & & Apresentação motivacional sobre a continuidade do programa \\
\hline
\end{tabular}

Fonte: Autoria própria (2017) 
O café da manhã contou com um cardápio especial e foram distribuídas camisas promocionais do Programa 5S

Foi solicitado os serviços da cooperativa local que faz a coleta seletiva dos resíduos sólidos para o Dia D. Eles passaram orientações quanto a separação dos materiais que seriam descartados, disponibilizaram Bags e ao final do dia fizeram a coleta do montante de resíduos descartado.

\subsubsection{CONTROLE}

Uma forma de dar continuidade ao Programa $5 S$ é através da realização de auditorias, com foco na avaliação dos níveis de cada um dos 5 sensos. Para isso, foram criados os checklists, um material composto por um formulário de perguntas sobre nível de adequação a cada senso, em que são atribuídas notas a cada resposta, de tal forma que traduza em números os resultados, e seja possível estabelecer metas quantitativas de adequação aos sensos. As questões devem ser respondidas da seguinte forma:

- Conforme: Dentro dos padrões préestabelecidos - nota 4;

- Com restrição: Há restrições no atendimento aos padrões préestabelecidos - nota 2;

- Não conforme: Não segue os padrões pré-estabelecidos - nota 0;

Para auxiliar os auditores na interpretação correta das perguntas sobre os sensos e orientá-los quanto aos pontos a serem observados na avaliação da implantação para responder as perguntas, foi criado um manual do auditor, que foi entregue a cada um dos auditores no dia do treinamento dos auditores, para ser estudados antes da primeira auditoria.

As respostas coletadas são lançadas na ferramenta de acompanhamento, elaborada através do software Microsoft Excel $\circledast$, contido no Pacote Office ${ }^{\circledR}$, para serem processadas e apresentar os resultados da aplicação de cada senso, em cada setor, em função da porcentagem de conformidade ao padrão ideal, que é publicado no manual de auditores, para auxiliar os auditores na avaliação da implantação dos sensos.
Após a elaboração do check-list, é preparado um treinamento com os auditores do programa, com o objetivo de apresentar a ferramenta de acompanhamento de resultados do Programa $5 \mathrm{~S}$, treinar os auditores para a realização dos check lists, desenvolver visão crítica nas avaliações dos sensos, desenvolver a capacidade de observar e avaliar as oportunidades de melhorias e promover ações de melhoria. As auditorias são realizadas na semana que completa 15 dias após a última auditoria, exceto a primeira auditoria que foi realizada 30 dias após o dia "D". Nas auditorias estão presentes $\mathrm{o}$ líder $5 \mathrm{~S}$ e os gerentes da empresa.

O programa deve ser contínuo, portanto, as auditorias não têm previsão de término. Com o tempo as auditorias poderão ter intervalos maiores para sua execução, dependendo da necessidade. Assim, as auditorias serão a principal ferramenta que contribuirá para consolidar os ganhos do programa ao longo do tempo.

\subsubsection{AÇÃO}

Ao final da semana do $15^{\circ}$ dia após a última auditoria são lançados no sistema os dados coletados pelos auditores, analisados pelos membros da equipe $5 \mathrm{~S}$, discutidos os resultados e as sugestões levantadas, para que no início da semana seguinte seja feita uma reunião com os líderes de setores para reportar as informações produzidas, e para que estes façam as medidas necessárias para corrigir as irregularidades, juntamente com os colaboradores do setor.

As ações que não alcançaram as metas propostas no plano de ação, são tratadas como pontos problemáticos, para que através de uma análise conduzida, sejam identificadas as causas do não atingimento das metas, para que estas sirvam de "lição", e conduzam à novos planos de ação. As ações que levaram ao atingimento de metas são legitimadas e padronizadas.

\section{ANÁLISE DOS RESULTADOS}

A Figura 3 mostra os resultados das auditorias no setor de empacotamento. 
Figura 3 - Gráfico Auditoria Empacotamento

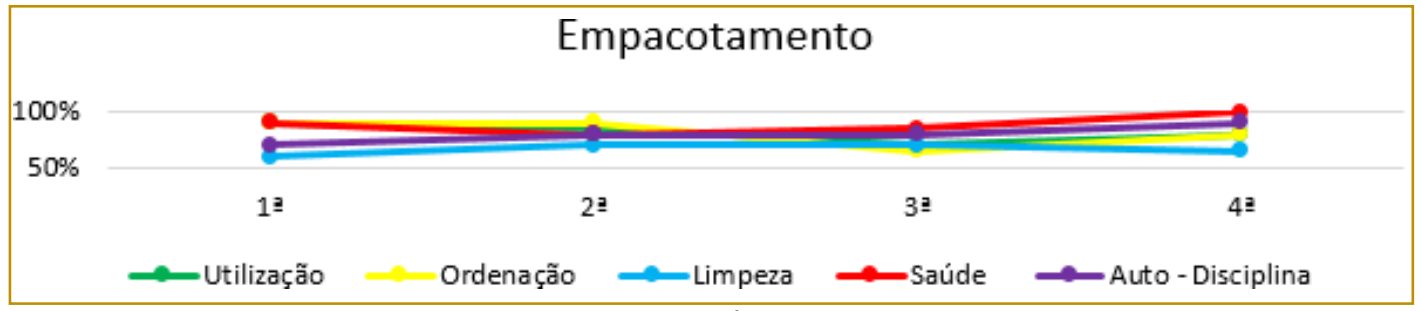

Fonte: Autoria própria (2017).

Antes da aplicação do Dia D era fácil notar a quantidade de produtos inúteis ao setor, como quadros de avisos danificados encostados nos cantos, equipamentos obsoletos, ferramentas estragadas, ferramentas em excesso e outras faltando, sucatas, materiais de outros setores que foram "esquecidos" ali, etc. Os excessos de materiais desnecessários geravam desperdícios de espaço, em um ambiente com várias limitações de área, deixa um aspecto visual ruim, como mostra a Figura 4.

Figura 4 - Empacotamento Antes e Depois.

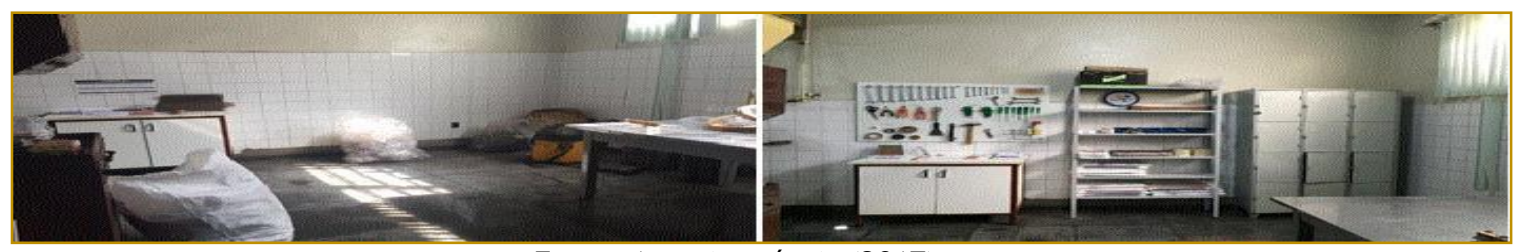

Fonte: Autoria própria (2017)

A fim de eliminar as perdas de ferramentas, facilitar o acesso e ter maior controle do uso e da quantidade de ferramentas necessárias, foi criado um quadro de ferramentas, conforme a Figura 5. Todas as ferramentas foram marcadas conforme o setor que pertence, identificando os locais de cada uma no quadro, de tal maneira que ao se retirar uma ferramenta do seu local, instantaneamente é possivel saber qual está faltando.

Figura 5 - Quadro de ferramentas.

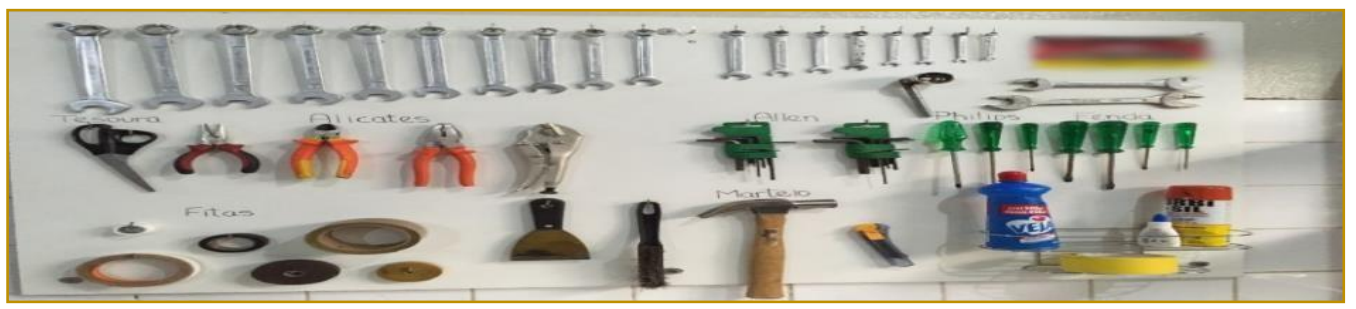

Fonte: Autoria própria (2017)

A Figura 6 lista algumas das ações tomadas durante as auditorias que obtiveram resultados satisfatórios. 
Figura 6 - Ações Eficazes no Empacotamento.

\begin{tabular}{|c|c|c|}
\hline Açōes eficazes/padronizadas & Senso Aplicado & $N^{2}$ Auditoria \\
\hline Quadro de Ferramentas & Ordenaş̄o & 0 \\
\hline Retirada de equipamentos inúteis para o setor & Utilizaçฐ̃o & 0 \\
\hline Compra de prateleira para ordenaçăo dos insumos & Ordenaçåo & 0 \\
\hline Recuperação de armário que estava ocioso em outro setor e identificação & Utilizaçäo & 0 \\
\hline POP para utilizaç̃̃o de equipamentos do setor & Ordenaçð̄o & 1 \\
\hline Gestäo à vista & Autodisciplina & 1 \\
\hline Identificação dos locais dos equipamentos, móveis, produtos e residuos & Ordenaçăo & 1 \\
\hline Renovaçäo dos EPIs & Saúde & 1 \\
\hline POP para descarte de residuos & Utilizaçð̃o & 1 \\
\hline POP para limpeza e lubrificaçбo de equipamentos & Limpeza & 2 \\
\hline Estoşöo de Limpeza & Limpeza & 2 \\
\hline Identificaçāo dos corredores & Saúde & 2 \\
\hline Folders de incentivo ao uso de EPI & Autodisciplina & 2 \\
\hline Reuniz̃o de avaliaçรo dos resultados e discussåo de melhorias & Autodisciplina & 2 \\
\hline Identificaçăo de armário, EPIs e ferramentas com o nome dos colaboradores & Ordenaç\$ొం & 2 \\
\hline Reuniz̄o de avaliaçāo dos resultados e discussāo de melhorias & Autodisciplina & 3 \\
\hline Treinamento com lider do setor para correçäo de desvios & Autodiseiplina & 3 \\
\hline
\end{tabular}

Fonte: Autoria própria (2017)

As ações que não atingiram as metas de adequação até o final do estudo estão listadas na Figura 7, sendo que a partir da implantação destas até a última auditoria foram realizados os "giros" do PDCA. Sendo investigadas as causas do não atingimento das metas a cada auditoria, são formulados novos planos para o alcance dos objetivos.

Figura 7 - Ações Ineficazes no Empacotamento.

\begin{tabular}{|l|c|c|}
\hline \multicolumn{1}{|c|}{ Ações ineficazes } & Senso Aplicado & № Auditoria \\
\hline Regras de retorno das ferramentas do quadro de ferramentas & Autodisciplina & 1 \\
\hline Manual e cronograma de limpeza do setor & Limpeza & 1 \\
\hline Revezamentos nas atividades de promoção do programa & Autodisciplina & 2 \\
\hline
\end{tabular}

Fonte: Autoria própria (2017)

A falta de retorno das ferramentas após o seu uso para o local definido e o desaparecimento de algumas ferramentas do quadro de ferramentas nos dias de auditoria gerou a elaboração de um plano de ação para corrigir esse desvio, no qual foi criado regras para a utilização das ferramentas do quadro após a primeira auditoria, no entanto, o problema persistiu até o final do estudo.

A limpeza no setor é realizada pelos próprios funcionários, sendo estas feitas ao final do expediente, ou por oportunidades, quando há paradas das máquinas ou tempo ocioso. Em dias em que a demanda é muito alta, podem não ocorrer limpeza no dia, mas no dia seguinte, antes de iniciar as operações, é feita. Foram criados procedimentos operacionais padrão para a limpeza do setor, e criado a "estação de limpeza", em que as ferramentas de limpeza ficam localizadas, de acordo com a Figura 8, após a segunda auditoria, porém os procedimentos e cronogramas não eram seguidos. Identificamos que a causa raiz do problema era má formulação do manual, contendo regras desnecessárias e inflexíveis em situações de flutuação da demanda. O plano de ação foi ineficaz, portanto, descartado. 
Figura 8 - Estação de Limpeza.

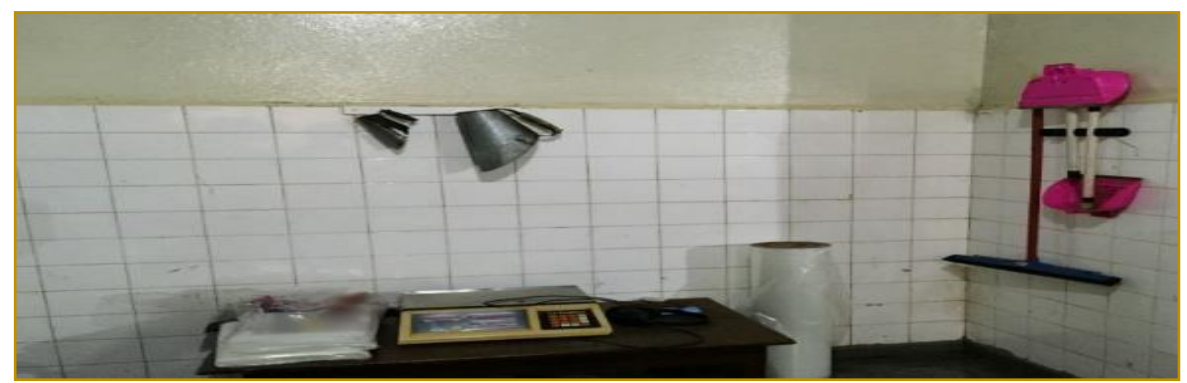

Fonte: Autoria própria (2017)

Foram identificadas algumas resistências às ações de promoção do programa, pois alguns colaboradores não estavam realizando as atividades de integração e promoção do programa voluntariamente. Foram reformuladas algumas ações para a promoção da marca do programa 5S, após a segunda auditoria, afim de melhorar a aceitação e propagação do programa, como uso da camisa nos dias de quarta-feira, integração entre setores, geração de ideias de melhorias, etc., porém, os planos de ação não alcançaram as metas.

\section{CONCLUSÃO}

A aplicação da ferramenta $5 S$ no setor de empacotamento conseguiu atingir bons objetivos, porém alguns pontos não mostraram melhora como: regra de retorno de ferramentas, manual do cronograma de limpeza do setor e revezamento das atividades de produção do programa. Essa

\section{REFERÊNCIAS}

[1] Cordeiro, F. Implantação do Programa 5S em Canteiro de Obra. Trabalho de Conclusão de Curso (Graduação) - Curso de Engenharia Cívil. Universidade Federal de Santa Catarina, Florianópolis, 2013.

[2] Deming, William Edward. Qualidade: a revolução da administração. Rio de Janeiro: Marques-Saraiva, 1990.

[3] Falconi, V. Gerenciamento pelas Diretrizes. 2 ed. Belo Horizonte: QFCO, 1996.

[4] Gandra, M. Programa 5S na Fábrica. Um suporte para implantação do Sistema de Gestão Integrada. Monografia apresentada como exigência para obtenção do Título de Especialista em Gestão e Tecnologia da Qualidade do CefetMG. Belo Horizonte, 2006. postura era esperada, pois a empresa possuía uma cultura familiar e está em busca de uma profissionalização de suas atividades. Desta forma a mudança cultural leva tempo e esforço dos gestores, e a implantação do $5 \mathrm{~S}$ foi um grande passo para essa mudança. Considera-se que algumas ações para enfrentar as resistências possam ter melhores resultados quando aplicadas nas etapas iniciais da implantação, mostrando o resultado que era esperado e o que aquilo faria de melhor no dia-a-dia.

Vale ressaltar que o programa 5S não deve ter fim, ou seja, a manutenção do programa deve ser contínua, para continuar motivando os colaboradores a manter a cultura, e desta forma, criar um ambiente favorável a maior rentabilidade da empresa.

\section{AGRADECIMENTOS}

Agradecemos aos nossos familiares, amigos e professores pela dedicação e carinho

[5] Gonzalez, E. F. Aplicando 5S na Construção Civil, Editora UFSC, 2.ed. Florianópolis, 2009.

[6] Jesus, Alex Ribeiro DE. Programa $5 S$. Comitê de Qualidade dos Correios, São Paulo, v. 65, 2003.

[7] Lapa, R. P, Programa 5S, Qualitymark Editora, Rio de Janeiro, RJ, 1998.

[8] Leme, P. H. M. V; Machado, R. T. M. Os pilares da qualidade: 0 processo de implementação do programa de qualidade do café (pqc). Artigo publicado em Organizações Rurais \& Agroindustriais, Lavras, v. 12, n. 2, p. 234-248, 2010.

[9] Neto, D. F. de A. Aplicação do Programa $5 \mathrm{~S}$ em Empreendimento de Conjunto Habitacional de Baixo Custo. Trabalho de Conclusão de Curso (Graduação) - Curso de Engenharia de Produção. 
Universidade Federal de Uberlândia, Ituiutaba/MG, 2015.

[10] Saes, M. S. M.; Farina, E. M. M. Q. Associação Brasileira da Indústria de Café - ABIC: ações conjuntas e novos desafios frente a reestruturação de mercado. In: Seminário Internacional Pensa de Agribusiness. Rio de Janeiro, 1998.
[11] Ribeiro, Haroldo. A bíblia do 5S, da implantação a excelência. Primeira edição Salvador: Casa da qualidade, 2006.

[12] Ribeiro, Haroldo. 5S. A Base para Qualidade Total/ Um Roteiro para Implantação Bem-Sucedida. Salvador: Casa da Qualidade, 1994. 


\section{Gapítulo 12}

\section{UTILIZAÇÃO DO MAPEAMENTO DE PROCESSOS PARA IDENTIFICAÇÃO DE FALHAS E MELHORIA CONTINUA EM UMA INDÚSTRIA PRODUTORA DE SACOS DE LIXO}

\section{Lucas Carvalho Martins}

\section{Isabella Silveira Ferro}

Isabela Lopes Gomes Torres

\section{Isabela Gonçalves Bastianini}

Resumo: Em um mercado tão vasto e competitivo conhecer o próprio processo produtivo é fundamental para o sucesso da organização. 0 mapeamento de processos foi utilizado neste estudo de caso para identificar todas as fases e tarefas de uma indústria produtora de sacos de lixos que utiliza fonte de matéria prima provinda da reciclagem urbana. A empresa apresenta alguns setores desde o administrativo até a expedição do produto final, e em todos os processos foi utilizada a ferramenta fluxograma para mapear e detalhar as atividades, afim de observar possíveis falhas produtivas e implementar um plano de ação. Todos os setores, fora a expedição, apresentaram falhas produtivas, e suas soluções foram propostas e implementadas, o que gerou significativa mudança e crescimento nos lucros da empresa. 0 mapeamento de processo conjuntamente com a ferramenta fluxograma e o plano de melhoria, foram extremamente eficientes neste trabalho. 


\section{INTRODUÇÃO}

No universo produtivo industrial existe a busca constante na redução de custos, buscando a maior competitividade e lucratividade. Dentro desse cenário o uso da Engenharia de Produção se destaca, pois suas ferramentas e conhecimentos podem alavancar o sucesso dos processos produtivos, reduzindo as falhas e desperdícios. Uma das ferramentas utilizadas é o mapeamento de processos. Esta ferramenta tem por objetivo tornar visível o processo industrial através de ilustrações que possam facilitar a visão dos acertos e falhas da atividade.

Segundo Villela (2000), o mapeamento de processos permite ao gestor, a visualização clara dos processos envolvidos dentro do sistema de produção da empresa, e com esse recurso é possível enxergar falhas, estabelecer metas de melhoria, executar ordens corretivas e preventivas e manter o sistema mais estável possível.

Dentro do mapeamento de processos é possível destacar o fluxograma, uma ferramenta capaz de ilustrar e identificar todas as etapas de uma seqüência produtiva. É um recurso essencial para qualquer linha de produção por poder atender as necessidades de controle.

0 presente trabalho teve por objetivo usar o fluxograma como ferramenta de mapeamento de processos em uma indústria de produção de sacos de lixo com material prima provinda da reciclagem do plástico usado. 0 objetivo foi detectar as falhas do sistema e criar alternativas de melhoria para a maior eficiência produtiva da indústria.

\section{REFERENCIAL TEÓRICO}

Nesta seção serão abordados os principais fundamentos sobre 0 mapeamento de processos, a ferramenta do fluxograma e suas principais características.

\subsection{O MAPEAMENTO DE PROCESSOS}

Mapeamento de processos, segundo Villela (2000), é uma ferramenta utilizada para a comunicação, sua finalidade é a melhoria dos processos já existentes e iniciar uma nova estrutura direcionada para os processos. 0 uso desse critério proporciona os seguintes benefícios para as organizações: redução dos custos para os processos, a redução de falhas, a integração dos processos e informações.

Esse critério exerce uma função de importância para as organizações, ele desafia os processos já existentes, determinando assim as oportunidades para seu desenvolvimento de desempenho para a identificação de falhas e também cria-se bases na implantação de novas tecnologias de integração e informação.

De acordo com Hunt (1996) o mapeamento de processos é desenvolvido e implantado para as áreas estratégicas e a melhoria de desempenhos, sendo para relatar, em fluxogramas e textos de suporte, cada etapa dos processos de negócios. O fluxograma ajuda as organizações a desenhar seus processos e também nas suas melhorias.

Segundo Biazzo (2000), existem diversos critérios para a representação e a elaborações de diversos mapas, contudo qualquer critério adotado para a elaboração do mapeamento de processos deve seguir 3 etapas:

a) Etapa 1: Definir os clientes e as fronteiras de seus processos, definir também os outputs e inputs de seu fluxograma de trabalho;

b) Etapa 2: Entrevistar os responsáveis das atividades, e dos documentos que estão disponíveis do processo;

c) Etapa 3: Criar o modelo com as informações adquiridas no decorrer das etapas e revisar o modelo.

O fluxograma é a ferramenta mais importante para o mapeamento de processos, pois é uma ferramenta de fácil entendimento e de fácil relacionamento com outros processos. Sendo um método que se descreve de maneira gráfica um processo já existente, ou algum processo que será proposto, usando símbolos, linhas, representando assim as atividades e as sequiências de seus processos.

Segundo Pinho (2006) existem diversas técnicas para a modelagem de processos e seu mapeamento, essas técnicas são:

- Mapeamento de processo de Barnes: é uma técnica de registro de processos de maneira rápida, utilizando símbolos padronizados para transportes, esperas, estoques e inspeções; 
- Mapofluxograma de Barnes: é um fluxograma de processos de plantas de edifícios;

- Diagrama de Fluxos de Dados (DFD): São informações de diferentes processos de um sistema

- Fluxograma Krajewki e Ritzman: São informações visuais dos processos, onde poderão ser registradas outras informações das tomadas de decisões;

- Linguagem de Modelo Unificado (UML): É um fluxograma com ênfase em atividades que irão ocorrer ao longo do tempo;

- Blueprint Fitzsimmons e Fitzsimmons: É um fluxograma ou mapa de todos os processos;

- DEF3: É um diagrama que mostra os comportamentos de seus clientes;

\subsection{FLUXOGRAMA}

A ferramenta do fluxograma é indispensável para a qualidade e o atendimento dos processos. Ela visa a facilidade e a identificação dos produtos que serão produzidos, a identificação também de seus fornecedores e clientes, suas funções e responsabilidades (PINHO, 2007).

Segundo Mello e Salgado (2005), a técnica do fluxograma é necessária para registrar pequenos processos, tendo uma melhor visualização e compreensão, para suas melhorias. A representação gráfica mostra os diferentes eventos como: a execução do processo, a identificação de cada etapa de suas atividades, o transporte, as inspeções, as esperar, e os documentos que serão registrados.

O processo do fluxograma é a descrições das sequiências que se destacam as fases operacionais, e que serão executadas, e também podem ser executadas em paralelo. Os diferentes tipos de operações são apresentados por diferentes símbolos (MELLO \& SALGADO, 2005).

Podemos observar nas Figuras 1 e 2, o significado de cada símbolo e um exemplo de uso do fluxograma.

Figura 1 - Significado de cada símbolo

\begin{tabular}{|l|l|}
\hline & Indica o inicio ou fim do processo \\
\hline & Indica cada atividade que precisa ser executada \\
\hline & Indica um ponto de tomada de decisào \\
\hline & Indica os documentos utilizados no processo \\
\hline & Indica uma espera do fluxo \\
\hline & $\begin{array}{l}\text { Indica que o fluxograma continua a partir desse ponto em outro } \\
\text { circulo, com a mesma letra ou numero, que aparece cm seu interior }\end{array}$ \\
\hline
\end{tabular}

Fonte: Pinto (2004) 
Figura 2 - Exemplo de uso do Fluxograma

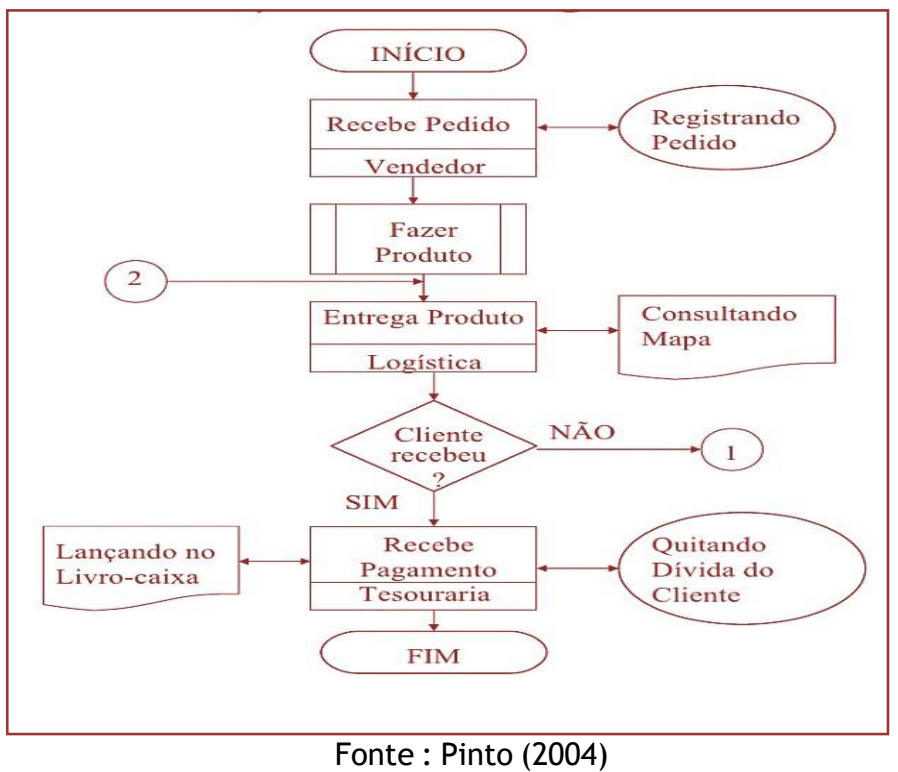

A Figura 3 representa algumas vantagens e desvantagens do uso do Fluxograma

Figura 3 - Vantagens e Desvantagens do fluxograma

\begin{tabular}{|c|c|}
\hline Vantagens & Desvantagens \\
\hline $\begin{array}{l}\text { Facilita o planejamento, análise e a soluções de } \\
\text { problemas; }\end{array}$ & $\begin{array}{l}\text { Conforme o tipo de atividade pode haver } \\
\text { dificuldades nos desenhos; }\end{array}$ \\
\hline Possui fatores concretos; & Testes e depurações, no geral não são fáceis \\
\hline Uso de símbolos, facilita a simplifica a leitura & $\begin{array}{l}\text { As vezes é necessário mais de uma pessoa para } \\
\text { completar um fluxograma; }\end{array}$ \\
\hline Repercussões positivas; & $\begin{array}{l}\text { Grande dificuldade no detalhadamente dos } \\
\text { fluxogramas; }\end{array}$ \\
\hline \multicolumn{2}{|l|}{$\begin{array}{l}\text { Análise de qualquer método do mais simples para } \\
\text { o mais complexo; }\end{array}$} \\
\hline Identificações rápidas, de pontos fracos e fortes; & \\
\hline
\end{tabular}

Fonte: Chinelato (2004)

\section{METODOLOGIA}

A metodologia empregada para ajudar na estruturação e organização deste trabalho será baseada na pesquisa qualitativa e quantitativa, por meio da utilização de mapeamento de processos.

Segundo Oliveira (2001) a pesquisa qualitativa apresenta a simplicidade em representar uma teoria mais elaborada, explorar a relação entre elementos que variam, entender e identificar métodos em atividade explorado por diversas comunidades. Já a pesquisa quantitativa busca mensurar informações, por meio de uma coleta, bem como admitir bens e métodos estatísticos e examinar os motivos que levaram a realização de tal acontecimento (OLIVEIRA, 2001).

Segundo Ajard (1998) o mapeamento de processos proporciona um olhar abrangente para reconhecer, registrar, observar e aperfeiçoar os processos. Além de indicar a relação entre entradas e saídas. Damelio (1996) entende que a avalição dos processos com o auxílio de mapas melhora a satisfação dos clientes, uma vez que são reconhecidas as práticas para diminuir custos, enriquecer a produtividade, excluir defeitos e atividades que não agregam valo ao processo. 
A pesquisa tem como objetivo apresentar as propriedades dos processos, a partir de métodos de arrecadação de dados e informações. Em relação aos procedimentos para sua elaboração o presente trabalho foi executado com o auxílio de colaboradores para entender os processos e assim detectar falhas dentro do sistema em uma indústria de processamento e reciclagem de plásticos para a produção de sacos de lixo.

Para dar início a apresentação do processo, foram realizadas entrevistas com os responsáveis por cada setor da fábrica para que esses relatassem toda e qualquer atividade realizada no dia-a-dia. Para o direcionamento da entrevista utilizou-se uma sucessão de perguntas capaz de auxiliar no entendimento dos processos. Além disso os pesquisadores observaram atentamente todas operações realizadas nos setores.

Depois de entendido o funcionamento de todos os setores da fábrica, foi realizada a modelagem do processo por meio do software Bizagi Process Modelerum programa de fácil entendimento e uma interface didática.
Posteriormente os pesquisadores observaram novamente todos os processos de maneira a enfatizar os pontos a serem melhorados, no que se refere ao uso de equipamentos de proteção individual, materiais que estavam sendo utilizados, ambiente e condições de trabalho, entre outros. Assim, algumas mudanças foram documentadas para amenizar todos os tipos de problemas encontrados.

\section{ESTUDO DE CASO}

$O$ estudo de caso foi realizado com o intuito de mapear o processo da indústria de produção de sacos de lixo, para que pudesse ser visualizadas as falhas em todos os processos e posteriormente realizar um plano de correção e melhoria contínua.

Verificou-se que na empresa o setor administrativo é responsável pelos demais setores da empresa, pois é a partir dele que a empresa recebe o pedido do cliente e destina o material para o setor correspondente, demonstrado na Figura 4 a seguir.

Figura 4 - Hierarquia dos setores

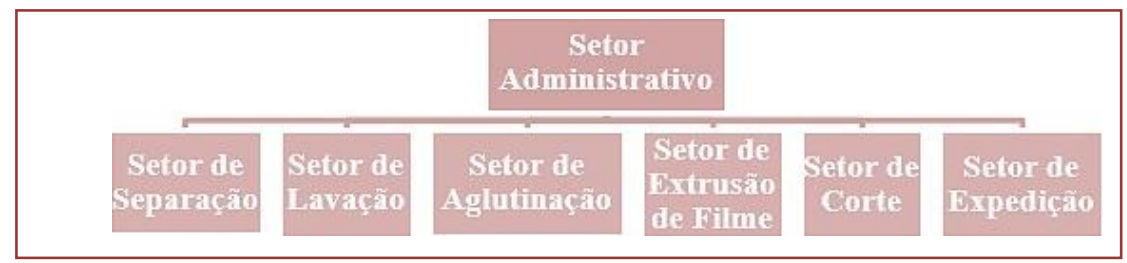

Fonte: Autoria própria

\subsection{DESCRIÇÃO DA EMPRESA}

A empresa Plásticos Pontal produz sacos de lixo de cores e tamanhos bem variados, a partir de materiais plásticos reciclados. Para a produção de plásticos coloridos utilizam-se materiais reciclados de diversas cores, porém a produção de plásticos brancos e transparentes utiliza-se somente as suas respectivas cores de materiais reciclados. A sua produção varia de acordo com os pedidos dos clientes sob a forma de encomenda e previsão de demanda. 0 estudo de caso foi realizado a partir de um fluxograma, com o objetivo de mapear todo o processo da empresa de modo a auxiliar na detecção de falhas.

\section{RESULTADOS E DISCUSSÕES}

Nesta sessão serão abordados a descrição dos setores, o mapeamento de cada um, a identificação as falhas $e$ as soluções encontradas.

\subsection{SETOR ADMINISTRATIVO}

Nesse setor os pedidos chegam para o escritório sobre qual volume e cor de saco plástico que desejam adquirir. Feito isso os responsáveis por esse setor emitem uma ordem de serviço com as informações que se devem produzir e passam para o gerente de produção. Caso o material já esteja fabricado ele precisará passar somente pelo setor de corte, caso contrário deverá seguir desde o setor de separação. O fluxograma do setor 
administrativo pode ser observado na Figura

5.

Figura 5 - Setor administrativo

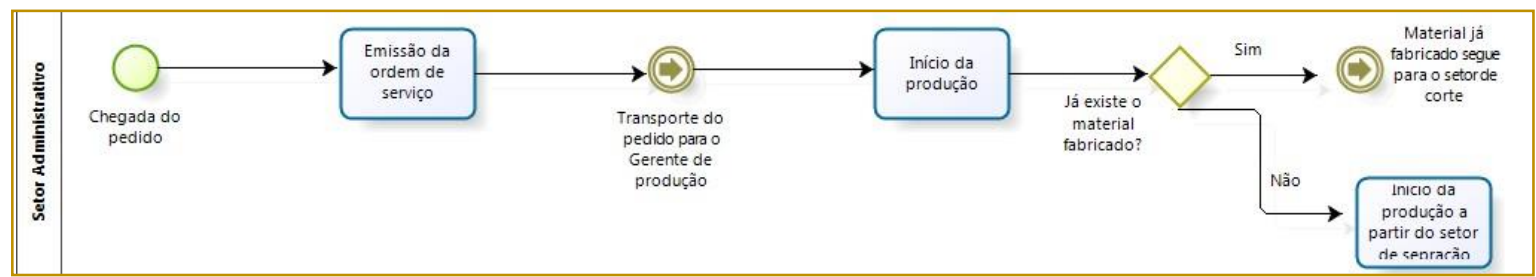

Fonte: Autoria própria

Neste setor foi possível verificar algumas questões importantes. Uma falha grave que foi identificada nesse setor foi na área de aquisições, pois o fornecedor estava com um preço de mercado $20 \%$ acima dos concorrentes, assim o fluxograma auxiliou muito na identificação das tarefas, e através dessa identificação foi possível acionar mudanças. Devido a esse fato hoje foi montada uma carteira de fornecedores potenciais, na qual se encontra todos os contatos dos principais fornecedores de plásticos provindos da reciclagem. Outra mudança no setor administrativo foi a dispensação de ordens de serviço, pois antes a ordem era emitida no escritório e passada diretamente para o setor de produção sem nenhuma explicação mais aprofundada, assim ocorriam muitos erros de pedidos e produtos produzidos. Com a ajuda do fluxograma e seu detalhamento foi possível enxergar essa falha e um sistema de comunicação digital por tablet foi inserido entre o setor administrativo e produtivo. 0 sistema de comunicação via tablet também auxiliou na verificação de produtos em estoque.

\subsection{SETOR DE SEPARAÇÃO}

O primeiro setor a ser analisado foi o da separação, que consiste na chegada dos caminhões com a matéria-prima que é adquirida por meio de um fornecedor. Os materiais reciclados são prensados e chegam à empresa em blocos totalizando cerca de 20 toneladas, que são transportados e descarregados por meio de um guincho até o setor. Inicia-se então o processo manual de separação, em que os funcionários em contato direto com esses materiais retiram do fardo os plásticos que podem ser usados para o processo dos que não podem ser usados, consiste também na separação por cores de materiais. Esses materiais que não entram no processo são separados ao lado e alguns vendidos para outros fins. Depois de realizado esse processo os materiais são destinados ao moinho para iniciar o processo de lavação. O fluxograma do setor de separação pode ser observado na Figura 6.

Figura 6 - Setor de separação

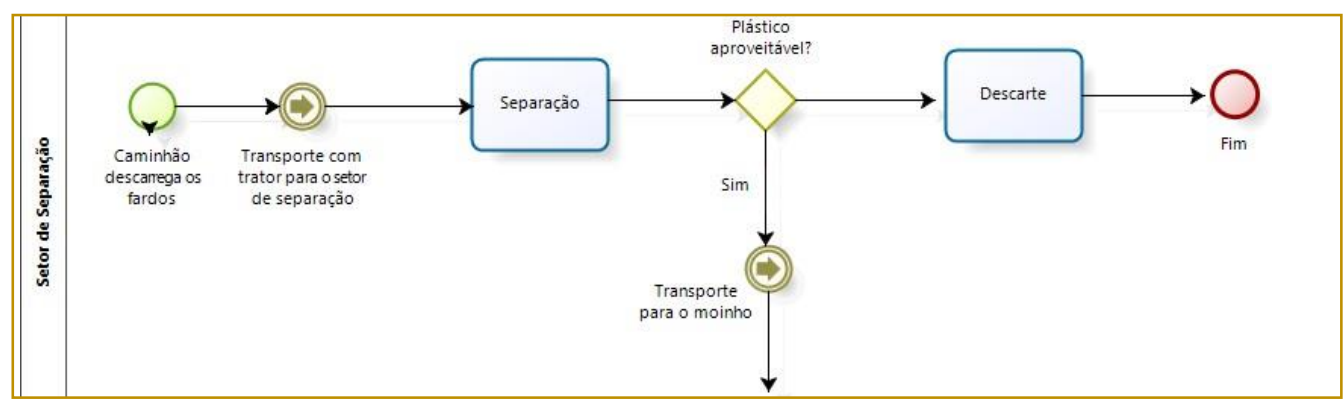

Fonte: Autoria própria

Neste setor as falhas principais foram a quantidade de funcionários obsoletos e falta de pesagem da matéria prima inicial. Foram identificadas falhas de programação de turnos e excesso de funcionários no setor, o que encarecia muito 0 processo. 0 mapeamento por fluxograma detalhado mostrou essas falhas e ações foram tomadas 
para otimizar o processo. Foi montada uma tabela onde se consegue calcular a quantidade de funcionários necessária para cada caminhão carregado de carga, assim, através de métodos de previsão de demanda foi possível estabelecer estimativas muito próximas da quantidade de funcionários necessária por matéria prima adquirida. Foram dispensados 3 funcionários, pois a mão de obra não estava sendo utilizada com eficiência devido a menor quantidade de matéria prima que chegava. Um dos pontos chaves desse trabalho é que uma parte da matéria prima que chega não é utilizada, pois contém papelão e plásticos não recicláveis, o gerente tinha uma estimativa imprecisa de perda de $10 \%$, e esse valor era descontado do fornecedor. Depois do mapeamento e observando muito o processo, foi adquirida uma balança, na qual chegou-se a estimativa de $25 \%$ de perda de matéria prima, assim a empresa estava pagando por matéria prima inutilizada. Com a aquisição da balança e o alto controle de perda de matéria prima, gerou-se um lucro líquido de $2 \%$ para a empresa.

\subsection{SETOR DE LAVAÇ̃̃O}

0 setor seguinte recebe o nome de lavação em que o material reciclado é moído e lavado em um tanque específico, esse tanque contém 3 pás que giram por meio de uma bomba. Para produzir uma cor diferente de saco plástico o tanque deve ser lavado e faz com que esse setor fique parado em torno de 12 horas. Consiste ainda de 3 tanques de decantação para retirada do barro dos materiais reciclados e depois essa água é descartada. Posteriormente esse plástico é secado e fica estocado em um outro departamento para receber a aglutinação. 0 fluxograma do setor de lavação pode ser observado na Figura 7.

Figura 7 - Setor de lavação

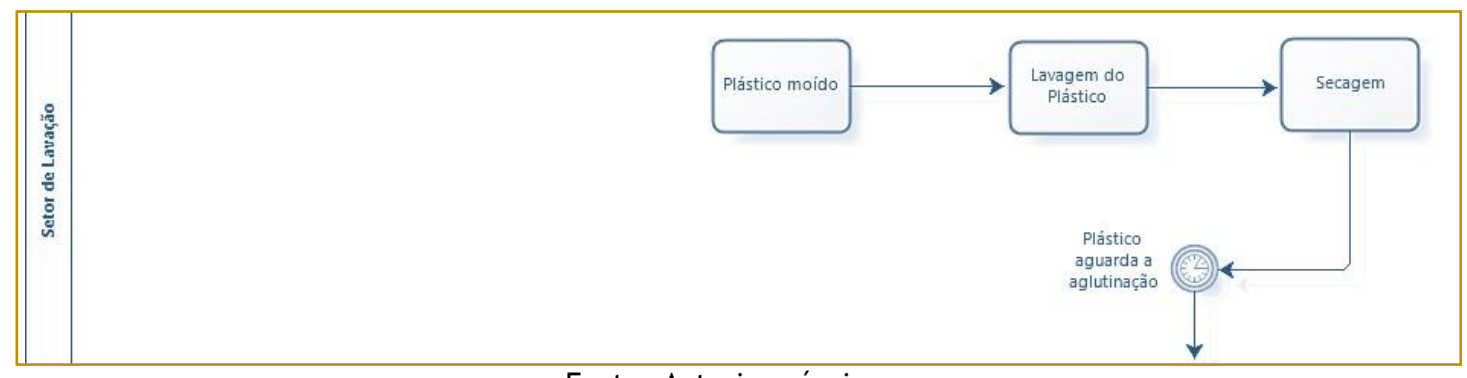

Fonte: Autoria própria

Neste setor o fluxograma detalhado auxiliou na verificação da manutenção e no controle de perda de plástico por fluído vazado. A empresa não praticava a manutenção preventiva pois a contratação de um mecânico por período integral não se mostrava viável, contudo veio a idéia de terceirizar a manutenção da empresa, assim a máquina de lavação do plástico e todas as outras receberiam manutenção preventiva, os ganhos foram surpreendentes, com uma queda de $68 \%$ nas paradas por falha mecânica. A máquina de lavação apresentava uma perda alta de fluido com plástico utilizável, com métodos de cálculos chegou a estimativa de $10 \%$ de perda por fluido vazado, assim foi criada uma canaleta de concreto e com uma bomba o fluido retorna para a máquina. Assim houve uma queda de perda para $2 \%$.

\subsection{SETOR DE AGLUTINAÇÃO}

A aglutinação nada mais é do que transformar o material flexível em uma forma mais rígida, a de grãos. No setor de aglutinação o material recebe o pigmento para a produção de plásticos coloridos ou pretos e para plásticos transparentes e brancos ele recebe o grão canela. Isso é utilizado para dar uma coloração mais forte ao plástico. Esse grão é inserido em uma extrusora de grãos, onde passará por um processo de aquecimento e logo em seguida por um resfriamento para torna-lo mais rígido. Assim, o material é destinado para o setor de extrusão de filme. 0 fluxograma do setor de aglutinação pode ser observado na Figura 8. 
Figura 8 - Setor de aglutinação

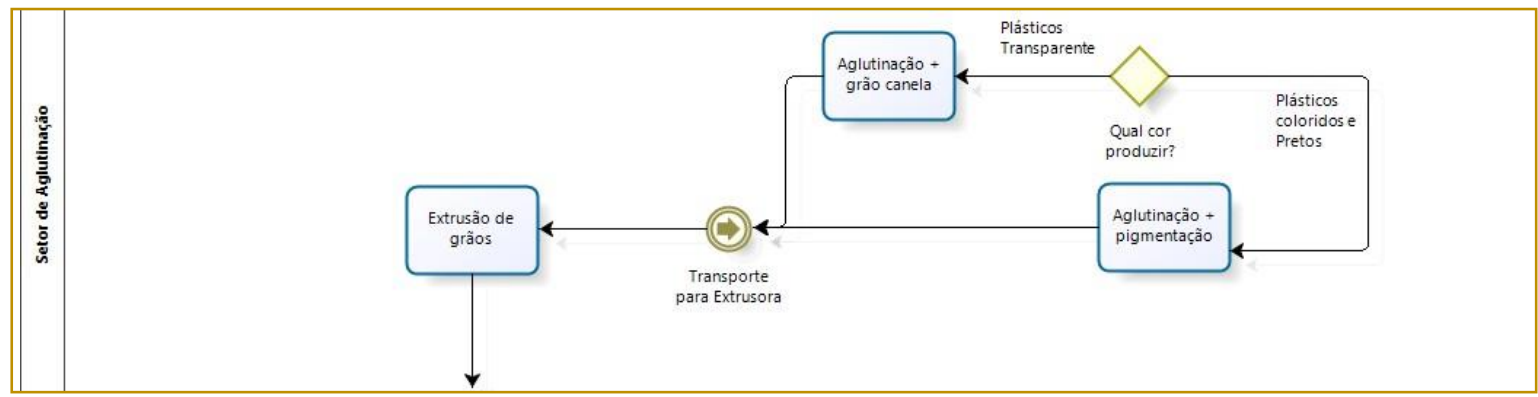

Fonte: Autoria própria

Neste setor o fluxograma auxiliou na identificação de falhas na parte de pigmentação do plástico. Os funcionários não colocavam a quantidade correta de pigmentação e isso ferava um gasto alto para a indústria, assim foi necessário estalar câmeras no local, para o devido monitoramento, além de um bom treinamento para os operadores.

\subsection{SETOR DE EXTRUSÃO DE FILME}

No setor de extrusão de filme ocorre a fabricação das bobinas de plástico. Os grãos produzidos no setor anterior são inseridos em uma máquina extrusora de filme que permite a produção de sacos de diferentes volumes regulada pela entrada de ar na máquina, o que consente em um mix variado de volumes de sacos de lixo. A bobina é pesada em uma balança e espera para então ser entregue para o último setor de fabricação, nomeado de corte e expedição. O fluxograma do setor de extrusão de filme pode ser observado na Figura 9.

Figura 9 - Setor de extrusão de filme

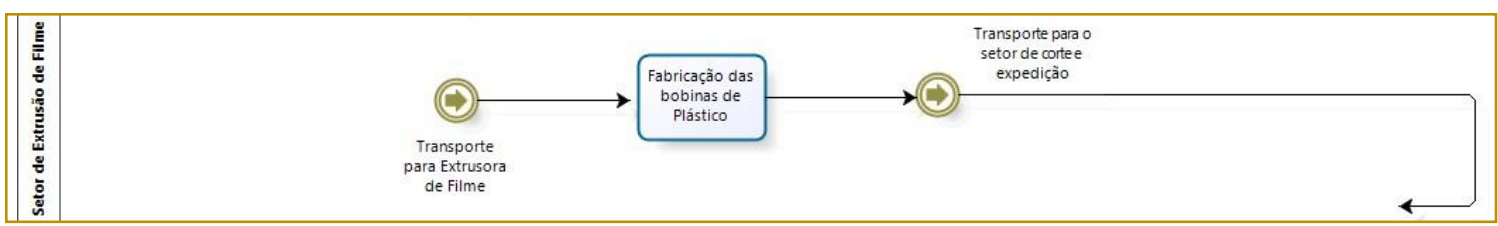

Fonte: Autoria própria

Neste setor o problema de destaque enxergado através do mapeamento foi a parte de manutenção, pois este processo era o que apresentava a maior quantidade de retrabalho. Assim com o mapeamento de processo, o levantamento de falhas e a terceirização da manutenção reduziu-se o trabalho duplicado em $50 \%$.

\subsection{SETOR DE CORTE}

Esse setor consiste no trabalho de máquinas de corte para separação e empacotamento dos sacos de lixo, que é realizado de acordo com o pedido dos clientes. Caso a bobina que o cliente deseja não tenha em estoque o processo retorna para o setor de separação, e assim segue todo o processo novamente. 0 fluxograma do setor de corte pode ser observado na Figura 10. 
Figura 10 - Setor de corte

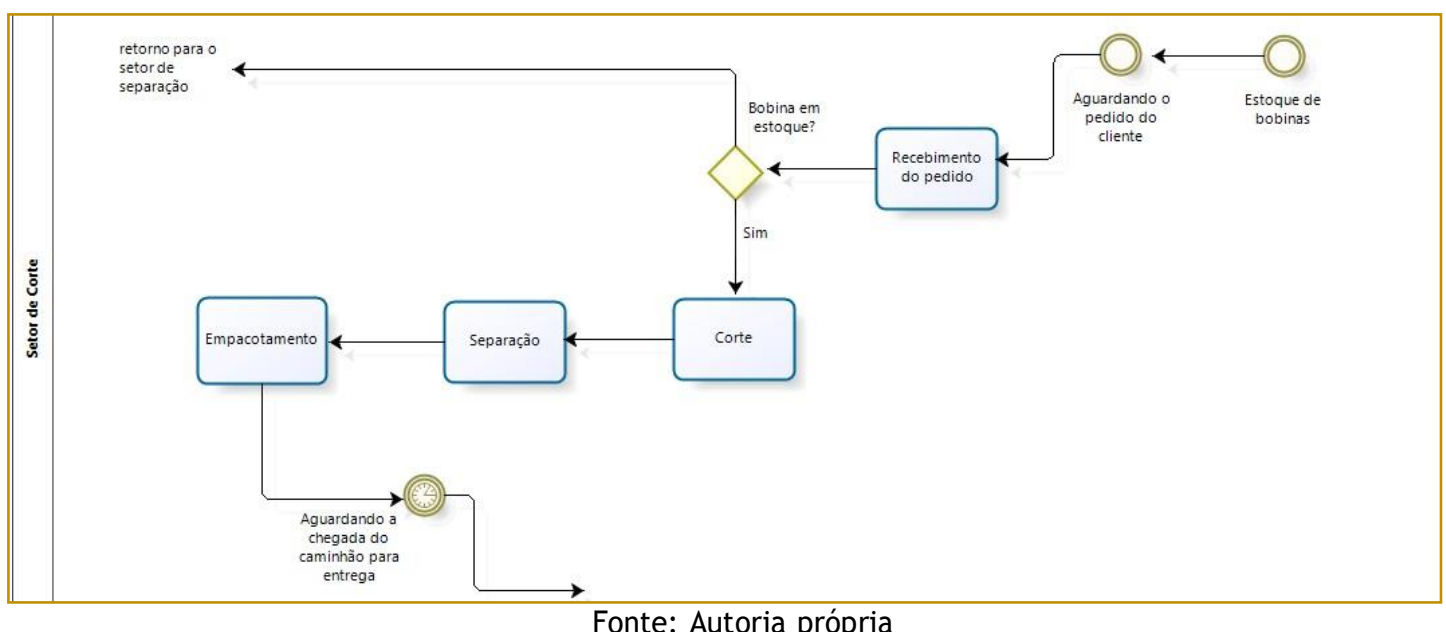

Neste setor foram vistas falhas ergonômicas, contratou-se um técnico de segurança do trabalho que realizou treinamentos e reformulou as instalações que deveriam ser reformuladas, para melhor acomodar os operadores. Os problemas ergonômicos foram resolvidos.

\subsection{SETOR DE EXPEDIÇÃO}

Nesse último setor quando os sacos plásticos já estão cortados e embalados segue para o caminhão estacionado ao lado do depósito e então é carregado pelos trabalhadores de forma manual, sem o auxílio de qualquer equipamento como empilhadeiras ou esteiras e assim segue para seu destino final. 0 fluxograma do setor de expedição pode ser observado na Figura 11.

Figura 11 - Setor de Expedição

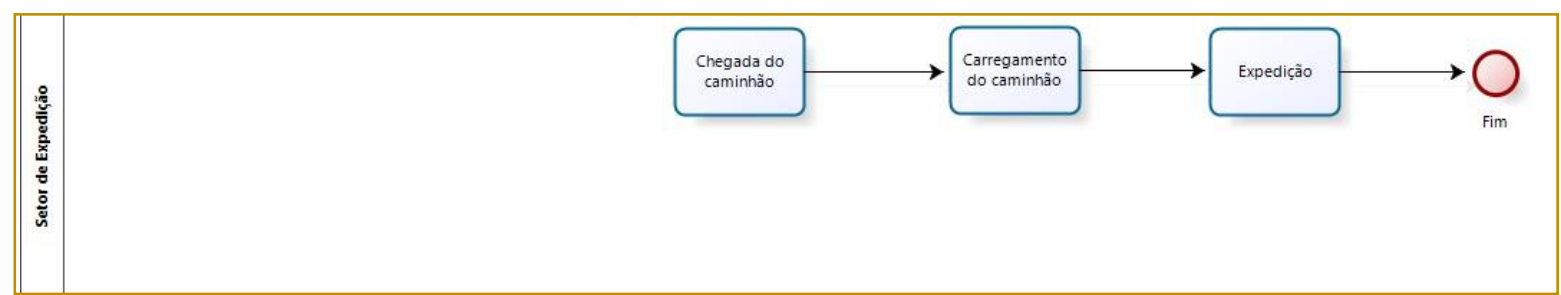

Fonte: Autoria própria

Neste setor não houveram falhas de processo, e foi o único a se manter no mesmo padrão de tarefas e instalações.

\section{CONCLUSÃO}

No presente trabalho foi possível ressaltar a importância de uma ferramenta simples e de grande valia para o meio industrial que é o mapeamento de processos através do fluxograma. Esta ferramenta permitiu ilustrar todo o processo industrial da produção de plásticos da empresa de forma clara, objetiva e eficiente. Além de representar todos os processos e suas precedências, foi possível também enxergar falhas que foram tratadas como pontos de melhoria para alavancar a qualidade e lucratividade, sempre visando minimizar o retrabalho e prevenção corretiva. o sistema de mapeamento mostrou os caminhos a serem melhorados, e através da gestão da manutenção, previsão de demanda e outras ferramentas de Engenharia foi possível elevar a lucratividade da empresa 


\section{AGRADECIMENTOS}

Agradecemos aos nossos familiares, amigos e professores pela dedicação e carinho

\section{REFERÊNCIAS}

[1] Anjard, R. Process Mapping: a valuable tool for construction management and other professionals. Facilities, 16, 79-81. 1988.

[2] Biazzo, S., Approaches to business process analysis: a review. Business Process Management Journal, Vol.6 N², 2000, pp.99-112.

[3] Chinelato, João, O\&M Integrado à informática. LTC., Fluxogramas Vantagens e Desvantagens.

"http://www.ivnet.com.br/educacional/osm/", Rio de Janeiro, 2004.

[4] Damelio, R. The Basics of Process Mapping, New York. 1996

[5] Hunt, V. D. (1996) - Process Mapping: How to Reengineer your Business Process.John Wiley\& Sons, New York.

[6] Mello, Carlos H. P.; Salgado, Eduardo G. Mapeamento dos Processos em Serviços: Estudo de Caso em Duas Pequenas Empresas da Área de Saúde. XXV Enegep - Encontro Nacional de Engenharia de Produção, Porto Alegre RS, Out. $2005 . \quad$ Disponível em $<$ http://www.abepro.org.br/biblioteca/ENEGEP2005 Enegep0207_0556.pdf >.

[7] Oliveira, Silvio Luiz de. Tratado de metodologia científica. São Paulo: Pioneira Thomson Learning, 2001.

[8] Pinho, Alexandre F. et al. Combinação entre as Técnicas de Fluxograma e Mapa de Processos no Mapeamento de um Processo Produtivo. XXVII Enegep - Encontro Nacional de Engenharia de Produção, Foz do Iguaçu PR.

[9] Villela, Cristiane da Silva Santos. Mapeamento de processos como ferramenta de reestruturação e aprendizado organizacional. Universidade Federal de Santa Catarina - UFSC. 2000. 


\section{Gapítulo 13}

\section{GESTÃO AVANÇADA COMO FUNDAMENTO PARA A IMPLANTAÇÃO DE CONCEITOS DA INDÚSTRIA 4.0}

\section{Mari Tomita Katayama}

\section{João Carlos Martins Coelho}

\section{Henrique Jun Muramatsu Seguchi}

Resumo: Tendo em vista a premente necessidade de aumentar a competitividade empresarial por meio do aumento de produtividade decorrente da aplicação dos conceitos da Indústria 4.0, e observando-se a realidade das pequenas e médias empresas nacionais, é proposta uma metodologia para a criação dos fundamentos básicos necessários à implementação dos primeiros passos das pequenas e médias empresas rumo aos conceitos da Indústria 4.0 iniciando a consolidação de uma rota tecnológica a ser trilhada pelas empresas. Essa metodologia, denominada Gestão Avançada, é essencialmente constituída pela combinação de ações tradicionais de gestão, com ações voltadas a digitalização do processo produtivo e de ações tecnológicas sobre esse processo. Essas ações apresentam um razoável nível de interdependência já que, uma alteração tecnológica no processo acarreta alterações na sua gestão. A Gestão Avançada foi aplicada, por meio de um programa piloto, a um conjunto de 13 empresas do setor de transformados plásticos tendo apresentado resultados tais como: aumento da produtividade de material, redução de custos, melhora da qualidade dos produtos, e o aculturamento digital das empresas e dos seus gestores, além de se mostrar aplicável a outros setores produtivos.

Palavras-chave: gestão avançada, indústria 4.0, transformados plásticos. 


\section{INTRODUÇÃO}

Uma parcela significativa do parque industrial tem voltado sua atenção para a manufatura avançada, isso porque em mercados altamente competitivos, a utilização da tecnologia digital relacionada à indústria 4.0, é fundamentalmente direcionada ao aumento de produtividade e à redução de custos. De acordo com a Agência Brasileira de Desenvolvimento Industrial - ABDI (apud Fiesp, 2018), a expectativa é que, em dez anos, $15 \%$ das indústrias atuem aplicando conceitos da manufatura avançada ou indústria 4.0, o que se dá, dentre outras ações, pela digitalização, automação e robotização. Hoje, menos de $2 \%$ das empresas brasileiras operam com base nesses conceitos, enquanto que a indústria 4.0 é realidade em países como Alemanha, Coreia do Sul, EUA, Israel, etc., e está crescendo anualmente. Cálculos da ABDI indicam que a adoção de conceitos da indústria 4.0 pode gerar economia anual de R\$ 73 bilhões para o setor produtivo com a redução de custos.

Segundo Filho (2016), o Brasil necessita instalar cerca de 165.000 robôs industriais para se aproximar da densidade robótica presente da Alemanha. Tendo em vista que são instalados cerca de 1.500 robôs por ano no país, mantendo-se esse ritmo, será necessário mais de 100 anos para alcançar essa densidade robótica. Entende-se que o reduzido percentual de empresas que aplicam os conceitos da indústria 4.0 no Brasil está fortemente ligado ao fato de que as micro e pequenas empresas (MPEs) representam 99\% dos estabelecimentos no Brasil (Sebrae, 2017) e que essas empresas têm baixa capacidade de investimento e, infelizmente, se tem a cultura de que a implantação da tecnologia da indústria 4.0, unindo os recursos físicos e virtuais com a instalação de robôs, internet das coisas, big data e cloud computing requer de altos investimentos, o que, não necessariamente, é a realidade. Esse cenário sugere que $\mathrm{o}$ adensamento da utilização dos conceitos da indústria 4.0 passa, obrigatoriamente, pela sua aplicação em pequenas e médias empresas que, em muitas situações, se encontram em estágio tecnológico defasado em relação a empresas de maior porte.

Em existindo essa defasagem tecnológica no Brasil, se apresenta um grande desafio que é o de demonstrar que as MPEs, desde que devidamente preparadas, podem participar da quarta revolução industrial e não estão condenadas a fechar.

Para enfrentar esse desafio, deve ser observado que a transformação de uma empresa com foco nos conceitos de manufatura avançada é um processo que envolve o aprimoramento contínuo da empresa como um todo, envolvendo processo produtivo, gestão, aculturamento do seu corpo produtivo, etc. Assim, observa-se que a implantação dos conceitos de manufatura avançada deve ser feita em etapas seguindose uma rota preliminarmente planejada e reavaliada sempre que necessário a qual deve ser constituída por um conjunto de etapas cuidadosamente definida em termos de prazos, custos e benefícios a serem auferidos. Naturalmente, entende-se que a etapa inicial deve ser centrada na busca do autoconhecimento da organização, levantando informações e digitalizando o processo produtivo, criando, dessa forma, uma cultura digital para que as empresas estejam minimamente organizadas para receberem as ferramentas relacionadas à indústria 4.0.

Observando este cenário, o Instituto de Pesquisas Tecnológicas do Estado de São Paulo - IPT, por meio do seu Núcleo de Atendimento Tecnológico à Micro e Pequena Empresa - NT-MPE, desenvolveu metodologia de trabalho buscando preparar, principalmente, as MPES para receberem a tecnologia da indústria 4.0. Essa metodologia foi desenvolvida a partir da concepção do conceito de gestão avançada a qual reúne todos os conceitos tradicionais e usuais de gestão do processo produtivo com conceitos complementares que envolvem aspectos digitais da gestão e que se complementam com forte atuação visando, por meio de apoio tecnológico, propor melhorias no processo produtivo gerando inovação, reduzindo custos e aumentando a produtividade.

Com o propósito de aplicar esse conceito metodológico, foi conduzido um projeto piloto, com o objetivo de prover, para as empresas participantes, aumento de produtividade e redução de custos. Esse projeto contemplou o apoio tecnológico a 13 pequenas e médias empresas do setor de transformados plásticos, no âmbito do Projeto Fábrica + Produtiva, do Programa de Incentivo à Cadeia do Plástico - PicPlast, conduzido pela Braskem e Abiplast. 
Além de tornar operacional a tecnologia proposta, esse projeto piloto, foi fundamentado em ações voltadas a organizar e preparar as micro, pequenas e médias empresas (MPMEs) para o mundo digital, para poderem receber e implantar as ferramentas voltadas à Indústria 4.0 que tivessem custo aceitável e viessem a resultar em ganhos significativos.

\section{SOBRE O NT-MPE DO IPT}

É um núcleo tecnológico do IPT destinado à resolução de problemas técnicos das empresas brasileiras, por meio de ações de extensão tecnológica e de desenvolvimento tecnológico, no sentido de torná-las cada vez mais competitivas e fortalecê-las para conquistar novos mercados, inclusive os internacionais, integrando tecnologia, inovação, design e cumprimento de requisitos normativos. Para as pequenas e médias empresas paulistas, os atendimentos de extensão tecnológica realizados pelo NT-MPE dispõem de recursos financeiros não reembolsáveis, cabendo às empresas uma pequena contrapartida. As atividades de extensão tecnológica, classificadas em cinco modalidades de atendimentos, são executadas no âmbito da Rede Estadual de Extensão Tecnológica do Sibratec, do MCTIC/Finep, e pelo Programa de Apoio Tecnológico às MPMEs, do Governo do Estado de S. Paulo.

\subsection{ATENDIMENTOS DE EXTENSÃO TECNOLÓGICA}

São as seguintes cinco modalidades de atendimento:

a) Gestão da produção - GESPRO. Consiste em atendimento tecnológico voltado à identificação e solução de problemas ligados à produção por meio de ações voltadas às questões que envolvam fluxos de processos produtivos. Contempla o gerenciamento dos insumos, materiais, métodos e outros recursos, para melhoria da capacidade produtiva. Envolve aspectos como: prazo de entrega, custos, produtividade, balanceamento da produção, fluxograma industrial.

b) Qualificação de produtos para o mercado interno - QUALIMINT. Qualificação técnica para aprimoramento de produtos, de diversos setores, visando o mercado interno. Tem como objetivo contribuir para o aumento de competitividade da empresa, satisfazendo os níveis de exigência do mercado nacional e, sempre que possível, elevando seus padrões técnicos para enfrentar a concorrência de produtos similares estrangeiros. 0 atendimento procura priorizar os seguintes aspectos: qualificação técnica para certificação nacional (Inmetro, Anvisa, etc.), atendimento às normas técnicas nacionais, atendimento aos regulamentos dos órgãos governamentais, como a agências reguladoras e ministérios.

c) Programa de apoio tecnológico à exportação - PROGEX. Tem como objetivo fortalecer no campo da tecnologia, principalmente, as micro, pequenas e médias empresas brasileiras. Contribui para sua inserção e ampliação no mercado internacional e, simultaneamente, reduzir seu índice de mortalidade como exportadora. 0 foco do programa está na adequação de produtos para atender às exigências específicas de um determinado mercado externo, frente a aspectos como: melhoria da qualidade, redução de custos, embalagem, design, atendimento às normas técnicas, qualificação técnica para certificações internacionais, cumprimento de exigências e superação de barreiras técnicas.

d) Produção mais limpa - PROLIMP. Ações para adoção de tecnologias mais limpas ou melhoria de processos visando à redução de emissões (gasosas ou líquidas) e de rejeitos de produção, ao consumo racional de matérias-primas, água e energia, à destinação correta e reciclagem de resíduos, e ao atendimento às normas e regulamentos ambientais.

e) Projeto Unidades Móveis - PRUMO. Consiste em atendimento voltado para o fortalecimento tecnológico das empresas, criando condições de evolução de processos produtivos, melhoria de qualidade dos produtos e a obtenção de inovações incrementais nas empresas. 0 atendimento leva às empresas um laboratório móvel, dotado de equipamentos para realização de ensaios e experimentos. As unidades são operadas por uma equipe formada por um engenheiro e um técnico, que vão às fábricas, e ficam até dois dias, para diagnosticar e resolver os principais problemas tecnológicos, em relação às matérias-primas, processos e produtos. Atende aos setores de transformação de plástico e borracha. 


\subsection{DESENVOLVIMENTO TECNOLÓGICO}

O IPT é uma unidade Embrapii (Empresa Brasileira de Pesquisa e Inovação Industrial) com foco no desenvolvimento de projetos de pesquisa, desenvolvimento e inovação na área de materiais compósitos, biotecnologia e nanotecnologia. Para microempreendedores individuais e MPEs brasileiras, o Sebrae Nacional participa da Embrapii com aporte de recursos financeiros não reembolsáveis para reduzir a contrapartida da empresa atendida.

\section{PROJETO PILOTO RUMO À INDÚSTRIA 4.0.}

A maioria das empresas não tem cultura digital requerida para iniciar o processo de ingresso e participação nos processos transformadores que caracterizam o que se convencionou denominar indústria $4.0 \mathrm{e}$, muitas vezes, não possuem informações essenciais das suas próprias empresas, do seu processo produtivo, desconhecem e/ou não utilizam indicadores, demonstrando falta de organização, planejamento, etc.

Assim, entende-se que o início fundamental para entrar no mundo digital parte da necessidade de adquirir uma cultura digital mínima e pela busca do autoconhecimento da organização. Esse autoconhecimento envolve o levantamento ou mapeamento do fluxo produtivo, registo correto das informações e dados referentes ao processo produtivo, definição e medição de indicadores considerados importantes para a avaliação do desempenho da produção, além da realização adequada do planejamento, monitoramento e avaliação contínua do processo produtivo, de modo que os empresários passem a ter uma visão correta sobre a realidade das suas empresas e tenham condições de tomar decisões baseadas em informações confiáveis e consistentes.

Nesse cenário insere-se o desenvolvimento desse projeto piloto fundamentado nos preceitos da gestão avançada com o propósito de preparar 13 empresas de transformados plásticos, com desenvolvimento e aplicação das modalidades de extensão tecnológica referentes ao GESPRO e PRUMO, com soluções tecnológicas para preparar as empresas para receberem as tecnologias digitais evoluindo rumo à indústria 4.0.

\subsection{METODOLOGIA DESENVOLVIDA PARA PREPARAR AS MPMES RUMO À MANUFATURA AVANCSADA}

A metodologia desenvolvida pelo IPT tem como característica criar um nível inicial de aproximação da empresa aos princípios da indústria 4.0, aliando soluções tradicionais de problemas associados à gestão do processo produtivo à cultura digital, complementando com ações tecnológicas sobre o produto e o processo produtivo.

Essa metodologia tem como base a atividade de virtualização do processo produtivo das empresas, que consiste, em essência, na digitalização de informações utilizando ferramentas computacionais. Dessa forma as empresas são obrigadas a realizar, além da coleta, a organização das informações de modo que estas possam ser adequadamente registradas em um ambiente digital.

A virtualização do processo é de interesse dos empresários porque obriga a empresa a aprofundar seus conhecimentos sobre o seu próprio processo produtivo por observar e registrar detalhes e colher informações que anteriormente passavam despercebidas, mas que são importantes do ponto de vista da busca pelo aumento da produtividade e ou redução de custos, além de permitir a criação dos fundamentos para outras ações digitais. Deve-se entender que o caminho para a manufatura avançada é um processo e de aprimoramento contínuo com foco no ambiente digital que se mostra, por um lado inevitável, e por outro perfeitamente factível, inclusive para as pequenas e médias empresas.

Nas 13 empresas participantes do projeto piloto foram realizadas ações tecnológicas sobre o processo produtivo e, simultaneamente, ações com foco no conhecimento e aculturamento digital às quais foram conduzidas em dois níveis. Note-se que a simultaneidade de ações conduz à forte interação entre a tecnologia de produção e a de gestão fundamentando o que se optou por denominar gestão avançada.

O primeiro nível da abordagem digital envolveu a digitalização de informações sobre o processo produtivo e é constituído pelas seguintes atividades:

Elaboração do lay-out da empresa na forma digital; 
Levantamento de informações relativas ao processo produtivo, análise do mix de produtos, especificação de máquinas e equipamentos, ficha de manutenção, etc. e sugestão de melhorias;

Elaboração do fluxograma do processo produtivo por meio do software livre denominado Bizagi;
Utilização da metodologia SIPOC traduzida na forma digital, para melhorar a visualização do processo e conhecimento da organização, permitindo identificar oportunidades de melhorias. Na Figura (1) apresenta-se o resultado da aplicação do SIPOC no processo de extrusão existente em uma das empresas do projeto piloto, fabricante de embalagens.

Figura 1: SIPOC com Bizagi do processo de extrusão de empresa fabricante de embalagens
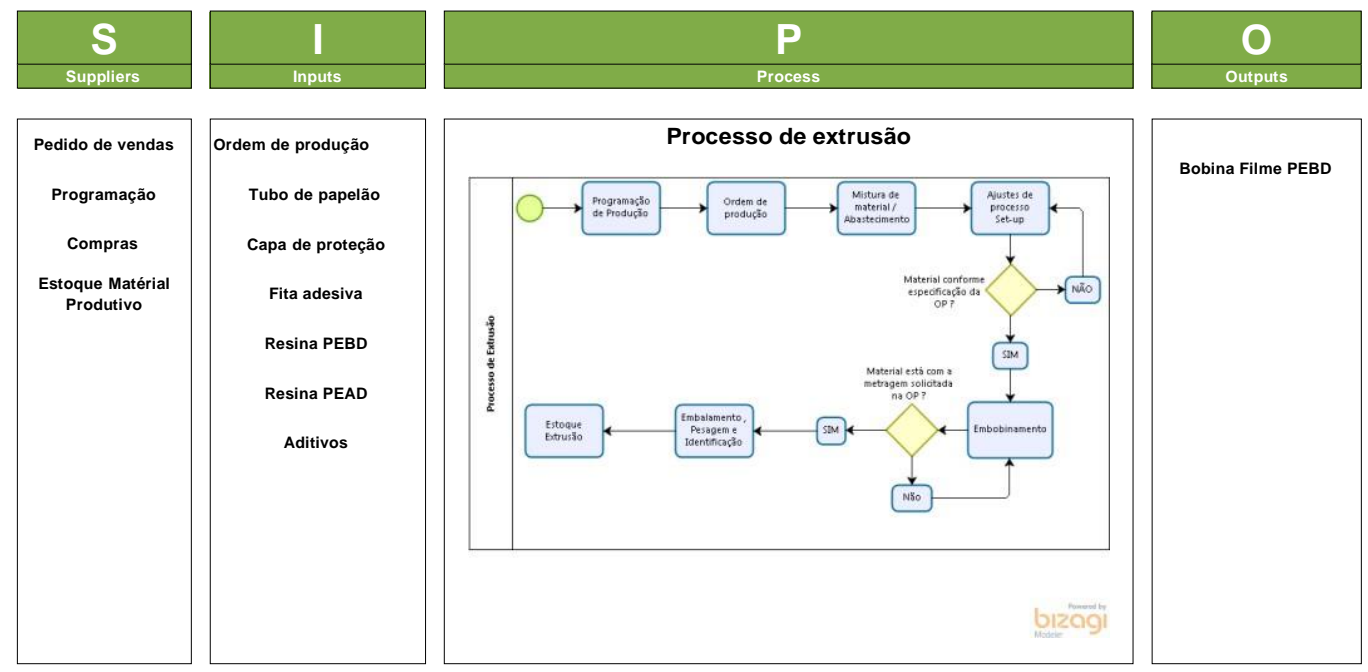
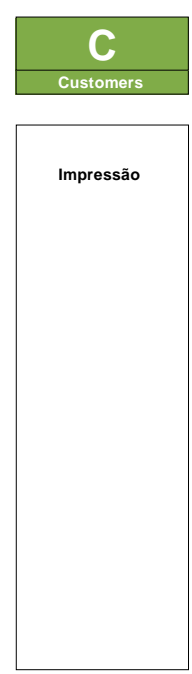

O segundo nível da ação digital consiste na simulação do processo produtivo, a qual consiste na aplicação de uma ferramenta computacional que, a partir do conhecimento aprofundado do processo produtivo e das suas variáveis, permite realizar uma análise em ambiente virtual desse processo. Assim, a partir dos dados de entrada inseridos, o software avalia as condições operacionais de, por exemplo, uma linha de produção. Dessa maneira, é possível analisar o processo produtivo da empresa em cenários distintos, permitindo-se verificar o efeito de possíveis alterações no processo, instalação de novos equipamentos e outras possíveis ações de modo a direcionar as proposições de melhorias conforme o desejo e/ou estratégia da empresa.

A simulação é uma ferramenta poderosa que exige um conhecimento bastante aprofundado do processo produtivo e dos meios de produção. Por este motivo ela somente pode ser aplicada após a finalização da etapa inicial e se a empresa estiver adequadamente preparada para tal.

\subsection{APLICAÇÃO DA METODOLOGIA EM 13 EMPRESAS}

A metodologia proposta foi aplicada em 13 empresas do ramo de transformados plásticos. A realização desse trabalho inicial levou à plena concepção de que nem sempre é possivel ter um nível de informações associado a um padrão de organização do processo produtivo que permita um avanço digital imediato. Essa realidade comprova a necessidade de trabalhar a organização e os procedimentos de gestão do processo produtivo de forma a se atingir um patamar de conhecimento do processo e da sua gestão mais elevado, permitindo ações direcionadas à incorporação de outras ferramentas digitais relacionadas ao aumento de produtividade.

Verificou-se que parte das empresas apresentou uma evolução do seu nível de maturidade tecnológica e por meio dos seus gestores, se comprometeram a aperfeiçoar seus métodos e aprofundar os conhecimentos. Neste período, optou-se pela segunda fase do processo, rumo ao caminho digital, que consistiu na simulação dos processos produtivos de empresas que tivessem superado o nível anterior. 
Entendendo-se que realizar o processo de simulação exige uma grande quantidade de informações com alto nível de detalhamento e confiabilidade, optou-se por simular parte do processo produtivo em 4 empresas que passaram pelo primeiro nível de digitalização e manifestaram interesse em aprofundar seus conhecimentos no assunto.

Simultaneamente às ações voltadas à gestão do processo produtivo, complementando o conceito de gestão avançada, a equipe do PRUMO conduziu ações tecnológicas com o propósito de promover a evolução do processo produtivo, com foco no aumento de produtividade, na melhoria da qualidade, redução do consumo de matérias-primas, alteração de formulações, parametrização correta das máquinas, modificação de moldes, redução de ciclos, redução de refugos e retrabalhos, entre outros.

Ao longo do programa, foram apresentadas proposições de melhorias, tanto em termos de gestão como de tecnologia, tais como: alteração de lay-out, organização de sistemas de estocagem de produtos finais e/ou semiacabados, alteração na produção buscando otimizar recursos e processos e assim por diante.

\section{RESULTADOS}

0 registro de informações do processo produtivo em forma digital mostrou-se como uma novidade para a maioria das empresas participantes do projeto piloto, tendo sido possível criar condições e cultura para que essas empresas estivessem minimamente organizadas para receberem as ferramentas relacionadas à manufatura avançada.

Em decorrência das proposições de melhorias, os principais resultados do programa, nas 13 empresas atendidas, redundaram na redução de custos obtida por meio de alterações de produto/processo em $62 \%$ das empresas e o aumento da produtividade de material em $23 \%$. Ainda, foram obtidos outros resultados tais como a melhora da qualidade do processo produtivo em $62 \%$ das empresas, melhora da qualidade do produto em $46 \%$ e a obtenção de produção mais limpa em $38 \%$ das empresas.

Constatou-se que todas as pequenas e médias empresas sob análise estão distantes dos conceitos da manufatura avançada, que demanda informação organizada, informatização, digitalização, simulação, robótica e outras ferramentas que conceituam essa nova revolução industrial, porém essa metodologia de gestão mostrou ser uma alavanca de criação de valor, preparando as empresas para o mundo digital, além de criar uma cultura e maturidade para que futuramente possam estar preparadas para se implantar tecnologias da manufatura avançada.

\section{CONCLUSÕES}

A metodologia proposta e aplicada se mostrou eficaz na medida em que, além de produzir aumento de produtividade, redução de custos e aculturamento digital, estimulou empresas a permanecerem na rota evolutiva, característica da indústria 4.0. Além disso, verificou-se, também, que essa metodologia pode ser aplicada com sucesso a outros setores produtivos.

Essa realidade reafirma a importância do desenvolvimento desse tipo de ação tecnológica, já que, de fato, criam condições evolutivas e preparam as empresas para a implantação de conceitos da manufatura avançada. Esse trabalho contribui também para a mudança de cultura do empresário, baseada na experiência e resultado prático, além da percepção da maioria dos empresários atendidos sobre a necessidade de se continuar aplicando novas ferramentas digitais que levem ao aumento de produtividade e, consequentemente, competitividade.

Os resultados das modalidades de extensão tecnológica indicam a necessidade de as instituições de pesquisa e desenvolvimento disporem de maior apoio financeiro para expandir suas ações contribuindo para que as micro, pequenas e médias empresas de qualquer setor produtivo, avancem e façam parte da quarta revolução industrial.

\section{PRÓXIMOS PASSOS}

Os resultados obtidos sugerem dois caminhos possíveis. O primeiro, com o propósito de consolidar a metodologia utilizada, é o de aplicá-la em empresas de outros setores a partir do desenvolvimento de um segundo Programa Piloto. 
O segundo caminho consiste na condução de um terceiro Programa Piloto visando ao aprofundamento da aplicação da tecnologias da Indústria 4.0 em empresas já adequadamente amadurecidas. Nesse caso

\section{REFERÊNCIAS}

[1]. FEDERAÇÃO DAS INDÚSTRIAS DO ESTADO DE SÃO PAULO - FIESP. Para garantir competitividade, empresas brasileiras se adaptam à indústria 4.0: Melhora na economia e diminuição de custos têm levado companhias a investir em processos de robotização e digitalização. Boletim técnico do departamento sindical $1357 / 2018$, São Paulo, p. 7-8, 2018. poderiam ser aplicados, por exemplo, conceitos de IoT, automação ou robótica dependendo das necessidades efetivas das empresas.

[2]. FILHO, J. R. H. A Era da Internet Industrial e a Indústria 4.0. Revista eletrônica Produção em foco, v. 6, n. 3, p. 1-4, 2016.

[3]. SERVIÇO BRASILEIRO DE APOIO ÀS MICRO E PEQUENAS EMPRESAS - SEBRAE.

Anuário de trabalho nos pequenos negócios: 2015. Brasília, DF, 2017.

\section{DIREITOS AUTORAIS}

Os autores são os únicos responsáveis pelo conteúdo do material incluído no seu trabalho. Trabalho este que foi publicado no II Simpósio de Engenharia de Produção (SIENPRO) da UFG/Catalão. 


\section{Gapítulo 14}

\section{PROCESSO DE IMPLANTAÇÃO DA DRENAGEM PLUVIAL PROVISÓRIA DE UMA REFINARIA DE PETRÓLEO, NA CIDADE DE IPOJUCA/PE}

\section{Fagner Tavares Xavier}

Resumo: As drenagens estão presentes na sociedade desde que deixamos de ser nômades, mesmo assim, ainda hoje, enfrentamos os mais diversos problemas causados pela falta de planejamento na gestão das águas. Com o aumento da população de forma exponencial nas áreas próximas a rios e lagos, as dificuldades tornam-se ainda mais evidentes, pois a interferência humana no curso normal das águas é quase sempre inevitável. Nas indústrias, a gestão da água que é estratégica e determinante para a implantação do parque fabril, na maioria das vezes, é negligenciada durante o processo de construção civil o que acaba gerando perdas. Neste trabalho será mostrado o processo de implantação do sistema de drenagem pluvial provisória de uma refinaria de petróleo na Cidade de Ipojuca, estado de Pernambuco. Serão abordados os métodos qualitativos e quantitativos e utilizanda a técnica de Estudo de caso para descrever o processo de implantação da drenagem pluvial provisória, quebusca reduzir os transtornos causados pelos alagamentos. Ao final do trabalho será possível concluir que existe uma melhora nos problemas causados pela falta de drengem pluvial, porém, por se tratar de um sistema provisório, o mesmo está passivo de falhas e é importante afirmar que as etapas de análise abordadas aqui não são as únicas nem as últimas opções de melhorias que devem ser tomadas.

Palavras-chave: Água. Drenagem. Pluvial. Processo. 


\section{INTRODUÇÃO}

\subsection{CONTEXTUALIZAÇÃO}

Qualquer cidadeonde toda a água da chuva tenha como destino ocupar as ruas que poderiam ser utilizadaspara o tráfego de pedestres e/ou veículos, com certeza, poderá lembrar a cidade de Veneza, porém até mesmo a cidade da Europa, que mais se assemelha com a descrição acima, tem a preocupação com a sua drenagem que é realizada exatamente por seus canais.

A drenagem torna-se um problema difícil de resolver onde não é realizado um planejamento prévio das ações mitigadoras dos efeitos das águas, seja em uma cidade, indústria ou até mesmo em residências, tais efeitos podem ser bastante nocivos e causadores de perdas expressivas de tempo, produtividade e até mesmo a perda de vidas, entretanto é possível prever os impactos e torna-los mais susceptíveis a acertos quando planejado desde o início.

Reduzir os problemas causados pela falha na drenagem é um desafio constante e, muitas vezes, ou na maioria das vezes, gestores desconsideram tais problemas por enxergar apenas o cenário presente sem ampliar a visão para um benefício de longo prazo que a drenagem bem feita pode proporcionar, e é nesse ponto que a drenagem pluvial provisória é deixada de lado nas etapas de concepção e execução dos projetos urbanísticos e industriais, causando, posteriormente, um efeito colateral elevado que não foi previsto, gerando perdas de produtividade significativa.

No Brasil, por exemplo, é comum presenciarmos cenas de ruas alagadas nos períodos mais chuvosos do ano e, diga-se de passagem, que isso acontece em épocas de estiagem também sendo as consequências causadas por esses fenômenos enormes e podem interferir na economia local causando danos que poderiam ter sido evitados. Um exemplo comum seria um empresário que saiu de casa para participar de um processo de licitação, mas que por causa do alagamento de uma determinada rua não conseguiu chegar a tempo na reunião de abertura da proposta, consequentemente, não participou do processo e deixou de contratar pessoas para a sua empresa, as pessoas, que por sua vez, não foram contratadas deixam de gerar receita para o governo por meio dos impostos pagos $\mathrm{e}$ ainda necessitam de assistência que onera o sistema público e prejudica a economia.

Exemplos como o citado acima ocorrem todos os dias em vários locais e, como podemos observar, os problemas ocasionados pela falta de investimento em drenagem atingem do governo ao cidadão comum.

Nas indústrias, a perda pode ser bastante significativa se considerarmos que a produção pode sofrer uma paralização parcial ou até mesmo total ocasionadas por problemas de drenagem pluvial de origem externa, quando podem impedir a chegada e a saída de insumos ou produtos devido à interdição das vias de acesso local, ou também de origem interna, que pode ser originada pela falta de manutenção do sistema de drenagem do parque fabril.

Para todo sistema de drenagem pluvial funcionar de forma satisfatória a prevenção dos danos deve ser sempre pensada em primeiro lugar, pois o devido tratamento dos possíveis problemas reduz os riscos de possíveis alagamentos e garante a continuidade das operações normais de uma indústria.

0 estudo do clima deve ser o grande aliado no planejamento de ações de prevenção, pois o período de chuvas põe em prova todo o sistema e suas falhas, sendo necessário rever o planejamento para mitigar os danos imediatos além do registrodo histórico para as ações futuras.

É definido como sistema de drenagem pluvial provisória o serviço realizado na fase de implantação de um empreendimento seja ele urbanístico, industrial ou residencial para que seja destinada, de forma eficiente, as águas provenientes da chuva.

Neste estudo será apresentado o sistema de drenagem pluvial provisória de uma Refinaria situada no Complexo Portuário de Suape, Estado de Pernambuco, para que assim seja possível verificar, através do estudo de caso, a funcionalidade do sistema.

\subsection{PERGUNTA DA PESQUISA}

Quais os processos para a implantação do sistema de drenagem pluvial provisória? 


\subsection{OBJETIVO GERAL}

O objetivo desta pesquisa é descrever os processos para implantação do sistema de drenagem pluvial provisória, que busca reduzir os transtornos causados pelos alagamentos.

\subsection{OBJETIVOS ESPECÍFICOS}

Este trabalho tem como objetivos específicos:

0 estudo para a implantação do sistema de drenagem;

Acompanhar o processo construtivo do sistema;

Acompanhar o processo de manutenção do sistema;

Apresentar os resultados da implantação do sistema.

\subsection{JUSTIFICATIVA}

A pesquisa é importante porque traz uma contribuição prática de soluções desenvolvidas no campo acadêmico, sendo também fundamental para que sejam criados parâmetros de comparação com outras unidades industriais e assim subsidiar gestores, técnicos de campo e demais interessados com informações que irão auxiliar na tomada de decisões de caráter construtivo das obras civis.

Segundo Yazigi (2014), perda pode ser considerada como qualquer ineficiência que resulta no uso da mão de obra, materiais e equipamentos em quantidades superiores àquelas necessárias à produção da edificação. Por isso, a contribuição acadêmica desenvolvida na prática torna-se uma aliada fiel na criação das soluções que agregam valor.

A pesquisa é, de fato, plausível considerando que as perdas por horas paradas ocasionadas por falha de drenagem pluvial provisória serão compensadas ao longo da obra e acabam sedo absorvidas pelas demais etapas do processo construtivo, gerando perda de produtividade.

\section{FUNDAMENTAÇÃO TEÓRICA}

\subsection{DRENAGEM PLUVIAL}

Segundo Silva e Santos (2010), Sistemas de drenagem são importantes, tanto para o homem, como também para as paisagens, estes vinculados aos processos de (re) modelagem do relevo do ambiente implantado.

Gribbin (2014, p. 01) fala

Os engenheiros não podem evitar o confronto com problemas causados pelas chuvas e seu consequente escoamento. Parte dos mais antigos esforços da humanidade concentrouse na velha batalha contra as forças da natureza em forma de água. Por muito tempo em nossa história, os engenheiros e seus antecessores lidaram com os problemas da água utilizando várias soluções empíricas, ou seja, qualquer coisa que parecesse dar certo. Recentemente é que os esforços tomaram uma forma sistemática de leis e fórmulas quantitativas.

De acordo com Wilken (1978), a maior parte da água que cai sobre a terra encontra seu caminho para o mar. Outra parte evapora durante a queda, outra evapora da própria terra e outra parte é transpirada pelas plantas.

Para Wilken (1978), a parte da água que encontra seu caminho fluvial ou marítimo o faz através da permeabilidade do solo ou por drenagem, esse conjunto formam as etapas de precipitação, evaporação, condensação e escoamento, o chamado ciclo hidrológico.

\subsubsection{FERRAMENTAS DE CONTROLE DA QUALIDADE}

A aplicação de ferramentas da qualidade é bastante útil durante toda a etapa de implementação da drenagem, desde a sua implantação até a manutenção do sistema, pois é a garantia de análise e melhoria a cada encontro do GT de drenagem.

Conforme Campos (1992), a identificação de um problema tem início quando se percebe uma alteração da rotina normal de trabalho.

Segundo Slack, Chambers e Johnston (2009), o melhoramento dos processos pode ser realizado de forma infinita, pois o ciclo de melhoria é contínuo.

Para Roldan, et. al. (2011), Brainstorming pode ser definido como uma reunião de pessoas que, juntas, expõem suas ideias para a resolução de problemas.

Ainda segundo Roldan, et. al. (2011), as pessoas envolvidas no processo de melhoria, reunidas com um membro do grupo denominado moderador, tentarão esgotar 
todas as possíveis soluções que podem ser adotadas para o alcance da melhoria proposta.

Para Paiva (2011), o Brainstorming pode ser definido como uma reunião de pessoas que expõem suas ideias em um curto espaço de tempo e da forma que surgirem na cabeça dos integrantes.

Segundo Andrade (2003), o ciclo PDCA envolve uma série de atividade de rotinas que são reiniciadas a cada término.

$\mathrm{Na}$ visão de Slack, Chambers e Johnston (2009), o ciclo PDCA está dividido da seguinte forma:

$P$ - Etapa de planejamento de uma possível melhoria com identificada no processo;

D - Etapa de implementação do planejamento da melhoria identificada anteriormente;

C - Etapa de avaliação do processo para eventual correção das etapas anteriores

A - Etapa de ajuste do processo para garantir a melhoria contínua.

\subsection{PROCESSO DE IMPLANTAÇÃO DE DRENAGEM}

Segundo Gribbin (2014), o primeiro projeto de drenagem conhecido surgiu, aproximadamente 5 mil anos atrás no Egito e nos milênios seguintes foram surgindo mais projetos no Mediterrâneo e Oriente Médio.

Para a implantação de drenagem pluvial provisória são consideradas apenas as etapas de precipitação e escoamento, pois são as duas etapas mais relevantes e importantes para o correto dimensionamento das galerias de escoamento (GRIBBIN, 2014).

Para Gribbin (2014), a chuva cai em padrões diferentes, o que dificulta a sua quantificação nos projetos, porém, a análise das estatísticas leva à determinação de uma chuva média ou típica.

A etapa inicial de um processo de implantação de drenagem está relacionada com o estudo do clima da região, pois a quantidade e a intensidade das chuvas são fatores primordiais para definição de capacidade mínima e máxima dos canais de coleta e descarte das águas (WILKEN, 1978).

O estudo do clima da região é uma ferramenta muito importante para a tomada de decisões, uma vez que, de posse dos dados pluviométricos mensais apresentados nos gráficos da climatologia, conformeexemplificado no Gráfico 1, é possível estabelecer um parâmetro confiável do comportamento do clima e assim traçar as diretrizes do plano de implantação e manutenção das drenagens pluviais (WILKEN,

1978).

Gráfico 1 - Climatologia da cidade de Recife / PE

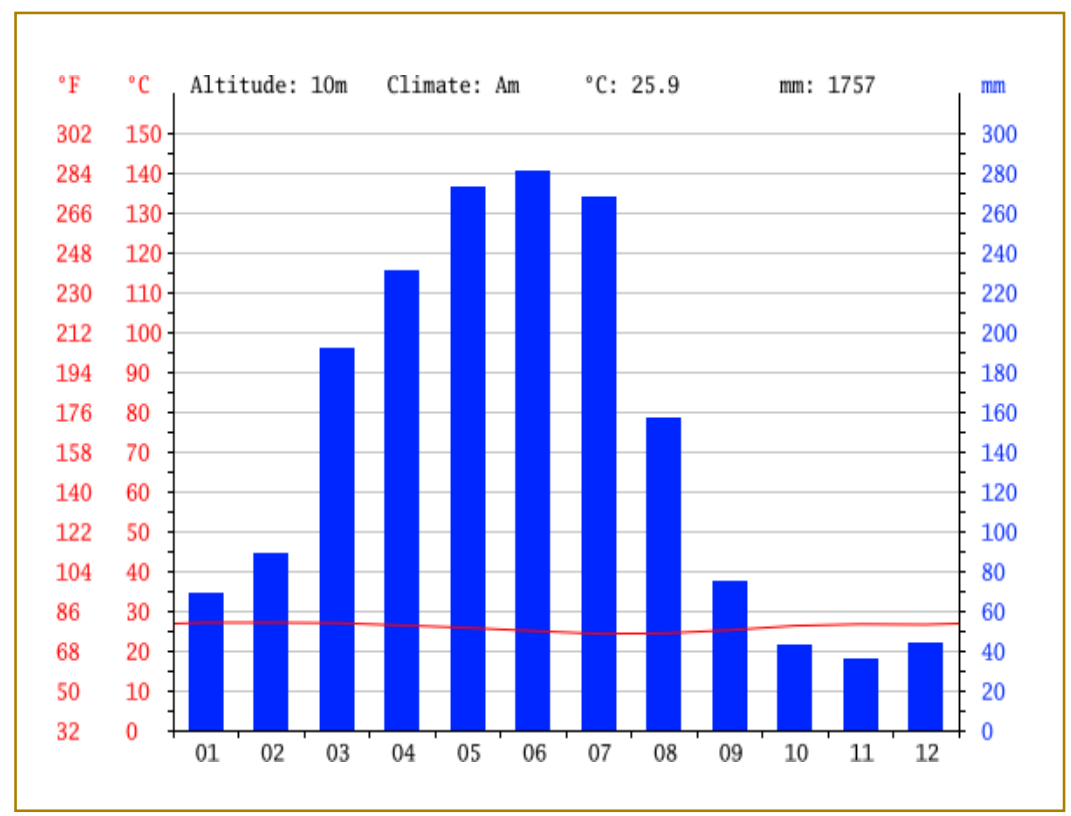

Fonte: Disponível em <http://pt.climate-data.org/location/5069/> 


\subsubsection{BACIAS DE DRENAGEM}

Segundo Gribbin (2014), antes de qualquer cálculo de vazão em um curso d'água resultante de um evento de chuva, devemos determinar a área sobre a qual a chuva incide e essa área pode ser chamada de bacia hidrográfica, bacia de drenagem ou área de captação. Toda água que incide sobre a bacia tem seu caminho determinado por seu curso e a água que incide fora segue para outro curso d'água.

A área que recebe a precipitação e que alimenta todo o processo do curso d'água até seus limites adjacentes é denominada bacia de drenagem (WILKEN, 1978).

Para Wilken (1978), existe uma diferença entre a grande bacia e a pequena bacia de drenagem, que não depende exclusivamente do tamanho. O tamanho da bacia não deve ser o único critério adotado para classificar como grande ou pequena, podendo o projetista incorrer em erros, pois duas bacias do mesmo tamanho podem ter comportamentos distintos sob o ponto de vista hidrológico.

A individualização da bacia contribuinte ou bacia de drenagem, é realizada através do traçado realizado na planta topográfica da região onde será implantado o sistema de drenagem, para que assim cada bacia tenha a área definida (WILKEN, 1978).

$\mathrm{Na}$ visão de Gribbin (2014), depois de demarcada a área da bacia de drenagem, o passo seguinte será medir a área da bacia, mas deve-se ter em mente que a área real da bacia nunca é conhecida com precisão absoluta.

\subsubsection{ARRANJO FÍSICO}

O arranjo de posição física é algo que, a maioria de nós, notamos assim que entramos em uma unidade produtiva, pois é ele quem determina a aparência do ambiente. (SLACK; CHAMBERS; JOHNSTON, 2009).
Para Slack, Chambers e Johnston (2009), arranjo de posição física dar-se-á quando os recursos transformados não se movem perante os recursos transformadores, pois o sujeito do serviço é muito grande para moverse de forma conveniente.

Segundo Ritzman eKrajewski (2004), a escolha do arranjo físico depende da análise do processo.

Ainda segundo Ritzman e Krajewski (2004), arranjo físico que tem posição fixa pode ser entendido como aquele processo onde os recursos transformadores caminham até os recursos transformados.

Para o planejamento de um arranjo físico, o gerente deve levar sempre em consideração o processo atual e como esse processo será no futuro, pois só assim ele tomará as decisões mais coerentes. (RITZMAN; KRAJEWSKI, 2004)

\subsubsection{DISPOSITIVOS HIDRÁULICOS UTILIZADOS}

Segundo Gribbin (2014), são denominados dispositivos hidráulicos as estruturas utilizadas para controle do fluxo de água. Tais dispositivos são capazes de transportar a água pluvial para o local determinado, sendo assim, considerada elemento indispensável no dimensionamento de uma drenagem pluvial.

Na opinião de Azevedo Neto (1998), canais apresentam superfícies livres e a água está em contato com a atmosfera.

O escoamento da água flui em declive em qualquer conduto com a superfície da água exposta à atmosfera em uma superfície livre, logo, diz-se que ela está submetida a um escoamento em canal aberto (GRIBBIN, 2014).

$\mathrm{Na}$ visão de Gribbin (2014), canais abertos, conforme exemplificado na Figura 1, são usados com bastante frequência para transportar cursos d'água em locais ocupados. 
Figura 1 - Exemplo de canal aberto, indústria do complexo portuário de Suape/PE

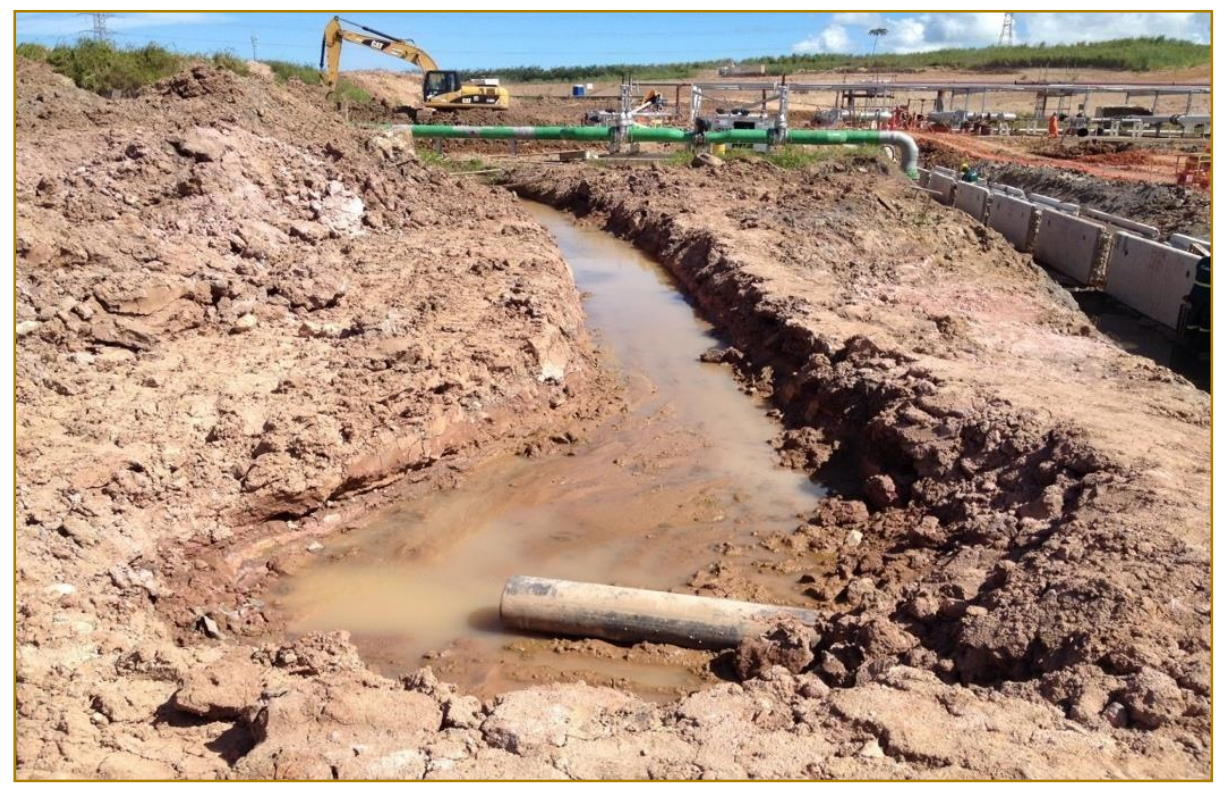

Fonte: Acervo pessoal, 2013

\subsection{MANUTENÇ̃̃O DO SISTEMA}

Manter o sistema refere-se ao conjunto de atividades que mantém os recursos físicos operacionais em pleno funcionamento e, em qualquer momento, pronto para a operação segura (CORRÊA, A. C., 2009; CORRÊA, L. H., 2009).

Na visão de Corrêa, A. C. (2009) e Corrêa, L. H. (2009), a confiabilidade do sistema é a probabilidade de todos os componentes funcionarem de forma satisfatória em condições estabelecidas e tempo especificado.

No dizer de Slack, Chambers e Johnston (2009, p. 597),

Sempre há a possibilidade de que as coisas possam sair erradas. Aceitar que ocorrerão falhas não é, entretanto, a mesma coisa que ignorá-las. Também não implica que a produção não possa ou não deva tentar minimizar falhas. Além disso, nem todas as falhas são igualmente sérias.

Para Slack, Chambers e Johnston (2009), manutenção é a tratativa das falhas do sistema que podem ser evitadas pelo cuidado com as instalações físicas.

$\mathrm{Na}$ visão de Slack, Chambers e Johnston (2009), existem três abordagens básicas para manutenção de instalações físicas.

Segundo Corrêa, A. C. (2009) e Corrêa, L. H. (2009), a manutenção preventiva tem por finalidade eliminar ou reduzir a probabilidade de falha do sistema.

Dentro desta linha Slack, Chambers e Johnston (2009), dizem que a manutenção preventiva visa reduzir as falhas do sistema através de manutenção pré-planejada.

Para Corrêa, A. C. (2009) e Corrêa, L. H. (2009), a manutenção preditiva tenta antecipar-se às falhas que são percebidas por alterações de comportamento e somente é realizada conforme a necessidade.

$\mathrm{Na}$ visão de Slack, Chambers e Johnston (2009), manutenção preditiva consiste em observar a operação e os resultados dessa observação serão a base de decisão para uma parada.

Segundo Slack, Chambers e Johnston (2009), a manutenção corretiva significa deixar a manutenção apenas quando existir a falha total do sistema.

Dentro desta linha Corrêa, A. C. (2009) e Corrêa, L. H. (2009), informam que a manutenção corretiva só é realizada após a ocorrência da falha ou quando ocorrem falhas inesperadas do sistema.

\section{METODOLOGIA}

O estudo aborda um sistema de drenagem pluvial de uma refinaria de petróleo que registrava, em ocorrência de chuva, alagamentos da sua área fabril, ocasionando 
paralizações dos serviços que estavam sendo executados no local e consequentemente ocasionando atrasos na execução dos demais cronogramas de obras civis.

A área do parque fabril é de aproximadamente $6,5 \mathrm{~km}^{2}$ que sofre de alagamentos provocados pelas águas oriundas de precipitação. Existe a necessidade de criação de um sistema que possa dar o encaminhamento correto das águas e assim contribuir para o cumprimento dos cronogramas.

\subsection{CLASSIFICAÇÃO DA PESQUISA}

Os paradigmas da pesquisa foramas abordagens quantitativas, pois foram analisados os dados estatísticos gerados durante $o$ processo $e$ as abordagens qualitativas, pois segundo Oliveira (2004), o estudo das correlações de assuntos mencionados pelos mais diversos autores é um aliado na chegada de uma conclusão final sobre o ponto de vista próprio, sendo possível aplicar, na prática, toda a teoria adquirida.

Em relação ao tipo, o trabalho foi classificado com exploratório, pois foi analisada uma ideia de solução aplicável para a resolução do problema de drenagem pluvial tornando o problema mais evidente para todas as pessoas envolvidas no estudo do caso.

Foram utilizadas as técnicas de pesquisa bibliográfica para melhor entendimento do objeto do estudo, após a revisão da literatura foi aplicado o método de observação direta intensiva participantepara melhor entendimento do problema e, por último, a elaboração do estudo de caso como a etapa mais concreta da análise geral dos dados.

\subsection{UNIDADE DE ANÁLISE}

A pesquisafoi realizada em uma obra de construção industrial de uma refinaria de petróleo, com uma área de aproximadamente $6,5 \mathrm{~km}^{2}$, localizada na cidade de Ipojuca, estado de Pernambuco.

\subsection{TRATAMENTO DOS DADOS}

Os dados gerados na observação direta foram obtidos por meio de fotografias do local, análise de documentos internos e análise dos dados da obra, criando um histórico de visualização do período anterior e posterior a implantação do sistema.

\section{ESTUDO DE CASO}

\subsection{HISTÓRICO DA EMPRESA}

A Empresa Petrolífera foi criada em 1953 pelo então Presidente da República Federativa do Brasil, Getúlio Vargas e tornou-se um monopólio estatal na produção e no refino do petróleo.

Tal realização só foi possível após uma intensa mobilização popular a qual recebeu o nome de - "O petróleo é nosso" - que pressionou o governo para a aprovação da lei $\mathrm{n}^{\circ} 2004$, de 03 de outubro de 1953.

A Empresa Petrolífera é fruto da luta de uma nação valente que tem orgulho do país e que sempre foi representada por toda a força de trabalho da companhia, mesmo nos períodos mais difíceis, buscando melhorias para a sociedade e contribuindo para o desenvolvimento tecnológico do Brasil.

A Empresa Petrolífera sempre se destacou positivamente perante o mercado internacional como uma empresa pioneira na criação de novas tecnologias de exploração de petróleo em água ultra profundas o que demonstrou ainda mais a capacidade dos seus empregados, tornando-se reconhecida como a maior empresa da América Latina.

Uma empresa integrada de energia que atua de forma rentável e com responsabilidade ambiental e social, promovendo as mais diversas ações que visam a melhoria do processo de exploração, aliada a melhor forma de preservação do ecossistema local.

Em suas operações no território brasileiro, a Empresa Petrolífera oferece uma vasta rede de produtos como gasolina, gás natural, óleo diesel, lubrificantes e nafta petroquímica. Os produtos são comercializados em sua rede de postos próprios e postosdos representantes. Além dos produtos comercializados existem serviços complementares aos produtos, como os centros de lubrificação e as lojas de conveniência, que oferecem espaço de convivência e alimentação.

Com o crescimento do consumo de derivados do petróleo no Brasil a partir da década de 1990, a Empresa Petrolífera vinha elaborado planos viabilidade para a expansão da sua rede de refinarias e a região nordeste foi contemplada com o investimento devido a sua posição de estratégica logística. 
Após a definição da região nordeste com a beneficiária dos investimentos de expansão, o estado de Pernambuco foi contemplado como o primeiro estado a receber os investimentos de construção de uma refinaria após 34 anos.

A cidade de Ipojuca foi escolhida para receber a refinaria devido a sua posição geográfica favorável, onde também está localizado o porto de Suape, que servirá como o ponto de recebimento e envio, respectivamente, de petróleo e produtos acabados.

Inicialmente a Refinaria teve seu projeto definido com foco em refino de petróleo para produção de óleo diesel que servirá para atender o mercado interno, abastecido por produto importado.

Parte dos investimentos para a construção seriam complementados, como forma de parcerias estrangeiras e a operação seria para processamento do petróleo do Brasil e de paísesparceiros, porém, por razões financeiras a estatal venezuelana desistiu do projeto e a estatal brasileira passou a ser a única proprietária do empreendimento, mas manteve o projeto conceitual de refino de petróleo venezuelano.

Atualmente, a refinaria é a $5^{\mathrm{a}}$ maior unidade em operação no Brasil, com capacidade de processamento de 230 mil barris de petróleo por dia e tem a tecnologia de transformar em diesel $70 \%$ do petróleo.

Além do óleo diesel, a refinaria também produz outros derivados como nafta, coque de petróleo, gás liquefeito de petróleo (GLP), gasóleo pesado para ser usado como óleo combustível industrial, ácido sulfúrico e enxofre.

A Refinaria, como mostra a Figura2, conta com cerca de 50 tanques de armazenamento de petróleo cru, produtos semiacabados e produtos acabados, além de uma capacidade de estocagem maior que $1.500 .000 \mathrm{~m}^{3}$.

Figura 2 - Imagem Aérea da Refinaria

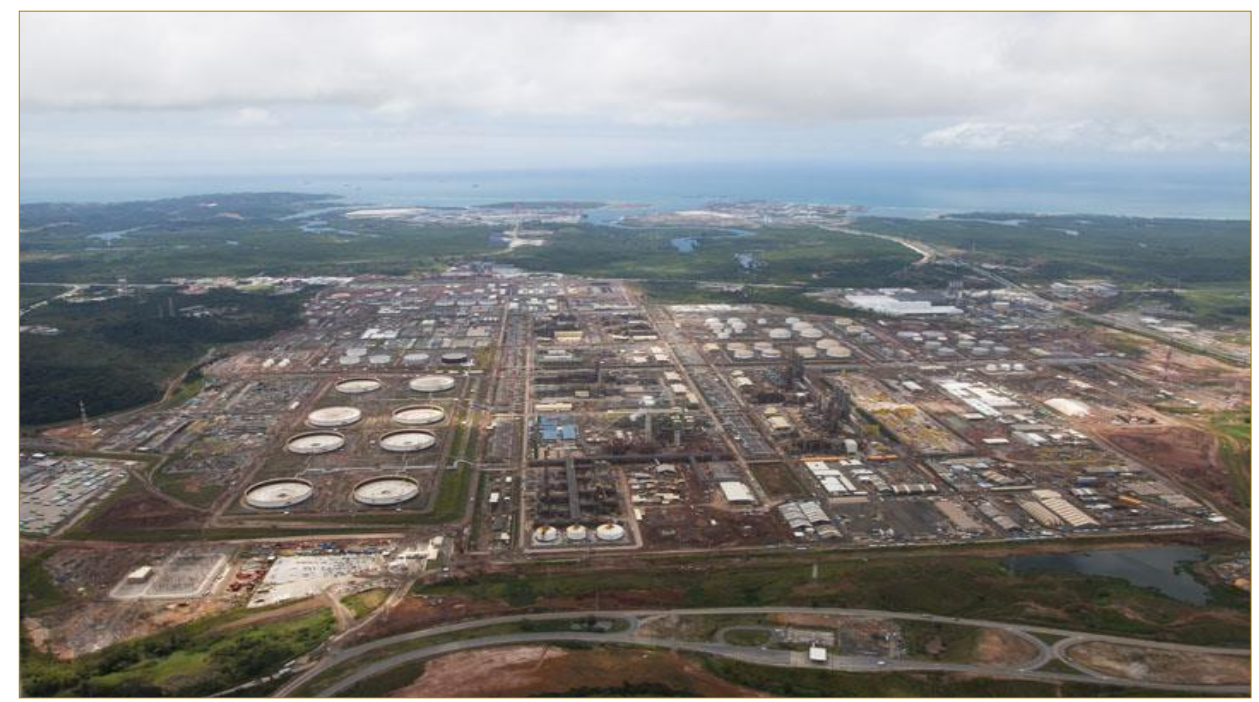

Fonte: Empresa Petrolífera, 2014

A Refinaria está divida em duas unidades de refino idênticas dentro do mesmo parque fabril e são denominadas trem de refino, o que a torna flexivél em operação, uma vez que os trens podem operar de forma independente. 0 projeto é o mais moderno já realizado no Brasil e conta com avançados níveis de automação e segurança, com respeito as normas internacionais de proteção ambiental, além do baixo custo de manutenção, baixo consumo de energia e alta segurança operacional.

A produção é focada em óleo diesel com baixo teor de enxofre, o denominado Diesel S10 que tem em concentração apenas 10 partes por milhão de enxofre, com capacidade de reduzir em até $80 \%$ a emissão de partículas sólidas e redução de até $98 \%$ na emissão de óxido de nitrogênio. 
A refinaria quanto estiver em plena operação será capaz, confome Figura 3, de abastecer,com Diesel S-10, 2 em cada 10 veículos no Brasil.

Figura 3 - Perfil de Produção da Refinaria

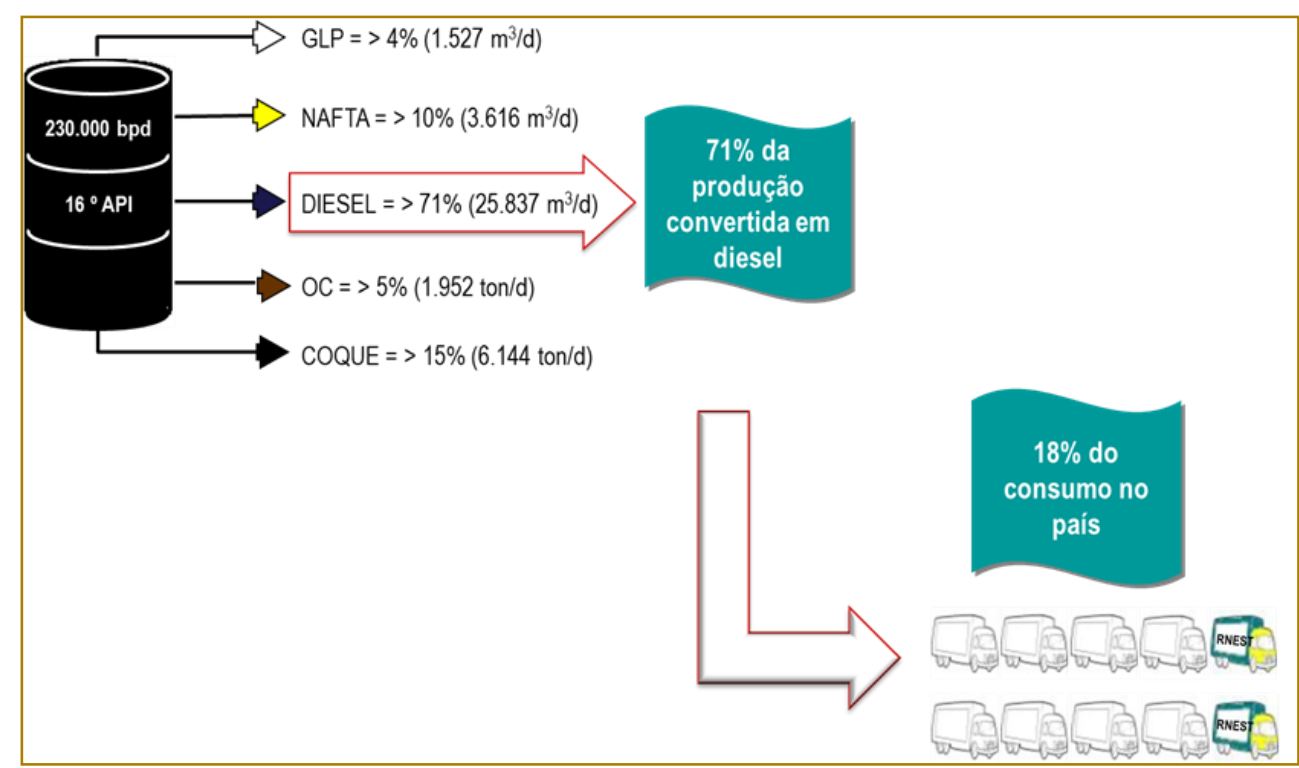

Fonte: Empresa Petrolífera, ano 2016

A refinaria, quando em plena operação, irá suprir os mercados consumidores do Norte e Nordeste do Brasil e será um grande avanço para o páis, pois alem de geração de emprego e renda, contribui para o desenvolvimento tecnológico.

Para a implantação de um projeto dessa magnitude, diversos profissionais das mais diversas área foram convocados e divididos em área de atuação. A etapa inicial da obra que correspondia a implantação da parte de construção civil contava com a maioria dos profissionais envolvidos, porém foi criado um setor específico para acompanhamento dos serviços provisórios que eram necessários para a execução dos serviços definifitivos e assim surgiu um grupo de trabalho (GT) que mapeava, direcionava, acompanhava e media a eficiência da execução dos serviços de drenagem.

\subsection{ANÁLISE PARA IMPLANTAÇÃO DA DRENAGEM PLUVIAL (PLAN)}

Uma das etapas iniciais de uma obra de construção civil é a terraplenagem, e é a partir dela que os demais serviços são realizados de forma sequencial.

Antes da implantação da drenagem pluvial provisória no ano de 2013, toda a obra apresentava problemas de alagamento pois, em ocorrência de precipitação, as águas não tinham direcionamento correto, causando uma série de dificuldades de locomoção como também de execução de serviços.

A primeira atividade realizada pelo Grupo de Trabalho de Drenagens, chamado simplesmente de $G T$, foi realizar um estudo do clima na região de Ipojuca, conforme mostrado no Gráfico2, para definir os períodos de implantação do ciclo PDCA da forma mais adequada possível, assim as equipes de serviços de campo poderiam realizar as intervenções que seriam necessárias para mitigar os efeitos das alagamentos. 
Gráfico 2 - Climatologia da Cidade de Ipojuca/PE

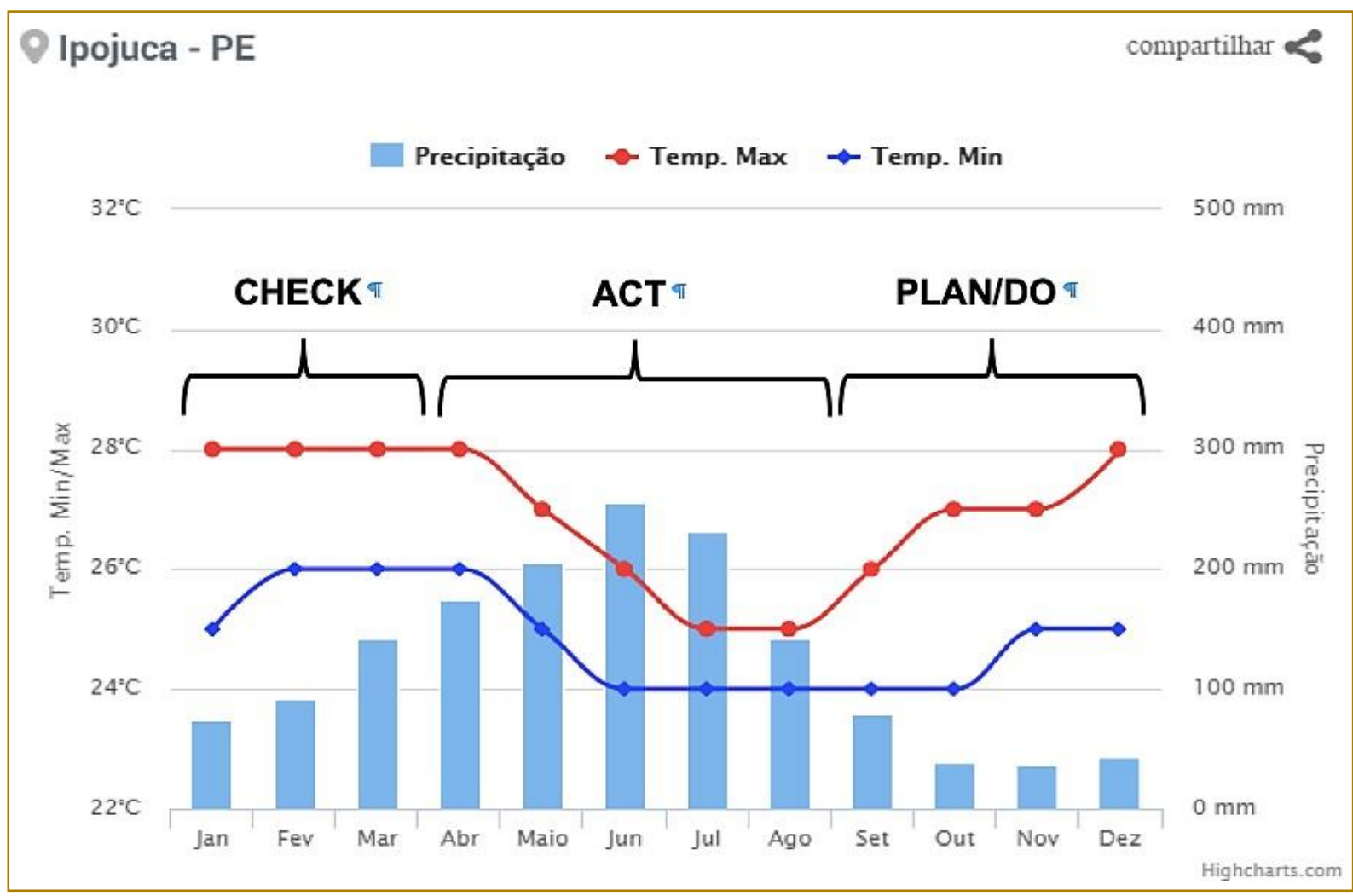

Fonte: Disponível em<http://www.climatempo.com.br/climatologia/2017/ipojuca-pe>

Após a análise do gráfico da climatologia, o GT de Drenagem definiu a sequência do PDCA, conforme os meses de menor incidência de chuvas na região, sendo que os meses de setembro a dezembro seriam para planejamento dos serviços e execução dos canais, janeiro a março para controle das atividades realizadas e de abril a agosto para teste de funcionalidade e correções emergenciais que poderiam se fazer necessárias no sistema no período de maior incidência de chuvas na região.

A partir dessa definição foi possível estabelecer com as empresas envolvidas na execução, que ora, estavam sendo penalizadas com problemas causados pela paralização dos funcionários em decorrência dos alagamentos, para que assumissem os custos de implantação, manutenção e eventual correção das drenagens que seriam propostas para que assim, o trabalhofosse repassado da Empresa Petrolífera para as contratadas que, em contra partida, não teriam mão de obra ociosa em decorrência de alagamentos.

As empresas contratadas aceitaram a proposta e a Empresa Petrolífera ficou com a responsabilidade, através do GT de Drenagem, de planejar, fiscalizar e cobrar a execução das atividades para que todas as empresas envolidas pudessem ser beneficiadas com a implantação do sistema e evitar que as chuvas causasem mais alagamentos, como exemplificado na Figura 4 , e consequentemente atrasos na obra. 
Figura 4 - Alagamento em decorrência da falta de drenagem pluvial.

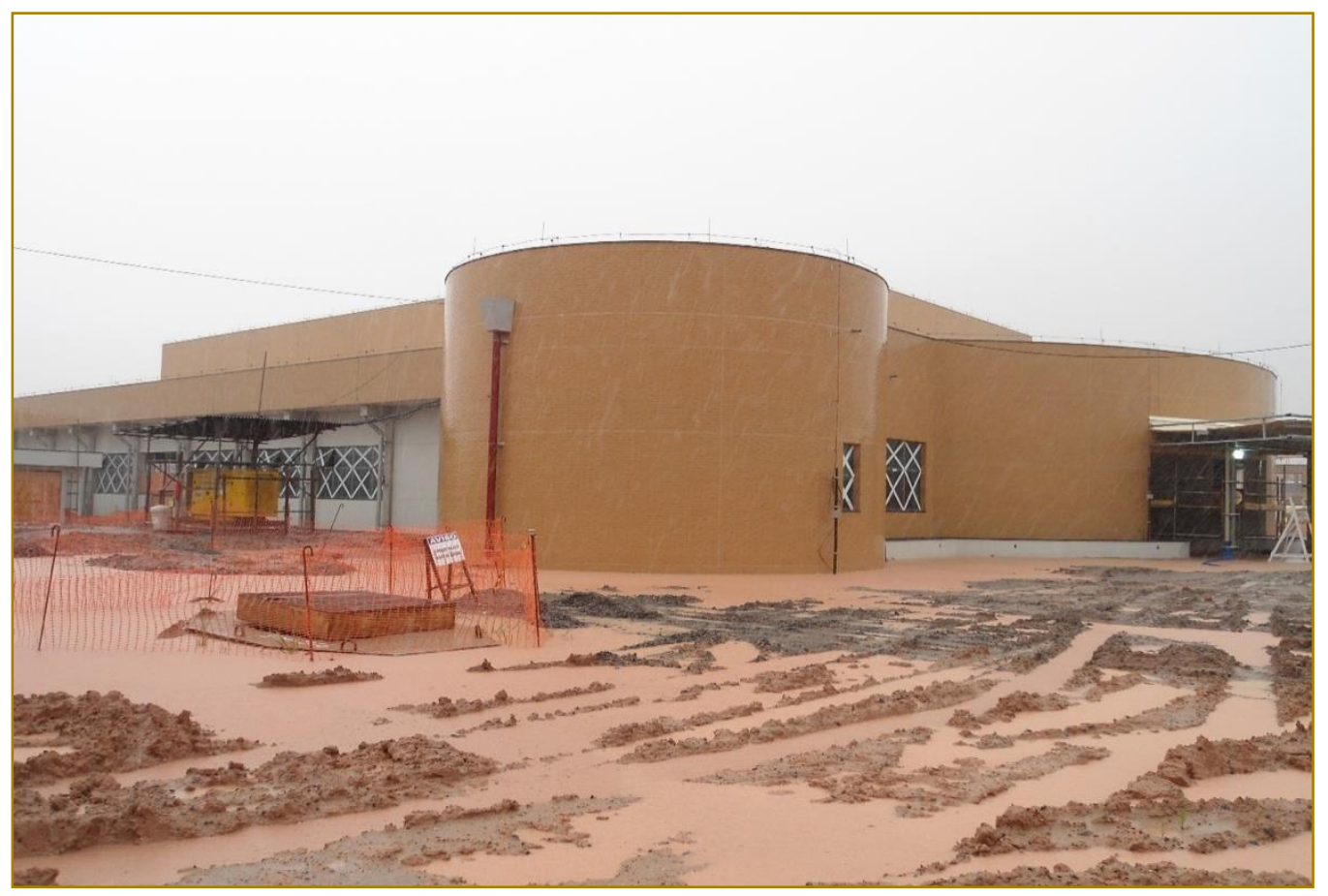

Fonte: Próprio Autor, 2012.

\subsection{DEFINIÇÃO DAS BACIAS DE DRENAGEM (DO)}

Após o estudo para implantação do sistema de drenagens através da climatologia, foi decidido também através do Brainstorming do GT que a área da refinaria, conforme mostrado na Figura 5, seria dividida em bacias de drenagem para que a maior parte possível do território de $6,5 \mathrm{~km}^{2}$ fosse contemplado com canais de drenagem.

Figura 5 - Planta de arranjo geral da refinaria

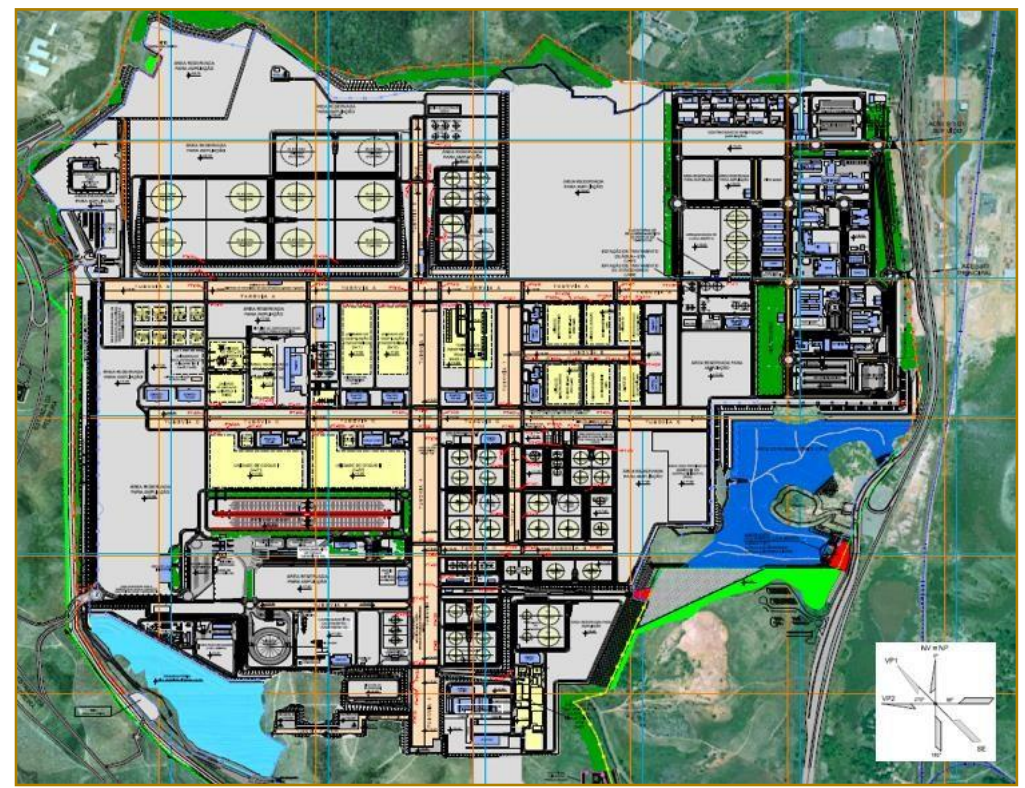

Fonte: Empresa Petrolífera, 2013 
Utilizando a planta de arranjo geral da refinaria, foi possivel identificar os níveis do terreno e, a partir dessa identificação, fazer as marcações das bacias de drenagem, conforme mostrado na Figura 6.

Esse trabalho foi elaborado pelo GT que, em seguida, passou a utilizar essa planta com as marcações das bacias para todas as tomadas de decisões presentes e futuras de todo o sistema de drenagem pluvial provisória da refinaria.

Cada bacia recebeu um nome específico conforme o ponto cardeal a ela atribuído e uma cor específica para auxiliar na identificação visual.

Figura 6 - Planta de arranjo geral da refinaria com divisão das bacias de drenagem.

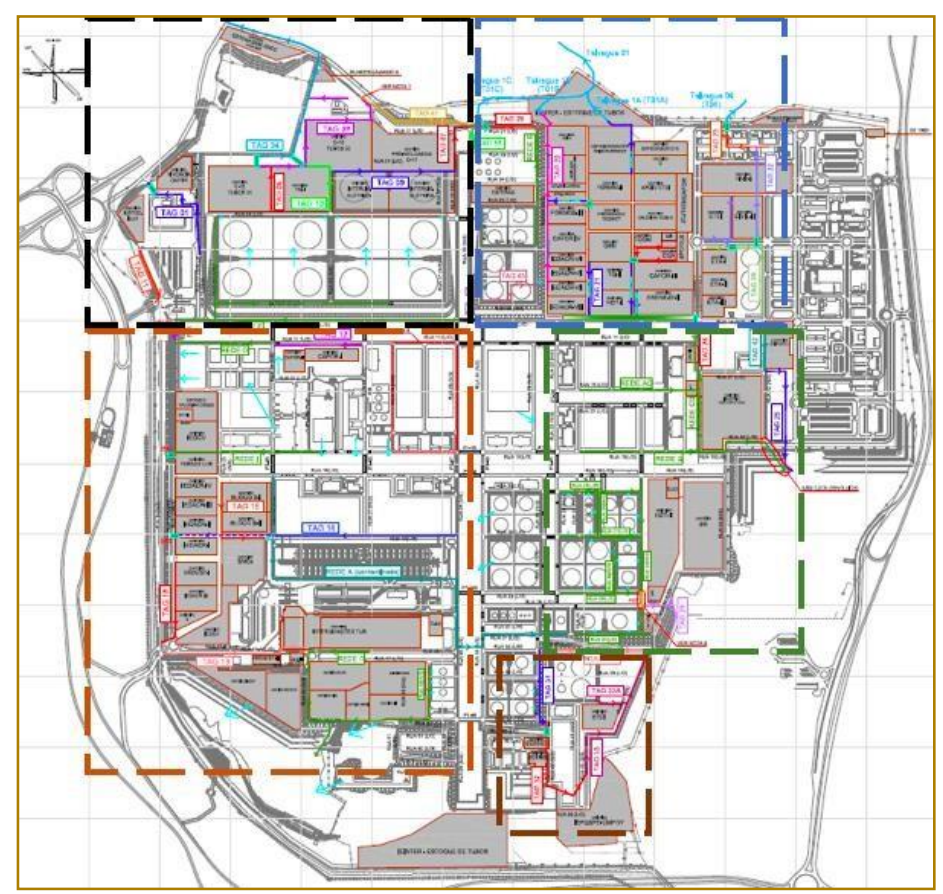

Fonte: Empresa Petrolífera, 2013

A divisão das bacias de drenagem, mostrada na Tabela 1 , contém todas as informações necessárias para a localização e identificação das bacias de drenagem que foram implantados na área da refinaria.

Tabela 1 - Divisão das bacias de drenagem

\begin{tabular}{|c|c|c|}
\hline \multicolumn{2}{|c|}{ Nome da Bacia } & Região Atendida \\
\hline Bacia Nordeste & Nordeste e Leste & \\
\hline Bacia Noroeste & Norte e Oeste & \\
\hline Bacia Sudeste & Sul e Leste & \\
\hline Bacia Sudoeste & Sul e Oeste & \\
\hline Bacia Sul & Sul e Leste & \\
\hline
\end{tabular}

Fonte: Empresa Petrolífera

\subsubsection{DEFINIÇÃO DOS CANAIS DE DRENAGEM (DO)}

Para a melhor tomada de decisões do GT, foi utilizada, conforme mostrado na Figura 6, a planta de arranjo geral da refinaria com divisão das bacias, para subsidiar as decisões sobre os melhores caminhos para implantação dos canais de drenagem.

Ficou estabelecido, também após reuniões do GT, que a forma mais viável seria a 
implantação dos canais de acordo com cada elevação do terreno.

Cada canal teria uma identificação numérica e que seria adotado, como ponto de referência, a localização por pontos cardeais, para uma identificação complementar que facilitaria a localização espacial até mesmo para quem não tinha o conhecimento da área da refinaria, como também para fácil localização das equipes de manutenção.

Todas áreas do parque fabril foram contempladas com canais independentes e cada consórcio de empresas foi contemplado com uma determinada área para implantação e manutenção afim de garantir o pleno funcionamento do sistema.

Os canais foram numerados do número 01 ao 50, mas alguns canais deixaram de existir ao longo dos anos da obra, e não ocorreu a alteração da numeração existente para não gerar divergências, apenas a exclusão dos números dos canais que deixaram de existir.

Os canais foram divididos dentro das áreas de cada bacia, e cada figura da planta de arranjo geral da refinaria com divisão das bacias de drenagem possuem os dados detalhados das elevações do terreno conforme a ordem das bacias a seguir:

Bacia Noroeste: Abrangendo as regiões norte e oeste da refinaria.

Cada canal da bacia noroeste, identificado na Figura 7 , foi devidamente sinalizado e direcionado para a melhor área de descarte na região periférica da Refinaria, identificado por sua seta de direção do canal, favorecendo o tráfego interno e a realização dos serviços na região sem a interferência de alagamentos. Cada canal poderia estar interligado com outro canal ou simplesmente com descarte independente para a área externa e desabitada da refinaria.

Figura 7 - Bacias de drenagem noroeste.

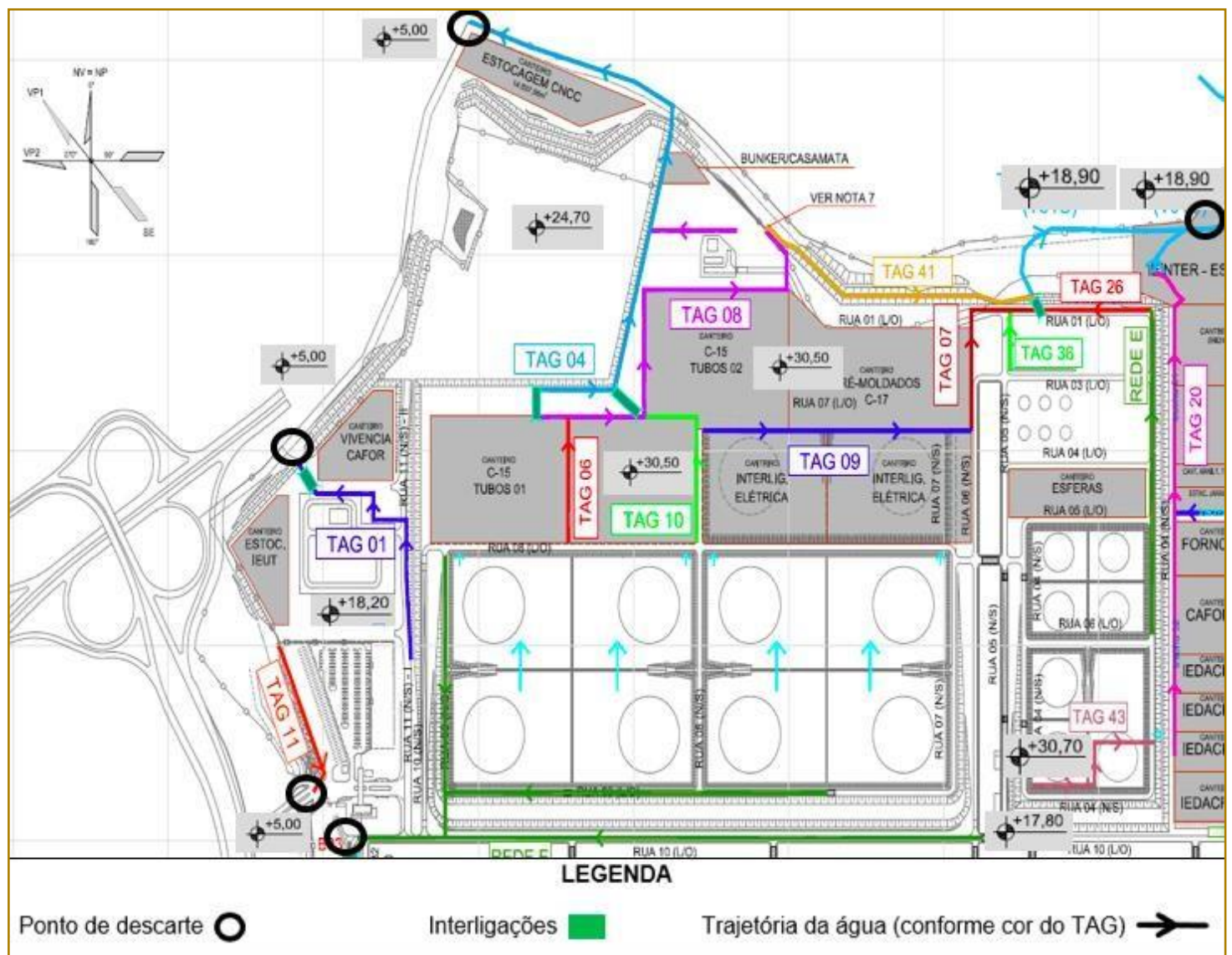

Fonte: Empresa Petrolífera, 2013 
A tabela 2, demonstra a quantidade de canais da região noroeste, sua identificação por cor, além das interligações com outros canais, caso exista.

Tabela 2 - Divisão dos canais de drenagem da bacia noroeste

\begin{tabular}{|c|c|c|c|c|}
\hline \multirow{2}{*}{ Nome do canal } & \multirow{2}{*}{ Identificação do canal } & \multicolumn{2}{|c|}{ Interligado } & \multirow{2}{*}{ Canal de interligação } \\
\hline & & Sim & Não & \\
\hline TAG 01 & & & $x$ & \\
\hline TAG 04 & 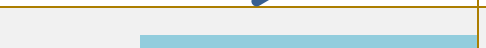 & $x$ & & TAG 08 \\
\hline TAG 06 & & $x$ & & TAG 08 \\
\hline TAG 07 & & $x$ & & TAG 09, 26 e 38 \\
\hline TAG 08 & & $x$ & & TAG 04, 06, 10 e 41 \\
\hline TAG 09 & & $x$ & & TAG 07 e 10 \\
\hline TAG 10 & & $x$ & & TAG 08 e 09 \\
\hline TAG 11 & & & $x$ & \\
\hline TAG 20 & & $x$ & & $\begin{array}{l}\text { TAG 21B - Bacia Nordeste e TAG } \\
43\end{array}$ \\
\hline TAG 26 & & $x$ & & TAG 07 \\
\hline TAG 38 & - & $x$ & & TAG 07 \\
\hline TAG 41 & & $x$ & & TAG 08 \\
\hline TAG 43 & 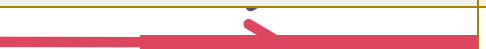 & $x$ & & TAG 20 \\
\hline REDE E & 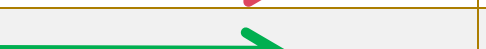 & & $x$ & \\
\hline
\end{tabular}

Fonte: Próprio autor

Bacia Nordeste: Abrangendo as regiões norte e leste.

A área nordeste, mostrada na Figura 8 , foi contemplada com canais que direcionam a água proveniente de precipitação para o trecho norte da refinaria, com cada canal identificado por sua seta de direção, além de interligação com canais da bacia sudeste. A área Administrativa situada na parte mais a leste não foi contemplada com canais de drenagem por ser um trecho com constante movimentação de terras subterrâneas para passagem de instrumentação, de modo que seria inviável e até mesmo prejudicial realizar escavações para implantação de drenagem provisória. 
Figura 8 - Bacia de drenagem nordeste

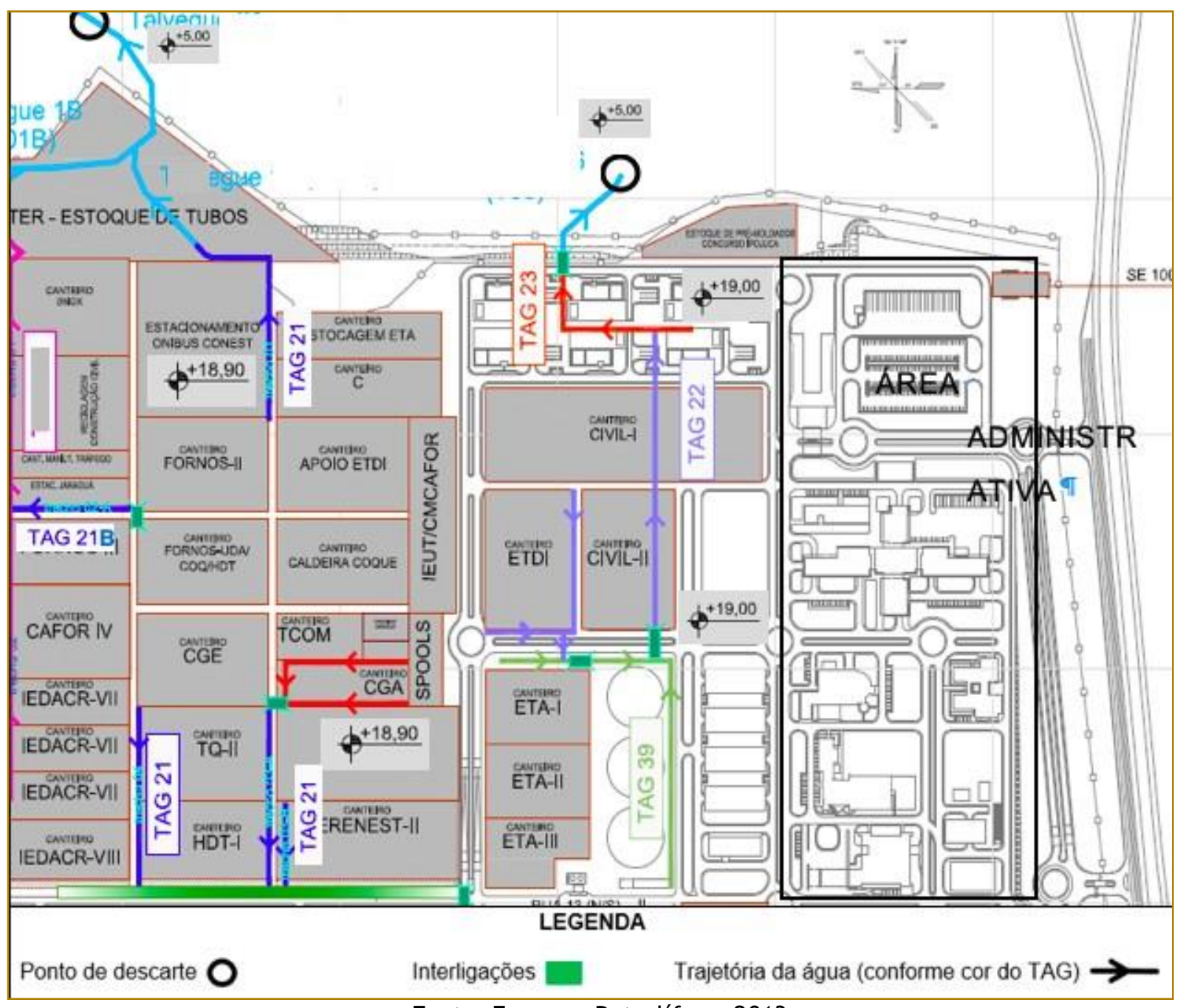

Fonte: Empresa Petrolífera, 2013

A tabela 3, demonstra a quantidade de canais da região noroeste, sua identificação por cor e a direção do canal, conforme seta, além das interligações, quando existirem.

Tabela 3 - Divisão dos canais de drenagem da bacia nordeste

\begin{tabular}{|c|c|c|c|c|}
\hline \multirow{2}{*}{ Nome do canal } & \multirow{2}{*}{ Identificação do canal } & \multicolumn{2}{|c|}{ Interligado } & \multirow{2}{*}{ Tipo de interligação } \\
\hline & & $\mathrm{Sim}$ & Não & \\
\hline TAG 21 & & $x$ & & TAG 24 - Bacia Sudeste \\
\hline TAG 21A & & & $\mathrm{x}$ & \\
\hline TAG 21B & & $\mathrm{x}$ & & TAG 20 - Bacia Noroeste \\
\hline TAG 21C & & $\mathrm{x}$ & & TAG 24 - Bacia Sudeste \\
\hline TAG 22 & - & $\mathrm{x}$ & & TAG 23 e 39 \\
\hline TAG 23 & 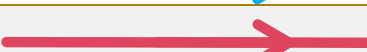 & $x$ & & TAG 22 \\
\hline TAG 39 & & $\mathrm{x}$ & & TAG 22 \\
\hline
\end{tabular}


Bacia Sudoeste: Abrangendo as regiões oeste e sul.

A área com a maior concentração de instalações provisórias de empresas contratadas e grande fluxo de funcionários.
A área tem como destino final o descarte das águas para a região oeste, conforme mostrado na Figura 9.

Figura 9 - Bacia de drenagem sudoeste

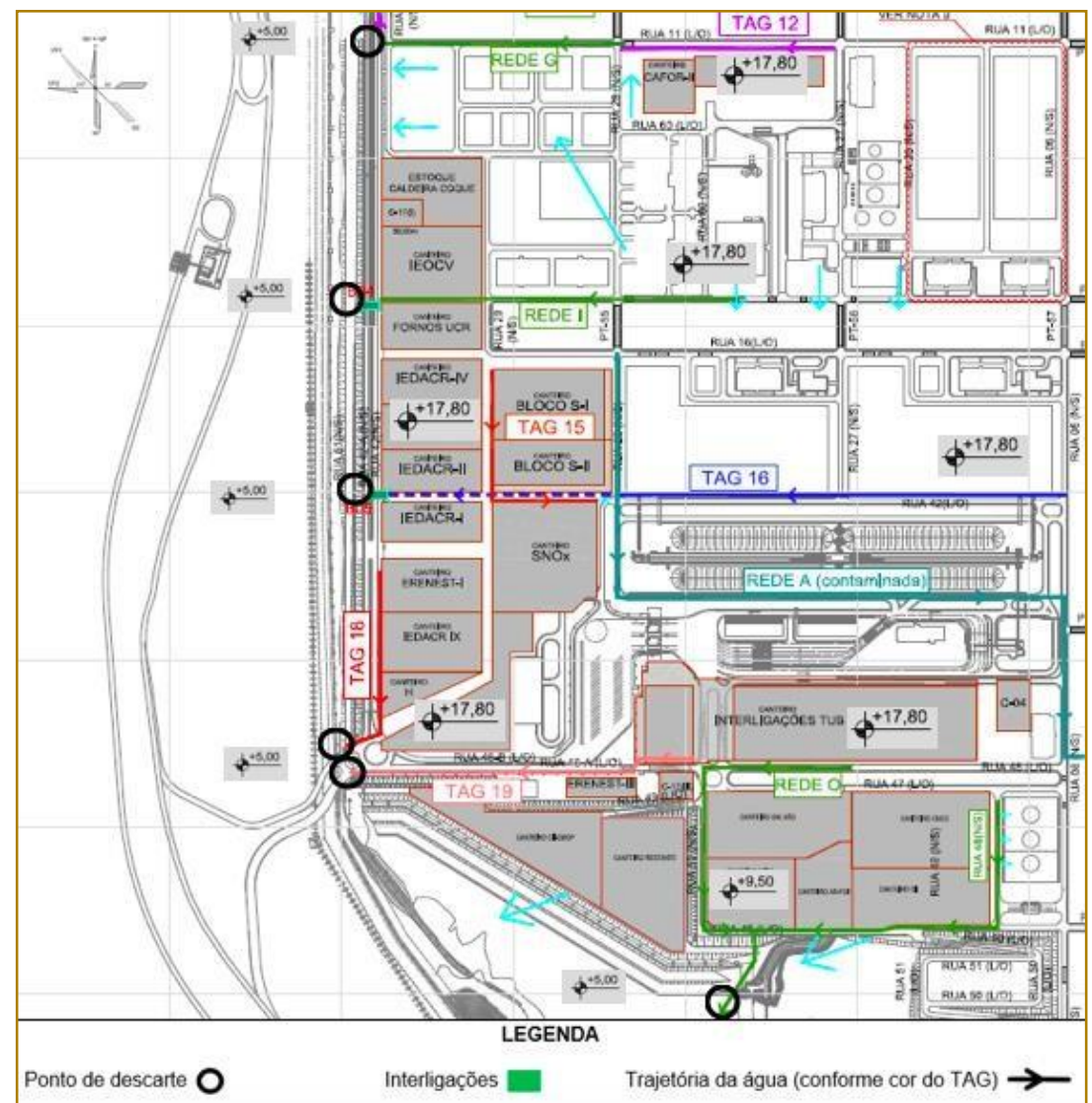

Fonte: Empresa Petrolífera, 2013

A tabela 4, demonstra a quantidade de canais da região sudoeste, sua identificação por cor e a direção do canal, conforme seta, além das interligações, quando existirem.

Tabela 4 - Divisão dos canais de drenagem da bacia sudoeste

\begin{tabular}{|c|c|c|c|c|}
\hline \multirow{2}{*}{ Nome do canal } & \multirow{2}{*}{ Identificação do canal } & \multicolumn{2}{|c|}{ Interligado } & \multirow{2}{*}{ Tipo de interligação } \\
\cline { 2 - 4 } & & Sim & Não & \\
\hline TAG 12 & & $\mathrm{x}$ & & REDE G \\
\hline TAG 15 & & $\mathrm{x}$ & & TAG 16 \\
\hline TAG 16 & & $\mathrm{x}$ & & TAG 15 \\
\hline TAG 18 & & & $\mathrm{x}$ & \\
\hline TAG 19 & & & $\mathrm{x}$ & \\
\hline REDE A & & $\mathrm{x}$ & & TAG 34 - Bacia Sul \\
\hline REGE G & & & $\mathrm{x}$ & TAG 12 \\
\hline REDE I & & & $\mathrm{x}$ & \\
\hline REDE O & & & & \\
\hline
\end{tabular}

Fonte: Próprio autor 
Bacia Sudeste: Abrangendo as regiões sul e leste.

Os canais da bacia sudeste, conforme Figura 10, absorveram toda a contribuição da área central da refinaria e toda a contribuição que não pode ser absorvida pelo trecho nordeste.

A área também recebe toda a contribuição dos tanques de produto acabado e faz o encaminhamento para a área externa da refinaria.

Cada bacia, como já foi dito anteriormente, foi dividida de acordo com o planalto do terreno, assim a adequação do curso d'água foi melhor, evitando custos com bombeamento.

Figura 10 - Bacia de drenagem sudeste

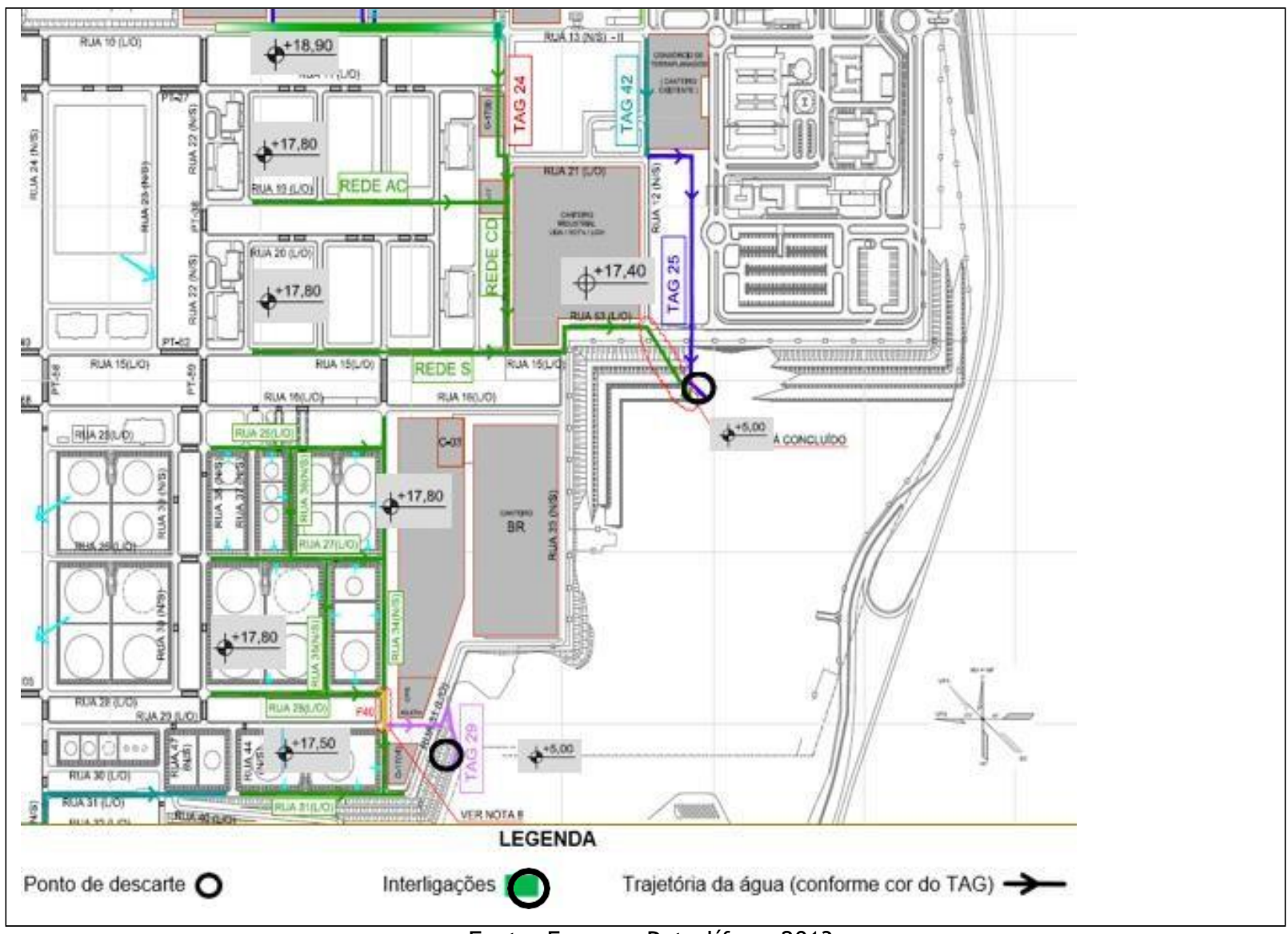

Fonte: Empresa Petrolífera, 2013

A tabela 5, demonstra a quantidade de canais da região sudeste, sua identificação por cor e a direção do canal, conforme seta, além das interligações, quando existirem. 
Tabela 5 - Divisão dos canais de drenagem da bacia sudeste

\begin{tabular}{|c|c|c|c|c|}
\hline \multirow{2}{*}{ Nome do canal } & \multirow{2}{*}{ Identificação do canal } & \multicolumn{2}{|c|}{ Interligado } & \multirow{2}{*}{ Tipo de interligação } \\
\hline & & Sim & Não & \\
\hline TAG 24 & & $x$ & & $\begin{array}{l}\text { TAG } 21 \text { e 21C - Bacia } \\
\text { Nordeste, REDE AC, REDE } \\
\text { CD e REDE S }\end{array}$ \\
\hline TAG 25 & $\geq$ & $\mathrm{x}$ & & TAG 42 \\
\hline TAG 29 & 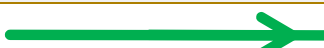 & & $\mathrm{x}$ & \\
\hline TAG 42 & - & $\mathrm{x}$ & & TAG 25 \\
\hline REDE S & 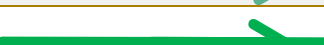 & $\mathrm{x}$ & & REDE CD \\
\hline REDE AC & & $\mathrm{x}$ & & REDE CD \\
\hline REDE CD & & $\mathrm{x}$ & & TAG 24 , REDE AC e REDE $S$ \\
\hline
\end{tabular}

Bacia Sul: Abrangendo a região sul.

A última bacia a ser implantada, mas não a menos importante, foi a bacia sul, conforme Figura 11, e sua configuração toda a contribuição gerada no planalto de cota mais baixa da refinaria.
A disposição dos canais não sofreu alteração de percurso, apenas alteração de cota de fundo com inversão do curso para assim ser capaz de direcionar a água para o novo destino.

Figura 11 - Bacia de drenagem sul

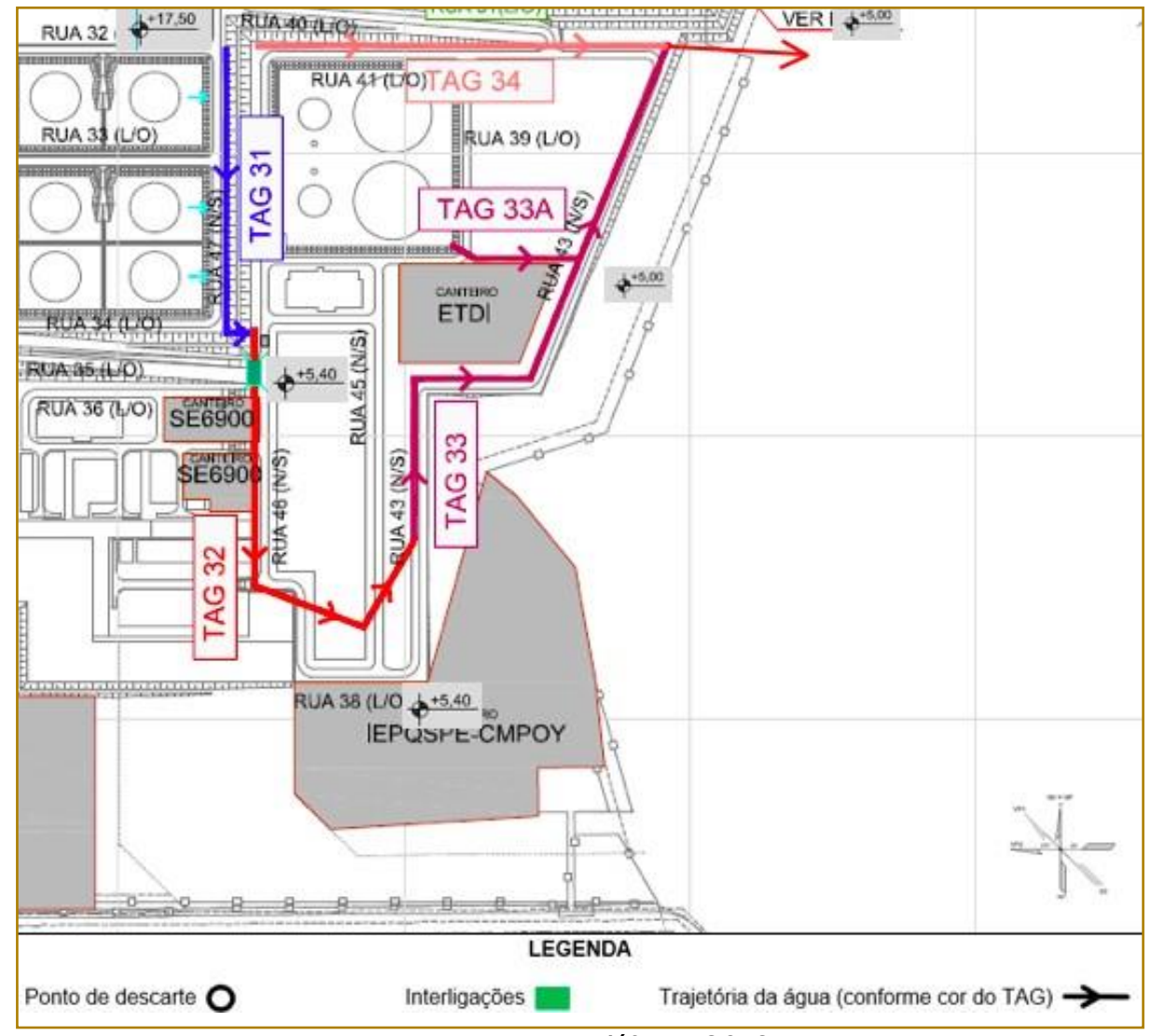

Fonte: Empresa Petrolífera, 2013 
A tabela 6, demonstra a quantidade de canais da região sul, sua identificação por cor e a direção do canal, conforme seta, além das interligações, quando existirem.

Tabela 6 - Divisão dos canais de drenagem da bacia sul

\begin{tabular}{|l|l|l|l|l|}
\hline \multirow{2}{*}{ Nome do canal } & \multirow{2}{*}{ Identificação do canal } & \multicolumn{2}{|l|}{ Interligado } & \multirow{2}{*}{ Tipo de interligação } \\
\cline { 2 - 3 } & & Sim & Não & \\
\hline TAG 31 & & x & TAG 32 \\
\hline TAG 32 & & x & TAG 31 e 33 \\
\hline TAG 33 & & x & TAG 32 e 33A \\
\hline TAG 33A & & x & TAG 33 e 34 \\
\hline TAG 34 & & $\begin{array}{l}\text { TAG 33 e REDE A - } \\
\text { Bacia Sudoeste }\end{array}$ \\
\hline
\end{tabular}

Fonte: Próprio autor

Controle da execução dos canais de drenagem (CHECK)

Para o controle dos processos sair de forma mais eficiente, um novo ciclo do PDCA foi implantado nesta etapa, assim, era possível adequar o ciclo para cada apresentação do relatório gerencial dos canais, conforme Figura 12.

Cada atraso na execução das atividades implicava em uma série de consequências que poderiam ser desde a dificuldade de locomoção na área interna da refinaria, como também a paralização total das atividades na área por consequência do alagamento.

Por isso, cada apresentação realizada era bastante discutida para que se chegasse a um comum acordo de replanejamento da execução da forma menos traumática para a obra e o mais rápido possível.

Figura 12 - Modelo do relatório gerencial (TAG 04 - Região Noroeste)

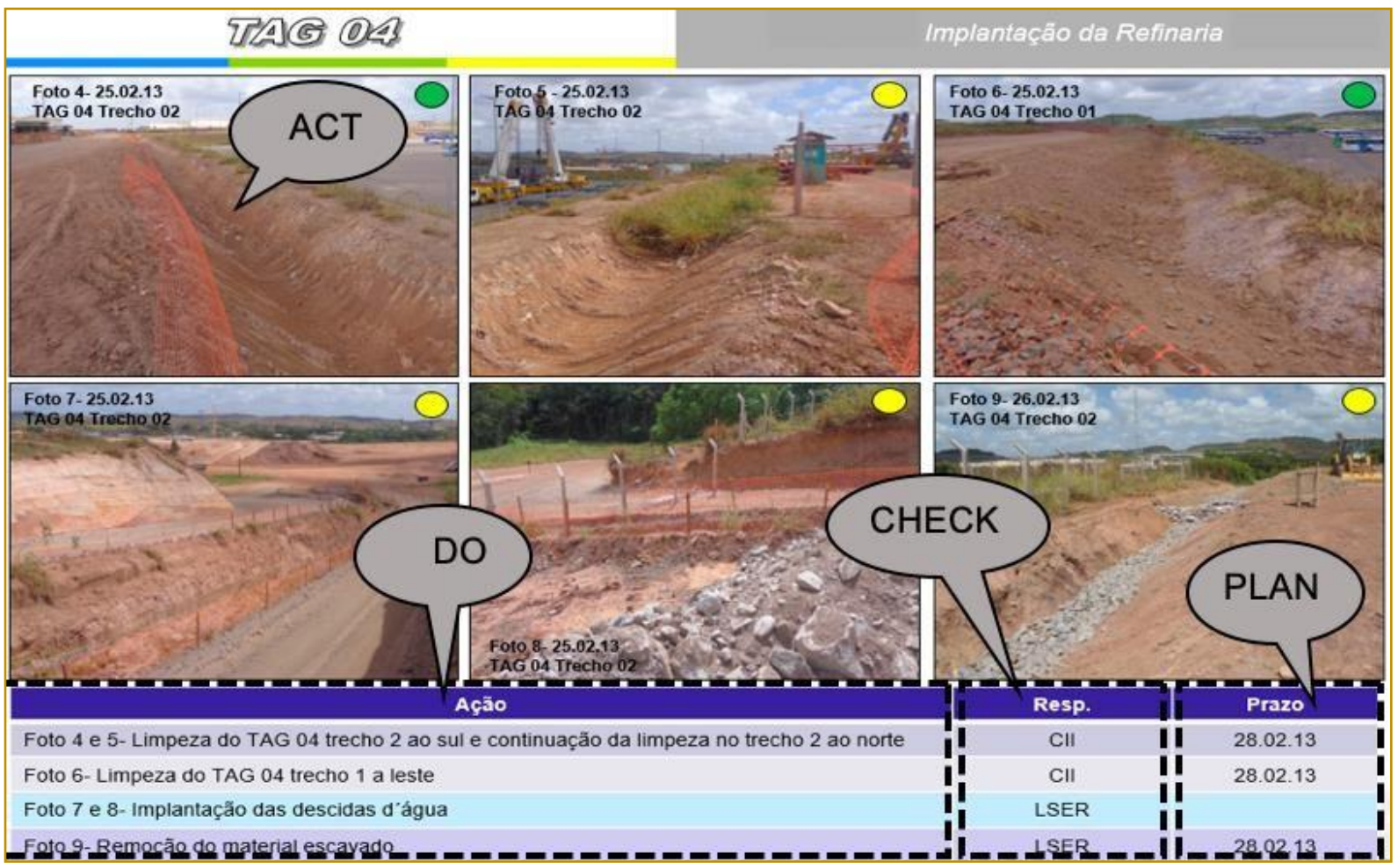

Fonte: Empresa Petrolífera, 2013 
$\mathrm{Na}$ primeira etapa do relatório gerencial (PLAN), O primeiro passo a ser realizado pelo moderador no brainstorming, no início de cada reunião do GT, era a definição dos prazos de execução dos serviços, para que as empresas pudessem realizar a sua programação individual e assim estar disponível para a realização da obra de execução do canal no prazo a ela estabelecido.

Em seguida, na etapa (DO), era definido como o serviço seria realizado pela empresa, conforme o canal estabelecido.

0 passo seguinte (CHECK), era a visita dos integrantes do GT na área onde estavam sendo executados os canais para verificação e registro fotográfico do local.

E o último passo (ACT), servia para a verificação da funcionalidade do sistema e solicitação das correções, caso necessário.

Com o processo definido, as empresas deram início a construção, onde o GT acompanhava a construção realizada pelas empresas responsáveis e elaborava os relatórios fotográficos e gráficos de evolução que eram apresentados semanalmente nas reuniões gerenciais como forma de cobrança dos prazos planejados.
A cada nova semana, o GT realizava a leitura do relatório da semana anterior na reuniãopara, em seguida, ouvir as justificativas do atraso ou não realização das solicitações, após essa fase, dava-se início a ouvida dos demais integrantes do GT para que todas as ideias de ajustes fossem esgotadas, chegando ao término da discussão e um novo planejamento de execução fosse elaborado.

Após o novo prazo de realização da atividade, um novo relatório fotográfico era realizado para a verificação da atividade em andamento.

Nas apresentações dos relatórios gerenciais, era possível identificar o canal pela sua numeração e cada foto era sinalizada com a marcação de verde para atividade concluída, amarelo para atividade em andamento e vermelho para atividade não concluída, conforme Mostrado na Figura 13.

Os relatórios poderiam conter espaços em branco, conforme mostrado também na Figura 13, pois o modelo padrão do relatório gerencial da Empresa petrolífera dispunha de apenas 6 linhas para texto, divididas para cada foto, assim, cada texto de que ultrapassasse 1 linha, significaria a exclusão obrigatória de uma foto.

Figura 13-Modelo do relatório fotográfico (Região Sudoeste)

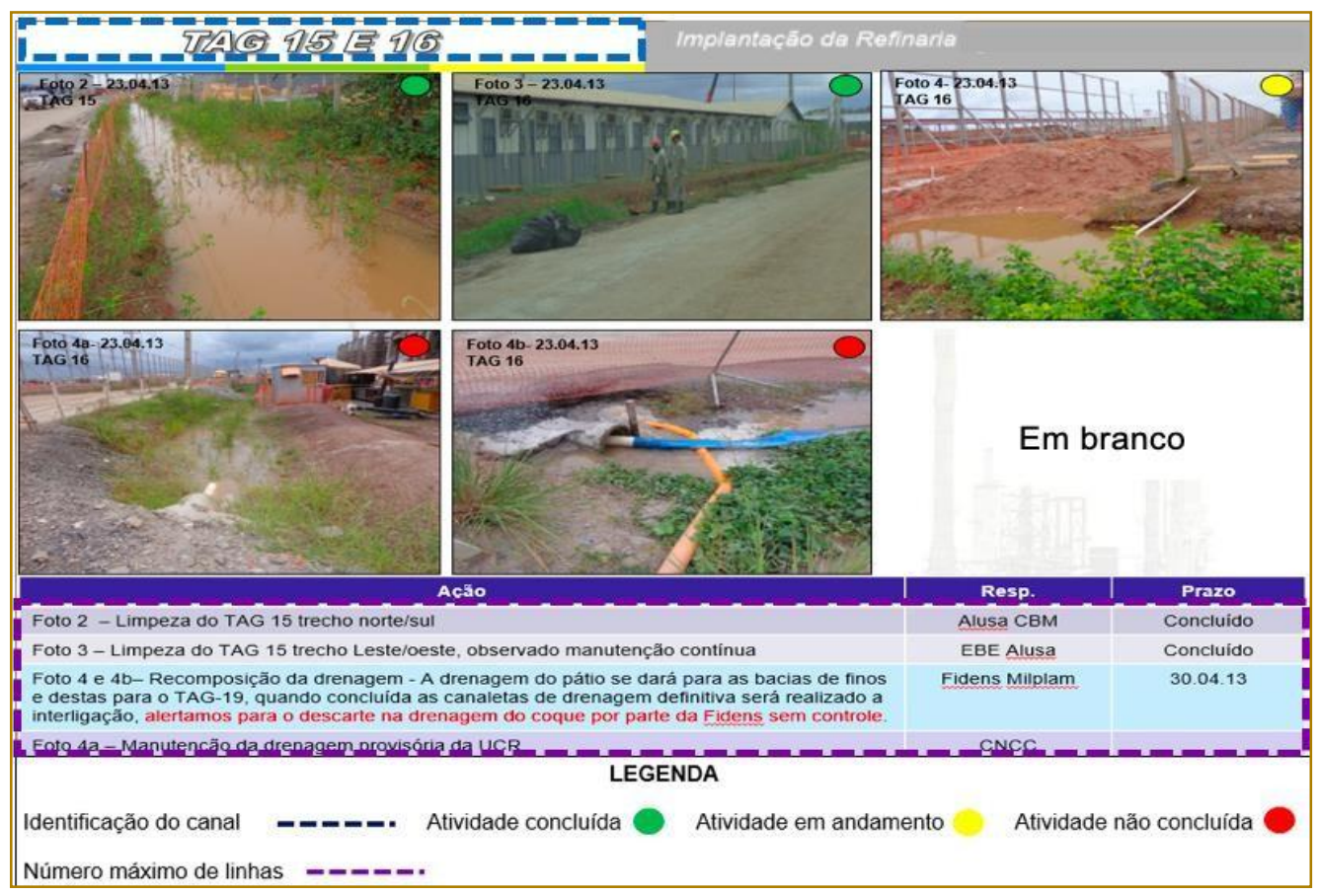

Fonte: Empresa Petrolífera, 2013 
Após a atualização dos ciclos e realização do brainstorming, eram gerados gráficos, Conforme Gráfico 3, consolidados para cada bacia de drenagem, contemplando as atividades envolvidas e o andamento de cada uma delas, assim, qualquer interessado tinha acesso as informações geradas pelo GT para acompanhamento de serviços e programações diversas de atividades nas áreas convenientes.
Os gráficos dispunham das informações gerais do andamento da construção dos canais de toda a bacia envolvida e servia de base de dados para comprovação de execução dos serviços por todas as empresas envolvidas e também subsidiar respostas para futuros questionamentos a respeito dos atrasos nas execuções dos demais serviços que não estavam diretamente envolvidos com drenagem.

Gráfico 3 - Modelo do gráfico de acompanhamento

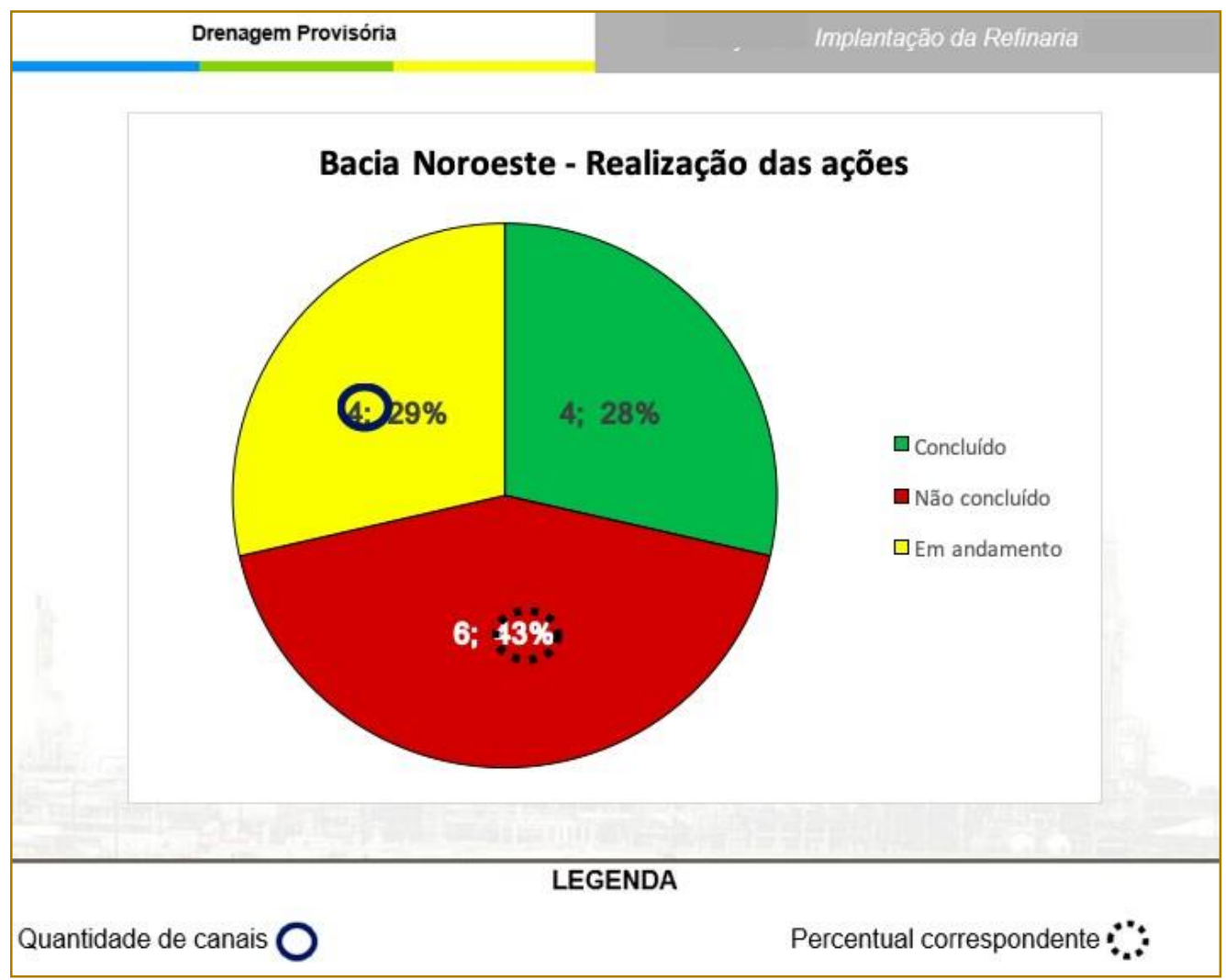

Fonte: Empresa Petrolífera

Depois de reunidas as informações por bacia, a última parte do encontro do GT consistia em disponibilizar a informação dos gráficos, no quadro de gestão a vista, de forma unificada, conforme Figura 14, para qualquer setor interessado na obtenção de informações do andamento dos serviços de drenagem e também como um indicador de eficiência das empresas envolvidas. 
Figura 14 - Modelo de gestão a vista dos indicadores de drenagem

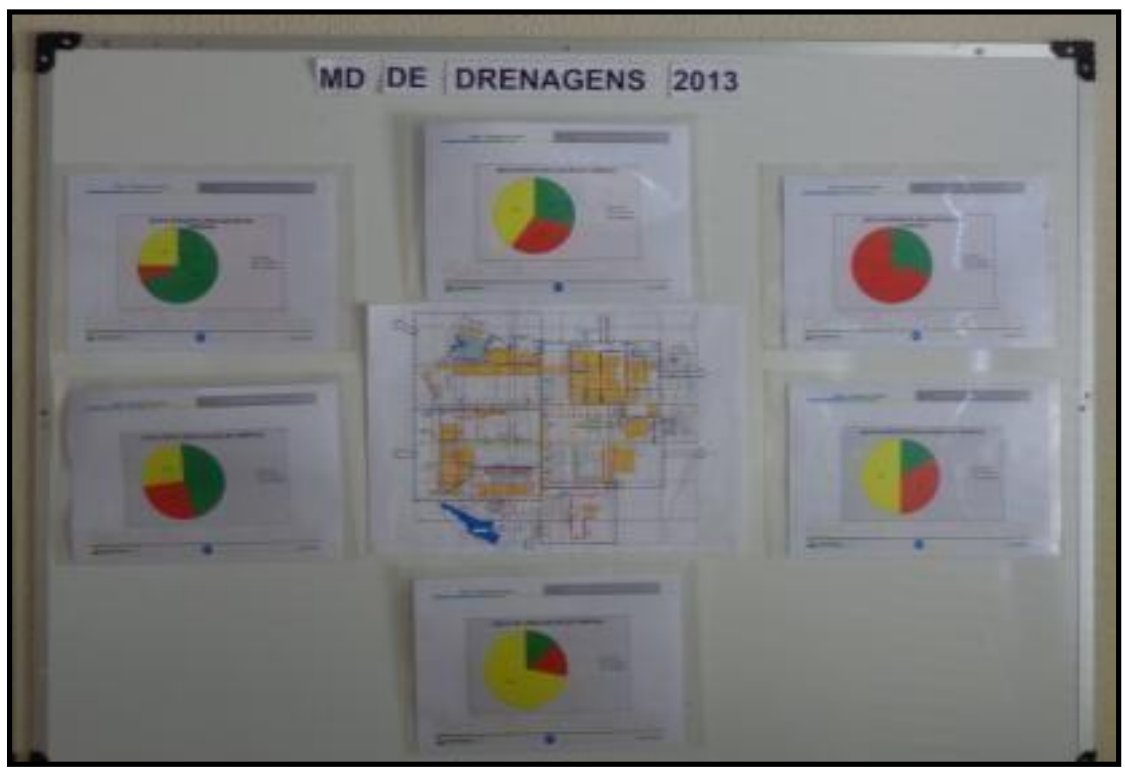

Fonte: Próprio autor, 2013

Ajuste do sistema (ACT)

Após todo o processo de execução dos serviços, a última etapa consiste na manutenção do sistema que já estava em pleno funcionamento para assim realizar todos os ajustes necessários para o próximo período de chuvas.

A vistoria era realizada após cada precipitação de chuva, assim era mais fácil programar as manutenções preventivas no sistema, como também identificar a necessidade de realização de manutenção corretiva.

As manutenções corretivas eram realizadas para solucionar problemas de drenagem que interferissem diretamente o tráfego interno da refinaria, dificultando ou interrompendo essas movimentações como mostrado nas Figuras15 e 16.

Figura 15 - Acesso com tráfego interrompido. (Antes da manutenção corretiva)

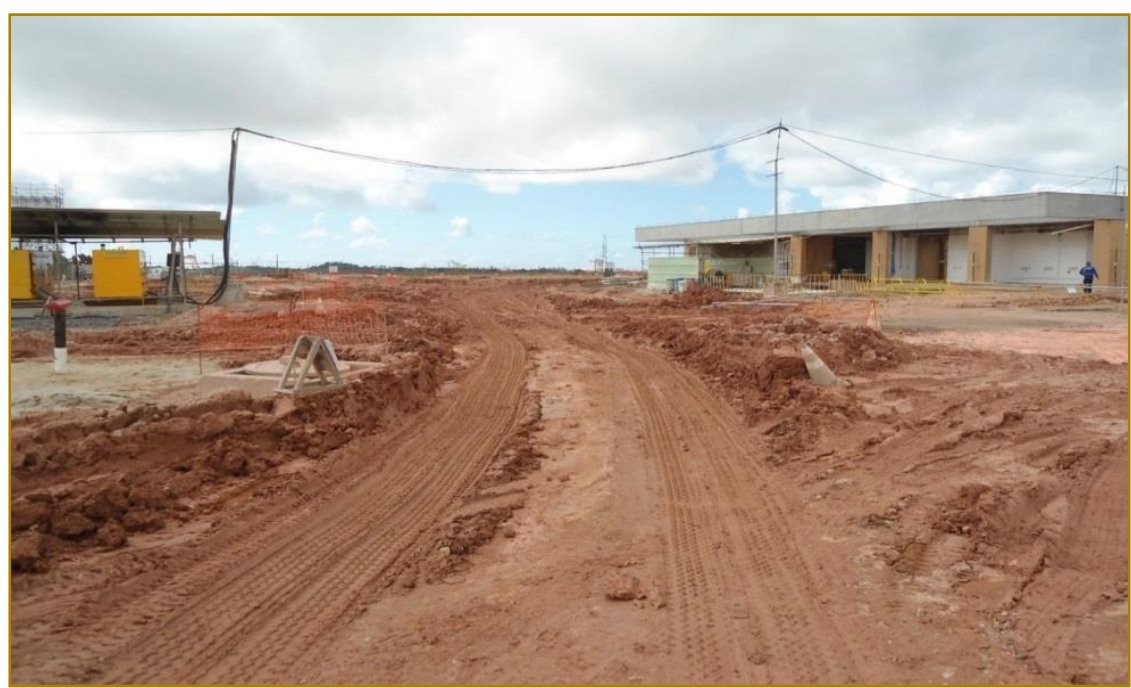

Fonte: Próprio autor, 2013 
Figura 16 - Acesso com tráfego liberado (Após a manutenção corretiva)

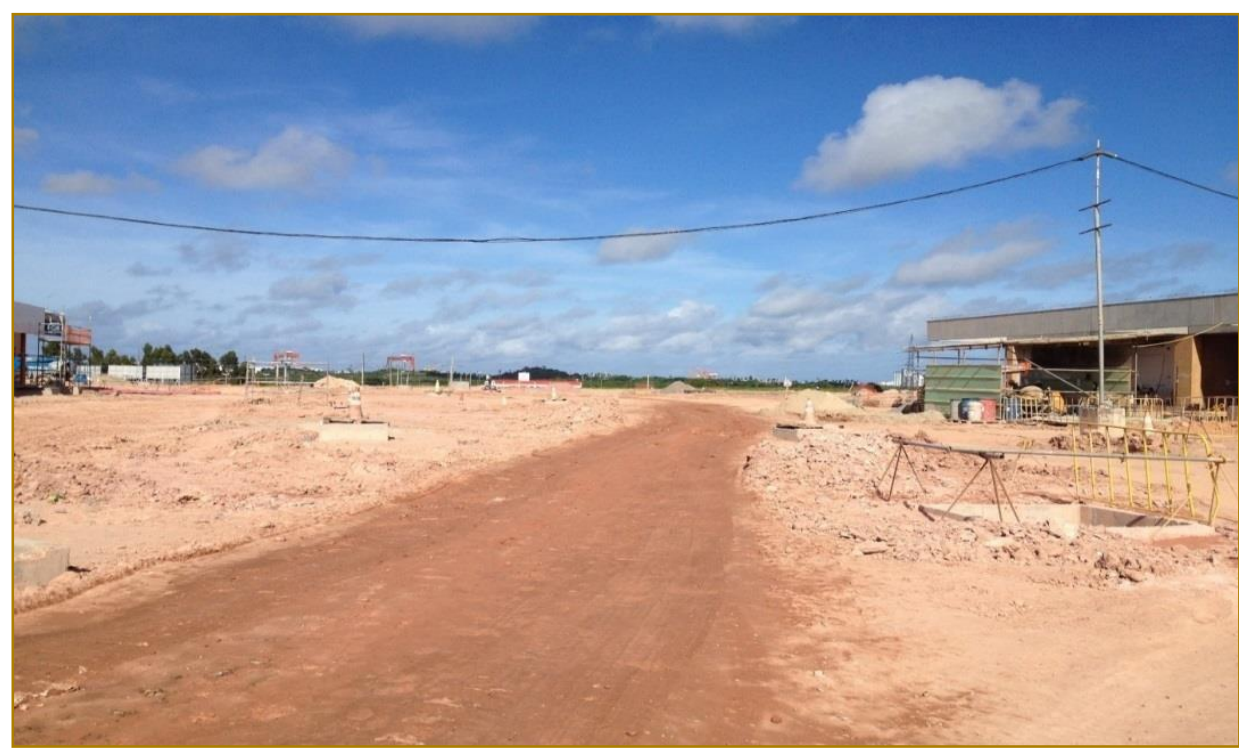

Fonte: Próprio autor, 2013

O GT também passou a acompanhar as atividades de fiscalização da manutenção das drenagens definitivas que ficaram prontas e foram substituindo as provisórias, assim cada serviço de manutenção realizado na drenagem definitiva também acabou sendo de competência do GT.
As atividades de manutenção das drenagens definitivas também passaram a integrar os relatórios gerenciais do GT, como mostrado na Figura 17.

Figura 17 - Relatório de manutenção (drenagem definitiva)

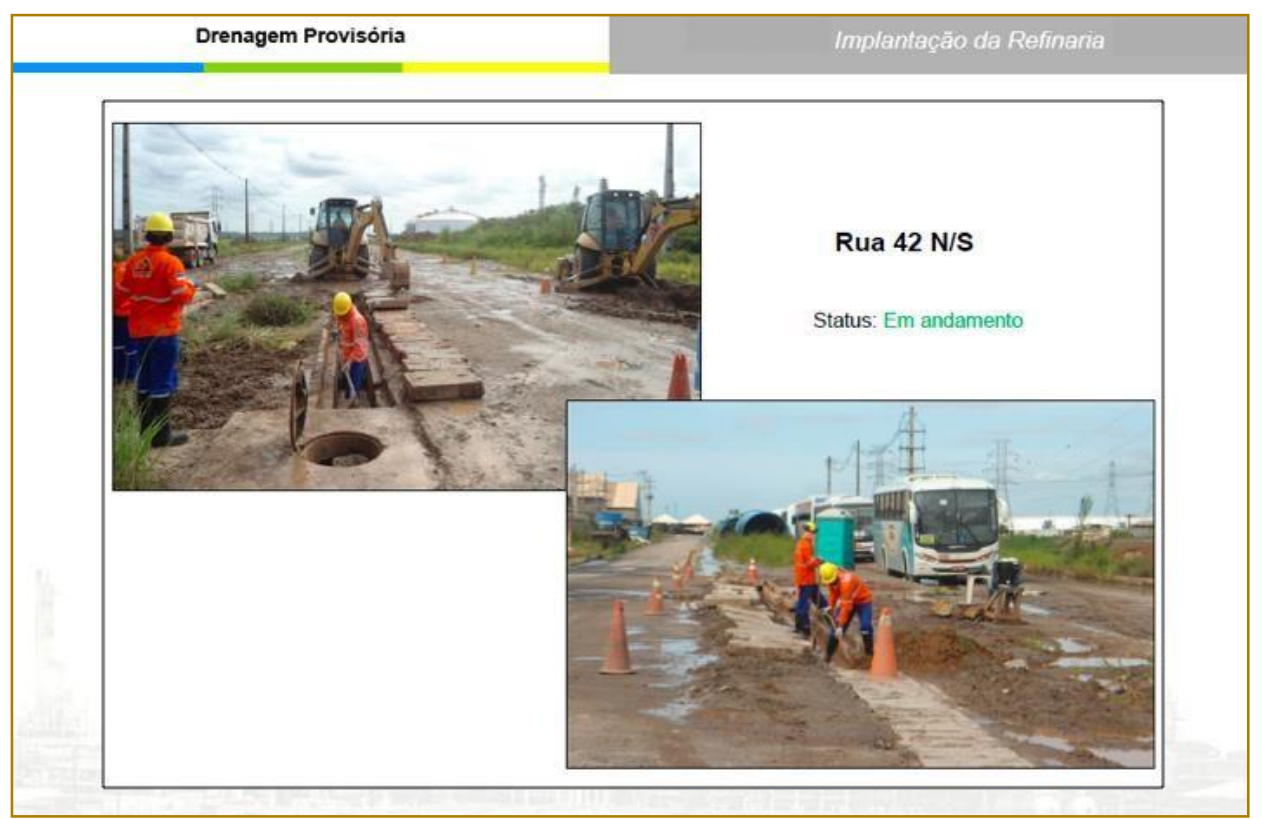

Fonte: Próprio autor, 2013

As drenagens provisórias passaram a interagir com as definitivas e isso fez com o que o relatório gerencial ficasse ainda mais completo de informações sobre manutenção, seja na parte provisória ou na parte definitiva, tornando-se um aliado bastante competente 
na busca da melhoria contínua do processo e auxiliando o corpo gerencial nas tomadas de decisões estratégicas para a operação definitiva da refinaria.

O GT tornou-se referência para os demais setores na questão do controle das informações e planejamento estratégico para eventuais mudanças, sendo um exemplo de que a união das equipes trazum benefício para toda a obra,com o objetivo de tornar a refinaria um exemplo a ser seguido por as outras unidades que irão surgir e as unidades que irão passar por processos de melhorias de operação.

\subsection{ANÁLISE E RESULTADO DOS DADOS}

Antes de todo o processo de execução e controle da drenagem pluvial provisória, foram analisados os bancos de dados em busca dos registros de paralisações, com duração superior a 7 horas e/ou equivalente a 1 dia de trabalho, nas obras da refinaria ocasionadas exclusivamente por problemas relacionados com a drenagem e, de posse desses dados foi elaborada a Tabela 7.

Tabela 7 - Registro de paralizações da obra no ano de 2013

\begin{tabular}{|c|c|c|c|}
\hline Mês & Número de paralizações & Julho & 12 \\
\hline Janeiro & 6 & Agosto & 8 \\
\hline Fevereiro & 6 & Setembro & 9 \\
\hline Março & 9 & Outubro & 5 \\
\hline Abril & 13 & Novembro & 3 \\
\hline Maio & 15 & Dezembro & 4 \\
\hline Junho & 12 & Péro de paralizações \\
\hline
\end{tabular}

Fonte: Empresa Petrolífera

Em seguida, foi gerado um gráfico para observação mais clara da distribuição dos registros, conforme mostrado no Gráfico 4.

Gráfico 4 - Paralisações da obra no ano de 2013

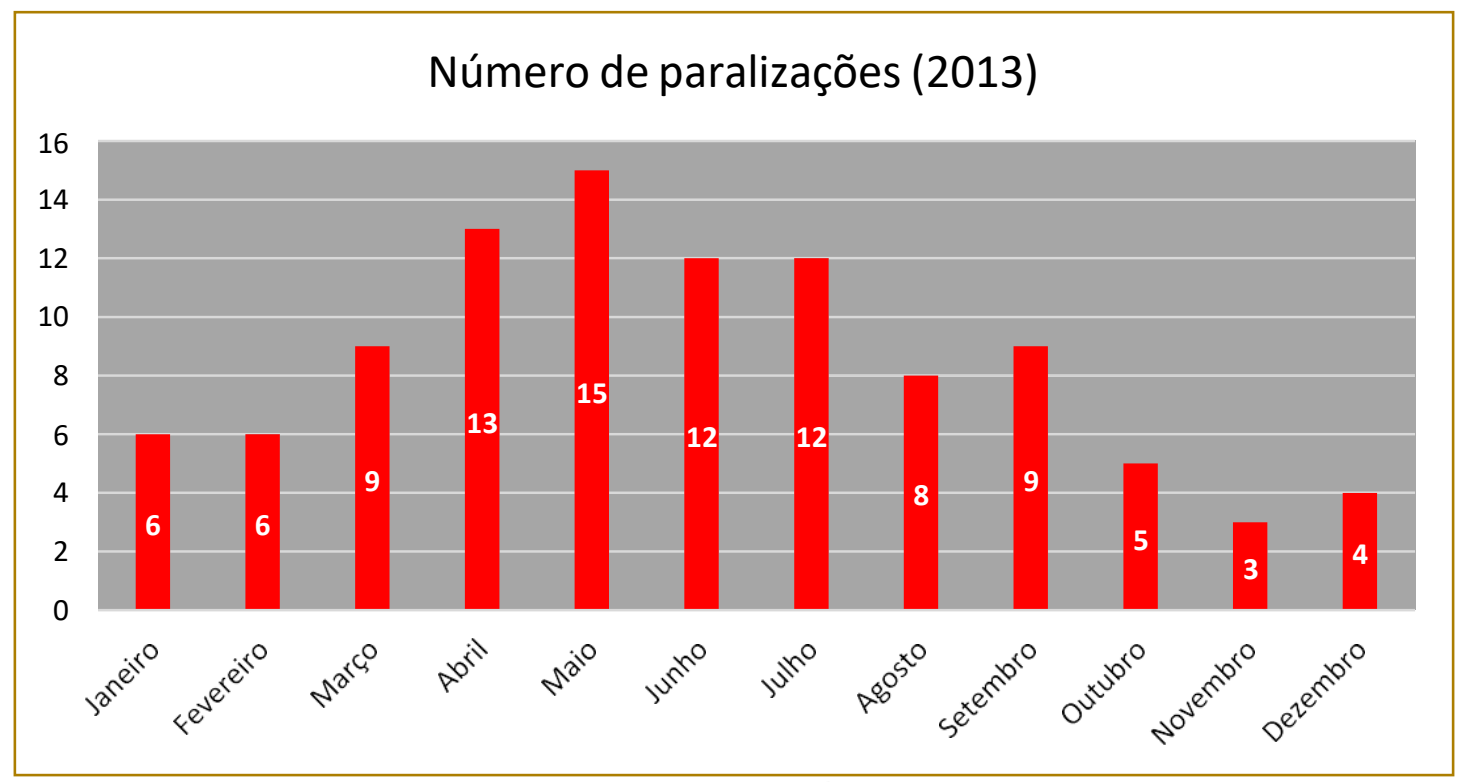

Fonte: Empresa Petrolífera, 2013 
Após a conclusão de todas as fases da implantação da drenagem pluvial provisória da refinaria, foi realizado um novo registro de paralizações, com duração superior a 7 horas e/ou equivalente a 1 dia de trabalho, nas obras da refinaria ocasionadas exclusivamente por problemas relacionados com a drenagem e, de posse desses dados foi elaborada a Tabela 8.

Tabela 8 - Registro de paralizações da obra no ano de 2014

\begin{tabular}{|c|c|c|c|}
\hline Mês & Número de paralizações & Julho & Número de paralizações \\
\hline Janeiro & 4 & Agosto & 6 \\
\hline Fevereiro & 5 & Setembro & 6 \\
\hline Março & 7 & Outubro & 5 \\
\hline Abril & 9 & Novembro & 2 \\
\hline Maio & 11 & Dezembro & 3 \\
\hline Junho & 8 & Fonte: Empro & \\
\hline
\end{tabular}

Fonte: Empresa Petrolífera

Em seguida, foi gerado um novo gráfico para observação mais clara da distribuição dos registros, conforme mostrado no Gráfico 5.

\section{Gráfico 5 - Paralisações da obra no ano de 2014}

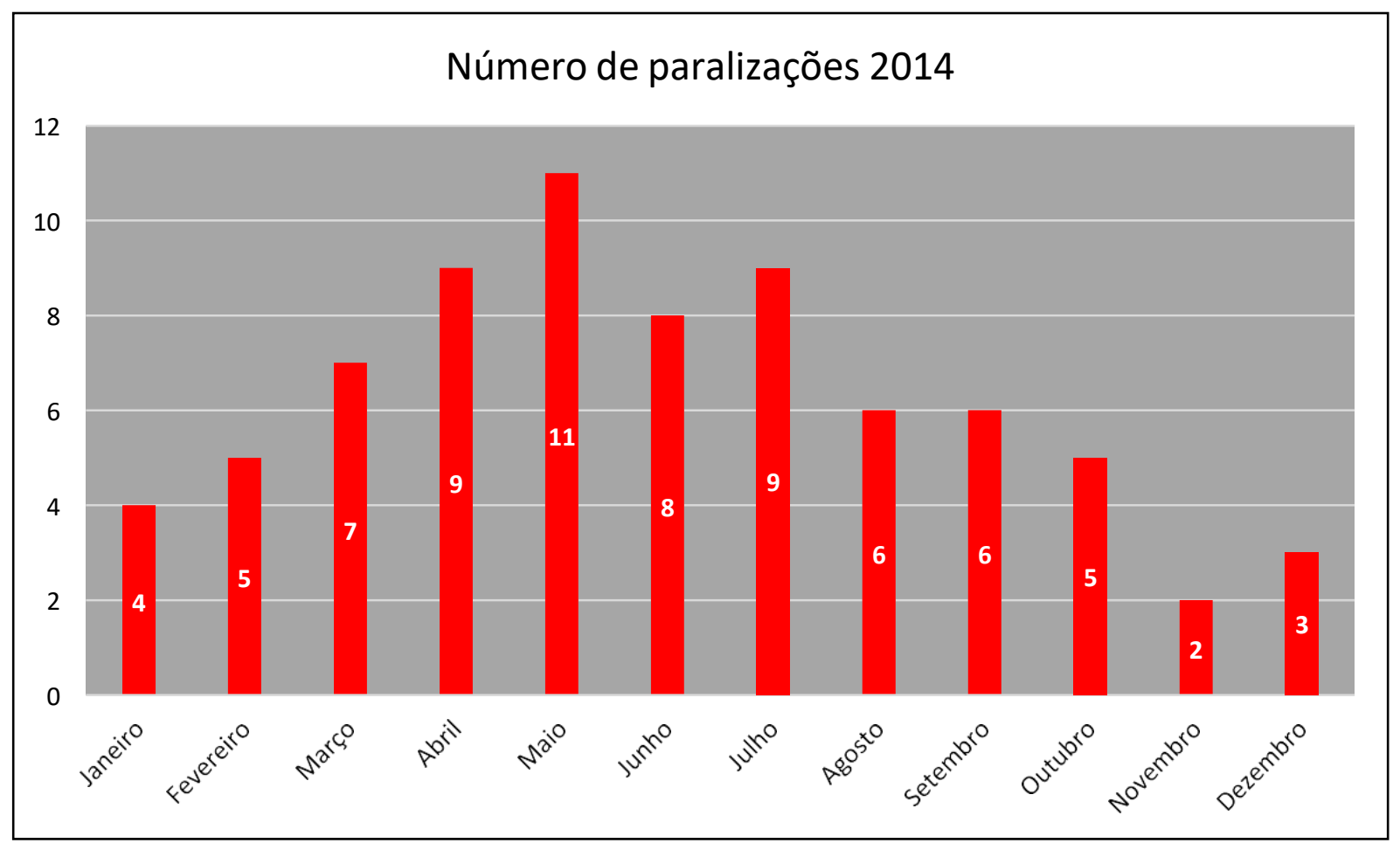

Fonte: Empresa Petrolífera, 2014

Após a consolidação dos dados, foi realizado um comparativo com os dados gerados antes e depois, para que assim fosse possível medir a eficiência da drenagem, conforme Gráfico 6. 
Gráfico 6 - Comparativo das paralisações dos anos de 2013 e 2014

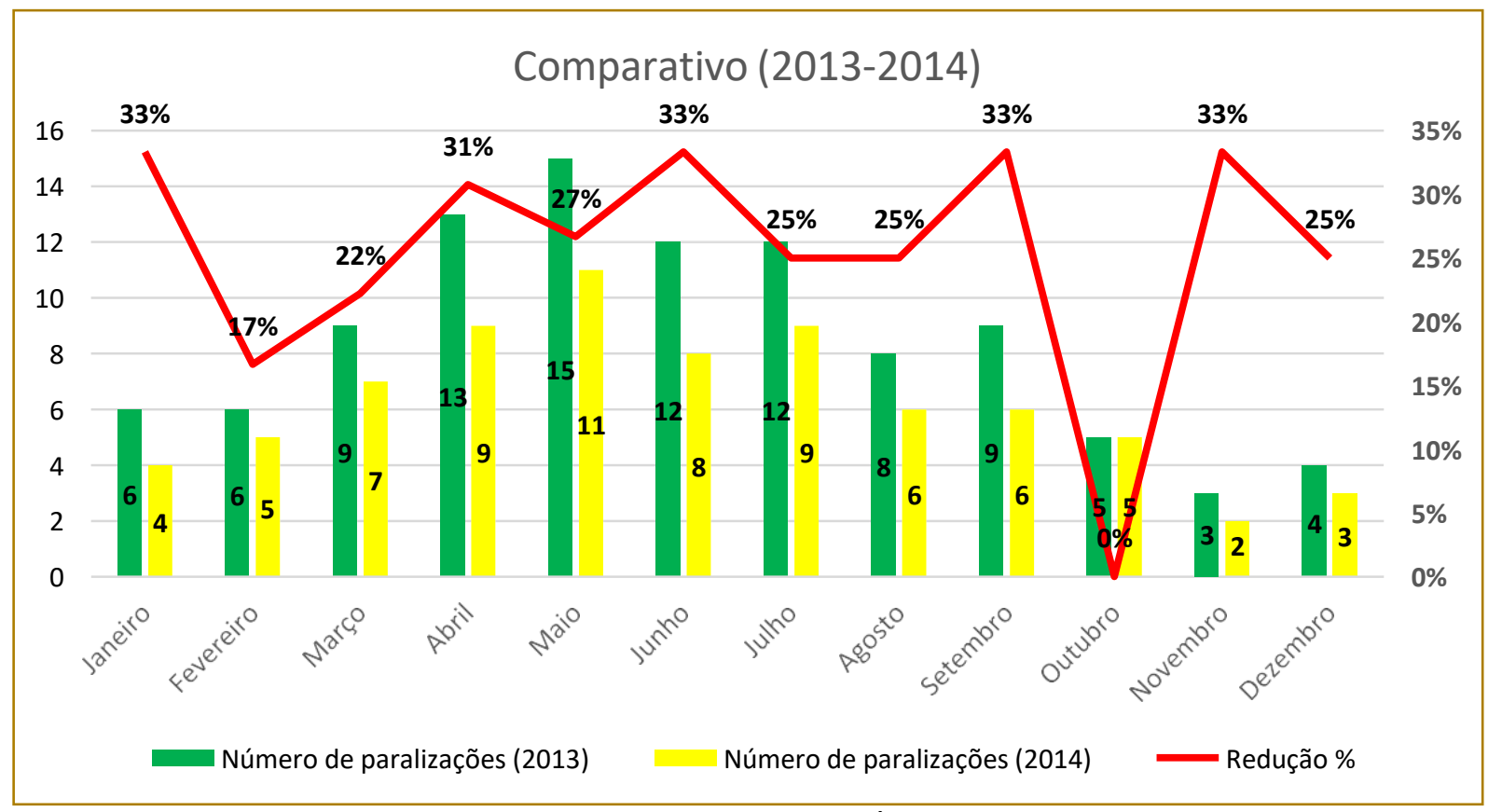

Fonte: Empresa Petrolífera

Não foi possível apurar exatidão o ganho financeiro gerado com a implantação do sistema de drenagem pluvial provisória, pois os dados não foram disponibilizados, mas, é possível afirmar que houve uma redução média nas paralizações na ordem de $25 \%$.

Após a observação dos dados obtidos foi possível verificar que é bastante coerente a hipótese de se implantar um sistema de drenagem pluvial, pois assim é possível garantir um melhor aproveitamento do tempo operacional das equipes de campo, haja vista aos dados apresentados.

Vale salientar que uma redução de apenas $25 \%$ no número de paralisações nas obras da refinaria ocasionadas exclusivamente por problemas relacionados com a drenagem ainda não é significativo para interromper os planejamentos futuros de melhorias do sistema.

Por se tratar de um sistema provisório, o mesmo está passivo de falhas e que é importante afirmar que não é única nem a última solução que deve ser tomada, pois a busca da melhoria contínua deve estar sempre presente.

Também foi possível analisar a viabilidade do planejamento do processo de implantação levando em consideração o estudo do clima da região, assim como a divisão da área em bacias de drenagem, embora o estudo do tamanho das bacias não se mostrou eficiente, pois observou-se que o dado não contribui de forma significativa em pequenas áreas.

A implantação de canais abertos foi bastante utilizada, ficando comprovada a sua eficiência no escoamento das águas além de mostrar-se um grande aliado no período de manutenção do sistema.

O estudo do arranjo físico na drenagem é mostrou-se muito útil para o melhor aproveitamento do layout da área, evitando também a relocação posterior de canais já construídos contribuindo assim para um trabalho provisório que não produz impacto no andamento do trabalho definitivo.

Os dados gerados através dos gráficos de acompanhamento dos serviços ajudaram na tomada de decisões gerenciais que norteavam o andamento das demais atividades de campo.

O estudo da manutenção do sistema de drenagem aliado ao conhecimento teórico pode ser comprovado de forma positiva, pois a rotina de manutenções manteve a confiabilidade do sistema durante todo o período. 


\section{CONSIDERAÇÕES FINAIS}

O estudo das drenagens é bastante importante para que possamos entender um pouco mais das dinâmicas envolvidas em uma obra de construção civil ou industrial, pois a não observação desse item bastante importante pode causar indiretamente ou diretamente perdas de produtividade acarretadas por paradas indesejadas, gerando consequentemente atraso no cronograma final da obra.

Tais atrasos podem também acarretar um aumento da despesa final de uma obra civil ou industrial, reduzindo sua margem ou zerando sua margem de lucro, sendo o segundo caso ocorrendo na área industrial pela não entrada em operação de uma planta fabril.

O estudo foi bastante desafiador, pois a coleta de informações teve início em 2013, justamente para que fosse possível registrar o período anterior e posterior da implantação da drenagem e seus benefícios alcançados com o passar do tempo.

Concluo afirmando que é de grande importância a implantação de uma drenagem pluvial provisória em uma obra, mas o planejamento e a gestão dos dados são tão importantes quanto a execução propriamente dita, pois são as partes que requerem o total empenho e dedicação das equipes de

\section{REFERÊNCIAS}

[1]. ANDRADE, F. F. O Método de Melhorias PDCA. 2003. 169 f. Tese (Mestrado em Engenharia) - Escola Politécnica da Universidade de São Paulo, São Paulo, São Paulo.

[2]. ANDRADE, M. M. Introdução à metodologia do trabalho científico: elaboração de trabalhos na graduação. $8^{\mathrm{a}}$ edição. São Paulo: Atlas, 2007.

[3]. ALMEIDA, M. S.Elaboração de projeto, TCC, dissertação e tese: uma abordagem simples, prática e objetiva. São Paulo: Atlas, 2011.

[4]. CAMPOS, V. F. Controle da Qualidade Total (no estilo japonês). Fundação Christiano Ottoni, Escola de Engenharia da UFMG. Rio de Janeiro: Bloch, 1992.

[5]. CORRÊA, CARLOS A; CORRÊA, HENRIQUE L.Administração da produção e operações: manufatura e serviços: uma abordagem estratégica. $2^{\mathrm{a}}$ edição, $4^{\mathrm{a}}$ reimpr., São Paulo: Atlas, 2009. planejamento e gestão para um melhor aproveitamento dos resultados obtidos.

É possível afirmar que o ganho de produtividade é realmente verificado com a implantação da drenagem mas, vale salientar, que uma redução de apenas $25 \%$ no número de paralisações nas obras da refinaria ocasionadas por problemas relacionados com a drenagem ainda não é significativo para interromper os planejamentos futuros de melhorias contínua do sistema, mesmo assim, a área de trabalho drenada favoreceu 0 tráfego interno mais rápido e reduziu o tempo ocioso das equipes que não podem executar atividades nas áreas alagadas.

Por se tratar de um sistema provisório, o mesmo está passivo de falhas e que é importante afirmar que as etapas de análise abordadas aquinão são as únicas nem as últimasopçõesde melhorias que devem ser tomadas, pois a busca da melhoria contínua deve estar sempre presente.

Sendo assim, o objetivo geral e os específicos do trabalho foram alcançados de forma satisfatóriaservindo como uma proposta para aprofundamento dos futuros trabalhos que envolvam drenagem pluvial provisória.

Esses dados poderão servir deapoio nos próximos investimentos na Empresa de Petrolífera e de qualquer outra entidade interessada.

[6]. GRIBBIN, J. E. Introdução a hidráulica, hidrologia e gestão de águas pluviais.revisor técnico: Marcelo Libânio; tradutora: Andrea Pisan. São Paulo: Cengage Learning, 2014.

[7]. MARCONI, M. A.; LAKATOS, E. M. Fundamentos da metodologia científica. $5^{a}$ edição, São Paulo: Atlas, 2003.

[8]. NetTo, J. M. A. Manual de hidráulica. Coordenação: Roberto Araújo; Co-autores: Miguel Fernandez Y Fernandez, Acácio Eiji Ito. $8^{a}$ edição São Paulo: Blucher, 1998.

[9]. OLIVEIRA, S. L. Tratado de Metodologia Científica: projetos de pesquisa, TGI, TCC, monografias, dissertações e teses. Revisão Maria Aparecida Bessana. - São Paulo: Pioneira Thomson Learning, 2004.

[10]. PAIVA, R. R. S. Gestão da Qualidade Total A.Minas Gerais, 2011. (Apostila).

[11]. RITZMAN, L. P.; KRAJEWSKI, L. J. Administração da Produção e Operações. 
Tradução Roberto Galman; revisão técnica Carlos Eduardo Mariano da Silva. São Paulo: Pearson Prentice Hall, 2004.

[12]. ROLDAN, L.W.B. et. al. BRAINSTORMING EM PROL DA PRODUTIVIDADE: um estudo de caso em três empresas de Varginha - MG. Revista Eletrônica de Iniciação Científica, v.1, n.7, 2011.

[13]. SILVA, T.M; SANTOS, B.P. SISTEMAS DE DRENAGEM E EVOLUÇÃO DA PAISAGEM. Revista Geográfica Acadêmica. Jun2010, Vol. 4 Issue 1, p. 5-19. 15p.

[14]. SLACK, N.; CHAMBERS, S.; JOHNSTON, R. Administração da Produção. $3^{a}$ edição. São Paulo: Atlas, 2009.

[15]. WILKEN, P. S. Engenharia de drenagem superficial. São Paulo, Companhia de Tecnologia de Saneamento Ambiental, 1978.

[16]. BROCKA, B. M., \& BROCKA, S. (1994). Gerenciamento da qualidade. São Paulo: Makron Books.

[17]. Devore, J. L. (2003). Probability and statistics in engineering and the sciences. California: Duxbury Press.

[18]. erlang.com.br. (02 de novembro de 2014). Histórico. Fonte: Erlang: http://www.erlang.com.br/brhistor.asp

[19]. Fogliatti, M. C., \& Mattos, N. M. (2007). Teoria das Filas. Rio de Janeiro: Interciência.

[20]. Guadalupe, E. (17 de agosto de 2007). Aula 4 - Expectativas dos Clientes acerca dos serviços. Fonte: Eduardo Guadalupe - Marketing: http://eduguadalupe.blogspot.com.br/2007/08/aula4-expectativas-dos-clientes-acerca.html

[21]. Hillier, F. S., \& Lieberman, G. J. (2006). Introdução à pesquisa operacional. São Paulo: McGraw Hill.
[22]. http://criticasecronicas. wordpress.com. (28 de março de 2008). A fila. Acesso em 11 de outubro de 2014, disponível em Críticas e Crônicas:

http://criticasecronicas.wordpress.com/2008/03/28/ a-fila/

[23]. J.Virtamo. (07 de novembro de 2014). Queueing Theory / The $M / M / *$ / queue. Fonte: Netlab: http://www.netlab.tkk.fi/opetus/s383143/kalvot/E_m m1jono.pdf

[24]. Lahoz, M., \& Lahoz, D. (02 de Julho de 2009). Programación Lineal Entera. Acesso em 19 de Novembro de 2014, disponível em ocw.unizar: http://ocw.unizar.es/ocw/ensenanzastecnicas/modelos-de-investigacionoperativa/ficheros/OCWProgEntera.pdf

[25]. PALADINI, \& al., E. P. (2005). Gestão da qualidade: teoria e casos. Rio de Janeiro: Elsevier.

[26]. Pena, R. A. (02 de novembro de 2014). Setor Terciário. Fonte: Brasil Escola: http: / / www. brasilescola.com/economia/setorterciario.htm

[27]. ROSS, S. M. (2003). Introduction to probability models. California: Academic Press.

[28]. SILVA, E. M. (1999). Pesquisa operacional: programação linear. São Paulo: Atlas.

[29]. Virtamo, J. (08 de 11 de 2005). Queueing Theory. Finlândia.

[30]. Virtamo, J. (2005). Queueing Theory / Discrete Distributions. Finlândia.

[31]. WALPOLE, R. E., MYERS, R. H., \& MYERS, S. L. (2007). Probability \& Statistics for Engineers \& Scientists ( $8^{\circ}$ ed.). Pearson Education International.

[32]. Willig, A. (1999). A Short Introduction to Queueing Theory. Berlin. 


\section{Gapítulo 15}

\section{PROCESSO PRODUTIVO DE LEITE CONDENSADO EM UM LATICÍNIO EM ARAXÁ - MG E SEUS ASPECTOS LOGISTICOS}

\section{Bárbara Andrino Campos Silva}

Humberto Elias Giannecchini Fernandes Rocha Souto

Marcelo Teotônio Nametala

Rafael Izidoro Martins Neto

Resumo: Este trabalho tem como objetivo descrever o processo produtivo do leite condensado em uma filial da indústria de laticínios na cidade de Araxá. Constituindo uma pesquisa de caráter qualitativo com investigação descritiva, foram coletados os dados através de visitas no local onde ocorreram entrevistas com o gerente de produção bem como acompanhamento de todos os processos da produção do leite condensado. Através da entrevista pôde-se apresentar a análise do processo produtivo, logística e materiais, arranjo físico, qualidade do produto, colaboradores, embalagem e rotulagem. Uma vez que os dados foram coletados e analisados, percebeu-se que o acompanhamento do leite em todo o processo é de extrema importância, assim como as condições de higiene, tendo em vista que se trata de um produto com alta perecibilidade. Foi verificada que, apesar da empresa ter sua fábrica em Minas Gerais, ela não tem o estado como seu potencial consumidor, destinando sua produção aos estados do Rio de Janeiro e São Paulo, onde possui grande participação no mercado. Foi concluído que a localização do posto de coleta e laticínio é de suma importância estratégica para a empresa devido a abundante oferta e menor custo, bem como a proximidade dos fornecedores e facilidade logística.

Palavras-chave: Laticínios; Leite Condensado; Produção, Qualidade, Logística. 


\section{INTRODUÇÃO}

- Brasil está localizado em uma região tropical onde o relevo, clima e a temperatura favorecem a agricultura. Tudo está aliado a um vasto território geográfico que resulta em um forte agronegócio, representando em sua maioria pela agricultura, contribuindo com cerca de $80 \%$ dessa produção.

Segundo dados do IBGE (2015), em 2014, a produção leiteira no Brasil foi de 35,17 bilhões de litros. A região sul foi responsável por produzir $34,7 \%$ de toda produção nacional, seguida da região sudeste, com $34,6 \%$ deste total, destacando-se como as regiões com maior produção nacional. Desta forma, notase que é um setor que gera uma enorme quantidade de empregos.

A importância do país no cenário mundial de lácteos se dá por fatos concretizados em um dos maiores eventos da América Latina, a Mega Leite, realizada na cidade de UberabaMG em 2014. Quando a anos de estudos e investimentos em melhoramento genético, uma vaca oriunda da cidade de Uberlândia MG quebrou o recorde mundial de produção de leite, onde o animal registrou a produção de $115,020 \mathrm{~kg}$ de leite em um único dia. (GIROLANDO, 2014).

Dessa forma, o posto de coleta tem atribuição importante por abrigar a produção de produtos/serviços em uma empresa, mas também dá apoio no desenvolvimento de novos produtos e serviços de maneira a suprir às necessidades e demandas no futuro relacionadas à tecnologia e inovação, aspectos sustentáveis e gestão de lucros do mercado. Ainda assim, a função produção é responsável por tarefas de planejar e controlar a mesma, estando ligada de forma direta com a criação de estratégias de produção, para que a indústria possa atender sua capacidade de produção com a demanda exigida (SLACK, 2009).

Entretanto, para que as indústrias consigam atingir de maneira eficiente suas metas, além de outros processos diretos como decisões baseadas em linha de informações que possibilitam tomar decisões acertadas em relação a cadeia de produção e modelo de gestão do mercado (REZENDE et. al, 2002). É necessário também emplacar medidas e ações em outros departamentos e tratar funções como a logística, a qualidade e a gestão ambiental.
Diante do exposto, determina-se como objetivo do estudo realizado, descrever o processo produtivo do leite condensado, assim como atividades de logística e qualidade de acordo com o processo.

\section{REFERENCIAL TEÓRICO}

\subsection{ADMINISTRAÇÃO DA PRODUÇÃO}

Administração da Produção, segundo Nigel Slack (2009), é a atividade de gerenciar recursos destinados à produção e disponibilização de bens e serviços. A função de produção é a parte da organização responsável por esta atividade. Moreira (2000) acrescenta ainda que 0 contexto de administração da produção é considerado a área de pesquisa das técnicas e opiniões para a ampliação das tomadas de decisões na função produção.

A função produção é o ponto central na organização, a fabricação de bens e serviços é o principal motivo de sua existência. Mesmo assim, não é de fato a única nem a mais importante. A produção se encontra interliga com outros dois processos importantes, a função marketing que intercala as vendas e a função desenvolvimento de um produto ou serviço. Todos esses processos começam desde os recursos na entrada (input), passa pela transformação e se resume em produtos/serviços na saída (output) até o consumidor final.

A responsabilidade pela área de administração da produção cabe ao gestor de produção, que exerce o dever e autonomia para decidir a melhor forma de empregar os recursos de produção, além da entrada de novas alternativas de se produzir, criar estratégias, planejar e controlar funções que são operadas afim de melhorar a performance de sua atividade. É função também do gerente interligar os objetivos da organização com os fins de desempenho da produção, demonstrando a tática em ações funcionais (SLACK, 2009).

De acordo com Slack (2007), a finalidade e função da produção seria a qualidade, que seria a entrega do produto dentro das condições adequadas e com menos alterações possíveis; rapidez, exige que todo contexto de produção seja mais prático e dinâmico; confiabilidade, se referindo a competência do processo produtivo, com cumprimento de prazo adequado; flexibilidade, possui maior transformação no 
número e variação produzida; e custo, onde os gastos das operações são bem reduzidos.

A organização tem que decidir quais objetivos de desempenho e onde será seu foco principal, definir seus esforços e tarefas das empresas em prol de um todo. Isso constitui que, para conseguir a competitividade da empresa, deve haver uma ligação entre as necessidades do consumidor, as tarefas da concorrência, o período de vida útil dos produtos e capacidade juntamente com as limitações da empresa (SLACK, 2007).

Além dos encargos diretos descritos, cabe ainda ao gerente de produção a responsabilidade ampliada que, de acordo com Slack (2009) é a compreensão dos conflitos nas tarefas de uma empresa pelo choque de globalização, influencia por defesa ambiental e responsabilidade social, novas tecnologias e gerência de informação.

De acordo com a ligação entre os deveres diretos, deveres ampliados, os objetivos de execução da função produzir e a observação do mercado, é que os gerentes de produção começam a elaborar estratégias do projeto e controle da produção com intuito de atingir os objetivos organizacionais (SLACK, 2007).

Para Veggian e Silva (2011), o Planejamento e Controle da Produção (PCP) é uma função operação administrativa, que tem como foco, planejar e orientar a produção, afim de conseguir domínio da mesma. De outra maneira, o PCP determina o que vai ser produzido, quando, como, onde e quando será produzido, possibilitando que o curso das operações trafegue de maneira de forma eficiente e dinâmica, assim gerando produtos e serviços convenientes as necessidades expostas do consumidor final.

\subsection{LOGÍSTICA}

Logística, segundo Daher, Silva e Fonseca (2006), é o processo de planejamento, onde ocorre a prática e controle de forma efetiva, dos gastos, das entradas de matéria-prima do estoque, dos produtos finalizados e dos elementos relacionados, desde o seu ponto de partida até a abordagem final.

Para Ballou (2004), a logística além de ser uma forma de planejamento, adição e controle do fluxo eficiente e eficaz de produtos, serviços e dados interligados desde 0 fornecedor até o cliente, tem como objetivo direcionar às necessidades da empresa em acolher os interesses pessoais de satisfação do cliente. Essa abordagem pode ser em dados como prazo, segurança e qualidade. Desta maneira, cumprir todos objetivos requer algumas atividades envolvidas, que, segundo Ballou (2004) podem ser divididas em tarefas primárias e de apoio.

As tarefas elementares envolvem: Transportes, o qual está ligado à várias formas mover os produtos e insumos, dessa forma apresenta papel fundamental ao apoio logístico. Na gerencia de estoque a ideia é trabalhar com níveis baixos de estocagem, mas sem que isso prejudique o atendimento ao consumidor, possibilitando atendê-lo quando solicitado. Tratar também de todo período de compra e atividade efetuada pelo cliente desde o início (BALLOU, 2004).

Ainda de acordo com Ballou (2004) dentre dessas tarefas de apoio são destacadas: armazenagem, que seria a organização do espaço indispensável para depositar o estoque, que busca otimizar e administrar os recursos físicos e informacionais, trabalhar todos materiais, que estão ligados ao movimento interno de transformação até sua saída. Embalagem e proteção, tratando de uma embalagem adequada para o transporte, estocagem e conserva do produto. Atividades como essas viabilizam os processos até por envolver fatores de programação, planejamento e seleção.

Determinar acordos com fornecedores comerciais bem efetuados, prazo de entrega acentuados. A programação do produto, interliga diretamente com a movimentação de saída, onde determina a quantidade, onde e quando deve ser produzido, e, manutenção de informações que busca obter dados para ajudar na tomada de decisões com relação ao consumidor, concorrentes, fluxo de vendas em função do estoque, e também as despesas relacionadas às atividades de estocagem, transporte e processos de vendas.

\subsection{GESTÃO DA QUALIDADE}

O princípio de gestão da qualidade é desenhado por um conjugado de atividades e tarefas efetuadas para garantir a qualidade dos produtos e serviços conduzidos dentro de uma organização. Essa busca é efetuada através do melhoramento do processo, aumento da produção e correção de falhas diretas, improvisos, além de da redução de 
custos, falhas, retrabalhos e perdas (FALCONI, 2004).

Desta maneira as tarefas simples de um sistema de gestão da qualidade em empresas de laticínios devem ser ajustadas de acordo com o fluxo de produção, possibilitando uma divisão em: controle de qualidade da matériaprima; controle de qualidade do processo; controle de qualidade do produto final; controle de qualidade no transporte e na distribuição e por último o controle da qualidade do produto no local de venda, sendo que as três primeiras descritas, são mais utilizadas (SCALCO; TOLEDO, 2002).

Como principais referências de pesquisa e instrumentos de qualidade constatada no procedimento de gestão da qualidade na etapa que ocorre o controle, menciona-se a verificação; a mão-de-obra para melhor qualificação pelos métodos de orientação como operações de higiene, boa conduta de produção, análise de riscos e pontos cruciais no controle de qualidade do processo; e as verificações de fatores físico-químicos no teste da qualidade final do produto buscando maior domínio de finalização e controle daquelas saídas (SCALCO; TOLEDO, 2002).

A implementação de métodos de qualidade pela indústria é proveniente de um aperfeiçoamento e qualificação no atendimento, desta maneira, reduzir defeitos, de forma inteligente, segura, e no prazo correto. No local e quantidade solicitada de acordo com às exigências dos seus clientes, possibilitando meios de saídas e vantagens competitivas dentro do negócio gerando alternativas e estratégias para o mercado competitivo (FALCONI, 2004).

\section{METODOLOGIA}

Metodologia é a ciência que examina os processos e formas de verificação de determinado problema, fazendo uma análise e desenvolvendo ressalvas, ou seja, levantando críticas, interpretações, gerando dados a partir da ligação entre a causa e efeito (OLIVEIRA NETTO, 2004).

Segundo Severino (2007), as táticas de pesquisas caracterizam-se pelo esboço de um caso individual, determinando a representação de um conjunto de casos parecidos. Nele, a coleta de dados, é realizada em condições naturais ao passo que as transformações ocorrem, sendo conferidos diretamente, sem influência ou ajustes por parte do pesquisador.

Goldenberg (2007) implementa o conteúdo descrito como um estudo de caso de uma análise planejada e distribuída de uma única situação, obtendo a maior quantidade de informações descritivas sobre o contexto, ainda com objetivo fixo de entender o caso e demonstrar seu grau de complicação.

Como possibilidades de se abordar um estudo, o enfoque qualitativo para Martins e Theóphilo (2009) apresenta-se como uma análise de grande processamento na descrição de fenômenos, as pessoas, situações, ocorrências e percepções, na qual a pesquisa é efetuada, coletando os dados que serão analisados.

Migrioli (2006), apresenta a pesquisa descritiva como uma maneira de investigação, onde ocorre um tipo de pesquisa com o objetivo de expressar e compreender as variáveis e os problemas de maneira geral, e posicionar essa relação. A descrição da problemática pode ser realizada através de entrevistas por quem faz a pesquisa do tipo semiestruturada, que de acordo com Oliveira (2008), seria a que melhor expressa opções abertas, como um guia de instrução para que ambas as partes consigam se identificar e se orientarem, afim de uma maior liberdade para introdução de ideias, assim gerando possibilidades como necessidades de compreensão e observações, podendo ser realizadas no local e no ato da ação.

0 estudo foi realizado em uma indústria de laticínios (filial) na cidade de Araxá- MG, onde abrange uma diversificada linha de produtos que são comercializados em todo território nacional. A escolha pelo processo produtivo do leite condensado originou-se por tratar de um alimento apreciado pelos brasileiros, e que serve como matéria prima para grande parte de doces que fazem parte do cotidiano, funcionando assim como um informativo técnico de um produto presente na casa dos brasileiros.

A empresa trata-se de uma unidade estratégica, uma vez que o seu mercado alvo está concentrado nos estados do Rio de Janeiro e São Paulo. Essa unidade foi adquirida em um leilão, objetivando-se absorver a grande oferta de produção de leite da região onde este tem um custo inferior, e mesmo tendo custos de logística este ainda é viável escoa-la para a central na cidade de Patrocínio Paulista-SP. 
Desta maneira, o presente trabalho incidiu em uma pesquisa de caráter qualitativo. 0 tipo de investigação foi expresso como descritivo. Toda coleta de dados e análise foi realizada através de visitas (in loco), onde ocorreram entrevistas, realizadas nos dias vinte e quatro de setembro e quinze de outubro de dois mil e dezessete, nos setores de produção e dependências do laticínio. A entrevista realizada foi com o gerente de produção da empresa com acompanhamento em todos os processos de produção do leite condensado transcrevendo assim uma observação direta do local também.

\section{ANÁLISE DOS RESULTADOS \\ 4.1 RESULTADOS E DISCUSSÃO}

Foram apontados aqui os resultados e os dados obtidos através da visita à empresa, dados primários obtidos com gerente da empresa e a percepção do entrevistador sob o panorama do laticínio. Os tópicos a serem discutidos subdividem-se em: análise do processo produtivo, logística e materiais, arranjo físico, qualidade do produto, colaboradores, embalagem e rotulagem.

A unidade do laticínio de Araxá-MG processa uma média de trezentos mil litros de leite por dia (sua capacidade instalada é de quatrocentos mil litros por dia). Quando há o excedente a unidade processa alguns produtos como manteiga, mussarela $e$ requeijão proporcionalmente à quantidade excedida. A fábrica funciona em três turnos de 50 funcionários cada, 24 horas por dia.

\subsection{PROCESSO PRODUTIVO}

0 processo detalhado da produção do leite condensado consiste em uma prévia seleção da matéria prima, onde a mesma passa por uma análise sensorial assim que chega aos postos de distribuição. A medida é realizada para detectar possíveis fraudes e o nível de acidez (máxima $18^{\circ}$ D) no leite que foi comprado dos fornecedores. $\mathrm{E}$ quando a matéria prima chega a fábrica realiza-se novas análises, para certificar a qualidade do leite que foi entregue. A partir do momento em que o leite é aprovado em todas as análises, transfere-se dos tanques das carretas, mantendo- o a uma temperatura baixa até as instalações da fábrica, que conta com 4 tanques iniciais isotérmicos de aço inoxidável, sendo dois tanques com capacidade de cem mil litros de leite, um tanque de cinquenta mil e um tanque de leite pasteurizado de duzentos mil litros.

Inicialmente o leite passa por um filtro onde elimina as impurezas, evitando que sujeiras fiquem aderidas às placas do resfriador, que por sua vez tem a função de resfriá-lo entre 3 a $8{ }^{\circ} \mathrm{C}$ de temperatura, contribuindo para manter a qualidade do leite inalterada até o momento de sua industrialização, e mantendo a temperatura do leite inalterada devido à dificuldade de troca de calor com meio externo. A etapa realizada a seguir chamada de filtração visa escoar e retirar dejetos do leite através do processo de centrifugação. Entre os sólidos indesejáveis este processo remove também uma quantidade considerável de células epiteliais.

O leite é enviado para tanques onde receberão outros tratamentos; inicialmente a padronização e a homogeneização, obtendose então o leite no padrão correto de porcentagem de gordura, sendo de $8,0 \%$ a $8,5 \%$, ao qual serão enviados para os tanques de pasteurização, que tem o objetivo de destruir enzimas, bactérias, mofos e leveduras. 0 açúcar não pode ser adicionado ao leite antes da destruição das enzimas, pois o mesmo desenvolve ação protetora sobre a lípase, prejudicando a qualidade do produto final. Para garantir a eliminação das lipases, o leite deve ser pasteurizado, no mínimo, a $82{ }^{\circ} \mathrm{C} / 60$ por segundos. A temperatura de pasteurização também exerce influência direta sobre a viscosidade do produto final, que é responsável pela sua estabilidade física durante o armazenamento, para que mantenha a qualidade padrão. Esse leite pasteurizado irá para um tanque de armazenamento de duzentos mil litros, mantendo a temperatura de 3 a $8{ }^{\circ} \mathrm{C}$.

O leite em seguida passará pelo processo de concentração em um aquecedor tubular, aquecido por vapor, permitindo o deslocamento para um conjunto de concentradores a vácuo, fazendo com que no processo de evaporação o teor de água da mistura passe de $87 \%$ para $27 \%$. Então é adicionado o açúcar no leite, através dos tanques de mistura. 0 teor de açúcar na água do leite condensado é um fator muito importante e deve estar entre $58,0 \%$ e $62,5 \%$ para manter a pressão osmótica no produto elevada, inibindo o crescimento microbiano. Antes de ser passado pela evaporação, o leite açucarado precisa ser pasteurizado novamente, a fim de eliminar a contaminação 
microbiológica provida do açúcar. A evaporação ocorre no equipamento a vácuo, que permite o leite entrar em ebulição a baixas temperaturas para que seja evitado seu escurecimento. Ele é resfriado imediatamente a $23{ }^{\circ} \mathrm{C}$, quando então é adicionada a lactose esterilizada, que por sua vez tem a função de cristalizar o açúcar em partículas imperceptíveis ao paladar humano. $A$ adição de lactose deve ser realizada com agitação constante e vigorosa, evitando a formação de blocos de cristais de açúcar e intensificando a micro cristalização.

Após o término desse processamento, o leite condensado é estocado em três tanques com capacidade para $20.000 \mathrm{~kg}$ cada, e em seguida transferido para uma máquina dosadora automática alimentada por uma bobina de embalagens tetra brik, capaz de envasar 9.000 caixas de leite condensado de 395 gramas cada, totalizando $3.555 \mathrm{~kg}$ de leite condensado por hora, em média, sendo a perda do processo equivalente a cerca de $1 \%$ ou $35,5 \mathrm{~kg}$ por hora que ocorre de forma comum e natural ao desenvolvimento do processo de envase.

Após o envase, uma máquina organiza 27 caixas de leite condensado em uma caixa de papelão, e que manualmente são empilhadas 105 caixas de papelão em um palhete para estocagem, que são identificados por data de fabricação e lote. O leite condensado fica no estoque por 10 dias, para etapa de finalização do produto. A seguir, no fluxograma da figura 1 são descritas todas as etapas do processamento desse leite condensado.

Figura 1: Fluxograma da produção do leite condensado

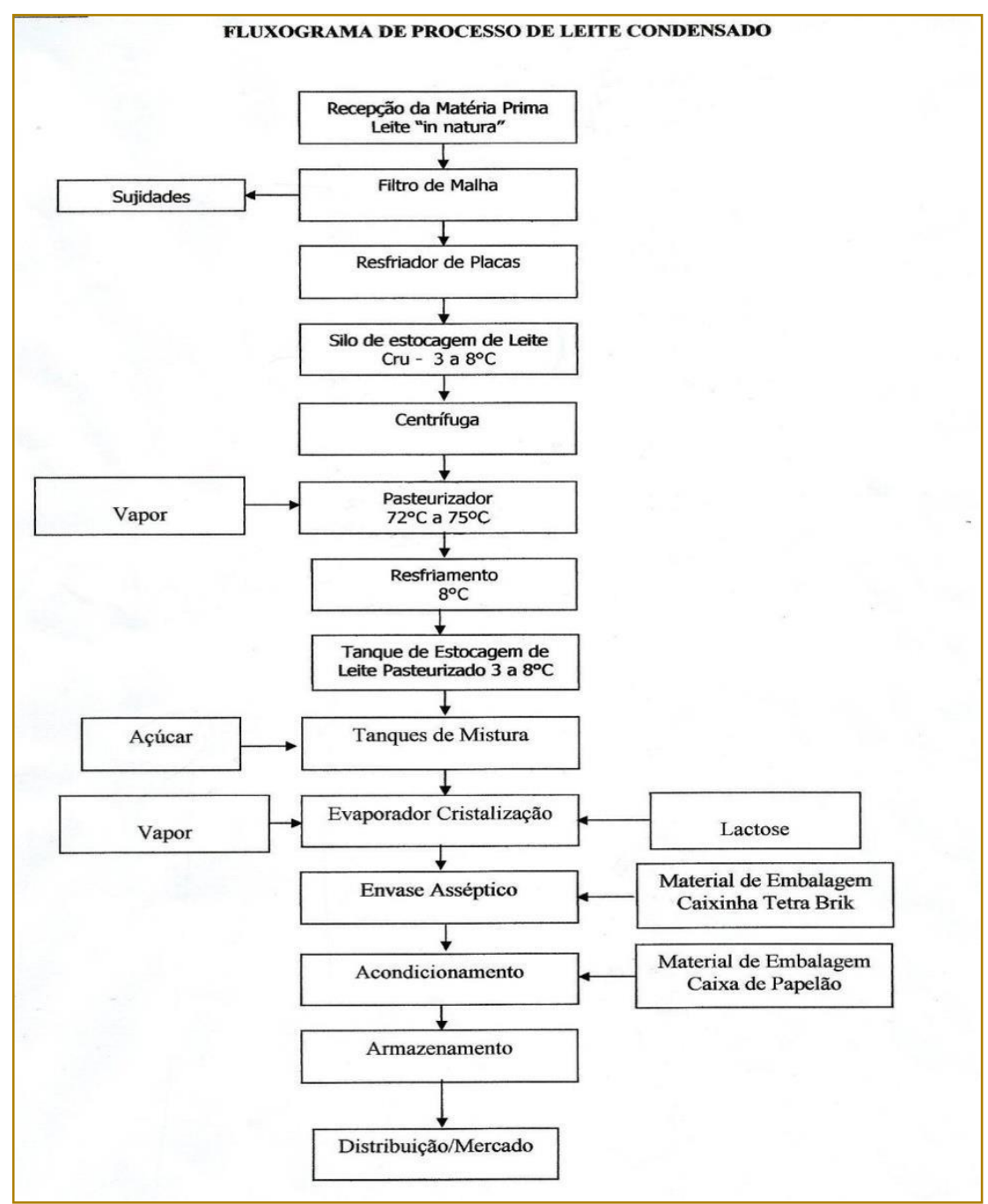

Fonte: Empresa estudada (2017) 


\subsection{LOGÍSTICA E MATERIAIS}

O fornecimento do leite cru é feito por carretas e caminhões próprios e terceirizados. Dos trezentos mil litros que são fornecidos em média por dia, duzentos e oitenta mil litros são vindos de postos de captação da empresa, localizados em Bambuí, Guarda Mor, Presidente Olegário, Uberaba e Sacramento. E os outros vinte mil litros são fornecidos por caminhões terceirizados, que fazem a coleta de leite na região de Araxá. A empresa tem dois fornecedores de embalagens, ambos localizados perto de Araxá. Seu fornecedor de embalagens tetra Brik está localizado em
Monte Mor e este tem um lead time de 20 dias para entregar seu produto após efetuado o pedido, já seu fornecedor de caixas de papelão a empresa Ímpar (localizada em Uberaba-MG) pede o prazo de 10 dias para realizar a entrega. A empresa trabalha com um estoque de segurança de ambas as embalagens de três dias. Sempre são compradas carretas fechadas, que no caso é a melhor opção de compra encontrada pela empresa segundo 0 setor responsável evitando transtorno como por exemplo, parar a produção por falta de matéria-prima e seus similares.

Figura 2: Trajeto dos fornecedores de leite da empresa

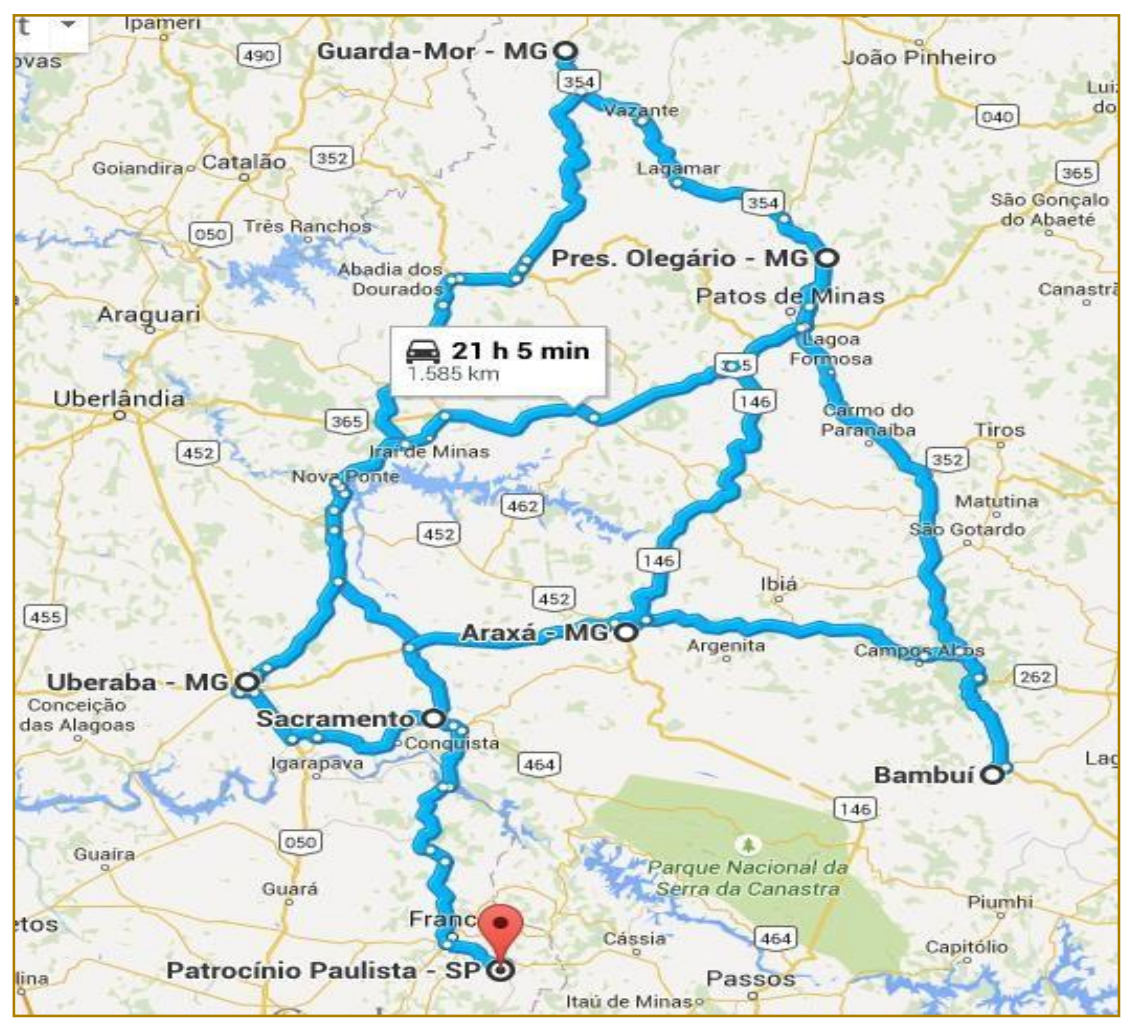

Fonte: Google Maps (2017)

A unidade da empresa em Araxá gera estoque de cinco dias apenas, respeitando o período em que o produto finalizado fica retido na fábrica para uma nova análise de um lote. No caso do leite condensado este período é de dez dias, devido à uma questão operacional, uma vez que o mesmo sai da linha de produção com uma consistência menos densa, e dez dias é o tempo necessário para se atingir uma maturação ideal para comercialização. Por não estocar o produto final na fábrica de Araxá são escoados uma média de 125.000 mil unidades de 395 gramas de leite condensado, e 15.000 mil caixas de leite integral e leite desnatado diariamente para a central.

Observa-se na cadeia produtiva da empresa o grande empenho envolvendo uma operação logística bem planejada e com pontos estratégicos bem definidos, o gráfico (Figura 3) a seguir representa o caminho percorrido pelo produto até sua chegada na central de distribuição. 
Figura 3: Descrição da distância e do deslocamento dos fornecedores à sede da empresa

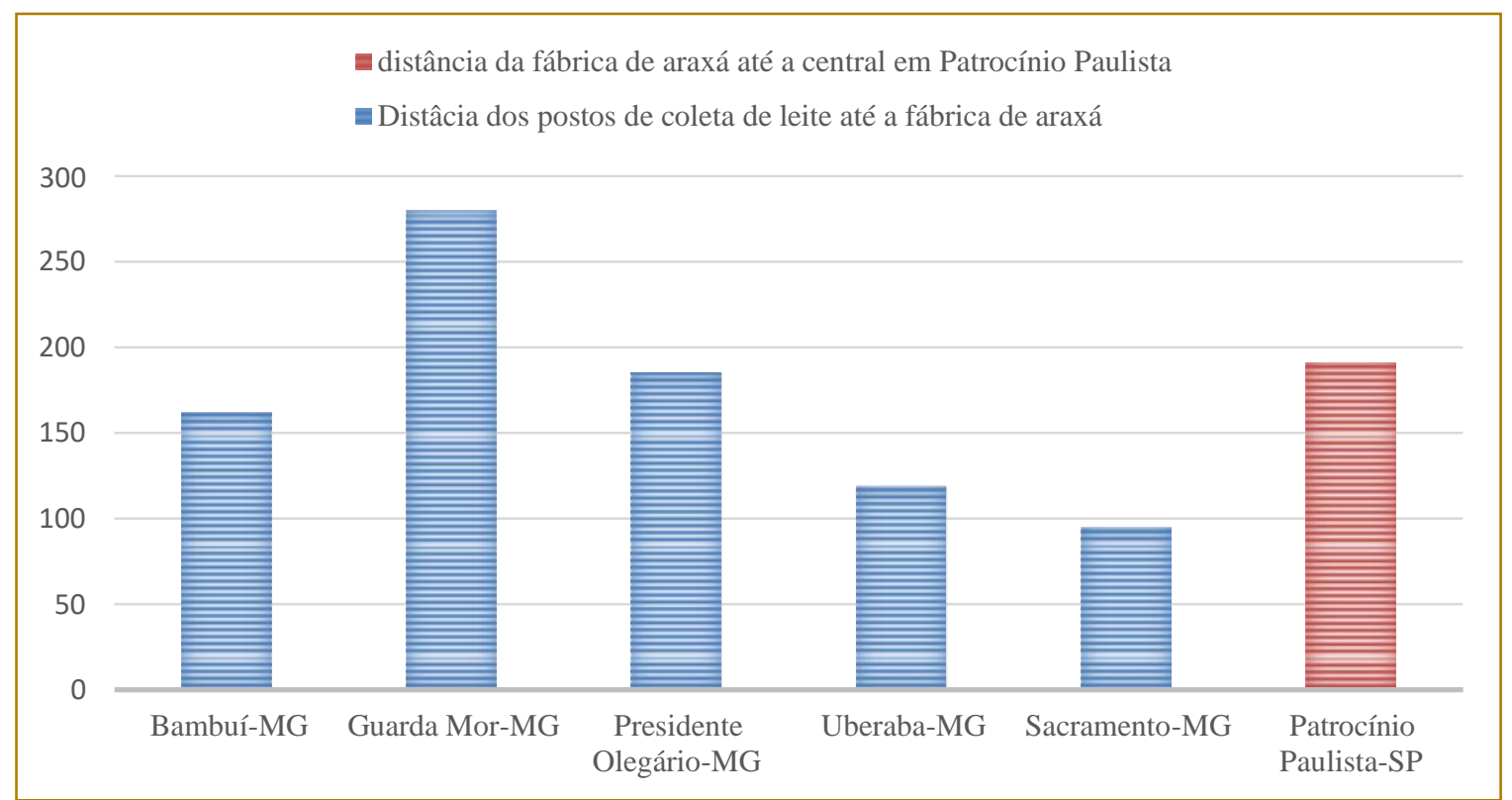

Fonte: Adaptado Google Maps (2017)

\subsection{ARRANJO FÍSICO}

O arranjo físico da produção do laticínio é do tipo celular-funcional, onde a produção se divide em grandes processos ou etapas até o produto finalizado, e todas etapas são realizadas de modo que todos processos estejam próximos uns aos outros (SLACK,2009). Toda produção ocorre por processos em massa, onde ocorre um alto índice de confecção e poucas mudanças de produtos, isso se deve por ter um trabalho de 30 horas corridos num sistema de turnos, modificando apenas os moldes de fabricação quando necessário.

\subsection{CONTROLE DE QUALIDADE}

O controle da qualidade do leite é feito durante todo o processo, desde a chegada do leite a fábrica até a obtenção do produto final. São colhidas amostras de leite para analisar se existe alguma porcentagem de água no leite, se está com um nível de acidez aceitável de acordo com o que é determinado para os padrões da empresa antes de enviálo para os tanques de armazenamento, para evitar que o leite indesejado contamine toda a parcela já armazenada, evitando que se elimine todo o leite, o que geraria prejuízo para empresa. As amostras de leite são enviadas ao laboratório, para serem realizados testes, certificando de que o leite não foi alterado em sua fórmula e manteve na temperatura ideal, em torno de $4{ }^{\circ} \mathrm{C}$. Ainda durante $\mathrm{O}$ processo, supervisores de qualidade e manutenção dão toda a assistência para certificar que o produto esteja dentro dos padrões exigidos pela empresa. São realizados testes de pesagens para saber a variação das maquinas $e$ configurações para manter o padrão.

É realizada uma limpeza pelo processo Clean In Place (CIP), de todos os instalações e equipamentos utilizados na produção do leite condensado, sendo que a cada 30 horas trabalhadas, cinco horas são destinadas para higienização. É extremamente importante para evitar possíveis contaminações no produto, garantindo ao final a qualidade necessária. Quando necessário, as partes moveis são lavadas com sabão e sanitizadas com solução de ácido peracético antes de contato com o produto.

\subsection{COLABORADORES}

A empresa dispõe de 150 colaboradores dos quais assumem os cargos de Gerente de Produção e Administrativo; Supervisor de Qualidade e Manutenção; Encarregados de Produção; Operadores de Processo Fabril; Operadores de Maquina e Ajudantes de 
Produção, que se revezam em três turnos de oito horas, vinte e quatro horas por dia.

\subsection{EMBALAGEM E ROTULAGEM}

A embalagem do produto deve garantir condição hermética e ausência de ar no interior da embalagem, sendo assim realizada em embalagem cartonada Tetra Brik. Apesar do produto e envase não serem assépticos, todos os cuidados com a higiene e boas práticas de fabricação devem ser adotadas para evitar uma possível contaminação do produto.

O setor de marketing é responsável pela criação da arte das embalagens, uma vez que como afirmado por Ballou (2007) a embalagem é tratada em três aspectos. Primeiramente, ela serve de promoção e uso do produto, porém a embalagem não possui grande diferencial competitivo, por apresentar características semelhantes a outras marcas. Em segundo lugar, proporciona proteção para o produto, esse aspecto é atendido de forma adequada por ser uma embalagem resistente e por último servindo como instrumento para aumentar a eficiência da distribuição.

\section{CONCLUSÃO}

Neste estudo analisou-se o processo produtivo do leite condensado, e constatou que é de suma importância o acompanhamento do leite, desde sua chegada ao posto de coleta até o produto final destinado ao consumo, uma vez que se trata de um produto com alta perecibilidade, é necessário que se tenha uma cadeia que ofereça condições de higiene desde seu início.

A qualidade do produto é satisfatória, no que se refere à adequação de normas impostas pela vigilância sanitária e órgãos reguladores e normativos da área. Porém mesmo tendo sua fábrica localizada em Minas Gerais, a empresa não tem o estado como potencial consumidor, destinando sua produção aos estados do Rio de Janeiro e de São Paulo, onde têm grande participação no mercado.

Conclui-se que a localização do posto de coleta e do laticínio em estudo é de suma importância estratégica para empresa, onde está visa adquirir o leite em uma região de abundante oferta e, consequentemente, com um menor custo, realizando seu processamento em uma unidade perto de fornecedores de matérias-primas e de fácil e rápido escoamento para sua central onde essa será incumbida da logística aos consumidores.

[5]. GOLDENBERG, M. A Arte de Pesquisar " Como fazer pesquisa qualitativa em ciências sociais". $10^{\text {a }}$ Ed. Rio de Janeiro, 2007.

[6]. IBGE, Instituto Brasileiro de Geografia e Estatística, 2015. Disponível em: <https: / /www.milkpoint.com.br/noticias-emercado/giro-noticias/ibge-producao-de-leitecresceu-27-em-2014-sul-tornouse-a-maior-regiaoprodutora-97326n.aspx>. Acesso em: 25 de ago de 2017.

[7]. MAPS, Google. 2017. Disponível em: <https://www.google.com.br/maps/>. Acesso em: 25 ago. 2017.

[8]. MARTINS, G. de A. THEÓPHILO, Carlos Renato. Metodologia da Investigação Científica para Ciências Sociais Aplicadas. $2^{\text {a }}$ Ed. São Paulo: Atlas, 2009.

[9]. MIGLIOLI, A. M. Tomada de Decisão $\mathrm{Na}$ Pequena Empresa: estudo multi caso sobre a utilização de ferramentas informatizadas de apoio à decisão. Escola de Engenharia de São Carlos USP. São Carlos, 2006. 
[10]. MOREIRA, D. A. Administração da produção e operações. $5^{\text {a }}$ Ed. São Paulo: Pioneira, 2000.

[11]. OlIVEIRA NETTO, A. A. de. Metodologia da pesquisa científica: guia prático para apresentação de trabalhos acadêmicos. $3^{\text {a }} \mathrm{Ed}$. Florianópolis: Visual Books, 2004.

[12]. OLIVEIRA, C. L. de. Um Apanhado TeóricoConceitual Sobre a Pesquisa Qualitativa: Tipos, Técnicas e Características. 2008.

[13]. REZENDE, A. et al. Custo de produção no setor de laticínios: um estudo de caso em Dany Laticínios Ltda. CONGRESSO DE ECONOMIA E SOCIOLOGIA RURAL, 40. 2002, Passo Fundo, RS. Anais... Brasília: SOBER, 2002.
[14]. SCALCO, A. R. TOLEDO, José Carlos de. Gestão da qualidade em laticínios do estado de São Paulo: Situação atual e recomendações. Revista de Administração, São Paulo v.37, n.2, p.17-25, abril/junho 2002.

[15]. SEVERINO, A. J. Metodologia do Trabalho

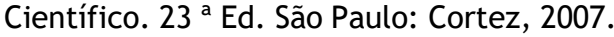

[16]. SLACK, N. CHAMBERS, S. JOHNSTON, R. Administraçãa da Produção. $2^{a}$ São Paulo: Atlas, 2007.

[17]. SLACK, N. CHAMBERS, S. JOHNSTON, R. Administração da Produção. $3^{a}$ Ed. São Paulo: Atlas, 2009

[18]. VEGGIAN, V. A. Silva, T. F. da. Planejamento e Controle da Produção. FAEF Revistas Eletrônicas. 21 ${ }^{\mathrm{a}}$ Ed. Dezembro, 2011. 


\section{Gapítulo 16}

\section{ESTUDO DO PROCESSO PRODUTIVO E COMERCIAL DO QUEIJO MINAS ARTESANAL FAZENDA EM MEDEIROS-MG}

\section{Bárbara Andrino Campos Silva \\ Humberto Elias Giannecchini Fernandes Rocha Souto \\ Marcelo Teotônio Nametala \\ Rafael Izidoro Martins Neto \\ Júlio César Benfenatti Ferreira}

Resumo: No ramo da produção de queijo, a Serra da Canastra em Minas Gerais se destaca sendo uma das principais regiões. Esse trabalho tem como objetivo estudar o sistema produtivo, logístico e mercadológico em uma fazenda que produz e comercializa o Queijo Canastra. Sendo um estudo de caso de abordagem qualitativa, a pesquisa foi realizada com coleta e análise de dados através de pesquisas documentais, entrevistas com o proprietário e visitas ao local. Com os dados coletados pôde-se estudar as normar que regem a produção do queijo, Layout da quejaria, Logística, Estoque, Marketing. Foi feito também o fluxograma do processo produtivo, bem como um estudo de tempos salientando os possíveis gargalos. A partir do levantamento e análise dos dados pode-se constatar que a unidade produtiva da fazenda trabalha com baixo tempo de produção em relação à legislação, sendo possível um aumento na produção. 0 marketing do produto é eficaz, sendo reconhecido no mercado por suas premiações e pela qualidade, porém poderia atuar nos meios em que as premiações não possuem abrangência. Relacionado à logística, foi sugerido ao produtor utilizar um método de controle de estoque a fim de evitar desperdícios e alguma possível interrupção da produção pela ausência de suprimentos.

Palavras-chave: Processo Produtivo; Queijo Canastra; Estudo de Caso. 


\section{INTRODUÇÃO}

O surgimento do queijo foi há mais de 8.000 anos nos vales entre os rios Tigres e Eufrates, atualmente Iraque (FOX, 1993). A transformação do leite em queijo surgiu como uma forma de conservação do leite, além de propiciar facilidade para mobilidade do produto.

0 queijo contribuiu de forma significante para o desenvolvimento de diversas civilizações, tendo sido citado inúmeras vezes na Bíblia e sendo na Grécia reverenciado como um alimento dos deuses (EPAMIG, 1989).

No Brasil, o queijo chegou com os portugueses, que foram os responsáveis por trazerem o gado bovino, que era muito usado como animal de tração e alimentação para os garimpeiros, os quais destinavam parte do leite produzido para o preparo do queijo (RIBEIRO, 1959).

Existem cerca de 27 mil produtores de queijo artesanal no estado de Minas Gerais, com uma produção anual de 70 mil toneladas por ano. As principais regiões mineiras produtoras do Queijo Minas Artesanal são localizadas na Serra da Canastra, Serro, Alto Paranaíba e Araxá (EMATER-MG, 2004b).

Este estudo, que foca o sistema de produção e comercialização de queijo, tem como referência a região da Canastra, que se localiza no Sudoeste do Estado de Minas Gerais, sendo composta pelos municípios de: Bambuí, Delfinópolis, Tapiraí, Medeiros, São Roque de Minas, Vargem Bonita e Piumhí (EMATER-MG, 2003a).

Os fatores edafoclimáticos da região da Canastra são favoráveis para a produção do queijo, concedendo um ambiente propício para o desenvolvimento de bactérias endógenas que se fazem presentes no "pingo", que é o soro que escorre de um dia para o outro durante a salga do queijo, e trazendo o sabor característico do queijo desta região (EMATER-MG, 2004a).

São diversos os fatores responsáveis por caracterizar tal região como ícone da produção do queijo, somados a séculos de prática que passa de geração a geração, garantindo sustentabilidade da agricultura familiar.

Assim, tem-se como objetivo do trabalho estudar uma fazenda de agronegócio que produz e comercializa o queijo Canastra. 0 trabalho teve como foco o sistema produtivo, logístico e mercadológico da fazenda.

\section{REFERENCIAL TEÓRICO}

\subsection{ADMINISTRAÇÃO DA PRODUÇÃO}

Segundo Moreira (2006), a administração da produção diz respeito às atividades voltadas para a produção de bens ou prestação de serviços. Em sua forma mais característica, a atividade industrial implica na fabricação de um produto físico, tangível. Neste sentido, Corrêa e Corrêa (2011, p. 24) a caracterizam como sendo a "atividade de gerenciamento estratégico dos recursos escassos (humanos, tecnológicos, informacionais e outros), de sua interação e dos processos que produzem e entregam bens e serviços, visando atender necessidades e/ou desejos de qualidade, tempo e custo de seus clientes".

\subsection{LAYOUT}

Para Slack, Chambers e Johnston (2009), layout é como recursos transformadores são dispostos em relação aos outros e a forma com que as tarefas serão destinadas a eles. A decisão do layout é de grande valia pois, se constar erroneamente, ocasionará em fluxos extensos e/ou confusos, tempos de processo retardados, operações rígidas, filas de consumidores e custos elevados.

\subsection{LOGÍSTICA}

A logística nasceu com as mudanças organizacionais, principalmente com a preocupação em atender seus clientes com eficiência, referenciando qualidade e desenvolvimento, reduzindo prazos e custos. Segundo Ballou (2001, p. 21), "a missão da logística é dispor a mercadoria ou o serviço certo, no lugar certo, no tempo certo e nas condições desejadas, ao mesmo tempo em que fornece a maior contribuição à empresa", se responsabilizando pelo planejamento, operação e controle do fluxo de mercadorias.

Segundo Christopher (2007, p. 03):

"Logística é o processo de gerenciamento estratégico da compra, do transporte e da armazenagem de matérias-primas, partes e produtos acabados (além dos fluxos de informação relacionados) por parte da organização e de seus canais de marketing, de tal modo que a lucratividade atual e futura 
sejam maximizadas mediante a entrega de encomendas com o menor custo associado".

Sendo assim, a logística empresarial pode ser entendida como o processo de gerenciar de forma estratégica a movimentação e armazenagem do produto. Sendo um conjunto de operações que se associam ao fluxo de materiais e informações para o processo.

\subsection{ESTOQUE}

Moreira (2006) conceitua estoque como quaisquer bens físicos que sejam armazenados, por algum intervalo de tempo até que alguém os use. Os estoques podem ser produtos acabados, como matériasprimas e componentes para a produção.

Neste mesmo conceito, Slack et. al. (1997) completam dizendo que não importa o que o estoque armazena ou qual sua posição na operação. Sua existência se dá por haver uma diferença na taxa de fornecimento e demanda.

\subsection{FLUXOGRAMA}

De acordo com Préve (2012), o fluxograma é uma ferramenta que faz uma representação gráfica passo a passo de um caminho a ser percorrido por um processo até atingir seu objetivo final.

De forma mais simplificada, fluxogramas são explicações de sequências de trabalho em formas de símbolos e desenhos para facilitar a análise. É um recurso visual utilizado pelos gestores para analisar o sistema produtivo, buscando, por meio deste, descobrir oportunidades de melhorias e evitar gargalos (PEINADO; GRAEML, 2007).

\subsection{ESTUDO DE TEMPOS}

0 estudo de tempos é estabelecido por Slack, Chambers e Johnston (2002), sendo uma técnica de medida do trabalho para registrar os tempos e o ritmo de trabalho para os elementos de uma tarefa e analisar os dados a fim de obter o tempo necessário para a realização deste.

Moreira (2009) afirma que há três tipos diferentes de tempo neste estudo: Tempo Real, que é o que realmente decorre durante a operação; Tempo Normal, que é o tempo gasto pelo operador realizar sua operação em velocidade normal; e Tempo Padrão, que pode ser identificada de quatro formas: Estudo de Tempos com Cronômetros, Tempos Históricos, Dados Padrão Prédeterminados e Amostragem do Trabalho.

Estudar tempos e movimentos tem como objetivo o desenvolver um sistema visando minimizar custos de produção, fazendo uma otimização do tempo dos processos para serem realizados em seu melhor tempo possível (VELOSO, et. al. 2012).

\subsection{GRÁFICO DE GANTT}

Para o bom planejamento e controle de uma produção, foram criadas ferramentas para auxiliar nesse processo. Segundo Pavan (2002), Henry Laurence Gantt dedicou seus estudos a organizações industriais e percebeu a necessidade da existência de um planejamento dos tempos para cada operação, criando então um gráfico para tal. 0 gráfico de Gantt é uma ferramenta simples e visual, que utiliza de barras horizontais, de forma a cada barra indicar o tempo de execução de uma tarefa de um processo.

\subsection{GARGALO}

Para Goldratt e Cox (2002, p. 152), "gargalo é qualquer recurso cuja capacidade é igual ou menor que a demanda de mercado imposta sobre ele". Conforme dita o autor, o gargalo tem sua existência pelo mercado exigir uma demanda maior que a capacidade de atendimento.

Almeida e Medeiros (2009) dizem que, atualmente, os principais focos da gestão são evitar gargalos que causem a perda de vendas, detectar as restrições das operações e otimizar os processos a fim de obter uma melhor performance para a empresa.

\subsection{MARKETING}

Para Kotler e Armstrong (2012, p. 4), "definido de maneira geral, o Marketing é um processo administrativo e social pelo qual os indivíduos e organizações obtêm o que necessitam e desejam por meio da criação e troca de valor com os outros". Pode-se definir o Marketing como uma construção de relacionamento com o cliente, que se dá por meio da criação de valor para o mesmo. 
Os principais canais de comunicação atribuídos no Marketing são: propagandas, que são técnicas para exibição de produtos, serviços e conceitos ligados a conteúdos impressos ou eletrônicos; promoção de vendas: incitação de curto prazo com a finalidade de proporcionar a compra de um produto ou serviço; eventos e experiências: são ações financiadas com intuito da aproximação dos consumidores à marca; relações públicas e publicidades: métodos de proteção a marca e a organização e seus serviços; marketing direto: são interações diretas com os clientes pelos veículos de comunicação; marketing interativo: interações com os consumidores de forma a buscar uma experiência de melhoramento da imagem da marca; vendas pessoais: são ações pessoais e diretas visando clientes potenciais (KOTLER; KELLER, 2007).

Além dos canais apresentados acima, Kotler e Armstrong (2012) ainda consideram que a comunicação boca a boca é um dos canais que geram mais influência para o mix de marketing.

\section{METODOLOGIA}

0 presente trabalho é caracterizado como um estudo de caso de abordagem qualitativa. 0 estudo de caso, de acordo com Nisbett e Watt (1978, p. 5), é uma "investigação sistemática de uma instância específica" e, ainda segundo Yin (2001), tem caráter prático, permitindo conhecimento aperfeiçoado dentro das metas estabelecidas em um objeto de estudo.

Para coleta e análise dos dados foram realizadas pesquisas documentais, entrevista com o proprietário, assim como visitas para o processo de observação e o registro de imagens do processo produtivo.

Segundo Cervo et. al. (2007, p. 31), "observar é aplicar atentamente os sentidos físicos a um objeto para dele obter um conhecimento claro e preciso. (...) É disso que depende o valor de todos os outros processos".

Entretanto, a observação, por si só, não se configura suficiente para a construção dos conhecimentos de que a ciência necessita. Portanto, faz-se necessário registrar os objetos obtidos no processo de observação, pois, segundo Cervo et. al. (2007), é esse processo que configura a técnica da descrição. Ainda dizem que a descrição tem por finalidade descrever, metodologicamente, os passos dados na aplicação de técnicas e efetivação da pesquisa; com isso, qualquer outro pesquisador, utilizando as mesmas técnicas de tal pesquisa, sendo orientado por iguais métodos e nas mesmas circunstâncias, tem a possibilidade de obter os mesmos resultados.

O objeto de pesquisa deste trabalho foi a instalação produtora do Queijo Minas Artesanal Canastra de uma Fazenda, localizada no município de Medeiros, no Centro-Oeste de Minas Gerais.

$\mathrm{Na}$ pesquisa documental, foram utilizados periódicos relacionados à Empresa de Assistência Técnica e Extensão Rural do Estado de Minas Gerais (EMATER-MG) e ao Instituto Mineiro de Agropecuária (IMA). A entrevista com o proprietário foi realizada em uma das visitas, no dia 21/04/2017, quando a mesma foi gravada. Juntamente com o processo de observação, foi realizada a medição, por meio de um cronômetro, dos tempos e movimentos dos processos produtivos. Também se utilizou do recurso da câmera de um smartphone para captura de imagens e filmagens dos processos produtivos, das instalações e da fazenda em geral.

Para a análise dos dados e transcrição da entrevista, utilizou-se 0 pacote Microsoft Office 2013.

\section{RESULTADOS E DISCUSSÃO}

\subsection{A EMPRESA}

A Fazenda referida produz o Queijo Minas Artesanal canastra desde 1995, sua extensão territorial é de 98 hectares. A mesma é uma fazenda familiar, onde o proprietário reside com sua família composta por quatro membros e todos trabalham nas atividades diárias do agronegócio. A produção de leite é a principal atividade desenvolvida diariamente, acrescida da produção de Queijo Minas Artesanal Canastra.

\subsection{NORMATIZAÇÃO}

A Lei $n^{\circ} 14.185$, de 31 de janeiro de 2002, é a lei que dispõe sobre o processo de produção do Queijo Minas Artesanal. Para enquadrar-se na categoria denominada "Queijo Minas Artesanal Canastra”, é necessário, ao produtor, atender à legislação cadastrando-se 
no Instituto Mineiro de Agropecuária - IMA, o que é previsto em tal lei:

Art. $3^{\circ}(\ldots) \S 1^{\circ}$ - 0 cadastramento no IMA para os fins deste artigo será feito em escritório local do órgão, individualmente ou por meio de entidade representativa, mediante preenchimento de formulário específico, em que o produtor assuma a responsabilidade pela qualidade dos queijos produzidos, e apresentação de laudo técnico-sanitário da queijaria, emitido por médico veterinário.

Adjunto à essa certificação, também considerado pré-requisito, o produtor deve, juntamente da EMATER-MG do seu município, fazer um curso com carga horária de 40 horas, promovido pela mesma, onde é ensinado práticas de fabricação, instalação, manuseio dos animais geradores de matéria prima, entre outros assuntos, os quais fazem parte do Programa de Melhoria do Queijo Minas Artesanal. Todos os passos que o produtor cadastrado deve seguir estão registrados, com riqueza de detalhes, no Manual de Boas Práticas de Fabricação do Queijo Minas Artesanal, assim como também no Memorial Descritivo do IMA, onde discorre sobre o projeto de criação da unidade de processamento da queijaria, o espaço físico, dentro do qual será de fato a produção,

Toda essa normatização está em conformidade com a Lei Estadual 19.476 conhecida como Lei da Agroindústria Familiar.

$\mathrm{Na}$ visita realizada à Fazenda, constatou-se, por meio de relatos do produtor, que ele possui o cadastro no IMA, em nome do mesmo. Foi averiguado junto aos registros do IMA e verificou-se que o registro foi feito dia $10 / 11 / 2011$, e o número do cadastro é $31413060^{* * *}$.

\subsection{LAYOUT}

A construção do espaço físico da queijaria segue o padrão descrito nas normas já citadas acima. Estão contidas nelas informações como: o teto, que deve ser revestido com forro PVC branco; 0 piso, branco e acondicionado em todo espaço físico da queijaria sendo, no chão de característica antiderrapante; 0 rejunte que segue igualmente na cor branca; Os portais, assim como as portas e janelas, são de madeira, na cor branca, com revestimento em telas para evitar a entrada de insetos ou pragas; E o declive, que deve ser de 3,00\% para escoar toda água e componentes para o esgoto. O layout do espaço físico do local de produção pode ser visto no anexo $\mathrm{A}$.

\subsection{LOGÍSTICA E ESTOQUE \\ 4.4.1 SUPRIMENTOS}

Todo o processo logístico do agronegócio estudado é organizado em etapas de acordo com as necessidades de demanda. Para a produção do Queijo Minas Artesanal Canastra, utiliza-se como matéria prima o leite cru, coalho, pingo, sal, embalagem e rótulo.

A propriedade realiza a produção de leite, que, também de acordo com a normatização, o mesmo deve ser produzido na própria fazenda (e não é permitido a mistura de leite de outras unidades produtivas). O leite na fazenda é ordenhado duas vezes ao dia: manhã e tarde. Todo o leite produzido no período da manhã é destinado à produção de queijo, e, o produzido à tarde, é vendido a um laticínio da região, o qual o próprio laticínio realiza o recolhimento do mesmo na propriedade.

Para a produção diária do queijo é utilizada uma média de 400 litros de leite cru recémordenhado onde, para cada 550 litros, são adicionados $30 \mathrm{ml}$ de coalho e $500 \mathrm{ml}$ de pingo, bem como uma unidade de embalagem e rótulo para cada queijo totalizando 35 a 40 por dia. 0 sal é disposto sobre cada peça de queijo à gosto do produtor. 0 pingo, assim como o leite, é um suprimento produzido na própria fazenda; as demais matérias primas são compradas de fornecedores externos.

\subsubsection{ESTOQUE}

De acordo com as observações feitas na fazenda e também relatos do produtor, não é utilizado um método específico para o controle de estoque dos suprimentos. Eles são comprados de acordo com a demanda, sempre que necessário nos dias em que o produtor vai à cidade ou são adquiridos com vizinhos em casos de maior urgência. Todos os suprimentos são acondicionados em um armário de alumínio, o qual fica na sala de fabricação do queijo (o que também é descrito no Memorial Descritivo do IMA).

0 estoque mais perceptível nesta unidade produtora foi o estoque de produto em elaboração. Durante a etapa de Descanso 24 
horas e a etapa de Maturação de no Mínimo 22 dias do processo de produção, os queijos ficam em estoque, armazenados nas bancas e nas prateleiras de maturação, respectivamente, aguardando a finalização do processo.

No que diz respeito ao estoque de produto acabado, observou-se que não há a existência dele pois, acordando com as regulamentações, o tempo mínimo previsto para a maturação é de 22 dias, não sendo estipulado um tempo máximo para ser transposto para o estoque. Assim, logo após a maturação desejada, os queijos já são embalados, rotulados e, em sequência, são distribuídos aos clientes, no mesmo dia.

\subsubsection{DISTRIBUIÇÃO FÍSICA}

A distribuição do Queijo Minas Artesanal Canastra produzido no empreendimento é realizada pelo próprio produtor utilizando uma caminhonete. 0 produto é distribuído nos municípios de Araxá, Ibiá e Bambuí. No município de Medeiros (onde a fazenda produtora é localizada), não existe nenhum ponto de distribuição física, porém o queijo é comercializado na própria fazenda quando há encomendas por clientes interessados. A armazenagem do produto é feita em caixas de papelão, com 16 queijos em cada caixa.

A entrega nos municípios de Araxá e Bambuí ocorre quatro vezes ao mês, especificamente aos sábados em Araxá e segundas-feiras em Bambuí. No município de Ibiá são distribuídos duas vezes ao mês de acordo com a demanda dos clientes.

\subsection{PROCESSO DE PRODUÇÃO}

0 processo produtivo se inicia com a obtenção do leite onde, primeiramente, é feita a limpeza do aparelho de ordenha. A preparação do gado tem início com o teste de caneca telada: é usada uma caneca com o bocal envolto por uma tela e feito o recolhimento de uma amostra do leite. 0 intuito é verificar se a vaca contraiu alguma doença nas tetas, pois o leite infectado muda a sua textura, deixando um pouco de resíduos na tela.

Antes do recolhimento do leite é realizada a higienização e secagem das tetas; esta última deve ser feita com papel toalha, que é descartado logo após o uso. A extração da matéria-prima é feita via ordenha. A fazenda estudada conta com a presença de três canos de ordenha. Enquanto as três primeiras vacas que foram preparadas estão sendo ordenhadas, mais três estão iniciando o processo de preparação; este ciclo (Apêndice A) se repete até que se conclua a ordenha das 51 vacas da fazenda produtora. Após a ordenha, o leite é imediatamente transportado para a queijeira por meio de dutos que o conduzirão até os tanques dispostos no local.

Estando o leite ordenhado armazenado no tanque, é feita a adição do pingo e do coalho. 0 pingo se trata do soro que escorre do queijo quando ele está no processo de Segunda Salga, ocorrendo de um dia para o outro. O coalho funciona como fator coagulante que divide o leite entre soro e massa, enquanto a mesmo fica em repouso no processo de coagulação. Tendo passado o período de repouso é feito o corte da massa, com o intuito de evitar a perda das propriedades que acontece na coagulação. 0 corte da massa é realizado manualmente com uma peça de madeira, tendo que ser feito com movimentos suaves para a mistura se tornar homogênea. Em seguida, acontece o processo de dessoragem, que consiste na separação do soro da massa que é gerada na coagulação. Enquanto o soro é aproveitado na alimentação de animais, a massa passa para o processo de prensagem manual, onde é pressionada com o intuito de retirar o excesso do soro ainda restante.

Logo após a dessoragem, a massa é disposta em formas e, nesse momento, o produtor desenha as iniciais de seu nome e de sua esposa no produto, o que se tornará uma marca gravada no queijo. Posteriormente à enformagem, é efetuada a primeira salga na superfície do queijo; há, então, um tempo de descanso para, em seguida, virar o queijo de lado e suceder a segunda salga.

o queijo descansa em uma banca por um período de vinte e quatro horas e, ao término deste ciclo, é transferido para o processo de maturação onde será lavado, retirado o excesso de sal, virado e repousará sobre uma prateleira de madeira por, no mínimo, vinte e dois dias. Ao término do prazo de Maturação é feita a Toalete, onde se dará o acabamento do queijo para, em seguida, passar pelo processo de embalagem, pesagem e por fim, a comercialização. A Figura 2 concede a visualização do processo. 
Figura 2: Vídeo do Processo Produtivo Queijo Canastra

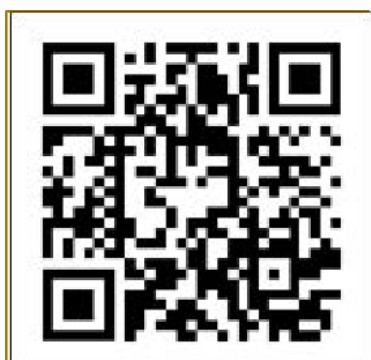

Fonte: Os Autores (2017)

\subsection{FLUXOGRAMA}

Figura 3: Fluxograma do processo produtivo do queijo

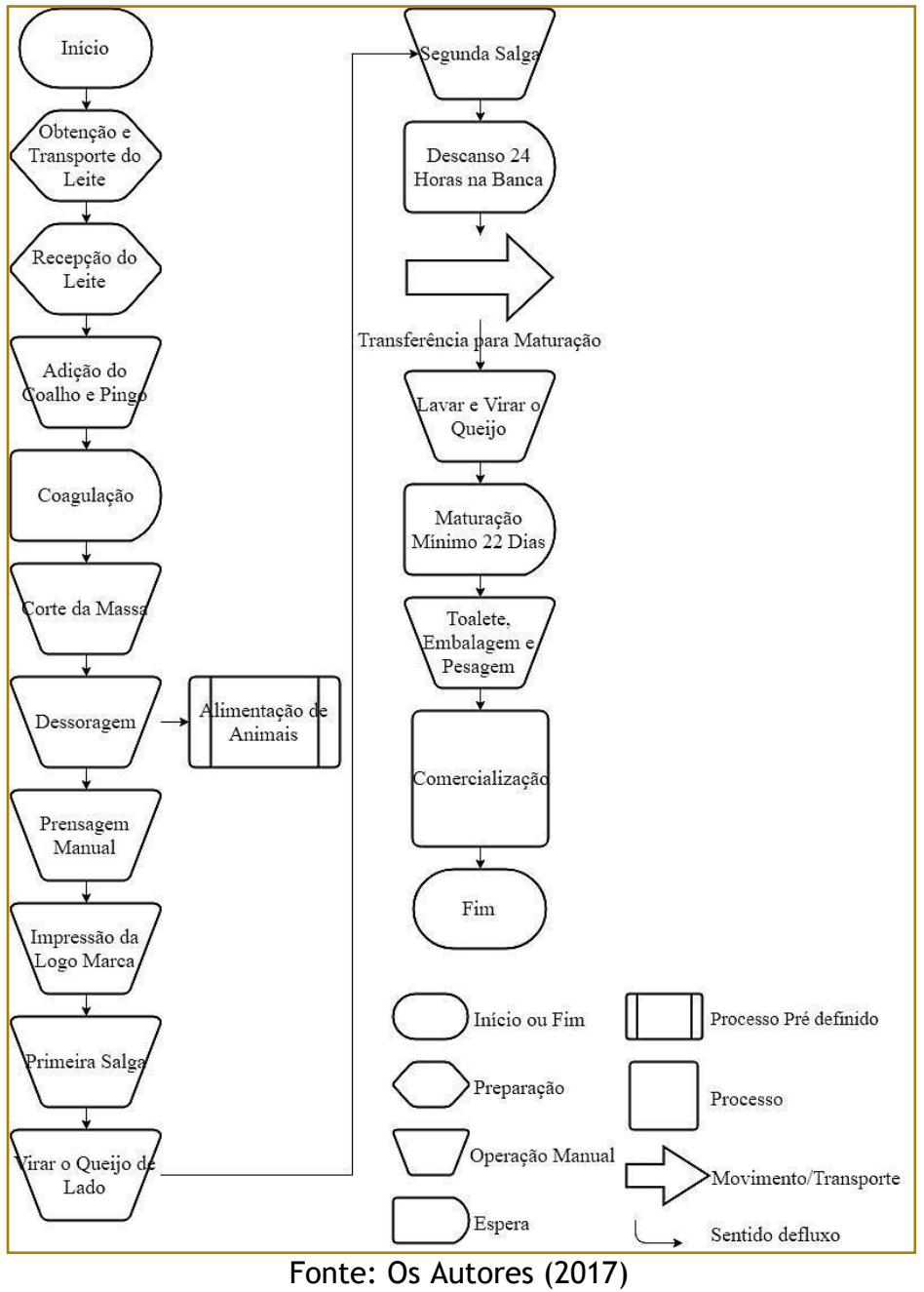

\subsection{ESTUDO DE TEMPOS}

Os Gráficos de Gantt no Apêndice A, B, C e D demonstram os tempos necessários para a realização de cada processo. Foram divididos entre quatro segmentos, sendo eles: obtenção da matéria prima (Apêndice A), produção do queijo até a segunda salga
(Apêndice B), produção do queijo até a maturação (Apêndice C) e acabamento (Apêndice D).

Foi feito o acompanhamento da produção de 23 queijos, totalizando um tempo total de 2 horas, 30 minutos e 16 segundos na somatória do tempo dos processos. 
No decorrer do dia, o produtor opera em três diferentes lotes de produção sendo: a produção que se inicia no dia até ir para o descanso de 24 horas, a produção do dia anterior que já passou pelo referido descanso e a produção que já passou pelo processo de Maturação e precisa passar pelo Toalete, Embalagem e Pesagem para então ser comercializada.

Todo o segmento de Acabamento, acontece simultaneamente com 0 processo de coagulação ( $3^{\mathrm{a}}$ etapa do Apêndice $\left.B\right)$, sendo este o único momento em ocorre operações nos lotes simultaneamente.

\subsection{GARGALOS}

Após a realização do estudo, feito 0 levantamento de todos dados e fontes trabalhadas, foram detectados modelos de processos que impediam o progresso ou desenvolvimento da produção e venda do Queijo Minas Artesanal Canastra.

No aspecto produção, o grande gargalo encontrado, é simplesmente a restrição imposta pela normativa do IMA, onde 0 produtor deve confeccionar no máximo quarenta e cinto unidades de queijo por dia com padrão de tamanho e peso. Assim, mesmo tendo grande volume de leite ou capacidade produtiva fica impossibilitado de aumentar a produção de queijo.

Outro gargalo encontrado diz respeito ao que - mercado demanda de Queijo Minas Artesanal Canastra, tendo em vista que a queijaria deve seguir o que é imposto pelas normativas vigentes de regulamentação. Segundo relatos do produtor, o grande interesse dos clientes e das fatias de mercado está na compra de queijo fresco, justificado por fatores culturais na região assim como a economia e instabilidade financeira do país, (visto que o queijo maturado tem um valor mais alto que o queijo fresco) e, com a adoção das normas, o produtor poderá somente vender seu produto passados vinte e dois dias de maturação de cada peça de queijo. Com isso, o cliente vem demonstrando menos interesse e receio em efetuar a compra desse produto, causando assim uma redução nas vendas.

Quanto ao gargalo encontrado no processo produtivo, notou-se que o processo em determinado momento, especificamente após a Prensagem Manual possui uma pausa na continuidade da produção para que se transfira a produção do dia anterior, que se encontra disposta sobre a banca tendo seu prazo de Descanso de 24 horas para as prateleiras de maturação. Sendo assim podese haver uma otimização de 18 minutos e 06 segundos no processo, se for realizado a Transferência para Maturação e Lavar e Virar - Queijo dessa produção do dia anterior em simultaneidade com a Coagulação.

\subsection{MARKETING}

Os tipos de queijo que são feitos na presente unidade produtiva estudada são: Queijo Canastra Merendeiro (600 a 700 gramas) $\mathrm{R} \$ 20,00 / \mathrm{kg}$, Queijo Canastra Tradicional $(1,0 \mathrm{~kg}$ a $1,3 \mathrm{~kg}) \mathrm{R} \$ 30,00 / \mathrm{kg}$ e Queijo Canastra Real (6 a $7 \mathrm{~kg}) \mathrm{R} \$ 50,00 / \mathrm{kg}$.

Segundo relatos do produtor, a partir da regulamentação da produção do Queijo Minas Artesanal Canastra a demanda cresceu. A embalagem e o rótulo também seguem as regras da normatização, sendo a embalagem de plástico e embalada a vácuo pelo próprio produtor. 0 rótulo na embalagem é personalizado, o qual se identifica como Queijo Minas Artesanal da região da Canastra, assim como dispõe o nome do produtor como marca, de forma a gerar sua identidade. Ele também possui uma marcação feita no próprio queijo durante o processo de produção, o que também permite identificar a marca do mesmo. Todo esse processo traz uma personalidade única ao produto e o torna diferente quando exposto para reconhecimento dos clientes.

A EMATER também promove periodicamente concursos do Queijo Minas Artesanal Canastra, onde participam os produtores cadastrados. 0 produtor da fazenda possui participação nestes concursos e feiras de queijos, o qual já foi ganhador de títulos, troféus e medalhas, adquirindo boas colocações. Tais participações e premiações, são utilizadas como marketing de propaganda do queijo, tendo em vista que em tais concursos há a presença de mídias, autoridades de vários órgãos, empresários, comerciantes e clientes, o que se torna oportunidade para expandir a fatia do mercado já alcançado pelo produtor.

Outra maneira de divulgação do queijo, relatada pelo produtor, foi o boca a boca feito por meio de seus próprios clientes, assim como dos pontos de vendas onde ele realiza a distribuição dos seus queijos. 


\section{CONSIDERAÇÕES FINAIS}

Mediante o levantamento de todos os dados apresentados, da observação realizada no local de produção, relatos do produtor e de sua família (a qual tem participação nos processos de produção) e relatos do técnico da EMATER-MG, pode-se considerar que a unidade produtiva da Fazenda é eficaz quanto ao padrão de qualidade instituído pela normatização e alcança também eficiência em seu processo de produção e logística, pois consegue atender a demanda.

Destaca-se o fato da importância das normas e leis que regulamentam o Queijo Minas Artesanal pois elas proporcionam um padrão de qualidade e também um suporte de assistência técnica ao produtor, onde 0 mesmo pode contar com instruções, participação em cursos e nos concursos, e também os manuais de Boas Práticas de fabricação para auxiliá-lo nas melhorias e manejo da produção. Porém, também percebe-se que tais normas destoam-se da realidade do mercado ao que diz respeito ao tempo de maturação do queijo e sugere-se que elas sejam revistas pelo Estado e pelos órgãos competentes, com intuito de evolução das mesmas normas, a fim de beneficiar o produtor, do mercado, da economia brasileira e também do consumidor.

A parte do processo produtivo flui bem, notou-se que há uma capacidade instalada suficiente para possíveis aumentos na quantidade produzida, assim como percebeuse com o estudo de tempos que o tempo de produção é baixo levando em consideração a

\section{NOTAS DE RODAPÉ:}

1 - Referente a condições de solo e clima.

2 - Para que seja possível a visualização do vídeo, abra a loja de seu Smartphone e baixe algum aplicativo leitor de código $Q R$, executeo, posicione a câmera sobre o código e abra a URL contida. jornada de trabalho diária máxima imposta pela Consolidação das Leis Trabalhistas.

Em relação à logística, sugere-se ao produtor, a fim de melhorias, a utilização de um método diferente de controle de estoque, para armazenar e organizar melhor suas compras de insumos. A eficiência de um estoque bem organizado pode evitar desperdícios e/ou alguma possível interrupção da produção pela ausência de suprimentos. Assim, a produção do queijo tem melhor desempenho no processo como um todo e consequentemente melhor resultado.

Nota-se que o marketing do produto é bem trabalhado, sendo reconhecido no mercado por suas premiações em concursos e pela qualidade. Por outro lado, não há uma preocupação em fidelizar e divulgar a marca além da forma citada, ficando o produtor preso à atuação da EMATER de promover os concursos. Sugere-se então ao produtor desenvolver uma divulgação da marca que atue também nos meios em que os congressos não possuem abrangência. Sugere-se ainda a tentativa, dentro das possibilidades de produção, do alcance de novos clientes nas cidades onde já é feita a venda, para que seja aproveitada o deslocamento e custo com o transporte já realizados.

No mais, percebeu-se uma harmonia entre os processos realizados para a produção do Queijo Minas Artesanal Canastra da Fazenda e também notou-se que não só o produtor, assim como sua família, estão satisfeitos e motivados com a realização de tal atividade.

3 - Código QR (sigla do inglês Quick Response) é um código de barras bidimensional que pode ser facilmente escaneado usando a maioria dos telefones celulares equipados com câmera. No caso deste artigo o código é convertido em um endereço URL que irá direcionar o usuário ao site 


\section{REFERÊNCIAS}

[1]. ALMEIDA, M. F. de; MEDEIROS, K. F. de. Análise do processo produtivo e a identificação de gargalos na produção do caulim. Salvador, 2009.

[2]. BALLOU, R. H. Gerenciamento da cadeia de suprimentos: planejamento, organização e logística empresarial. Porto Alegre: Bookman, 2001.

[3]. BRASIL. Lei $N^{\circ} 14.185$, de 31 de Janeiro de 2002. Disponível em: <https: / / www.almg.gov.br/consulte/legislacao/com pleta/completa. html?num=14185\&ano=2002\&tipo= LEI>. Acesso em: 8 mai. 2017.

[4]. BRASIL. Lei $N^{\circ} 19.476$, de 11 de Janeiro de 2011. Disponível em: <https://www.almg.gov.br/consulte/legislacao/com pleta/completa.html?tipo=LEl\&num=19476\&ano=2 011>. Acesso em: 8 mai. 2017.

[5]. CERVO, L.; BERVIAN P. A.; SILVA, R. da. Metodologia Científica. 6.ed. São Paulo: Pearson Prentice Hall. 2007.

[6]. CHRISTOPHER, M. Logística e gerenciamento da cadeia de suprimentos. São Paulo: Thomson, 2007.

[7]. CORRÊA, H. L.; CORRÊA, C. A. Administração de produção e operações: manufatura e serviços: uma abordagem estratégica. 2. ed. São Paulo: Atlas, 2011.

[8]. EMPRESA DE ASSISTÊNCIA TÉCNICA E EXTENSÃO RURAL DE MNAS GERAIS -

[9]. EMATER-MG. Caracterização da microrregião da Canastra como produtora de queijo Minas artesanal. São Roque de Minas, 2004a.

\section{[10]. EMPRESA DE ASSISTÊNCIA TÉCNICA E} EXTENSÃO RURAL DE MNAS GERAIS - EMATERMG. Caracterização da microrregião de Araxá com produtora de queijo Minas artesanal. Araxá, 2003a.

[11]. EMPRESA DE ASSISTÊNCIA TÉCNICA E EXTENSÃO RURAL DE MNAS GERAIS - EMATERMG. Queijos tradicionais de Minas com mais qualidade. Revista da Emater-MG, Muzambinho v. 22 , n. 80 , p. $8-9$, ago. 2004 b

\section{[12]. EMPRESA DE ASSISTÊNCIA TÉCNICA E} EXTENSÃO RURAL DE MNAS GERAIS - EPAMIG. Os queijos na fazenda. 3. ed. São Paulo: Globo, 1989. $219 \mathrm{p}$.

[13]. FOX, P. F. Cheese: Chemistry, physics and microbiology. London: General aspects, 1993. v. 1.

[14]. GOLDRATT, E. M.; COX, J. A Meta: um processo de melhoria contínua. 2. ed. São Paulo: Nobel, 2002
[15]. KOTLER, P.; KELLER. K. L. Administração de marketing. 12 edição. São Paulo: Ed. 2007.

[16]. KOTLER, P.; ARMSTRONG, G. Princípios de marketing. São Paulo: Pearson Prentice Hall, 2012.

[17]. MOREIRA, D. A. Administração da Produção e Operações. 2. ed rev. e ampl. São Paulo: Cengage Learning, 2009.

[18]. MOREIRA, D. A. Administração da produção e operações. 8. ed. São Paulo: Thomson Learning, 2006.

[19]. NISBETT, J. e WATT, J. Case Study. Redguide 26: Guides in Education Research. University of Nottingham Scholl of Education, 1978.

[20]. PAVAN, P. A. R. Gerenciamento de projeto de expansão de instituições hospitalares: estudo de caso. Monografia de Conclusão de Curso de Especialização em Gerência Empresarial e Negócios - Universidade de Taubaté, Taubaté, 2002.

[21]. PEINADO, J.; GRAEML, A. R. Administração da produção: operacões industriais e de serviços. Curitiba: UnicenP, 2007

[22]. PRÉVE, A. D. Organização, Sistemas e Métodos. Santa Catarina: UFSC, 2012.

[23]. RIBEIRO, J.A. Queijos do Brasil. Revista do Instituto de Laticínios Cândido Tostes (ExFelctiano), Juiz de Fora, v.14, n. 86, p. 33-34, set./out. 1959.

[24]. SLACK, N.; CHAMBERS, S.; HARLAND, C.; HARRISON, A.; JOHNSTON, R. Administração da Produção. São Paulo, SP: Editora Atlas S.A., 1997

[25]. SLACK, N.; CHAMBERS, S.; JOHNSTON, R. Administração da Produção. Tradução Maria Teresa Corrêa de Oliveira. 2. Ed. São Paulo: Atlas, 2002

[26]. SLACK, N.; CHAMBERS, S.; JOHNSTON, R. Administração da produção. 3. ed. São Paulo: Atlas, 2009.

[27]. VELOSO, R.; NAZARÉ, D. B.; CASTRO, F. P.; NEGRÃO, L. L. L.; CARNEIRO, M. P. Estudo de tempos aplicado a um serviço de revisão geral de motocicletas na cidade de Redenção - PA. In: Encontro Nacional de Engenharia de Produção, Bento Gonçalves, 2012. Anais... Bento Gonçalves, 2012.

[28]. YIN, R. Estudo de caso. Planejamento e métodos. 2a edição, Porto Alegre/RS: Bookman, 2001 
APÊNDICES E ANEXO

Apêndices $A, B, C$ e $D$ e Anexo $A$, disponíveis no código QR.

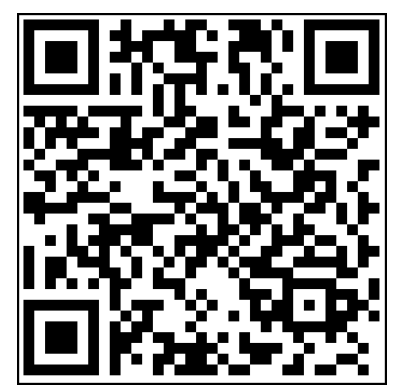

Fonte: Os Autores (2017) 


\section{Bapítulo 17}

\section{UM ESTUDO BIBLIOMÉTRICO SOBRE A UTILIZACÃO DE ANÁLISE MULTICRITÉRIO NA INDÚSTRIA DO ÓLEO E GÁS COM ENFOQUE EM DESCOMISSIONAMENTO}

\section{Thiago José da Costa Muniz \\ Marcilene de Fatima Dianin Vianna \\ Dalessandro Soares Vianna \\ Edwin Benito Mitacc Meza}

Resumo: com o avanço natural da obsolescência de inúmeros sistemas de produção de óleo e gás offshore pelo mundo, a discussão acerca do descomissionamento se torna questão chave para as empresas operadoras. Com o apoio das ferramentas de análise multicritério é possível argumentar, junto aos órgãos reguladores dos países que têm regulações mais travadas, outras alternativas de descomissionamento que atendam melhor as muitas nuances deste processo, diferentes do caso base de recolhimento total. 0 presente trabalho apresenta um estudo bibliométrico sobre as produções científicas que abordam conjuntamente os conceitos de descomissionamento e análise multicritério na indústria do óleo e gás, no período de 2005 a 2017. A pesquisa foi realizada nas bases SCOPUS e Web of Science e dos 20 trabalhos encontrados nesse período, dois foram analisados quanto às suas contribuições; o mais citado e o mais recente. Quanto ao descomissionamento, usando métodos de análise hierárquica diferentes, ambos trabalhos concluíram que a melhor opção é deixar a plataforma na locação.

Palavras-chave: Descomissionamento; Auxílio Multicritério à Decisão; AMD; Bibliometria; óleo e gás. 


\section{INTRODUÇÃO}

Do início da exploração comercial do petróleo até os dias de hoje, o meio que engloba este mineral enfrentou poucos momentos tão desafiadores para a sua existência quanto o que hoje vive. As tensões no mundo árabe, o barateamento e aumento de produtividade no óleo de xisto (shale oil) nos Estados Unidos, o avanço exponencial das energias alternativas e, principalmente, o excesso de produção que atualmente se vive, fez com que os preços dessa commodity, tão economicamente importante para o mundo, perdesse valor abruptamente desde 0 segundo semestre do ano de dois mil e catorze até o presente momento (MIMMI et al, 2017). A velocidade de recuperação do seu valor está se mostrando lenta, fazendo com que operadores do mundo inteiro tenham a necessidade incessante de buscar baratear seus custos de produção, isso sem comprometer a segurança das operações.

Especificamente no Brasil, além dos fatores externos, enfrenta-se uma grave crise econômica interna, motivada por momento de transição política, desvalorização de sua moeda local, queda na produção industrial e sucessivas perdas no seu grau de investimento, causando, entre outras coisas, evasão de investimentos externos, desemprego, inflação descontrolada.

Diante deste cenário interno e externo, as empresas produtoras de petróleo enfrentam uma diminuição muito expressiva nas receitas causadas pela queda no preço comercial do óleo. Como no Brasil há muitos campos de produção maduros, com baixa produção e instalações antigas, os cortes econômicos destes campos de produção vêm sendo antecipados, onde os fluxos de caixa estão se apresentando negativo no curto e/ou médio prazo (MIMMI et al, 2017). Esta constatação traz à tona um dos temas mais atuais e relevantes da indústria do óleo e gás mundial, especialmente no Brasil, que é o processo de descomissionamento de sistemas de produção que chegaram ao fim de sua vida econômica e/ou útil.

Uma das ferramentas que vem sendo bastante utilizada no momento de definição da destinação das instalações offshore em descomissionamento é o Auxílio Multicritério à Decisão $(A M D)$, visto que é um processo de alta complexidade e há diversas variáveis e partes interessadas, que precisam ser ponderadas e levadas em conta, e as ferramentas de análise multicritério fornecem suporte para a tomada de decisão .

Este artigo tem como objetivo geral realizar um estudo bibliométrico de publicações de auxílio multicritério à decisão aplicados e descomissionamento de estruturas offshore de óleo e gás. Para atingir tal objetivo geral, tem-se por objetivos específicos:

- Compor a evolução histórica das publicações;

- Elencar publicações de maior relevância;

- Realizar análise crítica dos resultados de maior relevância.

\section{DESCOMISSIONAMENTO}

Oriundo do termo em inglês decommissioning, o descomissionamento também é traduzido para o português como desmobilização, onde ambas as palavras retratam, de acordo com Ruivo (2001), o processo que ocorre no final da vida útil das instalações de exploração e produção de óleo e gás, referindo-se ao desmantelamento e, na maioria dos casos, na remoção dos equipamentos do leito marinho. Sua natureza é essencialmente multidisciplinar, pois requer um método detalhado e ponderado com diversas áreas da engenharia: ambiental, financeira, política e de bem-estar e segurança.

Sendo mais abrangente em sua definição, Prado (2015) descreve o descomissionamento como o processo que inicia na suspensão das operações, passando pela limpeza e remoção de hidrocarbonetos e outras substâncias, de acordo com os níveis requeridos e garantia da segurança das instalações. Engloba-se ainda como parte do processo de descomissionamento a avaliação das alternativas, a seleção daquela considerada a mais adequada e obtenção das permissões junto aos órgãos responsáveis. O processo tem seu fim com a operacionalização da alternativa selecionada, destinação dos materiais e remediação do local, quando necessário.

\section{ANÁLISE MULTICRITÉRIO}

Em várias definições sobre descomissionamento na literatura estudada para compor este trabalho, sempre é salientado a complexidade do processo, a 
quantidade de critérios envolvidos na tomada de decisão e as incertezas dos impactos gerados na operação de descomissionamento. Segundo Lev e Murphy (2007), tais incertezas que impulsionam os requisitos centrados em dados invocam a necessidade de garantir o gerenciamento e a utilização efetivos de dados para auxiliar na tomada de decisões proativas. No que diz respeito ao planejamento de projetos offshore, as incertezas, as complexidades e os volumes de dados de cisalhamento inerentes a tais empreendimentos tornam difícil para um grupo de tomadores de decisões humanas chegar à "melhor" solução baseada unicamente na tomada de decisão intuitiva.

O Auxílio Multicritério à Decisão vem a ser uma ferramenta científica de grande valor para a indústria de óleo o gás no que se diz respeito ao descomissionamento.

\section{BIBLIOMETRIA}

O termo bibliometria é introduzido por Allan Pritchard, em seu artigo Statistical Bibliography or Bibliometrics, publicado em 1969, para denotar a área de estudo que usa métodos matemáticos e estatísticos para investigar e quantificar os processos de comunicação escrita. Esses estudos tentam quantificar, descrever e prognosticar o processo de comunicação escrita, através de parâmetros observáveis tais como publicações, autores, palavras-chave, usuários, citações e periódicos, que são quantificados em estudos bibliométricos da literatura (PAO,1989). A principal definição utilizada por Pritchard (1969) é que bibliometria significa "todos os estudos que tentam quantificar os processos de comunicação escrita".

Segundo Vanti (2002), a bibliometria é utilizada para avaliar a produtividade e a qualidade da pesquisa dos cientistas, por meio da medição com base nos números de publicações e de citações dos diversos pesquisadores.

De acordo com Araújo (2006), a bibliometria foi inicialmente voltada apenas para a medida de livros (quantidade de edições e exemplares, quantidade de palavras contidas nos livros, espaço ocupado pelos livros nas bibliotecas, estatísticas relativas à indústria do livro), mas aos poucos foi se voltando para o estudo de outros formatos de produção bibliográfica, tais como artigos de periódicos e outros tipos de documentos, para depois ocupar-se, também, da produtividade de autores e do estudo de citações.

Dentre as áreas de estudos da bibliometria, a análise de citações é considerada a mais relevante devido à contribuição que pode prestar ao identificar e descrever os padrões na produção do conhecimento científico (Araújo, 2006).

A aplicação de técnicas bibliométricas, segundo Vanti (2002), apresentam-se em várias possibilidades, tais como:

- Identificar as tendências e o crescimento do conhecimento em uma área;

- Identificar as revistas do núcleo de uma disciplina;

- Prever as tendências de publicação;

- Estudar a dispersão e a obsolescência da literatura científica;

- Prever a produtividade de autores individuais, organizações e países;

- Medir o grau e padrões de colaboração entre autores;

- Analisar os processos de citação e cocitação;

- Determinar o desempenho dos sistemas de recuperação da informação;

- Medir o crescimento de determinadas áreas e o surgimento de novos temas.

\section{AS LEIS DA BIBLIOMETRIA}

Dentro do estudo da bibliometria, três pesquisadores tiveram grande destaque por descobertas importantes. Foram eles Lotka, Zipf e Bradford, onde cada um desenvolveu uma lei específica.

A Lei de Lotka, formulada em 1926, foi construída a partir de um estudo sobre a produtividade de cientistas, a partir da contagem de autores presentes no Chemical Abstracts, entre 1909 e 1916. Lotka descobriu que uma larga proporção da literatura científica é produzida por um pequeno número de autores, e um grande número de pequenos produtores se iguala, em produção, ao reduzido número de grandes produtores (ARAÚJO, 2006).

A Lei de Zipf, também conhecida como Lei do Mínimo Esforço, consiste em medir a frequência do aparecimento das palavras em 
vários textos, gerando uma lista ordenada de termos de uma determinada disciplina ou assunto (Vanti, 2002).

A lei de Bradford é também conhecida como de lei da dispersão e "permite, mediante a medição da produtividade das revistas, estabelecer o núcleo e as áreas de dispersão sobre um determinado assunto em um mesmo conjunto de revistas" (Vanti, 2002). Esta lei tem por objetivo, segundo Araújo (2006), descobrir a extensão na qual artigos de um assunto científico específico aparecem em periódicos destinados a outros assuntos, estudando a distribuição dos artigos em termos de variáveis de proximidade ou de afastamento.

\section{METODOLOGIA E RESULTADOS}

As plataformas escolhidas para a realização desta pesquisa bibiliométrica foram Web of Science e SCOPUS, por serem consideradas as mais importantes atualmente.

\subsection{SCOPUS}

Criada em 2004 pela Editora Elsevier, a base SCOPUS é uma plataforma de dados multidisciplinar, atualmente o maior banco de dados de artigos, resumos e citações da literatura científica revisada por pares no mundo, contendo mais de 21.500 títulos de mais de 5.000 editoras internacionais, cobrindo os diversos campos do conhecimento científico, tais como química, biologia, medicina, engenharia, matemática, ciências sociais, dentre outros (SCOPUS, 2016).

Utilizou-se as palavras chaves com os termos em inglês "decommissioning" e "multi-criteria" em busca de trabalhos que associem o Descomissionamento à Análise Multicritério. Não foi realizada pesquisa com termos em espanhol, tampouco em português, dado a baixa relevância das publicações nestas línguas. A pesquisa foi realizada no dia 10/09/2017, selecionando "Article Title, Abstract, Keywords" no campo Search Field Type.

Foram obtidos apenas 20 trabalhos no horizonte temporal de 2005 a 2017, o que denota a baixa produção científica associando de métodos de análise multicritério no universo do descomissionamento.

Figura 1 - Publicações por ano entre os anos 2005 e 2017.

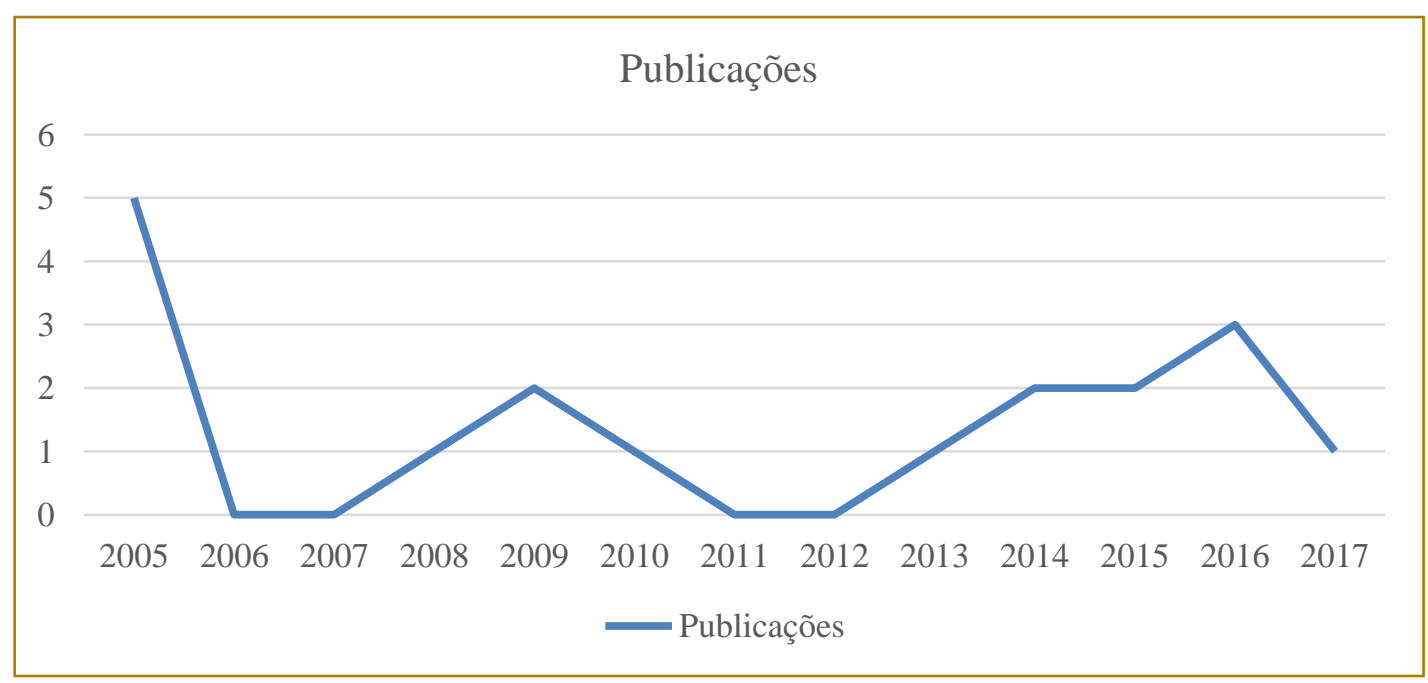

Fonte: Elaborado pelo autor.

\subsection{PUBLICAÇÕES POR TIPO}

A pesquisa na base SCOPUS revelou que a maioria das publicações, um percentual de
$45 \%$, se referem a artigos de periódicos. 0 restante das ocorrências se dividem em artigos publicados em conferências, 33\%, e revisões com $22 \%$. 
Figura 2 - Tipos de publicações.

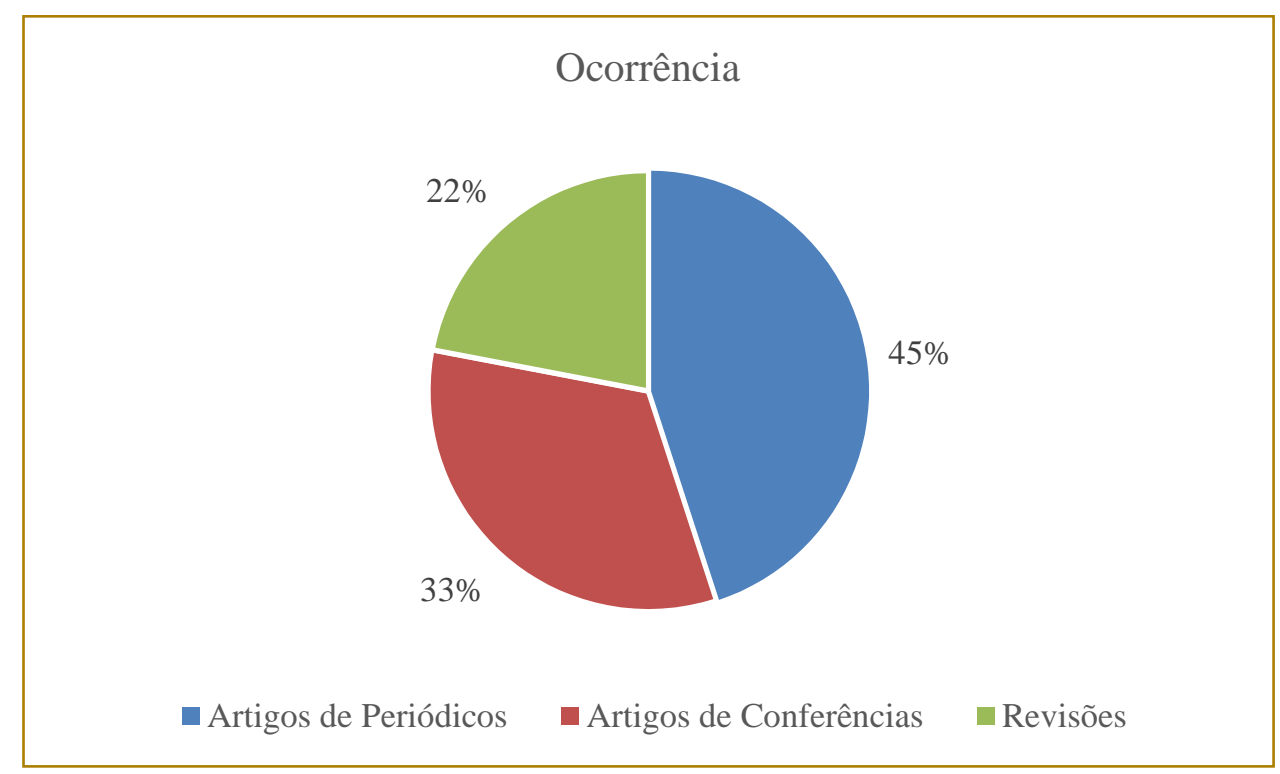

Fonte: Elaborado pelo autor.

\subsection{PUBLICAÇÕES EM DESTAQUE}

Dentre os poucos trabalhos encontrados que relacionam descomissionamento com análise multicritério, o trabalho elaborado por Fowler et al (2014), "A multi-criteria decision approach to decommissioning of offshore oil and gas infrastructure" é o mais citado, com 22 citações. O trabalho foi publicado no periódico Ocean \& Costal Management, que é um jornal publicado mensalmente pela editora holandesa Elsevier, que tem como principais temas o desenvolvimento sustentável e a conservação do oceano, bem como dos recursos costeiros. 0 artigo de Fowler será discutido neste trabalho para que se avalie suas contribuições.

Outro artigo eleito para discussão neste trabalho foi o elaborado por $\mathrm{Na}$ et al (2017), "An expert knowledge based decommissioning alternative selection system for fixed oil and gas assets in the South China Sea", escolhido por ser a publicação mais recente da base, 2017, e por se enquadrar no que se considera um exemplo claro do uso de uma ferramenta de análise multi-critério, no caso AHP (Analytic Hierarchy Process), para a tomada de decisão quanto a descomissionamento de um ativo de produção de óleo e gás offshore. 0 artigo foi publicado no periódico Ocean Engineering, que também pertence a editora Elsevier.

\subsubsection{DISCUSSÃO SOBRE O ARTIGO MAIS RELEVANTE: "A MULTI-CRITERIA DECISION APPROACH TO DECOMMISSIONING OF OFFSHORE OIL AND GAS} INFRASTRUCTURE"

0 trabalho trata-se de uma contextualização sobre 0 descomissionamento mundial, nivelado sobre suas nuances, complexidades e desafios nos próximos anos, bem como sugere a abordagem da análise multicritério para suportar as decisões neste âmbito. Fowler et al (2014) colocam que nos próximos 10 anos, caso de 2014 a 2024, milhares de estruturas offshore irão ficar obsoletas e irão demandar seu descomissionamento. Os autores pontuam também a regulação classificada como ultrapassada de algumas nações que demandam o recolhimento integral das estruturas, ainda que não seja provável que essa opção não traga resultados ótimos, seja no critério ambiental, econômico ou social. É proposta uma abordagem flexível que permita a escolha da solução do descomissionamento com base em uma gama de opções, analisando caso a caso, onde a análise multicritério compare as alternativas e promova uma opção.

No desenvolvimento do trabalho, os autores mostram com clareza as opções de destinação das estruturas offshore, bem como descrevem os critérios e subcritérios envolvidos na decisão de descomissionamento. 
A metodologia Multi-criteria Approval (MA) é escolhida por conseguir envolver critérios qualitativos e quantitativos no mesmo modelo. Com ela é feito um estudo de caso com uma plataforma localizada na costa da Califórnia, Estados Unidos. Especialistas foram utilizados para fazer um ranking dos critérios com base em sua importância e outro ranking com as opções de descomissionamento. O critério apontado como o mais importante para a decisão foi a "produção de biomassa explorável", e o critério "deixar a plataforma intacta na locação" foi identificado como a opção de descomissionamento mais apropriada.

\subsubsection{DISCUSSÃO SOBRE O ARTIGO “AN EXPERT KNOWLEDGE BASED DECOMMISSIONING ALTERNATIVE SELECTION SYSTEM FOR FIXED OIL AND GAS ASSETS IN THE SOUTH CHINA SEA"}

0 trabalho inicia com um nivelamento sobre a atividade de descomissionamento, abordando os riscos que a envolvem e a necessidade de um planejamento prévio e adequado para a realização das operações. É apontada a necessidade de reunir informações acerca de inúmeros aspectos para se tomar a decisão de como será o projeto de descomissionamento de sistemas de produção offshore.

É feita uma revisão sobre os métodos de análise multicritério, fazendo uma comparativo entre os mais estudados atualmente. 0 método BPEO (Best Praticable Enviromental Option) é o indicado na união europeia como o modelo que leva em consideração a estratégia de descomissionamento baseada em aspectos ambientais. Entretanto, os autores elegem o método AHP para construir um modelo e decidir sobre a estratégia de descomissionamento de um ativo de produção no Mar da China Meridional, por considerar esse método superior devido sua capacidade de comparação interna dos subcritérios via matriz paritária.

Após entrevistas com especialistas sobre os critérios e subcritérios, criaram um modelo em AHP, utilizado para decidir entre as três opções de descomissionamento: Reforma e Reuso, Disposição em Terra e Recife Artificial. A opção definida pelo modelo foi a de Recife Artificial, sendo ligeiramente mais atraente do que a Disposição em Terra. Um ponto de atenção que deve ser levado em conta é que o fator econômico não foi considerado, visto que os critérios eram baseados no aspecto operacional do projeto.

\subsection{WEB OF SCIENCE}

Após encontrar uma quantidade relativamente pequena de trabalhos na base Scopus (apenas 20 trabalhos), realizou-se uma busca com os mesmos termos ("decommissioning" e "multi-criteria") na base Web of Science, outra relevante plataforma de publicações acadêmicas, e não foi encontrado nenhum artigo relacionado.

\section{CONCLUSÃO}

Apesar da reconhecida importância acadêmica e empresarial do uso da análise multicritério para tomada de decisão em processos de descomissionamento de estruturas de óleo e gás offshore (NA et al, 2017), percebe-se que ainda há muito o que ser explorado, dado ao baixo número de publicações que envolvem os temas combinados. Os poucos artigos encontrados na pesquisa apresentam exemplos contundentes das justificativas científicas sobre opções de descomissionamento diferentes da remoção total, avaliando e ponderando os critérios que as englobam (NA et al, 2017; FOWLER et al, 2014; BERSTEIN, 2015).

Conforme apontam $\mathrm{Na}$ et al, 2017, o complexo ambiente de descomissionamento requer um planejamento aprimorado junto com as técnicas analíticas avançadas, que fariam uso significativo das informações complexas envolvidas. Além disso, os custos de desmantelamento são altamente difíceis de estimar e elevados. Para esse ambiente multicritérios, o processo intuitivo direto pode não ser aplicável.

Em seu estudo, Fowler et al, 2014, conclui que a mudança para uma abordagem flexível e holística descomissionamento será limitada pelo ambiente regulatório. A maioria das nações atualmente oferece poucas alternativas além da completa a remoção. À medida que as nações ampliam a gama de opções aceitáveis de descomissionamento, abordagens de decisão apoiadas pela análise multicritério serão essenciais para otimizar esses complexos problemas ambientais.

É necessário investimento em pesquisa para que o tema seja cada vez mais debatido e mais soluções de descomissionamento sejam 
avaliadas, principalmente em países como o Brasil, onde a regulamentação atual indica a remoção total do sistema de produção,

\section{REFERÊNCIAS}

[1]. ARAÚJO, Carlos Alberto. Bibliometria: evolução história e questões atuais. Porto Alegre, Em Questão, 2006.

[2]. BERNSTEIN, B. B. Decision framework for platform decommissioning in California. Integrated Environmental Assessment and Management, Volume 11, Número 4, 2015.

[3]. FOWLER, A. M., MACREADIE, P. I., JONES, D. O. B. e BOOTH, D. J. A multi-criteria decision approach to decommissioning of offshore oil and gas infrastructure. Ocean and Coastal Management, 2014.

[4]. LEV, V., MURPHY, D. Analysis of Multicriteria Decision-Making Methodologies for the Petroleum Industry. International Petroleum Technology Conference, Dubai, 2007.

[5]. MCCANN, B., HENRION, M., e BERNSTEIN, B. A decision support model for platform decommissioning: Successful applications in California and implications for worldwide use, SPE International Conference and Exhibition on Health, Safety, Security, Environment, and Social Responsibility, Stavanger, Norway, 2016.

[6]. MIMMI, F., RALSTON, S., SILVA, M. M., e SILVA, P. M. Baseline for Planning and Cost Estimation of Brazilian Decommissioning, Offshore Technology Conference, Houston, 2017. solução esta que nem sempre é reconhecida na literatura como solução ótima, quando posta em um espectro multicritério.

[7]. NA, K. L.; LEE, H. E.; LIEW, M. S. e ZAWAWI, N. A. An expert knowledge based decommissioning alternative selection system for fixed oil and gas assets in the South China Sea. Ocean Engineering, $n^{\circ}$ 130, 2017.

[8]. PAO, M. L. Concepts of information retrieval. Englewood, Colorado: Libraries Unlimited Inc, 1989.

[9]. PRADO, Diogo D. Desmobilização de dutos em sistemas marítimos de produção de petróleo - uma proposta de método de suporte ao planejamento. Dissertação (mestrado em planejamento energético) - UFRJ/COPPE, Rio de Janeiro, 2015.

[10]. RUIVO, F. M. Descomissionamento de Sistemas de Produção Offshore. Dissertação (mestrado em Ciências e Engenharia de Petróleo) Universidade Estadual de Campinas, Campinas, 2001.

[11]. SCOPUS, S. Content coverage guide. Amsterdam, Netherlands: Elsevier BV, 2016.

[12]. VANTI, Nadia Aurora. Da bibliometria à webometria: uma exploração conceitual dos mecanismos utilizados para medir o registro da informação e a difusão do conhecimento. Brasília, Ciência da Informação, 2002. 


\section{Gapítulo 18}

\section{ESTUDO COMPARATIVO DAS CARACTERISTICAS FISICO-QUIMICAS DOS BIODIESEIS OBTIDOS A PARTIR DE ÓLEO RESIDUAL DE FRITURA E DO ÓLEO DO COCO}

\section{Gisela Kloc Lopes \\ Flávia Targa Martins \\ Maycon Tavares Morete}

Resumo: O fim da era da energia renovável, após a revolução industrial, foi marcado pelo uso do carvão mineral, originando a era dos combustíveis fósseis. No entanto, estudos de prospecção realizados no final do século XX revelaram que as principais reservas de petróleo do planeta deverão se esgotar em cerca de 100 anos. Devido a essa problemática, vários combustíveis vêm ganhando destaque ao longo dos anos, pois é necessário encontrar uma alternativa ao uso excessivo dos combustíveis fósseis. Diante disso, destaca-se o biodiesel, um biocombustível oriundo de fonte renovável, como óleos vegetais e gorduras animais. O Brasil é um dos maiores produtores de biodiesel do mundo, isso ocorre devido a abundância de matéria prima, grande extensão territorial e condições climáticas favoráveis. Dessa forma, a substituição dos combustíveis fósseis tem sido motivada por fatores ambientais, econômicos e sociais. A decomposição do óleo residual, emite metano na atmosfera, esse gás de efeito estufa contribui para o superaquecimento terrestre. Por outro lado, no Brasil, são produzidos anualmente 1.116.969.000 frutos estimando-se que $80 \%$ da produção brasileira de coco se destinam à indústria, tendo como subproduto a casca. Enquanto que o conteúdo de óleo na polpa é superior a $60 \%$. Assim sendo, o presente projeto teve como principal objetivo a obtenção e a caracterização de biodieseis produzidos a partir de duas fontes diferenciadas, óleo residual de fritura e do óleo de coco. Inicialmente foi realizado a coleta e caracterização das propriedades físico-químicas dos óleos de fritura e do coco. Obtenção do biodiesel a partir da reação de transesterificação. Os produtos finais obtidos foram avaliados quanto as características físico-químicas e rendimento. 


\section{CONSIDERAÇÕES INICIAIS}

\subsection{INTRODUÇÃO}

0 índice populacional mundial aumentou consideravelmente após a revolução industrial devido ao advento de novas tecnologias, avanços na infraestrutura e no saneamento básico. Porém, a partir dessa transformação, a degradação ambiental começou a aumentar em uma escala extremamente alta e preocupante. A população mundial cresceu de 2,5 bilhões em 1950 para 6,2 bilhões no ano 2000 e, atualmente, a taxa de crescimento se aproxima a $1,13 \%$ ao ano (BRAGA, 2005). Com toda essa alteração no cenário mundial, o meio ambiente passa a sofrer uma pressão para a extração dos serviços ecossistêmicos de forma a satisfazer a humanidade. O fim da era da energia renovável, após a revolução industrial, foi marcado pelo uso do carvão mineral, originando a era dos combustíveis fósseis. Com o declínio das reservas mundiais, o petróleo consagrou-se como a principal fonte energética mundial. A substituição dos combustíveis fósseis tem sido motivada por fatores ambientais, econômicos e sociais, uma vez que toda a sociedade depende de seu uso (OLIVEIRA, SUAREZ e DOS SANTOS, 2008). O uso de combustíveis fósseis tem aumentando consideravelmente nas últimas décadas. No entanto, estudos de prospecção realizados no final do século XX revelaram que as principais reservas de petróleo do planeta deverão se esgotar em cerca de 100 anos. Embora estas reservas sejam realmente finitas, novas jazidas vêm sendo descobertas a cada dia, causando certa incerteza sobre a sua verdadeira extensão e sua real viabilidade como fonte de energia para a sociedade moderna (RAMOS et al., 2011). Devido a essa problemática, vários combustíveis vêm ganhando destaque ao longo dos anos, pois é necessário encontrar uma alternativa ao uso excessivo dos combustíveis fósseis. Diante disso, destacase o biodiesel, um biocombustível oriundo de fonte renovável. O Brasil é um dos maiores produtores de biodiesel do mundo, isso ocorre devido a abundância de matéria prima, grande extensão territorial e condições climáticas favoráveis. Um dos principais atributos do biodiesel é a sua capacidade de reduzir a emissão de poluentes atmosféricos em comparação com o óleo diesel, contribuindo para a redução do efeito estufa com melhorias na qualidade de vida e da saúde pública (MEC, 2006).
Como externalidades ambientais positivas salienta-se a significativa redução de emissões, tanto dos gases do efeito estufa quanto de outras substâncias nocivas à saúde humana. Estima-se que, no primeiro caso, haja uma diminuição das emissões da ordem de $70 \%$ quando considerado o ciclo de vida do biodiesel puro, enquanto que no segundo percebesse sensível melhoria na qualidade do ar das grandes cidades em virtude da redução de envios de materiais particulados, hidrocarbonetos e monóxido de carbono à atmosfera (MAPA, 2013). 0 Ministério de Minas e Energia (MME) define Biodiesel como: 0 biodiesel é um combustível biodegradável derivado de fontes renováveis como óleos vegetais e gorduras animais. Estimulados por um catalisador, eles reagem quimicamente com álcool. Existem diferentes espécies de oleaginosas no Brasil que podem ser usadas para produzir o biodiesel. Entre elas estão a mamona, dendê, canola, girassol, amendoim, soja e algodão. Matériasprimas de origem animal, como o sebo bovino e gordura suína, também podem ser utilizadas na fabricação do biodiesel.

Os óleos e gorduras são substâncias de origem vegetal, animal ou microbiana, insolúveis em água e solúveis em solventes orgânicos. A decomposição do óleo, assim como de todo material orgânico, emite metano na atmosfera, esse gás de efeito estufa contribui para o superaquecimento terrestre. Portanto, quanto mais o cidadão evitar o descarte do óleo no lixo comum, mais estará contribuindo para a preservação da atmosfera do planeta onde vive (FREITAS, BARATA e NETO, 2010). É interessante acrescentar, o óleo de cozinha usado em frituras é altamente prejudicial ao meio ambiente e quando jogado na pia (rede de esgoto) causa entupimentos, havendo a necessidade do uso de produtos químicos tóxicos para a solução do problema. Jogar o óleo na pia, em terrenos baldios ou no lixo acarreta fins desastrosos a esse óleo (KLINGELFUS, 2011). Permanece retido no encanamento, causando entupimento das tubulações se não for separado por uma estação de tratamento e saneamento básico; se não houver um sistema de tratamento de esgoto, acaba se espalhando na superfície dos rios e das represas, causando danos à fauna aquática e quando retido no solo, impermeabiliza o solo e contribui com enchentes, ou entra em decomposição, liberando gás metano durante esse processo, causando mau cheiro, além de agravar o 
efeito estufa. Segundo Berkenbrock (2009), hoje, ao jogarmos apenas um litro de óleo residual na pia ou no esgoto, contaminamos até um milhão de litros de água. Este volume equivale ao consumo de água que um ser Humano precisa para quatorze anos de sua vida. Além disso, ao descartar o óleo de cozinha na pia de casa, a tubulação é entupida, porque a substância ao esfriar se une a outros contaminantes com um aumento de viscosidade. Além disso, se a quantidade descartada for muito alta, o óleo pode entupir a rede pública de esgoto. Então, jogar esse resíduo na pia da cozinha, é um crime ambiental.

O óleo ou azeite de coco é um óleo vegetal conhecido também como manteiga de coco é uma substância graxa que contém cerca de
90\% de ácidos saturados extraídos mediante prensagem da polpa ou cerne dos cocos (SANTOS et al., 2013). O coqueiro (Cocus nucifera L.) é de origem asiática e foi introduzido no Brasil por volta de 1553. É uma planta de grande importância social nos trópicos, por fornecer óleo, gorduras, minerais e vitaminas essenciais e fruto fresco (Figura 1). A casca do coco é usada na fabricação de cordas, tapetes, chapéus e encosto de veículos. O coco é a maior fonte mundial de ácido láurico, um ácido orgânico com aplicações diretas na indústria alimentícia, de cosméticos e na extração de álcool. 0 conteúdo de óleo na polpa é superior a $60 \%$ e pode ser extraído mediante prensagem fria ou quente ou com utilização de solvente, sendo extremamente versátil (SCHECHT, AMARAL e THIENGO, 2013).

Figura 1: Cocos Nucifera L

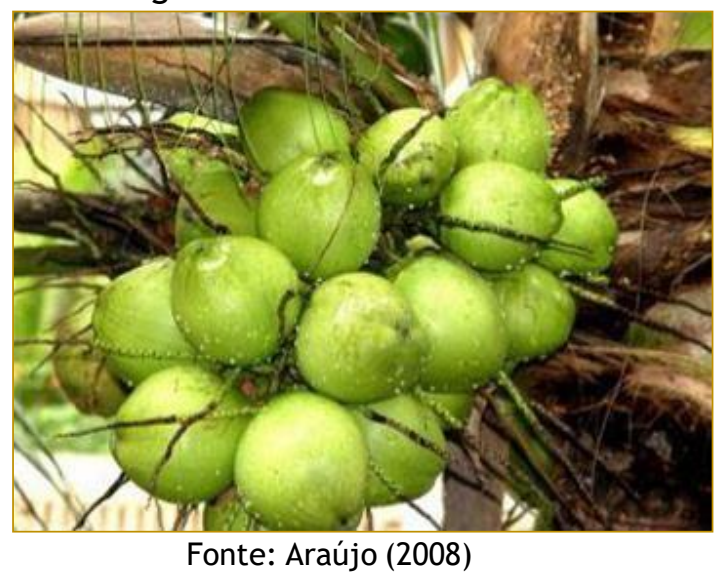

No Brasil, são produzidos anualmente 1.116.969.000 frutos com peso médio de casca de $0,9 \mathrm{~kg}$ (coqueiro-gigante) e rendimento médio de aproximadamente 30\% de fibra e $70 \%$ de pó no processo industrial. Estimando-se que $80 \%$ da produção brasileira de coco se destinam à indústria, tendo como subproduto a casca (EMBRAPA).

A inclusão da cultura do coqueiro entre as oleaginosas com potencial para produção de biodiesel no Brasil constitui-se numa alternativa a ser analisada pelos órgãos de desenvolvimento, reforçando assim a necessidade de implementação de um programa de revitalização da cultura, sob pena de não ser atendido o significativo aumento da demanda de matéria prima (ARAÚJO, 2008).

O biocombustível substitui total ou parcialmente o diesel de petróleo, em motores de caminhões, tratores, caminhonetes, automóveis e também motores de máquinas que geram energia. A produção e o uso do biodiesel no Brasil propiciam o desenvolvimento de uma fonte energética sustentável sob os aspectos ambiental, econômico e social e também traz a perspectiva da redução das importações de óleo diesel. Além da diminuição da dependência do diesel importado, o biodiesel traz outros efeitos indiretos de sua produção e uso, como o incremento às economias locais e regionais, tanto na etapa agrícola como na indústria de bens e serviços (ANP, 2016).

\subsection{FORMULAÇÃO DA SITUAÇÃO PROBLEMA}

Os combustíveis fósseis são utilizados pela sociedade como fonte de energia renovável. Porém, sabe-se que o mesmo tem seu uso finito e sua utilização é altamente impactante. 
Uma alternativa a esse problema ambiental é a reutilização do óleo para a obtenção de biodiesel. 0 presente estudo considera que na região local há uma grande produção de coco, o que possibilita a extração de óleo de coco. No entanto, também existe a formação de grande quantidade de óleo residual nas residências. Dessa forma, a proposta desse estudo foi a obtenção e a avaliação das características físico-químicas dos biodieseis obtidos a partir de óleo residual de fritura e do óleo de coco.

\subsection{OBJETIVO GERAL}

Obter biodieseis produzidos a partir do óleo residual de fritura e do óleo de coco, por meio de reação química de transesterificação. A partir do produto obtido realizar um estudo comparativo das características físicoquímicas dos biodieseis.

\section{METODOLOGIA}

\subsection{COLETA DOS ÓLEOS}

O óleo residual foi coletado a partir de doações de alunos, professores e funcionários da Universidade Veiga de Almeida, campus Cabo Frio. O óleo de coco comercial foi proveniente da empresa Vila Alimentos.

\subsection{CARACTERIZAÇÃO DAS MATÉRIAS- PRIMAS}

A densidade foi determinada com o uso de picnômetro de $10 \mathrm{~m}^{3}$ previamente calibrado com água destilada a $25^{\circ} \mathrm{C}$. Sendo realizadas três repetições para o cálculo da densidade real (ARAÚJO, 2008). $0 \mathrm{pH}$ foi utilizado o pHmetro de Marca MS Tecnopon e modelo mPA210. A viscosidade foi determinada em equipamento Rotary Viscometer, Série VR 3000 , na rotação $200 \mathrm{rpm}$, com o uso do fuso R2.

\subsection{OBTENÇÃO DOS BIODISEIS}

Para a produção do biodiesel foi utilizada a proporção de um litro de óleo devidamente filtrado (óleo residual de frituras), $220 \mathrm{ml}$ de metanol ou etanol e $5 \mathrm{~g}$ de soda cáustica. Aqueceu o óleo a $55^{\circ} \mathrm{C}$. Misturou a soda com o metanol/etanol, para obter um metóxico e agitou-se por 20 minutos. Ao fim de 30 minutos de descanso, a glicerina decantou (FREITAS, BARATA E NETO, 2010). Para a purificação do biodiesel seguiu a seguinte metodologia. Primeiramente, foi adicionado $220 \mathrm{ml}$ de água morna, sob agitação. Repetir quantas vezes for necessário, aumentando a intensidade do agitar até que a água fique transparente. Para remover resíduos de água e álcool que podem comprometer a qualidade do biodiesel, o biodiesel foi levado para uma estufa á $103^{\circ} \mathrm{C}$ por 2 horas (FERNANDES, 2011). Os produtos obtidos foram nomeados com base no seu óleo de origem, o óleo residual de fritura e o óleo de coco, o ORF e OC, respectivamente.

\subsection{CARACTERIZAÇÃO DOS BIODIESEIS}

A caracterização do Biodiesel foi avaliada quanto a cor, aspecto físico, combustão, pH, viscosidade, teor de umidade e voláteis e viscosidade. 0 teor de umidade foi determinado por meio da Equação 1.

Umidade e matéria volátil = perda de peso $\mathrm{x}$ 100/peso da amostra (Equação 1)

0 rendimento do biodiesel foi calculado como sendo a massa de biodiesel pesada depois da reação em função da massa de óleo empregada na transesterificação, como mostra a Equação 2 (OLIVEIRA et al., 2012).

Rendimento $(\%)=$ Massa biodiesel $\times 100 /$ Massa óleo empregada (Equação 2)

\section{RESULTADOS}

\subsection{CARACTERIZAÇÃO FÍSICO - QUÍMICA DOS ÓLEOS}

Após a purificação do óleo (óleo residual de fritura), a caracterização físico-química dos óleos foi determinada por meio de medidas de viscosidade, $\mathrm{pH}$ e a densidade. A Tabela 1 mostra os resultados obtidos. 
Tabela 1: Características físico-químicas dos óleos

\begin{tabular}{|c|c|c|}
\hline Análise & Óleo de fritura residual & Óleo de coco \\
\hline Viscosidade (mPa.s) & 131 & 120 \\
\hline pH & 7,34 & 5,00 \\
\hline Densidade & 0,91 & 0,90 \\
\hline
\end{tabular}

\subsection{PRODUÇÃO DO BIODIESEL}

0 biodiesel pode ser obtido por meio de reação química denominada de transesterificação. Em modos gerais, a reação ocorre entre o óleo ou gordura com álcool de cadeia curta e em presença de catalisador, produzindo um novo éster e subprodutos
(FERNANDES, 2011). A Figura 2 mostra a reação para obter o biodiesel e subproduto, o glicerol, também conhecido como glicerina. A Figura 3 mostra o produto da reação obtido, o biodiesel e o resíduo da reação, a glicerina.

Figura 2: Reação de Transesterificação

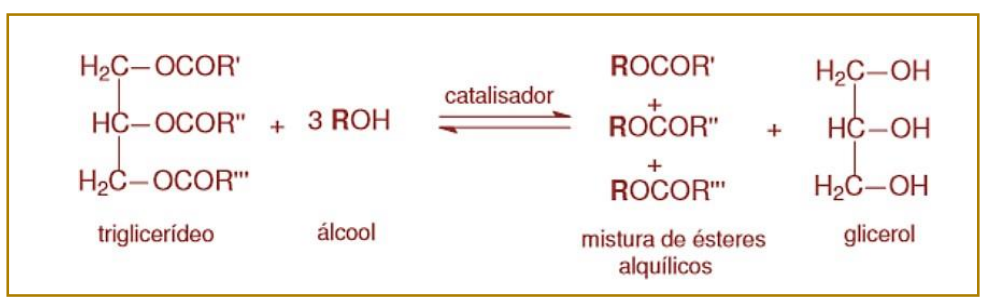

(Garcia, 2006)

Figura 3: Separação do biodiesel e a glicerina, provenientes das reações com óleo de coco (A) e óleo residual de fritura (B)

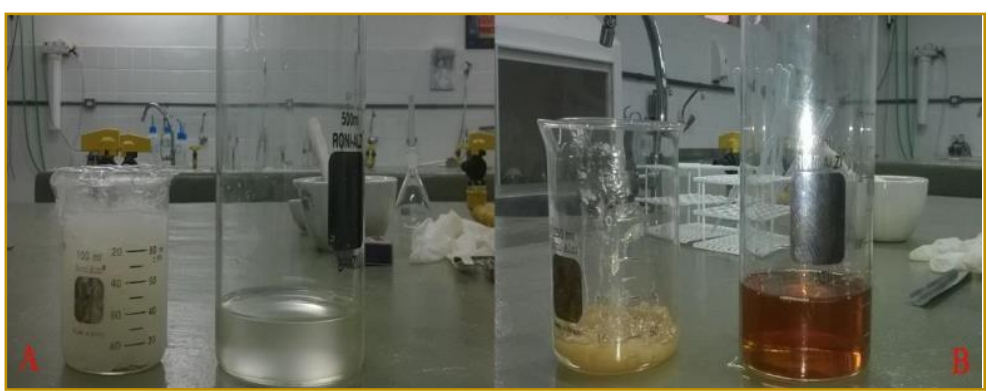

\subsection{TESTE DE COMBUSTÃO}

A análise tem por finalidade testar a possível capacidade de queima dos biodieseis produzidos. Sendo esse o grande resultado esperado ao final do processo de obtenção do biocombustível. A Tabela 2 mostra o tempo gasto de combustão para cada tipo de material.

Tabela 2: Tempo de combustão

\begin{tabular}{|l|c|}
\hline \multicolumn{1}{|c|}{ Material } & Tempo de combustão \\
\hline Gaze sem biodiesel & $55: 00 \mathrm{~s}$ \\
\hline Gaze com óleo de coco & $6: 25 \mathrm{~s}$ \\
\hline Gaze com óleo residual & $8: 36 \mathrm{~s}$ \\
\hline Biodiesel ORF & $18: 38 \mathrm{~s}$ \\
\hline Biodiesel OC & $20: 14 \mathrm{~s}$ \\
\hline \multicolumn{2}{|c|}{ Biodiesel ORF - Biodiesel do óleo residual de fritura, biodiesel OC - Biodiesel do óleo de coco }
\end{tabular}


Os materiais com biodieseis continuaram a queimar por mais tempo, quando comparado aos demais materiais (Figura 4). Esse resultado mostra que os biocombustíveis possuem uma boa performance, no que se refere à combustão. O menor tempo de combustão no biodiesel proveniente do óleo de fritura pode ser justificado pela a umidade mais elevada nesse produto final.

Figura 4: Teste de combustão para o óleo de coco $(A)$, o biodiesel de óleo de coco (B), o óleo residual de fritura (C) e o biodiesel do óleo de fritura (D)

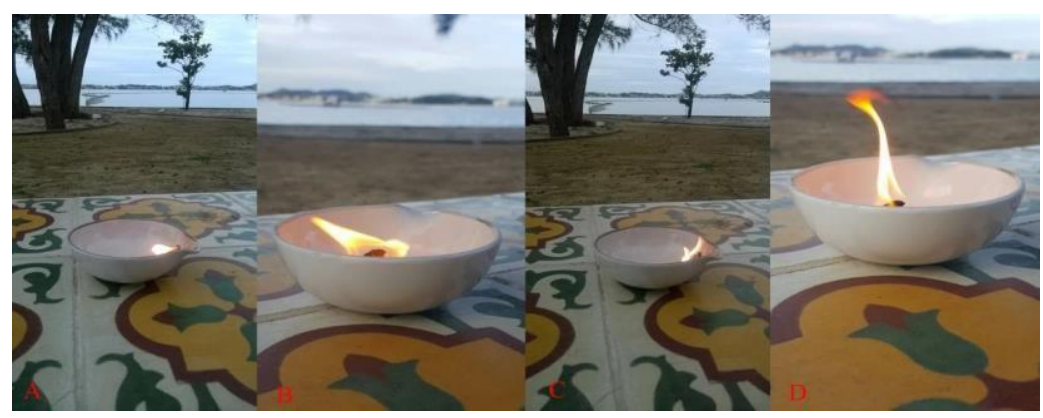

\subsection{CARACTERIZAÇÃO FÍSICO - QUÍMICA DOS BIODIESEIS}

Os biodieseis foram avaliados quanto a características físico-química. A Figura 5 mostra a avaliação quanto a cor e aspecto. Os produtos de biodieseis obtidos mostramse homogêneos, não apresentaram contaminantes e possuíram aspecto límpido e isento de impurezas. A Tabela 3 mostra os resultados finais das características físicoquímicas dos biocombustíveis produzidos. A diferença entre os produtos foi somente na coloração, que decorrente, a matéria-prima de partida, óleo residual e óleo de coco, apresentam coloração de castanho claro a incolor, respectivamente. A densidade dos biodieseis ficou dentro do esperado na literatura (Lôbo; Ferreira, 2009). Na análise de $\mathrm{pH}$, o resultado apresentou acima do valor esperado e carácter levemente básico. Esse resultado mostra a presença de $\mathrm{NaOH}$ livre no meio. Duas alternativas de processo poderiam ser propostas, o aumento do tempo reacional e a execução de maior número de lavagens do produto final, até ser atingido a um produto final com caráter neutro. Valores afastados da neutralidade tornam o produto final com características corrosivas ao ambiente de trabalho.

Figura 5: Produtos finais obtidos, biodiesel de óleo residual $(A)$ e do óleo de coco (B)

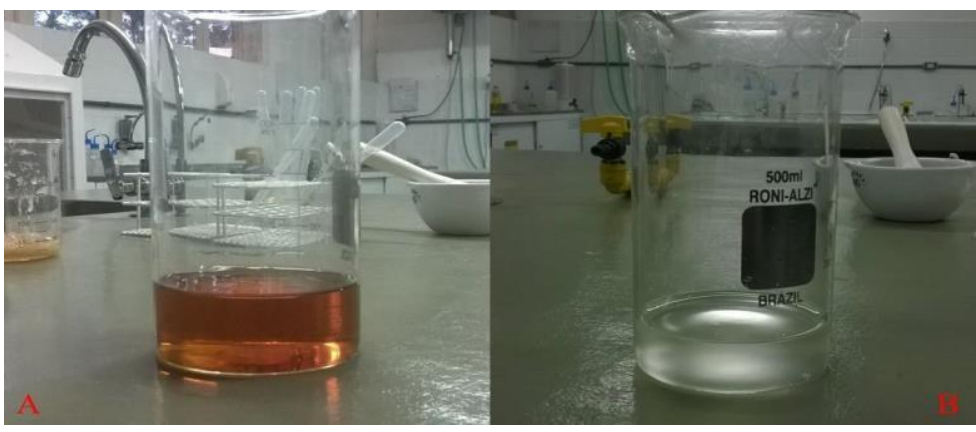

0 valor encontrado para a viscosidade resultou em valores iguais, mostrando que os produtos apesar de serem de fontes diferenciadas possuem o mesmo escoamento. A umidade e matéria volátil dos biodieseis ficaram com valores muito diferenciados. Esses resultados mostram que o óleo de soja retém maior umidade. No entanto, a reprodutibilidade da reação seria necessária para verificar a veracidade dessa 
característica. 0 rendimento do biodiesel obtido a partir do óleo residual de fritura foi de $77,8 \%$ e o biodiesel produzido com óleo de coco apresentou 70\%. Esses resultados mostraram-se satisfatórios, quando comparados aos da literatura. Uma vez que a obtenção dos produtos foi realizada em um sistema operacional aberto, sem recursos para controle operacionais e reprodutíveis.

\subsection{AVALIAÇÃO DOS RENDIMENTOS}

O biodiesel produzido a partir do óleo residual de fritura apresentou rendimento superior ao biodiesel de óleo de coco, o mesmo resultou em um rendimento de $77,8 \%$. O biodiesel produzido com o óleo de coco teve rendimento de $70 \%$ (Tabela 3). Dessa forma, os resultados mostraram que 0 biodiesel obtido proveniente de óleo de fritura, ou seja, de soja, oferece maior rendimento.

Tabela 4: Características Físico-químicas dos biodieseis

\begin{tabular}{|c|c|c|c|}
\hline Análise & Biodisel ORF & Biodiesel OC & Literatura \\
\hline Cor & Sem contaminantes & Sem contaminantes & Sem contaminantes \\
\hline Aspecto & $\begin{array}{l}\text { Límpido e isento de } \\
\text { impurezas }\end{array}$ & $\begin{array}{l}\text { Límpido e isento de } \\
\text { impurezas }\end{array}$ & $\begin{array}{l}\text { Límpido e isento de } \\
\text { impurezas }\end{array}$ \\
\hline Densidade $(\mathrm{g} / \mathrm{cm} 3)$ & 0,9 & 0,9 & $0,85-0,9$ \\
\hline $\mathrm{pH}$ & 8,2 & 8,3 & Neutro \\
\hline Viscosidade $\mathrm{mPa}$ & 61 & 61 & --- \\
\hline Material volátil (\%) & 4.7 & 2.9 & 0,05 (\% volume) \\
\hline Rendimento (\%) & 77,8 & 70,0 & 87- 95 \\
\hline
\end{tabular}

Biodiesel ORF - Biodiesel do óleo residual de fritura, Biodiesel OC - Biodiesel do óleo de coco

A Figura 6 mostra o subproduto da reação a glicerina, que foi obtida durante a obtenção dos biodieseis. Observa-se que quanto ao produto residual, a glicerina está em maior quantidade quando utilizado o óleo de coco como fonte de matéria-prima.

Figura 6: Glicerina produzida durante o processo, do biodiesel obtido a partir do óleo de coco (A), do óleo residual de fritura (B)

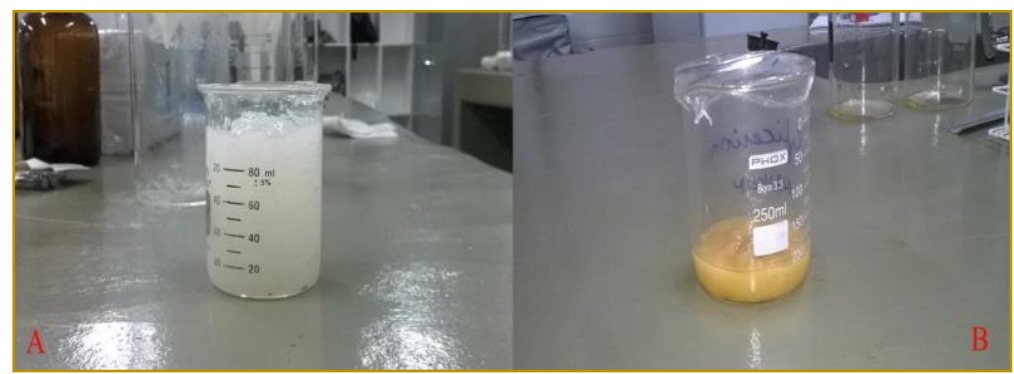

\section{CONCLUSÃO}

O processo de obtenção dos biodieseis foi realizado com materiais de baixo custo e processos simples, a partir do óleo de coco e do óleo residual de fritura, o biodiesel ORF e o biodiesel OC. Os produtos finais obtidos apresentaram aspectos semelhantes em relação a viscosidade, aspecto e performance em combustão. Quanto ao pH, umidade, material volátil resultados finais acima do esperado foram encontrados. 0 biodiesel de óleo residual apresentou rendimento superior ao mesmo produzido de óleo de coco. Porém, em outras propriedades obtidas como cor, aspecto e densidade ficaram dentro do esperado. Portanto, fica evidente a continuidade do presente estudo, no que se refere principalmente ao processo, de forma a se obter novas e fontes alternativas de biocombustíveis. Para que a sociedade possa começar a inserir o uso dos mesmos e diminuir a dependência dos combustíveis de origem fósseis. 


\section{BIBLIOGRAFIA}

[1] Anp. Agência Nacional do Petróleo, Gás Natural e Biocombustíveis, 2014. Disponível em:http: / /www.anp.gov.br/?pg=73292\&m=\&t1=\&t2 $=\& \mathrm{t} 3=\& \mathrm{t} 4=\& \mathrm{ar}=\& p s=\& 1469033141682$ Acesso em: 07 Setembro 2016

[2] Araújo, G. S. Produção de biodiesel a partir de óleo de coco (Cocos nucifera L.), 2008. Dissertação (Mestrado em Engenharia Química), Universidade Federal do Rio Grande do Norte, Natal Disponível em:<https://repositorio.ufrn.br/jspui/bitstream/1234 56789/15750/1/GiselleSA.pdf>. Acesso em: $22 / 09 / 2016$

[3] Braga, B. Introdução á Engenharia Ambiental - 0 Desafio do Desenvolvimento Sustentável. $2^{\circ}$. ed. São Paulo: Pearson Prentice Hall, 2005

[4] Berkenbrock, P. E. projeto óleo de cozinha. SENAC -SC, Itajaí, 2009. Disponível em: < http: //www.sc.senac.br/talento/projetospremiados/2 009/tec_3.pdf >. Acesso em:24/01/2017

[5] Embrapa. Programa Nacional de Produção e Uso de Biodiesel (PNPB). Disponivel em:<http://www.agencia.cnptia.embrapa.br/gestor/ agroenergia/arvore/CONT000fj8n3kmr02wyiv809gk z514c1vjh7.html>. Acesso em: 22 outubro 2016

[6] Fernandes, W. D. R. Produção DE Biodiesel A Partir de Óleo de Fritura, 2011. Trabalho de conclusão de curso. Disponível em:<http://repositorio.roca.utfpr.edu.br/jspui/bitstre am/1/294/1/PB_COQUI_2011_1_09.pdf>. Acesso em:16/11/2016

[7] Fernandes et al. Produção de biodiesel a partir de óleo de fritura: Uma alternativa energética e desenvolvimento sócio-ambiental, 2008. XXVIII Encontro Nacional de Engenharia de Produção Disponível

em:<http://www.abepro.org.br/biblioteca/enegep20 08_TN_STO_077_542_12014.pdf >. Acesso em:16/11/2016

[8] Freitas, C. F. D.; Barata, R. A. D. R.; Neto, L. D. S. M. Utilização do óleo de cozinha usado como fonte alternativa na produção de energia renovável, buscando reduzir os impactos ambientais. São Paulo - Brasil, 2010. Disponível em: <http://www.resol.com.br/textos/enegep2010_tn _stp_123_796_16087.pdf >. Acesso em:22/10/16

[9] Garcia, C. M. Transesterificação de óleos. 2006. Dissertação de Mestrado - Universidade Estadual de Campinas (Unicamp), Instituto de Química, 2006.Disponível em:< https://docente.ifrn.edu.br/edsonmesquita/pfrh/cata lise-acida-4 >. Acesso em: 20/09/2016

[10] Klingelfus, V. M. reaproveitamento do óleo de cozinha: possibilidades de projetos nas escolas do Campo. Universidade federal do Paraná,
Paranaguá - Paraná, 2011. Disponível em:< http: //acervodigital.ufpr.br/bitstream/handle/1884/3 8534/R\%20-\%20E\%20-

20VERA\%20MARIA\%20klingelfus.pdf?sequence $=1$ >. Acesso em:24/01/2017

[11] Lôbo, I. P.; Ferreira, S. L. C. Biodiesel: parâmetros de qualidade e métodos analíticos. Química Nova - Vol. 32, Salvador - BA, Brasil, 2009. Disponível <http://www.scielo.br/pdf/qn/v32n6/44.pdf> Acesso em : 24/09/2016

[12] Mapa. Benefícios Ambientais da Produção e do Uso do Biodiesel. Ministério da Agricultura, Pecuária e Abastecimento, Brasília, 2013. Disponível em:< http://www.agricultura.gov.br/arq_editor/relatorio_bi odiesel.pdf >. Acesso em:22/10/2016

[13] Mec - Ministério da Educação, 2006. Cartilha biodiesel. Disponível em: <http://portal.mec.gov.br/setec/arquivos/pdf/cartilh a_biodiesel.pdf>. Acesso em: 02 nov. 2016

[14] Mme. Ministério de Minas e Energia.

Perguntas e Respostas. Disponível em: <http://www.mme.gov.br/programas/biodiesel/men u/biodiesel/perguntas.html>. Acesso em: 26 Julho 2016

[15] Oliveira et al. Obtenção do Biodiesel Através da Transesterificação Do óleo de Moringa Oleífera Lam. Holos - volume 1, Mossoró - RN, 2012. Disponível http://www2.ifrn.edu.br/ojs/index.php/HOLOS/articl e/view/803/524. Acesso em 13/10/2016

[16] Oliveira, F. C. C.; Suarez, P. A. Z.; Santos, W. L. P. D. Biodiesel: Possibilidades e Desafios. Química Nova Escola, v. $\mathrm{N}^{\circ}$ 28, maio 2008.Disponível em:< http://qnesc.sbq.org.br/online/qnesc28/02-QS 1707.pdf >. Acesso em:22/10/2016

[17] Ramos et al. Tecnologias de Produção de Biodiesel. Rev. Virtual Química, Curitiba - PR, Brasil, v. 3, n. No. 5|, p. 385-405, Outubro 2011. Disponível em: $<$ http://sistemas.eel.usp.br/docentes/arquivos/12858 70/52/Tecnologiasdeproducaodebiodiesel.pdf >. Acesso em:24/09/2016

[18] Santos, F. V. F. D. identificação, análise e comparativo do status atual. Escola de Engenharia de Lorena Universidade de São Paulo, São Paulo, 2011. Disponível em: < http://sistemas.eel.usp.br/bibliotecas/monografias/2 011/MEQ11003.pdf >. Acesso em 22 de janeiro de 2017

[19] Schechter, A.; Amaral, I.; Thiengo, P. 2013. Trabalho de conclusão do Curso Técnico de Biotecnologia.Disponível em:<https://bteduc.com/orientacoes/2013_Apresen tacao_O_Coco_PF_Biotecnologia.pdf>.Acesso em: 22 de janeiro de 2017 


\section{Gapítulo 19}

\section{PREVISÃO DE DEMANDA NUM SIMULADOR DE GESTÃO DA PRODUÇÃO: AÇÕES ESTRATÉGICAS}

\section{Luan Bahia Araújo}

Sávio de Araújo Almeida

Taís Santos Barreto

Juliano Zaffalon Gerber

Luane Alcântara Nunes

Resumo: 0 presente trabalho tem por objetivo apresentar ações estratégicas com ênfase nas previsões de demanda associadas a uma técnica de correção das previsões quando há erros ou disparidades significativas em relação à demanda real. A técnica foi aplicada num jogo de empresas que simula a gestão da produção juntamente com métodos matemáticos para demonstrar a efetividade da mesma. Ao final são apresentadas as principais considerações no que tange à busca pela minimização dos erros nas previsões, bem como um caminho para evitar perdas e também a adoção de estratégias mais efetivas.

Palavras-chave: Previsão de Demanda. Simulação. GP-1. Correções. 


\section{INTRODUÇÃO}

Por intermédio da previsão de demanda é possível estimar o futuro cenário do mercado, disponibilizando assim os recursos necessários para tomadas de decisões estratégicas, bem como para suprir a demanda e não permitir que faltas ocorram nas vendas ou níveis de estoques se tornem inadequados.

Algumas técnicas de previsão de demanda permitem que a empresa elabore seu planejamento estratégico tendo como base informações sobre as vendas históricas. Nestes casos, a previsão deve estar relacionada a um conjunto de métodos e ao conhecimento do previsor sobre o mercado, ao invés da simples adivinhação (FERNANDES e GODINHO FILHO, 2010).

Para realizar uma previsão de demanda, pode-se utilizar uma série de métodos e técnicas, sejam eles quantitativos ou qualitativos (TUBINO, 2009). Os métodos qualitativos baseiam-se principalmente na intuição, na opinião e no conhecimento do previsor (SLACK et al., 2009), enquanto que os métodos quantitativos se apoiam fundamentalmente em modelos matemáticos e estatísticos. A regressão linear simples entra como umas das principais técnicas na classificação de métodos quantitativos, pois envolve uma equação linear que descreva o relacionamento entre duas variáveis (STEVENSON, 2001).

Embora existam diferentes métodos e técnicas disponíveis para se calcular a previsão de demanda e estes sejam utilizados de forma combinada em prol da assertividade dos resultados, sempre há casos em que ocorrem erros nas previsões. Esses erros podem ser ocasionados por diversos fatores, tais como o uso inadequado de métodos e técnicas de previsão, variações abruptas do mercado ou no ambiente, eventos aleatórios, entre diversos outros motivos. Logo, é comum ser necessário ajustar a previsão alinhando-a ao cenário atual de forma que se torne mais próxima da realidade, evitando perdas e levando a decisões estratégicas mais eficientes e competitivas para empresa. 0 método de ajuste da previsão de demanda é altamente recomendado por serem simples e fornecerem resultados com ausência de possíveis erros. (PELLEGRINI,2000).

$O$ uso de programas de simulação, também conhecidos por jogos de empresas, estimula o aprendizado através da vivência de situações que se assemelham às encontradas na vida real. Segundo Feinstein, Mann e Corsun (2002), a simulação é uma atividade de aprendizado experimental que permite a visualização de situações e também dos resultados da manipulação de variáveis em um ambiente dinâmico. Além disso, a simulação contribui para uma análise da realidade sem grandes dificuldades (ABDURAHIMAN et al.2000). Por fim, a prática da teoria, associada as decisões e ações tomadas, além dos erros cometidos ao longo das simulações, permitem uma reflexão mais profunda sobre os resultados encontrados ao final da simulação.

O simulador GP-1, por sua vez, trabalha a dinâmica de planejamento estratégico da produção por meio da elaboração de um plano de produção de longo prazo para uma fábrica virtual de móveis (SCHAFRANSKI e TUBINO, 2013).

Sendo assim, neste trabalho, o jogo de empresas GP-1 será utilizado como instrumento e cenário para a elaboração de previsões e uso de uma técnica de correção da previsão de demanda quando seu comportamento tende a um regime linear. Também serão apresentadas as principais teorias relacionadas aos temas plano de produção, previsão de demanda assim como os resultados obtidos.

\section{PLANO DE PRODUÇÃO, PREVISÃO DE DEMANDA E SUAS RELAÇÕES}

O plano de produção é um dos fatores cruciais para o sucesso das organizações, determinando quais serão os recursos necessários para o acompanhamento e desenvolvimento do processo produtivo (TUBINO, 2000 e 2009). Em mercados competitivos, é essencial que a empresa consiga dimensionar o que irá produzir ou quais serviços serão ofertados com excelência, para que desta forma possa atender a demanda de seu mercado consumidor.

O plano de produção tem a responsabilidade de garantir a eficiência do planejamento de manufatura, através da integração de estratégias. Com base nessa abordagem é possível dimensionar as quantidades que serão planejadas, baseadas nas expectativas de demandas presentes e futuras, analisar a capacidade produtiva e como a organização deve se planejar para obter os recursos 
necessários que permitam atingir os seus objetivos (RUSSOMANO, 2000).

Outra abordagem, diz que a principal funcionalidade do plano de produção, é permitir o balanceamento e coordenação dos suprimentos e das demandas dos produtos finais, analisando todos os períodos e proporcionando a programação detalhada da produção. As alternativas para auxiliar as tomadas de decisões são a utilização de estoques de produtos acabados, analise de pedidos para verificar se é possível atender a demanda, necessidade de uso de horas extras ou subcontratação. É importante sempre levar em consideração a verificação da quantidade de pedidos, se há material disponível e se há capacidade de produção (CORRÊA, GIANESI e CAON, 2001).

Pode-se observar nas abordagens acima, que o plano de produção está intimamente relacionado ao planejamento estratégico e ao dimensionamento da produção para que a demanda seja atendida, ou seja, torna-se necessário estimar, prever uma demanda futura. Como? Por intermédio dos métodos e técnicas de Previsões de Demanda.

Tubino (2000 e 2009) ratifica essa afirmativa; segundo o autor, a previsão de demanda é a base do planejamento estratégico de uma empresa, determinando o andamento da produção, das vendas e finanças. Ela permite que os administradores possam prever 0 futuro e planejar as suas ações, preparando as organizações para os seus desafios constantes.

A previsão contribui diretamente na tentativa de controle de eventos externos e internos, permitindo a programação da organização com base na análise econômica, no comportamento de clientes e concorrentes, e nas decisões internas. As duas principais técnicas utilizadas para a realização da previsão são métodos qualitativos e quantitativos. A previsão qualitativa será baseada análises de especialistas e opiniões de comportamento do mercado, já as técnicas de previsão quantitativa se baseiam em registros de dados, ou por meio de algum modelo matemático para obter a sua projeção (CORRÊA e CORRÊA, 2009).

Para auxiliar na previsão de demanda empregada no trabalho, foi utilizada a técnica de regressão linear de dados, maximizando o potencial estratégico da análise e em correções de erros. Segundo Gaither e Frazier (2006), este modelo causal objetiva relacionar uma variável resposta a uma ou mais variáveis independentes em uma equação linear ou em uma função não linear, possibilitando a diminuição de desvios quadrados dos dados.

\section{CENÁRIO DA SIMULAÇÃO}

0 jogo de empresas GP-1, simulador computacional desenvolvido no Laboratório de Simulação em Sistemas de Produção da Universidade Federal de Santa Catarina, permite a gestão da produção de uma fábrica de móveis através da elaboração de um plano de produção composto por 8 períodos (trimestres), permitindo a interação com os participantes pela geração de resultados baseados nas decisões tomadas durante 0 processo de simulação. 0 jogo fornece os parâmetros necessários para o desenvolvimento de decisões de nível estratégico envolvendo principalmente previsão de demanda, políticas de produção, de estoque e finanças (SCHAFRANSKI e TUBINO, 2013).

Com base na demanda histórica fornecida pelo simulador e com auxílio do editor de planilhas Microsoft Excel, foi calculada a previsão de demanda, base para a elaboração do plano de produção. Para a obtenção dos resultados da demanda futura, os valores da demanda histórica foram inicialmente inseridos em uma nova planilha no Microsoft Excel. Na sequência, foi plotado o gráfico com esses valores, sendo calculada a respectiva equação da reta, fornecida diretamente pelo próprio programa, utilizando a técnica de regressão linear (Gráfico 1). 
Gráfico 1 - Plotagem dos valores de demanda histórica e a equação da reta.

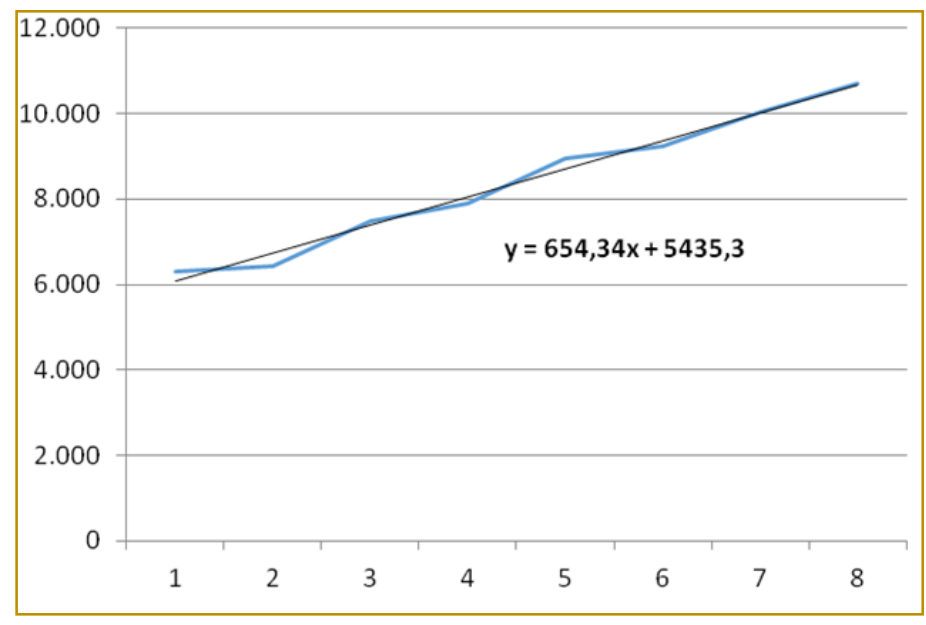

Fonte: Autores.

Dessa forma, levando em consideração a equação da reta obtida com coeficiente angular igual a 654,34 e coeficiente linear $5.435,30$, a previsão de demanda pode ser vista na Figura 1. Esses valores foram obtidos substituindo, na equação da reta encontrada, a variável dependente $(X)$ pelos índices dos períodos, variando de 9 a 16 .

Figura 1 - Previsão de demanda inicial.

\begin{tabular}{|c|c|}
\hline \multicolumn{2}{|c|}{$\begin{array}{c}\text { Previsão de Demanda } \\
\text { Período }\end{array}$} \\
\hline $9(1)$ & 11.324 \\
\hline $10(2)$ & 11.979 \\
\hline $11(3)$ & 12.633 \\
\hline $12(4)$ & 13.287 \\
\hline $13(5)$ & 13.942 \\
\hline $14(6)$ & 14.596 \\
\hline $15(7)$ & 15.250 \\
\hline $16(8)$ & 15.905 \\
\hline
\end{tabular}

Entretanto, o jogo apresenta restrições quanto ao número mínimo de unidades para a demanda, uma informação auxiliar do ambiente simulado que faz as vezes de vendas firmes ou contrato firmado. No caso do cenário em questão, a restrição indicou uma demanda mínima para os próximos períodos de 12.000 unidades. Ademais, o valor mínimo de 12.000 foi acrescido ainda em 1.000 unidades para corresponder a um cenário otimista. Para o ajuste dos valores, a técnica utilizada foi encontrar o fator de multiplicação de forma que a quantidade prevista no primeiro período fosse, então, igual ao valor desejado de 13.000. O fator encontrado foi de 1,148.

Após multiplicar todos os valores de demanda prevista por esse fator, foram obtidas as previsões corrigidas apresentadas na Figura 2 , agora satisfazendo as restrições. 
Figura 2 - Previsão de demanda final.

\begin{tabular}{|c|c|}
\hline \multicolumn{2}{|c|}{$\begin{array}{c}\text { Previsão de Demanda } \\
\text { Período }\end{array}$} \\
\hline $\mathbf{l}$ & 13.000 \\
\hline $\mathbf{2}$ & 13.752 \\
\hline $\mathbf{3}$ & 14.503 \\
\hline $\mathbf{4}$ & 15.254 \\
\hline $\mathbf{5}$ & 16.005 \\
\hline 6 & 16.756 \\
\hline $\mathbf{7}$ & 17.508 \\
\hline 8 & 18.259 \\
\hline
\end{tabular}

Fonte: Autores.

Ao plotar esses valores em um gráfico e calcular a nova equação da reta, obteve-se o que pode ser visto no Gráfico 2. Esses são os números utilizados para a elaboração dos planos de produção, estoque e financeiro, que serão apresentados no próximo item.

Gráfico 2 - Plotagem dos valores de demanda prevista e a equação da reta.

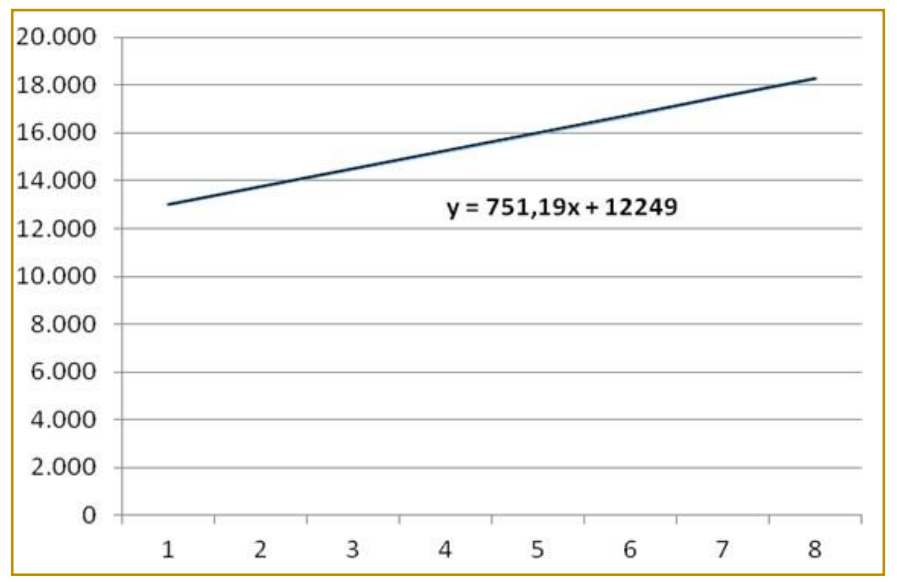

Fonte: Autores.

\section{POLÍTICA DE ESTOQUE, FINANCEIRA E DE PRODUÇÃO}

Levando em consideração o cenário otimista e as imprevisibilidades do mercado, bem como os custos com expansão de área de estoque ou mal-uso do espaço, foi estabelecido um estoque mínimo de aproximadamente 1.250 unidades do produto para todos os períodos subsequentes ao primeiro trimestre, que contava com 450 unidades sob estocagem no início da simulação. Além disso, para acompanhamento e melhor controle durante o processo de simulação, foram estabelecidos limites (superior e inferior) de mais ou menos 450 unidades do produto em estocagem em torno das 1.250 unidades.

O valor inicial disponível em caixa para investimentos foi de 450.000,00 Unidades Monetárias (UM). Assim, partiu-se para a busca de um planejamento no qual os gastos com investimentos como, por exemplo, ampliações da fábrica, ficassem dentro do orçamento inicial apresentado na simulação.

Além disso, devido aos altos custos relacionados à produção terceirizada ou em turno extra, optou-se por evitá-las ao máximo, utilizando esse tipo de estratégia apenas quando estritamente necessário.

Por fim, a ociosidade é vista como desperdício e, assim, a decisão foi evitá-la. Entretanto, foi necessário considerar as políticas de forma integrada e, dessa forma, as decisões tomadas durante as simulações podem não necessariamente convergir com o planejado. 


\section{TÉCNICA DE CORREÇÃO DA DEMANDA}

Por vezes, a previsão de demanda não é compatível com a demanda real. 0 mesmo pode acontecer durante processos de simulação uma vez que o objetivo é também incorporar as imprevisibilidades do mercado real nesses ambientes.

Durante o processo de simulação a ser apresentado, pode-se observar que a previsão de demanda inicial estava, de fato, aquém dos valores efetivos. Dessa forma, foram necessárias atitudes no sentido de aliviar e corrigir essas discrepâncias. Dessa forma, foi desenvolvida uma técnica que consiste no ajuste da equação da reta com base na demanda real imediatamente anterior ao período a ser considerado.

A fórmula geral para o ajuste, base da técnica apresentada, consiste em:

$$
D_{t-1}=A_{t} \cdot X_{t-1}+12249
$$

Eq. 1

onde:

$D_{t-1}:$ demanda efetiva obtida para o período t-1 (anterior);

$A_{t}$ : novo coeficiente angular para o período $t$;

$\mathrm{X}_{\mathrm{t}-1}$ : índice do período $\mathrm{t}-1$ (anterior), variando de 1 a 7 .

É possível perceber que o coeficiente linear permanece constante durante o processo de simulação e eventuais ajustes. Isto pressupõe um modelo de regressão linear, construído com base na demanda histórica, de comportamento inicial próximo ao real. Dessa forma, com base no comportamento apresentado efetivamente pela demanda é possível ajustar o planejamento de forma a se aproximar o máximo possível da realidade e minimizar os erros.

A técnica pode e deve ser utilizada sempre que se chegue à conclusão que 0 planejamento pode não ser capaz de suprir as necessidades de um determinado período, ou ainda de não atender aos critérios estabelecidos nas políticas de estoque, finanças e produção. Assim, a decisão deve ser feita levando em consideração as diferentes variáveis envolvidas e deve estar pautada em bons argumentos.

Ao final do trabalho, será apresentada uma comparação entre o comportamento real apresentado pela demanda no decorrer dos períodos e a previsão de demanda ajustada com base nessa técnica, bem como a previsão inicial, a base de tudo.

\section{A SIMULAÇÃO}

O Plano de Produção preenchido com a demanda prevista, levando em consideração as ressalvas feitas nas políticas de estoque, produção e financeira, pode ser visto na Figura 3.

Figura 3 - Plano de Produção

\begin{tabular}{|c|c|c|c|c|c|c|c|c|}
\hline PERIOODO & 1 & 2 & 3 & 4 & 5 & 6 & 7 & 8 \\
\hline Demanda Histórica & 6.316 & 6.423 & 7.491 & 7.895 & 8.964 & 9.223 & 10.032 & 10.695 \\
\hline Demanda Prevista & 13.000 & 13.752 & 14.503 & 15.254 & 16.005 & 16.756 & 17.508 & 18.259 \\
\hline Demanda Projetada & 0 & 0 & 0 & 0 & 0 & 0 & 0 & 0 \\
\hline Demanda Efetiva & 0 & 0 & 0 & 0 & 0 & 0 & 0 & 0 \\
\hline Estoque Inicial & 450 & 1.000 & 1.248 & 1.245 & 1.291 & 1.286 & 1.280 & 1.272 \\
\hline Capacidade Instalada & 12.000 & 16.000 & 16.000 & 16.000 & 16.000 & 16.000 & 20.000 & 20.000 \\
\hline Produção Normal & 12.000 & 14.000 & 14.500 & 15.300 & 16.000 & 16.000 & 17.500 & 18.250 \\
\hline Produção Terceirizada & 1.550 & 0 & 0 & 0 & 0 & 750 & 0 & 0 \\
\hline Turno Extra & $\checkmark$ & $\checkmark$ & $\checkmark$ & $\checkmark$ & $\checkmark$ & $\checkmark$ & $\checkmark$ & 0 \\
\hline Produção Efetiva & 13.550 & 14.000 & 14.500 & 15.300 & 16.000 & 16.750 & 17.500 & 18.250 \\
\hline Ampliação da Capacidade & $4,000 \quad \nabla$ & \begin{tabular}{l|l}
0 & $\quad$
\end{tabular} & $\begin{array}{ll}0 & \quad\end{array}$ & $\begin{array}{ll}0 & \quad\end{array}$ & $0 \quad-$ & $4,000 \quad \boldsymbol{T}$ & $\begin{array}{ll}0 & \nabla\end{array}$ & $0 \quad-$ \\
\hline
\end{tabular}

Fonte: Jogo de empresas GP-1 (SCHAFRANSKI e TUBINO, 2013) 
A capacidade total disponível para produção no primeiro período corresponde a 12.000 , insuficiente, ainda que levando em consideração o estoque, para suprir a demanda prevista de 13.000 para o período 1. Dessa forma, a opção considerada mais viável foi a de terceirizar a produção de 1.550 itens. Levando em conta os altos custos incorridos nesse tipo de estratégia, optou-se por um estoque final de 1.000 para balancear os custos. Com o objetivo de ser capaz de atender às demandas seguintes, optou-se por ampliar a capacidade de produção em 4.000. Diante disso, foram iniciadas as rodadas de simulação. 0 acompanhamento de cada rodada é apresentado a seguir.

\subsection{PERÍODO 1}

Após a simulação do período 1 , constatou-se que a demanda efetiva foi de 12.993 unidades, muito próxima do previsto de 13.000. 0 estoque final foi equivalente a 1.007 unidades. Considerando que esse valor se encontra dentro dos níveis de estoque considerados aceitáveis, não se julgou necessário nenhum ajuste no plano de produção.

\subsection{PERÍODO 2}

A demanda efetiva após a simulação do período 2 foi de 14.476, superior em 724 unidades com relação à demanda prevista. Como o estoque inicial era de 1.007 unidades, não houveram vendas perdidas. Porém, o estoque final para o período foi reduzido para apenas 531 unidades, fora dos limites estabelecidos na política de estoque. Assim, fica claro que um ajuste no plano de produção planejado é necessário.

Devido à grande variação de demanda levando a uma diferença relativamente alta entre a demanda prevista e a efetiva, é preciso fazer um ajuste no plano de produção, especificamente na demanda prevista dos períodos subsequentes.

Entra em cena a técnica de correção das previsões que se baseia em ajustar o coeficiente angular, encontrado no Gráfico 2, com base no real comportamento da demanda no período anterior. A fórmula, então, utilizada foi:

$$
14.476=A_{3} * 2+12.249
$$

Eq. 2

Como resultado, foi encontrado um valor de $A_{3}=1113,5$. A nova previsão de demanda calculada para o período 3 utilizando o coeficiente angular ajustado foi de aproximadamente 15.600 unidades. Para suprir essa demanda, optou-se por aumentar a produção normal para 16.000 unidades. Além disso, um módulo de ampliação em 4.000 unidades foi escolhido para que a empresa fosse capaz de atender às demandas seguintes.

\subsection{PERÍODO 3}

Após a simulação, a demanda efetiva foi de 17.228, muito além da demanda prevista de
15.600. Por conta da decisão de apenas elevar a produção normal até a capacidade instalada total desconsiderando, de certa forma, as ponderações feitas na política de estoque em detrimento dos custos julgados altos incorridos por estratégias alternativas de produção, a empresa teve um total de 697 vendas perdidas.

Como a demanda prevista foi muito inferior à efetiva, torna-se necessário um novo ajuste do coeficiente angular. Em virtude do comportamento do mercado ser muito instável a técnica de ajuste do coeficiente angular é novamente aplicada. A fórmula utilizada é dada 
Dessa forma, o novo coeficiente angular $A_{4}$ encontrado equivale a 1659,7. A nova demanda prevista ajustada para o período 4 com base na nova equação da reta é de 18.888. Por fim, ajusta-se a produção normal para a capacidade total de 20.000 unidades.

\subsection{PERÍODO 4}

Ao fim da simulação, a demanda efetiva do período 4 foi de 18.234 , sendo inferior a demanda prevista de 18.888 unidades. Como foi produzido uma quantidade equivalente a 20.000 unidades do produto, foi gerado um estoque de 1.766 unidades e, portanto, acima do nível de segurança estabelecido.

Como a demanda prevista desse período ficou relativamente próxima à efetiva, sendo superior em 654 unidades, optou-se por permanecer com o mesmo coeficiente angular $\mathrm{A}_{4}$ para o cálculo da demanda prevista do período 5. Assim, a demanda prevista utilizada para a simulação do período seguinte foi de 20.550 .

Prevendo um aumento da demanda nos períodos seguintes acima da capacidade de produção atual, decide-se também pela sua ampliação em 4.000 unidades.

\subsection{PERÍODO 5}

Após a simulação deste período, a demanda efetiva recebida foi de 21.021, superior à prevista de 20.550. Como no período anterior foi conseguido um estoque de 1.766 unidades, foi possível suprir a demanda efetiva não gerando perdas. Por outro lado, o estoque ficou reduzido a 745 unidades.

Levando em consideração o planejamento para o período e o que de fato ocorreu, um novo ajuste na previsão de demanda para o período 6 foi visto como necessário. Através da técnica apresentada, calculou-se o novo coeficiente angular por meio da fórmula:

$$
21.021=A_{6}^{*} 5+12.249
$$

Eq. 4

Foi obtido, como resultado, $A_{6}=1754,4$. Assim, a nova demanda prevista para 0 período 6 equivale a 22.780 unidades, e optou-se pela produção máxima de 24.000 unidades referente a capacidade produtiva total.

\subsection{PERÍODO 6}

Após a simulação do período 6 , observou-se que a demanda efetiva foi de 23.082 unidades do produto, superior à demanda prevista de 22.780. Entretanto, por conta da decisão de produção da capacidade total, foi possível suprir a demanda efetiva e ainda gerando um estoque de 1.663 unidades.

Um novo ajuste na demanda prevista foi realizado para a posterior simulação do período 7. A fórmula utilizada para o cálculo do novo coeficiente angular foi: 
A demanda prevista para o período $7 \mathrm{com}$ o novo coeficiente angular foi de 24.890 . Com a capacidade produtiva equivalente a $\mathbf{2 4 . 0 0 0}$ unidades, e mesmo com o estoque do período anterior, não seria possível atingir o nível de segurança do estoque sob essas condições. Assim, optou-se por terceirizar 500 unidades para manter um nível de estoque adequado.

Levando em conta que a demanda prevista desse período ultrapassou a capacidade produtiva atual, decidiu-se pela ampliação de 4.000 unidades no valor de 100.000,00 UM para que nos próximos períodos fosse possível atender às demandas do mercado.

\subsection{PERÍODO 7}

Após a simulação, constatou-se que a demanda efetiva do período 7 foi de 25.446 unidades, sendo superior à demanda prevista de 24.890; porém, como no período anterior houve um estoque de 1.663 unidades e foram terceirizadas 500 unidades, foi possível manter um estoque de 717 unidades, sem vendas perdidas no período.

Considerando que a demanda efetiva foi razoavelmente superior à prevista e levando em conta o baixo nível de estoque que isso gerou, decidiu-se por aplicar a técnica uma última vez.

O novo coeficiente angular foi calculado através da fórmula:
Com o novo coeficiente angular, a demanda prevista encontrada foi equivalente a $\mathbf{2 7 . 3 3 2}$ unidades. Dessa forma, optou-se pela produção da capacidade produtiva total de 28.000 .

\subsection{PERÍODO 8}

Após a simulação, observou-se que a demanda efetiva do período 8 foi de 27.883 unidades, sendo pouco superior à demanda prevista de 27.332. Assim, a quantidade produzida somada ao estoque gerado no período anterior conseguiram atender a demanda efetiva gerando, ainda, um estoque final de 834 unidades, dentro dos níveis de estoque adequados.

\section{RESULTADOS E DISCUSSÃO}

O Gráfico 3 abaixo mostra uma comparação entre as previsões de demanda iniciais, previsões ajustadas por meio da técnica de correção da demanda e a demanda efetiva ou real.

Gráfico 3 - Comparação entre as previsões de demanda e demanda efetiva.

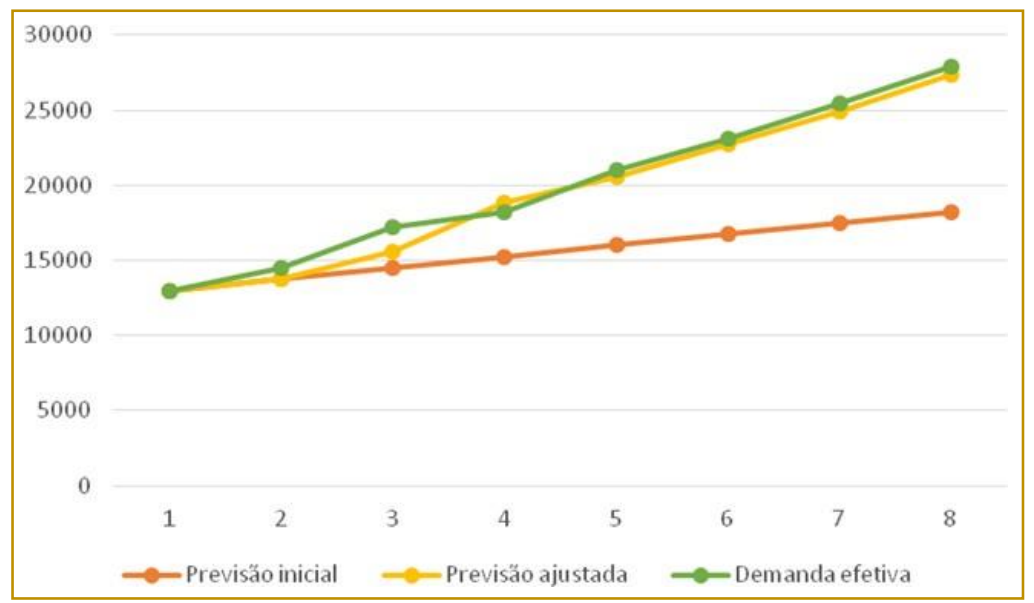

Fonte: Autores. 
É possível notar que a previsão inicial, ainda que tenha sido calculada com base na demanda histórica fornecida pelo jogo, se difere drasticamente da demanda efetiva encontrada ao longo do processo de simulação. Talvez um aquecimento da economia ou do mercado no qual a empresa está inserida deveria ter sido levado em consideração.

No período 3, especificamente, é possível notar uma variação anormal na demanda, considerando a tendência apresentada pelos dados no decorrer dos períodos iniciais. Foi exatamente nesse período que, durante a simulação, a empresa obteve vendas perdidas e, portanto, prejuízo.
Ainda assim, a técnica de ajuste no coeficiente angular da equação da reta se mostrou bastante efetiva tendo em vista que a previsão de demanda ajustada, calculada no decorrer da simulação dos períodos, ficou bastante próxima da demanda real.

$\mathrm{Na}$ política de estoques, ficou estabelecido um estoque mínimo de 1.250 unidades do produto e, como forma de controle, foram escolhidos como limites superior e inferior 1.700 e 800 , respectivamente.

o Gráfico 4 mostra os níveis de estoque no decorrer dos períodos em comparação com os limites estabelecidos e o nível de segurança de 1.250 unidades.

Gráfico 4 - Estoque final durante os períodos em comparação com os limites estabelecidos.

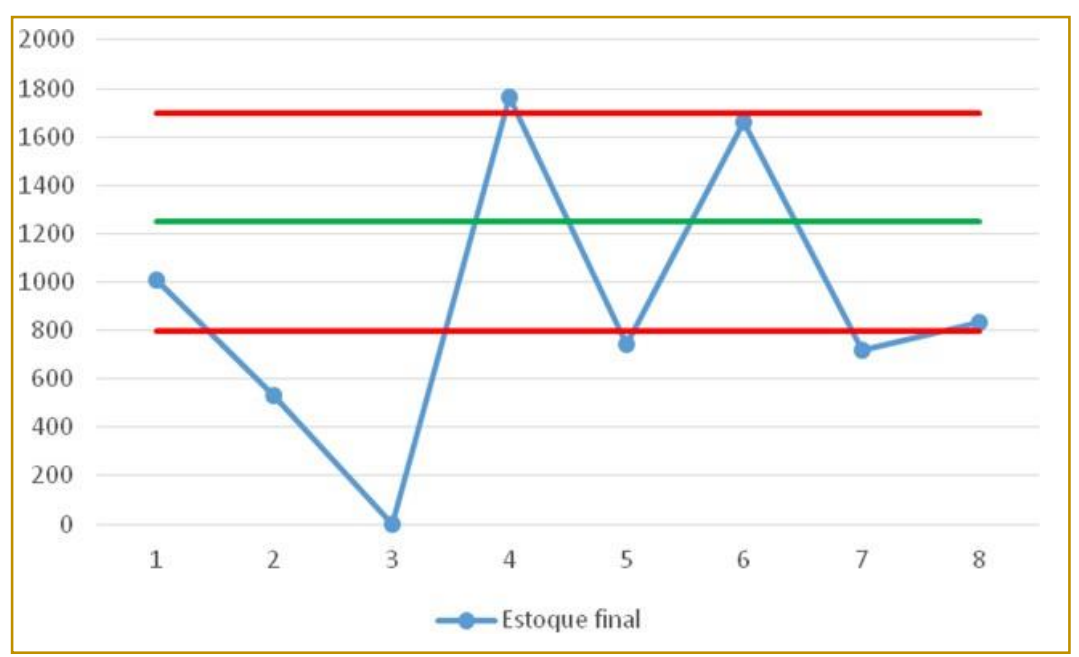

Fonte: Autores

Nos períodos 2, 3, 4, 5 e 7 o nível de estoque ficou fora dos limites determinados. Entretanto, o único prejuízo relacionado a falta de produto (perdas) ocorreu no período 3 uma vez que o nível de estoque do período anterior não fora considerado corretamente. Isso poderia ter sido evitado caso tivesse sido utilizado a terceirização, produção em turno extra ou através de ampliação da capacidade total no período anterior.

o Gráfico 5 mostra o comportamento do nível de estoque durante os períodos com representação do estoque inicial no período, do estoque final e estoque médio. 
Gráfico 5 - Histórico dos níveis de estoque inicial e final nos períodos.

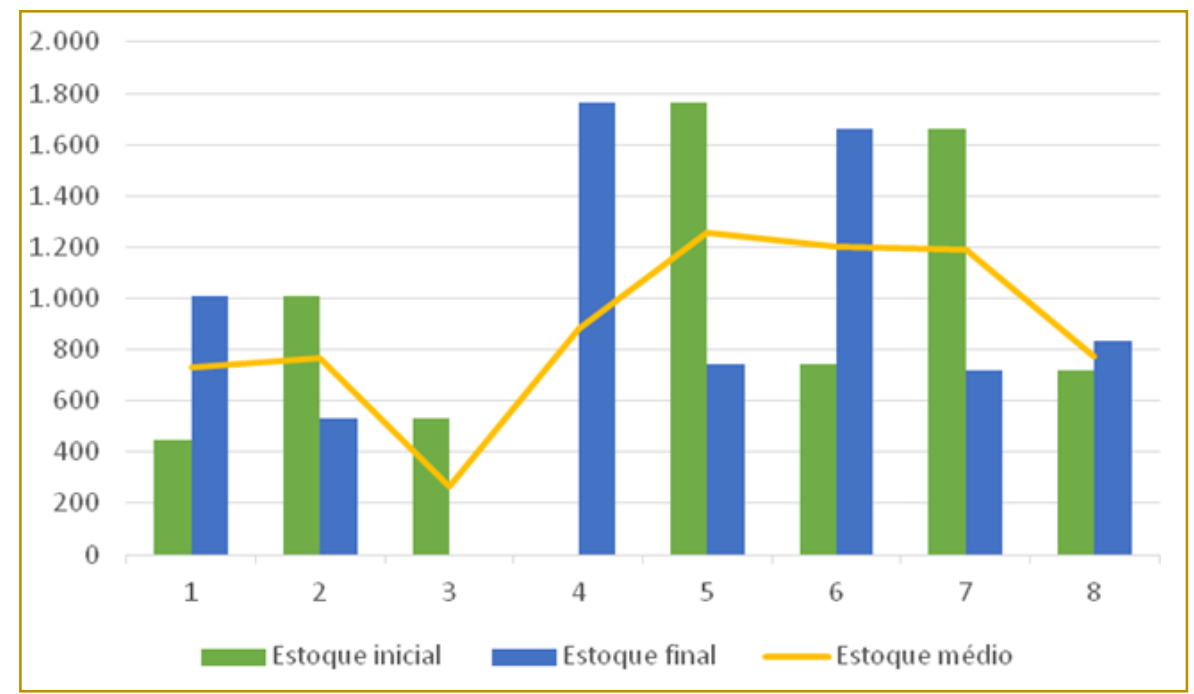

Fonte: Autores

É possível perceber uma queda no nível de estoque médio no período 3 , correspondente ao período em que houveram faltas ou vendas perdidas, principal motivo desse desvio.
Por fim, o Gráfico 6 mostra uma comparação entre os lucros operacionais previstos considerando o primeiro Plano de Produção e os lucros operacionais efetivos, obtidos ao final da simulação.

Gráfico 6 - Comparação entre os lucros operacionais previstos no primeiro plano de produção e lucros operacionais efetivos.

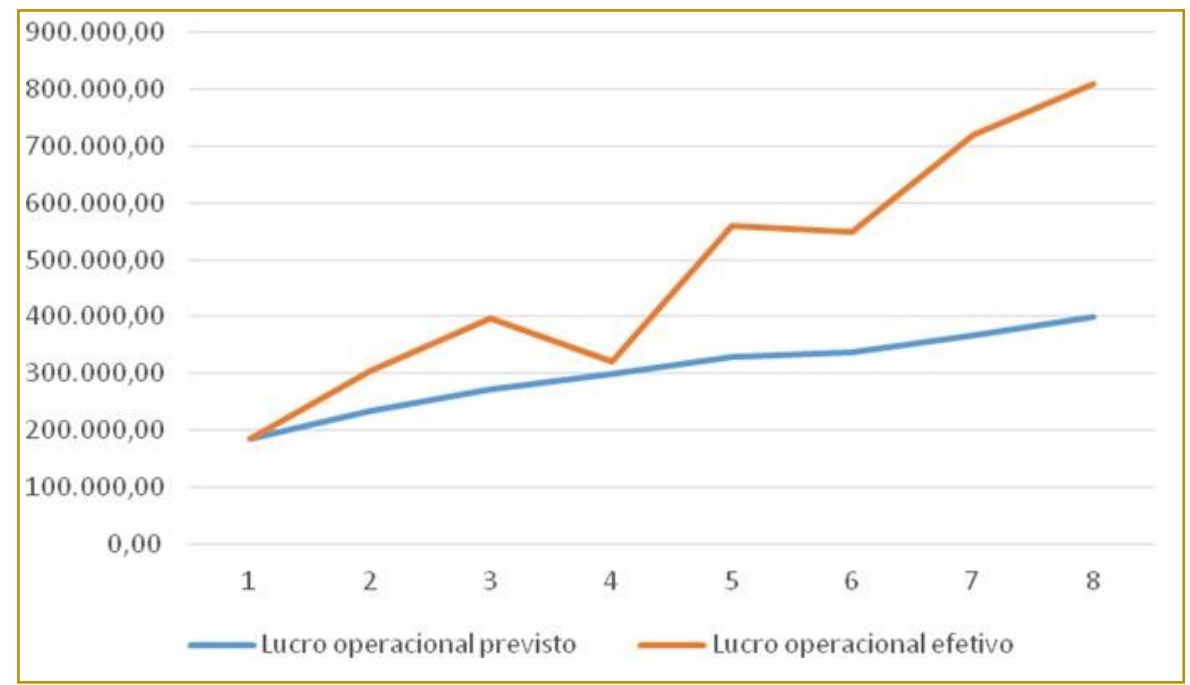

Fonte: Autores

Analisando o relatório financeiro, percebe-se que a queda no lucro operacional efetivo no período 4 decorre, na verdade, de um aumento substancial nos custos fixos e variáveis relacionados ao volume produtivo que sofreu um salto de 16.000 no período 3 para 20.000 no período seguinte. Isso se deve ao fato de que a nova demanda prevista se mostrou muito superior à demanda prevista inicial, indo de encontro ao planejamento inicial. 


\section{CONCLUSÕES}

As ferramentas de simulação são capazes de expandir o conhecimento de uma outra forma, indo além de explicações meramente teóricas. A análise dos resultados encontrados, das ações tomadas bem como dos erros acometidos, permite uma importante reflexão e maior proximidade com as circunstâncias encontradas em uma empresa e mercado da vida real.

O jogo de empresas GP-1 é uma dessas ferramentas, permitindo a elaboração de um Plano de Produção semelhante aos encontrados nas empresas para posterior simulação - incluindo as incertezas encontradas em um mercado real.

Através de métodos matemáticos e análises coerentes, foi construído um Plano de Produção inicial que, mais tarde, provou não

\section{REFERÊNCIAS}

[1]. ABDURAHIMAN, V.; HIRATA, C. M.; KIENBAUM, G.; PAUL, R. J. An Intelligent Simulation Modelling Environment. VI International Conference on Industrial Engineering and Operations Management., , São Paulo, 2000.

[2]. CORRÊA, H. L.; GIANESI, I. G. N.; CAON, M. Planejamento, Programação e Controle da Produção MRP II/ERP: conceitos, uso e implantação. 4a ed. São Paulo: Atlas, 2001.

[3]. CORRÊA, H. L.; CORRÊA, C. A. Administração de produção e de operações Manufatura e Serviços: Uma Abordagem Estratégica. 2a ed. São Paulo: Atlas, 2009.

[4]. FEINSTEIN; A. H.; MANN; S.; CORSUN; D. L. Charting the experiential territory - Clarifying definitions and uses of computer simulation, game, and role play. Journal of Management Development. v. 21. n. 10., 2002.

[5]. FERNANDES, F. C. F.; GODINHO FILHO, M. Planejamento e Controle da Produção: Dos Fundamentos ao Essencial. 1a ed. São Paulo: Atlas, 2010.

[6]. GAITHER, N.; FRAZIER, G. Administração da produção e operações. 8a ed. São Paulo: Thomson Learning, 2006. ser tão efetivo. Entretanto, como forma de revisão, foi desenvolvida uma técnica matemática capaz de corrigir a previsão de demanda. Por outro lado, uma disparidade na demanda real levou a vendas perdidas. Ainda assim, a nova estratégia adotada com base na técnica apresentada no trabalho se mostrou, de fato, eficiente, e a simulação fora completada sem maiores problemas.

Assim, é possível perceber a importância de analisar, sempre, todas as variáveis envolvidas bem como todos os planos estabelecidos. As decisões devem ser tomadas de forma integrada, seja com relação à equipe quanto aos programas e/ou planejamentos iniciais. Por fim, caso necessário, pode-se e deve-se mudar a maneira de atuação de forma a atender às expectativas do mercado e, especialmente, da empresa e de sua administração.

[7]. RUSSOMANO, V. H. PCP: Planejamento e Controle da Produção. 4a ed. São Paulo: Pioneira, 2000.

[8]. SCHAFRANSKI, L. H. e TUBINO, D. F. Simulação Empresarial em Gestão da Produção. São Paulo: Atlas, 2013.

[9]. SLACK, N.; CHAMBERS, S.; JOHNSTON, R. Administração da Produção. 3a ed. São Paulo: Atlas, 2009.

[10]. STEVENSON, W. J. Estatística aplicada à Administração. São Paulo: Harbra, 2001.

[11]. TUBINO, D. F. Manual de Planejamento e Controle da Produção. 2a ed. São Paulo: Atlas, 2000.

[12]. TUBINO, D. F.; SCHAFRANSKI, L. E. Simulação Empresarial em Gestão da Produção. Manual de Simulação. Universidade Federal de Santa Catarina, 2000.

[13]. TUBINO, D. F. Planejamento e Controle da Produção: Do Essencial ao Prático. São Paulo: Atlas, 2009. 


\section{Gapítulo 20}

\section{MÉTODOS DE PREVISÃO DE DEMANDA BASEADOS EM SEERIES TEMPORAIS EM UMA LANCHONETE}

\section{Lucas Carvalho Martins}

Roberta Oliveira Gonçalves

Resumo: A atividade de previsão de demanda é essencial para o planejamento de qualquer organização, fornecendo uma base de como a empresa deve se preparar para atender seus clientes no futuro, seja este de curto, médio ou longo prazo. Desta forma, quanto mais bem elaborada uma previsão, melhor será o desempenho da organização. Este trabalho teve como objetivo estudar os métodos quantitativos de previsão de demanda de séries temporais, aplicando-os e identificando quais seriam os melhores métodos para os produtos propostos de acordo com análise de erros. A pesquisa realizada foi exploratória e bibliográfica, culminando em um estudo de caso. No desenvolvimento do trabalho foi realizada análise qualitativa para escolha dos produtos a serem estudados, em seguida, foram aplicados os métodos quantitativos mais comuns de previsão de demanda de séries temporais apontados na literatura. Os métodos aplicados foram Métodos Ingênuos, Média Móvel Simples, Média Móvel Ponderada, Suavização Exponencial Simples, Suavização Exponencial Dupla, Processos com Sazonalidade e Permanência e Processos com Sazonalidade e Tendência. Os métodos que apresentaram menores desvios variaram entre os produtos, sendo os de Processos com Sazonalidade e Permanência e Processos com Sazonalidade e Tendência os mais assertivos.

Palavras-chave: Planejamento, Sazonalidade, Têndencia, Lanchonete, previsão de demanda 


\section{INTRODUÇÃO}

A previsão de demanda é uma atividade que serve como orientação para a tomada de decisões de uma organização. Segundo Tubino (2009), tal atividade é a base para o planejamento estratégico da produção, vendas e finanças de qualquer empresa.

De forma geral, a previsão de demanda é realizada através da utilização de vários métodos disponíveis que se baseiam em dados históricos e/ou na experiência do previsor, sendo que os dados podem ser quantitativos ou qualitativos. 0 objetivo principal do uso de previsões de demanda é realizar uma análise prévia do cenário futuro de vendas de determinada organização, de forma a obter informações que possibilitem que o planejamento das atividades para 0 controle de recursos produtivos e atendimento ao cliente seja cada vez mais assertivo.

0 objetivo geral da pesquisa foi estudar os métodos de previsão de demanda existentes através da literatura disponível e, posteriormente, avaliar qual o método mais adequado para previsão de demanda de uma lanchonete. Os objetivos específicos da pesquisa foram coletar dados históricos e dados de como é realizada a previsão de demanda atualmente, identificar e definir qual método melhor se adapta para este caso e, por fim, analisar os resultados obtidos.

A justificativa deste estudo se dá devido à grande importância da atividade de previsão de demanda para uma organização que fornece produtos alimentícios e atua na linha estreita entre atendimento ao cliente no momento que é solicitado e venda de produtos com baixíssimo prazo de validade, que são descartados caso não sejam vendidos, acarretando em custos decorrentes de desperdício. Sendo assim, uma boa previsão garante uma melhor programação de compras de matérias primas e assertiva programação da produção para atendimento ao cliente no momento desejado, com boa qualidade e custos adequados.

\section{REFERENCIAL TEÓRICO}

Neste capítulo serão abordados os principais conceitos referentes à atividade de previsão de demanda, desde a importância de sua aplicação, quais fatores devem ser considerados para escolha da melhor abordagem, os métodos existentes nas previsões quantitativas de séries temporais e, ainda, como realizar o controle de erros das previsões.

\subsection{PREVISÃO DE DEMANDA}

Segundo Tubino (2009), a previsão de demanda é a atividade que fornece à organização um direcionamento que irá guiar a empresa em um rumo no qual ela andará. A partir realização de uma previsão da demanda adequada, as empresas passam a ter condições de desenvolver seus planos de capacidade, estoques, produção, mão de obra, compras, etc.

As previsões de demanda são classificadas de acordo com o horizonte de planejamento, que podem ser divididos em curto, médio e longo prazo. Previsões de longo prazo guiam o planejamento estratégico da organização, como o aumento de capacidade ao planejar novas instalações, gastos de capital, investimento em novos produtos, etc. As previsões de médio prazo afetam o planejamento tático da organização, como a previsão agregada de itens e análise de capacidade agregadas. Já as previsões de curto prazo, afetam as decisões no nível operacional, como alocação da mão de obra, análise de capacidade de curto prazo, compras, etc. (FERNANDES; FILHO, 2010).

Desta forma, é possível observar a importância da atividade de previsão de demanda para uma organização, já que sua realização atinge todos os níveis da empresa, possibilitando certa segurança nas tomadas de decisões. Para Ballou (2006), a atividade de previsão de demanda é vital para toda a organização, pois fornece as informações básicas para o devido planejamento e controle das áreas funcionais de uma empresa, tais como Logística, Finanças, Marketing e Produção.

\subsection{CRITÉRIOS PARA ESCOLHA DA ABORDAGEM DA PREVISÃO}

Para escolha da abordagem de previsão a ser utilizada, deve-se levar em consideração as características particulares de cada caso. Um caminho sugerido por Fernandes e Filho (2010) é analisar uma sequência de fatores, dada a seguir.

Primeiramente, deve-se analisar se existem dados disponíveis e, em caso negativo, se é possível coletar os dados. Se não for possível, ou se os dados coletados não forem 
quantitativos, a abordagem deve ser qualitativa. Se os dados forem quantitativos, avalia-se se existem fatores causais. Em caso afirmativo, a abordagem deve ser causal, já em caso negativo, a análise deve ser baseada em séries temporais.
Após determinação da abordagem a ser utilizada, deve-se escolher entre os diversos métodos disponíveis para cada uma delas. Os métodos mais comuns de previsão, segundo Fernandes e Filho (2010), podem ser vistos na Figura 1.

Figura 1 - Métodos mais utilizados para previsão de demanda

\begin{tabular}{|c|c|c|}
\hline $\begin{array}{c}\text { ABORDAGEM } \\
\text { QUALITATIVA }\end{array}$ & ABORDAGEM CAUSAL & SÉRIES TEMPORAIS \\
\hline $\begin{array}{c}\text { Consenso do comitê } \\
\text { executivo }\end{array}$ & Regressão linear simples & Métodos ingênuos \\
\hline Analogia histórica & Regressão linear curvilinea & Média móvel \\
\hline Pesquisa de mercado & Regressão mültipla & Média móvel ponderada \\
\hline Pesquisa de clientes & Sistemas simultâneos & $\begin{array}{c}\text { Suavização exponencial } \\
\text { simples }\end{array}$ \\
\hline Pesquisa da equipe de vendas & Simulação & $\begin{array}{c}\text { Suavização exponencial } \\
\text { dupla }\end{array}$ \\
\hline Método Delphi & - & $\begin{array}{c}\text { Processos com sazonalidade } \\
\text { e permanência }\end{array}$ \\
\hline - & Fonte: Própria (2016) & $\begin{array}{c}\text { Processos com sazonalidade } \\
\text { e tendência }\end{array}$ \\
\hline
\end{tabular}

\subsubsection{ABORDAGEM QUALITATIVA}

A abordagem qualitativa tem caráter subjetivo e é utilizada nas situações em que os dados históricos são difíceis de coletar, não há tempo hábil para coleta e análise dos mesmos, ou, ainda, quando os dados existentes são meramente qualitativos.

Outros fatores que justificam a adoção de abordagem qualitativa é a introdução de algum produto novo no mercado, sobre o qual ainda não há dados disponíveis e nos casos de panorama político e econômico instáveis, que provoca obsolescência nos dados históricos rapidamente (TUBINO, 2009).

\subsubsection{ABORDAGEM CAUSAL}

A abordagem causal utiliza técnicas baseadas em correlações, onde os dados históricos são relacionados com uma ou mais variáveis que tenham influência na demanda do produto (TUBINO, 2009). A partir da relação entre as variáveis, são geradas equações matemáticas que possibilitam que o valor da previsão de demanda (variável dependente) seja obtido a partir dos valores das variáveis independentes (FERNANDES; FILHO, 2009).

\subsubsection{SÉRIES TEMPORAIS}

Segundo Morettin e Toloi (2006) "uma série temporal é qualquer conjunto de observações ordenadas no tempo". Para Fernandes e Filho (2010), a abordagem baseada em séries temporais além de utilizar um conjunto de informacões ordenadas no tempo, assume que os fatores que terão influência no futuro são os mesmos que influenciaram no passado. Para Tubino (2009), por este método fornecer bons resultados se bem elaborado, é considerado o mais simples e usual entre os métodos de previsão.

Para Fernandes e Filho (2010), a primeira etapa a ser realizada para a escolha do método a ser utilizado dentro da abordagem de séries temporais deve ser a determinação do padrão histórico de comportamento da demanda. Os padrões mais comuns de comportamento e, portanto, mais fáceis de prever, são aqueles relacionados a:

processo constante, no qual a demanda tende a permanecer estável ao longo do tempo;

processo com tendência, no qual há crescimento ou decrescimento da demanda de forma uniforme ao longo do tempo, ou seja, sem picos;

processo com sazonalidade e permanência, no qual há ocorrência de oscilações regulares da demanda ao longo do tempo; 
processo com sazonalidade e tendência, no qual ocorrem oscilações regulares da demanda e crescimento ou decrescimento da mesma simultaneamente, ao longo do tempo.
As representações dos padrões de demanda dos processos citados podem ser vistas na Figura 2.

Figura 2: Gráficos dos padrões de demanda em séries temporais

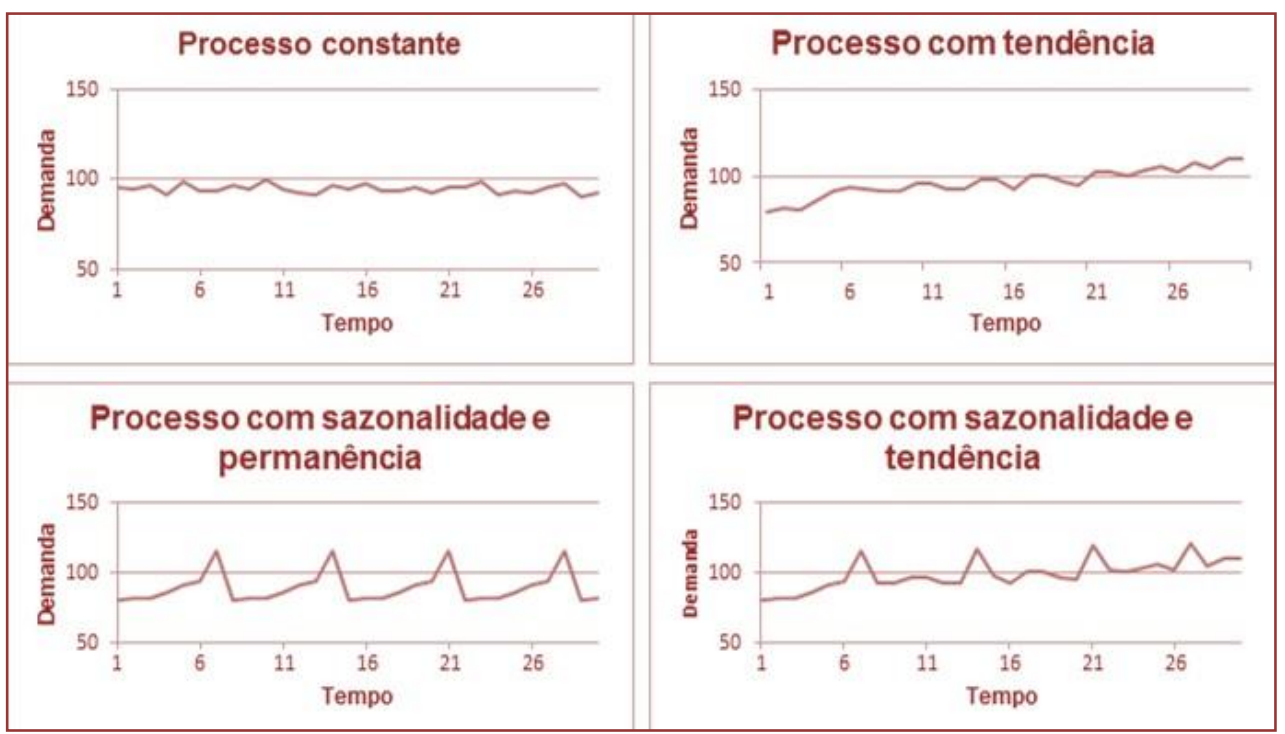

Fonte: Própria (2016)

\subsubsection{MÉTODOS INGÊNUOS}

Seu valor é dado pela Equação 1 (FERNANDES; FILHO, 2010).

$$
P_{t+k}=d_{t}
$$

Onde,

$P_{t+k}=$ previsão para o período $t+k, k \geq 1$

$d_{t}=$ demanda real no período $t$

\subsubsection{MÉDIA MÓVEL}

Esta previsão é calculada de acordo com a Equação 2 (FERNANDES; FILHO, 2010).

$M_{T}=\frac{1}{N} \sum_{t=T-N+1}^{T} d_{t}$

Onde,

$M_{T}=$ média móvel para o período $T$

$N$ = número de períodos escolhido

$d_{t}=$ demanda real do período $t$

\subsubsection{MÉDIA MÓVEL PONDERADA}

A previsão de demanda realizada por este método pode ser calculada de acordo com a Equação 3, respeitando o que é atribuído na Equação 4, que diz simplesmente que a soma dos pesos atribuídos não deve ultrapassar o valor unitário (FERNANDES; FILHO, 2010).

$M P_{T}=\frac{1}{N} \sum_{t=T-N+1}^{T} w_{t} d_{t}$

$\sum_{t=T-N+1}^{T} w_{t}=1$

Onde,

$M P_{T}=$ média móvel ponderada para o período $T$

$N$ = número de períodos escolhido

$w_{t}=$ peso atribuído ao período $t$

$d_{t}=$ demanda real do período $t$ 


\subsubsection{SUAVIZAÇÃO}

\section{SIMPLES}

EXPONENCIAL

A previsão é realizada de acordo com a Equação 5 (FERNANDES; FILHO, 2010).

$P_{T+k}=S_{T}$

$S_{T}=\alpha d_{t}+(1-\alpha) S_{t-1}$

$S_{T-1}=P_{T}$

Onde,

$S_{T}=$ previsão suavizada para o período $T$

$S_{T-1}=$ previsão suavizada para o período $T-$ 1

$\alpha=$ constante de suavização (valor entre $0 \mathrm{e}$

1)

$d_{T}=$ demanda real do período $T$

$P_{T+k}=$ previsão para o período $T+k$

\subsubsection{SUAVIZAÇÃO EXPONENCIAL DUPLA}

Este método leva em consideração o tempo e a tendência, assim a previsão (Equação 8) é realizada através de uma soma da previsão realizada com suavização exponencial (Equação 9) e uma estimativa de tendência, que é calculada de acordo com a Equação 10 (FERNANDES; FILHO, 2010).

$$
\begin{aligned}
& P_{T+k}=S_{T}+k T_{T} \\
& S_{T}=\alpha d_{t}+(1-\alpha)\left(S_{T-1}+T_{T-1}\right) \\
& T_{T}=\beta\left(S_{T}-S_{T-1}\right)+(1-\beta)\left(T_{T-1}\right)
\end{aligned}
$$

Onde,

$S_{T}=$ previsão suavizada para o período $T$

$S_{T-1}=$ previsão suavizada para o período $T$ 1

$\alpha=$ constante de suavização (valor entre $0 \mathrm{e}$ 1)

$T_{T}=$ estimativa de tendência para o período $T$

$\mathrm{k}=$ número de períodos futuros a serem previstos

$\beta$ = constante de suavização (valor entre $0 \mathrm{e}$ 1)

$d_{T}=$ demanda real do período $T$

$P_{T+k}=$ previsão para o período $T+k$

\subsubsection{PROCESSOS COM SAZONALIDADE E PERMANÊNCIA}

A sazonalidade pode ser diária, semanal, mensal ou anual. Neste método, aplica-se um fator de sazonalidade (Equação 11) à previsão suavizada exponencialmente (Equação 12), a previsão é calculada de acordo com a Equação 13 (FERNANDES; FILHO, 2010).

$$
\begin{aligned}
F_{T} & =\frac{d_{t}}{\text { demanda média no ciclo de sazonalidade }} \\
S_{T} & =\alpha\left({\underline{d_{t}}}_{F_{T}}\right)+(1-\alpha) S_{T-1} \\
P_{T} & =S_{T} \times F_{T}
\end{aligned}
$$

Onde,

$P_{T}=$ previsão para o período $T$

$S_{T}=$ previsão suavizada para o período $T$

$F_{T}=$ fator de sazonalidade no período $T$

$d_{t}=$ demanda real do período $t$

$S_{T-1}=$ previsão suavizada para o período $T$ 1

$\alpha=$ constante de suavização (valor entre $0 \mathrm{e}$ 1)

\subsubsection{PROCESSOS COM SAZONALIDADE E TENDÊNCIA}

Este método estima os parâmetros de sazonalidade e tendência (Equação 14 e Equação 15, respectivamente) que, juntamente com os dados de previsão suavizada exponencialmente (Equação 16) nos períodos anteriores, são utilizados para realizar a previsão para os próximos períodos. As previsões neste método são realizadas a partir da Equação 17 (FERNANDES; FILHO, 2010).

$$
\begin{aligned}
& S_{T}=\alpha\left(\frac{d_{T}}{F_{T-L}}\right)+(1-\alpha)\left(S_{T-1}+T_{T-1}\right) \\
& T_{T}=\beta\left(S_{T}-S_{T-1}\right)+(1-\beta)\left(T_{T-1}\right) \\
& F_{T}=\gamma\left(\frac{d}{S_{T}}\right)+(1-\gamma) F_{T-L} \\
& P_{T+k}=\left(S_{T}+k T_{T}\right) F_{T+k-L}
\end{aligned}
$$

Onde,

$S_{T}=$ previsão suavizada para o período $T$ $S_{T-1}=$ previsão suavizada para o período $T$ 1

$\mathrm{k}$ = número de períodos futuros a serem previstos

$\alpha=$ constante de suavização (valor entre $0 \mathrm{e}$ 1)

$T_{T}=$ estimativa de tendência para o período $T$ $\beta=$ constante de suavização (valor entre $0 \mathrm{e}$ 1) 
$d_{T}=$ demanda real do período $T$

$P_{T+k}=$ previsão para o período $T+k$

$\gamma=$ constante de suavização (valor entre $0 \mathrm{e}$ 1)

$\mathrm{L}=$ número de variações sazonais em uma unidade de tempo

\subsection{CONTROLE DE PREVISÃO}

Segundo Lustosa et al. (2008), após a escolha do método a ser utilizado, faz-se necessária a calibração do modelo e avaliação de sua confiabilidade.

Após a escolha e calibração do método de previsão que será utilizado, é necessário o acompanhamento do desempenho das previsões para validar seu uso diante o que está acontecendo realmente. Para que as previsões sejam sempre confiáveis, é preciso que o modelo esteja atualizado e monitorado. 0 monitoramento pode ser realizado através do cálculo e análise dos erros das previsões (TUBINO, 2009).

Para Fernandes e Filho (2010), o objetivo de controle das previsões é a determinação de erros que possivelmente estão sendo gerados nas mesmas. O erro de uma previsão é, basicamente, a diferença entre 0 valor previsto e a demanda real observada, e pode ser calculado de acordo com a Equação 18.

$e_{t}=p_{t}-d_{t}$

Onde,

$e_{t}=$ erro da previsão para o período $t$

$p_{t}=$ previsão para o período $t$ $d_{t}=$ demanda real do período $t$

\subsubsection{SOMATÓRIA ACUMULADA DE ERROS}

Segundo Fernandes e Filho (2010), a avaliação conjunta dos erros é uma medida que visa descobrir se os erros estão variando aleatoriamente em torno de um ponto ao longo do tempo através da somatória dos mesmos, que deve se aproximar de zero. 0 cálculo da somatória acumulada de erros pode ser realizado de acordo com a Equação 19.

$E_{T}=\sum_{t=1}^{T} e_{t}$

Onde,

$E_{T}=$ erro acumulado

$e_{t}=$ erro da previsão para o período $t$

$T=$ número total de períodos
Ainda segundo Fernandes e Filho (2010), na avaliação conjunta dos erros alguns fatores podem ocorrer, e merecem atenção:

se a somatória dos erros for um valor longe de zero, isto indica que o sistema de previsão está com problemas;

se a somatória dos erros crescer um decrescer a uma taxa aproximadamente constante, significa que a previsão está com um erro padrão que pode ser subtraído ou acrescentado à previsão para normalização;

se a somatória dos erros estiver crescendo a uma taxa crescente, significa que o método escolhido está errado ou o processo utilizado para escolha do modelo teve alterações.

\subsubsection{DESVIO ABSOLUTO MÉDIO}

O desvio absoluto médio é uma medida dos erros absolutos da previsão, que realiza a média dos erros, desconsiderando o sinal, com objetivo de sanar o problema citado acima. Seu cálculo é realizado de acordo com a Equação 20 (FERNANDES; FILHO, 2010).

$D A M=\frac{1}{T} \sum_{t=1}^{T}\left|e_{t}\right|$

Onde,

$D A M=$ desvio absoluto médio

$e_{t}=$ erro da previsão para o período $t$

$T=$ número total de períodos

\subsubsection{PORCENTAGEM MÉDIA ABSOLUTA}

O cálculo da porcentagem média absoluta é realizado de acordo com a Equação 21 e visa relacionar o erro absoluto da previsão com o valor da demanda, de modo que seja encontrado o percentual de afastamento do valor encontrado na previsão com o valor real de demanda observado no período (FERNANDES; FILHO, 2010).

$P M A=\frac{1}{T}\left(\sum_{t=1}^{T} \frac{\left|e_{t}\right|}{d_{t}}\right)$

Onde,

$P M A=$ porcentagem média absoluta

$e_{t}=$ erro da previsão para o período $t$

$d_{t}=$ demanda real observada no período $t$

$T=$ número total de períodos 


\subsubsection{ERRO MÉDIO QUADRÁTICO}

0 erro médio quadrático é realizado através da média do quadrado dos erros das previsões, quanto menor for seu valor, mais precisa é a previsão. Esta medida de erro é calculada de acordo com a Equação 23 (LUSTOSA et al., 2008).

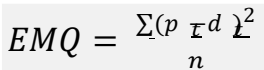

Onde,

$E M Q=$ erro médio quadrático

$d_{t}=$ demanda real observada no período $t$

$p_{t}=$ previsão para o período $t$

$n=$ número de previsões

\section{METODOLOGIA}

Para desenvolvimento do trabalho foram utilizadas pesquisa bibliográfica, pesquisa de campo de caráter exploratório e estudo de caso.

A pesquisa bibliográfica caracteriza-se pelo desenvolvimento do trabalho com base em materiais já elaborados, fornecendo ao pesquisador uma ampla gama de informações que irão facilitar sua pesquisa no sentido de não necessitar ir atrás de cada dado necessário exaustivamente (GIL, 2002).

A pesquisa exploratória visa proporcionar maior conhecimento do pesquisador sobre determinado tema, com o objetivo de considerar vários aspectos relacionados ao problema a fim de resolver a questão chave da pesquisa (GIL, 2002).
Para coleta de dados, foi realizada pesquisa de campo de caráter exploratório, que tem como objetivo a formulação de questões com finalidade de desenvolver hipóteses, clarear conceitos ou, ainda, coletar dados que servirão para pesquisas futuras mais precisas. Os dados coletados podem ser quantitativos ou qualitativos, cabendo ao pesquisador relacioná-los de acordo com o ambiente e contexto em que estão inseridos (MARCONI; LAKATOS, 2003).

0 estudo de caso é realizado com a intenção de estudar profundamente um ou mais objetos, de modo a obter amplo e detalhado conhecimento, sendo seus resultados apenas hipóteses, e não conclusões definitivas (GIL, 2002).

\section{ESTUDO DE CASO}

O trabalho tem como foco o estudo da previsão de demanda de uma lanchonete considerada, pela classificação do SEBRAE (2016) em relação ao número de funcionários, como uma pequena empresa. O objetivo é identificar como é realizada a previsão de demanda desta empresa atualmente e indicar qual o método de previsão melhor se adequa a cada produto escolhido para estudo, através da aplicação de métodos quantitativos de previsão baseados em séries temporais.

\subsection{A EMPRESA}

$\mathrm{Na}$ Figura 4, pode ser analisada a estrutura da empresa.

Figura 4 - Estrutura da empresa

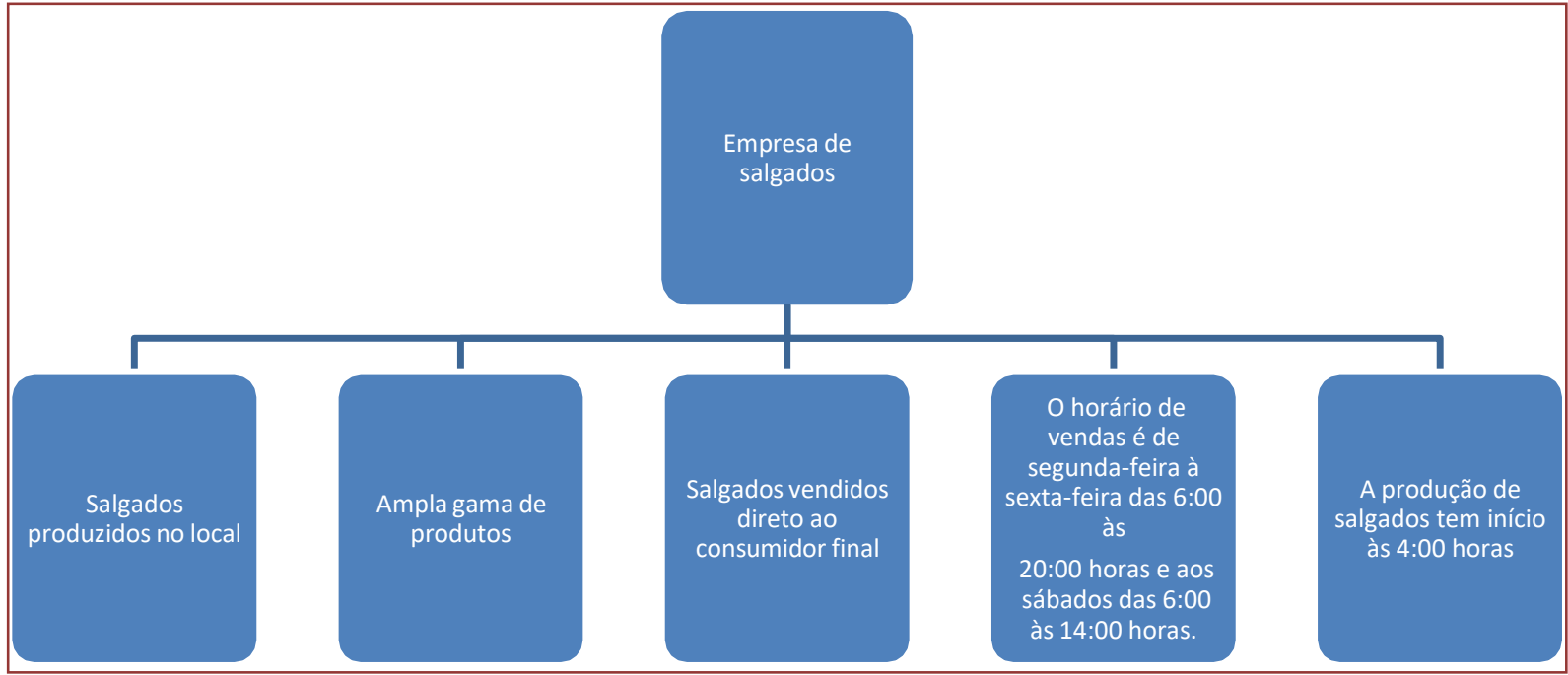

Fonte: Própria (2016) 


\subsection{MÉTODO DE PREVISÃO ATUAL}

A Figura 5 mostra como se utilizava o método de previsão de demanda da empresa

Figura 5 - Previsão de demanda atual.

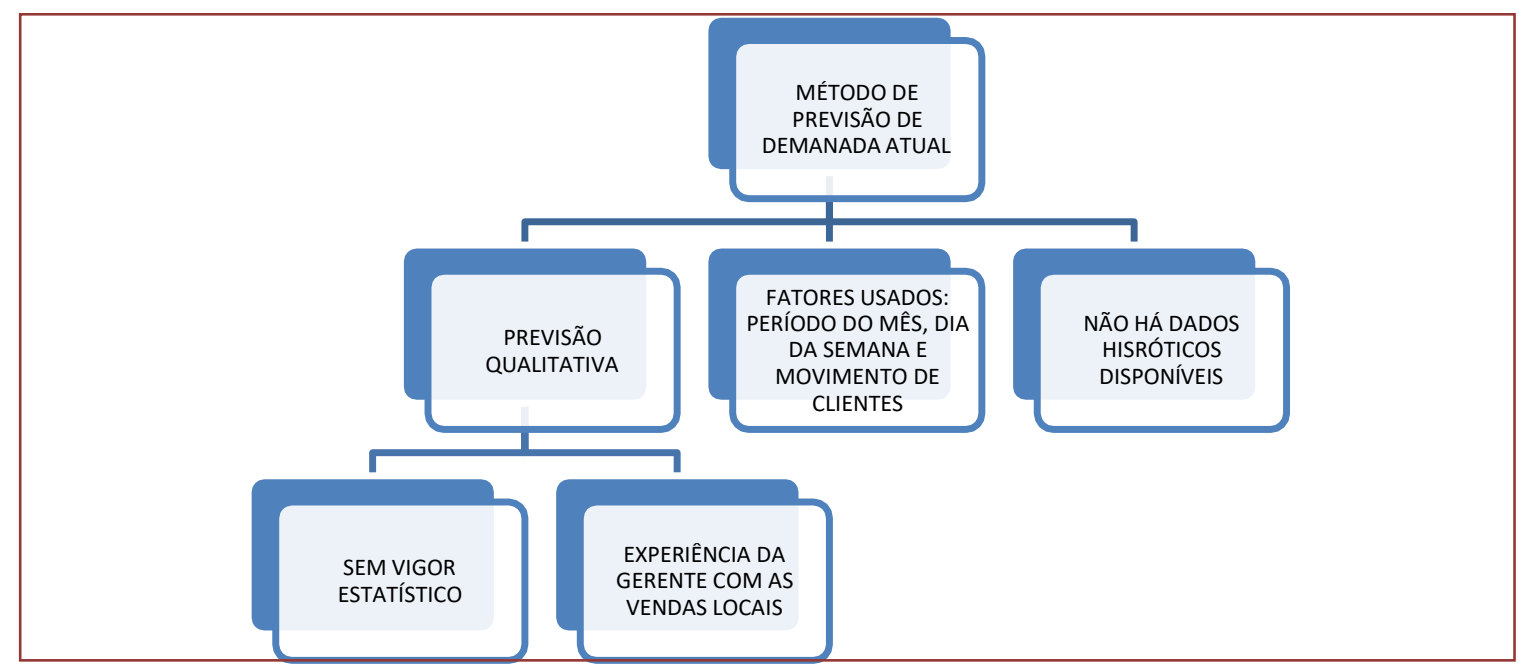

Fonte : Própria (2016)

\subsection{ESCOLHA DOS PRODUTOS A SEREM ANALISADOS}

Os salgados produzidos no estabelecimento são divididos entre as famílias de fritos e assados, sendo que para realização da análise do melhor método para previsão de demanda foi escolhida a família de salgados assados. Tal escolha deve-se a algumas características observadas que foram julgadas importantes, que são destacadas a seguir.
Os salgados assados possuem preço mais alto, pois demandam matéria prima mais cara e maior tempo de produção. Além disso, os salgados assados não podem ser produzidos e armazenados para venda em outro dia, pois perdem sua qualidade sendo que, nos casos de sobra, são doados aos funcionários.

O mix de produtos que compõe a família de salgados assados pode ser visto na Figura 6.

Figura 6 - Mix de salgados assados produzidos no estabelecimento

\begin{tabular}{|c|c|}
\hline \multicolumn{2}{|c|}{ SALGADOS ASSADOS } \\
\hline Pizza & Esfirra de came \\
\hline Enroladinho de presunto e queijo & Esfirra de frango \\
\hline Hambúrguer & Catupiry \\
\hline Salsicha com queijo & Frango e bacon \\
\hline Enroladinho de salsicha & - \\
\hline
\end{tabular}

Fonte: Própria, 2016 


\subsection{COLETA E ANÁLISE PRELIMINAR DOS \\ DADOS}

O método usado para coleta de dados pode ser analisado na Figura 7.

Figura 7 - Método de coleta de dados

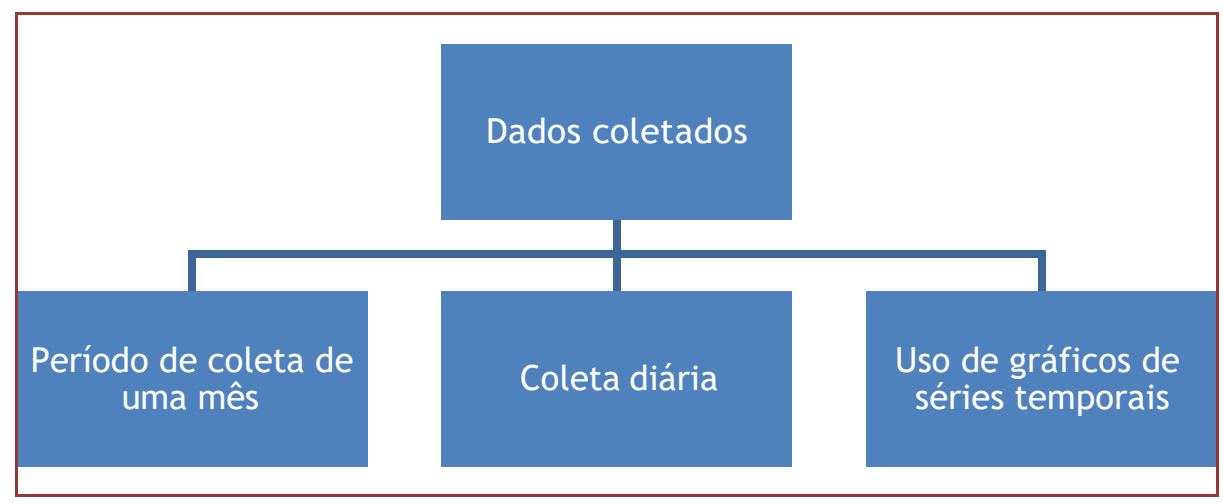

Fonte: Própria (2016)

Nos gráficos abaixo é possível observar o comportamento da demanda dos salgados para o período de 24 dias, correspondente a um mês de vendas, com valores coletados dia a dia.

A Figura 8 mostra os gráficos das séries temporais dos salgados, modeladas no software Excel, sendo que no eixo das ordenadas está a variável independente, tempo (medido em dias), e no eixo das abcissas está a demanda do produto em unidades físicas.

Figura 8: Gráficos das séries temporais individuais dos salgados assados

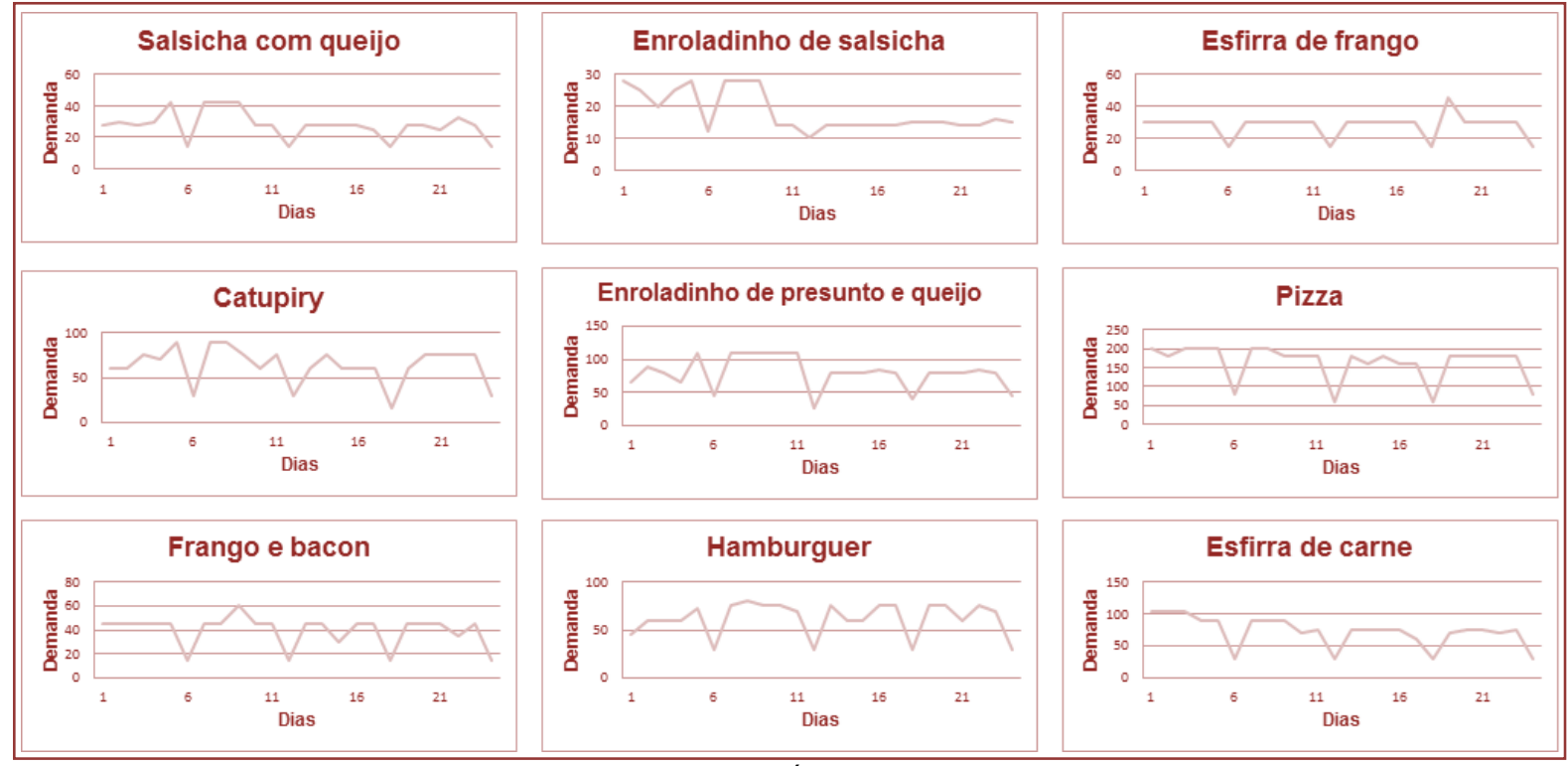

Fonte: Própria, 2016

0 gráfico de séries temporais da família de salgados assados, para análise agregada da demanda, pode ser visto na Figura 9. 
Figura 9: Gráfico de séries temporais da família de salgados assados

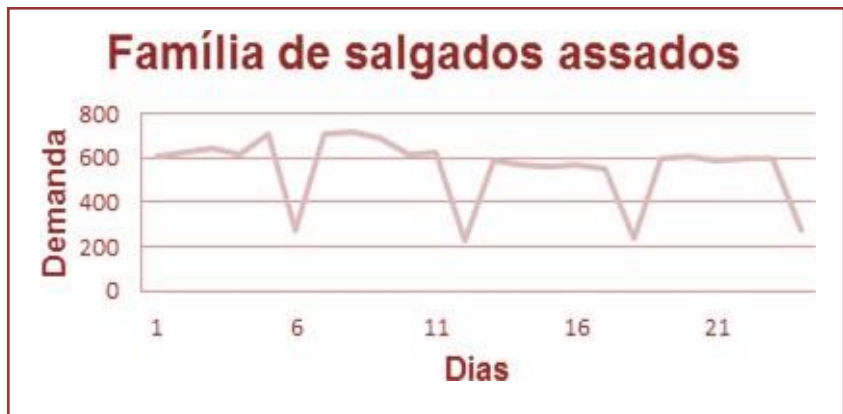

Fonte: Própria, 2016

Através dos gráficos de séries temporais, é possível perceber que os salgados, tanto individuais como agregados, possuem padrões de demanda dinâmicos, apresentando ciclo de sazonalidade onde o valor de demanda decresce e volta a crescer regularmente. Tal fato é decorrente, na maioria das vezes, da demanda observada aos sábados, que é o dia da semana que o estabelecimento permanece aberto por um período menor de tempo.

\subsection{ANÁLISE DOS MÉTODOS DE PREVISÃO}

Foram aplicados os métodos quantitativos baseados em séries temporais mais comuns à família de salgados assados e a cada salgado individualmente utilizando os dados de demandas passadas coletados, a fim de descobrir quais métodos incorrem em menores erros para previsão agregada e desagregada dos itens. Tais resultados podem ser vistos nas Figuras 10 e 11.

Figura 10: Comparativo entre métodos a partir da análise de erros - Previsão desagregada

\begin{tabular}{|c|c|c|c|c|c|c|c|c|c|}
\hline \multicolumn{5}{|c|}{ FFANGOE BACON } & \multicolumn{5}{|c|}{ ENROLADINDDE SALSICHA } \\
\hline METO00 & $\begin{array}{c}\text { Semalisia de } \\
\text { erres }\end{array}$ & $\begin{array}{c}\text { Desvin modio } \\
\text { absoluto }\end{array}$ & $\begin{array}{c}\text { Erro } \\
\text { quadtafico }\end{array}$ & $\begin{array}{c}\text { Porcentagem } \\
\text { Méds }\end{array}$ & METODO & \begin{tabular}{|c|}
$\begin{array}{c}\text { Somatónt de } \\
\text { erros }\end{array}$ \\
\end{tabular} & \begin{tabular}{|c|} 
Dessive medos \\
absoluto
\end{tabular} & $\begin{array}{c}\text { Erro } \\
\text { quadritico }\end{array}$ & $\begin{array}{c}\text { Porcentegem Media } \\
\text { Absoluta }\end{array}$ \\
\hline Inginue & 30 & B & $\$ 22$ & $518 \%$ & Ingitnuo & B & 3 & 3 & $20,0 \%$ \\
\hline Média máved & 33 & e & 230 & $51 \%$ & Mécke móvel & ह & 4 & 31 & $23,5 \%$ \\
\hline Media ponderada & 18 & $B$ & 2क & $568 \%$ & Média ponderada & 51 & 4 & 37 & $25 \%$ \\
\hline Suavizapjo simples & 48 & 9 & E & $37 \pi$ & Survizosjo simgles & 55 & $t$ & 3 & $20,2 x$ \\
\hline Suarizessos dupla & 9 & 5 & 4 & $8.7 \%$ & Suavizacbo dupla & 4 & 2 & 8 & $143 x$ \\
\hline $\begin{array}{l}\text { Saxsonalidade e } \\
\text { permanincia }\end{array}$ & 30 & 5 & 39 & $28 \%$ & $\begin{array}{l}\text { Sazonididade e } \\
\text { permenéncis }\end{array}$ & 1 & 2 & 6 & nook \\
\hline $\begin{array}{l}\text { Sazonalidade e } \\
\text { Iendincis }\end{array}$ & -5 & 6 & 8 & $\nabla, 2 x$ & $\begin{array}{l}\text { Sazondidade e } \\
\text { tenditencis }\end{array}$ & 5 & $t$ & 23 & $20,7 \%$ \\
\hline \multicolumn{5}{|c|}{ SALSICHA COM QUEIJO } & \multicolumn{5}{|c|}{ CATUPIRY } \\
\hline MÉTODO & \begin{tabular}{|c|}
$\begin{array}{c}\text { Somatória de } \\
\text { erros }\end{array}$ \\
\end{tabular} & \begin{tabular}{|c|}
$\begin{array}{c}\text { Desvio médio } \\
\text { absoluto }\end{array}$ \\
\end{tabular} & $\begin{array}{c}\text { Erro } \\
\text { quadrático }\end{array}$ & $\begin{array}{c}\text { Porcentagem } \\
\text { Média }\end{array}$ & MÉTODO & \begin{tabular}{|c|}
$\begin{array}{c}\text { Somatória de } \\
\text { erros }\end{array}$ \\
\end{tabular} & \begin{tabular}{|c|}
$\begin{array}{c}\text { Desvio médio } \\
\text { absoluto }\end{array}$ \\
\end{tabular} & \begin{tabular}{|c|} 
Erro \\
quadrático \\
\end{tabular} & $\begin{array}{c}\text { Porcentagem Média } \\
\text { Absoluta }\end{array}$ \\
\hline Ingênuo & 14 & 7 & 126 & $35,0 \%$ & Ingênuo & 30 & 20 & 791 & $50,9 \%$ \\
\hline Média móvel & 14 & 8 & 98 & $37,5 \%$ & Média móvel & 30 & 19 & 596 & $49,6 \%$ \\
\hline Média ponderada & 74 & 8 & 117 & $40,6 \%$ & Média ponderada & 169 & 20 & 699 & $55,1 \%$ \\
\hline Suavização simples & 17 & 6 & 72 & $25,0 \%$ & Suavização simples & 4 & 16 & 438 & $37,0 \%$ \\
\hline Suavização dupla & 9 & 3 & 20 & $14,4 \%$ & Suavização dupla & 28 & 9 & 117 & $19,0 \%$ \\
\hline $\begin{array}{c}\text { Sazonalidade e } \\
\text { permanência }\end{array}$ & 15 & 4 & 19 & $13,8 \%$ & $\begin{array}{c}\text { Sazonalidade e } \\
\text { permanência }\end{array}$ & -21 & 6 & 47 & $9,8 \%$ \\
\hline $\begin{array}{c}\text { Sazonalidade e } \\
\text { tendência }\end{array}$ & -20 & 9 & 110 & $34,9 \%$ & $\begin{array}{c}\text { Sazonalidade e } \\
\text { tendência }\end{array}$ & -92 & 14 & 278 & $30,4 \%$ \\
\hline
\end{tabular}


Figura 10: Comparativo entre métodos a partir da análise de erros - Previsão desagregada (continuação)

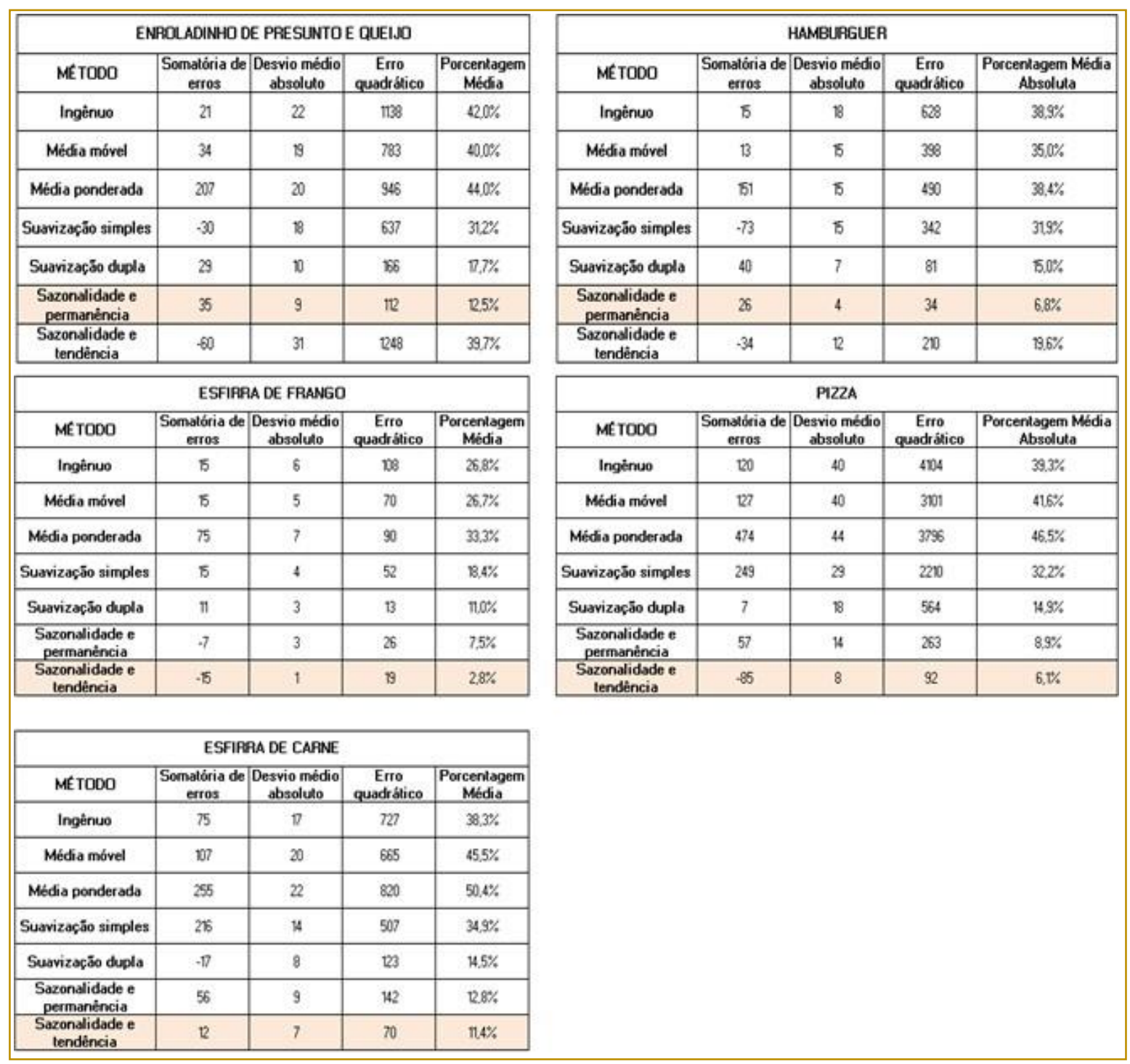

Fonte: Própria, 2016

Figura 11: Comparativo entre métodos a partir da análise de erros - Previsão agregada

\begin{tabular}{|c|c|c|c|c|}
\hline \multicolumn{6}{|c|}{ SALGADOS ASSADOS - PREVISÃO AGREGADA } \\
\hline MÉTODO & $\begin{array}{c}\text { Somatória de } \\
\text { erros }\end{array}$ & $\begin{array}{c}\text { Desvio médio } \\
\text { absoluto }\end{array}$ & $\begin{array}{c}\text { Erro quadrático } \\
\text { médio }\end{array}$ & $\begin{array}{c}\text { Porcentagem } \\
\text { Média Absoluta }\end{array}$ \\
\hline Ingênuo & 333 & 131 & 44648 & $36,3 \%$ \\
\hline Média móvel & 389 & 135 & 33093 & $38,0 \%$ \\
\hline Média ponderada & 1573 & 141 & 40869 & $42,1 \%$ \\
\hline Suavização simples & 512 & 96 & 23366 & $27,8 \%$ \\
\hline Suavização dupla & 61 & 59 & 6109 & $13,9 \%$ \\
\hline $\begin{array}{c}\text { Sazonalidade e } \\
\text { permanência }\end{array}$ & 197 & 42 & 2113 & $8.0 \%$ \\
\hline $\begin{array}{c}\text { Sazonalidade e } \\
\text { tendência }\end{array}$ & -564 & 62 & 6658 & $11,8 \%$ \\
\hline
\end{tabular}

Fonte: Própria, 2016 
Através das análises realizadas observou-se que o método que apresentou menor erro variou para cada caso, tendo no geral que os métodos de sazonalidade e permanência e sazonalidade e tendência se mostraram mais adequados devido ao menor desvio apresentado em relação ao valor real de demanda observado.

\section{RESULTADOS E DISCUSSÕES}

Os resultados e discussões podem ser vistas na Figura 12.

Figura 12 - Resultados e discussões

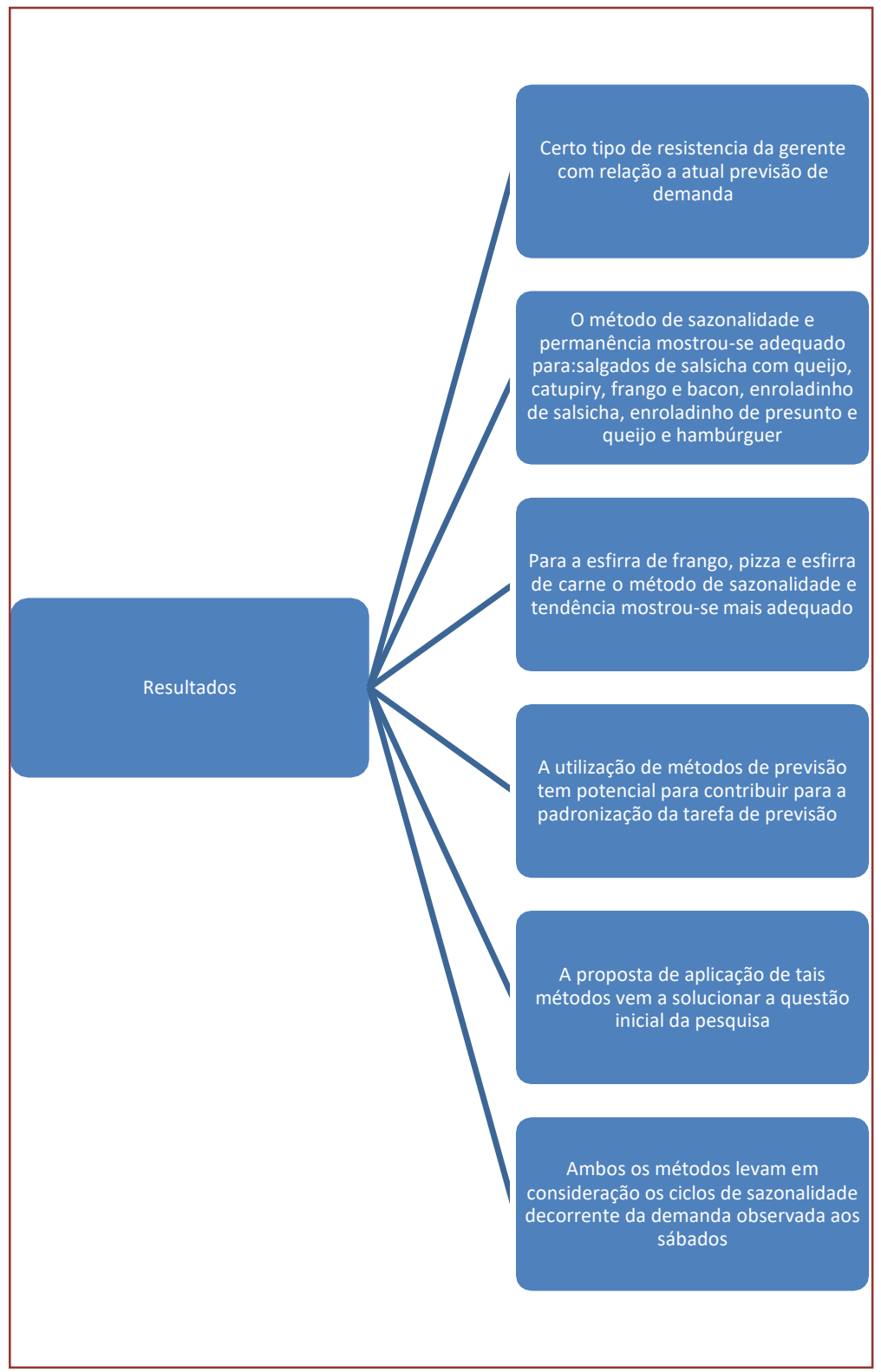

Fonte: Própria (2016)

\section{CONSIDERAÇÕES FINAIS}

Neste trabalho foram estudados e aplicados métodos quantitativos de previsão de demanda à família de salgados assados de uma lanchonete denominada "Sr. Lázaro
Salgados Express". Para aplicação de tais métodos são utilizados dados históricos de vendas, culminando na previsão da demanda para períodos futuros, que neste caso em particular é de curto prazo, medido em dias. 
Para escolha de quais produtos teriam sua demanda prevista, levou-se em consideração dados qualitativos, baseados em informações fornecidas pela gerente, visto que o estabelecimento não possui em sua rotina a coleta e documentação de informações referentes às vendas realizadas.

Ao realizar a análise preliminar dos dados notou-se que o histórico de vendas apresenta ciclos de sazonalidade, decorrentes da demanda observada aos sábados. Para alguns tipos de salgados observou-se permanência nos dados, já para outros foi possível identificar processos com tendência.

Após escolha de quais produtos teriam sua demanda prevista, optou-se por utilizar o software Excel para realização dos cálculos subsequentes referentes às previsões $e$ análises de erros. Foram aplicados os métodos ingênuos, de média móvel, média móvel ponderada, suavização exponencial simples, suavização exponencial dupla, processos com sazonalidade e permanência e processos com sazonalidade e tendência.

Para cada método aplicado foram realizadas análises de erro tais como somatória acumulada de erros, desvio absoluto médio, porcentagem média absoluta e erro médio quadrático. Para comparação entre os métodos de previsão, considerou-se como mais adequados os métodos que apresentaram menores valores de porcentagem média absoluta, que é um indicador de quanto a previsão está se afastando dos dados reais observados.

As análises realizadas permitiram comprovar que os métodos que levam em consideração a média dos períodos anteriores não são eficazes no caso de processos com sazonalidade e tendência, já que não considera tais componentes em seus cálculos, gerando maiores erros de previsão.

É necessário ressaltar que, por mais bem aplicado que seja o método de previsão, estas sempre incorrerão em erros, por tratarse justamente de uma previsão baseada em dados anteriores e não uma afirmação certeira sobre o que ocorrerá no futuro. Fatos como promoções, entrada de novos concorrentes e instabilidade do mercado devem ser observados atentamente para reação imediata, pois tais fatores podem impactar diretamente nas vendas do estabelecimento. Entretanto, tal fato não deve desencorajar o uso das previsões, visto que seu uso fornece uma base para a tomada de decisões e deve ser utilizada como aliada do previsor.

Com a utilização dos métodos de previsão propostos, espera-se que a empresa passe a produzir seus salgados de forma mais assertiva, possibilitando $\mathrm{o}$ atendimento adequado a seus clientes. A utilização de métodos de previsão também proporciona uma mudança cultural na empresa, visto que a coleta e documentação de dados históricos passam a ser essenciais, gerando informações para vários tipos de decisões que a empresa possa ter que tomar no futuro.

Assim sendo, o objetivo geral da pesquisa foi alcançado, pois conseguiu-se selecionar os produtos que possuem maior necessidade de previsão devido à suas características. Foi possível também aplicar os métodos propostos inicialmente, comparando-os através da análise de erros, encontrando que os métodos baseados em processos de sazonalidade e permanência e sazonalidade e tendência se mostraram mais adequados para tipos diferentes de salgados.

A partir dos objetivos alcançados com o trabalho, é possível responder à questão tema do trabalho "Qual método de previsão de demanda deveria ser utilizado em uma lanchonete, de forma que o cliente seja atendido com o nível de serviço desejado?". A solução proposta, baseada nos cálculos e análises realizadas é a utilização do método de sazonalidade e permanência para a previsão agregada de demanda e para os salgados de salsicha com queijo, catupiry, frango e bacon, enroladinho de salsicha, enroladinho de presunto e queijo e hambúrguer. Já para a esfirra de frango, pizza e esfirra de carne o método de sazonalidade e tendência mostrou-se mais apropriado.

Para estudos futuros, sugere-se a análise de todos os salgados produzidos no estabelecimento, possibilitando maior assertividade na compra de insumos e produção dos salgados, tanto assados como fritos. Recomenda-se também a continuação da coleta de dados para monitoramento dos métodos propostos, permitindo a validação dos resultados obtidos. 


\section{REFERÊNCIAS}

[1] BALLOU, R. H. Gerenciamento da cadeia de suprimentos / logística empresarial. Porto Alegre: Bookman, 2006.

[2] FERNANDES, F. C. F.; FILHO, M. G. Planejamento e controle da produção: dos fundamentos ao essencial. São Paulo: Atlas, 2010.

[3] GIL, A. C. Como elaborar projetos de pesquisa. São Paulo: Atlas, 2002.

[4] LUSTOSA, L.; et al. Planejamento e controle da produção. Rio de Janeiro: Elsevier, 2008.

[5] MARCONI, M. A.; LAKATOS, E. M. Fundamentos de metodologia científica. São Paulo: Atlas, 2003.
[6] MORETTIN, P. A.; TOLOI, C. M. C. Análise de séries temporais. São Paulo: Edgard Blücher, 2006.

[7] SEBRAE, Critérios de classificação de empresas: MEI, ME, EPP. Disponível em: <http://www.sebrae-

sc.com.br/leis / default. asp?vcdtexto=4154>. Acesso em: 8 de junho de 2016.

[8] TUBINO, D. F. Planejamento e controle da produção: teoria e prática. São Paulo: Atlas, 2009. 


\section{Gapítulo 21}

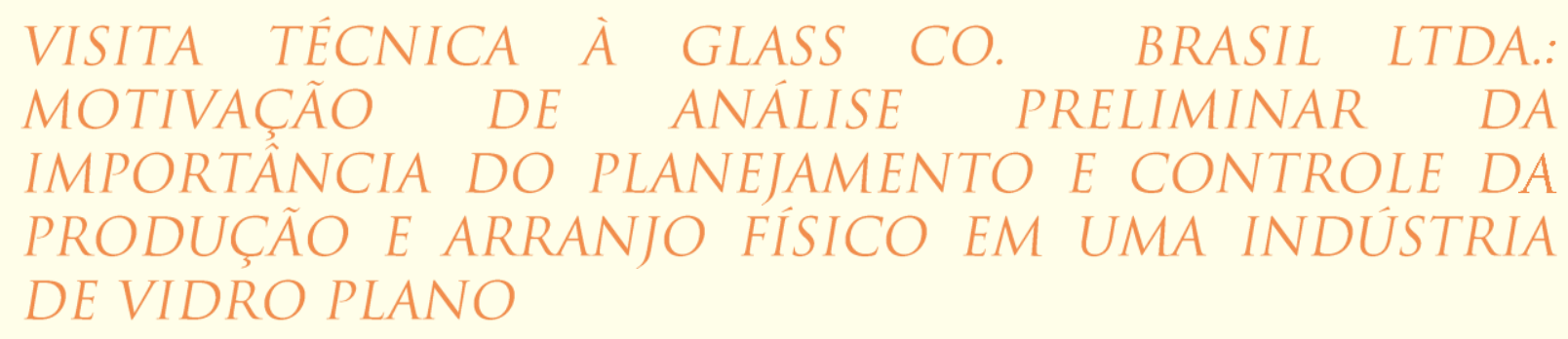

Leonardo dos Anjos Fernandes da Cruz

Marcos Felippe Gallo Veríssimo

Matheus Peccin Amaral

Renata Larcher Cury

Mario Santos de Oliveira Neto

Resumo: Com base em uma Visita Técnica realizada à uma unidade fabril da Glass Co. no Brasil, este trabalho destaca o PCP (Planejamento e Controle da Produção) com os processos realizados na fabricação do vidro plano. As empresas focam na qualidade e minimização nas perdas produtivas através da otimização do processo, visando agregar valor aos produtos na busca de diferencial competitivo. Um elemento fundamental que contribui para alcance de ganhos e vantagens mercadológicas é também o arranjo físico adequado, que pode ser entendido como a localização e distribuição espacial dos recursos produtivos. Realizou-se uma revisão bibliográfica e uma pesquisa exploratória em referências atuais de destaque e importância.

Palavras-Chave: Arranjo Físico, PCP, Processo Produtivo. 


\section{INTRODUÇÃO}

Com base na visita técnica realizada na unidade-sede brasileira, a Glass Co., em 24 de março do presente ano, foram observadas todas as etapas de produção de vidro, seu arranjo físico, desde a escolha das misturas da matéria-prima até a armazenagem do produto acabado. Será abordado, então, a necessidade de haver o planejamento da produção e estoque por três meses de antecedência da venda do vidro, cobertura de estoque estabelecida, bem como a importância do controle em todos os processos, a fim de garantir que 0 planejamento seja seguido.

O setor vidreiro teve considerável aumento de concorrência nos últimos anos. As maiores fabricantes mundiais de vidro e espelhos em volume de produção presentes no Brasil hoje são AGC, Saint-Gobain, Guardian Industries e Pilkington. Houve um crescimento da demanda interna por vidros planos no país nos últimos anos, principalmente nos setores automobilístico e de construção civil. Novos fabricantes foram atraídos pelo mercado nacional, enquanto os que já atuam têm lançado projetos de ampliação da capacidade produtiva.

\subsection{OBJETIVO GERAL}

Destacar a importância da otimização do PCP e do Arranjo Físico na maximização da produtividade nas empresas, além de tratar o processo produtivo da planta da fábrica de vidros e espelhos da Glass Co.

Discorrer sobre a indústria vidreira, sua posição no mercado nacional e como a Glass Co. está inserida neste contexto. Abordar a importância do planejamento correto e do adequado arranjo físico, respeitando as especificidades dos processos produtivos, capacidade produtiva e tipo de negócio; apresentar o layout e fluxo de produção observados na visita técnica; e analisar arranjo físico apontando pontos fortes e oportunidades.

\section{REFERENCIAL TEÓRICO}

\subsection{A HISTÓRIA DO VIDRO}

0 ano exato da descoberta do vidro é incerto, porém sabe-se que ocorreu em meados de 5000 A.C. A história conta que mercadores, ao fazerem uma fogueira apoiada sobre blocos de nitrato de sódio na beira da praia, se depararam com uma situação inusitada, onde o fogo, a areia e o nitrato formaram um líquido transparente, que viria a ser o vidro. "Não se pode afirmar com precisão a data de origem do vidro, mas, com a descoberta de objetos de vidro nas necrópoles egípcias, pode se garantir que ele é conhecido há pelo menos 4 mil anos" (BLINDEX, 2017). Segundo a AkzoNobel (2017) essa descoberta é atribuída por alguns aos fenícios, que teriam descoberto o vidro acidentalmente, enquanto utilizavam panelas de nitrato de sódio sob a areia do deserto. Eles teriam percebido esse material desconhecido se formando embaixo das panelas. Outros acreditam que foram navegadores fenícios que teriam feito a descoberta, enquanto acendiam fogueiras em praias onde haviam as duas matérias primas, areia e nitrato de sódio. Apenas em meados de 100 a.C. o processo de criação de vidro foi aperfeiçoado. Os romanos desenvolveram a técnica do sopro e possibilitaram a criação em massa do vidro - figura 1.

Figura 1 - Descoberta do vidro

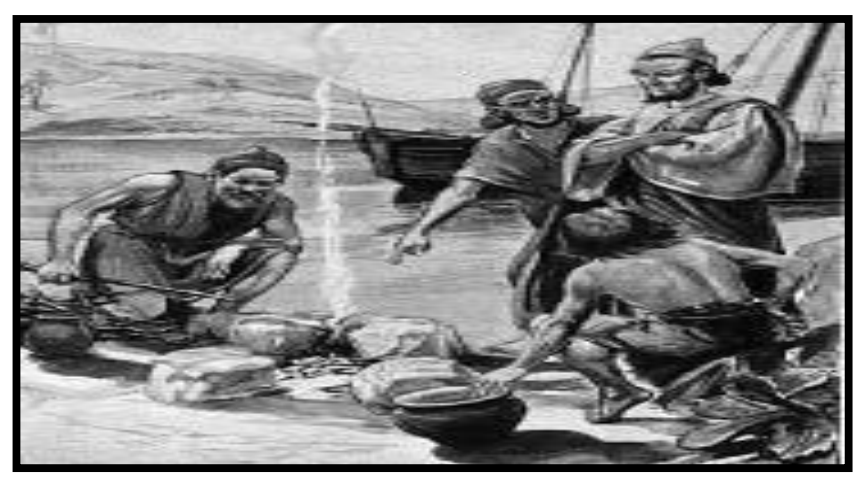

Fonte: https://static.wixstatic.com/media/ (2017) 
Com o passar dos anos as técnicas de manuseio do vidro evoluiram. Em 1773 o palácio de Versalhes era uma enorme construção para a família real francesa, onde foi necessário a abertura de técnicas de artesões da França e Inglaterra para poder criar vidros ajustados para tais moldes.

A produção em massa de vidros teve início graças a primeira Revolução Industrial, no setor automotivo no século XX e também a partir da invenção de duas novas técnicas de produção que se denominavam folha estirada e flutuação (float), onde a massa de vidro desliza sobre o estanho sem se misturar, estabelecendo um perfeito paralelismo, tornando o vidro totalmente liso. Mais tarde a indústria automobilística Ford foi responsável por criar uma nova base de produção em massa de vidros.

Em 1952 houve uma inovação que mudou todo o processo: a Pilkington Brothers (PILKINGTON, 2017) criou a técnica denominada float, fazendo flutuar o vidro derretido em estanho líquido; eram produzidos vidros tão planos que não se faziam necessários polimentos árduos. Assim era possível economizar material na obtenção de vidros de baixa espessura, além da nova possibilidade de produção em grandes quantidades. Esta inovação foi capaz de revolucionar a indústria de vidros. 0 processo é apto a produzir folhas finas sem irregularidades na superfície e chapas com melhor acabamento do que o produto antes desgastado e polido. A indústria Pilkington Brothers chegou a tamanha magnitude que foi capaz de ditar termos à indústria de vidros devido as suas patentes e licenças.

A Glass Co. surge nos Estados Unidos em 1932 , e nos anos 80 inicia competição com as demias fábricas existentes, deesafiando seus concorrentes com a utilização do sistema de flutuação e posteriormente cresceu a ponto de se tornar uma das maiores indústrias de vidro americanas. No ano de 1983 alcança o patamar das 100 maiores do mundo.

\subsection{COMPOSIÇÃO}

O vidro é uma substância líquida, com um altíssimo grau de viscosidade, variando em função da temperatura. É composto basicamente por areia (sílica ou vitrificante) sulfato ou carbonato (abaixo da temperatura de fusão da sílica) e um estabilizante (geralmente cal, que atribui resistência ao vidro). Quando essa mistura é elevada à temperatura de $1500^{\circ} \mathrm{C}$, forma uma massa plástica e viscosa. Suas propriedades dependerão de sua temperatura, pressão e das diversas temperaturas pelo qual passou no processo de resfriamento (AKZONOBEL, 2017) - figura 2.

Figura 2 - Composição do vidro

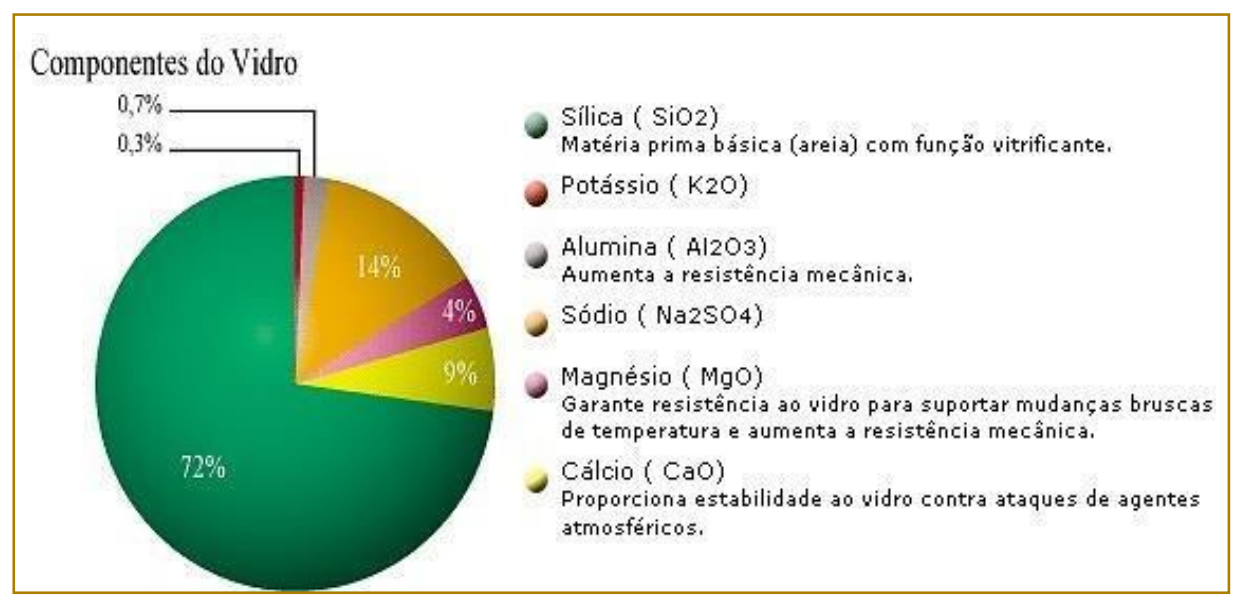

Fonte: http://s3.amazonaws.com/magoo/ABAAAA6DkAH-2.jpg (2017)

\subsection{GLASS CO.}

A Glass Co., é uma das maiores fabricantes de vidros do mundo, presente nos cinco continentes, em mais de 25 países, e emprega cerca de 18.000 pessoas. Segundo a revista Forbes (2017), a Glass Co. é uma 
das 100 maiores companhias privadas do mundo, estando na $67^{\mathrm{a}}$ posição, avaliada em U\$ 5,6 bilhões. No Brasil, possui duas unidades fabris e um centro de distribuição. Iniciou atividades em 1932 nos Estados Unidos produzindo para-brisas para automóveis. Em 1970 a empresa abriu uma outra fábrica para iniciar a produção do seu vidro cristal float.

\subsection{O PLANEJAMENTO E CONTROLE DA PRODUÇÃO (PCP)}

O PCP é responsável pela coordenação e aplicação dos recursos produtivos de forma a atender da melhor maneira possível aos planos de produção, administrando as informações que advém de diversas áreas do sistema produtivo (MOLINA \& RESENDE, 2006).

De acordo com Chiavenato (2008) apud Silva (2015) o planejamento da produção é vital para o sucesso da empresa pois fundamentase na previsão de vendas como base no que se pretende colocar no mercado e na capacidade de produzir, obtendo as informações das previsões de venda e alinhando à capacidade produtiva. Controle é uma das funções administrativas mais importantes porque consiste em medir e corrigir o desempenho para assegurar que os objetivos da empresa sejam atingidos. Esta tarefa é um processo cíclico e contínuo, verificando cada etapa do processo produtivo, corrigindo e aperfeiçoando os desvios daquilo que foi planejado figura 3 .

Figura 3 - PCP - Planejamento e Controle da Produção

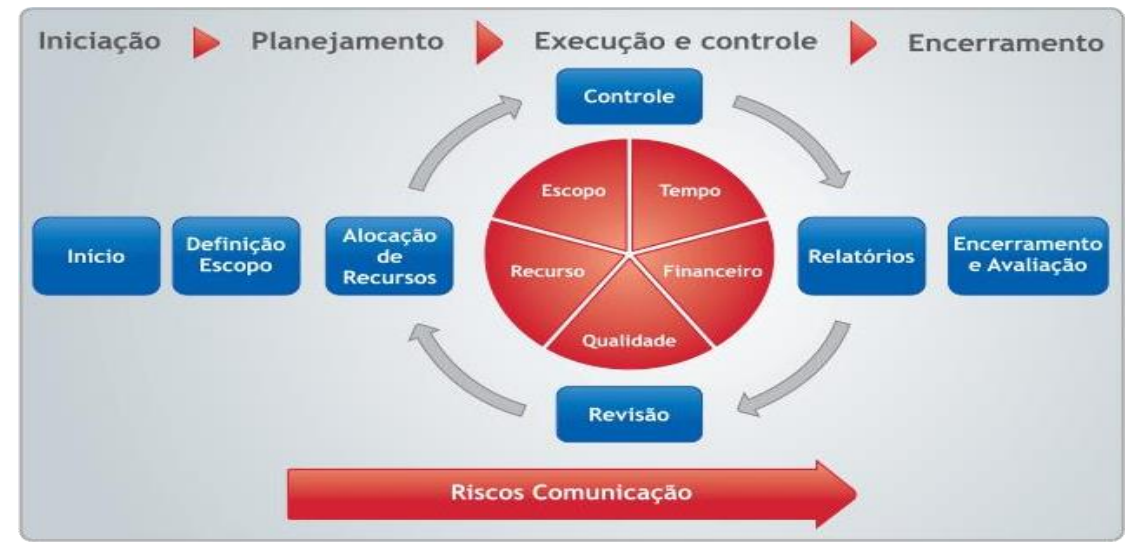

Fonte: https://media.licdn.com/mpr/mpr/ (2017)

\subsection{ARRANJO FÍSICO}

Segundo Silva \& Rentes (2012) "o layout ou arranjo físico do setor de produção de uma organização é definido como a localização e a distribuição espacial dos recursos produtivos, como máquinas, equipamentos, pessoas, instalações, no chão de fábrica". O que reforça Aguiar, Painado e Graeml (2007), que arranjo físico é a preocupação com a localização física dos recursos, máquinas e equipamentos.

Já Oliveira, Marins \& Dalcol (2012) dizem que o arranjo físico está diretamente ligado ao risco e à segurança. Deve contemplar aspectos de risco e segurança do trabalho, através do manuseio e movimentação de materiais, cargas, máquinas, ferramentas e equipamentos (OLIVEIRA; MARINS; DALCOL, 2012).
Gonçalves Filho (2001) afirma que as organizações devem se atentar a elementos fundamentais como um arranjo físico.

É a disposição de homens, máquinas e ferramentas em um conjunto capaz de integrar o fluxo de materiais e a movimentação destes de modo que a produção e todos os processos produtivos compreendidos nela sejam capazes de gerar produtos ou serviços. Além disso, um layout pode ser considerado ideal quando visa à redução de distância de movimentação de materiais, cargas e recursos humanos, bem como facilita a flexibilidade do sistema produtivo (MANTOVANI; LAIATE; LUCHE, 2016). 


\section{ASPECTOS METODOLÓGICOS}

A metodologia utilizada para o desenvolvimento deste estudo possui uma pesquisa bibliográfica, baseada nos principais autores de Planejamento e Controle da Produção e o processo de fabricação de vidro; visita técnica à empresa Glass Co. 0 artigo apresenta um estudo de caso de caráter crítico e descritivo focado também na análise do layout produtivo de uma empresa vidreira.

A metodologia adotada consiste em uma revisão bibliográfica com 0 intuito de fundamentar a necessidade de um layout de produção e observação in loco de uma produção vidreira, desde a matéria-prima até o armazenamento do produto acabado para uma análise descritiva de seu processo produtivo.

A linha de pesquisa seguida é a de Gestão da Produção, sendo empreendida uma revisão de literatura pertinente, considerando fontes de boa reputação acadêmica, tais como artigos publicados em periódicos e anais de seminários, ambos com avaliação cega pelos pares, teses, dissertações e trabalhos de conclusão de curso.

\subsection{VIDROS}

Para Barros (2010), não se sabe ao certo quando e nem qual povo foi o responsável pela descoberta do vidro, entretanto, alguns autores divergem neste aspecto, atribuindo sua criação aos egípcios ou aos fenícios. Embora tenha sido por volta do século 100 a.C. na antiga Roma que as primeiras janelas foram produzidas a partir do vidro. Na Idade Média é que sua utilização ascendeu com as vidraças das igrejas medievais. Porém alguns autores afirmam que o homem primitivo já o usava para a fabricação das suas armas, sendo as lâminas feitas de obsidianas (vidro escuro).

É inegável que com o aumento do conhecimento sobre os processos em geral, os mesmos tendem a se tornar mais simplificados. Com o "restrito" conhecimento sobre a produção em maior escala e com as dificuldades tecnológicas da época a fabricação do vidro exigia muito conhecimento dos artistas e demasiado esforço dos operários, constituídos em sua grande maioria por escravos. Os elementos para a fabricação eram basicamente os mesmos utilizados hoje em dia, como a barrilha, a sílica, o cal, o cálcio e o potássio (PINHEIRO, 2007).

Segundo Barros (2010) o vidro possui uma variedade de diferenciações, que podem ser classificadas quanto ao tipo (vidro recozido, vidro de segurança temperado, vidro de segurança laminado, vidro térmico absorvente e vidro composto); quanto à forma (chapa plana, chapa curva, chapa perfilada e chapa ondulada); quanto à transparência (vidro transparente, vidro translúcido, e vidro opaco); quanto ao acabamento da superfície (vidro liso, vidro polido, vidro impresso, vidro fosco, vidro espelhado, vidro gravado, vidro esmaltado e vidro termo); quanto à cor (incolor e colorido).

\subsubsection{VIDROS FLOAT}

De acordo com a Blindex (2017), o processo do vidro float (flutuação) foi desenvolvido pela Pilkington em 1952 e é padrão mundial para a fabricação de vidro plano de alta qualidade. $O$ índice de deformação e de ondulação da superfície do vidro float é bem menor do que o vidro comum. Segundo Pinheiro (2007), os vidros produzidos através do processo de flutuação têm como características óticas, planimétricas e de resistência com graus mínimos de imperfeição e alta qualidade. Segundo Montano \& Bastos (2013), através desse meio contínuo de fabricação de vidro float, utilizado por quase toda a produção mundial de vidro plano, é possível produzir vidros de diferentes espessuras para serem usados em revestimentos de edifícios e na indústria automotiva como para-brisas de carros. O processo de fabricação de vidros float pode ser dividido em seis partes, segundo Akerman (2103) - para os itens (a) e (b), e Pinheiro (2007) - para os itens (c), (d), (e) e (f):

\section{Mistura das matérias-primas}

As matérias-primas são precisamente misturadas, de acordo com o tipo de vidro a ser produzido, e logo são transportadas ao forno de fusão.

\section{Forno de fusão}

Segundo Pinheiro (2007), o forno pode chegar até uma temperatura de $1.600^{\circ} \mathrm{C}$ para que as matérias-primas sejam fundidas e transformadas em vidro. Dentro do forno há uma piscina sempre cheia de vidro fundido, onde o controle da quantidade é feito por um 
sistema que mede o nível do banho com extrema precisão, diminuindo e aumentando o ritmo do forno de acordo com o nível da piscina. Sobre a piscina fica o espaço para a combustão do combustível utilizado (normalmente gás), o que mantém a piscina aquecida e líquida. O forno é regenerativo, pois aproveita o calor da fumaça antes de descartá-la.

\section{Banho de flutuação}

O vidro fundido é derramado em uma piscina de estanho líquido. Esse processo contínuo é feito a $1.000^{\circ} \mathrm{C}$. Graças à diferença de densidade, o vidro flutua sobre o estanho. A espessura do vidro é determinada pela velocidade da linha, ou seja, quanto maior a velocidade, menor a espessura, e vice-versa.

\section{Recozimento}

$\mathrm{Na}$ galeria de recozimento a chapa de vidro passa por um túnel de arrefecimento, onde é resfriada controladamente até aproximadamente $120^{\circ} \mathrm{C}$. Esse processo permite acabar com as tensões do material recém saído do estado líquido para o sólido, possibilitando seu corte posteriormente.

\section{Inspeção}

Antes do corte o vidro deve passar por inspeção para garantir sua qualidade. Caso seja encontrado alguma falha, a folha será encaminhada para reciclagem.

\section{Corte}

O corte automático transversal, diagonal e linear é realizado com o vidro em movimento em resposta a ordens contidas nos computadores. Os lotes de vidro são apanhados e empilhados aos lados da linha para serem estocados.

\subsection{PROCESSO PRODUTIVO}

Composto fundamentalmente por uma cadeia de atividades desenvolvidas de modo a produzir um produto. São necessários controles rigorosos sobre o processo a fim de garantir confiabilidade e padrão de qualidade para todos os stakeholders - principais interessados envolvidos (COSTA JUNIOR, 2008).

\subsubsection{PRODUÇÃO EM FLUXO CONTÍNUO}

Segundo Braga (2008), agregado ao contexto da Manufatura Enxuta, emprega-se o conceito de produção em fluxo contínuo, sendo um aspecto de muita importância e valor para o sucesso de atividades em um processo produtivo. Quando esse conceito é instituído aos processos de fabricação favorece as operações gerando ganhos consideráveis de produtividade. De acordo com Kosaka (2009), a produção em fluxo contínuo é um sistema originado por Henry Ford, conseguindo reduzir drasticamente o lead time do processo produtivo e o custo de fabricação. Para o autor, o processo de fluxo contínuo objetiva reduzir à zero as paradas ou perdas de velocidade do processo. A premissa básica para alcançar esse objetivo de forma eficaz é alcançar processos estáveis.

\subsection{REAPROVEITAMENTO DE MATÉRIA- PRIMA}

Algumas empresas adotam, em sua gestão, o conceito de Produção Mais Limpa, que consiste em aprimorar as estratégias produtivas com medidas preventivas de redução de riscos ambientais e sociais. Com a utilização desse método a organização obtém vantagens financeiras, ambientais e sociais devido à diminuição do desperdício gerado (NASCIMENTO et al., 2008). Segundo Gomes (2013), o vidro descartado no processo produtivo pode ser reutilizado, sendo necessário sua coleta, limpeza, seleção e trituração.

\subsection{PCP - PLANEJAMENTO E CONTROLE DA PRODUÇÃO}

Planejamento estratégico da produção: “...consiste em estabelecer um plano de produção para determinado período segundo as estimativas de vendas e a disponibilidade de recursos financeiros e produtivos..." (TUBINO,2000). O PCP - Planejamento e Controle da Produção - assume importante papel no alcance de bons resultados na atividade industrial. Busca a otimização dos recursos para o alcance das metas de produção em certo tempo (KARIMI; GHOMI; WILSON, 2003).

\subsubsection{PREVISÃO DE DEMANDA}

A previsão de demanda consiste na busca de informações utilizando modelos estatísticos, matemáticos ou econométricos em relação ao valor das vendas futuras tanto de um item 
quanto de um conjunto de itens (MOREIRA, 2002). É essencial na operacionalização de diversos aspectos do gerenciamento de produção, como gestão de estoque e desenvolvimento de planos agregados de produção (PELLEGRINI, 2000). Ferramenta de previsão acurada auxilia na estratégia para operacionalização eficaz da produção facilitando o reconhecimento das prioridades, destinação de recursos (SILVA, 2016).

\subsubsection{ESTOQUE}

São produtos, mercadorias ou materiais que são preservados e mantidos fisicamente na empresa no aguardo do fluxo produtivo normal ou de serem vendidos (ASSAF NETO, 2009). Ballou (2006) descreve que quanto maior precisão na previsão de demanda mais inteligível será o controle dos estoques.

\section{VISITA TÉCNICA À GLASS CO.}

\subsection{A EMPRESA}

Essa unidade da Glass Co. começou a operar em 1998 constituindo uma de suas duas unidades fabris no Brasil. Atualmente conta com uma capacidade produtiva diária de 600 toneladas.

\subsection{PRODUTOS PRODUZIDOS}

No Brasil, a empresa produz os seguintes produtos:

$\begin{array}{lll}\text { Box } & \text { UltraClear } & \text { Cristal } \\ \text { Espelhado } & \text { Vidro Float } & \text { DiamondGuard } \\ \text { SatinDeco } & \text { Antirreflexo } & \text { DecoCristal } \\ \text { Espelho } & & \text { Reflect Glass Co. } \\ \text { Glass Co. } & & \end{array}$

\subsection{RECEPÇ̃̃O}

Antes de adentrar à linha de produção da Glass Co. houve uma pequena palestra sobre os pré-requisitos de segurança, pois é um local de alto risco. Por se tratar de uma produção de vidros, existe uma grande fornalha que chega a $1.600^{\circ} \mathrm{C}$ na parte interna do forno e $90^{\circ} \mathrm{C}$ na parte externa. Por isto devem-se usar os EPI's (Equipamentos de Proteção Individual) de maneira rigorosa, como capacete, sapatos de couro, óculos de proteção e protetor auricular, fora a regra que consiste em não encostar em qualquer superfície ao redor da fornalha.

\subsection{TOUR \\ 4.4.1. PROCESSO PRODUTIVO}

Através da visita foi possível in loco verificar as etapas que integram o processo produtivo da Glass Co. Atualmente, a fábrica possui uma linha de produção de vidros float. 0 processo produtivo dá-se em fluxo contínuo seguindo as etapas descritas a seguir:

Inicia-se a separação do "mix" de matériaprima necessária para a produção do vidro, de acordo com a especificação, coloração e dimensões desejadas. A mistura é transportada por esteiras ao forno para fundição a cerca de $1600^{\circ} \mathrm{C}$.

Após a este processo a massa fundida é direcionada para um compartimento com estanho derretido a uma temperatura de, aproximadamente, $600^{\circ} \mathrm{C}$.

Após isso, o vidro é guiado para fora do banho de estanho por esteiras. As dimensões do vidro são controladas de acordo com a velocidade de tracionamento que o mesmo é extraído desse compartimento.

Subsequente a isso a folha de vidro passa por um processo de recozimento dentro de fornos lineares sendo resfriada de maneira controlada, possibilitando alcançar tensão, dimensões e espessura desejados.

Posteriormente, o vidro é inspecionado por scanners que localizam defeitos, sinalizando aos operadores se há ou não a necessidade de intervenção no processo.

Após esta etapa, o vidro é cortado de maneira automatizada de acordo com as especificações da linha a ser produzida naquele momento.

$\mathrm{Na}$ sequência, finalizando, as chapas passam por esteiras sendo direcionadas através de sensores para duas saídas onde são empilhadas automaticamente por robôs. Cada lote é embalado e direcionado ao estoque da planta industrial, para ser transportado posteriormente.

\subsubsection{DETALHAMENTO}

O processo todo ocorre através de uma imensa esteira que vai desde a fornalha até a armazenagem do vidro. No início é colocada 
a matéria-prima (areia, calcário, barrilha, óxido de alumínio, sódio e ferro). Uma curiosidade é que dependendo da porcentagem de ferro, altera-se a coloração do vidro (incolor, verde e fumê). Também são misturados os cacos de vidro que são reaproveitados da própria linha de produção ou que retornam de outras empresas ou revendedores de vidro - figura 4.

Figura 4 - Processo de fabricação do vidro float

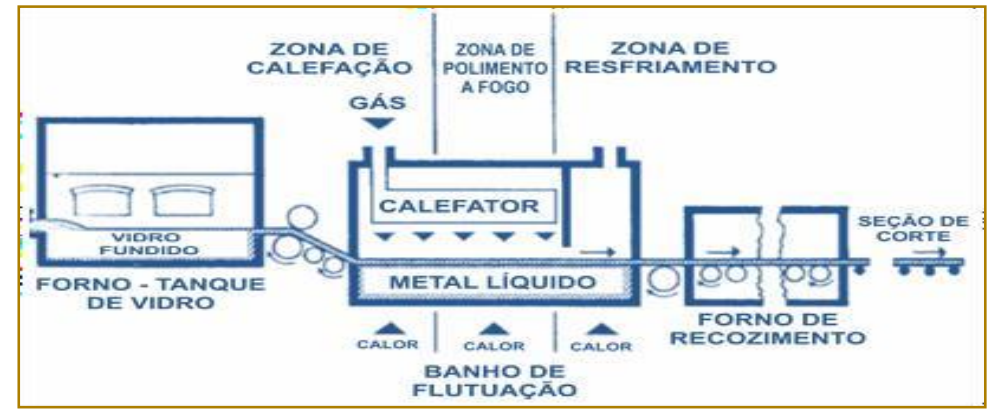

Fonte: https://static.wixstatic.com/media/.png (2017)

Os colaboradores que estavam presentes no setor esclareceram algumas perguntas específicas de como é determinado a quantidade de vidro a ser produzida, o quanto de matéria-prima será necessária, os critérios da coloração para a produção, dimensões da chapa de vidro, tempo de produção, como que é feita a manutenção da fornalha, dentre outros pontos.

O primeiro ponto comentado foi de que a estrutura do forno possui 20 anos de vida útil. Nesse meio tempo ela não para de trabalhar, funcionando 24 horas por dia durante essas duas décadas. Isso se deve pelo fato de que o forno não pode esfriar, pois levaria aproximadamente 30 dias para reaquecê-lo gradativamente novamente sem afetar a estrutura do material que o compõem. Quando sua vida útil expira a estrutura é totalmente desmontada para que a nova possa substituí-la. O tempo para executar esta tarefa é de cerca 120 dias (90 dias de montagem e 30 para aquecimento).

A Glass Co. está em um período que precisa fazer um enorme estoque para suportar esses 120 dias, visto que sua fornalha já possui 20 anos de utilização. É preciso ter um magnífico planejamento para que tudo ocorra de maneira ordenada, cumprindo os prazos para que a empresa enfrente positivamente esta transição de equipamentos - figura 5.

Figura 5 - Forno

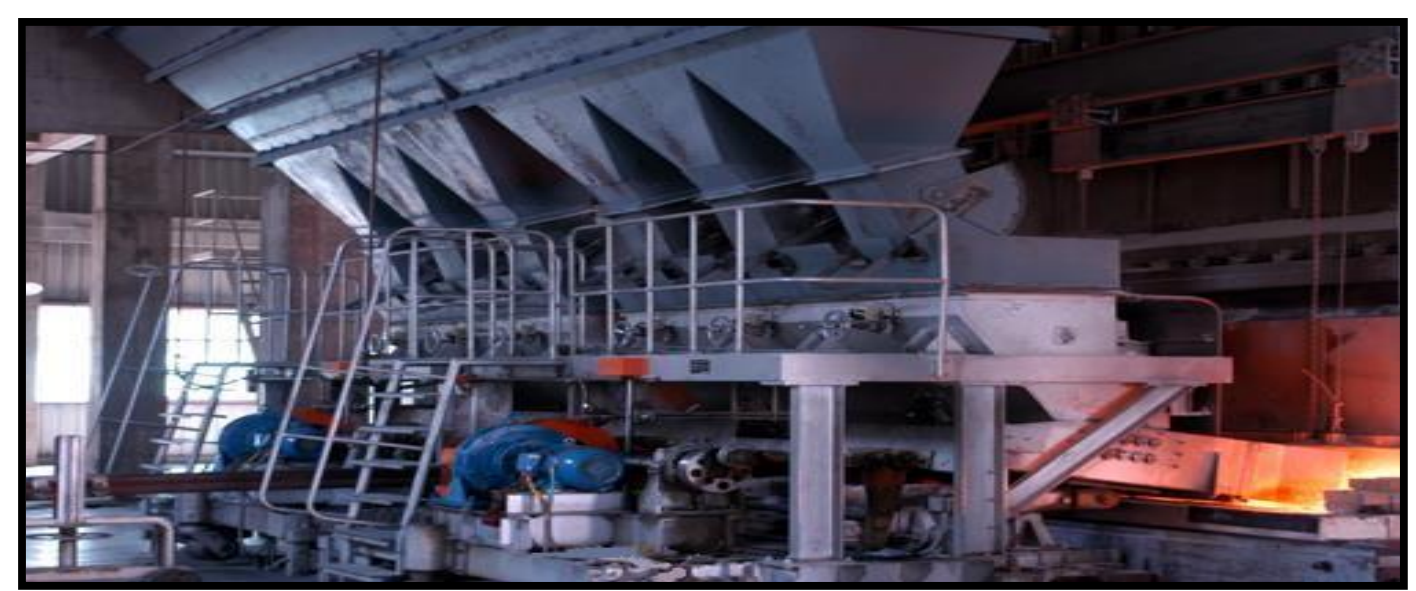

Fonte: https://allaboutthatglass.files.wordpress.com/2015/02/propriedade1.jpg (2017) 
O encarregado explicou os tipos de vidros e os critérios para produção de cada tipo de coloração. O vidro produzido pela Glass Co. possui um tamanho padronizado, com a espessura variando de $2 \mathrm{~mm}$ a $19 \mathrm{~mm}$. Em relação às cores, produz-se o incolor primeiro, depois o verde e posteriormente o fumê. Esta ordem justifica-se pela quantidade de ferro necessária em cada tipo. Quando é necessário fazer a transição do incolor para o verde, acrescenta-se ferro, a mesma coisa para a cor fumê. Para que seja produzida a coloração exata dos vidros existe um tempo de transição de uma cor para a outra. Do incolor para o verde são 3 dias, do verde para o fumê 5 dias, e o maior período é do fumê para 0 incolor, onde são necessários 7 dias, após este período que a linha de produção se "purifica" do ferro e o vidro retorna a ficar incolor - figura 6, em espessuras de 3, 4, 6, 8 e $10 \mathrm{~mm}$.

Figura 6 - Cores

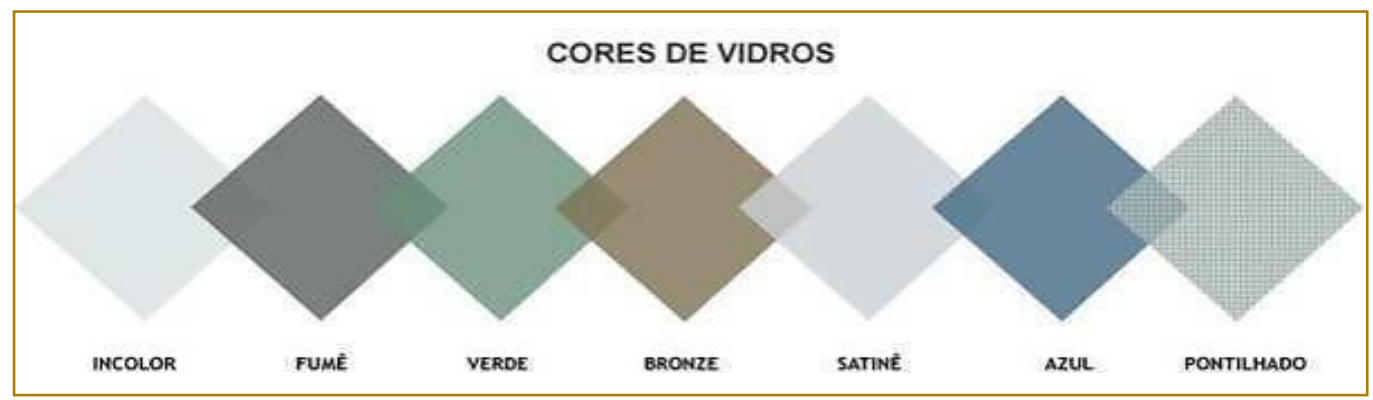

Fonte: http://vidroformas.com.br/wp-content/uploads/2012/01/cores-vidros.jpg (2017)

Durante o tempo de transição entre as colorações, ou seja, entre os lotes de produção, a indústria utiliza cacos de vidro junto à matéria-prima, assim há uma economia e reaproveitamento do material inutilizado por não ter a coloração ou os padrões estipulados. 0 processo de mudança de coloração no processo fabril gera grande preda de produção que pode variar até três dias de operação para atingir o padrão desejado. 0 refugo gerado é direcionado ao material reciclado para adição à matériaprima que comporá a mistura original.

A vantagem de trabalhar com o vidro é que $100 \%$ do material pode ser reaproveitado. $\mathrm{Na}$ verdade, é essencial que se faça isso, pois, segundo os gestores locais, é muito mais barato reaproveitar o vidro do que utilizar a matéria prima.

Depois desta primeira etapa de fundição a esteira com matéria-prima é encaminhada para o forno, e em seguida para uma piscina de estanho. Lá o vidro flutua sobre o estanho (por isso o nome float - "flutuar"). A justificativa de ser o estanho é devido à diferença de densidade dos materiais. Neste momento que é determinada a espessura do vidro, através da velocidade da esteira e estiramento, tração do vidro na mesma. Quanto mais lento o tracionamento, mais espesso; mais rápido, mais fino.

Conduzido para fora da piscina à etapa de recozimento. Em uma sala reservada, empregados ficam observando em monitores - vidro passando pela esteira. Qualquer defeito, desvio, bolhas que ocorra, rapidamente aciona-se o alarme e outros trabalhadores colocam ferros em formato de gancho dentro da esteira para acertar o vidro. Isto ocorre, devido ao fato já explicado de que a esteira nunca para. Então, deve-se ter muita agilidade e habilidade para não deixar que todo aquele segmento de vidro seja danificado.

Outra observação é que em cada etapa da produção a temperatura é controlada rigorosamente, visto que não podem haver choques térmicos e também para permitir que o vidro seja cortado posteriormente. A etapa seguinte ao recozimento é o corte, onde o vidro passa pelo scanner e o sistema computadorizado seleciona e dimensiona o tamanho dos cortes. O vidro "contínuo" agora é cortado em chapas de dimensões exigidas pelo mercado - figura 7. 
Figura 7 - Corte

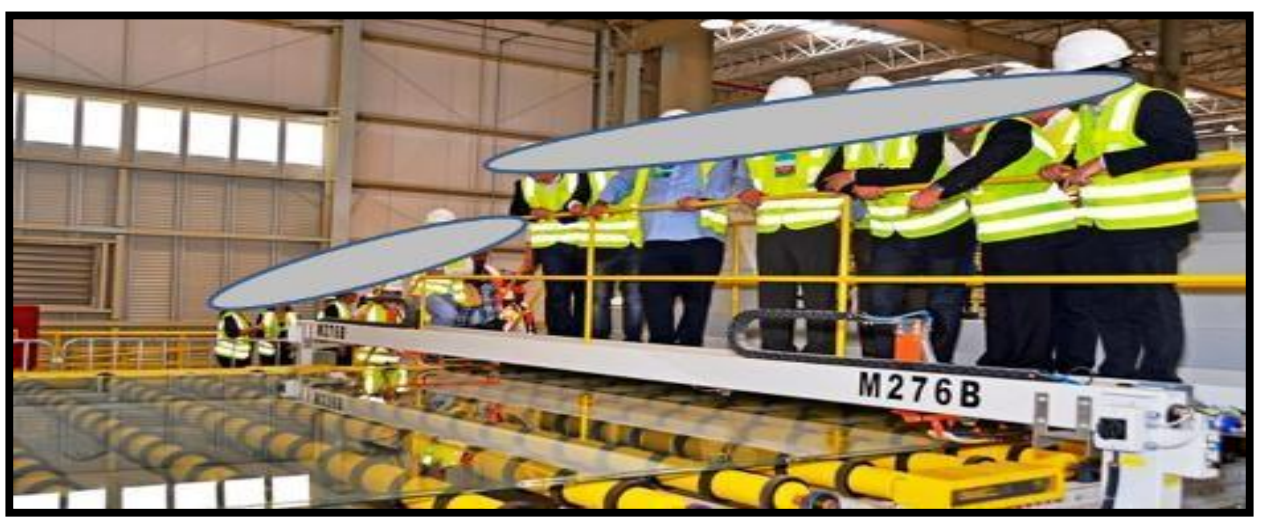

Fonte: http://www.abividro.org.br/wp-content/uploads/2014/04/vivix3.jpg (2017)

Depois do corte existe um segundo scanner, de alta precisão, que é responsável por identificar defeitos pontuais, ópticos e dimensionais que eventualmente apareçam. Caso seja captado alguma chapa de vidro com defeito, esta é automaticamente encaminhada para outras esteiras e será reaproveitada. Um detalhe importante é que todo o vidro que estava sendo produzido durante a visita será vendido depois de meses, pois não é possível trabalhar com produção posterior a pedidos. 0 vidro todo é estocado, de acordo com previsões e estatísticas feitas no planejamento, e quando um cliente faz um pedido, a Glass Co. já possui tudo guardado pronto para retirada. Geralmente tem-se cobertura de estoque de três meses - figura 8.

Figura 8 - Armazenagem \& Estoque

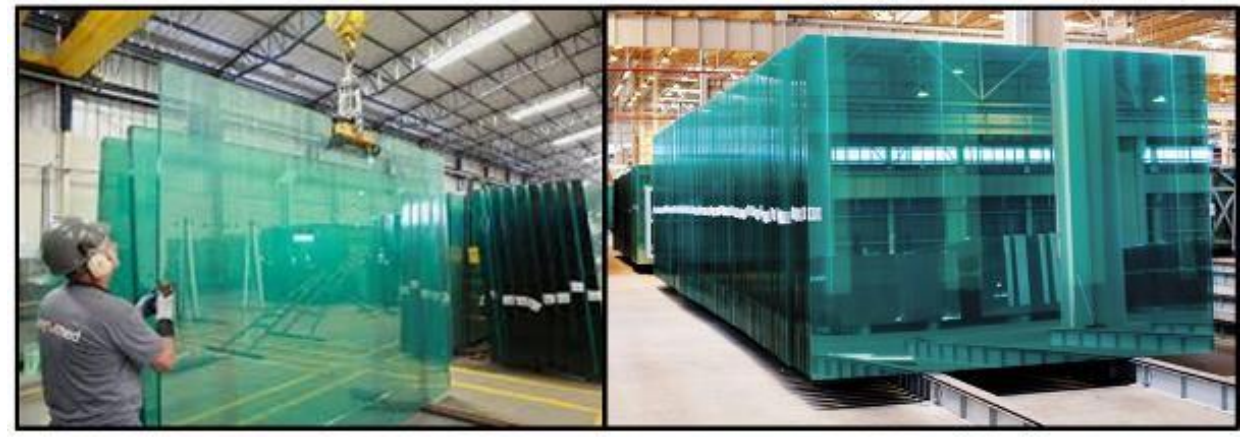

Fonte: http://www.vidros.inf.br/wp-content/uploads/2015/ed95/mercado_e_negocios/Estoque1.jpg (2017)

\subsection{REAPROVEITAMENTO DE MATÉRIA- PRIMA}

Outro aspecto importante foi observado: a redução do desperdício. Todo o resíduo (vidro) gerado no processo, seja durante o corte das placas, bem como acidentalmente, é coletado através de esteiras localizadas embaixo da planta, sendo direcionado novamente para 0 início do processo produtivo, onde é realizada a triagem e seleção do material a ser reaproveitado no processo produtivo, de acordo com a especificação do vidro a ser produzido. 0 vidro quebrado oriundo dos clientes também é reciclado.

\subsection{VIDA ÚTIL DO FORNO}

O forno utilizado na planta industrial funciona continuamente, sem ser desativado em momento algum durante 0 processo produtivo. Dessa forma, o mesmo possui uma vida útil de aproximadamente 20 anos, que serão completados em abril de 2018, o que ocasionará a parada da linha de produção durante 120 dias para a substituição de componentes. E a Visita Técnica foi oportuna 
porque contemplou o momento de preparação para parada do forno para sua manutenção a suportar mais 20 anos, que exige três meses de desligamento e mais um para sua gradativa reativação total. Ou seja, mais quatro meses de estoque serão incorporados ao planejamento padrão de cobertura de estoque adotado regularmente de três meses, totalizando pelo menos sete de meses de produto acabado estocado lotando as dependências da unidade, exigindo muita atenção e cuidados relativos à segurança.

\section{RESULTADOS \& DISCUSSÕES}

A produção da Glass Co. é planejada para ser estocada e vendida depois de meses, pois não seria possível produzir uma dada quantidade de vidro para um cliente no tempo, normalmente curto, solicitado. Além da questão da perda de tempo para troca de coloração do vidro, o que causaria uma necessidade de prazo maior. Planejar é estipular planos e metas para atingir um objetivo. A Glass Co. necessariamente vive com o que ela planeja. Ela precisa determinar o quanto e que tipo de vidro produzir hoje para ser vendido futuramente. Se houver um pequeno erro no planejamento, a fábrica terá um enorme prejuízo.

Então, cores, espessuras, forno, matériaprima, ..., perdas em mudança de processo são questões importantes a considerar para justo planejamento buscando o mínimo de perdas.

Controlar é submeter a exame de vigilância para garantir que o que foi planejado venha a ser concluído. Em todo o processo produtivo

\section{REFERÊNCIAS}

[1] AGUIAR, G. F., PAINADO, J., GRAEML, A. R. Simulações de arranjos físicos por produto e balanceamento de linha de produção: 0 estudo de um caso real no ensino para estudantes de engenharia. In: Congresso Brasileiro de Educação a Engenharia, 35, Curitiba, 2007. Anais... Curitiba: COBENGE, 2007, p. 1-15.

[2] AKERMAN, M. Introdução ao vidro e sua produção. Center for Research, Technology and Education in Vitreous Materials, Fevereiro de 2013. p. $35-43$.

[3] AKZONOBEL. A origem do vidro. Disponível em: https://www.akzonobel.com/wood/br/news/index/art igos/. Acesso em 16 de mai. 2017. da fábrica há funcionários, câmeras, sensores e alarmes para que ações rápidas sejam tomadas assim que haja o surgimento de alguma eventualidade ou emergência. 0 planejamento e controle rigoroso são fundamentais.

Outro fato a se destacar é que, apesar da mecanização e utilização de sensores e câmeras durante todo o processo, a tomada de decisão e intervenção é humana.

\section{CONSIDERAÇÕES FINAIS}

No caso da Glass Co. o planejamento é a vital. Todas as vendas que fazem dependem da disposição de produtos no estoque e repetido planejamento. Porém, vale ressaltar que um bom planejamento não é a certeza do sucesso. É preciso sempre fiscalizar o andamento dos processos para saber principalmente se o planejamento vem sendo respeitado.

A adequada disposição do arranjo físico também é de fundamental importância para o bom funcionamento de um processo produtivo, no caso, uma fábrica de vidros planos, evitando perdas com retrabalho e movimentação de materiais, redução de desperdícios, bem como ganhos na segurança dos colaboradores.

Outro aspecto fundamental observado foi o reaproveitamento de matéria prima, evitando o desperdício do vidro "perdido" durante o processo e diminuindo gastos com matériaprima e energia.

[4] ASSAF NETO, A. Finanças corporativas e valor. $4^{\mathrm{a}}$ ed. São Paulo: Atlas, 2009.

[5] BALLOU, R. H. Gerenciamento da cadeia de suprimentos: planejamento, organização e logística empresarial. $5^{\mathrm{a}}$ ed. Porto Alegre: Boockman, 2006.

[6] BARROS, C. Apostila de vidros - materiais de construção, edificações. Instituto Federal de Educação, Ciência e Tecnologia Sul-riograndense. Pelotas, 2010.

[7] BLINDEX. História do vidro. Disponível em: < http://www.blindex.com.br/sobre-ablindex/historia-do-vidro>. Acesso em 15 de mai. 2017.

[8] BRAGA, R. M. Os desafios para estabelecer um fluxo contínuo numa linha de produção: caso da indústria automobilística. 2008. 
79 f. Dissertação (Mestrado) - Curso de Programa de Pós-graduação em Engenharia Civil, Universidade Federal de Santa Catarina, Florianópolis, 2008. Cap. 5.

[9] COSTA JUNIOR, E. L. Gestão em processos produtivos. Curitiba: Ibpex, 2008.

[10] FORBES. Guardian industries. Disponível em: https://www.forbes.com/companies/guardianindustries/. Acesso em 15 de mai. 2017.

[11] GOMES, F. N. de O. A logística reversa e a reutilização do lixo eletrônico na matéria-prima de novos produtos. 2013. 67f. Monografia (Graduação em Administração) - Universidade Federal do Rio Grande do Sul, Porto Alegre, 2013.

[12] GONÇALVES FILHO, E.V. Arranjo físico de fábrica: um modelo para o processo de projeto e algoritmo genético para a formação de células de fabricação. Tese (livre docência) - Escola de Engenharia de São Carlos. Universidade de São Paulo. São Carlos. 2001.

[13] KARIMI, B., GHOMI, S. M. T. F., e WILSON, J. M. The capacitated lot sizing problem: a review of models and algorithms. Omega International Journal of Management Science, v. 31, n.5, p. 365- 378, 2003.

[14] KOSAKA, G. Fluxo contínuo. 2009. Disponível

http: / /www.lean.org.br/artigos/366/fluxo-

continuo.aspx. Acesso em: 05 abr. 2017.

[15] MANTOVANI, F. P.; LAIATE, J.; LUCHE, J. R. D. Proposta de melhoria do layout de um armazém de vidros automotivos. In: ENCONTRO NACIONAL DE ENGENHARIA DE PRODUÇÃO, 36., 2016, João Pessoa. Anais. Rio de Janeiro: Abepro, 2016. p. 1 - 20.

[16] MOLINA, Caroline Cristina; RESENDE, João Batista. Atividades do planejamento e controle da produção (PCP). Revista Científica Eletrônica de Administração-ISSN, p. 1676-6822, 2006.

[17] MONTANO, P. F., BASTOS, H. B. A indústria de vidro plano: conjuntura atual e perspectivas. BNDES, 2013. Disponível em: http://www.bndes.gov.br/SiteBNDES/export/sites/de fault/bndes_pt/Galerias/Arquivos/conhecimento/bns et/set3807.pdf. Acesso em 20 de Abril de 2017. p. 266 e 267.
[18] MOREIRA, D. A. Administração da produção e operações. São Paulo: Pioneira Thomson Learning, 2002.

[19] NASCIMENTO, L. F.; LEMOS, A. B. da C.; MELLO, M. C. A. de. Gestão socioambiental estratégica. Porto Alegre: Bookman, 2008.

[20] OLIVEIRA, U. R. de; MARINS, F. A. S.; DALCOL, P. R. T. Análise das dimensões de flexibilidade de manufatura requeridas para a prevenção de problemas em uma indústria de vidros. In: ENCONTRO NACIONAL DE ENGENHARIA DE PRODUÇÃO, 32., 2012, Bento Gonçalves. Anais... Rio de Janeiro: Abepro, 2012. p. 1 - 11.

[21] PELLEGRINI, F. R. Metodologia para implementação de sistemas de previsão de demanda. Porto Alegre, 2000. 146f . Dissertação (Mestrado) - Escola de Engenharia, Universidade Federal do Rio Grande do Sul, Porto Alegre, 2000.

[22] PILKINGTON. Revolução do float. Disponível em: < https://www.pilkington.com/pt$\mathrm{br} / \mathrm{br} /$ about-us/historia/revolucao-do-float>. Acesso em 15 de mai. 2017.

[23] PINHEIRO, F. C. et al. Evolução do uso do vidro como material de construção civil. 2007. Monografia - Curso de Engenharia Civil, Universidade São Francisco. p. 19-21.

[24] SILVA, A. L. da; RENTES, A. F. Um modelo de projeto de layout para ambientes job shop com alta variedade de peças baseado nos conceitos da produção enxuta. Gestão \& Produção, v. 19, n. 3, p. 531-541, 2012.

[25] SILVA, Carina Alves de. Planejamento e controle da produção, 2015. Disponível em:< http://www.administradores.com.br/artigos/academi co/planejamento-e-controle-da-producaopcp/92383/>. Acesso em 16 de mai. 2017

[26] SILVA, S. K. A. R. Aplicação de método de previsão de demanda e desenvolvimento de uma política de estoques em uma indústria de vidros temperados. 2016. 59f. Monografia (Engenharia de produção). Faculdade de Engenharia da Universidade Federal da Grande Dourados, 2016.

[27] TUBINO, D. F.. Manual de Planejamento e controle da produção. $2^{\mathrm{a}}$ ed. São Paulo: Atlas, 2000. 


\section{Bapítulo 22}

\section{APLICAÇÃO DA TEORIA DAS RESTRIÇÕES EM UMA}

INDÚSTRIA DE CONFECÇÕES

\section{Manoel Isac Maia Júnior \\ Plácido Carlos Fernandes de Queiroz}

Resumo: O objetivo primordial foi investigar os principais problemas do seu processo produtivo utilizando as ferramentas da Teoria das Restrições (Theory of Constraints - TOC), que busca aperfeiçoar a produção de uma organização por meio da identificação das restrições do sistema, minimizando-as ou eliminando-as, e sugerir a implementação de mudanças a fim de melhorar o desempenho global da fábrica. Os resultados apontaram que a principal restrição do sistema é a etapa ponto de cós. Assim foram usados alguns princípios da teoria das restrições como forma de tentar minimizar os impactos causados nessa etapa em relação ao restante do processo. Foi sugerida, então, a utilização das ferramentas citadas como forma de solução para as restrições. Agora surge a necessidade do emprego, pela empresa, das sugestões propostas, de modo a evidenciar - ou não a melhoria nos resultados. A pesquisa desempenhada é aplicada e exploratória, e, para proceder à coleta de dados, foram realizadas entrevistas e visitas à fábrica.

Palavras-chave: Teoria das restrições. Gargalo. Processo produtivo. 


\section{INTRODUÇÃOO}

A principal importância para a criação de métodos que auxiliem a tomada de decisão se dá devido a grandiosidade do mercado e sua crescente concorrência. Seguindo esse contexto foi desenvolvida por Eliyahu Goldratt, no ano de 1970 a Teoria das Restrições também denominada TOC, utilizada para aprimorar e acelerar o desempenho das organizações. A TOC serviu como base para a criação de um software de programação denominado de Optimezed Production Technology ou Tecnologia da Produção Otimizada (OPT), que foi projetado como uma técnica de planejamento com ênfase em gargalos. (VILLAR; SILVA; NÓBREGA, 2008).

Esse estudo tem como objetivo analisar os principais problemas do processo produtivo fazendo-se o uso das ferramentas da teoria das restrições - TOC e propor mudanças na busca de melhorar o desempenho geral da fábrica. Através de entrevistas colheram-se os dados necessários e feito observações nos processos de produção. Utilizaram-se os princípios da TOC baseados nos cinco passos e as regras de programação. Dessa forma será possível identificar as possíveis restrições de capacidade das operações e tentar minimizar os impactos causados por ela.

\section{REFERENCIAL TEÓRICO}

\subsection{TEORIA DAS RESTRIÇÕES}

O Dr. Eliyahu Goldratt em seu livro, A Meta, desenvolveu uma teoria que ficou conhecida como Teoria das Restrições, também denominada de TOC (Theory of Constraints). Esta teoria é de certa forma recente no aspecto prático da tomada de diversas decisões nas quais existem restrições nos processos de fabricação das empresas.

Como a teoria das restrições se baseia como o próprio nome diz, em restrições, necessitamos entender o que é uma restrição. Uma restrição é qualquer maquina ou atividade numa empresa que a impede ou limita a sua capacidade produtiva. É claro que a aplicação da TOC em uma empresa tem que ser levada em conta a definição dos objetivos feitos por elas a serem atingidos. Para a maior parte das empresas, o objetivo principal é o lucro presente e sua sustentabilidade no futuro.
Conforme Corrêa e Gianesi, (1996), os gargalos são considerados como recursos restritivos, ou seja, aqueles que limitam a capacidade produtiva e os não-gargalos possuem capacidade maior do que a demanda, sendo assim, deverá haver um balanceamento do fluxo, devendo os recursos não gargalos estar subordinados aos gargalos para que não haja um acumulo de estoques. Existem dois tipos básicos de restrições:

a) Físicas: $\mathrm{Na}$ maior parte das vezes estão relacionadas a recursos: máquinas, equipamentos, veículos, instalações, sistemas etc.

b) Não-Físicas: As restrições não-físicas podem ser a demanda por um produto, um procedimento corporativo ou mesmo um paradigma mental no encaminhamento de um problema.

\subsection{APLICAÇÃO E IMPLEMENTAÇÃO DA TEORIA DAS RESTRIÇÕES}

A TOC tem sido aplicada em três diferentes níveis de tomada de decisão: gerência da produção, na resolução de problemas e principalmente relacionados aos gargalos, à programação e à redução dos estoques; análise de rentabilidade, levando à mudança de decisões baseadas em custo para decisões baseadas na melhoria contínua das operações que afetam a rentabilidade; e, gestão de processos, na identificação de fatores organizacionais, que não são necessariamente recursos, que impedem as empresas de atingirem seus objetivos.

A teoria das restrições tem cinco passos para se chegar no objetivo, esses cinco passos são um ciclo onde o quinto sempre voltara para o primeiro, pois quando se melhora uma restrição, fazendo com que a mesma não seja mais restrição, outra atividade passa a ser o novo gargalo da produção. Os cinco passos são:

I. Identificar a restrição/gargalo do sistema produtivo: Numa empresa industrial, a restrição pode ser o tempo disponível ou a capacidade de uma máquina, de um departamento ou de uma estação de trabalho. Para empresas de serviços ou de alta tecnologia, a restrição pode ser o tempo disponível dos funcionários mais capacitados.

II. Calcular a rentabilidade por unidade de recurso consumida na restrição: Este valor é 
obtido pela divisão da rentabilidade ou margem de contribuição unitária pelo consumo de recursos da restrição para produzir um produto. A chave para maximizar o lucro é concentrar na produção e na comercialização de produtos com a maior rentabilidade por unidade de recurso consumida na restrição.

III. Subordinar o sistema à restrição: Os recursos e estoques devem ser gerenciados de modo a prover exatamente o necessário para atingir os objetivos definidos para a restrição. Este passo pode implicar na ociosidade de recursos que não são restrições. Normalmente o sistema é subordinado a restrição através de um método de programação e controle da produção chamado de Tambor-Pulmão-Corda (Drum-Buffer-Rope ou DBR).

IV. Romper ou elevar a restrição do sistema: Através da melhoria contínua das operações, da aquisição de capacidade ou de flutuações na demanda, por exemplo, a restrição do sistema pode ser rompida ou elevada, de modo que a esta restrição deixe de sê-lo. Uma nova restrição física ou não física, interna ou externa, assumirá o papel da restrição anterior.

V. Identificar a nova restrição do sistema caso a restrição seja rompid0: Deve ser observado, no entanto, que a implementação da TOC pode exigir uma mudança substancial na maneira com que a empresa opera. Por exemplo, suponha que, numa empresa, produzir e comercializar o produto de menor preço unitário e maior demanda maximize o lucro (objetivo). Se a empresa remunera sua força de vendas com base em comissões como um percentual da receita, pode existir um incentivo implícito para vender os produtos mais caros. Este cenário demandaria uma nova política de remuneração da força de vendas.

\subsubsection{OS PRINCÍPIOS DA TEORIA DAS RESTRIÇÕES}

São nove os princípios da Teoria das Restrições para a programação da produção. Segundo Goldratt apud Cogan (2007, p. 25) são eles:

1. Balancear $o$ fluxo $e$ não $a$ capacidade: A importância está no equilíbrio do fluxo de produção da fábrica e não da demanda, ou seja, a ênfase recai sobre o fluxo de materiais e não na capacidade instalada dos recursos. Mas para isso é necessária a identificação das restrições do sistema que vão limitar o fluxo.

2. 0 nível de utilização de um recurso não-gargalo não é determinado pelo seu próprio potencial, mas por outra restrição do sistema: Determina que a utilização de um recurso não-gargalo é estabelecida em função das restrições existentes no sistema, por limitação de capacidade de um recurso ou de demanda de mercado.

3. A utilização e a ativação de um recurso não são sinônimas: A utilização representa o uso do recurso não-gargalo de acordo com a capacidade do recurso gargalo, já a ativação, representa o uso do recurso não-gargalo em volume maior do que a capacidade do recurso gargalo, este não contribui com os objetivos da otimização que seria o balanceamento do fluxo.

4. Uma hora perdida no gargalo é uma hora perdida no sistema inteiro: Tendo em vista que deve haver um balanceamento do fluxo estabelecido pelo gargalo, qualquer tempo perdido neste, diminui o tempo total disponível para atender o volume, sendo assim, somente haverá benefício na programação da produção reduzindo o tempo de preparação nos recursos gargalos, aumentando assim a capacidade do fluxo.

5. Uma hora economizada onde não é gargalo é apenas uma ilusão: A economia de tempo em um recurso gargalo é uma miragem, pois tendo em vista que os recursos não-gargalos trabalham de acordo com o nível do gargalo, esta economia não trará nenhum benefício, pois estaria elevando o montante de tempo ocioso já existente.

6. Os gargalos governam os ganhos e o inventário: Conforme exposto acima o sistema é governado pelo recurso gargalo, tendo em vista que este determina o fluxo de produção e consequentemente $o$ inventário e os ganhos.

7. 0 lote de transferência não pode e muitas vezes não deve ser igual ao lote de processamento: 0 lote de transferência deve ser de acordo com a capacidade do setor em que será executada a próxima atividade no produto, tendo em vista que não é vantajoso repassar todo lote processado se este não puder ser efetivamente concluído em uma próxima etapa.

8. O lote de processo deve ser variável e não fixo: Os lotes de processamento podem 
variar de uma operação para outra, ao contrário dos modelos de sistemas tradicionais, conduzindo a um problema de escolha do tamanho do lote a ser adotado, uma vez que as características das operações individuais podem conduzir a um cálculo de lote diferente.

9. Os programas devem ser estabelecidos considerando todas as restrições simultaneamente: A programação da produção, o quanto e quando se deve produzir, seguirá de acordo com as restrições do sistema.

\subsubsection{TAMBOR-PULMÃO-CORDA (DBR)}

O DBR é o método de programação e controle da produção que permite subordinar o sistema à restrição. Seu objetivo é assegurar a máxima utilização da restrição para atende à demanda. O Tambor (Drum) é a programação detalhada da restrição, com os itens a ser produzidos, suas quantidades, os horários de início e de término. A demanda é o ponto de partida para a determinação do Tambor.

Os recursos que não são restrição devem seguir o ritmo da restrição. É por isto que a programação da restrição é chamada de Tambor, por "determinar o ritmo de toda a tropa". Os recursos que não são restrição devem ser gerenciados de modo a não faltarem itens na restrição, caso contrário, o objetivo será ameaçado. Como os recursos que não são restrição possuem maior capacidade que a demanda, não é necessário programá-los. 0 método DBR sinaliza para a liberação dos itens necessários para a alimentação do Tambor e para que os recursos que não são restrição processem esta quantidade o mais rápido possível.

Em função das incertezas, uma proteção deve ser criada para a liberação dos itens algum tempo antes de seu processamento na restrição. Esta proteção é chamada de Pulmão (Buffer), e na TOC, o Pulmão é medido em unidades de tempo, e não quantidades de itens. A duração do Pulmão é influenciada pela velocidade dos outros recursos que não são restrições e pela variância do tempo de resposta das operações. Maior a variância, maior a duração do Pulmão. Maior a velocidade dos outros recursos, menor o Pulmão.
Em linhas gerais o Pulmão é criado para proteger a programação. É uma antecipação do instante de liberação dos itens de modo a garantir o cumprimento do programa de produção. Na TOC pode haver três tipos de pulmão:

1. Pulmão da Restrição (Constraint Buffer): Objetiva proteger o Tambor com a liberação antecipada dos itens para a restrição.

2. Pulmão do Carregamento (Shipping Buffer): A restrição não é o único elemento com programas a serem observados. 0 carregamento dos produtos acabados também deve ser protegido com um pulmão, de modo a ser assegurada a confiabilidade dos prazos para os clientes.

3. Pulmão da Montagem (Assembly Buffer) - Quando os itens que foram processados pela restrição devem ser montados com itens que não passaram pela restrição, é necessário criar outra proteção. Neste caso, todas as partes que passaram pela restrição devem ser utilizadas para formar o produto acabado e desta forma, nenhum item "não-restrição" deve estar faltando. Nem todas as empresas industriais necessitam dos três tipos de pulmão. Esta decisão depende do tipo de processo e da localização da restrição. Se existe uma restrição física, associada a um recurso, haverá pelo menos dois pulmões, o da restrição e o do carregamento. O Pulmão da Montagem será necessário se houver uma operação que conjuga itens que foram com outros que não foram processados por restrições. Todos os itens se enquadram em duas alternativas:

- Os itens que são processados pela restrição terão em seu fluxo dois pulmões: da Restrição e do Embarque;

- Os itens que são montados com outros itens que são processados pela restrição terão em seu fluxo dois pulmões: da Montagem e do Embarque.

Tomando o Tambor como o ponto de partida e subtraindo o Pulmão da Restrição é possível determinar o instante da liberação dos itens. A Corda assegura que será liberada a quantidade exata de itens que será processada pela restrição. Em outras palavras, através da Corda é assegurado que todos os recursos operarão no mesmo ritmo que a restrição, sem elevação nos níveis de estoque em processamento. 


\section{METODOLOGIA}

Em suma, para a realização desta pesquisa, inicialmente foram estudados em profundidade os conceitos da base teórica adotada, isto é, os conceitos da Teoria das Restrições. Para a coleta de dados, foram realizadas entrevistas com uma gerente de produção. Também foram realizadas observações nos processos de produção no interior da fábrica durante a realização de algumas visitas. Após essa fase, as entrevistas continuaram por redes sociais e por troca de mensagens via correio eletrônico para o esclarecimento de dúvidas que iam surgindo no decorrer da pesquisa. Após a coleta dos dados, foram usados os cinco passos para a focalização e as regras de programação da produção da Teoria das Restrições.

\section{ESTUDO DE CASO \\ 4.1. DESCRIÇÃO DA EMPRESA}

Este estudo foi realizado em uma prestadora de serviços do grupo Guararapes Confecções $\mathrm{S} / \mathrm{A}$. Está localizada no município de Mossoró/RN, começou a atuar no mercado em meados de 2015. Seu mix de produtos é composto por calças, shorts e saias, tendo como matéria prima o jeans. A matéria prima é oriunda da matriz que fica situada na cidade de Natal/RN.

\subsection{PROCESSO PRODUTIVO}

Quadro 1 - Etapas do processo de confecção de costura

\begin{tabular}{|c|c|}
\hline Etapas & Operação \\
\hline 1 & Frente bolso (pregar visto) \\
\hline 2 & Pregar bolso frente \\
\hline 3 & Acabamento \\
\hline 4 & Fixação do bolso \\
\hline 5 & Pregar ziper \\
\hline 6 & Fazer o jota do ziper \\
\hline 7 & União das partes (frente frontal) \\
\hline 8 & Fechamento das palas \\
\hline 9 & Marcação \\
\hline 10 & Pregar bolso traseiro \\
\hline 11 & Inspeção de qualidade \\
\hline 12 & Fechamento lateral \\
\hline 13 & Desponto lateral \\
\hline 14 & Fechamento entre perna \\
\hline 15 & Cós \\
\hline 16 & Colocação da etiqueta \\
\hline 17 & Ponto de cós \\
\hline 18 & Bainha \\
\hline 19 & Acabamento \\
\hline 20 & Passante cinto \\
\hline 21 & Limpeza \\
\hline 22 & Inspeção de qualidade \\
\hline
\end{tabular}


Inicia-se a partir da coleta do jeans no estoque para dar início à primeira etapa de preparação da peça na primeira estação de trabalho, que é pregar a vista do produto, feito isso será costurado o bolso da frente e realizado o acabamento.

Após o termino do acabamento, é o momento de fixar as partes internas dos bolsos. Feito isso, é fixado o zíper e feito o "jota" do mesmo, que é finalizado na união das partes, dianteira e traseira. Finalizando, assim, a primeira parte do processo.

A segunda parte, do início com o fechamento das palas e a marcação dos bolsos traseiros para que seja pregado no processo seguinte e indo até uma inspeção de qualidade intermediaria, etapa em que o produto semiacabado será analisado em buscas de possíveis avarias.

Caso o item não esteja de acordo com os critérios de qualidade, ele irá voltar à primeira operação, onde será desmanchado e terá sua produção reiniciada. Caso o item esteja conforme com os padrões de qualidade, prosseguirá na linha de montagem para a etapa em que ocorrerá o fechamento lateral da peça, seguido pelo desponto lateral e fechamento entre perna, assim finalizando mais uma etapa do processo produtivo.

Na última etapa é inserido o cós, seguido pela prega da etiqueta e após isso é feito o ponto de cós. Uma operação bastante detalhada, umas das mais complexas no processo de confecção de roupas. E por fim, teremos 0 processo de costura da bainha, acabamento, fixação dos passantes do cinto, limpeza final da peça, onde será retirado as sobras de linha para enfim, a peça ser encaminhada para a inspeção de qualidade para que se possa avaliar a conformidade final do produto. Caso esteja conforme as especificações emitidas pela Guararapes S/A, o item vai para o estoque final, caso contrário, a peça será concertada.

\subsection{APLICAÇÃO DA TEORIA DAS RESTRIÇÕES}

Ao definir as etapas do processo produtivo de uma facção de costura e identificar as características da empresa, será necessário aplicar os cinco passos da Teoria das Restrições (TOC), para identificação das deficiências, de forma que seja possível mitigar os problemas encontrados e sugerir soluções para a reestruturação do processo produtivo da empresa.

\subsubsection{IDENTIFICAÇÃO DA RESTRIÇÃO DO SISTEMA}

De acordo com Noreen et al. (1996), as restrições podem ser identificadas facilmente, desde que a fábrica seja bem organizada, por meio da localização de inventários de material em processo. Através de uma reunião com a gerente de produção foi possível estabelecer a meta prevista por dia, para estimar a meta foi utilizada a seguinte equação:

$$
\left\{M d=\left(\frac{Q M D * Q F}{T P}\right) * 0,70\right\}=\left\{M d=\left(\frac{480 * 23}{23,36}\right) * 0,70\right\}=330 \text { PEÇAS POR DIA }
$$

- Quantidade de minutos por dia (QMD): quantidade de minutos trabalhado por dia;

- Quantidade de funcionários (QF): quantidade de funcionários;

- Tempo de produção da peça (TP): tempo de produção da peça, sendo este fornecido pela Guararapes S/A, através do relatório de produção.

Ao realizar os cálculos, foi possível estimar que a meta por dia era de 320 peças, com esse dado é possível determinar o takt-time.

Para determinar o takt-time, utilizamos a seguinte expressão:

$$
\text { TAKT TIME }=\frac{\text { Tempo disponível para produção (segundos) }}{\text { Número de unidades a serem produzidas }} * 0,70
$$


TDP: tempo disponível de produção

$\sqrt{10}$ produzidas

NP: Número de unidades a serem

A partir dos cálculos, foi encontrado um takttime de 61,1 segundos, então é possível notar que existem alguns recursos que apresentam tempos bem superiores em relação aos demais. Como a produção mensal pretendia era de 320 peças e cada operação deve trabalhar de acordo com o takt-time encontrado, é possível observar que existem 9 operações que superam o ritmo de produção desejado, é possível observar isso no quadro 2.

Quadro 2 - Recursos Críticos

\begin{tabular}{|c|c|}
\hline OPERAÇÃO & TEMPO MÉDIO (S) \\
\hline UNĨ̃O DAS PARTES & 129,92 \\
\hline PREGAR BOLSO TRASSEIRO & 68,675 \\
\hline INSERIR O CÓS & 76,412 \\
\hline PONTA DE CÓS & 373,84 \\
\hline BAINHA & 106,85 \\
\hline ACABAMENTO & 83,025 \\
\hline PASSANTE DO CINTO & 146,09 \\
\hline LIMPEZA FINAL & 127,32 \\
\hline INSPEÇÃO DE QUALIDADE & 116,84 \\
\hline TAKT-TIME & 61,1 \\
\hline
\end{tabular}

Fonte: Autoria Própria

É possível observar, a operação ponta de cós possui um tempo extremamente elevado em relação as demais operações, é notório o atraso que ela causa no processo de produção do produto, ela foi considerada como a principal restrição, na qual as ações de melhoria devem se concentrar.

\subsubsection{EXPLORANDO A RESTRIÇÃO DO SISTEMA}

A restrição foi encontrada baseada na análise dos tempos de operação, foi possível observar que a restrição do sistema se encontra na operação ponta de cós, devido ela apresentar um maior tempo de processo, esses tempos podem ser visualizados a partir do anexo. Foi coletado uma amostra de vinte tempos por cada operação, tendo em vista que quanto maior o número de amostras, maior sua precisão. Após identificada a restrição do sistema, é planejado como obter o máximo desempenho daquela operação. A operação ponto de cós foi identificado como sendo o gargalo do sistema de acordo com o quadro (1), mesmo com dois funcionários nesta mesma operação. Para que o gargalo não fique ocioso é necessário explorá-lo por completo, então foi sugerido ao gerente de produção a inserção de um estoque pulmão antes da operação gargalo para que no momento que ocorrer paradas inesperadas, como a quebra de máquinas nas etapas anteriores o gargalo, evitando que o mesmo fique ocioso indo de encontro ao quarto princípio da teoria das restrições.

Figura 1 - Quantidade de peças produzidas no dia

\begin{tabular}{|l|r|r|r|r|r|r|r|r|r|}
\hline OP - 155179 & $08: 00$ & $09: 00$ & $10: 30$ & $11: 30$ & $14: 00$ & $15: 00$ & $16: 00$ & $17: 30$ & TOTAL \\
\hline SEGUNDA-FEIRA & 40 & 40 & 40 & 80 & 30 & 20 & 0 & 0 & 250 \\
\hline TERÇA-FEIRA & 10 & 20 & 20 & 50 & 10 & 30 & 30 & 40 & 210 \\
\hline QUARTA-FEIRA & 30 & 20 & 40 & 40 & 30 & 30 & 20 & 40 & 250 \\
\hline QUINTA-FEIRA & 20 & 0 & 30 & 40 & 20 & 40 & 40 & 30 & 220 \\
\hline SEXTA-FEIRA & 25 & 30 & 40 & 10 & 30 & 30 & 30 & 0 & 195 \\
\hline \multicolumn{10}{c|}{ Fonte: autoria própria }
\end{tabular}


A figura apresenta a quantidade de peças produzidas e armazenadas, durante o período de uma semana, é possível observar algumas área em vermelho onde não houve produção. Essas áreas representam a produção no momento em que houve a quebra de uma máquina antes do recurso gargalo, devido não existir um estoque pulmão a produção ficou parada por falta de peças.

Foi observado durante um determinado período, a máquina que mais apresenta problemas é justamente uma das máquinas que antecedem o gargalo. Apesar de existir um mecânico disponível para eventuais problemas, notou-se que a empresa não possui uma gestão de manutenção de seus equipamentos. A manutenção é feita apenas de forma corretiva, portanto, sugere-se que seja desenvolvido um plano de manutenção preventiva para diminuir uma possível parada indesejada da operação gargalo por problemas de maquinário.

\subsubsection{SUBORDINANDO OS DEMAIS RECURSOS}

A etapa gargalo é quem dita o ritmo do processo produtivo, desta forma as demais operações devem se adequar ao gargalo, ou seja, devem operar em função do gargalo. Csillag e Corbett (1998), diz que tal etapa tem como objetivo proteger o conjunto de decisões relativas ao aproveitamento da restrição durante as operações diárias. Não podem deixar faltar material para a restrição trabalhar, pois assim ela pararia e o desempenho do sistema seria afetado negativamente. Porém, os recursos não restritivos não devem trabalhar mais rápido que a restrição, pois não estariam aumentando o nível de produção da linha.

\subsubsection{ELEVANDO A CAPACIDADE DA RESTRIÇÃO}

Esta etapa tem o objetivo de aumentar a capacidade das máquinas que representavam as restrições analisando também a viabilidade econômica de realizar essa mudança.

As medidas sugeridas para elevar a capacidade das restrições seriam o treinamento do operador através de cursos de capacitação afim de diminuir o tempo para cumprimento dessa atividade e também a adoção de premiações para o colaborador que errar menos como a inclusão de um ganho variável por peça produzida.

A empresa não tinha disponibilidade de investir em novos recursos. A solução seria extrair o máximo da capacidade de ambas as restrições, fazendo com que as mesmas trabalhassem o tempo todo sem interrupções.

Segundo Noreen et al. (1996), nesta etapa deve-se "elevar" a utilização da restrição. Desta maneira, parte do trabalho que rotineiramente passaria pela restrição pode ser enviado para fábricas externas e, se a restrição for uma máquina, outra pode ser adquirida.

Para Cogan (2007), melhoramentos, como redução do tempo de preparação de máquinas, redução do tempo de parada de manutenção preventiva ou aumento do nível de habilidade do operário, podem ser realizados para melhorar o desempenho do sistema. 5. Elevar a inércia do sistema.

\subsubsection{ELEVANDO A INÉRCIA DO SISTEMA}

No último passo, Csillag e Corbett Neto (1998) dizem que é preciso renovar o ciclo de melhoria para elevar a inércia do sistema. Se a restrição dos passos anteriores foi quebrada deve-se começar de novo.

De acordo com Travessini et al. (2013), se no quarto passo a restrição foi elevada e deixou de ser o elo mais fraco da corrente, deve-se retornar ao primeiro passo e identificar novamente o que impede a organização de alcançar um melhor desempenho. Desta forma, evita-se que inércia se torne a restrição do sistema.

\section{CONCLUSÃO}

Partindo do pressuposto de que a meta de toda empresa é ganhar dinheiro, a metodologia abordada pela Teoria das Restrições é fundamentada no ganho e não nos custos.

Esta metodologia estabelece o alcance desta meta através dos cinco passos: identificar as restrições do sistema; explorar as restrições do sistema; subordinar qulquer outra coisa à decisão acima; elevar as restrições do sistema; se nos passos anteriores uma restrição foi quebrada, volte ao primeiro passo, mas não deixe que a inércia se torne uma restrição do sistema. 
A partir do estudo realizado em uma empresa de confecção de roupas, foi possível verificar que a identificação das restrições nas atividades não é uma tarefa fácil, em comparação com outros estudos realizados em empresas de natureza industrial. Mas sua aplicação não se restringe somente à empresa de manufatura, pois a ideia principal é focalizar a atenção nos problemas que possam impedir a empresa no alcance de suas metas, podendo então ser aplicada em qualquer entidade.

No estudo realizado foi identificada a restrição se encontra na operação ponta de cós, a

\section{REFERÊNCIAS}

[1] Cogan, Samuel. Contabilidade Gerencial: uma abordagem da teoria das restrições. São Paulo: Saraiva, 2007.

[2] Corrêa, Henrique L.; Gianesi, Irineu G.N. Just In Time, MRP II e OPT: um enfoque estratégico. $2^{a}$ ed. São Paulo: Atlas, 1996.

[3] Csillag, J. M.; Corbett Neto, T. Utilização da teoria das restrições no ambiente de manufatura de empresas no Brasil. São Paulo: Núcleo de Pesquisas e Publicações. EAESP/FGV/NPP, 1998. (Relatório de Pesquisas n. 17).

[4] Noreen, E. W.; Smith, D.; Mackey, J. T. A teoria das restrições e suas implicações na partir destas informações obtidas, verificou-se a necessidade de explorar esta restrição, através o treinamento do operador através de cursos de capacitação afim de diminuir o tempo para cumprimento dessa atividade e também a adoção de premiações para o colaborador que errar menos como a inclusão de um ganho variável por peça produzida. Conclui-se que a Teoria das Restrições pode ser utilizada como instrumento de gestão na atividade. Com efeito, ressalta-se que, nessa atividade, há um imenso campo para aplicação desta teoria e conceitos na condução de seus negócios.

contabilidade gerencial: um relatório independente. São Paulo: Educator, 1996.

[5] Cogan, S. Contabilidade gerencial: uma abordagem da teoria das restrições. São Paulo: Saraiva, 2007

[6] Travessini, R. Zocche, L. Baumgartner, D. Back. L. Identificação de gargalo em uma indústria de mangueiras com auxílio da Teoria das Restrições. In: III Congresso Brasileiro de Engenharia de Produção, 2013, Ponta Grossa. Anais... Ponta Grossa, 2013.

[7] Villar, A. M.; Silva, L. M. F. \& Nóbrega, M. M. Planejamento, programação e controle da produção. João Pessoa: Universitária, 2008. 
ANEXO

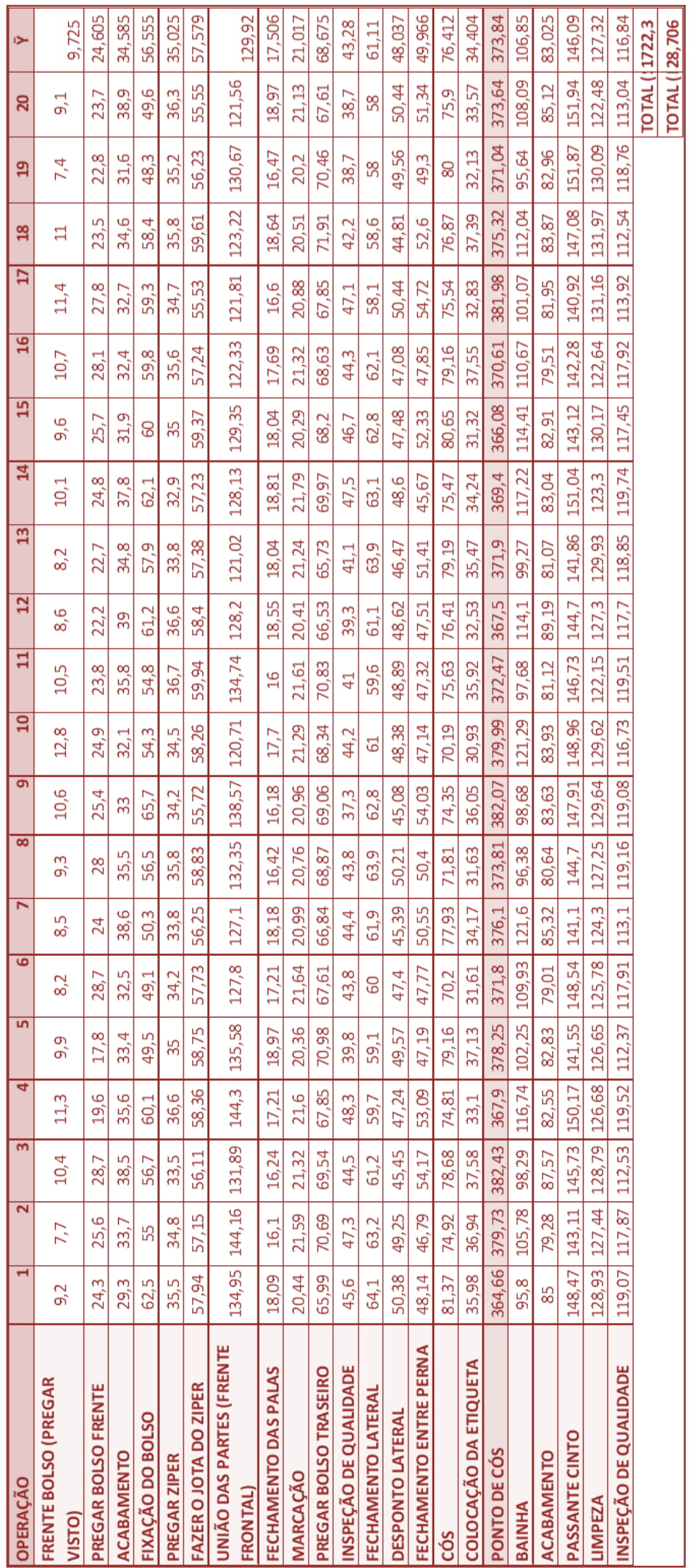




\section{Bapítulo 23}

\section{RESOLUÇÃO DE PROBLEMAS DE PROGRAMAÇÃO LINEAR UTILIZANDO O MÉTODO GRÁFICO NA PLATAFORMA EXCEL}

Deyvid Ricardo Ramos Gonçalves

Erika Mayra Antunes Rocha

Gilberto Antunes de Sousa Junior

Giuseppe Bruno de Almeida Mendes Rocha

Oscar Martins Rennó

Eliane Aparecida dos Santos Silva

Marcos Vinícius Maia Fonseca

Resumo: Este artigo tem por objetivo a apresentação de um aplicativo que auxilia em resoluções de problemas de programação linear utilizando o método gráfico com duas variáveis e seis restrições. Foi utilizado o software MS Excel na criação de planilhas inteligentes através do uso de Macros que, mediante a inserção de dados, gera um gráfico que representa as restrições do problema estudado e após escolhidas as interseções forma-se um polígono representando a área de soluções viáveis. $\mathrm{O}$ gráfico gerado corresponde muito bem aos dados inseridos nas tabelas, assim como o polígono correspondente às interseções escolhidas responde satisfatoriamente. 0 programa se mostra eficiente no auxílio à resolução de problemas de programação linear utilizando o método gráfico, além disso o mesmo pode ser integrado em cursos que necessitem deste tipo de abordagem.

Palavras-Chave: Pesquisa Operacional, Programação Linear, Método Gráfico, Aplicativo (App). 


\section{INTRODUÇÃO}

Desde a Revolução Industrial percebe-se um grande aumento das linhas de produção, acompanhado da grande segmentação, especialização e departamentalização do trabalho. Sendo assim, a medida que o número de recursos aumenta tornar-se mais difícil a alocação dos mesmos de maneira mais eficiente para toda a organização. Com o aparecimento destes problemas, e a necessidade de desenvolver métodos de soluciona-los, abriu-se espaço para o surgimento da Pesquisa Operacional (PO) utilizando-se de métodos matemáticos para auxiliar na solução de problemas relacionados à tomada de decisão. (HILLIER e LIEBERMAN, 2013)

A PO tem sua origem na Inglaterra durante a Segunda Guerra Mundial. Segundo Murthy (2007) os recursos eram limitados e o objetivo consistia em vencer a guerra com os recursos disponíveis, além de distribuí-los à população de forma eficaz. Sendo assim equipes de cientistas multidisciplinares trabalharam juntos fazendo pesquisas de operações militares sobre uma solução possível ao problema abordado. A introdução da Pesquisa Operacional em âmbito empresarial se dá devido ao sucesso da mesma quando surgiu e à semelhança entre os problemas encontrados na guerra e nas empresas, o que levou a uma rápida aceitação e disseminação nas indústrias.

Para Andrade (2009) as mudanças no mercado atual aumentam o nível de complexidade no ambiente de negócios, o que leva as empresas à necessidade de adaptação a tais mudanças a fim de se manterem competitivas. Em decorrência desse fato, é exigido que os profissionais das empresas estejam capacitados cada vez mais para análise de mercado, as transformações que este sofre e na previsão de cenários futuros. Dito isto, saber aplicar conhecimentos e ferramentas de Pesquisa Operacional se mostra de extrema importância para estes profissionais, e consequentemente para as empresas, de forma a otimizar seus resultados.

Dentro deste contexto a Programação Linear $(\mathrm{PL})$ surge como uma das principais técnicas utilizadas na Pesquisa Operacional. Segundo Luenberger e Ye (2008), a PL busca a otimização de um determinado problema que possui muitas soluções possíveis, através da maximização ou minimização de uma função linear em que as restrições consistem em equações e inequações lineares.

Didaticamente, dentro da Programação Linear, existe o método gráfico, que permite encontrar soluções viáveis a um certo problema utilizando duas variáveis em um sistema de eixos ortogonais. A solução gráfica de um problema de PL pode ser feita em três passos: identificação da região viável, determinação das curvas de nível e identificação do ponto ótimo. (COLIN, 2013)

Este artigo tem por objetivo apresentar um programa, desenvolvido utilizando o MS Excel, licença para estudante, e suas linguagens, que busca solucionar problemas de programação linear de duas variáveis utilizando o método gráfico.

\section{DESENVOLVIMENTO}

O programa foi desenvolvido na planilha do MS Excel, licença para estudante, e sua estrutura foi criada utilizando a linguagem VBA (Visual Basic Application) e suas funções. A escolha do software MS Excel se deu devido à sua ampla disseminação no mercado de trabalho e em meio acadêmico, além de apresentar grandes vantagens sobre outros softwares.

É amplamente conhecido que o aplicativo Excel possui recursos para organização e tratamento estatístico de dados, bem como apresentação de resultados em forma de tabelas e gráficos. A realização de cálculos simples é familiar para a comunidade tecnológica. [...] O Excel é bem conhecido, mesmo por pessoas sem formação superior [...] sendo por isso muito conveniente para o ensino em cursos de graduação. (MOURA, 2007, p. 11)

Outro importante fator a ser citado foi o uso da função Macro, derivada do VBA, que permitiu o desenvolvimento do gráfico e do polígono final formado pelas interseções. O VBA é uma ferramenta usada para automatizar procedimentos em situações variadas. 0 Macro por sua vez tem a função de realizar rotinas, isso quer dizer que fórmulas muito repetitivas, longas ou mesmo que seja um conjunto de instruções que, por exemplo, tem de ser executadas várias vezes em várias células diferentes pode ser automatizada utilizando o Macro, o que facilita imensamente o trabalho do programador/desenvolvedor. Quando o Macro é acionado e começa a gravar os comandos, os mesmos são escritos 
em uma linguagem que o computador possa entender, e essa linguagem é justamente o VBA.

Um aplicativo desse tipo não foi ainda publicado no Brasil, desta forma este será o pioneiro. Se bem implementado será um grande auxílio para o ensino de PO nas universidades em aulas práticas, o que acaba facilitando tanto o ensino como o aprendizado dos alunos. Além disso, irá mostrar para os acadêmicos a importância da Pesquisa Operacional no mercado de trabalho e na tomada de decisões

\subsection{VERSÃO 1.0}

A primeira fase do programa era bastante simples, consistia em uma única tela contendo duas planilhas como mostra Figura 1. $\mathrm{Na}$ primeira planilha eram inseridas as coordenadas dos pontos no gráfico cartesiano, ou seja, as restrições do problema. Já a segunda tinha como objetivo a escolha das interseções pelo usuário, através da ligação dos pontos. Além disso, ao lado das planilhas estava localizado o gráfico gerado, onde era criado o polígono representando a área de soluções viáveis.

Figura 21 - Interface da versão 1.0

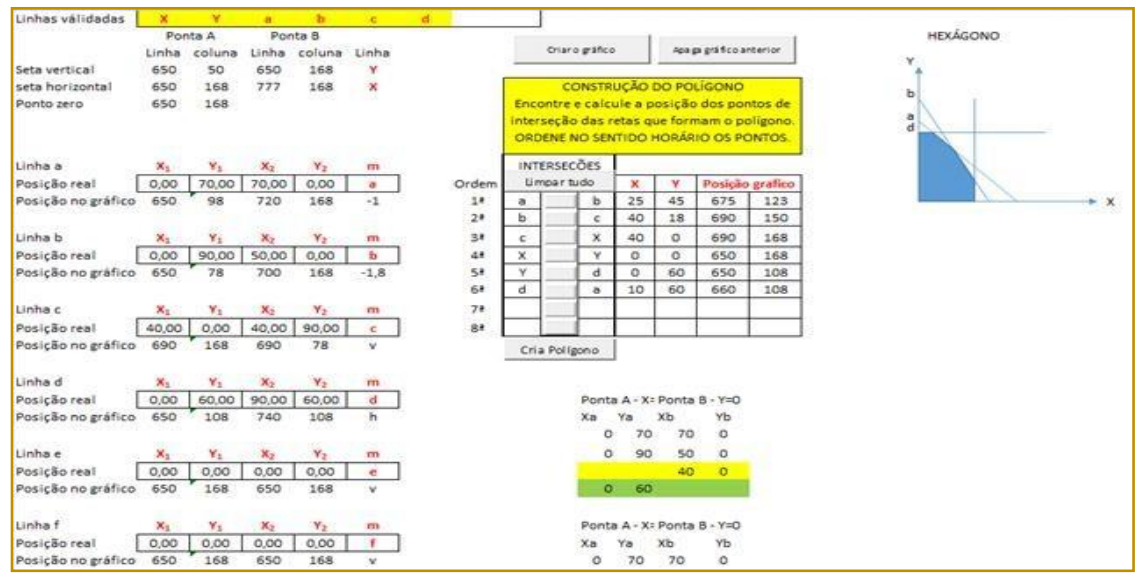

Fonte: Próprios autores

Como apontado na Figura 2 abaixo, a primeira tabela mostrava as restrições inseridas no problema, comportando até um máximo de seis. A 'posição real' descrita na planilha são os campos de inserção dos dados do seu problema, de forma mais clara são a posição em relação ao gráfico, já que este tem sua posição definida dentro da planilha do Excel. Já a 'posição no gráfico' são as posições das coordenadas em relação ao Excel.

Figura 22 - Tabela de restrições

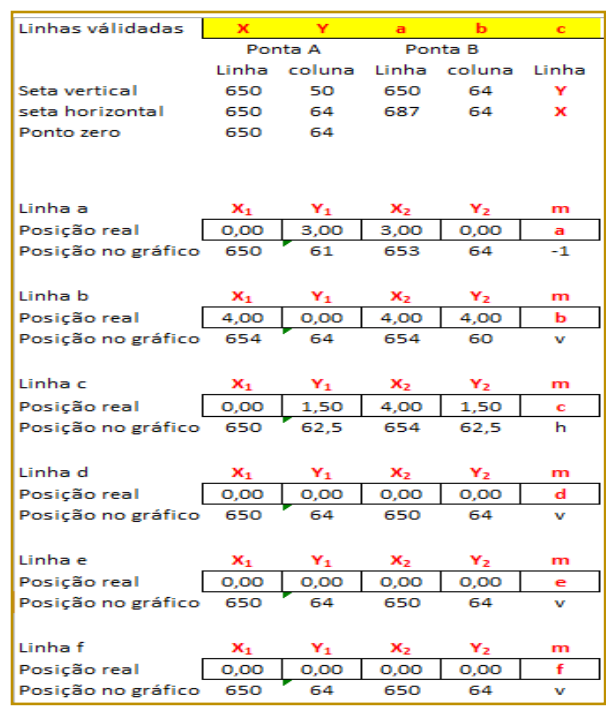

Fonte: Próprios autores 
Após selecionar a opção 'Criar o gráfico' (Figura 1) o programa irá desenhar automaticamente, através do Macro gravado, um gráfico com retas que correspondem às interseções inseridas na primeira tabela, como mostrado na Figura 3.

Figura 23 - Exemplo de um gráfico gerado na versão 1.0

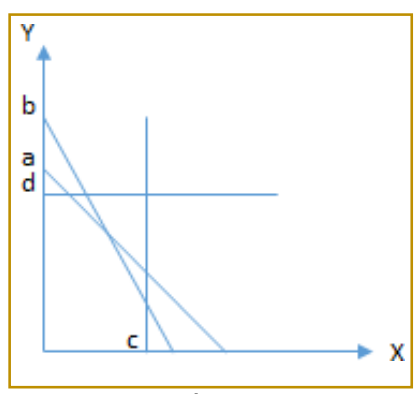

Fonte: Próprios autores

Após ser criado o gráfico e o mesmo disponibilizado na interface do programa, passa-se à escolha dos pontos de interseção, onde existem 8 opções que podem ser selecionadas, como na Figura 4, para gerar um polígono correspondente que é destacado em cor azul na Figura 1. A seleção dos pontos de interseção será definida pelo usuário para determinar a área ótima que podem ser trabalhados os resultados obtidos.

Figura 24 - Tabela de interseções

\begin{tabular}{|c|c|c|c|c|c|c|}
\hline \multirow{4}{*}{$\begin{array}{c}\text { Ordem } \\
1 \geq\end{array}$} & \multicolumn{6}{|c|}{$\begin{array}{l}\text { CONSTRUÇÃO DO POLÍGONO } \\
\text { Encontre e calcule a posição dos pontos de } \\
\text { interseção das retas que formam o polígono. } \\
\text { ORDENE NO SENTIDO HORÁRIO OS PONTOS. }\end{array}$} \\
\hline & \multirow{2}{*}{\multicolumn{2}{|c|}{$\begin{array}{l}\text { INTERSECÕES } \\
\text { Limpar tudo }\end{array}$}} & \multirow{3}{*}{$\frac{x}{25}$} & \multirow{3}{*}{$\frac{Y}{45}$} & \multirow{2}{*}{\multicolumn{2}{|c|}{ Posição grafico }} \\
\hline & & & & & & \\
\hline & a & b & & & 675 & 19 \\
\hline $2 \geqq$ & b & c & 40 & 18 & 690 & 46 \\
\hline $3 \geq$ & c & $\mathrm{X}$ & 40 & 0 & 690 & 64 \\
\hline 43 & $\mathrm{x}$ & $Y$ & 0 & 0 & 650 & 64 \\
\hline $5 \geq$ & $Y$ & d & 0 & 60 & 650 & 4 \\
\hline $6 \geq$ & d & a & 10 & 60 & 660 & 4 \\
\hline $7 \geqq$ & & & & & & \\
\hline $8 a$ & & & & & & \\
\hline & & & & & & \\
\hline
\end{tabular}

Fonte: Próprios autores

A primeira versão demandava um conhecimento mais avançado em MS Excel por parte do usuário, o que poderia torna-lo de difícil entendimento para os mesmos. Após o desenvolvimento da segunda versão, embora a interface tenha ficado maior, facilitou seu uso e entendimento.

\subsection{VERSÃO 2.0}

Com a evolução do projeto o programa se encontra atualmente na sua versão 2.0. Diversas melhorias e mudanças foram implementadas. A estrutura do programa consiste agora em três janelas que interagem entre si conforme o usuário insere as informações sobre o problema abordado. Aqui as janelas serão referidas como 
Formulário, Problema e Gráfico respectivamente.

O Formulário é a janela inicial do programa, o primeiro contato do usuário com a interface.
Quando acionado o botão de início aparecerá um formulário onde são inseridas a descrição do problema, nomeação das variáveis, bem como a configuração da função objetivo e das restrições.

Figura 25 - Formulário inicial do aplicativo

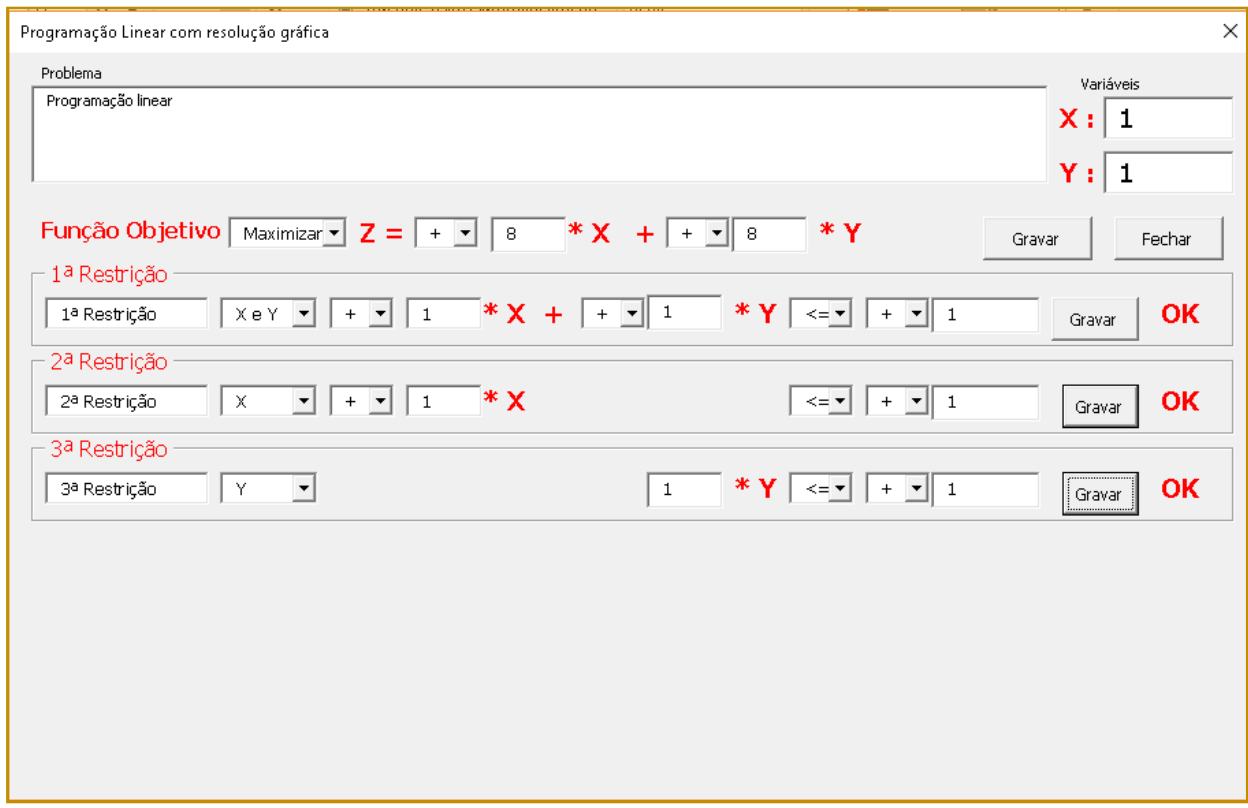

Fonte: Próprios autores

Os dados inseridos no formulário da Figura 5 são direcionados para a janela "Problema", e após ativar o botão "Ponta A e B da reta" desta tela o valor real (coordenadas em relação ao gráfico) e o valor imaginário (coordenada do ponto em relação à planilha do MS Excel) aparecerão na tabela, como mostrados na Figura 6. Esta janela ainda conta com uma opção que permite a correção dos dados informados, basta clicar na opção "carregar formulário" que o formulário da primeira janela será novamente carregado. Em comparação à primeira versão a tabela está mais organizada e simples, com valores e informações importantes em destaque.

Figura 26 - Planilha do "Problema"

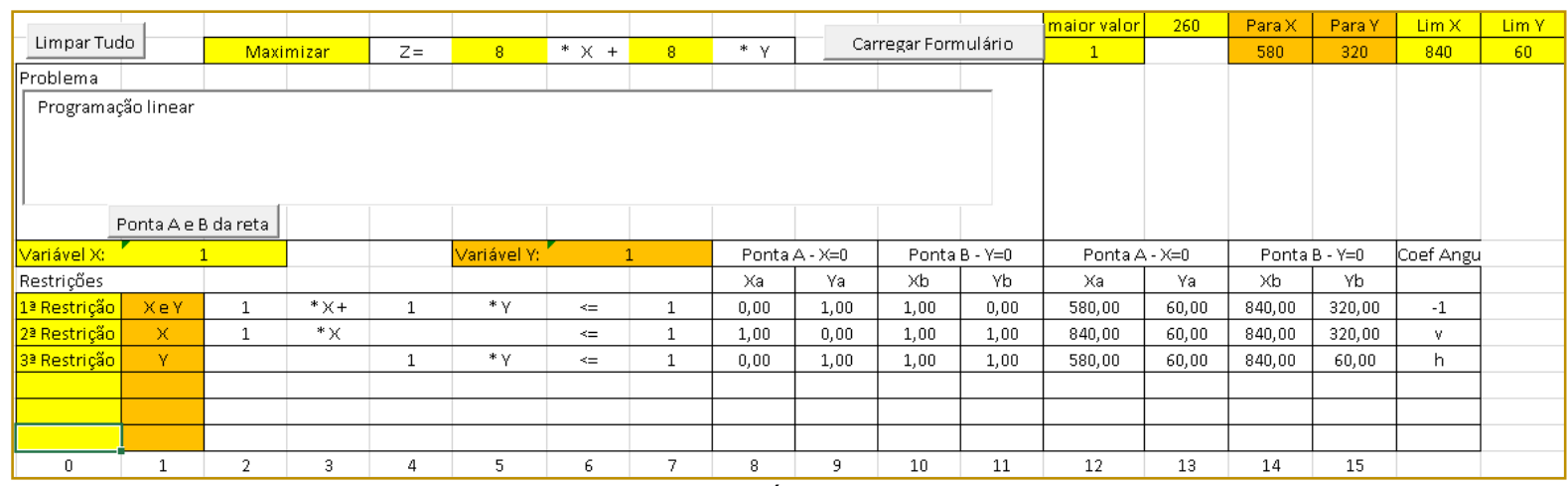

Fonte: Próprios autores

0 gráfico é gerado na terceira tela assim que a opção "Gerar Gráfico" for acionada. Percebe-se que o gráfico, nesta versão do aplicativo, é maior o que facilita a visualização dos pontos e interseções dentro da escala do mesmo. 
Figura 27 - Exemplo de um gráfico na versão 2.0

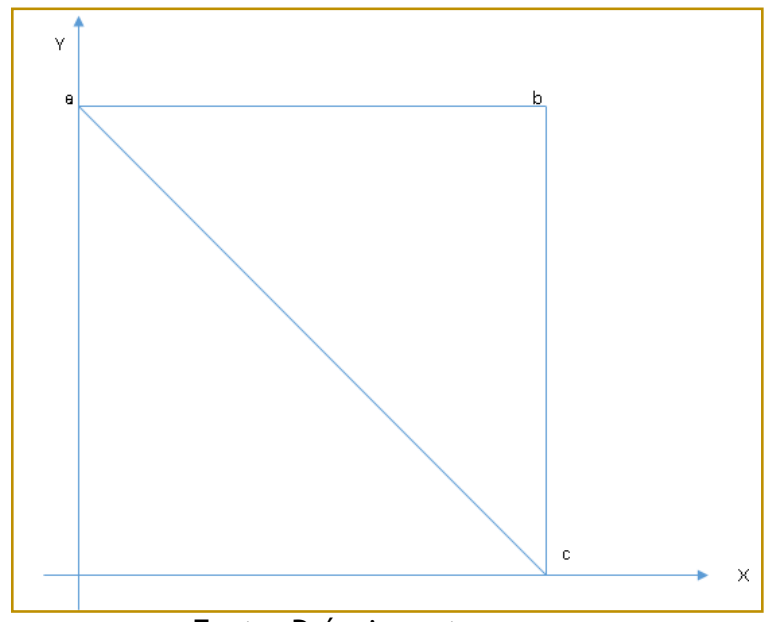

Fonte: Próprios autores

Esta tela ainda consiste numa planilha onde o usuário escolhe as intercessões a serem usadas, de forma que as mesmas devem ser organizadas em sentido horário ou anti- horário, é importante seguir uma sequência lógica dentro do programa, como exemplificado na Figura 8.

Figura 8 - Intercessões em sequência lógica dentro do programa

\begin{tabular}{|c|c|c|c|c|c|c|}
\hline \multirow{2}{*}{$\begin{array}{r}\text { Ordem } \\
1 \mathfrak{a}\end{array}$} & \multicolumn{2}{|c|}{ INTERSEÇÕ̃ES } & \multirow{2}{*}{$\frac{x}{260}$} & \multirow{2}{*}{$\begin{array}{l}Y \\
0\end{array}$} & \multicolumn{2}{|c|}{ Posição grafico } \\
\hline & a & $x$ & & & 840 & 320 \\
\hline $2^{a}$ & $x$ & $\gamma$ & 0 & 0 & 580 & 320 \\
\hline $3^{\mathrm{a}}$ & $\mathrm{Y}$ & a & 0 & 260 & 580 & 60 \\
\hline $4 a$ & & & & & & \\
\hline $5 a$ & & & & & & \\
\hline $6 a$ & & & & & & \\
\hline $7 \mathrm{a}$ & & & & & & \\
\hline $8 \mathrm{a}$ & & & & & & \\
\hline
\end{tabular}

Fonte: Próprios autores

Após a escolha das interseções gera-se um polígono correspondente a área de soluções viáveis, bem como é mostrado o tipo de figura formada. O polígono usado como exemplo é mostrado na Figura 9. 
Figura 9 - Polígono gerado na versão 2.0

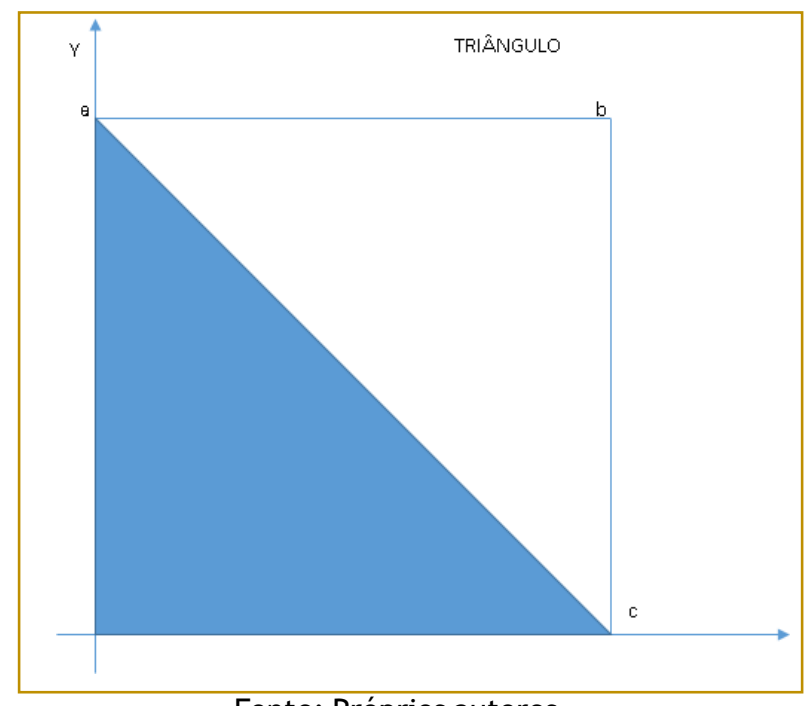

Fonte: Próprios autores

\section{CONCLUSÃO}

Com a grande competitividade do mercado atual as empresas procuram profissionais mais eficientes, assertivos quanto à tomada de decisões. Os conhecimentos de Pesquisa Operacional e suas ferramentas oferecem um leque de métodos e modelos para desenvolver tais técnicas - um exemplo é a programação linear- e são de grande valor para empresas que querem se manter ou tornar-se competitivas.

Dito isto, este trabalho apresentou um aplicativo que, utilizando o método gráfico, dá suporte na resolução de problemas de programação linear e consequentemente auxiliando em tomadas de decisão. 0 programa é desenvolvido no MS Excel utilizando ferramentas da linguagem VBA para sua estruturação e está em sua segunda

\section{REFERÊNCIAS}

[1]. COLIN, Emerson C. Pesquisa Operacional. 170 Aplicações em Estratégia, Finanças, Logística, Produção, Marketing e Vendas. Rio de Janeiro: LTC, 2013. p. 21

[2]. HILLIER, Frederick S.; LIEBERMAN, Gerald J. Introdução à Pesquisa Operacional $9^{\text {a }}$ edição. Porto Alegre: AMGH, 2013. p.1

[3]. LUENBERG, David G.; YE, Yinyu. Linear and Nonlinear Programming Third edition. Nova York: Springer Science+Business Media, LLC, 2008. p. 11 versão, em comparação a sua versão anterior o mesmo se mostra de fácil entendimento, visto que sua interface é mais simples e interativa.

0 aplicativo tem se mostrado promissor em relação aos resultados obtidos até 0 momento, e continua a ser melhorado para então ser disponibilizado para uso. Seu intuito inicial é de auxiliar o desenvolvimento dos acadêmicos nas instituições visando ampliar a percepção de como a Pesquisa Operacional influencia positivamente nas tomadas de decisões nos diversos níveis empresariais. Além disso espera-se que os mesmos possam desenvolver uma mentalidade mais estratégica no desenvolvimento de atividades que exigem tomadas de decisão.

[4]. MOURA, Luiz Fernando de. Excel para Engenharia. Formas simples para resolver problemas complexos. Volume 1. São Carlos: EDUFSCAR, 2007. p. 11

[5]. MURTHY, P. Rama. Operations Research Second edition. Nova Delhi: New Age International (P) Ltd., Publishers, 2007. p. 3-4

[6]. ANDRADE, Eduardo Leopoldino de. Introdução à Pesquisa Operacional $4^{\mathrm{a}}$ Edição. Rio de Janeiro: LTC - Livros Técnicos e Científicos Editora Ltda. 2009. p. 1 


\section{Capítulo 24}

\section{ELABORAÇÃO DO CONCEITO DO APLICATIVO MESA BRASIL}

\section{Rodrigo Lanzoni Fracarolli}

Resumo: A fome é combatida por diversas instituições ao redor do mundo, entre as quais está o SESC com seu programa Mesa Brasil, no qual doações diárias são levadas até os mais necessitados. 0 grupo do programa Mesa Brasil da cidade de Maringá enfrenta problemas de logística e, por isso, entrou em contato com a Universidade para propor uma parceria, na qual será desenvolvido um aplicativo capaz de racionalizar as rotas diárias de coleta e entregas e de ampliar o número de alimentos recebidos pelo programa para doação. 0 conceito deste aplicativo é apresentado neste artigo, em uma etapa anterior à construção e à validação do aplicativo.

Palavras-chave: logística humanitária, doação, roteirização. 


\section{INTRODUÇÃO}

Ainda no século XXI, a fome é uma preocupação a nível mundial que mata ou compromete a vida de milhões de pessoas. 0 problema não é raro nem distante, no Brasil aproximadamente 7 milhões de pessoas enfrentam a fome em seu cotidiano.

Neste contexto, inúmeros programas e iniciativas populares ganham destaque por sua eficácia no combate à fome. Um exemplo de importância em território nacional é o Programa Mesa Brasil, organizado pelo SESC, o qual possui metas ousadas como entregar cerca de 42 milhões de quilogramas de alimentos por ano.

No SESC de Maringá, Paraná, o programa tem como meta entregar 1,8 milhão de quilogramas de alimento para grupos necessitados. Com uma equipe reduzida e sem formação na área da logística, esta instituição entrou em contato com a universidade para estabelecimento de uma parceria na qual será estudada, a partir deste artigo, uma forma de racionalizar as entregas diárias realizadas pelo programa, e de aumentar o número de doadores, permitindo com que qualquer cidadão interessado possa se tornar um doador voluntário.

Com este fim, o presente artigo procura levantar o embasamento teórico necessário para trabalhar com o tema, e propor a criação de um aplicativo capaz de conectar doadores voluntários a receptores, e de oferecer informações para um sistema de roteirização das rotas diárias de entrega de alimentos.

A literatura estudada para construção do aplicativo envolve logística humanitária, pelo trabalho de logística com rapidez e organização apresentado por organizações como a Cruz Vermelha, Sistema Toyota de Produção, principalmente pelo conceito de just in time, que reduz os estoques e seus custos, e Roteirização, utilizada na logística e na pesquisa operacional para determinação de rotas ótimas para empresas como o correio, e para atividades como a coleta de lixo, entre outras.

\subsection{LOGÍSTICA HUMANITÁRIA}

A logística surgiu no meio militar em resposta às necessidades de abastecimento de suprimentos, necessários à manutenção das atividades de combate. Posteriormente, seus conceitos foram adaptados para o meio empresarial e passou a ser utilizada também como ferramenta de otimização de recursos e redução de custos.

Ao longo do tempo, a logística passou a ser utilizada em todos os ramos de atividade, inclusive na solução de problemas emergenciais, como catástrofes e desastres. A área da logística que trata de problemas de ordem emergencial é chamada de logística humanitária e pode ser definida como "a função que visa o fluxo de pessoas e materiais de forma adequada e em tempo oportuno na cadeia de assistência, com o objetivo principal de atender de maneira correta o maior número de pessoas" (BEAMOM, 2004).

Assim como no processo logístico empresarial, a logística humanitária também envolve os processos de movimentação, armazenagem, transporte e gerenciamento de suprimentos. No entanto, o seu principal objetivo é reduzir o sofrimento das pessoas que encontram ou encontravam-se em situações de risco, ocasionadas por catástrofes naturais e/ou humanas.

Nesse contexto, Silva (2011) afirma que a logística humanitária trabalha em parceria com empresas e órgãos para prestar o auxílio, com a entrega eficaz de medicamentos, alimentos, abrigos provisórios, roupas, remoção de feridos, controle de movimentação e transportes alternativos nas áreas atingidas. Além disso, ela engloba o processo de planejamento antes da ocorrência do desastre e a apoio para reestruturação pós desastre.

De acordo com a Política Nacional de Defesa Civil (2000), o gerenciamento de desastres pode ser dividido em três fases distintas: a preparação, a fase do desastre e a fase pósdesastre. A fase de preparação tem o objetivo de desenvolver projetos para a melhoria e aumento da capacidade de atendimento aos necessitados, por meio do planejamento de todos os recursos envolvidos como o estabelecimento de parcerias, desenvolvimento de modelos e treinamento de pessoas.

A fase do desastre consiste na fase de atendimento e socorro às vítimas. Nesta fase, que demanda maior urgência, são realizados levantamentos de acessibilidade, levantamento das necessidades de sistemas de transporte alternativos, levantamento das necessidades de suprimentos, além de 
campanhas para arrecadação e distribuição de suprimentos.

$\mathrm{Na}$ fase pós-desastre o objetivo é possibilitar o retorno às condições de normalidade, por meio da retomada das atividades sociais e econômicas da região, além de reestabelecer o funcionamento dos serviços públicos. Essa fase também se caracteriza pela preocupação com o bem-estar da população atingida, e o maior desafio é garantir o abastecimento de produtos que possibilitem a reconstrução das moradias e retomar a rotina.

No entanto, um dos principais problemas da logística humanitária está relacionado ao gerenciamento das doações. 0 grande desafio enfrentado pelas organizações humanitárias tem sido buscar a minimização o custo relativo a doações inutilizáveis e, ao mesmo tempo, solucionar problemas como falta de suprimentos adequados e o tempo de resposta ao desastre.

\subsection{SISTEMA TOYOTA DE PRODUÇÃO}

Criado por Eiji Toyoda e Taiichi Ohno, o Sistema Toyota de Produção (STP) foi baseado no trabalho de grandes especialistas da qualidade, como Henry Ford, Frederick Taylor e sofreu influência dos estudos realizados por Deming. Partindo da percepção do desperdício de recursos do modelo Ford, Toyoda e Ohno criaram o STP com base em dois conceitos que servem de pilares de sustentação, o Just in Time (JIT) e a Autonomação.

Just in Time (JIT) é um processo de fluxo contínuo, no qual nada deve ser produzido, transportado ou comprado antes da hora exata. Autonomação consiste em facultar ao operador ou à máquina a autonomia de parar o processo sempre que for detectada qualquer anormalidade no processo.

Estudos superficiais limitam-se a resumir STP como JIT, mas analisando mais profundamente, verifica-se que o JIT está inserido no conceito do STP associado à autonomação e o Controle de Qualidade Zero Defeitos e outros métodos e conceitos, para a "completa eliminação das perdas" (GHINATO, 1995)

No Sistema Toyota de Produção, o Controle de Qualidade Zero Defeitos não é um programa, mas um método racional $e$ científico capaz de eliminar a ocorrência de defeitos por meio da identificação e controle das causas, usando quatro pontos fundamentais:

1) Utilização da inspeção na fonte. Este método de inspeção tem caráter preventivo, capaz de eliminar completamente a ocorrência de defeitos, pois a função controle é aplicada na origem e não sobre os resultados.

2) Utilização de inspeção $100 \%$ ao invés de inspeção por amostragem.

3) Redução do tempo decorrido entre a detecção do erro e a aplicação da ação corretiva.

4) Reconhecimento de que os trabalhadores não são infalíveis. Aplicação de dispositivos à prova-de-falhas ("Poka-Yoke") cumprindo a função controle junto à execução.

Dessa forma, para melhor entendimento deste trabalho, quando citado, o Sistema Toyota de Produção, entenda-se que além do Just in Time, outros métodos e conceitos como Autonomação e Controle de Qualidade Zero Defeitos estão inseridos no processo.

\subsection{ROTEIRIZAÇÃO}

Problemas de roteirização são cada vez mais frequentes no cotidiano de empresas que necessitam coletar e distribuir materiais, como alimentos, eletrodomésticos, revistas, entre outros tantos. Bodin et al. Classificam os problemas de roteirização em três grupos: problemas de roteirização pura de veículos, problemas de programação de veículo e tripulações, e problemas combinados de roteirização e programação de veículos.

0 problema de roteirização pura de veículos é aquele em o tempo não é considerado, bastando o trabalho com o espaço. Naruo (2003) coloca o problema do caixeiro viajante, o problema do carteiro chinês e o problema de múltiplos caixeiros viajantes dentro deste grupo.

No segundo grupo estão aqueles problemas em que o tempo deve ser considerado. Neste caso, a condicionante do tempo deve ser representada no algoritmo para determinação do tempo de deslocamento e do tempo de operação (FARKUH NETO e LIMA, 2006).

Os problemas combinados de roteirização e programação são aqueles em que existe uma precedência de tarefas, como a coleta antes da entrega, e a atividade deve estar dentro de um limite de tempo estabelecido. 
Campelo Júnior (2010) afirma que algumas condições devem ser respeitadas dentro de um problema de roteamento de veículos. Em primeiro lugar, as rotas devem começar a terminar no mesmo ponto. Outra condição é que todos os pontos precisam ser visitados somente uma vez por um veículo. Para finalizar, a demanda total da rota deve ser menor ou igual à capacidade de carga do veículo.

Um dos principais problemas de roteirização de veículo é o problema do caixeiro viajante,
- qual é estudado por diversos pesquisadores e ainda não foi solucionado. Este problema serve como base para problemas derivados, com especificidades ligadas ao tempo, ao sequenciamento, ao veículo e à mão de obra, por exemplo.

Goldbarg e Luna (2005) apresentam o modelo matemático proposto por Dantzig, Fulkerson e Johnson como um modelo base para o problema do caixeiro viajante, conforme demonstrado abaixo.
Para aproximação da realidade de cada caso, ou para tentativa de resolução geral, diversas metodologias são desenvolvidas e aplicadas ao problema do caixeiro viajante. As metodologias determinísticas possuem como característica a certeza do resultado obtido, mas a capacidade dos computadores em trabalhar com um grande número de dados ainda é baixa, demandando um tempo inviável para a obtenção dos resultados.

Buscando viabilidade nos cálculos com muitas informações, utiliza-se métodos heurísticos para aproximação com a realidade. Os métodos heurísticos são classificados em métodos construtivos, busca de vizinhança, metaheurísticas, heurísticas sistemáticas e heurísticas híbridas (CAMPELO JÚNIOR, 2010).

\section{OBJETIVO}

A presente pesquisa tem como objetivo geral propor a criação de um aplicativo capaz de facilitar a doação de alimentos e o gerenciamento logístico das operações.

\section{MÉTODO}

\subsection{FUNDAMENTAÇÃO TEÓRICA}

O primeiro passo para a elaboração do presente artigo foi a aproximação da literatura referente aos principais temas ligados à pesquisa.

O tópico "logística humanitária" foi estudado como diretriz da pesquisa, embora o caso não esteja enquadrado como um desastre. De forma análoga, a exigência de rapidez e a busca por menores custos para execução das atividades de doação se aproximam do contexto da logística humanitária, a qual oferece, desta forma, uma metodologia de referência para o programa estudado.

Fundamental para a recuperação japonesa pós-guerra, o Sistema Toyota de produção propõe uma forma de articular matéria prima e produção sem o intermédio de estoques, o que acarreta economia de espaço e de dinheiro. Para o programa de doações, além da economia financeira ligada à redução dos estoques, a doação direta atribui confiança aos doadores, que, desta forma, podem sentir o impacto positivo de sua contribuição.

Algoritmos de roteirização são utilizados em larga escala por empresas a fim de definir um roteiro ótimo de coleta ou de entregas, o qual reduz de forma significativa os custos e o 
tempo de transporte. Organizações relacionadas à logística humanitária também fazem uso de algoritmos de roteirização para redução do tempo, já que este é um fator decisivo para a sobrevivência das pessoas no momento imediato após a ocorrência de um desastre.

\subsection{CONTATO COM VOLUNTÁRIOS DO PROGRAMA MESA BRASIL}

O contato com o Programa Mesa Brasil aconteceu de maneira informal em reunião com uma voluntária do projeto e uma funcionária do SESC. Durante esta reunião o Mesa Brasil foi apresentado, assim como as especificidades do programa na cidade de Maringá, PR, e as principais demandas e contribuições foram discutidas.

O Programa Mesa Brasil é uma rede nacional de banco de alimentos proposta pelo SESC que busca contribuir para segurança alimentar e nutricional de indivíduos necessitados, atuando principalmente na redução do desperdício e na promoção de doações. O programa nasce em São Paulo, SP, em 1994, já com o objetivo de combater a fome e minimizar desperdícios. Em 1997 surge a modalidade "Colheita Urbana", na qual os alimentos são recolhidos no doador e levados diretamente ao receptor, reduzindo assim o custo com estoques. Em 2000 surge, no Rio de Janeiro, RJ, a modalidade banco de alimentos, na qual as empresas podem doar alimentos ao armazém SESC, de onde este material é direcionado para pontos receptores em automóveis do Programa.

Os doadores cadastrados no Programa são empresas, indústrias, feiras livres e outras instituições que lidam com alimentos. Para cadastro de receptores, o SESC disponibiliza assistentes sociais que fazem 0 direcionamento para creches, asilos, escolas, hospitais ou famílias ligadas a um grupo de apoio.

No caso específico do funcionamento do Programa em Maringá, uma assistente social e uma nutricionista gerenciam as atividades e enfrentam problemas relacionados aos custos logísticos de transporte e armazenagem, o que fez com que a voluntária procurasse os autores deste artigo para o desenvolvimento da pesquisa. Nesta primeira conversa ficaram definidas as principais demandas do programa em Maringá e das principais contribuições por parte dos autores. 0 primeiro ponto a ser trabalhado é a elaboração de um algoritmo de roteirização para coleta e distribuição de alimentos no município, e o segundo é ampliar a captação e facilitar a gestão das doações. Para alcance destas metas será desenvolvido um banco de dados e um aplicativo, tratado neste artigo, para utilização de voluntários candidatos a doadores. No próximo subtítulo o funcionamento do aplicativo é detalhado.

\subsection{DESENVOLVIMENTO DO CONCEITO DO APLICATIVO}

O aplicativo em desenvolvimento para o Programa Mesa Brasil apresentará uma interface para o usuário doador e outra para o gestor. Em linhas gerais, o sistema deve cruzar as informações das necessidades dos receptores cadastrados com as informações dos doadores, para depois emitir um roteiro de coleta e entregas que será utilizado pelos motoristas do programa.

As informações de cadastro dos receptores são registradas pela assistente social. Este cadastro deve conter os produtos necessários para este receptor, as datas para recebimento de doações, o número de pessoas atendidas, o endereço para entrega, e a existência de alguma restrição alimentar para 0 caso de indivíduos celíacos, diabéticos, intolerantes à lactose, entre outros.

No cadastro de doadores, os produtos necessários e algumas datas já estão estipuladas, bastando ao usuário selecionar sua forma de contribuição dentre as disponíveis. Caso o usuário não encontre um produto ou uma data condizente com suas possibilidades, ele pode ficar cadastrado, apontando seu desejo, e assim que for encontrado um receptor ele será avisado. 0 doador deve definir em seu cadastro o seu endereço e um login para emissão de relatórios.

Internamente, o sistema deve considerar as informações dos receptores cadastrados, dos doadores cadastrados e da estrutura disponível para emitir uma "ordem de ação". Dentre os dados da estrutura disponível estão o número de funcionários, a quantidade de automóveis com suas capacidades de carga e detalhamento sobre seus custos e a localização do estacionamento.

A emissão de uma ordem de ação pode ser dividida em quatro etapas: a) necessidade do 
dia; b) confirmação de doações; c) roteirização do(s) trajeto(s); d) efetuação das entregas.

Para organização das informações que indicaram as necessidades do dia, o sistema deve considerar os receptores daquele dia, quais e quantos produtos são requisitados e o endereço de entrega. Todas as informações levantadas nesta etapa são registradas em um relatório de necessidades, que será disponibilizado para todos os doadores cadastrados no programa.

Com os dados das necessidades do dia determinadas, o sistema uma mensagem de confirmação para cada doador envolvido. Em caso de confirmação do doador, este passa a ser contabilizado na entrega. Se o doador não confirmar a doação, então um novo doador é contatado para fechamento da entrega do dia. Esta etapa é finalizada com a emissão de um relatório de doadores, disponível para visualização dos envolvidos.

$\mathrm{Na}$ etapa de roteirização do trajeto são considerados os endereços de coleta e de entrega, a capacidade de carga do veículo e o número de viagens necessárias. Para realização dos cálculos são utilizados métodos heurísticos, como heurísticas sistemáticas, busca de vizinhança, heurísticas híbridas ou metaheurísticas. Após a definição do melhor roteiro, o sistema disponibiliza um mapa para o motorista e gera um relatório dos gastos envolvidos com a atividade.

A entrega dos alimentos é acompanhada da assistente social, responsável pelas alterações nos cadastros dos receptores e pela conferência das entregas realizadas no dia.

O aplicativo permite troca de informações dos usuários com a equipe do programa e oferece uma série de informações pertinentes com o objetivo de capacitar o cidadão no quesito doação, já que diversos autores apontam uma falha no entendimento da população brasileira com relação ao tema.

\section{RESULTADOS}

\subsection{APRESENTAÇ̃̃O DO CONCEITO}

A partir das informações obtidas em reunião com voluntários do Programa Mesa Brasil de Maringá, PR, foi possível a elaboração de um sistema organizado para geração de rotas diárias para os veículos do programa e para aumento do número de doações realizadas por intermédio do Mesa Brasil.

O sistema de roteirização tem potencial para suprimir o principal problema enfrentado pelos gestores do programa, que é a falta de racionalização das rotas de entrega, com a qual são ampliados os custos de se manter o funcionamento das atividades.

Com o funcionamento do aplicativo, o programa Mesa Brasil terá condições de atingir e superar sua meta de doações para 2015, estimado em aproximadamente 42,5 milhões de quilogramas de alimentos distribuídos no ano. A unidade de Maringá possui como meta a entrega de 1,8 milhão de quilogramas de alimentos distribuídos. Aumentar a dimensão do programa é parte da missão, da visão e dos valores do mesmo.

Após apresentação e aceite do sistema de gestão e do aplicativo, as demandas da equipe do SESC devem realinhar o projeto e, com um nível mais detalhado de informações, a metodologia de roteirização e a plataforma do aplicativo podem ser definidos, dando início a uma nova etapa do trabalho.

\section{CONCLUSÕES}

A proposta de criação do aplicativo para gerenciamento das doações e para ampliação do número de alimentos doados está embasada na literatura relacionada aos principais tópicos envolvidos com o tema e alinhada aos objetivos do Programa Mesa Brasil, de dimensão nacional.

A partir dos conceitos da logística humanitária será possível atribuir velocidade às entregas e formação aos doadores, que receberão informações sobre a importância da doação, como doar e, principalmente, o que doar.

Os conceitos ligados ao estoque zero do sistema Toyota de produção e de logística com uso de roteirização baseada em algoritmos têm potencial de oferecer racionalidade à construção das rotas e economia aos gestores do programa, aumentando a eficiência das atividades.

A partir desta pesquisa, é possível sugerir o desenvolvimento de pesquisas do mesmo tipo para outras entidades, com utilização de diferentes métodos de roteirização e com outras restrições. Para o caso específico do Programa Mesa Brasil, a próxima etapa deve ser definida em conjunto com os gestores locais. Nesta nova etapa os métodos serão 
determinados e o sistema, com o aplicativo, entra em fase de validação, antes da

\section{REFERENCIAS}

[1]. BEAMON, B. M. Humanitarian Relief Chains: Issues and Challenges, R 34th International Conference on Computers and Industrial Engineering San Francisco, CA, USA, 2004.

[2]. BODIN, L. D., GOLDEN, B., ASSAD, A., BALL, M., 1983. Routing and Scheduling of Vehicle and Crews: The State of the Art. Computers and Operations Research, v. 10, n. 2, p.63-211.

[3]. CAMPELO JÚNIOR, J. U. Proposta de otimização da roteirização dos distritos dos carteiros: um estudo de caso no centro de entrega de encomendas de Fortaleza. Dissertação (mestrado) - Universidade Federal do Ceará Programa de mestrado em logística e pesquisa operacional, Fortaleza, 2010.

[4]. FARKUH NETO, A.; LIMA, R. S. Roteirização de veículos de uma rede atacadista com o auxílio de sistemas de informações geográficas (SIG). Revista Pesquisa e implementação.

Desenvolvimento Engenharia de Produção, p. 18 39, n 5, 2006.

[5]. GHINATO, P. Sistema Toyota de produção: mais do que simplesmente Just-in-Time. Prod., São Paulo, v. 5, n. 2, p. 169-189, 1995. Disponível em: <http://www.scielo.br/scielo.php?script=sci_arttext \&pid=S010365131995000200004\&lng=en\&nrm=iso>. Acesso em: 27 de setembro de 2015.

[6]. NARUO, M. K., 2003. O estudo do consórcio entre municípios de pequeno porte para disposição final de resíduos sólidos urbanos utilizando Sistemas de Informação Geográficas. São Carlos, 2003. 283p. Dissertação (Mestrado) Escola de Engenharia de São Carlos, Universidade de São Paulo.

[7]. SILVA, A. Logística humanitária. 2011. Acesso em: 26 de setembro de 2015. 


\section{Gapítulo 25}

\section{OTIMIZACÃO EM REDES UTILIZANDO O ALGORITMO DO CAMINHO MINIMO PARA ROTEIRIZAÇÃO DE UMA COOPERATIVA AGROPECUÁRIA}

\section{Jarbas Ancelmo da Silva Júnior \\ Natália Cibele de Sousa Santos \\ Lara Cristine Pereira dos Santos \\ Nayara Felício de Oliveira}

Resumo: 0 mundo vem enfrentando grandes modificações desde a Revolução Industrial, principalmente no âmbito empresarial. Tais modificações trouxeram bons resultados, como também alguns problemas, diante deste cenário, se tornam importante a adoção de ferramentas que auxiliem as empresas na tomada de decisões. Dentre estas ferramentas está a Pesquisa Operacional (PO), a qual, aliada a outras áreas da Engenharia de Produção, proporciona a empresa vantagens competitivas. Nesse sentido, o presente trabalho tem como objetivo modelar uma rede contendo todos os pontos de entrega de uma Cooperativa e determinar o menor caminho entre a origem e o ponto de entrega mais distante, utilizando o método do caminho mínimo. Para isso foi empregado o procedimento de pesquisa experimental devido ao uso do método de otimização em redes. Verificou-se a eficiência do método ao aplicá-lo no problema proposto. Este trabalho proporcionou um maior entendimento acerca do uso de algoritmos e modelagens matemáticas intuitivas para resolução de problemas cotidianos.

Palavras-Chave: Pesquisa Operacional; Logística; Caminho mais curto. 


\section{INTRODUÇÃO}

0 mundo vem constantemente sofrendo diversas modificações, principalmente, no âmbito organizacional. Isso se torna mais visível, observando as mudanças que ocorreram a partir da Revolução Industrial. Estas mudanças, além de bons resultados também trouxeram alguns problemas. Um deles de acordo com Hillier e Lieberman (2010) é que conforme aumentam a complexidade e a especialização em uma organização, torna mais difícil alocar os recursos disponíveis para as diversas atividades de maneira mais eficiente. Com isso, a necessidade de resolver esses problemas contribuiu para o surgimento da Pesquisa Operacional (HILLIER e LIEBERMAN, 2010).

A Pesquisa Operacional teve suas primeiras atuações no período da Segunda Guerra Mundial, auxiliando na tomada de decisão sobre o melhor destino dos materiais $e$ equipamentos utilizados na guerra (TAHA, 2008). Atualmente, ela pode ser encontrada como sendo umas das áreas da Engenharia de Produção, atuando no desenvolvimento industrial e tecnológico.

De acordo com Andrade (2009) a Pesquisa Operacional é uma área da ciência administrativa que fornece instrumentos para análise de decisões. Uma das ferramentas utilizadas na prática é conhecida como Problema de Caminho Mínimo, que é considerado como um algoritmo simples, cujo objetivo é o de identificar a partir da origem o caminho mais curto para cada um dos nós da rede (TAHA, 2008). Permitindo diminuir custos logísticos, redução da rota e um menor tempo de entrega da empresa escolhida.

A empresa a ser estudada é uma Cooperativa que atua no mercado a aproximadamente cinquenta anos. Foram disponibilizados pela empresa alguns pontos de entrega que no presente estudo correspondem aos nós, interligados por arcos que representam a distância entre os pontos. Dentre todos os pontos de entrega, escolheu-se um total de sete considerando os mais distantes da origem (empresa), por meio de algoritmos que serão detalhados nos próximos tópicos, determinou-se o caminho mais curto a ser percorrido.

Desta forma, o objetivo geral do trabalho é modelar o problema de caminho mínimo por meio dos dados coletados. Com os resultados obtidos traçou-se a rota mais curta, cuja aplicação poderia reduzir custos logísticos da empresa e melhorar o serviço ao cliente.

Para cumprir o objetivo, o presente trabalho foi estruturado da seguinte forma: na seção 2 há o referencial teórico; a seção 3 apresenta a metodologia; a seção 4 expõe os resultados obtidos; e, por fim, na seção 5 há as considerações finais.

\section{REFERENCIAL TEÓRICO}

Esta seção apresentará o referencial teórico sobre a otimização de redes pelo método do caminho mínimo e, logo após uma aplicação interdisciplinar com a técnica utilizada neste trabalho com problemas da área de logística.

\subsection{OTIMIZAÇÃO DE REDES - CAMINHO MÍNIMO}

Segundo Andrade (2009), a Expressão Pesquisa Operacional foi empregada pela primeira vez durante a Segunda Guerra Mundial. O sucesso dessas aplicações moveu o mundo acadêmico e empresarial a utilizar estas técnicas.

Segundo Arenales, et al (2007), a Pesquisa Operacional tem sido chamada de Ciência e tecnologia de decisão. Científico devido a ideias e processos para modelar problemas de decisão. Associado a tecnologia devido a utilização de ferramentas de software e hardware para coletar, comunicar e organizar dados, utilizando-os para gerar, otimizar modelos e analisar seus resultados.

Em pesquisa operacional o tipo e a complexidade do modelo matemático é que definem a natureza do método de resolução. Segundo Taha (2010), existem vários métodos para resolver todos os modelos matemáticos que podem surgir na prática. Um destes métodos é a otimização em redes, na qual o problema pode ser modelado como uma rede, técnica que será utilizada neste trabalho.

As redes surgiram em vários ambientes e de muitas maneiras distintas. Segundo Hillier e Liberman (2010), as representações em formato de rede são bastante utilizadas para problemas de diversas áreas como produção, distribuição, planejamento de projetos, administração de recursos, posicionamento de instalações e planejamento financeiro. Essa área da Pesquisa Operacional faz parte das conquistas mais fascinantes dos últimos 
anos, devido ao rápido avanço na metodologia, na aplicação de modelos e no avanço de algoritmos de otimização em redes.

Ainda segundo Hillier e Liberman (2010), uma rede é feita por um conjunto de pontos e de retas conectando certos pares de pontos. Os pontos são denominados nós e as retas arcos. Os arcos são identificados dando-se nomes aos nós em cada uma de suas extremidades. Segundo Taha (2010) um caminho é uma sequência de arcos distintos que ligam dois nós passando por outros nós, independentemente da direção de fluxo em cada arco.

Como uma grande quantidade de situações de pesquisa operacional pode ser modelada e resolvida com o uso de redes há uma variedade de algoritmos de otimização em redes. Segundo Taha (2010), os quatro principais são árvore geradora mínima que objetiva diminuir custos dentro de uma rede em que os nós são ligados dois a dois, algoritmo do caminho mínimo usado para definir o menor caminho entre os nós de origem e destino, algoritmo de fluxo máximo que busca constatar a capacidade máxima do fluxo que há entre os nós, e por fim o algoritmo do caminho crítico que determina um cronograma de atividades, onde se definem os tempos máximos e mínimos das atividades.

Segundo Hillier e Liberman (2010), existem outros algoritmos para resolver problemas do caminho mínimo, como algoritmo Dijkstra, o qual liga a origem a outro nó qualquer da rede, e Floyd, que conecta quaisquer dois nós na rede, porém focaremos em um algoritmo mais simples para resolução desse problema, que apresenta uma rede conectada com dois nós especiais chamados origem e destino, onde o objetivo é encontrar o caminho mais curto da origem ao destino.

Existem softwares que auxiliam na resolução e análise destes problemas, como o LINGO (Linear, Interactive and General Optimizer "Otimizador Linear, Interativo e Geral"), o qual consiste em uma ferramenta simples para usar o poder da otimização linear ou nãolinear para formular problemas grandes concisamente, resolvê-los e analisar a solução. O Solver, complemento do Microsoft Excel, faz parte de um conjunto de programas chamados de ferramentas de análise hipotética, pode localizar um valor ideal para uma fórmula em uma célula, denominada célula de destino em uma planilha, pode-se aplicar restrições para restringir os valores que o Solver poderá utilizar e a restrições podem se referir a outras células que afetem a fórmula da célula de destino.

\subsection{PESQUISA OPERACIONAL ALIADA À LOGÍSTICA}

As empresas estão inseridas em um ambiente de extrema concorrência, acirrada ainda mais pela crise econômica em que o país está inserido. Neste contexto, para se garantir em plenas condições de concorrência se torna primordial o uso de todas as ferramentas e métodos disponíveis. De acordo com Ferreira e Bachega (2011) as empresas podem fazer o uso de técnicas para rever operações, objetivando the auxiliar em uma boa execução estratégica e com intuito de amplificar sua eficiência em suas atividades e minimizar seus custos.

A problemática foco do estudo se apresenta a partir do intuito em se realizar a determinação do caminho mais curto da entrega de um empresa do setor de laticínios da cidade de Catalão- GO, em que para a resolução da mesma foi utilizada a associação de ferramentas, da pesquisa operacional com as da logística, objetivando a minimização do caminho a ser percorrido pelo transporte de entrega da empresa, mas mesmo assim, atendendo integralmente os destinos previamente acordados com os clientes.

De Souza Junior et al. (2013) definem logística como sendo uma ferramenta de gestão em que proporciona a empresa se manter no mercado competitivo, devido a junção da tecnologia, permitindo a agilidade do processo, redução dos custos e, ainda, a satisfação do cliente.

Livato e Souza (2010) e, também, Souza et al. (2014) destacam a necessidade em se apurar custos relacionados com a logística, o que exige da empresa a adoção de ferramentas que thes auxiliem na tomada de decisões. E, neste cenário que a pesquisa operacional se insere, como Jesus, Toralles, Behrens (2015) a definem como sendo uma ferramenta com características matemáticas de auxílio ao processo decisório.

Foi utilizado o método de caminho mínimo, instrumento este da pesquisa operacional, com o auxílio do Solver ${ }^{\circledR}$ - ferramenta do Excel, pois este apresenta um desempenho 
satisfatório em se tratando deste tipo de problemática.

Após realizado o procedimento, pode-se inferir, que, realmente, as ferramentas quando associadas resultou em uma minimização da distância total percorrida pelo caminhão de entrega, resultando em um caminho ótimo a ser percorrido (quando de tratado apenas a distância), vale ressaltar que outros aspectos não foram analisados, como exemplo: qualidade do asfalto, presença de semáforos na vias a serem percorridos, pontos de lentidão, dentre outros.

No que se refere ao método de pesquisa e análise dos dados, o presente trabalho se enquadra em uma abordagem quantitativa e um procedimento experimental. Fonseca (2002, p.20) destaca "que os resultados da pesquisa quantitativa podem ser quantificados", segundo o autor "como as amostras geralmente são grandes e consideradas representativas da população, os resultados são tomados como se constituísse um retrato real de toda a população alvo da pesquisa", o que se apresenta bastante útil, visto que, o trabalho relaciona as distâncias entre 0 ponto de partida, a cooperativa, e os pontos de entrega de produtos acabados (supermercados, mercearias, entre outros) com o objetivo de traçar o caminho mais curto a ser percorrido até o ponto mais distante.

De acordo com Gil (2010, p.32) "a pesquisa experimental constitui o delineamento mais prestigiado nos meios científicos." Gil (2010) também aponta que a pesquisa experimental se resume em definir um objeto de estudo, eleger as variáveis passíveis de influenciá-lo e por fim determinar as formas de controle e análise dos efeitos que a mesma provoca no objeto. A fim de resolver o problema apresentado neste trabalho, utilizou-se 0 Algoritmo do Caminho Mínimo, em síntese esse procedimento se espalha em todas as direções partindo da origem, assinalando gradativamente o menor caminho referente a cada um dos nós da rede na ordem crescente de suas distâncias (mais curtas) a começar da origem e assim, desvendar o problema quando $O$ nó de destino é alcançado (HILLIER; LIEBERMAN, 2013).

A coleta de dados resultou de duas entrevistas realizadas no mês de Dezembro/2016 com o gerente responsável pela elaboração das rotas e rotina de entregas da Cooperativa. Primeiramente definiu-se o dia da semana cujo roteiro de entregas seria estudado, a quinta-feira, neste dia tem-se menor quantidade de entregas e as mesmas são realizadas somente na parte da manhã, o que facilita a criação da rede. De acordo com Lachtermacher (2007, p.119) "redes são diagramas compostos por uma coleção de vértices ou nós ligados entre si por um conjunto de arcos", neste caso, os nós são os pontos de entrega que estão conectados pelos arcos orientandos os quais correspondem às distâncias.

De posse dos dados obtidos, utilizou-se o software online Google Maps ${ }^{\circledR}$ com o intuito de obter as distâncias entre os pontos, o qual também auxiliou na visualização da rede como um todo.

Em seguida utilizou-se o Excel para desenvolver e solucionar o problema, Hillier e Lieberman $(2013$, p.347) ressaltam que "esse algoritmo fornece uma maneira particularmente eficiente para resolver problemas do caminho mais curto de grandes dimensões", a modelagem se deu com o auxílio da ferramenta Solver, disponível na planilha Excel.

Segundo Taha (2008) é possível estabelecer algumas orientações para condução da PO na prática, sendo as principais fases enunciadas abaixo:

- Definição do Problema: delimita o escopo do problema em análise, com o intuito de definir as alternativas de decisões, o propósito do estudo, e as restrições do sistema;

- Construção do Modelo: consiste em traduzir o sistema em fórmulas matemáticas de acordo com as definições apresentadas;

- Solução do Modelo: parte do uso de algoritmos de otimização já definidos, levando em conta a análise de sensibilidade que trata da observação do comportamento da solução ótima quando parâmetros são alterados.

- Validação do Modelo: verifica se a solução tem sentido, ou seja, se os resultados são aceitáveis.

- Implementação da Solução: expressa os resultados em orientações operacionais, as quais podem ser emitidas às pessoas envolvidas.

É importante destacar que a fase "Validação do Modelo" não foi executada, uma vez que, a possibilidade de existirem caminhos mais curtos que o software online Google Maps ${ }^{\circledR}$ 
não tenha apresentado é muito grande. A fase "Implementação da Solução" demandava abertura da cooperativa a um novo padrão operacional, e estrutura para organizar e repassar as diretrizes aos interessados, o que não ocorreu em virtude do estudo ter sido realizado em um curto período tempo.

\section{RESULTADOS E DISCUSSÕES}

\subsection{DEFINIÇÃO DO PROBLEMA}

A partir dos dados coletados com o gerente da empresa, foram listados os locais para onde são feitas as entregas. Elas são:

- Comércio 1 -Av Vera Cruz; Bairro das Américas;

- Comércio 2 - Av Dr Lamartine P. de Avelar; Bairro: Vila Chaud;

- Comércio 3 - Rua: Suécia; Bairro: Ipanema;

- Comércio 4 - Av Dr Lamartine P. de Avelar; Bairro: Vila Chaud;

- Comércio 5 - Rua: Ladislau J. Alcântara; Bairro: Ipanema;

- Comércio 6 - Rua: Sessenta e oito; Bairro: Ipanema.
O objetivo deste estudo é encontrar o menor caminho ou rota entre a distribuidora e o comércio mais longe de Catalão, onde são feitas entregas.

0 Comércio 6 é 0 mais distante geograficamente, estando a, aproximadamente, $4 \mathrm{~km}$ de distância. É importante ressaltar que, para que fosse possível a construção da rede, foram consideradas as possíveis rotas e suas respectivas distâncias, obtidas através da ferramenta Google Maps ${ }^{\circledR}$.

\subsection{CONSTRUÇÃO DO MODELO}

A partir dos dados coletados e do objetivo definido do estudo, foi elaborada uma rede com os possíveis caminhos, representados por retas, e suas respectivas distâncias em metros entre os nós (comércios), representados por círculos. No total são seis comércios mais a distribuidora, totalizando sete nós, que foram nomeadas, sendo $\mathrm{O}$ a origem (distribuidora), de $A$ até $E$ os comércios (de 1 a 5 ) e $\mathrm{T}$ o destino (comércio 6). A rede é apresentada na Figura 1.

Figura 1 - Representação em rede.

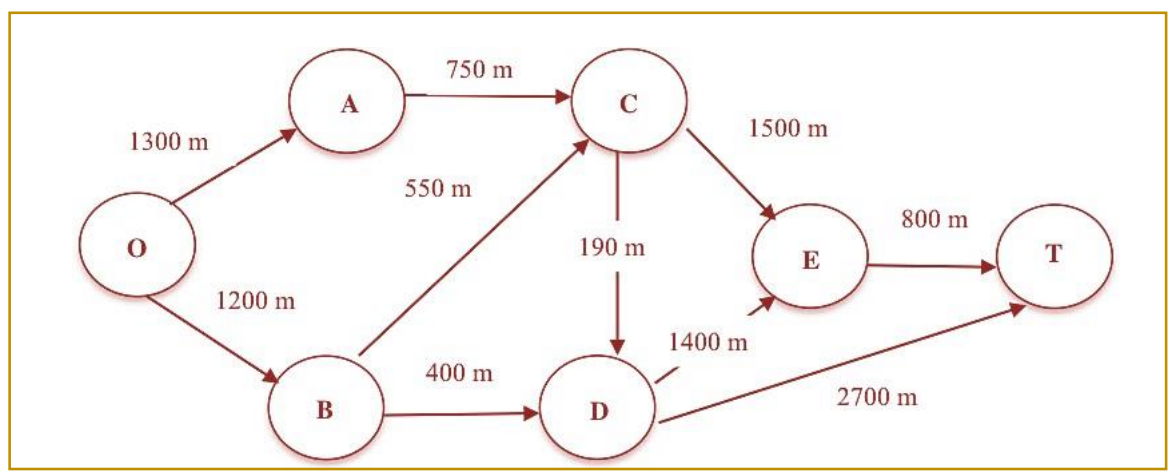

Fonte: Elaborada pelos autores (2017). 
A mesma rede também é representada através da Tabela 1.

Tabela 1-Representação dos comércios

\begin{tabular}{|c|c|c|}
\hline \multicolumn{1}{|c|}{ De } & Para & Distância em metros \\
\hline O & A & 1300 \\
\hline O & B & 1200 \\
\hline A & C & 750 \\
\hline B & C & 550 \\
\hline B & D & 400 \\
\hline C & E & 1500 \\
\hline C & D & 190 \\
\hline D & E & 1400 \\
\hline D & T & 2700 \\
\hline E & T & 800 \\
\hline
\end{tabular}

Fonte: Elaborada pelos autores (2017).

Construída a rede, estes dados foram inseridos em uma planilha do Excel, para se chegar a um caminho mais curto com a utilização da ferramenta Solver®. Os dados foram organizados da seguinte maneira na planilha:

Coluna $B$, representando os nós de saída da rota - B4 a B13;

- Coluna C, representando os nós de chegada da rota - C4 a C13;

- Coluna D, representando as distâncias, em metros, entre as respectivas rotas - D4 a D13;

- Coluna $\mathrm{E}$, representando as variáveis de decisão, contendo a rota selecionada - E4 a E13;

- Coluna $G$, contendo os nós que constituem a rede $(\mathrm{O}, \mathrm{A}, \mathrm{B}, \mathrm{C}, \mathrm{D}, \mathrm{E}, \mathrm{T})-\mathrm{G} 4 \mathrm{a}$ G10;

- Coluna $\mathrm{H}$, representando os fluxos líquidos - $\mathrm{H} 4$ a H10;

- Coluna I, representando as respectivas ofertas/demandas de cada caminho.

- A célula E17 fornecerá a distância total em metros do caminho selecionado.

$\mathrm{Na}$ coluna $\mathrm{H}$, que representa o fluxo líquido, fez-se necessário a utilização de fórmulas. 0 fluxo líquido no nó pode ser definido como o fluxo que sai menos o fluxo que entra, e, assim sendo, o fluxo líquido na origem será 1 , nos nós intermediários será 0 e no destino será -1. Na coluna I da planilha, que representa a oferta/demanda, estão especificadas essas condições. Na célula E17, foi utilizada a função soma de produtos entre as colunas $D$ e $E$ para que fosse possível chegar ao resultado final desejado, ou seja, a distância mínima.

\subsection{ANÁLISE DOS RESULTADOS}

Utilizando o Solver ${ }^{\circ}$, no campo "Definir célula de destino" selecionou-se a célula E17, sendo definido minimizar 0 valor dessa célula, minimizando a distância total entre a Coacal e o comércio mais distante. No campo "Células Variáveis" selecionou-se o intervalo de células E4 a E13. Esse intervalo receberá os seguintes valores:

- $\quad$, caso o arco não seja selecionado;
1, caso o arco seja selecionado.

Dessa forma, a rota selecionada será obtida. Em relação às restrições que o problema foi submetido, definiu-se que Fluxo líquido é igual a Oferta/Demanda. Definiu-se também que as variáveis devem assumir valores nãonegativos e irrestritos e como método de resolução, o LP Simplex. Então, clicou-se em "Resolver", onde foram gerados três relatórios, que serão discutidos a seguir.

A Tabela 2 mostra a solução ótima do problema. 
Tabela 2 - Solução ótima.

\begin{tabular}{|c|c|c|c|}
\hline De & Para & Distância em metros & Rota selecionada \\
\hline O & A & 1300 & 0 \\
\hline O & B & 1200 & 1 \\
\hline A & C & 750 & 0 \\
\hline B & C & 550 & 0 \\
\hline B & D & 400 & 1 \\
\hline C & E & 1500 & 0 \\
\hline C & D & 190 & 0 \\
\hline D & E & 1400 & 1 \\
\hline D & T & 2700 & 0 \\
\hline E & T & 800 & 1 \\
\hline \multicolumn{2}{|c|}{ Distância Total } & 3800 \\
\hline
\end{tabular}

Fonte - Elaborada pelos autores a partir do resultado do Solver® Excel (2017).

De acordo com a solução ótima do problema, o caminho que resulta na menor distância entre a Coacal $(0)$ e o comércio $6(\mathrm{~T})$ é o que passa pelos pontos: comércio $2(B)$, comércio $4(D)$, comércio $5(E)$. Assim, os entregadores deverão sair da Coacal em direção ao comércio 2, percorrendo $1200 \mathrm{~m}$, em seguida para o comércio 4 , percorrendo mais $550 \mathrm{~m}$, em seguida para o comércio 5 , percorrendo mais $1400 \mathrm{~m}$, e por fim, chegar ao destino, percorrendo mais $800 \mathrm{~m}$, totalizando 3800 metros totais percorridos.

Analisando o Relatório de Resposta I, representado na figura 2 , oram necessárias 8 iterações para se chegar ao resultado final. Na primeira tabela, a célula do objetivo mostra valor final de 3800 , que representa a distância total mínima. A segunda tabela, traz os valores 0 e 1 , indicando a rota selecionada. $E$ a terceira tabela mostra as restrições que estão relacionadas ao fluxo líquido, apresentando $1, \quad 0$ e $\quad-1$ referentes, respectivamente, às células relacionadas aos nós de origem, intermediários e de destino. Este relatório não apresenta nenhuma informação adicional, apenas apresenta a resposta de forma mais organizada.

Figura 2 - relatório de resposta i gerado pelo solver $\circledast$

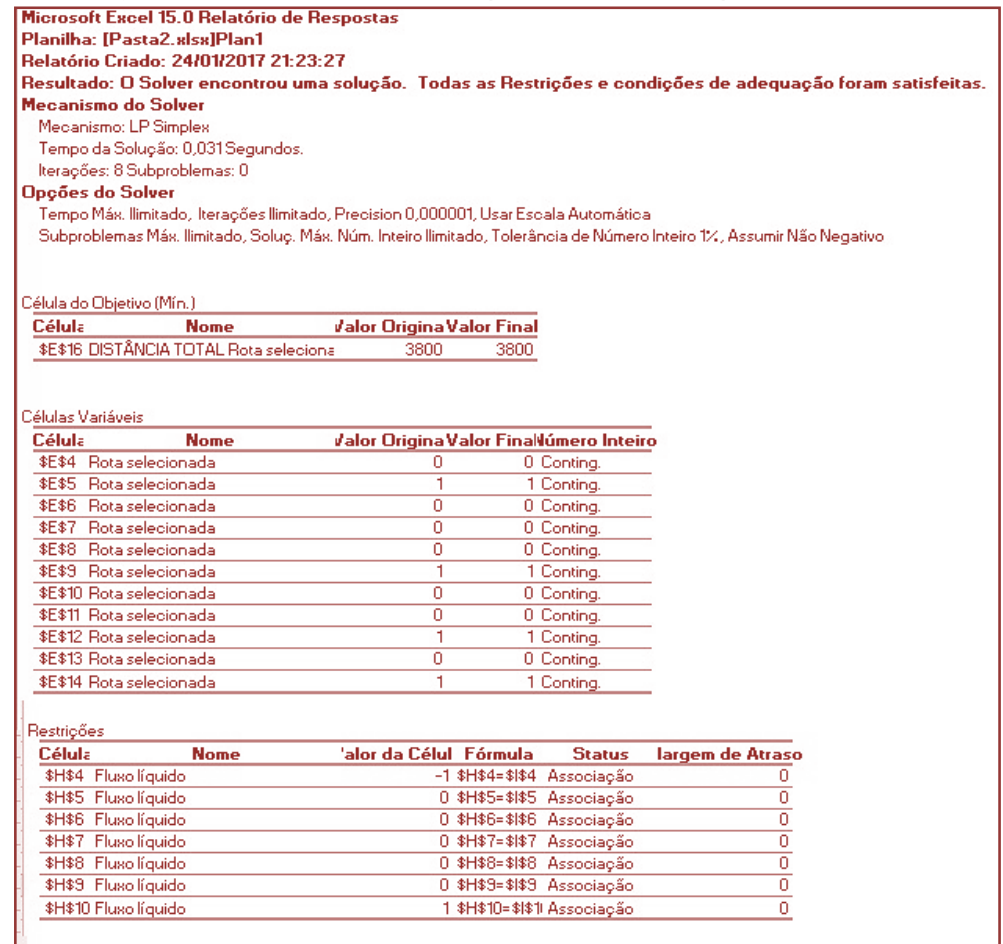

Fonte: solver excel ${ }^{\circledR}$. 


\subsection{VALIDAÇÃO DO MODELO}

Não foi possível a validação do modelo, pois, mesmo se utilizando a ferramenta online Google Maps ${ }^{\circledR}$, que apresenta os caminhos e as respectivas distâncias, e mesmo escolhendo o menor caminho dentre todos os apresentados por essa ferramenta, podem existir outros caminhos que chegariam a um caminho menor que o Google Maps ${ }^{\circledR}$ pode não ter encontrado. Assim sendo, não se tem certeza se os caminhos são realmente os menores. Seriam necessários mais estudos a respeito do trabalho para que o mesmo pudesse ser validado.

\section{CONCLUSÃO}

O objetivo inicialmente proposto pelo trabalho foi atingido. Foi modelado uma rede contendo todos os pontos de entrega que a Cooperativa atende e a determinação do menor caminho entre a origem e o ponto de entrega mais distante, utilizando o Algoritmo do Caminho Mínimo modelado no software Solver $\circledast$, onde foi possível verificar a eficiência do método quando aplicando a este tipo de problemática.

No presente estudo verificou-se a interdisciplinaridade entre duas grandes

\section{REFERÊNCIAS}

[1] Andrade, E. L. Introdução à pesquisa operacional: métodos e modelos para análises de decisões. 4. Ed. Rio de Janeiro: LTC, 2009.

[2] Arenales, M.; Armentano, V.; Morabito, R.; Yanasse, H. Pesquisa Operacional para cursos de engenharia. 3. ed. Rio de Janeiro: Elsevier, 2007.

[3] De Souza Junior, A.A.; Videira, N.P.; Uebelhart, S.C.; Lima, V.C. Análise das publicações sobre logística junto ao Abepro. In: Encontro Nacional DE Engenharia de Produção, 33., 2013, Salvador. Anais... Salvador: ABEPRO, 2013.

[4] Ferreira, F.M.; Bachega, S.J.; Programação linear: um estudo de caso sobre os custos de transporte em uma empresa do setor de confecções de Catalão-GO. In: Encontro Nacional de Engenharia de Produção, 31., 2011, Belo Horizonte. Anais...Belo Horizonte: Abepro, 2011

[5] Fonseca, J. J. S. Metodologia da pesquisa científica. Fortaleza: UEC, 2002. Apostila

[6] GIL, A. C. Como Elaborar Projetos de Pesquisa. 5. ed. São Paulo, Atlas, 2010. áreas da Engenharia de Produção: a pesquisa operacional e a logística. Sendo que a primeira, oferece alternativas viáveis, por meio de modelagem matemática e algoritmos, para a resolução de problemas apresentados na logística, como a procura por métodos que otimizem seus processos e minimize custos. Tal interdisciplinaridade pôde ser perceptível no presente trabalho, ao passo que se utilizou técnicas da PO, o algoritmo do caminho mínimo para a resolução de problemas de roteirização de uma empresa local.

0 presente trabalho contribuiu para a área acadêmica, visto que novos estudos sobre otimização de redes foram acrescidos na literatura da área, ainda, propicia aos estudantes a oportunidade de pôr em prática o conteúdo visto em sala de aula. Contribuiu, também, para o meio empresarial ao passo que novas alternativas para resolução de problemas cotidianos são apresentadas através de algoritmos e modelagens matemáticas intuitivas e de fácil manuseio, como a ferramenta Solver ${ }^{\circledR}$ Excel - software bastante conhecido e utilizado nas empresas.

Para trabalhos futuros sugere-se a aplicação desta técnica na empresa estudada, como, também, realizar melhorias no modelo proposto e aplicar à realidade de outras empresas do ramo da logística.

[7] Hillier, F. S.; Lieberman, G. J. Introdução à Pesquisa Operacional. 8. ed. Porto Alegre: Amgh, 2010.

[8] Hillier, F.S; Lieberman, G. J. Introdução à pesquisa operacional. 9. ed. McGraw Hill, 2013.

[9] Jesus, R.J.B; Toralles, R.P.; Behrens, P.A.C. Pesquisa operacional: uma ferramenta do processo decisório no setor de compras. In: Encontro Nacional de Engenharia de Produção, 35., 2015, Fortaleza. Anais...Fortaleza: Abepro, 2015.

[10] Lachtermacher, Gerson. Pesquisa Operacional. São Paulo: Pearson, 2007.

[11] Livato, M.; Souza, A.P.M. Gestão de custos logísticos na cadeia de suprimentos: um estudo sobre o custo de transporte de cargas. In: Encontro Nacional de Engenharia de Produção, 30., 2010, São Carlos. Anais... São Carlos: ABEPRO, 2010.

[12] Souza et al. Aplicação da Técnica de Varredura no Replanejamento da Malha de Transporte: um Estudo de Caso em uma Empresa de Transporte e Distribuição de Cargas Fracionadas.In: Encontro Nacional de Engenharia 
de Produção, 2014, Curitiba. Anais... Curitiba: Abepro, 2014. 14 p.

[13] Taha, H. A. Pesquisa Operacional: uma visão geral. 8. ed. São Paulo: Pearson Prentice Hall, 2008.
[14] Taha, H. A. Pesquisa Operacional: uma visão geral. 91. ed. São Paulo: Pearson Prentice Hall, 2010. 


\section{Gapítulo 26}

\section{ANÁLISE DA APLICAÇÃO DO BALANCED SCORECARD EM UM HOTEL}

\section{Vitor de Carvalho Pisco}

Lucas Carvalho Martins

José Carlos de Toledo

Resumo: O ramo hoteleiro é considerado altamente lucrativo e competitivo. Hotéis, neste ambiente competitivo e volátil, devem dedicar recursos, a fim de medir seu desempenho e alcançar seus objetivos estratégicos. O modelo balanced scorecard (BSC) desenvolvido por Kaplan e Norton, traduz a estratégia organizacional em quatro perspectivas equilibradas. Tal modelo emergiu da necessidade de melhorar o desempenho do planejamento, monitoramento e avaliação de forma mais robusta. No setor estudado, o BSC ganhou ampla aceitação como meio de proporcionar foco em recursos humanos, ativos intangíveis e desafios relacionados à manutenção do padrão do serviço oferecido, sem negligenciar 0 aspecto financeiro. O presente artigo analisará a aplicação do BSC em um hotel como meio de medir seu desempenho e ganhar vantagem competitiva.

Palavras-chave: Balanced Scorecard (BSC), Medição de desempenho, Setor Hoteleiro, Indicadores de Desempenho 


\section{INTRODUÇÃO}

As empresas, como unidades organizacionais, sofrem contratempos constantes criados pela concorrência. 0 atual mercado hoteleiro é considerado altamente lucrativo e competitivo. Segundo o Fórum de Operadores Hoteleiros do Brasil, estima-se que no ano de 2015 haviam 10.050 empreendimentos com, respectivamente

500.212 quartos. Hotéis, neste ambiente altamente volátil, devem dedicar recursos, tempo e energia a fim de medir seu desempenho para alcançar seus objetivos estratégicos. 0 modelo balanced scorecard (BSC) desenvolvido por Kaplan e Norton, traduz a estratégia organizacional em quatro perspectivas equilibradas. Tal modelo emergiu da necessidade de melhorar as funções de desempenho do planejamento, monitoramento e avaliação de forma mais robusta. No setor de hotéis, o BSC ganhou ampla aceitação como meio de proporcionar foco em recursos humanos, ativos intangíveis e desafios relacionados à manutenção consistente de padrões do serviço oferecido, sem negligenciar $\mathrm{o}$ aspecto financeiro. 0 presente artigo analisará a aplicação do BSC em um hotel de médio porte como meio de medir seu desempenho e ganhar vantagem competitiva.

\section{REFERENCIAL TEÓRICO}

No presente tópico serão discorridos assuntos de relevância ao trabalho, tais como o Balanced Scorecard e o mapa estratégico.

\subsection{O BALANCED SCORECARD}

No decorrer dos anos, o Balanced Scorecard tem se apresentado como uma ferramenta útil na criação de valor e na sustentabilidade a longo prazo nas mais diversas organizações. No setor hoteleiro tal ferramenta é amplamente utilizado, uma vez que este modelo não contempla somente medidas financeiras, que visam resultados de curto prazo, mas também medidas não financeiras, voltadas a obtenção de valor a longo prazo.

Ferreira (2009) cita que a utilização destes dois tipos de medidas, contribui para o equilíbrio entre medidas de resultado (i.e. lag) e medidas de futuro (i.e. lead).

Kaplan e Norton (1992) ao perceberem que a gestão das organizações envolvia a compilação de variadas informações, advindas de diversas áreas, optaram por traduzir a visão, estratégia, medidas, metas e iniciativas sob a ótica de quatro perspectivas de informação: financeira, dos clientes, dos processos internos e de aprendizado e crescimento.

Segundo estes autores, a primeira perspectiva, a financeira, envolve medidas ou indicadores de curto prazo, sendo voltada principalmente aos investidores e tendo como objetivos a rentabilidade, crescimento da empresa e valor do ponto de vista dos acionistas.

A perspectiva seguinte, denominada perspectiva dos clientes tem em seu escopo a obtenção da satisfação dos clientes, de maneira a fidelizar os existentes e ainda obter novos compradores, prevendo e avaliando suas necessidades.

A perspectiva de processos internos tem como meta a garantia de excelência no funcionamento dos processos internos, também satisfazendo os clientes e, de maneira direita, os investidores.

A última perspectiva, de aprendizagem e crescimento, objetiva a continuidade de um bom funcionamento no futuro.

A figura 1 ilustra a relação causal entre as perspectivas e a visão e estratégia. 
Figura 1 - Balanced Scorecard

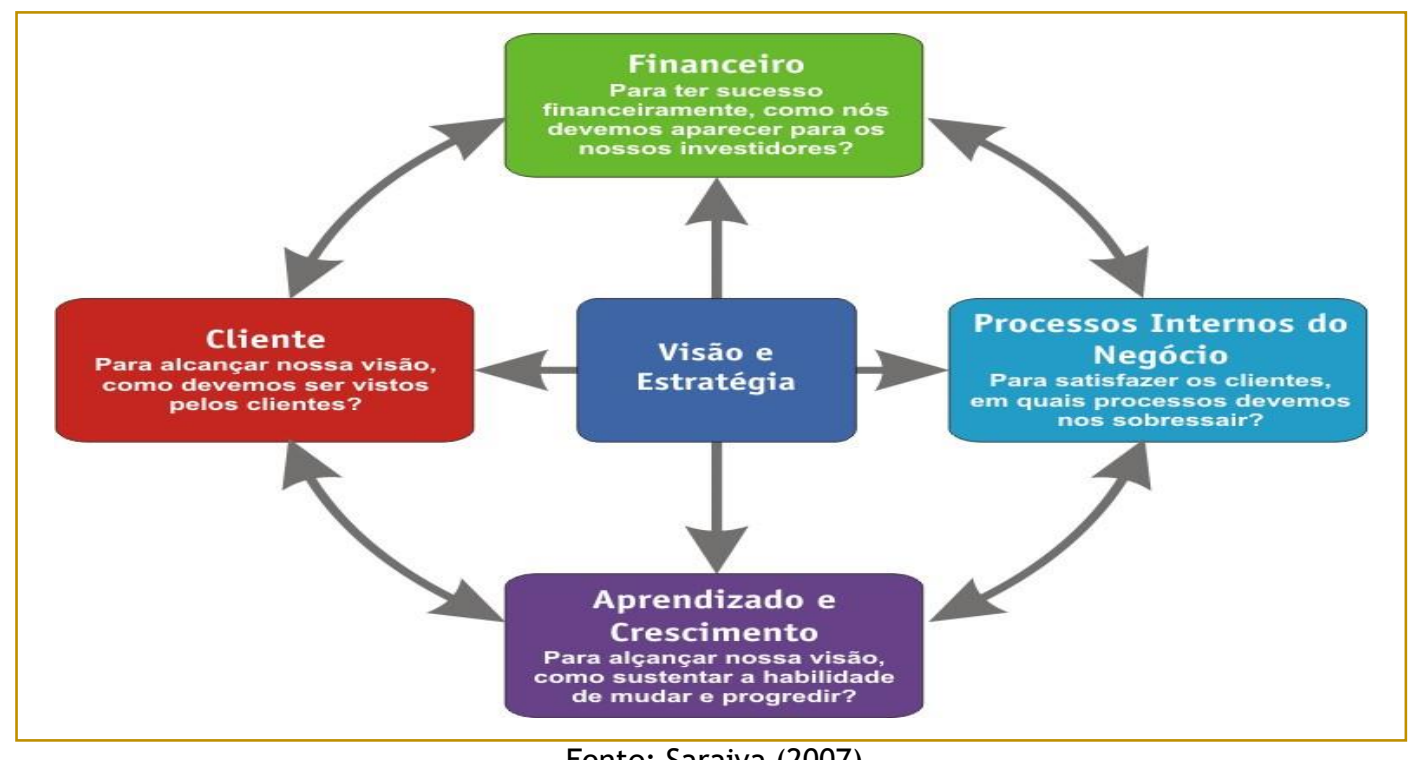

Fonte: Saraiva (2007)

Segundo Kaplan e Norton (1996), para um bom funcionamento do balanced scorecard, sua definição deve seguir alguns princípios básicos: as medidas devem se basear nos objetivos definidos na visão e estratégia da empresa; e relações de causa e efeito devem ser asseguradas entre as perspectivas do BSC.
Dessa forma, o mapa estratégico é um componente fundamental ao bom funcionamento do BSC, tratando-se de uma ferramenta onde os objetivos estratégicos estão divididos nas quatro perspectivas e há identificação das relações causais entre as diversas medidas. (Kaplan e Norton, 2001b)

Figura 2 - Mapa estratégico

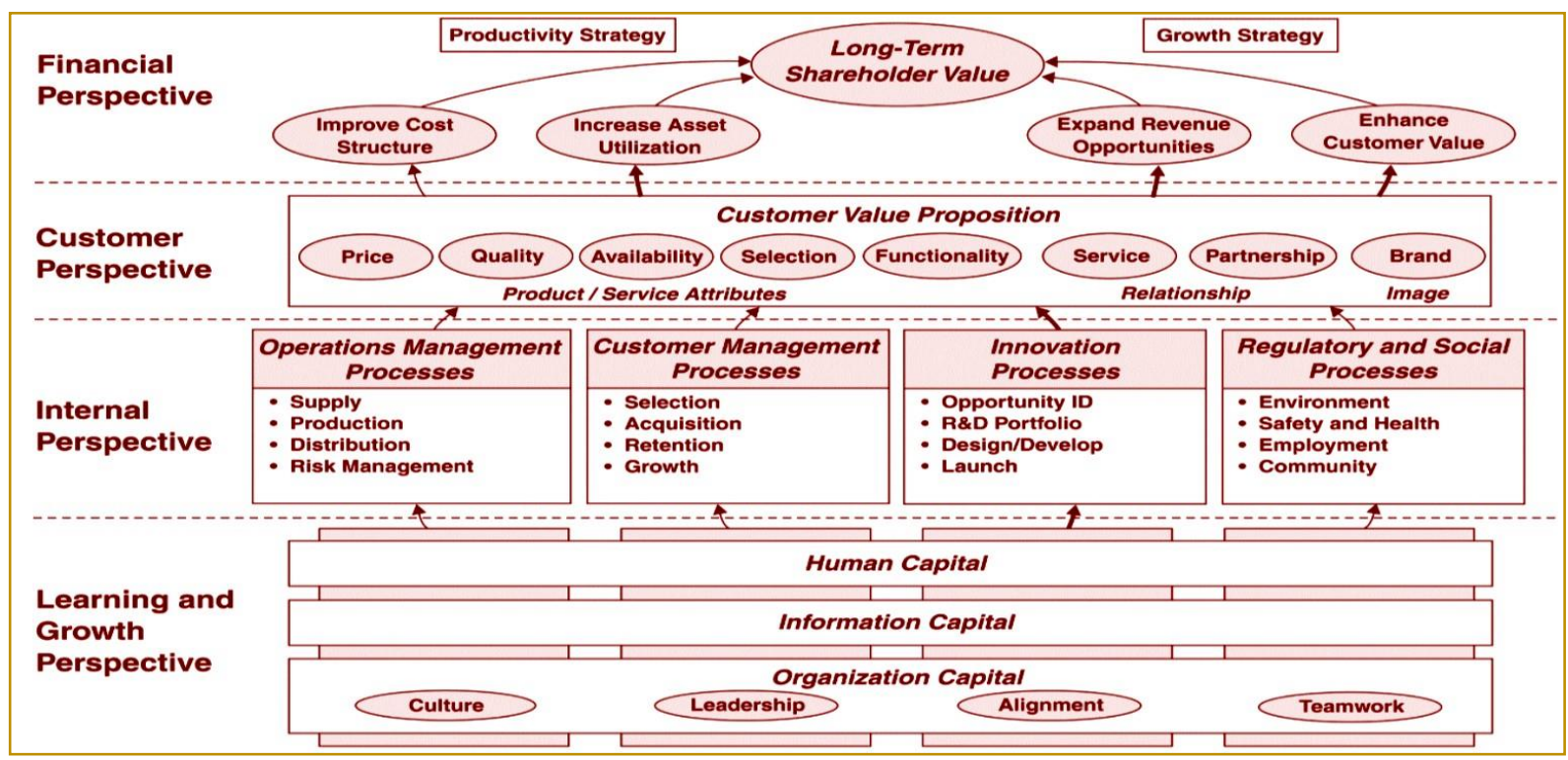

Fonte: Kaplan e Norton (2004, p.66)

Um dos tópicos normalmente vinculados ao Balanced Scorecard é sua manutenção e continuidade ao longo do tempo. Russo (2006), refere que para ampliar a probabilidade de sucesso do modelo, devese assegurar alguns aspectos:

- Liderança: o Balanced Scorecard deve ter o setor estratégico como responsável 
pela determinação e compartilhamento da visão e estratégia por todos os níveis;

- Responsabilidade: deve-se elencar responsáveis pelos processos, para que os objetivos e metas do plano de ação sejam alcançados;

- Comunicação: é necessário que haja comunicação e divulgação de informações pertinentes ao bom funcionamento do BSC, de modo que haja envolvimento de todos os colaboradores;

- Mudança: relativo ao aspecto de melhoria contínua, a estrutura da empresa deve ter enraizado na sua cultura que é primordial o empenho de esforços na melhoria contínua do desempenho organizacional;

- Aprendizagem e aperfeiçoamento: o aperfeiçoamento do modelo ocorre com o passar do tempo, onde novos conceitos são aprendidos e experiência adicional é adquirida.

\section{MÉTODO DE PESQUISA}

0 estudo foi realizado em uma empresa do terceiro setor e baseia-se na coleta e análise de informações relativas ao planejamento estratégico e medição de desempenho da organização.

Utilizou-se para a coleta de dados um roteiro estruturado previamente formulado dividido em duas etapas: a primeira, de coleta do histórico e de informações referentes às instalações do hotel; a segunda, a utilização de ferramentas do planejamento estratégico da empresa, os procedimentos e técnicas adotadas.

O presente estudo contou com a participação de diversos setores da empresa como recepção, gerência e administrativo, que forneceram dados colhidos em forma de entrevista para a discussão dos resultados que foram utilizados para alimentar o modelo BSC.

\section{ESTUDO DE CASO}

O presente tópico faz uma descrição sucinta da empresa, e de sua estrutura organizacional a fim de criar o ambiente para aplicação do modelo BSC.

\subsection{A EMPRESA}

O hotel estudado está situado no estado de Minas Gerais, precisamente na mesorregião do Triangulo Mineiro e Alto Paranaíba, posicionando-se na liderança entre os hotéis locais, segundo indicadores próprios. É um empreendimento novo, com aproximadamente 10 anos de existência. Faz parte de um grupo de empresas do setor sucroalcooleiro, sendo que há somente este empreendimento inserido no ramo hoteleiro.

Visto o crescente desenvolvimento da economia local, em conjunto com a carência de hotéis, emergiu a oportunidade de criar um novo conceito em hotel, visando a qualidade nos serviços prestados e preço justo.

É considerada uma empresa de pequeno porte, com aproximadamente 21 funcionários. A classificação do hotel de acordo com critérios de luxo e comodidade é de três estrelas. O faturamento anual da empresa é estimado em um milhão de reais.

\subsection{ESTRUTURA ORGANIZACIONAL}

Embora atualmente o hotel apresente boa participação de mercado, sua estrutura organizacional é relativamente simples, com baixa departamentalização e com divisão clara de autoridade e responsabilidade entre os níveis hierárquicos, sendo considerada uma estrutura do tipo centralizada.

$\mathrm{Na}$ figura 3, é apresentado o organograma da empresa, onde pode-se verificar os níveis hierárquicos. 
Figura 3 - Organograma do hotel

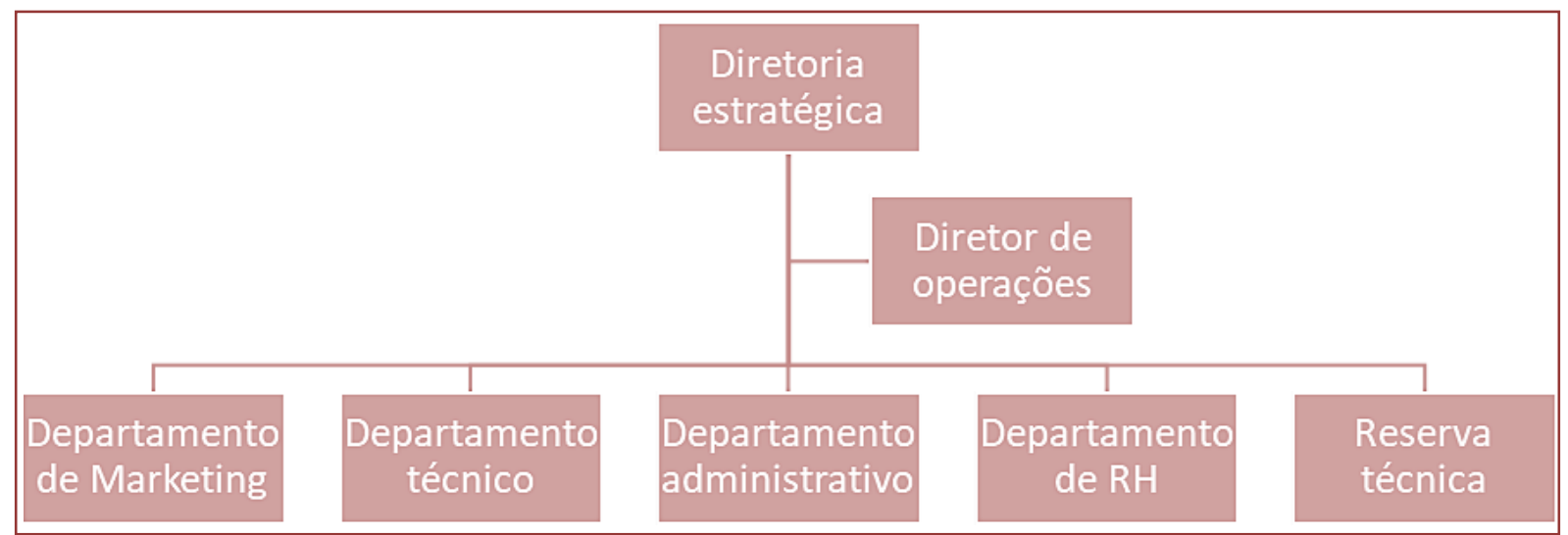

Fonte: Autoria própria

Percebe-se a inexistência de vários níveis hierárquicos, o que facilita e agiliza a comunicação entre os departamentos e a diretoria estratégica.

\section{CONCEPÇÃO DO BALANCED SCORECARD}

0 presente trabalho tem como objetivo a aplicação do Balanced Scorecard visando uma melhor tradução da estratégia, visão e valores a todos os colaboradores, por meio do alinhamento dos objetivos e metas. As iniciativas a serem adotadas permitirão a sustentabilidade da empresa a longo prazo.

Para a utilização da ferramenta, alguns passos foram adotados:

- Determinação da missão, visão, valores e estratégia da empresa

- Escolha das perspectivas de desempenho

- Determinação dos objetivos estratégicos

- Construção do mapa estratégico

- Determinação dos indicadores de desempenho

- Identificação das iniciativas

- Sustentabilidade do BSC

\subsection{DETERMINAÇÃO DA MISSÃO, VISÃO,} VALORES E ESTRATÉGIA DA EMPRESA

Ao determinar-se uma estratégia, é primordial que a missão traduza o propósito da organização; a visão retrata a posição da empresa no futuro e os objetivos de médio a longo prazo; e os valores elucidam aspectos da cultura organizacional como comportamentos e atitudes.

O hotel estudado tem como missão:

"Oferecer e prestar um serviço da melhor maneira possível dentro dos padrões, satisfazendo o máximo possível o cliente"

Por meio da missão adotada, identificam-se os valores da empresa:

- Excelência no atendimento, qualidade e satisfação dos clientes.

Definiu-se, por fim, a visão da empresa:

"Ser uma empresa de referência no cenário hoteleiro regional, oferecendo uma ampla variedade de serviços de qualidade, de maneira inovadora e sustentável"

Por meio da visão declarada, identifica-se os objetivos estratégicos da empresa:

- Excelência operacional, diversificação e crescimento, inovação e sustentabilidade.

Os objetivos estratégicos funcionarão como balizadores para a organização alcançar sua visão.

\subsection{ESCOLHA DAS PERSPECTIVAS DE DESEMPENHO}

Na definição do BSC do hotel, propor-se-á as perspectivas elaboradas por Kaplan e Norton (1996a). As perspectivas irão auxiliar na implementação das metas de médio e longo prazo, ou seja, a visão da empresa.

Para que as metas sejam alcançadas, objetivos estratégicos serão desdobrados em: 
- Perspectiva financeira;

- Perspectiva dos clientes;

- Perspectiva dos processos internos;

- Perspectiva de aprendizagem e crescimento.

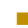

\subsection{DETERMINAÇÃO DOS OBJETIVOS ESTRATÉGICOS}

A determinação dos objetivos estratégicos é extremamente relevante pois há uma estreita relação com a prosperidade da empresa a longo prazo. Dessa forma, os objetivos devem ser realizáveis e serem pareados com a visão e missão.

Na tabela 1, encontram-se os objetivos estratégicos nas perspectivas que a empresa se concentrará.

Tabela 1 - Objetivos estratégicos

\begin{tabular}{|c|c|c|}
\hline Perspectiva & Item & Objetivo estratégico \\
\hline \multirow{3}{*}{ Financeira } & 1 & Redução de custos \\
\hline & 2 & Aumentar taxa de ocupação \\
\hline & 3 & Equilibrar rentabilidade do restaurante \\
\hline \multirow{3}{*}{ Clientes } & 1 & Fidelizar clientes já existentes \\
\hline & 2 & Obter novos clientes de concorrentes \\
\hline & 3 & Aumentar satisfação dos clientes \\
\hline \multirow{2}{*}{ Processos internos } & 1 & Inovar nos serviços prestados \\
\hline & 2 & Otimizar mão de obra em diversos setores \\
\hline \multirow{2}{*}{ Aprendizagem e crescimento } & 1 & Aumentar índice de capacitação de colaboradores \\
\hline & 2 & Aperfeiçoar sistemas de informação da empresa \\
\hline
\end{tabular}

Após a determinação dos objetivos estratégicos das perspectivas de desempenho, a próxima etapa é a elaboração do mapa estratégico.

\subsection{CONSTRUÇÃO DO MAPA ESTRATÉGICO}

O mapa estratégico tem como função descrever e comunicar a estratégia da organização. Tais funções são obtidas por meio da determinação dos objetivos estratégicos e suas relações causais.
Dessa forma, baseando-se nos objetivos definidos anteriormente, definiu-se o mapa estratégico do hotel, elucidando mais claramente a visão e estratégia da empresa aos colaboradores.

A tabela 2 resume as relações de causa e efeito entre cada objetivo estratégico e o relacionamento entre as perspectivas de desempenho. 
Tabela 2 - Mapa Estratégico do hotel

"Ser uma empresa de referência no cenário hoteleiro regional, oferecendo uma ampla variedade de serviços de qualidade, de maneira inovadora e sustentável”

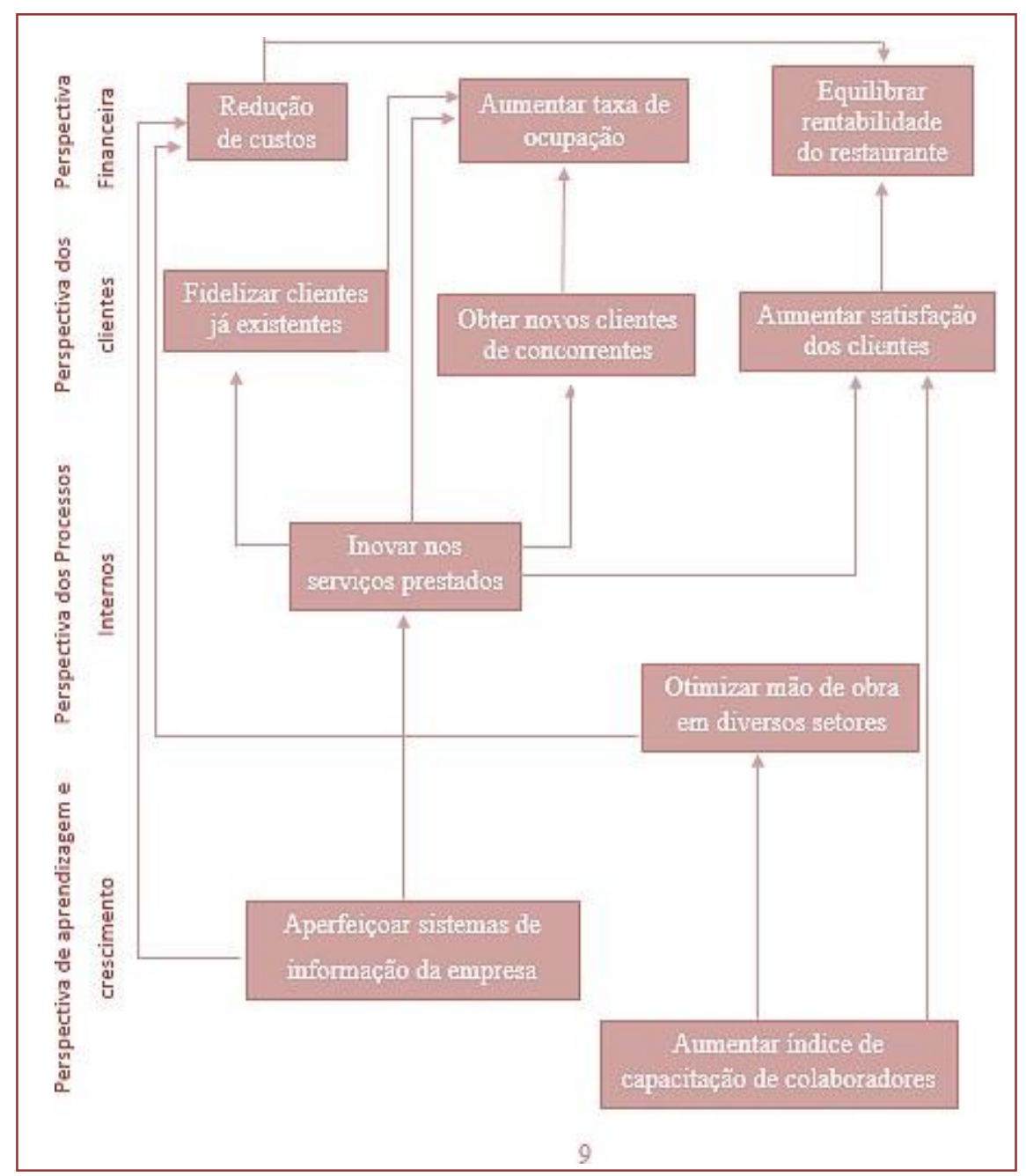

Fonte: Autoria própria

\subsection{DETERMINAÇÃO DOS INDICADORES DE DESEMPENHO}

Após a criação da primeira saída do Balanced Scorecard, o mapa estratégico, a etapa seguinte é a elaboração da segunda saída, o scorecard.

Nesta fase são definidos os indicadores chave de desempenho (key performance indicators -KPIs), ou seja, são métricas capazes de avaliar a obtenção dos objetivos estratégicos levantados anteriormente na etapa de determinação do mapa estratégico.

Dessa forma, criou-se um plano com os indicadores chave em cada objetivo estratégico, conforme ilustrado na tabela 3. 
Tabela 3 - Indicadores chave

\begin{tabular}{|c|c|c|c|c|c|c|c|}
\hline Perspectiva & Item & $\begin{array}{l}\text { Objetivo } \\
\text { estratégico }\end{array}$ & Indicador & $\begin{array}{l}\text { Tipo de } \\
\text { indicador }\end{array}$ & $\begin{array}{l}\text { Modo de } \\
\text { calcular }\end{array}$ & Responsável & Periodicidade \\
\hline \multirow{4}{*}{ Financeira } & 1 & $\begin{array}{l}\text { Redução de } \\
\text { custos }\end{array}$ & $\begin{array}{l}\text { Rateio de } \\
\text { custos }\end{array}$ & Lag & $\begin{array}{l}\text { Rateio de } \\
\text { custos }\end{array}$ & $\begin{array}{c}\text { Diretor de } \\
\text { operações/ } \\
\text { administrativo }\end{array}$ & Mensal \\
\hline & 2 & $\begin{array}{l}\text { Aumentar taxa } \\
\text { de ocupação }\end{array}$ & $\begin{array}{c}\text { Ocupação dos } \\
\text { quartos }\end{array}$ & Lag & $\begin{array}{l}\text { Quartos } \\
\text { ocupados/ } \\
\text { Total de } \\
\text { quartos }\end{array}$ & $\begin{array}{l}\text { Diretor de } \\
\text { operações }\end{array}$ & Mensal \\
\hline & 3 & $\begin{array}{c}\text { Equilibrar } \\
\text { rentabilidade } \\
\text { do restaurante }\end{array}$ & Rentabilidade & Lag & $\begin{array}{l}\text { Receita/Cu } \\
\text { sto }\end{array}$ & $\begin{array}{c}\text { Dep. } \\
\text { Administrativo }\end{array}$ & Mensal \\
\hline & 1 & $\begin{array}{l}\text { Fidelizar } \\
\text { clientes já } \\
\text { existentes }\end{array}$ & $\begin{array}{l}\text { Número de } \\
\text { reclamações }\end{array}$ & Lead & $\begin{array}{c}\mathrm{N}^{\circ} \\
\text { absoluto }\end{array}$ & $\begin{array}{l}\text { Dep. De } \\
\text { Marketing }\end{array}$ & Mensal \\
\hline \multirow[t]{3}{*}{ Clientes } & 2 & $\begin{array}{l}\text { Obter novos } \\
\text { clientes de } \\
\text { concorrentes }\end{array}$ & $\begin{array}{l}\text { Número de } \\
\text { novos } \\
\text { cadastros }\end{array}$ & Lag & $\begin{array}{c}\mathrm{N}^{\circ} \\
\text { absoluto }\end{array}$ & $\begin{array}{l}\text { Dep. De } \\
\text { Marketing }\end{array}$ & Trimestral \\
\hline & 3 & $\begin{array}{c}\text { Aumentar } \\
\text { satisfação dos } \\
\text { clientes }\end{array}$ & $\begin{array}{l}\text { Satisfação } \\
\text { global dos } \\
\text { clientes }\end{array}$ & Lag & $\%$ & $\begin{array}{l}\text { Diretor de } \\
\text { operações }\end{array}$ & Semestral \\
\hline & 1 & $\begin{array}{c}\text { Inovar nos } \\
\text { serviços } \\
\text { prestados }\end{array}$ & $\begin{array}{c}\text { Receita de } \\
\text { novos serviços }\end{array}$ & Lead & $\begin{array}{c}\mathrm{N}^{\circ} \\
\text { absoluto }\end{array}$ & $\begin{array}{l}\text { Diretor de } \\
\text { operações }\end{array}$ & Semestral \\
\hline \multirow[t]{2}{*}{$\begin{array}{c}\text { Processos } \\
\text { internos }\end{array}$} & 2 & $\begin{array}{l}\text { Otimizar mão } \\
\text { de obra em } \\
\text { diversos } \\
\text { setores }\end{array}$ & $\begin{array}{l}\text { Avaliação de } \\
\text { desempenho }\end{array}$ & Lead & $\%$ & Dep. de RH & Anual \\
\hline & 1 & $\begin{array}{c}\text { Aumentar } \\
\text { índice de } \\
\text { capacitação } \\
\text { de } \\
\text { colaboradores }\end{array}$ & $\begin{array}{l}\text { Número de } \\
\text { horas de } \\
\text { treinamento } \\
\text { por } \\
\text { colaborador }\end{array}$ & Lead & $\begin{array}{c}\mathrm{N}^{\circ} \\
\text { absoluto }\end{array}$ & Dep. de RH & Semestral \\
\hline $\begin{array}{l}\text { Aprendizagem e } \\
\text { crescimento }\end{array}$ & 2 & $\begin{array}{l}\text { Aperfeiçoar } \\
\text { sistemas de } \\
\text { informação da } \\
\text { empresa }\end{array}$ & $\begin{array}{c}\text { Tempo para } \\
\text { implementaro } \\
\text { novas } \\
\text { soluções }\end{array}$ & Lead & $\begin{array}{c}\mathrm{N}^{\circ} \\
\text { absoluto }\end{array}$ & Dep. Técnico & Anual \\
\hline
\end{tabular}

Fonte: Autoria própria

\subsection{IDENTIFICAÇÃO DAS INICIATIVAS}

A próxima ação a ser adotada é a elaboração de um plano de ação que guiará a organização para a obtenção dos objetivos estratégicos que foram propostos.

Segundo Kaplan e Norton (2008), cada iniciativa deve ter um score atribuído, pois dessa forma pode-se perceber as ações que tem maior impacto nos objetivos estratégicos.

Os scores estabelecidos na Tabela 4 foram definidos em reuniões com os setores responsáveis da empresa. 
Tabela 4 - Plano de ação

\begin{tabular}{|c|c|c|c|c|c|c|c|c|c|c|c|}
\hline \multirow{3}{*}{ Iniciativas Estratégicas } & \multicolumn{10}{|c|}{ Perspectivas } & \\
\hline & \multicolumn{3}{|c|}{ Financeiro } & \multicolumn{3}{|c|}{ Clientes } & \multicolumn{2}{|c|}{ Processos Internos } & \multicolumn{2}{|c|}{$\begin{array}{l}\text { Aprendizagem e } \\
\text { crescimento }\end{array}$} & \\
\hline & 1 & 2 & 3 & 1 & 2 & 3 & 1 & 2 & 1 & 2 & Score \\
\hline Criar ações de marketing de massa & 0 & 3 & 1 & 2 & 3 & 0 & 0 & 0 & 0 & 0 & 9 \\
\hline $\begin{array}{l}\text { Aplicação de seeding (fornecer } \\
\text { produto ou serviço ao usuário no } \\
\text { momento certo e desejado) }\end{array}$ & 1 & 3 & 3 & 3 & 3 & 0 & 3 & 0 & 0 & 0 & 16 \\
\hline $\begin{array}{l}\text { Divulgação de cartões de visita a } \\
\text { clientes em potencial }\end{array}$ & 0 & 3 & 3 & 1 & 3 & 1 & 1 & 0 & 0 & 0 & 12 \\
\hline $\begin{array}{l}\text { Aplicação de referenciação (clientes } \\
\text { satisfeitos referenciam o hotel a } \\
\text { amigos) }\end{array}$ & 2 & 2 & 0 & 2 & 3 & 2 & 1 & 0 & 0 & 0 & 12 \\
\hline $\begin{array}{l}\text { Diferenciação dos serviços (camas } \\
\text { maiores e com massageador) }\end{array}$ & 0 & 0 & 0 & 3 & 3 & 3 & 3 & 0 & 2 & 0 & 14 \\
\hline $\begin{array}{c}\text { Montagem do cardápio do restaurante } \\
\text { pelo cliente }\end{array}$ & 0 & 0 & 3 & 2 & 2 & 3 & 3 & 3 & 2 & 0 & 18 \\
\hline Oferecimento de serviço de translado & 0 & 0 & 0 & 1 & 2 & 2 & 3 & 2 & 2 & 0 & 12 \\
\hline $\begin{array}{l}\text { Descontos especiais para reservas de } \\
\text { grande volume ou longo prazo }\end{array}$ & 3 & 3 & 2 & 1 & 1 & 1 & 0 & 2 & 2 & 0 & 15 \\
\hline $\begin{array}{c}\text { Implantação de sala de jogos e } \\
\text { entretenimento }\end{array}$ & 0 & 0 & 0 & 2 & 1 & 1 & 3 & 3 & 2 & 1 & 13 \\
\hline $\begin{array}{c}\text { Utilização de benchmarking para } \\
\text { comparação de serviços, produtos e } \\
\text { práticas }\end{array}$ & 1 & 0 & 0 & 0 & 2 & 2 & 2 & 2 & 3 & 3 & 15 \\
\hline Treinamento de pessoal & 1 & 0 & 0 & 0 & 0 & 0 & 2 & 3 & 3 & 3 & 12 \\
\hline $\begin{array}{l}\text { Investimento em comunicação digital } \\
\text { (economizando com uso de papel) }\end{array}$ & 3 & 3 & 0 & 1 & 2 & 2 & 2 & 2 & 0 & 0 & 15 \\
\hline $\begin{array}{l}\text { Criação de plano de formação, por } \\
\text { departamentos, visando melhoria dos } \\
\text { colaboradores }\end{array}$ & 0 & 0 & 0 & 0 & 0 & 0 & 3 & 3 & 3 & 3 & 12 \\
\hline
\end{tabular}

Fonte: Autoria própria

Os maiores scores são os de maior relevância para a tomada de ação. Para que a identificação das iniciativas fosse facilitada, os maiores scores foram destacados em verde, os de menor relevância em amarelo e por fim os vermelhos, pouco relevantes.

\section{CONCLUSÃO}

A existência das empresas ao longo do tempo está condicionada à habilidade de fornecer serviços ou produtos de qualidade a um valor que o consumidor esteja disposto a pagar. Neste contexto, o Balanced Scorecard permite às organizações um equilíbrio entre o curto e longo prazo, concebendo um sistema de gestão estratégica adequado à realidade atual.

O modelo BSC, desenvolvido por Kaplan e Norton em 1992, surgiu como um modelo de avaliação de desempenho, evoluindo para um modelo de gestão estratégica.

Assim, o presente artigo construiu um modelo de BSC adequado às necessidades de um hotel, seguindo o passo a passo planejado. Este modelo pretende facilitar a visão global da performance organizacional, por meio de diferentes perspectivas e acompanhamento de resultados, auxiliando, por fim, a sustentabilidade da empresa a longo prazo. 


\section{REFERÊNCIAS}

[1] DI Cunto, Kuki, Gorenstein, Eric, Gorni Manuela, Mader, Ricardo, Michels, Kent. Hotelaria em números Brasil 2015. Fórum de Operadores Hoteleiros do Brasil, 2015. Disponível em < http: //www.jll.com.br/brazil/pt$\mathrm{br} /$ Research/Hotelaria\%20em\%20N\%C3\%BAmeros \%20Brasil\%202015.pdf?38e06e74-d437-4e40b4da-49862ded0850> Acesso em 15/01/2018

[2] Ferreira, A. 2009. Sistemas de Medição do Desempenho e o Balanced Scorecard. In Major, M.; Vieira, R. (Coord), Contabilidade e Controlo de Gestão, Teoria, Metodologia e Prática: 302-329. Lisboa: Escolar Editora.

[3] Kaplan, R., Norton, D. The Balanced Scorecard - Measures That Drive Performance Harvard Business Review, 1992, p. 71-79.
[4] Kaplan, R., Norton, D. The Balanced Scorecard - Translating strategy into action. Boston: Harvard Business School Press, 1996a.

[5] Kaplan, R., Norton, D. Using the Balanced Scorecard as a Stretegic Management System. Harvard Business Review, 1996b, p.75-85.

[6] kaplan, R., Norton, D. Strategy maps: converting intangible assets into tangible outcomes. Boston: Harvard Business School Press, 2004.

[7] kaplan, R., Norton, D. Transforming the Balanced Scorecard from performance measurement to streategic management: part I. Accounting Horizons, 2001b, 15 (1):87-104.

[8] Russo, J. Balanced Scorecard para PME. Lidel: Lisboa - edições técnicas, 2006.

[9] Saraiva, A. C. P.; Borrego, J. L. S., Estratégia: estratégia nas organizações. Coimbra, 2007. 


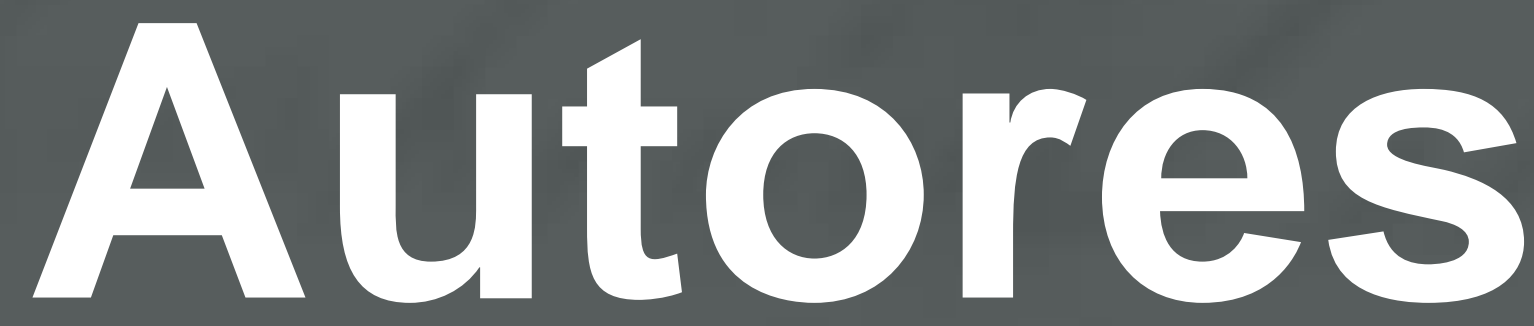




\section{ADAURI SILVEIRA RODRIGUES JUNIOR}

Mestrado em Materiais, Pós Graduação em Gerenciamento Industrial, MBA em Gestão de Pessoas e Graduação em Engenharia Mecânica.24 anos de experiência atuando como Engenheiro de Desenvolvimento de Produto e com Controle Estatístico de Processo dentro de um programa 6 sigma como Black Belt Atualmente Coordenador do Curso de Engenharia de Produção da Universidade Severino Sombra e professor universitário.

\section{ADRIANO OLIVIERI BRITO}

Médico de Família pela SBMFC, especialista em Geriatria pela FCMMG, com atuação assistencial prévia no interior de Minas Gerais, na Prefeitura de Belo Horizonte e Saúde Suplementar (Vitallis e Unimed-BH). Atualmente atua com Gerente Ambulatorial na UnimedBH e cursa MBA em Gestão de Serviços de Saúde na Fundação Getúlio Vargas-IBS.

\section{BÁRBARA ANDRINO CAMPOS SILVA}

Cursando Bacharelado em Administração - IFMG. Técnica em Informática - IFMG.

\section{BÁRBARA DACAL DE AZEVEDO}

Graduada em Engenharia Mecânica pela Universidade Tecnológica Federal do Paraná Campus Guarapuava.

\section{CHRISTIAN PACHECO DE MORAES}

Engenheiro de Produção e Sistemas pela Universidade do Estado de Santa Catarina (UDESC, 2018).

\section{CLAUDIO DECKER JUNIOR}

Engenheiro de Produção e Sistemas pela Universidade do Estado de Santa Catarina (2011). Mestre em Engenharia Mecânica (2015) e doutorando em Engenharia Mecânica, ambos pela Universidade Federal de Santa Catarina. Experiência em manutenção industrial, gestão da segurança, gestão de serviços (gerenciamento de equipes nos trabalhos de adequação, implementação e expansão de sistemas de abastecimento de ar comprimido, água e gases industriais) gestão de estoques (vendas técnicas na área de componentes e equipamentos elétricos). Atualmente é professor colaborador na Universidade do Estado de Santa Catarina, no Curso de Engenharia de Produção e Sistemas.

\section{CRISTIANE MARIANO ZAVATI SILVA}

Atualmente é Tecnologista (servidora) do Instituto Nacional de Pesquisas Espaciais - SJC, na Engenharia e Tecnologia Espacial, na área de Garantia do Produto Espacial e Garantia do Produto de Software. Mestrado em Engenharia e Tecnologia Espaciais (INPE - 2017). Especialista em Segurança de Aviação e Aeronavegabilidade Continuada pelo ITA (2010), tem experiência na área de Certificação de Produtos Aeroespaciais, foi Coordenadora da Certificação Militar da Aeronave KC-390 da EMBRAER, IFI/DCTA. Possui graduação em Engenharia Mecânica pela Universidade Estadual Paulista Júlio de Mesquita Filho (2007).

\section{DALESSANDRO SOARES VIANNA}

Possui graduação em Ciência da Computação pela Universidade Federal Fluminense (1996), mestrado em Ciência da Computação pela Universidade Federal Fluminense (1999) e doutorado em Informática pela Pontifícia Universidade Católica do Rio de Janeiro (2004). Atualmente atua como: vice-diretor do Instituto de Ciência e Tecnologia (ICT/UFF); vicecoordenador do Programa de Mestrado em Engenharia de Produção e Sistemas 
Computacionais; professor adjunto da Universidade Federal Fluminense (ICT/UFF); professor colaborador da Universidade Candido Mendes - UCAM-Campos; orientador de dissertações do Programa de Mestrado em Engenharia de Produção e Sistemas Computacionais do ICTUFF e do Programa de Mestrado em Pesquisa Operacional e Inteligência Computacional da UCAM-Campos; referee dos Periódicos Enterprise Information Systems, Brazilian Journal of Operations \& Production Management, Journal of the Brazilian Computer Society, Revista Gestão \& Produção, Revista Produção, Revista Produção Online, Revista Sistemas \& Gestão, Revista Gestão Industrial, Cadernos do IME - Série Estatística, Pesquisa Operacional para o Desenvolvimento, dentre outros; e consultor Ad Hoc do CNPq e da FAPERJ. Em 2007 recebeu o prêmio \&quot;Jovem Cientista do Estado do Rio de Janeiro\&quot; concedido pela FAPERJ. Em 2016 recebeu o prêmio de Excelência em Docência da UFF. Tem experiência nas áreas de Ciência da Computação e Engenharia de Produção, tendo como principais temas de pesquisa: programação metaheurística; inteligência computacional; programação paralela; programação matemática; otimização combinatória multiobjetivo; e pesquisa operacional.

\section{DEISA VALERIA COSTA CONEGUNDES}

Tem 10 anos de experiência em construção e planejamento. Atualmente lidera do turnaround organizacional da Andrade Gutierrez, de uma filosofia tradicional de gestão para uma filosofia enxuta. Engenheira Civil, Administradora e Lean Master Black Belt

\section{DEYVID RICARDO RAMOS GONCALVES}

Graduado em Engenharia de Produção - Faculdades Santo Agostinho (FASA) (2012), Mestre em Ciência da Engenharia Civil - Universidade Federal de Ouro Preto (UFOP) (2015). Possui certificação Black Belt - Lean Six Sigma. É coordenador do curso de Engenharia de Produção e ministra aulas nos cursos de Engenharia de Produção, Engenharia Civil e Administração pelas Faculdades Santo Agostinho e Fundação Educacional de Mariana nas áreas de Administração da Produção e Operações, Engenharia de Processos, Pesquisa Operacional, Gestão de Pessoas, Materiais de Construção, Resistência dos Materiais e Teoria das Estruturas.

\section{ED CARLO ROSA PAIVA}

Engenheiro Civil (1997); Mestre em Engenharia Civil - Saneamento Ambiental (2008) e Doutor em Engenharia Agrícola - Recursos Hídricos e Ambientais (2011) pela Universidade Federal de Viçosa (UFV). Professor do Curso de Engenharia Civil da Universidade Federal de Goiás Regional Catalão desde de julho de 2009. Atua nas áreas de Saneamento: água, águas residuárias e resíduos sólidos. Também atua na área de patologia de revestimentos, uso de materiais alternativos para construção, uso racional da água, e conforto térmico e eficiência energética.

\section{EDSON PACHECO PALADINI}

Professor Titular do Departamento de Engenharia de Produção e Sistemas da Universidade Federal de Santa Catarina. Membro Titular da Academia Brasileira da Qualidade. Doutorado em Engenharia de Produção (UFSC, 1992), Mestrado em Engenharia de Sistemas (UFPb, 1979), Especialização em Administração da Produção (UFPb, 1981) e Graduação em Matemática (UFSC, 1975). Atua nas áreas de Engenharia, Gestão e Avaliação da Qualidade. É autor de diversos livros e de artigos técnicos publicados em periódicos qualificados no país e no exterior. Integrou o Comitê de Avaliação dos Programas de Pós-graduação da CAPES na área das Engenharias III. Coordenador do Programa de Pós-graduação em Engenharia de Produção da UFSC (2002-2006). 


\section{EDWIN BENITO MITACC MEZA}

Possui graduação em Engenharia Industrial pela Universidad de Lima, ULIMA (1997), mestrado em Engenharia de Produção pela Universidade Federal Fluminense, UFF (2000), mestrado em Computação Aplicada e Automação pela Universidade Federal Fluminense, UFF (2001) e doutorado em Ciências da Computação pela Universidade Federal Fluminense, UFF (2006). Atualmente é professor Associado I da Universidade Federal Fluminense no Instituto de Ciência e Tecnologia em Rio das Ostras (UFF/RIC). Tem experiência na área de Engenharia Elétrica, com ênfase em Sistemas Elétricos de Potência, atuando principalmente nos seguintes temas: Sistemas de distribuição e transmissão de energia elétrica, redes neurais artificiais, sistemas de inferência nebulosa e otimização. Também tem experiência na área de Engenharia de Produção, com ênfase em Pesquisa Operacional, atuando principalmente nos seguintes temas: Gestão da Produção, Otimização Combinatória e Inteligência Computacional.

\section{ELIANE APARECIDA DOS SANTOS SILVA}

Graduanda do $8^{\circ}$ período de Engenharia de Produção- FACET. Experiência na área de gestão de processos de produção e gestão da qualidade.

\section{ELISA HENNING}

Engenheira Civil pela Universidade do Estado de Santa Catarina (UDESC, 1992), mestrado em Matemática, Estatística e Computação pela UAb (2014), mestrado em Engenharia Ambiental (1998) e doutorado em Engenharia de Produção (2010), ambos pela Universidade Federal de Santa Catarina (UFSC). Atualmente é professora associada da Universidade do Estado de Santa Catarina. Desenvolve pesquisa na área de Educação Estatística, Previsão e Controle Estatístico de Processos

\section{ELISANGELA ELIAS DE SOUZA}

Graduada em Administração, analista de negócios com atuação na área de Business Intelligence Analytics. Responsável pelo alinhamento entre as áreas de negócio e a área de TI. Integra a equipe da Gerência de Desenvolvimento de Informação para o Negócio da Unimed-BH.

\section{FAGNER TAVARES XAVIER}

Técnico em Edificações pela Faculdade de Arquitetura e Urbanismo de Pernambuco, Graduado em Engenharia de Produção de Faculdade Boa Viagem. Já atuou como monitor das disciplinas de Desenho aplicado à Engenharia e Pesquisa Operacional de Modelos Probabilísticos. Atualmente é Analista de Planejamento e Controle da Produção no Grupo Bimbo.

\section{FRANCIELE BONATTO}

Professora assistente da Universidade Tecnológica Federal do Paraná (UTFPR). Graduação e mestrado em engenharia de produção pela UTFPR e doutorado em andamento em Engenharia de Produção pela mesma universidade. Trabalha com os temas: gestão da qualidade, planejamento e controle da produção e cadeia de suprimentos.

\section{GILBERTO ANTUNES DE SOUSA JUNIOR}

Acadêmico do $9^{\circ}$ período de Engenharia de Produção - FASA 


\section{GISELA KLOC LOPES}

Formação em Química Industrial pelas Faculdades Reunidas Nuno Lisboa (1990), Licenciatura em Química pela Universidade Salgado Oliveira (2009), Especialização em Ciência e Tecnologia de Polímeros (1990), pela Universidade Federal do Rio de Janeiro, no Instituto de Macromoléculas (UFRJ/IMA). Em 2002, Mestrado em Ciência e Tecnologia de Polímeros e Doutorado em Ciência e Tecnologia de Polímeros pela UFRJ/IMA (2006). Experiência Profissional na indústria de adesivos nos setores de Controle de qualidade, Desenvolvimento, Produção e Suprimentos. Na pesquisa, execução de projetos na UFRJ/IMA, no desenvolvimento de nanocompósitos superabsorventes e termoplásticos biodegradáveis. Atualmente, leciona na Universidade Veiga de Almeida (UVA), campus Cabo Frio, no curso de graduação da Engenharia. Em projetos de iniciação científica e monografias atua com os seguintes temas; compósitos poliméricos e cimentícios, termoplásticos, manejos sustentável de resíduos e recursos naturais, estudos em qualidade ambiental e combustíveis renováveis.

\section{GIUSEPPE BRUNO DE ALMEIDA MENDES ROCHA}

Estudante de Engenharia de Produção das Faculdades de Ciências Exatas e Tecnológicas Santo Agostinho. Atualmente desenvolvendo projetos com foco em Pesquisa Operacional, produção e logística. Admirador das áreas de Gestão de Projetos e Pesquisa Operacional procuro me aperfeiçoar nestes campos de atuação e me tornar gestor.

\section{GUILHERME MOREIRA DE SOUZA}

Major Aviador da Força Aérea Brasileira, é atualmente o Chefe da Subdivisão de Processos de Certificação de Produtos Aeroespaciais do Instituto de Fomento e Coordenação Industrial. Mestre em Aviation Safety \& Aircraft Airworthiness pelo Institut Supérieur de l'Aéronautique et de l'Espace (2015). MBA em Gestão Pública pela Universidade da Força Aérea - RJ (2016) . É auditor da qualidade e tem experiência na área de Certificação de Produtos Aeroespaciais, Recebimento de Aeronaves, Credenciamento de Organizações de Projeto Aeronáutico (Design Organisation Approval) e foi Coordenador da Certificação Militar da Aeronave Gripen E/F da SAAB, no IFI/DCTA. Acumula atualmente a função de Gerente Industrial do Projeto FX2 (Gripen NG) da FAB. Possui graduação em Ciências Aeronáuticas pelo Academia da Força Aérea (2003).

\section{HENRIQUE JUN MURAMATSU SEGUCHI}

Graduado em Engenharia de Produção na Universidade Anhembi Morumbi e pós graduando (especialização) em produtividade e qualidade pela Fundação Vanzolini. Pesquisador no Núcleo de Atendimento Tecnológico à Micro e Pequena Empresa (NT-MPE) do Instituto de Pesquisas Tecnológicas do Estado de São Paulo (IPT). Tem experiência na área de Engenharia de Produção, com ênfase em energia, capim elefante e atua na execução de programa, no apoio tecnológico às micro, pequenas e médias empresas referente a gestão de produção.

\section{HUMBERTO ELIAS GIANNECCHINI FERNANDES ROCHA SOUTO}

Técnico em Manutenção Automotiva - IFMG. Cursando Bacharelado em Administração IFMG. 


\section{INGRID DE FIGUEIREDO ASTIGARRETA}

Formada em engenharia de produção pela Universidade La Salle do Rio de Janeiro e pós graduanda no curso de Especialização em Engenharia de Segurança do Trabalho pela Universidade Federal Fluminense. Atualmente trabalha na área de petróleo e gás como analista na Siemens Subsea auxiliando nos processos de venda e qualidade de conectores elétricos submarinos.

\section{ISABELA GONÇALVES BASTIANINI}

Engenheira de Produção

\section{ISABELA LOPES GOMES TORRES}

Engenheira de Produção

\section{ISABELLA FERRO}

Engenheira de Produção

\section{JARBAS ANCELMO DA SILVA JÚNIOR}

Graduado em Engenharia de Produção pela Universidade Federal de Goiás - Regional Catalão. Integrante do Grupo de Estudos em Modelagem e Simulação (GEMS), liderado pela Prof ${ }^{a}$ Dr. Stella Jcyszyn Bachega.

\section{JESIMAR DA CRUZ ALVES}

Mestre em Ciências Ambientais com ênfase em Gestão de Processos, Bacharel em Administração, Pós Graduado em Tecnologias Educacionais, com MBA em Gestão de Pessoas e Licenciatura Plena. Atuou como Gestor do Núcleo de Educação a Distância do SENAI/FIRJAN Regional I. Atua como Professor dos cursos de Administração, Engenharia de Produção e Pedagogia. Tem experiência em coordenação de curso e docência universitária e técnica.

\section{JOÃO CÂNDIDO JÚNIOR}

Graduado em Engenharia Civil pela Universidade Federal de Goiás (UFG) - (2017), com experiência em gestão de pessoas; Acompanhamento de obras; Controle de materiais, mão de obra e empreiteiros; Elaboração de orçamentos; Medições, experiência adquirida por meio de estágio profissional na empresa Techina Construtora LTDA.

\section{JOÃO CARLOS MARTINS COELHO}

Graduado em Engenharia Mecânica pelo Instituto Tecnológico de Aeronáutica (1974) e mestre em Engenharia de Processos Químicos e Bioquímicos pelo Instituto Mauá de Tecnologia (2006). Atualmente é professor associado da Escola de Engenharia Mauá e Coordenador Operacional do Progex - Programa de apoio à Exportação conduzido no Estado de S. Paulo pelo Instituto de Pesquisas Tecnológicas do Estado de São Paulo S.A. Tem experiência na área de Energia e Fluidos e na área de Adequação de Produtos para Exportação englobando aposição de Marca CE a produtos diversos, elaboração de dossiês técnicos, de análise de riscos e outras ações associadas a quesitos tecnológicos para exportação. Paralelamente, tem trabalhado em Comissões de Estudo da ABNT - Associação Brasileira de Normas Técnicas contribuindo para a elaboração de normas técnicas diversas. 


\section{JOÃO DALLAMUTA}

Engenheiro de Telecomunicações pela UFPR. MBA em Marketing pela FAE Business School. Mestre em Engenharia pela UEL. Iniciou a carreira atuando como trainee de inteligência de mercado no segmento de telecomunicações. Atuou como analista de marketing no mercado de máquinas agrícolas. Como executivo de marketing atuou no mercado de ensino a distância via satélite e no exigente segmento de Franchising. Desde 2004 leciona Engenharia, Gestão e Marketing em Universidades públicas e privadas para cursos de graduação e pós-graduação. Desde 2015 leciona na UTFPR.

\section{JOSÉ CARLOS DE TOLEDO}

Graduação em Engenharia de Produção pela Universidade Federal de Goiás, Brasil(2018)

\section{JOSÉ WALDO MARTÍNEZ ESPINOSA}

Possui graduação em Engenharia Química pela Universidade Federal de São Carlos (1988), mestrado em Ciência e Engenharia dos Materiais pela Universidade Federal de São Carlos (1992) e doutorado em Ciência e Engenharia dos Materiais pela Universidade Federal de São Carlos (2000). Atualmente é professor associado da Universidade Federal de Goiás Regional Catalão. Atua na área de Engenharia de Produção e Ciência dos Materiais, com ênfase em materiais nanoestruturados e fotoluminescência. Engenharia Ambiental com ênfase em produção mais limpa e sustentabilidade.

\section{JULIANO ZAFFALON GERBER}

Possui graduação em Análise de Sistemas pela Universidade Católica de Pelotas, mestrado e doutorado em Engenharia de Produção pela Universidade Federal de Santa Catarina. Tem experiência, tanto na pesquisa quanto na docência, nas áreas de Engenharia de Produção e Administração de Empresas, ambas com ênfase em Planejamento, Gestão e Controle da Produção, Coaching Executivo e de Negócios, Logística, Teoria dos Jogos e Sustentabilidade. Atua como professor adjunto no curso de Engenharia de Produção, Departamento de Ciências Exatas e Tecnológicas da Universidade Estadual de Santa Cruz UESC.

\section{JÚLIO CESAR BENFENATTI FERREIRA}

Professor e pesquisador do IFMG-Campus Bambuí, tem experiência como coordenador de curso e diretor de instituição de ensino. Formado em Administração pela UFSJ, mestre em Administração pela UFLA e doutorado em Engenharia Agrícola pela UFV. Atua na área de teoria geral e administração estratégica. Desenvolve pesquisa na área de jogos empresariais.julio.ferreira@ifmg.edu.br

\section{LARA CRISTINE PEREIRA DOS SANTOS}

Graduação em Engenharia de Produção pela Universidade Federal de Goiás, Brasil(2018)

\section{LARISSA VILELA CRUZ}

Médica graduada pela FCMMG em 1995. Cursou a residência credenciada pelo MEC em cirurgia geral e cirurgia pediátrica. Possui MBA em Gestão Hospitalar e Serviços de Saúde pela FGV. Trabalhou como diretora no Hospital Odilon Behrens e atualmente atua com Gerente Ambulatorial na Unimed-BH. 


\section{LAURA NEVES FOLLY}

Pós-graduada em Docência para Ensino Superior na Anhanguera (2018), Engenheira de Produção na Anhanguera (2018) e Estatista pela Universidade Estadual do Estado do Rio de Janeiro (2009). Consultora de Gestão, na Evox Empresarial, especialista Black Belt do Programa Lean Seis Sigma.

\section{LEONARDO DE ABREU FERREIRA}

Graduado em Administração (2006) e especialista em Gestão da Qualidade integrada ao Meio Ambiente (2008) pela PUC MINAS. Experiência em sistema integrado de gestão nos ramos: automobilístico, logística e saúde. Atualmente atuando como Analista de Gestão SR na Gerência de Planejamento, Processos e Projetos da Unimed-BH.

\section{LEONARDO DOS A. F. DA CRUZ}

Graduado em Engenharia de Produção em dezembro/2017 pelo Centro Universitário Serra dos Órgãos (UNIFESO). Monitor da disciplina de Cálculo 1 em 2014 nos cursos de Engenharia de Produção e Engenharia de Ambiental e Sanitária. Integrante do Diretório Acadêmico de Engenharia de Produção (2015-2016). Cursando Certificação Green Belt Six Sigma. Atualmente trabalha no setor de bebidas na empresa Grupo Petrópolis atuando em análises dos indicadores estratégicos, táticos e operacionais, auditorias de qualidade no Programa Boas Práticas de Fabricação (BPF), $5 \mathrm{~S}$, Total Productive Maintenance (TPM) e auditorias dos apontamentos fabris no Manufacturing Execution System (MES).

\section{LEOPOLDO PEDRO GUIMARÃES FILHO}

Doutor em Ciências Ambientais - Universidade do Extremo Sul Catarinense (UNESC). Mestre em Engenharia de Produção - Universidade Federal de Santa Catarina (UFSC). Graduado em Engenharia de Produção Civil - Universidade Federal de Santa Catarina (UFSC). Coordenador e docente do curso de Engenharia de Produção na Universidade do Extremo Sul Catarinense (UNESC). Atua em pesquisas nas seguintes áreas: sistemas produtivos, resíduos sólidos de construção civil, gestão de custos, gestão organizacional.

\section{LUAN BAHIA ARAÚJO}

Graduando em Engenharia de Produção pela Universidade Estadual de Santa Cruz. Atua como planejador de produção na Barry Callebaut, moageira de cacau situada na Cidade de Itabuna-BA.

\section{LUANE ALCÂNTARA NUNES}

Possui graduação em Engenharia de Produção e Sistemas pela Universidade Estadual de Santa Cruz - UESC. É Especialista em Engenharia de Segurança do Trabalho pela Faculdade de Tecnologia e Ciências - FTC, Mestre em Desenvolvimento e Meio Ambiente pelo PRODEMA/UESC e Doutoranda em Engenharia Industrial pela Universidade Federal da Bahia - UFBA. Autora dos livros Coaching Executivo e de Negócios (ISBN:9788569910015) e Comunhão com Deus (ISBN:9788593081002). Atualmente é professora do Instituto Federal da Bahia de Eunápolis-BA na área de Higiene e Segurança do Trabalho.

\section{LUCAS CARVALHO MARTINS}

Engenheiro de Produção. Especialista em Gestão de Projetos. Cursando Mestrado em Engenharia de Produção 


\section{LUIZ ANTONIO DA PAZ CAMPAGNAC}

Possui graduação em Engenharia Elétrica pela Associação Educacional Veiga de Almeida (1981), especialização em Gestão pela Qualidade Total pela Universidade Federal Fluminense (2000), mestrado em Sistemas de Gestão pela pela Universidade Federal Fluminense (2002) doutorado em Programa de Pós Graduação em Engenharia Civil pela Universidade Federal Fluminense (2008). Tem experiência na área de Engenharia de Produção / Engenharia Elétrica / Administração , atuando principalmente nos seguintes temas: Geração e Distribuição de Energia, Automação de Processos, Competitividade Industrial. Analise de Investimentos. Gerenciamento de Projetos; Empreendimentos Complexos, Qualidade Total, Administração da Produção, Estratégia, Organizações e Mudanças Organizacionais, Formação de Custos e Preços e Marketing Industrial. Trabalhou como executivo de contas na Emerson Process e na General Electric e atualmente trabalha na Siemens como gerente executivo de vendas. Tem mais de 30 anos de experiência na área de Óleo \& Gás. Professor do curso de graduação em Engenharia de Produção da Anhanguera.

\section{LUIZ AUGUSTO CESCON TAVARES}

Mestrado em Sistemas de Gestão na UFF (Defesa realizada em Janeiro de 2016) Universidade Federal Fluminense, possui MBA em organizações e estratégia pela UFF (2015) e MBA em gerenciamento de projetos pela UFF (2009) é graduado em Informática com ênfase em Análise de Sistemas (Bacharelado) pela Universidade Estácio de Sá (2006). Certificação internacional em gerenciamento de projetos PMP (Project Management Professional) do PMI (Project Management Institute) e em Métodos Ágeis (CSM) pela Scrum Alliance. Atua profissionalmente como Gerente de Projetos da empresa Impar e também como Coordenador dos cursos de Engenharias de Produção, Química e Ambiental da faculdade Anhanguera em Niterói.

\section{MANOEL ISAC MAIA JUNIOR}

Mestrando em Engenharia de Produção pela Universidade Federal do Rio Grande do Norte, Engenheiro de Produção pela Universidade Federal Rural do Semi Árido, com certificação Green e Black Belt em Lean six sigma. Atua na área de planejamento e controle da produção com conhecimentos em modelagem de processos, simulação de sistemas e filosofias PDCA, DMAIC e Lean Manufacturing.

\section{MARCELO ARESE}

Marcelo Arese é Engenheiro Mecânico pela Universidade Gama Filho e Analista de Sistemas pela Universidade Estadual do Rio de Janeiro. Possui especialização em Engenharia de Manutenção pela Universidade Federal do Rio de Janeiro, Engenharia de Segurança do Trabalho pela Universidade Federal Fluminense e Administração Financeira pela Fundação Getúlio Vargas. Mestre em Sistemas de Gestão e Doutorando em Sistemas de Gestão Sustentáveis pela Universidade Federal Fluminense. É certificado Black Belt em Lean Six Sigma. Trabalhou em planejamento e controle de produção, manutenção e projetos nas empresas Cosigua, Texaco, Bayer, Santista Alimentos, Votorantim Metais, FCC, Braskem. Atuou como gerente de operaçoes na Mills e SKMTech. Prestou consultoria pela IBM à Vale, Novartis, CENESP e Queiróz Galvão Óleo e Gás em mapeamento e melhoria de processos. Leciona em MBAs do Latec/UFF há 16 anos, nas disciplinas: Planejamento e Controle da Produção, Controle Estatístico de Processo, Gestão de Processos e Gestão da Manutenção. Instrutor da Abraman, do IPETEC e do CREA-RJ. Coordenador executivo do MBA Gestão Estratégica da Produção e Manutencão da Universidade Federal Fluminense. Professor assitente do curso de graduação em Engenharia de Produção da UFF campus Petrópolis e da Unilasalle. 


\section{MARCELO LOPES DE OLIVEIRA E SOUZA}

Engenheiro Eletrônico pelo Instituto Tecnológico de Aeronáutica - ITA, em São José dos Campos, São Paulo, Brasil em 1976. Ingressou no Instituto Nacional de Pesquisas Espaciais INPE em São José dos Campos, São Paulo em 1977. Ele trabalhou na primeira missão técnica de satélite do INPE / Brasil para aprender e trabalhar no Centro Nacional D'Etudes Spatiales-CNES, em Toulouse, França em 1979. Mestre em Ciências Espaciais / Mecânica Orbital pelo INPE em 1980. Ph.D. em Aeronáutica e Astronáutica pelo Instituto de Tecnologia de Massachusetts-MIT em Cambridge, Massachusetts, EUA, em 1985. Professor desde 1985 e Pesquisador Sênior do Curso de Engenharia e Tecnologia Espacial / Mecânica Espacial e Controle ETE / CMC do INPE desde 1991, onde coordena o Laboratório de Ambientes Computacionais para o Desenvolvimento de Sistemas AOCS - LAYSYSTEMS desde 2002. Desde 1977 trabalha e supervisiona trabalhos em vários temas quanto aos Sistemas de Atitude e Controle de Órbita - AOCS; e, posteriormente, em Modelagem, Identificação, Simulação e Controle de Sistemas Dinâmicos (principalmente aeroespaciais) e seus ambientes de desenvolvimento. 0 autor é um membro sênior de sociedades de prestígio como a Associação de Ex-Alunos do MIT, etc. em cujos periódicos e congressos publicou muitos trabalhos sobre essas e outras áreas afins.

\section{MARCELO TEOTÔNIO NAMETALA}

Cursando Bacharelado em Administração - IFMG

\section{MARCILENE DE FÁTIMA DIANIN VIANNA}

Possui graduação em Licenciatura em Matemática pela Universidade Estadual de Maringá (1998), mestrado em Matemática pela Pontifícia Universidade Católica do Rio de Janeiro (2001) e doutorado em Ciências Naturais pela Universidade Estadual do Norte Fluminense Darcy Ribeiro (2013). Atualmente atua como: professora adjunta da Universidade Federal Fluminense - UFF - Rio das Ostras; professora do Programa de Mestrado em Engenharia de Produção e Sistemas Computacionais (MESC), subchefe do Departamento de Computação, referee do Periódico IJM\&P - Independent Journal of Management \& Production. Tem experiência na área de Matemática, com ênfase em Álgebra Linear, Cálculo Diferencial e Integral, Cálculo Numérico, Equações Diferenciais, Lógica, Probabilidade e Estatística, Auxílio Multicritério à Decisão, Heurísticas e Análise Multivariada (RMN, metabolômica, PCA, PLS).

\section{MARCOS F. G. VERÍSSIMO}

Engenheiro de Produção graduado em dezembro/2017 pelo Centro Universitário Serra dos Órgãos (Unifeso). Monitor das disciplinas de Cálculo 3 (2015) e Processo Decisório (2017); Presidente do Diretório Acadêmico de Engenharia de Produção (2015-2016).

\section{MARCOS VINÍCIUS MAIA FONSECA}

Graduando no curso de Engenharia de Produção pelas Faculdades Santo Agostinho Campus JK

\section{MARI TOMITA KATAYAMA}

Possui graduação em Ciências da Computação pela Universidade de São Paulo (1974). Atualmente é consultora ad hoc - Financiadora de Estudos e Projetos e Diretora do Núcleo de Atendimento Tecnológico à Micro e Pequena Empresa- NT-MPE do Instituto de Pesquisas Tecnológicas do Estado de São Paulo - IPT. Tem experiência na coordenação e execução de projetos de âmbito nacional, no apoio tecnológico às micro, pequenas e médias empresas, na coordenação de trabalhos de adequação/desenvolvimento de produtos de diversos setores, em especial equipamentos médico-hospitalares, atendendo às exigências técnicas 
do mercado internacional, nos aspectos de segurança, saúde, design e meio ambiente, e no apoio tecnológico às empresas de arranjos produtivos locais.

\section{MARIO SANTOS DE OLIVEIRA NETO}

Graduado em Engenharia Elétrica pela USU - Universidade Santa Úrsula, e com Mestrado Strictu Senso em Engenharia de Produção, com concentração na área de Transporte e Logística pela PUC-RJ (bolsista Capes com dedicação exclusiva), tem 25 anos de sólida experiência adquirida nas áreas de logística, operações, serviços, facilities e comercial em empresas de médio e grande porte dos segmentos de varejo, de transporte de cargas e de passageiros, telecomunicações e de serviços, atuando diretamente em toda a cadeia de suprimentos. Também tendo participado de projetos no segmento de consultoria empresarial, desenvolvimento de estudos e implantação de projetos logísticos. Atualmente é professor para engenharia de produção no UNIFESO - Centro Universitário Serra dos Órgãos.

\section{MATHEUS PECCIN AMARAL}

Engenheiro de Produção, graduado em 2017.1 pelo Centro Universitário Serra dos Órgãos (UNIFESO). Concluinte do Ciclo Básico de Engenharia pela Universidade Federal do Rio de Janeiro (UFRJ) em 2014.1. Monitor da disciplina de Física Experimental II do Instituto de Física da UFRJ (Janeiro a Dezembro de 2013). Monitor do Instituto de Química da UNIFESO (Fevereiro a Novembro 2015). Diretor Financeiro do Diretório Acadêmico de Engenharia de Produção (DAEP-UNIFESO, de Setembro 2015 a Maio 2016). Diretor Financeiro da InsetiSerra Imunizações e Saneamento (Outubro 2014 até hoje). Consultor Financeiro e Diretor Executivo da Lumus Engenharia e Consultoria. Cursando MBA em Controladoria e Finanças (UCP, 2018.2).

\section{MAYCON TAVARES MORETE}

Graduação em Engenharia Ambiental pela Universidade Veiga de Almeida (2017). Experiência em projetos de iniciação científica, Semana do meio ambiente (2017) e Semana da Engenharia na Universidade Veiga de Almeida (2017). Conselheiro na Empresa Júnior da Universidade Veiga de almeida (2015-2016). Participação no congresso CNEG - INOVARSE (2018). Ajudante voluntário no laboratório de águas da Universidade Veiga de almeida (2017).

\section{MICHELE PEREIRA FIGUEIREDO DE ABREU}

Mestre em Engenharia de Produção pelo Instituto Alberto Luiz Coimbra de Pós-Graduação o e Pesquisa de Engenharia - COPPE/UFRJ (2016), Engenheira de Segurança no Trabalho pela Universidade Federal Fluminense (2014) e Engenheira de Produção pela Universidade do Estado do Rio de Janeiro (2012), graduada em Petróleo e Gás pela Universidade Estácio de Sá (2008).

\section{MICHELLEN DOS SANTOS VASQUES DA SILVA}

Engenheira de Produção e técnica em alimentos e bebidas, com experiência em empresas do ramo alimentício e do ramo ferroviário, nas áreas de qualidade, produção, segurança do trabalho, treinamentos, aplicação de ferramentas de qualidade em processos de melhoria e suporte na gestão de equipes.

\section{MURILO CARVALHO FRANCO BARROS}

Engenheiro de Produção 


\section{NATÁLIA CIBELE DE SOUSA SANTOS}

Graduanda em Engenharia de Produção pela Universidade Federal de Goiás - Campus Catalão. Estagiária na HPE Automotores na área de Administração de Materiais. Integrante do Grupo de Estudos em Modelagem e Simulação (GEMS), foi integrante do projeto de Iniciação Científica em Simulação de Sistemas de Emissão de Ordens.

\section{NAYARA FELÍCIO DE OLIVEIRA}

Graduação em Engenharia de Produção pela Universidade Federal de Goiás, Brasil(2018)

\section{OLGA MARIA FORMIGONI CARVALHO WALTER}

Engenheira de Produção e Sistemas pela Universidade do Estado de Santa Catarina (UDESC, 2007). Mestrado em Engenharia de Produção (2012) e doutoranda em Engenharia de Produção, ambos pela UFSC. Atuou no Planejamento e Controle da Produção e Materiais em indústrias do ramo metal mecânico no polo industrial de Joinville/SC (2006-2010) e como professora colaboradora na Universidade do Estado de Santa Catarina (2013-2017). Pesquisadora na área de Lean Six Sigma e Métodos Estatísticos para Qualidade

\section{OSCAR MARTINS RENNÓ}

Professor universitário, com diversas titularidades na área de engenharia e gestão empresarial, vem desenvolvendo soluções em gestão através da ferramenta Excel da plataforma da Microsoft. Além das ferramentas de gestão com o uso de planilhas inteligentes e automatizadas, desenvolve jogos de empresa que simulam situações organizacionais para desenvolvimento de habilidades e competências de seus alunos. Informações acadêmicas complementares: http://lattes.cnpq.br/8798095125427379

\section{PATRÍCIA PEREIRA PACHECO}

Engenheira de Produção pela Universidade do Extremo Sul Catarinense - UNESC (20112016). Especialização em Engenharia de Segurança do Trabalho - UNESC (2016-2019). Núcleo de Estudos em Engenharia de Produção - UNESC - Membro pesquisador (2016atual). Colunista do Blog da Engenharia. Atua na indústria metalúrgica, nas áreas de PPCP e Materiais. Áreas de estudo: Manutenção, Gestão da Qualidade, Segurança do Trabalho.

\section{PLÁCIDO CARLOS FERNANDES DE QUEIROZ}

Engenheiro de Produção pela Universidade Federal Rural do Semi Árido, participando ativamente como liderança em movimentos estudantis e projetos de extensão durante a graduação. Atua na área Comercial desenvolvendo papel de liderança, com conhecimentos em técnicas de vendas, gestão e desenvolvimento de equipe.

\section{PRISCILA FERNANDA MORAIS CHAVES BOATO}

Graduada em Gestão de Serviços de Saúde na Universidade Federal de Minas Gerais (UFMG) e pós-graduada em Gestão de Projetos (IETEC). Possui experiência na área pública tendo trabalhado na Secretaria de Estado de Saúde de Minas Gerais (SES-MG) e na Fundação Ezequiel Dias (FUNED). Atualmente integra a equipe da Gestão de Planejamento, Processos e Projetos (GEPP) da Unimed-BH como analista de gestão responsável pela liderança de projetos corporativos. 


\section{RAFAEL IZIDORO MARTINS NETO}

Bacharel em Administração - IFMG. Pós-Graduação em Docência - IFMG. Professor de Filosofia e Sociologia - Rede Pitágoras. Assessor Jurídico na empresa Bambuí BioEnergia/ SA

\section{RENATA LARCHER CURY}

Engenheira de Produção graduada em dezembro/2017 pelo Centro Universitário Serra dos Órgãos (Unifeso). Participação no Programa de Iniciação Científica e Pesquisa (PICPq)/2016 e 2017 e apresentação no CONFESO II (Unifeso). Cursando MBA em Planejamento e Finanças pela Universidade Federal do Rio de Janeiro (UERJ). Trabalhando atualmente na área administrativa com experiência no Centro Educacional Serra dos Órgãos (CESO/Unifeso).

\section{ROBERTA OLIVEIRA GONCCALVES}

Engenheira de Produção

\section{RODRIGO LANZONI FRACAROLLI}

Engenheiro de Produção formado pela Universidade Estadual de Maringá, especialista em Projetos e Edificações de Obras Públicas, mestre em Engenharia Urbana e professor assistente no departamento de Engenharia Têxtil da Universidade Estadual de Maringá.

\section{SÁVIO DE ARAÚJO ALMEIDA}

Graduado em Engenharia de Produção pela Universidade Estadual de Santa Cruz

\section{SIMONE MILIOLI DA LUZ}

Possui graduação em Licenciatura em Matemática pela Universidade Federal de Santa Catarina e mestrado em Engenharia de Minas, Metalúrgica e de Materiais pela Universidade Federal do Rio Grande do Sul. Atualmente é professora da SATC - Associação Beneficente da Indústria Carbonífera de Santa Catarina.

\section{TAÍS SANTOS BARRETO}

Graduada em Engenharia de Produção pela Universidade Estadual de Santa Cruz

\section{THIAGO JOSÉ DA COSTA MUNIZ}

Possui graduação em Engenharia de Produção pela Universidade Federal do Rio Grande do Norte (2011). É mestrando do programa MESC - Mestrado em Engenharia de Produção e Sistemas Computacionais da Universidade Federal Fluminense, UFF (2019). Atualmente é engenheiro de produção na Petróleo Brasileiro S.A. em Macaé/RJ. Tem experiência na área de Engenharia de Produção, com ênfase em Descomissionamento, Gerenciamento de Projetos e Engenharia Econômica.

\section{VILIMAR MENEGON BRISTOT}

Doutor em Engenharia de Minas, Metalúrgica e de Materiais pela Universidade Federal do Rio Grande do Sul - UFRGS (2012), Mestre em Engenharia Elétrica pela Universidade Federal de Santa Catarina - UFSC (2002), Especialista em Automação Industrial pela Universidade Federal de Santa Catarina - UFSC (2000), Engenheiro Agrimensor pela Universidade do Extremo Sul Catarinense - UNESC (1994), Técnico em Mecânica - Desenhos e Projetos pela Escola Técnica General Oswaldo Pinto da Veiga - SATC (1989). Atualmente é Relações 
Externas e Professor do Ensino Básico, Técnico e Tecnológico do Instituto Federal de Santa Catarina - Campus Criciúma.

\section{VILSON MENEGON BRISTOT}

Doutor em Engenharia de Minas, Metalúrgica e de Materiais pela UFRGS - Universidade Federal do Rio Grande do Sul. Mestre em Engenharia Mecânica - pela UFRGS - Universidade Federal do Rio Grande do Sul. Engenheiro de Segurança do Trabalho - IERGS - Instituto Educacional do Rio Grande do Sul - (2017), Engenheiro Agrimensor - UNESC - Universidade do Extremo Sul Catarinense (2003), Técnico em Desenho Industrial - SATC . Atuou profissionalmente durante 15 anos na Eliane S/A Revestimentos Cerâmicos exercendo a função de Coordenador do Departamento de Engenharia Industrial. Atualmente é professor do quadro regular da UNESC nos cursos de graduação e Pós Graduação Lato Sensu. É Coordenador adjunto do curso de Engenharia de Produção da UNESC.

\section{VITOR CAMARGO DA SILVA}

Engenheiro de Produção

\section{VITOR DE CARVALHO PISCO}

Graduação em Engenharia de Produção pela Universidade Federal de Uberlândia, Brasil(2016) 


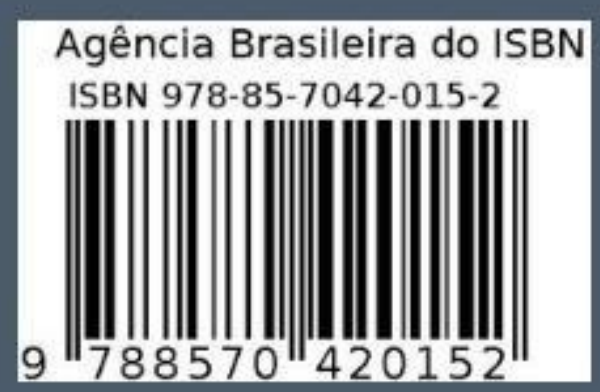

